\title{
George STAUNTON
}

\author{
VOYAGE \\ dans l'intérieur de la \\ CHI NE \\ et en \\ TARTARI E
}

fait dans les années 1792, 1793 et 1794 par Lord MACARTNEY

ambassadeur du Roi d'Angleterre

auprès de l'Empereur de la Chine

Un document produit en version numérique par Pierre Palpant, collaborateur bénévole

Courriel : ppalpant@uqac.ca

Dans le cadre de la collection : "Les classiques des sciences sociales " fondée et dirigée par Jean-Marie Tremblay, professeur de sociologie au Cégep de Chicoutimi.

Site web : http://classiques.uqac.ca

Une collection développée en collaboration avec la Bibliothèque Paul-Émile Boulet de I'Université du Québec à Chicoutimi.

Site web : http://bibliotheque.uqac.ca 


\section{Voyage dans l'intérieur de la Chine et en Tartarie}

Un document produit en version numérique par Pierre Palpant, collaborateur bénévole,

Courriel : ppalpant@uqac.ca

à partir de :

\section{VOYAGE DANS L'INTÉRIEUR DE LA CHINE ET EN TARTARIE, par Sir George STAUNTON (1737-1801).}

G. Nicol, Londres, 1797.

Traduction française de J. CASTERA, éditions Buisson, 1798.

Nombreuses rééditions. Dernière en date: Éditions Olizane, Genève, 2005 (avec une préface de Matthias Huber), 830 pages.

Police de caractères utilisée : Verdana, 12 et 10 points.

Mise en page sur papier format Lettre (US letter), 8.5'x11"

[note : un clic sur @ en tête de volume et des chapitres et en fin d'ouvrage, permet de rejoindre la table des matières.

Nous n'avons repris, de la relation de G. Staunton, après les préparatifs en Angleterre, que la partie relatant le voyage en Chine proprement dit, depuis l'arrivée aux côtes de la Chine, jusqu'au départ de Macao (pages 21-58, 283768 et 783-790 des éditions Olizane)

Le lecteur curieux trouvera l'intégralité de la relation dans l'ouvrage des éditions Olizane.

On utilisera enfin avec profit les cartes de l'ouvrage d'Elisée Reclus, l'Empire du milieu. ]

Édition complétée le 15 décembre 2006 à Chicoutimi, Québec. 


\section{Voyage dans l'intérieur de la Chine et en Tartarie}

\section{TABLE DES MATIÈRES}

\section{Avertissement}

\section{PREMIÈRE PARTIE}

Chapitre premier: Motifs qui ont déterminé la cour de Londres à envoyer une ambassade à la Chine.

Chapitre II : Préparatifs de l'ambassade.

\section{DEUXIÈME PARTIE}

Chapitre premier : Traversée de la Cochinchine aux îles des Larrons, près de Macao.

Chapitre II : Navigation dans la mer Jaune. Entrée de l'ambassadeur dans la rivière qui conduit à Tien-Sing.

Chapitre III : L'ambassade remonte la rivière de Pei-Ho, pour se rendre dans la capitale de la Chine. Les vaisseaux quittent le golfe de Pé-Ché-Lée.

Chapitre IV: L'ambassade débarque près de Tong-Choo-Foo. Elle traverse Pékin pour se rendre dans un palais qui est au-delà. Elle retourne dans la capitale.

\section{TROISIÈME PARTIE}

Chapitre premier: Voyage aux frontières septentrionales de la Chine. Vue de la grande muraille.

Chapitre II: L'ambassade anglaise arrive auprès de l'empereur de la Chine, en Tartarie, dans le palais où ce prince fait sa résidence pendant l'été.

Chapitre III : Retour à Pékin. Séjour de I'ambassade dans cette capitale et à YuenMin-Yuen. Observations qui y ont rapport.

Chapitre IV : L'ambassade quitte Pékin. Voyage à Han-Choo-Foo, fait en partie sur le canal impérial.

Chapitre V : Voyage à Han-Choo-Foo, et de Han-Choo-Foo à Chu-San.

\section{QUATRIÈME PARTIE}

Chapitre premier: Voyage de Han-Choo-Foo à Canton. Passage du Lion et de I'Indostan de Chu-San à Canton.

Chapitre II : Séjour de l'ambassade anglaise à Canton et à Macao.

\section{APPENDICES}

Appendice 1 : Tableau de la population et de l'étendue de la Chine propre, séparée de la Tartarie chinoise par la grande muraille. 


\section{Voyage dans l'intérieur de la Chine et en Tartarie}

Appendice 2: Tableau des revenus entrés dans le trésor impérial de Pékin, et provenant des différentes provinces de la Chine propre.

Appendice 3 : Liste des Officiers civils de la Chine.

Appendice 4 : Liste des principaux Officiers militaires de la Chine, avec leur nombre, leur rang et leurs appointements.

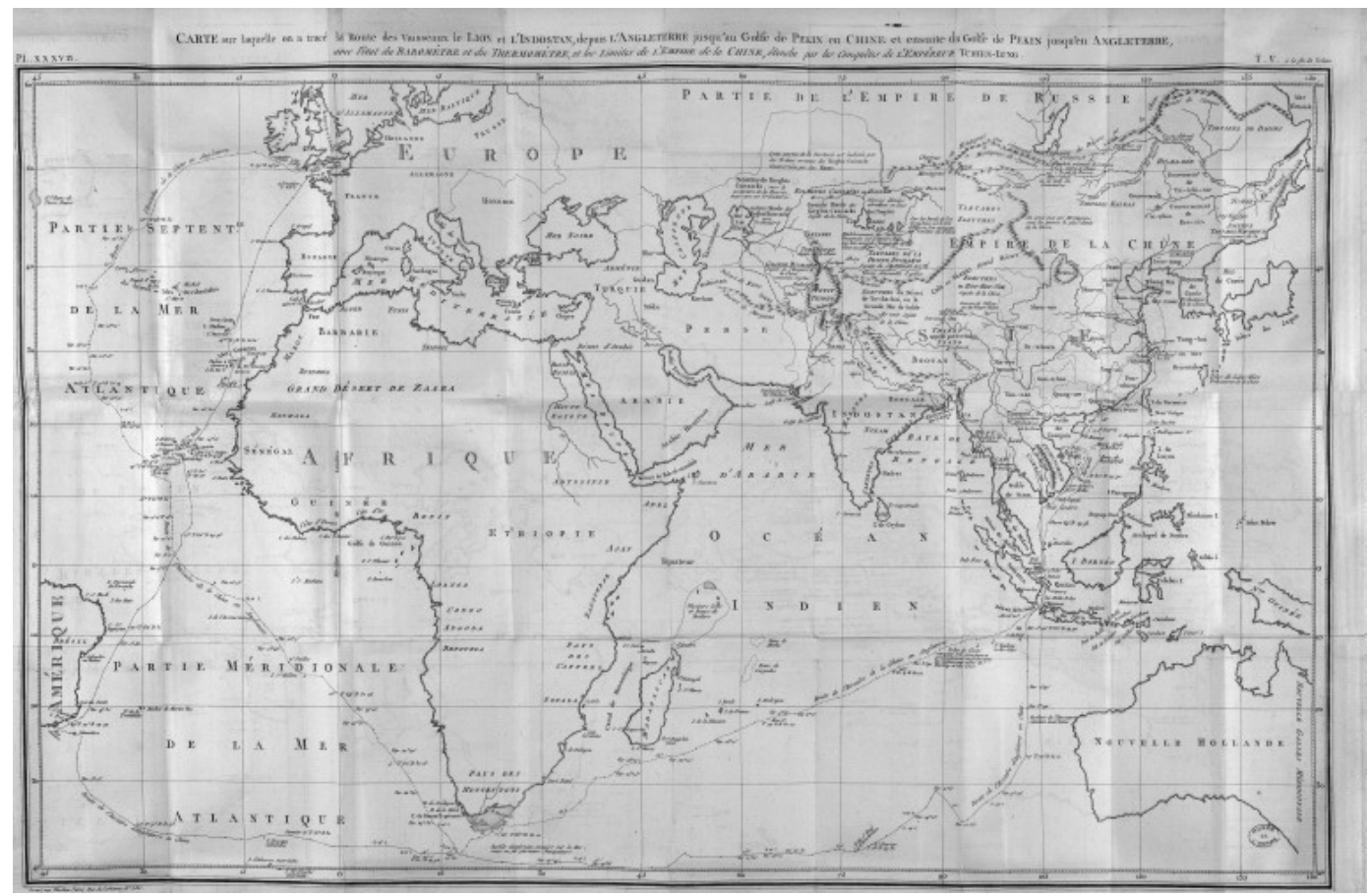

Carte sur laquelle on a tracé la route des vaisseaux le Lion et I'Indostan depuis I'Angleterre 


\section{Voyage dans l'intérieur de la Chine et en Tartarie}

\section{AVERTISSEMENT DE L'AUTEUR}

Cet ouvrage a été composé pour obéir au public. Les raisons qui avaient déterminé à envoyer une ambassade à la Chine, les préparatifs qui furent faits à cette occasion, la route que suivit l'ambassadeur, les pays qu'il visita, ses négociations, tout excitait une curiosité que le gouvernement a cru devoir s'empresser de satisfaire. II a aussi vraisemblablement pensé qu'il convenait de ne confier la rédaction de ce voyage qu'à un homme instruit, dès l'origine, des particularités qui y ont eu rapport, et témoin de tous les événements qui l'ont suivi.

Cet homme a senti l'importance du devoir qu'une telle confiance lui imposait, et s'est efforcé de le remplir avec tout le zèle que lui a permis sa mauvaise santé. II savait d'ailleurs que le travail des artistes, employés aux cartes et aux gravures qui accompagnent cet ouvrage, lui laisserait assez de temps pour l'empêcher d'être en retard. Enfin, il espère que les motifs qui l'ont engagé à écrire cette relation lui mériteront plus d'indulgence que s'il l'avait publiée de son propre mouvement, et dans la seule persuasion que ses talents littéraires lui donnaient le droit de défier la sévérité des critiques. 
Voyage dans l'intérieur de la Chine et en Tartarie

PREMI È R E

P A R T I E 


\section{Voyage dans l'intérieur de la Chine et en Tartarie}

\section{CHAPITRE PREMIER}

\section{Motifs qui ont déterminé la cour de Londres à envoyer une ambassade à la Chine}

On a remarqué, avec raison, que les entreprises et les succès d'une aussi grande et aussi riche partie de la nation anglaise que celle qui s'occupe du commerce fixent dans tous les temps l'attention du gouvernement, et influent sur la plupart de ses démarches. Lorsque le projet d'envoyer une ambassade à la Chine fut connu, on pensa donc assez naturellement que cette ambassade n'avait qu'un but commercial. On était même d'autant plus fondé à le croire que les relations qui subsistaient entre la Chine et l'Angleterre exigeaient un changement qui nous les rendît plus avantageuses. Ni dans les premiers temps où les Anglais allèrent trafiquer à Canton, ni depuis, il ne s'était présenté aucune circonstance qui pût les faire mieux traiter des Chinois, et ils étaient, à cet égard, les moins favorisés des Européens.

Les Portugais furent les premiers qui fréquentèrent les côtes de la Chine. II y a environ deux cents ans qu'ils y abordèrent. C'était l'époque de leurs plus brillants exploits, et de la grande réputation qu'ils leur acquirent. Ils rendirent de si importants services aux Chinois, qu'en récompense, ceux-ci leur accordèrent à l'extrémité méridionale de leur empire, un terrain pour bâtir une ville auprès d'un port sûr, avec divers autres avantages ; et quoique leur puissance déchue et leur gloire ternie aient fait insensiblement enlever aux Portugais une partie de leurs privilèges, le souvenir de leurs anciennes et utiles liaisons leur attire encore, de la part des Chinois, un accueil plus facile et plus confiant qu'aux autres nations de l'Europe, et même, dans beaucoup d'occasions, une préférence marquée sur elles.

Vers le milieu du siècle dernier, les Hollandais aidèrent les Chinois à soumettre un dangereux rebelle, nommé Cosching-Ga, dont les flottes infestaient les mers orientales de la Chine. Pour prix de ce secours, le gouvernement les favorisa quelque temps. Ils furent même invités à aller à Pékin, où régnait alors le premier empereur de la race des Tartares- 


\section{Voyage dans l'intérieur de la Chine et en Tartarie}

Manchoux. Son successeur, le grand Cam-Hi, ou plutôt, comme on le prononce, Caung-Schée, accueillit favorablement pendant la durée de son règne, long et prospère, tous les étrangers instruits des arts et des sciences, dans lesquels l'Europe l'emporte sur la Chine. II prit plusieurs de ces étrangers à son service, leur accorda sa confiance, et en employa quelquesuns dans des négociations politiques.

Tous ces étrangers, nés en différentes contrées de l'Europe, appartenaient à divers ordres de moines de la religion catholique; et comme ils s'étaient montrés zélés pour la propagation de leur foi, leurs supérieurs les avaient chargés d'aller la prêcher parmi les nations éloignées. La plupart d'entre eux s'acquirent beaucoup d'estime et de crédit, tant par leurs connaissances et leurs talents que par l'austérité de leurs mœurs, leur désintéressement et leur extrême modestie; aussi leur conduite qui ne permettait guère de leur supposer, au moins en ce qui concernait les affaires temporelles, les vues ambitieuses des autres hommes, leur attirait le respect de ceux qui étaient le moins disposés à suivre leur exemple. Non seulement ils firent beaucoup de prosélytes à leur religion, mais ils inspirèrent une haute idée des pays qui les avaient vu naître, et ils servirent efficacement ceux de leurs compatriotes qui faisaient le commerce dans les ports de la Chine.

Les Anglais ne trouvèrent ni l'occasion de rendre des services à l'empire chinois, ni d'y faire respecter leur caractère et protéger leur commerce. Cependant leur gouvernement avait encouragé et soutenu d'une manière imposante les opérations mercantiles qu'ils avaient entreprises en d'autres pays lointains.

On lit dans l'histoire du commerce d'Angleterre, qu'en l'année 1599, la reine Elisabeth fit partir John Mildenhall, qui se rendit, par terre, de Constantinople à Delhy, afin d'obtenir du Grand Mogol quelques privilèges pour une compagnie anglaise qui était prête à se former. John Mildenhall fut longtemps en contact étroit avec les jésuites espagnols et portugais, qui étaient à la cour du Mogol, et qui, pour susciter des ennemis aux Anglais, n'épargnèrent ni les intrigues ni les présents. Mais enfin, l'envoyé d'Elisabeth l'emporta. On sait aussi que cette sage princesse écrivit à l'empereur de la Chine pour lui recommander, de la manière la plus pressante, les chefs d'une expédition qui partait pour Canton : mais les malheurs que cette expédition 


\section{Voyage dans l'intérieur de la Chine et en Tartarie}

éprouva à la mer l'empêchèrent de se rendre à sa destination. II se passa ensuite beaucoup de temps sans que l'Angleterre tentât de faire aucun commerce régulier avec la Chine. Les Portugais semblaient s'être arrogé le privilège exclusif de fréquenter les mers de cet empire. Ce ne fut qu'en 1634 que, par un traité particulier, le vice-roi de Goa permit l'entrée de la Chine et de tous les établissements portugais dans l'Inde, à quelques négociants anglais qui, malgré la charte exclusive, accordée par la reine Elisabeth à la Compagnie des Indes Orientales, venaient d'obtenir de Charles $\mathrm{I}^{\mathrm{er}}$ la permission de trafiquer dans les mêmes contrées.

Ces négociants firent armer plusieurs vaisseaux, et en donnèrent le commandement au capitaine Weddell qui, d'après le traité signé par le viceroi de Goa, pensa qu'il lui suffirait d'avoir des lettres pour le gouverneur de Macao, afin d'en obtenir la protection nécessaire pour trafiquer sans inconvénient avec les Chinois de Canton. Mais suivant la relation qui paraît avoir été dictée par la simple vérité, le procurador de Macao se rendit bientôt à bord du principal vaisseau des Anglais, et dit qu'il leur ferait fournir les rafraîchissements dont ils auraient besoin, mais qu'il ne pourrait pas leur faciliter les moyens de traiter à Canton, parce que les Chinois n'y consentiraient pas. II prétendit même que ces derniers tenaient les Portugais dans une cruelle oppression.

Cependant, les Anglais résolurent de reconnaître la rivière de Canton. Ils expédièrent une barque et une grande chaloupe, avec environ cinquante hommes qui, après deux jours de navigation, arrivèrent à l'embouchure de la rivière, où ils aperçurent un passage très facile, mais qui était absolument interdit aux Portugais. Les Chinois n'y admettent même volontiers aucun étranger, parce que c'est l'endroit où se retirent leurs meilleures jonques marchandes et leurs jonques de guerre. Les Portugais n'allaient donc trafiquer à Canton que dans de petits bâtiments, et en passant sur des hauts-fonds et à travers une multitude de petites îles peu éloignées de la grande terre.

Tandis que la barque était à l'ancre en attendant que le vent et la marée lui permissent d'entrer dans la rivière, on découvrit de matin, de très bonne heure, une jonque de pêcheurs. Thomas Robinson se mit aussitôt à sa poursuite, et fut assez longtemps avant de l'atteindre, parce que la quantité d'avirons dont ces sortes de bateaux sont armés leur donne beaucoup de 


\section{Voyage dans l'intérieur de la Chine et en Tartarie}

vitesse. L'Anglais avait espéré qu'il y aurait dans la jonque un pilote ou au moins un interprète ; mais il n'y trouva ni l'un ni l'autre. II traita les Chinois avec douceur, et les relâcha presque aussitôt, ce qu'ils étaient loin d'espérer. Peu près, il joignit une seconde jonque; mais aussi bienveillant que la première fois, il ne fut pas plus heureux.

$\mathrm{Au}$ bout de quelques jours, un canot chinois s'avança vers la grande chaloupe pour lui offrir des rafraîchissements. Les Anglais demandèrent, par signes, aux Chinois de conduire quelques-uns d'entre eux à Canton, et de leur faire parler aux mandarins; à quoi les Chinois consentirent. Le lendemain, la chaloupe faisant voile et profitant de la marée et du bon vent passa près d'un château délabré, et rencontra une flotte, composée d'une vingtaine de grandes jonques et commandée par le contre-amiral de la mer, qui descendait la rivière de Canton. Cet officier fit dire poliment aux Anglais de jeter I'ancre. Ils obéirent. Ensuite, John Mounteney et Thomas Robinson se rendirent à son bord, où ils trouvèrent quelques nègres, déserteurs des établissements portugais, lesquels leur servirent d'interprètes.

Les Chinois commencèrent par se plaindre avec quelque aigreur de ce que les Anglais étaient venus jusque là et avaient cherché à découvrir les endroits interdits aux étrangers et les passages secrets de l'empire d'un aussi grand prince que le leur. Ils demandèrent aussi quels étaient les pilotes des Anglais? Thomas Robinson répondit que lui et ses compagnons venaient d'Europe, dans l'intention de faire le commerce avec les Chinois, d'après un accord qui fût également avantageux aux deux nations et à leurs souverains, espérant qu'il pourrait être aussi légitimement permis aux Anglais qu'aux habitants de Macao de trafiquer à Canton, en payant les droits d'usage. Que, quant aux pilotes, ils n'en avaient point; mais que chaque matelot de son équipage était assez habile pour découvrir des passages plus difficiles que celui qu'ils venaient de trouver.

Les Chinois devinrent alors beaucoup plus affables. Ils offrirent de fournir une jonque légère pour porter jusqu'à Canton le capitaine Carter, John Mounteney et Thomas Robinson, ou tel autre Anglais qu'il leur plairait de choisir, à condition que la grande chaloupe n'irait pas plus loin ; car, quoique chaque jonque de leur flotte eût des canons et fût bien équipée, ils n'osaient point s'opposer d'une manière hostile à la marche des Anglais. 


\section{Voyage dans l'intérieur de la Chine et en Tartarie}

Le même soir, le capitaine Carter, Thomas Robinson et John Mounteney quittèrent la chaloupe, après avoir donné ordre à leurs compagnons de les attendre dans le même endroit, et s'étant embarqués dans une petite jonque du port d'environ trente tonneaux, ils firent voile vers Canton, dans le dessein de demander au vice-roi la permission de faire le commerce dans les pays soumis à sa domination.

II paraît que le bruit de leur arrivée était déjà parvenu jusqu'à Canton et y avait répandu l'alarme, car ils en étaient encore à cinq lieues lorsqu'ils furent poliment invités à ne pas s'approcher davantage, et à retourner vers leurs vaisseaux. On leur promit en même temps qu'on travaillerait à leur procurer la permission de traiter avec les Chinois, s'ils voulaient chercher à Macao des personnes propres à les servir, et surtout abandonner, sans délai, la rivière de Canton. Les Anglais se soumirent à ces conditions avec d'autant moins de difficulté qu'ayant déjà fait la découverte qu'ils désiraient, ils étaient bien aises de faire cesser l'inquiétude que leur longue absence pouvait causer au reste de la flotte.

Peu de temps après leur retour à Macao, une flottille portugaise, composée de six petits navires, partit pour le Japon. Les Anglais se flattèrent alors d'obtenir la permission de commerce qu'on leur avait fait espérer pour cette époque. Mais leurs rivaux, qui ne craignaient plus qu'ils s'emparassent de leur flottille, se moquèrent insolemment de leur crédulité. Ils firent plus : ils tinrent un conseil, dont le résultat fut d'envoyer signifier aux Anglais qu'ils ne voulaient pas se mêler de leurs affaires.

Le même jour, le capitaine Weddell assembla à son bord le capitaine Carter, John Mounteney et Thomas Robinson; et après avoir mis sous leurs yeux la carte de la rivière de Canton et leur avoir rappelé leurs entreprises, leurs succès et leurs espérances, il leur proposa de faire voile pour Canton avec toute la flotte; ce qui fut résolu d'un commun accord. Ils arrivèrent en peu de jours vis-à-vis du château délabré dont nous avons déjà fait mention ; et comme ils s'étaient pourvus de quelques mauvais interprètes, ils ne tardèrent pas à faire connaître aux mandarins, qui étaient sur les jonques impériales, le sujet de leur voyage. Ils leur déclarèrent que leur dessein était de vivre en paix et amicalement avec eux, de trafiquer avec la même liberté 


\section{Voyage dans l'intérieur de la Chine et en Tartarie}

que les Portugais, et d'obtenir, en payant, les provisions dont ils avaient besoin pour leurs vaisseaux.

Tous les mandarins leur promirent de solliciter en leur faveur le vice-roi de Canton, et en conséquence, ils demandèrent un délai de six jours. En attendant, les Anglais arborèrent pavillon blanc à la poupe de leurs vaisseaux. Cependant, depuis la première expédition de la chaloupe dans la rivière de Canton, les perfides Portugais, jaloux de la bonne conduite des Anglais, n'avaient cessé de les calomnier auprès des Chinois, en les leur peignant comme des misérables, des voleurs, des scélérats. Les Chinois, séduits par ces discours, profitèrent de la nuit pour transporter, dans le fort qui était sur le bord de la rivière, quarante-six canons de fer du poids de six à sept cents livres chacun, et bien proportionnés; et au bout de quatre jours, se croyant suffisamment fortifiés, ils aperçurent une chaloupe anglaise qui allait faire de l'eau pour l'équipage, et ils lui tirèrent plusieurs coups de canon, qui heureusement ne l'atteignirent point. Toute la flotte, indignée de cette agression, déploya aussitôt ses pavillons rouges, et levant l'ancre dès que la marée le lui permit, elle alla s'embosser devant le fort, qui se mit aussitôt à la canonner, mais sans pouvoir toucher ni les vaisseaux, ni leur gréement. Chaque vaisseau lui tira alors plusieurs bordées et, au bout de deux ou trois heures, s'étant aperçus que le feu des Chinois diminuait, les Anglais envoyèrent leurs canots à terre avec une centaine d'hommes. A cet aspect, les Chinois épouvantés prirent la fuite. Les matelots anglais, étant débarqués, entrèrent dans le fort et y plantèrent l'étendard de leur nation. Le même soir, ils mirent à leur bord les canons des Chinois, brûlèrent l'appartement du gouverneur et démolirent une partie des murailles. Ils s'emparèrent aussi de deux jonques, dont l'une était chargée de planches et de bois de charpente, l'autre de sel.

Peu de temps après, ils arrêtèrent un troisième bâtiment chinois, et ils profitèrent de son canot pour envoyer une lettre au principal mandarin de Canton. Ils se plaignaient, dans cette lettre, de ce qu'on avait rompu l'accord fait avec eux, ce qui les avait forcés d'attaquer la forteresse, et ils demandaient fièrement la liberté dont ils avaient besoin pour leur commerce. La lettre fut, sans doute, exactement remise; car, le lendemain, on vit s'avancer vers les vaisseaux un canot portant pavillon blanc. A bord de ce 


\section{Voyage dans l'intérieur de la Chine et en Tartarie}

canot était un Chinois nommé Paulo-Noretty, mandarin d'un ordre inférieur, et converti depuis quelque temps au christianisme par les Portugais. Les Anglais lui firent part des outrages qu'ils avaient reçus, et de l'intention où ils étaient de traiter avec les Chinois d'une manière franche et amicale, assurant, en outre, qu'ils ne les combattraient jamais que pour se défendre. Ensuite, ils firent quelques présents à cet officier, et le congédièrent. II se fit débarquer sur une pointe de terre, où l'on voyait à cheval quelques-uns des principaux mandarins qui, dès qu'il leur eut appris ce qu'on lui avait dit à bord de la flotte, le renvoyèrent dans une petite jonque, avec l'ordre de conduire à Canton ceux des Anglais qui voudraient y aller demander la permission dont ils avaient besoin.

Thomas Robinson et John Mounteney furent choisis pour remplir cette mission. Ils s'embarquèrent dans la jonque, et le lendemain au soir ils arrivèrent sous les murs de la ville et y mouillèrent vis-à-vis du palais du grand amiral Champin. Le jour suivant, Paulo-Noretty leur ayant procuré les moyens de faire dresser une pétition dans la forme accoutumée, ils furent conduits à terre. On les fit d'abord passer entre deux triples rangs de soldats, qui formaient la garde des mandarins assemblés. Ensuite on leur dit de s'agenouiller suivant l'usage du pays; et enfin Thomas Robinson, élevant audessus de sa tête la pétition déployée, la remit à Paulo-Noretty, qui la présenta à l'amiral Champin.

Le contenu de cette pétition parut si raisonnable à l'amiral qu'il accepta sur-le-champ les propositions des Anglais, et leur promit toute assistance. En même temps, il blâma hautement la trahison et les calomnies des Portugais, qu'il accusa d'avoir été les seuls auteurs de la mésintelligence qui avait régné entre les Anglais et les Chinois. Thomas Robinson et John Mounteney s'en retournèrent très satisfaits à bord de leur flotte. Les canons des Chinois furent débarqués et remis dans le fort, les jonques congédiées, et la paix et la bienveillance parfaitement rétablies.

Ce récit prouve quelle est la modération des Chinois envers les étrangers ; ou plutôt elle montre la faible et incertaine administration d'une dynastie chancelante; mais elle fait voir, en même temps, sous quels fâcheux auspices ont commencé les relations des Anglais avec la Chine. Ces téméraires aventuriers semblaient n'appartenir à aucun peuple, n'étaient 


\section{Voyage dans l'intérieur de la Chine et en Tartarie}

avoués par aucune puissance, et se voyaient calomniés par ceux auxquels ils s'étaient confiés. Ils n'avaient pas même été précédés par quelque voyageur de leur nation, qui, animé par des motifs de piété ou de curiosité, eût pu donner aux Chinois quelque idée avantageuse de son pays. Ce pays continua à être peu connu en Chine, même après que les Anglais eurent commencé à trafiquer à Canton. Les Chinois, enfin, ne distinguant longtemps les Anglais que par la méprisante épithète de Hoong-mow-zhin, qui, autant qu'elle peut être rendue dans notre langue, signifie « la race à la caboche rousse ».

Quand l'Angleterre eut accru son commerce au point d'envoyer annuellement un grand nombre de vaisseaux à Canton, et que le bruit de ses victoires dans I'Indostan, et de la conquête des îles Philippines dans les mers de la Chine, eut fixé l'attention de la cour de Pékin, cette cour chercha, sans doute, à connaître la nation qui se distinguait d'une manière si éclatante. Mais les questions qu'elle fit à cet égard ne purent être adressées qu'à des missionnaires, et leurs réponses furent dictées par les préjugés religieux que cette espèce d'hommes conserve jusqu'à présent contre les Anglais. II leur fallait beaucoup de précautions, et une conduite très réservée, pour effacer l'impression défavorable qu'on avait donnée d'eux. Mais cette conduite ne s'accordait pas toujours avec l'esprit d'indépendance et de liberté qui les caractérise et qui, quelque louable qu'il soit, pouvait quelquefois avoir une apparence d'orgueil et de présomption aux yeux des hautains et despotiques magistrats de la Chine, surtout lorsqu'ils le remarquaient dans des hommes adonnés au commerce, profession qu'ils regardent comme l'une des dernières de la société. Des matelots ignorants et grossiers, ou d'autres personnes d'un état inférieur, abusaient encore plus souvent de la liberté qu'on leur laissait, et leurs excès ne pouvaient qu'avoir des suites fâcheuses. Livrés à leurs passions, à leurs caprices, ils se croyaient tout permis, et ils révoltaient, par des scènes scandaleuses, un peuple dont les moindres actions sont motivées par des préceptes ou des règlements particuliers.

D'après tout cela, les Anglais étaient certainement représentés à la cour de Pékin comme les plus dangereux des étrangers qui fréquentaient les ports de la Chine, et on les traitait à Canton avec la plus grande rigueur possible. Les officiers impériaux, à l'inspection desquels ils se trouvaient soumis, pouvaient impunément les maltraiter, et gêner leur commerce. Quand cette 


\section{Voyage dans l'intérieur de la Chine et en Tartarie}

injustice excitait quelques plaintes, on les regardait comme frivoles ou mal fondées, et on les attribuait à un esprit inquiet et déraisonnable. On avait même pris des mesures assez efficaces pour empêcher les Anglais de faire entendre à l'avenir leurs réclamations; car on avait sévèrement puni quelques Chinois, soupçonnés de leur en avoir traduit dans la langue du pays. Le peu d'Anglais qui avaient quelque connaissance de cette langue étaient nécessairement employés à faire des représentations en faveur de leurs compatriotes, ce qui les exposait eux-mêmes beaucoup, et empêchait que d'autres n'apprissent le chinois. Que dis-je ? II n'était pas même sans danger, pour un maître de langue, de leur en donner des leçons. La nation anglaise se trouvait donc dans la nécessité de se confier entièrement aux négociants chinois, qui avaient un grand avantage à apprendre assez de mots anglais pour y traiter quelques affaires mercantiles. En outre, la grande supériorité que les Chinois, revêtus de quelque dignité, ont sur toute espèce de marchands, empêchait qu'ils ne fréquentassent les Anglais qui étaient à Canton; et quoiqu'il y eût plus de cent ans qu'une factorerie anglaise fût établie dans cette ville, il n'y avait pas eu dans les mœurs, les sentiments, la parure, les habitudes des deux nations, le moindre de ces rapprochements qui facilitent ailleurs les vues du commerce, et consolent souvent ceux qui vont s'y livrer loin de leur patrie.

Les préventions qu'on a contre les étrangers, préventions qu'inspirent toujours davantage ceux qu'on connaît le moins, ne pouvaient manquer de subsister, à Canton, dans toute leur force. Non seulement elles influaient sur la conduite des Chinois, mais elles la réduisaient en système, car ce peuple croit fermement être parvenu au plus haut degré de la civilisation; et la comparaison qu'il fait de ses mœurs avec celles des autres nations, le portant à regarder ces nations comme des barbares, il prend toute sorte de moyens pour maintenir dans le devoir tous les Européens qui abordent sur ses côtes. II semble aussi qu'il veut éviter par là le dangereux effet que pourraient avoir de mauvais exemples. La Chine n'avait ouvert aux vaisseaux étrangers qu'un seul de ses ports, et quand la saison de leur départ s'approchait, on obligeait chaque Européen de s'embarquer, ou au moins d'abandonner le territoire chinois; ainsi la factorerie anglaise restait déserte, et la terminaison d'une partie des affaires était forcément remise à l'année suivante. Des lois si 


\section{Voyage dans l'intérieur de la Chine et en Tartarie}

sévères étaient imposées, sans scrupule, aux étrangers. Quelle idée pouvait avoir de l'importance de leur commerce le gouvernement d'un pays où l'on voit tant de différents climats, et qui produit, si non tout ce qui fait les délices de la vie, au moins tout ce qui lui est nécessaire?

Quant au peuple chinois, quoiqu'il ait vu plusieurs de ses marchands s'enrichir en trafiquant avec les Européens, il continua à attribuer l'admission de ces étrangers, dans l'un de ses ports, à des principes d'humanité et de bienveillance envers les nations qui manquent des productions dont la Chine abonde. II croit qu'on ne traite avec ces nations que pour suivre les préceptes de ses anciens sages, et non dans le dessein d'en retirer un avantage réciproque.

II est vrai que, pendant longtemps, les marchandises d'Europe eurent fort peu de débit à la Chine. La nécessité où étaient les étrangers de payer en argent le surplus des objets qu'ils y achetaient ne pouvait flatter les Chinois comme elle aurait flatté d'autres nations, qui font sans cesse des remises de fonds de divers côtés. A la Chine, on est rarement dans ce cas. II fallut donc, dès lors, plus de métal pour y représenter la valeur des autres objets, et l'augmentation de ce métal y devint plutôt un inconvénient qu'un avantage.

L'opinion qu'on avait du commerce étranger rendit donc ceux qui étaient chargés de le surveiller, très indifférents sur ses progrès. Ils le souffraient plutôt qu'ils ne l'encourageaient ; et les Européens, employés à ce commerce, pouvaient très rarement intéresser les mandarins en leur faveur, ou même en obtenir justice. Les Anglais surtout étaient exposés à ce désavantage. Presque entièrement privés des moyens de défendre leur cause à Canton, ils n'avaient, dans la capitale, personne qui prît leurs intérêts à cœur et pût les mettre à l'abri des vexations. Ils éprouvaient enfin beaucoup de désagréments dans leur négoce, et étaient souvent personnellement insultés. Cependant, ils ne pouvaient croire qu'un pareil traitement fût autorisé par l'empereur de la Chine, ni même que ce prince en fût instruit. C'est pourquoi plusieurs agents de la Compagnie des Indes, employés au commerce de la Chine, sollicitèrent le gouvernement anglais pour qu'il envoyât une ambassade à Pékin, dans l'espoir que l'empereur donnerait des ordres pour faire cesser les injustices dont ils avaient à se plaindre. Des hommes intelligents qui, ayant résidé dans la capitale de la Chine et ayant même été 


\section{Voyage dans l'intérieur de la Chine et en Tartarie}

attachés à la cour, en qualité de mathématiciens ou d'artistes, s'étaient trouvés dans le cas d'observer les dispositions de ceux qui composaient cette cour, pensaient également qu'une ambassade sagement conduite ne pourrait manquer d'avoir d'heureux effets.

Les Anglais, comme nous l'avons déjà observé, n'étaient guère connus à Pékin que par les rapports infidèles de leurs rivaux. Ceux qui résidaient à Canton étaient seulement regardés comme des individus qui, n'ayant été ni recommandés, ni même avoués par leur gouvernement, n'avaient aucun droit de prétendre à une protection particulière. On sentit que la présence d'un ambassadeur d'Angleterre, à Pékin, offrirait un spectacle nouveau et flatteur, qui serait probablement bien reçu. On vit en même temps que les intérêts de la politique et du commerce, qui engagent la Grande-Bretagne à entretenir des ministres auprès des cours de l'Europe, et même en Turquie, l'obligeaient d'en avoir également un à Pékin, si sa résidence y était permise. Le commerce qui se fait entre les Chinois et les Anglais s'élève chaque année à plusieurs millions sterling; et quoique l'Angleterre soit à quelques milliers de lieues de distance de la capitale de la Chine, les territoires dépendant des deux empires ne sont éloignés que d'environ deux cents milles, du côté de I'Indostan. La plus grande partie du pays, qui s'étend entre les limites des possessions anglaises dans le Bengale, et l'extrémité occidentale de la province chinoise de Schen-Sée, est occupée par des petits princes qui se font presque continuellement la guerre, mais qui en même temps recherchent avidement l'alliance et la protection de l'un ou l'autre de leurs puissants voisins. Ces circonstances doivent, suivant l'ordre ordinaire des choses, et ainsi qu'on l'a déjà éprouvé, donner lieu à des discussions qui, sans l'interposition de personnes avouées par leur gouvernement, et revêtues d'un titre respectable, pourraient occasionner, entre les deux cours, une dangereuse mésintelligence.

Le même inconvénient n'est pas moins à craindre dans le cours des relations commerciales qui ont lieu sur l'une des autres frontières de la Chine. Il y a quelques années qu'un accident, qui arriva à Canton, faillit, dit-on, y faire cesser tout à coup le commerce étranger. Dans une réjouissance particulière, l'un des vaisseaux qui font le cabotage entre les établissements anglais de l'Inde et Canton, mais qui n'appartiennent point à la compagnie 


\section{Voyage dans l'intérieur de la Chine et en Tartarie}

anglaise, ni ne sont, en aucune manière, soumis à ses règlements, tira ses canons. Malheureusement ceux qui les avaient chargés avaient eu l'imprudence d'y mettre des boulets, et deux Chinois qui étaient dans un canot peu éloigné du vaisseau furent tués. Le meurtre est certainement moins fréquent, et excite bien plus d'horreur à la Chine que dans la plupart des contrées de l'Europe: aussi ne l'y pardonne-t-on jamais. Le vice-roi de Canton, indigné de l'atrocité supposée, ou de l'extravagance d'une action par laquelle un Européen avait ôté la vie à deux Chinois, fit demander sur-lechamp qu'on lui livrât l'Anglais qui avait mis le feu aux canons, ou celui dont il avait exécuté les ordres. Ce dernier s'était déjà sauvé ; et le premier n'ayant fait qu'obéir à l'autre, fut jugé innocent par les agents de la factorerie anglaise, lesquels résolurent de le protéger. Ils intercédèrent en sa faveur, et observèrent que le funeste accident qui avait eu lieu n'était point prémédité. Néanmoins, le vice-roi qui était déjà prévenu contre les Anglais et les croyait enclins à toute sorte de scélératesse déclara qu'une victime devait expier le crime qui avait été commis, et insista pour qu'on lui livrât le canonnier ; pour être même plus sûr de l'obtenir, il fit arrêter un des principaux supercargues de la Compagnie.

Cette mesure extraordinaire répandit l'alarme dans toutes les autres factoreries, et leurs agents firent aussitôt cause commune avec les Anglais. Les vaisseaux européens qui se trouvaient alors à Canton étaient en grand nombre et bien armés; les capitaines de ces vaisseaux se joignirent aux employés du commerce, et tous ensemble se disposèrent à résister aux intentions du vice-roi. Cet officier fit avancer alors un nombre immense de troupes sur les bords de la rivière de Canton, et parut déterminé à employer la force pour se faire obéir. II appréhendait d'autant moins d'user de la voie des armes, qu'il lui était aisé de justifier sa conduite aux yeux de l'empereur, puisqu'il pouvait seul lui rendre compte de toute l'affaire, exciter son ressentiment contre les Anglais et lui faire approuver la vengeance qu'il aurait cherché à tirer d'eux. Les Anglais, de leur côté, n'avaient nul moyen de réfuter, à Pékin, les accusations du vice-roi, ni de le détourner de ses

desseins. Ils ne purent prévenir une rupture absolue qu'en sacrifiant le malheureux canonnier, et ils le livrèrent avec le faible espoir qu'on le mettrait à mort sans le faire souffrir. 


\section{Voyage dans l'intérieur de la Chine et en Tartarie}

Si l'on en était venu aux mains, la perte de ceux qui seraient tombés des deux côtés n'eût peut-être pas été le seul malheur qui en eût résulté. On craignit avec raison que le gouvernement chinois, qui prend facilement l'alarme et prévoit toujours la possibilité des maux les plus éloignés, ne résolût d'empêcher le renouvellement de pareilles scènes, et n'interdît l'entrée de ses États aux étrangers, pour qu'ils ne missent plus en péril la vie de ses sujets, et qu'ils ne troublassent plus leur tranquillité.

La cessation du commerce de la Chine eût non seulement fait perdre à la Compagnie des Indes une partie de ses grands profits, mais elle eût privé l'État des impôts immenses que ce commerce lui procure. Elle eût, de plus, fait suspendre tout à coup le débit des marchandises que nos manufactures fournissent à la Chine où, par des sacrifices qu'un particulier ne pourrait jamais entreprendre, la Compagnie est parvenue à étendre ce débit bien audelà de ses espérances. Sans doute quelque funeste qu'eût été cet événement, le commerce eût insensiblement trouvé, sous les auspices d'un gouvernement protecteur, les moyens de se dédommager, et de fleurir encore en proportion des capitaux, de l'industrie et de l'intelligence de la nation qui s'en occupe.

Mais indépendamment de toute espèce de profit, on sait qu'un des principaux articles que nous tirons de la Chine et qu'on ne peut se procurer ailleurs, est devenu un objet de nécessité dans presque toutes les classes de la société en Angleterre. Jusqu'à ce que du thé d'une qualité aussi parfaite que celui de la Chine puisse se trouver dans un autre pays, en aussi grande quantité et à un prix aussi raisonnable, il faut donc continuer à l'aller chercher à Canton, et ne négliger aucune précaution pour s'en assurer, du moins tant que l'usage n'en diminuera pas dans notre pays.

Il est certain que le thé n'était connu dans aucune partie de l'Europe avant le commencement du dernier siècle. Dans ce temps-là, des aventuriers hollandais, cherchant quelque chose qui pût avoir du prix à la Chine, et apprenant que la boisson ordinaire y était faite avec les feuilles d'un arbuste qui se trouvait dans le pays, voulurent essayer si les Chinois feraient quelque cas d'une plante européenne à laquelle on supposait de très grandes vertus et s'ils voudraient la recevoir comme un objet de commerce. Les Hollandais leur portèrent donc de la sauge, herbe que l'école de Salerne vantait autrefois 


\section{Voyage dans l'intérieur de la Chine et en Tartarie}

comme un puissant préservatif contre plusieurs sortes de maladies. Les chinois payèrent la sauge avec du thé, que les Hollandais portèrent en Europe. Mais l'usage de l'herbe européenne ne dura pas longtemps à la Chine, et la consommation du thé augmenta chaque jour dans nos climats.

Vers le milieu du dernier siècle, on vendait en Angleterre, dans les tavernes et dans d'autres maisons, des infusions de thé, et le Parlement mit un impôt sur ces ventes. II n'y a pas encore cent ans que la Compagnie des Indes ne vendait pas annuellement plus de cinquante mille livres pesant de thé, et il n'en était, en outre, importé clandestinement qu'une très petite quantité. Aujourd'hui, les ventes de la Compagnie s'élèvent tous les ans à vingt millions pesant de livres; ce qui, en moins d'un siècle, fait une augmentation de quatre cent fois la même quantité, et équivaut à une livre par personne de tout rang, de tout sexe et de tout âge, dans les possessions de la Grande-Bretagne, en Europe et en Amérique.

L'interruption soudaine de l'importation du thé en Europe serait sans doute une grande calamité, et l'on ne connaît rien qui pût y suppléer. Cependant, on a déjà essayé d'introduire la culture du thé dans quelques-uns des cantons que les Anglais possèdent dans l'Indostan, et où le sol et le climat semblent le plus favorables à cet arbuste. II y en a aussi dans l'île de Corse une petite plantation qui est, dit-on, très florissante ; mais les frais qu'a coûtés jusqu'à présent la préparation du thé qu'on y a recueilli excèdent la valeur du produit. Malgré cela, il est très probable que par la suite on pourra, sans dépendre d'une puissance étrangère, se procurer tout le thé dont on aura besoin. Mais en attendant, la prudence a exigé qu'on cherchât à éviter le danger d'en manquer, et qu'on tâchât de former avec la cour de Pékin des liaisons qui rendissent moins précaire et plus avantageux le commerce que les Anglais font à la Chine. II fallait aussi prévenir les difficultés et écarter la jalousie que pouvaient occasionner les intrigues et les faux rapports des princes alliés ou tributaires de la Chine et de la Grande-Bretagne.

On était loin de se flatter qu'une si importante entreprise pût tout à coup s'exécuter et réussir complètement. On savait que la cour de Pékin se conduisait d'après des maximes particulières. Peu portée à avoir des relations avec les autres puissances, elle pense que ses sujets jouissent d'un bonheur qu'elle doit sagement conserver, en écartant d'eux de profanes étrangers. II 


\section{Voyage dans l'intérieur de la Chine et en Tartarie}

n'était guère vraisemblable que cette cour dérogeât à ses principes en faveur d'une nation dont l'empereur et ses mandarins connaissaient sans doute les richesses, les conquêtes et le pouvoir, mais peu les vertus.

Toutefois, on devait espérer que lorsque plusieurs Anglais, élevés en dignité, auraient successivement résidé à Pékin, et su, par une conduite prudente et des mœurs douces, mériter l'estime des principaux Chinois et le respect des autres, ils pourraient vaincre leurs préjugés, se concilier leur bonne volonté, et établir une confiance nécessaire à l'alliance qu'on désirait de former avec eux. L'admission des Anglais à Pékin était pourtant difficile, même incertaine. Un agent de la Compagnie des Indes, lequel, ayant été envoyé très jeune à Canton, était parvenu à apprendre la langue du pays, avait été puni, par ordre de la cour, pour avoir tenté de pénétrer jusque dans la capitale, où ses supérieurs l'envoyaient pour présenter un mémoire sur les vexations qu'éprouvait la factorerie anglaise.

Mais on pensait que les Chinois feraient un tout autre accueil à un envoyé d'un rang élevé et chargé d'une mission faite pour commander le respect chez toutes les nations civilisées. Un homme d'une naissance illustre et distingué par son mérite, résolut d'en faire l'épreuve. II était accompagné par des

personnes connues par leurs talents et leur capacité; mais sa mort prématurée l'empêcha d'acheter son entreprise. Cependant, ce ne fut qu'un retard. On ne renonça pas au projet qu'on avait formé, et dont les circonstances nouvelles pressaient encore l'exécution. On l'envisagea même alors sous des rapports plus étendus. Des vues d'humanité et de philosophie se joignirent à celles de la politique et du commerce.

Parmi les événements qui illustrent le règne de Georges III, quelques-uns des plus mémorables, sans doute, sont les voyages entrepris sous les auspices de ce prince. Alors les limites des sciences ont été reculées, et le globe a été parcouru sans aucun motif de lucre ou de conquête. Mais on a encore obtenu des avantages plus durables et plus dignes des âmes élevées. 


\section{Voyage dans l'intérieur de la Chine et en Tartarie}

Un homme ${ }^{1}$, que le gouvernement avait choisi, et que son intrépidité, sa raison, son expérience et l'étendue de ses connaissances rendaient capables des entreprises les plus difficiles, perfectionna beaucoup la navigation; et après des tentatives réitérées, résolut des problèmes géographiques non moins importants que curieux. Un autre homme ${ }^{2}$ qui, jeune encore, possédait déjà toutes les connaissances des plus savants naturalistes et qui, avide de s'illustrer par des découvertes nouvelles, abandonnait volontairement les jouissances de la fortune et du luxe, pour aller dans les climats les plus opposés et dans des mers inconnues, parvint à enrichir toutes les branches de l'histoire naturelle. De telles entreprises étaient si fort audessus de celles qui occupent ordinairement les hommes, et avaient un but si utile qu'elles devinrent sacrées pour un ennemi digne de les admirer; et, sans qu'on eût besoin de le demander, le navire de Cook fut à l'abri des attaques auxquelles la guerre exposait tous les autres vaisseaux anglais.

Des particuliers, qui possèdent une grande fortune, s'honorent sans doute lorsqu'ils en font un emploi utile et généreux en faveur de la société : ainsi les rois et les nations prospères ne peuvent faire un plus glorieux usage des moyens qui sont en leur pouvoir, qu'en s'efforçant d'éclairer le genre humain et d'augmenter son bonheur. Une telle conduite n'est même jamais sans avantage pour ceux qui la tiennent. Nul peuple ne peut se flatter que la nature lui ait prodigué assez de biens pour qu'il ne puisse pas en acquérir davantage, ni que l'usage qu'il fait de ce qu'il a, soit assez bien entendu pour n'être pas susceptible d'une plus grande perfection. Si l'on peut quelquefois apprendre des choses très utiles dans des pays où la civilisation est peu avancée, il est probable qu'on en apprendra bien davantage parmi la plus ancienne des sociétés et dans l'empire le plus peuplé de l'univers.

Le peu de voyageurs qui avaient trouvé le moyen de pénétrer à la Chine contribuaient plutôt à exciter la curiosité qu'à la satisfaire. Quelques-uns de leurs récits sont contradictoires, d'autres suspects; mais tous assurent que les productions du sol et des arts, la politique constante du gouvernement, le

\footnotetext{
${ }^{1}$ Le fameux capitaine Cook.

2 Sir J oseph Banks.
} 


\section{Voyage dans l'intérieur de la Chine et en Tartarie}

langage, les mœurs, les opinions du peuple, les maximes de morale, les institutions civiles, l'ordre et la tranquillité qui règnent dans l'État sont le spectacle le plus étonnant qui puisse être offert aux regards des hommes. Le gouvernement chinois n'a opposé des obstacles aux observations des voyageurs que parce qu'il s'est imaginé qu'il y avait du danger à communiquer avec des étrangers turbulents et sans mœurs. Ce préjugé ne pouvait donc être détruit que par la conduite exemplaire des Européens qui résideraient à Pékin.

Mais des exemples d'une bonne conduite ne suffisaient pas, sans toutes les qualités propres à les rendre remarquables sur un théâtre si nouveau, et au milieu de préjugés si invétérés. Un ambassadeur étant une fois admis à la Chine, le succès de sa mission devait certainement dépendre de l'idée qu'on prendrait de lui et de sa suite, lorsqu'il traverserait l'empire et qu'il serait présenté à la cour. S'il trouvait le moyen de se rendre agréable au peuple, s'il savait gagner la bienveillance des mandarins, s'il parvenait à faire changer les préventions qu'inspirait contre elle la nation qui l'avait envoyé ; s'il pouvait, enfin, obtenir que les Chinois désirassent d'avoir constamment un ambassadeur anglais à leur cour, quoiqu'ils soient dans l'usage de n'y souffrir la résidence habituelle d'aucun ministre étranger, alors le premier objet de l'ambassade était rempli, et on avait la facilité de s'assurer des grands avantages qui pouvaient résulter d'un rapport intime avec toutes les parties de la Chine.

Cependant, ces avantages ne devaient s'acquérir qu'avec le temps : trop d'empressement d'abord n'aurait fait que les retarder. Quelques-uns des plus sages directeurs de la Compagnie des Indes, qui connaissaient combien leur commerce à Canton avait à souffrir de gêne et de tracasseries, mais qui sentaient aussi quel tort immense ferait à la Compagnie la cessation de ce commerce, recommandèrent de prendre les précautions les plus grandes dans les commencements de la négociation, de peur que si l'on insistait trop vivement sur la réparation des injustices, ou si l'on demandait prématurément des privilèges étendus, la cour de Pékin ne prît l'alarme, ne s'aigrît et ne pensât qu'il était temps de prévenir des querelles et des usurpations de la part des étrangers, en leur fermant entièrement ses ports. 


\section{Voyage dans l'intérieur de la Chine et en Tartarie}

Il convenait donc que le gouvernement britannique ne confiât une mission aussi importante et aussi difficile qu'à un homme qui aurait donné des preuves de sa prudence et de son habileté, par un long séjour dans des cours étrangères, et qui, sans vouloir jouir d'un avantage soudain, se contentât de préparer des succès. On ne pourrait pas soupçonner que celui qui obtiendrait un tel honneur le dût à la faveur ministérielle ou à l'influence parlementaire. Dans plusieurs circonstances importantes qui avaient rapport à la Compagnie des Indes, le ministre avait su montrer que le seul droit auprès de lui, pour obtenir des emplois, était d'avoir les qualités propres à les remplir ; et les places les plus lucratives, les plus honorables avaient été accordées à des hommes qui ne les sollicitaient ni ne les attendaient. II fallait donc, en cette occasion, en agir de la même manière; mais quelque temps s'écoula avant qu'on se fût entièrement décidé dans le choix qu'on voulait faire. 


\section{Voyage dans l'intérieur de la Chine et en Tartarie}

\section{CHAPITRE II}

\section{Préparatifs de l'ambassade}

Quelque flatteur qu'il soit pour un ministre de pouvoir accorder des places, il faut convenir que, dans les occasions importantes, c'est un devoir très délicat et très difficile à remplir. Responsable des plans qu'il forme, il ne l'est pas moins du choix des personnes auxquelles il en confie l'exécution. Ses plans dépendent de son génie, et l'on ne peut les attribuer à des affections particulières ; mais quand il nomme à quelque emploi, il a besoin, pour se mettre à l'abri de la censure, d'être également en garde, et contre ses propres inclinations et contre les sollicitations de ses plus intimes amis; il ne peut être véritablement tranquille sur le choix qu'il fait que lorsque son opinion s'accorde avec la voix publique.

C'est ce qui lui réussit en nommant à l'ambassade de la Chine. Lord Macartney brillait au nombre de ceux dont la réputation de talent, d'habitude aux affaires et de probité, est solidement établie. Peu d'hommes ont eu occasion de se montrer dans des situations plus diverses, et peut-être était-il le seul qui, après avoir rempli une des premières places dans l'Inde, eut réuni les suffrages des deux partis qui divisent le Parlement. Ses amis avaient joui de la satisfaction d'entendre prononcer son éloge, le même jour, par les deux principaux orateurs de ces différents partis. Envoyé dans sa jeunesse à Pétersbourg, il y conclut, pour vingt ans, un traité de commerce à des conditions si favorables que l'impératrice de Russie reconnaissant enfin qu'il était trop à l'avantage de la Grande-Bretagne, refusa longtemps de le renouveler ${ }^{1}$. Lord Macartney eut depuis plusieurs occasions de prouver, en différentes parties du globe, combien son habileté et sa prudence étaient utiles au bien de son pays. II avait, à la vérité, refusé le gouvernement du

1 Sir George Staunton se trompe. Les délais qu'apporta Catherine II au renouvellement de ce traité, n'avaient pour motif que le mécontentement que lui avait occasionné l'accession du roi d'Angleterre à la ligue des électeurs. (Note du 


\section{Voyage dans l'intérieur de la Chine et en Tartarie}

Bengale, place où l'on jouit de plus de pouvoir et où l'on acquiert plus de richesses que dans aucune autre de celles qui dépendent du ministère ; mais une ambassade à la cour de Pékin était, à d'autres égards, si extraordinairement attrayante, et offrait tant de satisfaction à une âme ardente et avide de s'instruire, que dès qu'elle lui fut offerte, il ne balança pas à l'accepter.

Lord Macartney ne proposa alors aucune condition au gouvernement. M. Dundas, secrétaire d'Etat, qui avait conçu le plan de l'ambassade, et auquel doivent être attribués tous les avantages qui en résulteront, choisit, de son propre mouvement, un des amis ${ }^{1}$ même de lord Macartney, pour l'accompagner en qualité de secrétaire d'ambassade, et pour le remplacer au besoin. Cet homme était déjà connu pour avoir acquis quelque expérience dans les affaires, et pour avoir, en 1784, négocié la paix avec Tippoo-Saïb. Toutes les autres personnes attachées à l'ambassade furent nommées sur la recommandation de l'ambassadeur.

On ne fut pas longtemps incertain sur la route que l'ambassade devait suivre. Quoique Pékin soit situé du même côté de l'équateur que Londres, et qu'il n'y ait qu'une différence de onze degrés entre la latitude de ces deux villes; quoiqu'en tirant une ligne directe de l'une à l'autre, cette ligne passe sur une très petite partie de mer, et à travers des pays agréables et où le climat est doux et salubre, il n'en est pas moins vrai que la plupart de ces pays sont habités par des nations trop peu civilisées pour qu'on puisse voyager parmi elles avec aisance et sécurité, et que la distance de Londres à Pékin est de cinq mille neuf cent quatre-vingt-dix milles anglais. On pensa donc que la route par mer était la seule praticable, bien que les circuits qu'elle oblige de faire triplent au moins la longueur du chemin.

Le premier lord de l'amirauté pensa alors que puisqu'on était en paix, on ne pouvait pas mieux employer un des vaisseaux ${ }^{2}$ du roi qu'à faire ce

Traducteur.)

${ }^{1}$ C'était sir George Staunton, auteur de cette relation.

2 Le Lion, de 64 canons. 


\section{Voyage dans l'intérieur de la Chine et en Tartarie}

voyage: il l'offrit à l'ambassadeur et le pria d'en choisir lui-même le commandant. Ce choix n'était certainement pas une chose indifférente. II ne suffisait pas de posséder les qualités nécessaires pour diriger un long voyage avec sécurité et agrément pour les passagers et pour l'équipage. II fallait encore être capable de traverser des mers infréquentées; car on avait le dessein de faire voile directement pour le port le plus près de la capitale de la Chine, en parcourant un espace de dix degrés de latitude et de plus de cinq degrés de longitude dans la mer Jaune, et le golfe de Pékin, qu'aucun navigateur européen n'avait encore fait connaître.

La mer Jaune est, excepté à son entrée, bornée par les côtes orientales et septentrionales de la Chine, et par celles de la Tartarie et de la Corée, également dépendantes des Chinois; ainsi, pour y pénétrer, et acquérir des connaissances qui manquaient à la navigation, sans donner le moindre ombrage à la cour de Pékin, on ne pouvait pas trouver une occasion plus favorable que celle de l'ambassade qu'on envoyait dans cette même cour. En outre, il était bien plus convenable de suivre cette nouvelle route que d'aller aborder à Canton, sur la côte occidentale de la Chine, et d'entreprendre ensuite, pour se rendre dans la capitale de l'empire, un voyage par terre d'environ quatorze cents milles anglais. Il y aurait eu trop d'inconvénient à s'exposer aux délais qu'une aussi longue marche aurait pu naturellement occasionner, aux obstacles qu'on aurait peut-être volontairement suscités, et aux intrigues dont on n'eût pas alors manqué de trouver de nombreux prétextes. Ces intrigues auraient été l'ouvrage des magistrats et des marchands de Canton, dont les uns auraient craint que les représentations de l'ambassadeur n'influassent sur leur autorité, et ne fissent mettre des bornes à leur oppression, et les autres, qu'elles ne diminuassent les profits de leur commerce exclusif avec les étrangers.

Le capitaine Gower, élevé depuis au rang de chevalier baronnet sous le nom de sir Erasme Gower, était connu par ses talents et son expérience dans tout ce qui a rapport à la marine. Non seulement il avait donné, dans divers combats, des preuves de sa bravoure, mais il avait, dans sa jeunesse, fait deux fois le tour du monde, et contribué d'une manière distinguée à parer aux accidents et à surmonter les nombreux obstacles auxquels on est inévitablement exposé dans de si longs et si périlleux voyages. Ainsi, il était 


\section{Voyage dans l'intérieur de la Chine et en Tartarie}

accoutumé à affronter des routes nouvelles et à remédier aux inconvénients qui s'y rencontrent. Ce fut lui qui, à la sollicitation de lord Macartney, eut le commandement du vaisseau de guerre le Lion. Maître de nommer ses officiers, il les choisit tous d'après la connaissance particulière qu'il avait de leur mérite. Une foule de marins brigua l'avantage de servir sous lui, dans une occasion si intéressante. Des enfants des premières familles d'Angleterre, remplis de ce courage entreprenant, qui est le partage de la jeunesse, furent embarqués à bord du Lion, en qualité de gardes-marine, et leur nombre excéda de beaucoup celui qu'on a coutume d'avoir dans un vaisseau.

On accorda aussi à l'ambassadeur une garde militaire, ainsi que cela se pratique dans l'Orient, non qu'une telle suite soit presque jamais nécessaire à la sûreté d'une ambassade, mais parce qu'elle ajoute à sa dignité.

Les gardes de lord Macartney n'étaient pas en grand nombre; mais ils avaient été choisis dans les meilleurs régiments d'infanterie et d'artillerie. Ils avaient quatre pièces de campagne ; et l'on se flattait que la manière rapide et nouvelle dont ils manieraient ces canons, et les diverses évolutions militaires auxquelles ils étaient très exercés, pourrait être un spectacle intéressant pour l'empereur de la Chine, et lui donner une idée de ce qu'est l'art de la guerre parmi les Européens. Cette espérance était d'autant mieux fondée qu'on savait que ce prince s'enorgueillissait d'avoir conquis des pays très vastes et subjugué plusieurs nations tartares. Cependant, en accordant des gardes à l'ambassadeur, il était indispensable de maintenir parmi eux une discipline sévère, afin de prévenir des excès et même des oublis qui, quoique de peu de conséquence ailleurs, auraient pu paraître scandaleux aux yeux d'hommes aussi amis de l'ordre que les Chinois, et fortifier les préjugés dont ils étaient déjà imbus contre les Anglais.

Cet objet fut rempli en donnant le commandement de la garde au major Benson ${ }^{1}$ et aux lieutenants Parish et Crewe ${ }^{2}$. On verra, dans le cours de cet ouvrage, que le lieutenant Parish, qui est un excellent dessinateur, a beaucoup contribué à nous mettre à même de satisfaire la curiosité du public,

\footnotetext{
1 Le major Benson est maintenant colonel.

2 Le lieutenant Parish est capitaine, et le lieutenant Crewe, lieutenant-colonel.
} 


\section{Voyage dans l'intérieur de la Chine et en Tartarie}

par les dessins de plusieurs objets intéressants que nous rencontrâmes sur la route. On avait, en outre, attaché à l'ambassade un peintre et un dessinateur habile, qui ont fourni le dessin d'une partie des gravures que nous joindrons ici.

Le docteur Gillan fut nommé médecin de l'ambassade; car il était non seulement nécessaire qu'un homme de sa profession accompagnât des personnes destinées à voyager en divers climats, mais on ne doutait pas que, lorsque nous serions arrivés à la Chine, les preuves secourables qu'il donnerait de sa science n'excitassent l'admiration et la reconnaissance d'un peuple chez lequel la médecine a fait bien moins de progrès qu'en Europe, et ne concourussent au succès de l'ambassade. Le docteur Gillan était en outre très habile chimiste ; et comme la chimie est la base de plusieurs arts utiles, il était naturel de penser que ses connaissances lui serviraient à juger jusqu'à quel degré de perfection ces arts étaient parvenus dans les différents pays que nous devions visiter. Nous avions pour chirurgien le docteur Scot, dès longtemps connu par ses talents et par ses services à bord des vaisseaux du roi.

Le docteur Dinwiddie et M. Barrow, habiles en astronomie, en mécanique, et dans tout ce qui a rapport à la géométrie, furent adjoints à l'expédition, à laquelle ils ne pouvaient, sans doute, qu'être très utiles.

M. Acheson Maxwell, qui avait déjà accompagné dans l'Inde lord Macartney et mérité sa confiance, abandonna la place qu'il occupait dans un des bureaux du ministère, pour remplir celle de secrétaire de l'ambassadeur, et on lui donna pour adjoint le jeune Edward Winder, agrégé à l'université.

On choisit un nouvel écrivain de la Compagnie des Indes, M. Henry Barring, pour accompagner l'ambassade à Pékin, afin que les connaissances qu'il acquerrait dans cette capitale le missent à même de servir plus efficacement la Compagnie, à Canton. 


\section{Voyage dans l'intérieur de la Chine et en Tartarie}

On donna aussi à l'ambassadeur un jeune page ${ }^{1}$, accompagné de son instituteur, qui était un étranger distingué par son érudition. $\mathrm{Ni}$ cet instituteur, ni son élève ne furent inutiles à l'expédition.

Il est, sans doute, à regretter que nous ne puissions pas joindre à cette liste le nom de quelque naturaliste célèbre; car il n'eût pas manqué d'occasions de faire des observations intéressantes dans le cours du voyage. Le plus jeune de ceux que nous avons nommés était peut-être le moins ignorant en histoire naturelle. M. Afzelius, Suédois, qui était alors en Angleterre, et qu'on connaissait pour être très savant, fut sollicité de nous accompagner ; mais il s'était déjà engagé d'aller dans le nouvel établissement de Sierra Leone sur la côte d'Afrique.

Cependant, le zèle des naturalistes ne fut pas en défaut, et on choisit deux jardiniers botanistes, dont l'un aux frais du gouvernement, et l'autre à ceux d'un des membres de l'ambassade. Leur soin devait être de rassembler, durant l'expédition, tout ce qui paraîtrait le plus propre à enrichir l'histoire naturelle.

II restait encore à remplir l'emploi le plus nécessaire et le plus difficile : c'était celui d'interprète et de traducteur en langue chinoise. Dans toute l'étendue de l'empire britannique, il n'existait pas un seul homme en état d'occuper cette place. Plusieurs supercargues de la Compagnie des Indes étaient revenus en Angleterre après avoir résidé plusieurs années à la Chine ; mais ils ne savaient pas un mot de chinois, et l'on n'en sera point surpris si on se rappelle ce que nous avons dit dans notre premier chapitre. M. Flint, qui avait fait exception à cette règle et qui, après un long séjour à Canton, avait été emprisonné et ensuite banni pour avoir tenté d'aller à Pékin, était mort depuis peu en Angleterre. Un Français, nommé M. Galbert, qui, ayant aussi longtemps résidé à Canton et appris le chinois, avait été choisi pour servir d'interprète à l'ambassade projetée avant celle de lord Macartney, venait également de payer son tribut à la nature.

\footnotetext{
${ }^{1}$ Ce page était le fils de sir George Staunton.
} 


\section{Voyage dans l'intérieur de la Chine et en Tartarie}

II n'était nullement sûr de compter qu'on trouverait à Canton les interprètes dont on avait besoin. Quelques habitants de cette ville savaient bien assez d'anglais ou de portugais pour servir de truchement aux marchands européens, en ce qui concerne leurs ventes ou leurs achats ; mais il leur eût été impossible de soutenir la conversation sur tout autre sujet. II y a même plus : le chinois qu'ils parlent communément n'est pas compris à Pékin ; et l'expérience a souvent appris à douter de leur intelligence, non moins que de leur fidélité. II fallait donc chercher, dans le continent de l'Europe, quelques hommes dignes de confiance, lesquels eussent résidé assez longtemps à la Chine pour y apprendre la langue des mandarins, ou bien essayer, si on n'y parvenait pas, de découvrir quelques Chinois qui eussent quitté leur pays et appris les langues européennes. On savait que les missionnaires qui étaient tolérés à Pékin, sous la protection immédiate de l'empereur, obtenaient très rarement la permission de retourner dans leur patrie. Mais quelques autres, qui y avaient pénétré sous des déguisements, ont échappé par hasard à cette loi. Quelques lettrés chinois avaient trouvé le moyen de se rendre à Rome, où ils étaient employés à examiner les livres et les manuscrits chinois de la bibliothèque du Vatican; et le zèle du christianisme a fondé à Naples un collège consacré à l'éducation des jeunes Chinois que les missionnaires ont l'adresse de faire sortir de leur pays.

Il était sans doute incertain qu'aucun de ces Chinois consentît à se mettre à la suite de l'ambassade anglaise; mais on ne voyait pas d'autre moyen d'avoir un interprète. Le secrétaire d'ambassade partit donc de Londres au mois de janvier 1792, dans le dessein de chercher l'homme qu'on désirait. II se rendit d'abord à Paris, où il y avait encore deux maisons fondées pour les missionnaires ; celle de Saint-Lazare et celle des Missions étrangères. Dans la première, il ne se trouva alors personne qui fût allé en Chine ; dans l'autre, il y avait un prêtre qui en était revenu depuis vingt ans : mais il ne se rappelait que quelques mots de la langue chinoise, et il ne voulut, à aucune condition, retourner dans un pays aussi éloigné.

Il fallut donc, malgré les rigueurs de la saison, traverser les Alpes et se rendre en Italie. Les Chinois lettrés qui avaient été au Vatican n'existaient déjà plus: cependant le voyage de Rome ne fut pas inutile à sir George Staunton. Le cardinal Antonelli, préfet de la congrégation établie pour la 


\section{Voyage dans l'intérieur de la Chine et en Tartarie}

propagation de la foi catholique, lui donna des lettres de recommandation très pressantes pour les missionnaires italiens qui étaient à la Chine, et pour les curateurs du collège des Chinois, à Naples. A son arrivée dans cette capitale, sir George trouva dans le collège divers jeunes Chinois, dont quelques-uns y étaient depuis plusieurs années et parlaient avec facilité le latin et l'italien. En leur enseignant ces langues, on avait eu soin d'empêcher qu'ils n'oubliassent la leur ; car ils étaient tous destinés à être prêtres, et renvoyés dans leur pays, pour qu'ils s'y occupassent du salut de ceux de leurs compatriotes qui étaient déjà chrétiens, et qu'ils s'efforçassent de persuader à d'autres de le devenir. Il y en avait même dont l'éducation était achevée et qui, ayant reçu l'ordre de prêtrise, étaient prêts à s'embarquer. Mais les curateurs du collège, fidèles à l'esprit de leur institution, et montrant non moins de vigilance qu'une mère qui craint qu'on ne séduise sa fille chérie, étaient loin de vouloir confier leurs élèves sans précaution, de peur que, pendant le voyage, quelque circonstance fatale ne les détournât de leur pieuse destination.

Cependant, grâce à l'entremise de sir William Hamilton, ministre d'Angleterre, lequel avait eu occasion de rendre quelque service au collège ; grâce également à don Gaetano d'Ancora, Napolitain respectable, et ami particulier des curateurs, on triompha des scrupules de ces bons prêtres. Sir George revint à Londres au mois de mai avec deux jeunes Chinois pleins de vertu, de candeur, d'aménité, et capables de rendre parfaitement les expressions de leur langue en latin et en italien, qu'entendait très bien l'ambassadeur.

Ces interprètes commencèrent bientôt à se rendre utiles. D'après ce qu'ils pouvaient connaître ou se rappeler du goût de leur pays, ils indiquèrent les choses les plus propres à y réussir. Ils aidèrent surtout dans le choix des présents, que conformément aux usages de l'Orient, il fallait offrir à l'empereur et aux grands de sa cour. Une partie de ces présents fut aussi composée de ce qu'on savait être le plus recherché et donner le plus de profit à Canton. Souvent, on y avait vendu, à des prix excessifs, des ouvrages de mécanique, ingénieux et très compliqués, formés d'un riche métal, ornés de pierres précieuses, et qui, par le moyen de quelques rouages, de quelques ressorts secrets, paraissaient avoir un mouvement qui semblait spontané. Ces choses, il est vrai, n'étaient d'aucune utilité ; mais l'esprit des mandarins qui 


\section{Voyage dans l'intérieur de la Chine et en Tartarie}

étaient à la tête du gouvernement en avait été tellement frappé, qu'ils avaient instamment recommandé aux marchands du pays de s'en procurer à quelque prix que ce fût. II était dangereux de se soustraire à cet ordre ; mais ensuite les ouvrages demandés ne furent acceptés que comme des présents, ou bien les personnes qui les reçurent, voulant avoir l'air de les payer, donnèrent en retour une somme légère et très peu proportionnée à ce qu'ils avaient coûté à Londres. Ce fut ainsi que des armateurs particuliers introduisirent en Chine pour plus d'un million sterling de ces brillants joujoux ou, pour parler le jargon corrompu de Canton, de ces sing-song, dont la plus grande partie fut portée peu à peu dans les palais de l'empereur et de ses ministres. Les mandarins de Canton commencèrent par obtenir ces choses en promettant à leurs inférieurs de les protéger, et ensuite ils les firent passer à Pékin, dans l'espoir d'obtenir eux-mêmes la protection de leurs supérieurs.

Peut-être eût-ce été en vain que le gouvernement tentât de surpasser en présents, de l'espèce dont nous venons de parler, soit pour l'ouvrage, soit pour le prix, ce que de simples particuliers avaient déjà envoyé à la Chine. En outre, il y avait lieu de croire qu'on y avait porté une trop grande quantité de ces magnifiques bagatelles pour qu'elles pussent y causer encore quelque plaisir. Mais on pensa que tout ce qui montrerait le génie des sciences et des arts de l'Europe procurerait une satisfaction plus vraie et plus durable à un prince, que son âge devait naturellement porter à ne chercher dans tous les objets que ce qu'ils avaient d'utile.

Comme l'astronomie est particulièrement estimée en Chine, et qu'elle y fait même partie des travaux du gouvernement, on jugea que la cour de Pékin recevrait avec joie les instruments astronomiques les plus nouvellement inventés et les mieux travaillés, ainsi que l'imitation la plus parfaite qui eût encore été faite des mouvements célestes.

Des ouvrages sortis des meilleures manufactures anglaises, et tout ce qu'on a de mieux imaginé de nos jours pour servir aux agréments de la vie, semblaient devoir remplir la double intention de faire plaisir à ceux à qui ils étaient destinés, et d'occasionner par la suite un plus grand débit dans la vente des objets de la même espèce. La Compagnie des Indes fournit un de ses vaisseaux les plus grands et les plus commodes pour porter les présents qu'on envoyait à la cour de la Chine, ainsi que les personnes de l'ambassade 


\section{Voyage dans l'intérieur de la Chine et en Tartarie}

qui ne pourraient pas être assez agréablement logées à bord du Lion. Le vaisseau de la Compagnie fut mis sous le commandement du capitaine Mackintosh, marin sage et expérimenté. Un autre vaisseau d'une moindre grandeur fut, en même temps, armé pour servir d'allège.

La nouvelle de ces préparatifs ayant déjà été plusieurs fois écrite à la Chine, par des voies étrangères, on ne devait pas douter qu'elle n'y fût connue avant que l'ambassade n'y abordât. II était donc nécessaire de l'annoncer expressément au gouvernement chinois, afin de s'assurer des effets de la première impression, et d'empêcher que par erreur, ou par quelque intention malveillante, il ne prît cette mission pour une entreprise hostile et dangereuse, et ne refusât peut-être de recevoir l'ambassadeur. La Compagnie avait récemment nommé, parmi ses employés les plus capables, trois commissaires pour aller régler ses affaires à Canton. Ce fut à eux qu'on confia le soin d'annoncer authentiquement la mission de lord Macartney. Sir François Baring, président des directeurs de la Compagnie, écrivit, à cet effet, une lettre au vice-roi de Canton, et il chargea les commissaires de la remettre d'une manière si publique, que quels desseins qu'eût cet officier, il ne lui fût pas permis de la dérober à la connaissance de l'empereur.

Sir François Baring disait dans cette lettre :

«Que son très gracieux souverain avait appris que ses sujets établis à Canton avaient eu dessein d'envoyer une députation à la cour de Pékin, pour complimenter l'empereur sur ce qu'il venait d'entrer dans la quatre-vingtième année de son âge, mais que, comme ce dessein était resté jusqu'alors sans exécution, la cour en avait été très mécontente; que, désirant de cultiver l'amitié de Sa Majesté chinoise, d'accroître les rapports de la bonne harmonie qui existaient entre les cours de Pékin et de Londres, et d'étendre les liaisons du commerce entre leurs sujets respectifs, le roi d'Angleterre avait nommé son très cher cousin et conseiller, lord Macartney, homme d'une vertu, d'une sagesse et d'une capacité distinguées, ambassadeur auprès de l'empereur de la Chine, et l'avait chargé de le représenter, et de témoigner, dans les termes 


\section{Voyage dans l'intérieur de la Chine et en Tartarie}

les plus expressifs, la satisfaction qu'il éprouverait, si cette marque de bienveillance et de considération servait à établir entre eux une alliance et une amitié perpétuelles; que sa majesté britannique, envoyant en même temps à l'empereur divers présents d'une grandeur et d'un mécanisme trop délicat pour être transportés par terre sans inconvénient, à une aussi grande distance que celle qu'il y avait de Canton à Pékin, l'ambassadeur s'embarquerait avec une suite convenable dans un des vaisseaux du roi, et se rendrait directement à Tien-Sing, port le plus rapproché de la résidence de sa majesté chinoise.

Sir François terminait sa lettre en demandant :

«Que cet avis fût, sur-le-champ, transmis à la cour de Pékin, parce qu'il espérait que cette cour donnerait des ordres pour que les vaisseaux du roi de la Grande-Bretagne, ainsi que l'ambassadeur et sa suite, fussent reçus d'une manière convenable dès qu'ils arriveraient à Tien-Sing, ou sur les côtes voisines.

Les présents mentionnés dans cette lettre étaient d'un si grand prix que quelques personnes crurent que la cour d'Angleterre avait conçu quelque projet extraordinaire. Les membres du corps diplomatique, qui regardent comme un devoir d'épier tout ce que fait le gouvernement auprès duquel ils résident, furent très attentifs en cette occasion. L'un d'entre eux qui, encore imbu de ce préjugé méprisé qu'inspire une jalousie mercantile, semblait ignorer que le globe est assez grand pour ceux qui veulent y trafiquer, et que le commerce fleurit toujours davantage par l'extension de ses rapports, ne manqua pas d'attribuer au gouvernement anglais et à la Compagnie des Indes, le projet d'envahir le commerce de la Chine, à l'exclusion de tous les autres Européens, et proposa à sa cour de faire partir une contre-ambassade pour prévenir ce malheur. Cependant, les Anglais étaient si éloignés de songer au monopole impraticable, dont on leur imputait le dessein, que comme la Hollande était alors leur alliée, et qu'ils s'intéressaient véritablement au commerce qu'elle faisait à la Chine, ils s'empressèrent de prévenir les Etats généraux de la mission de lord Macartney, et leur offrirent les bons offices de ce ministre, si quelque circonstance exigeait que la factorerie hollandaise de Canton eût besoin d'avoir recours à lui. 


\section{Voyage dans l'intérieur de la Chine et en Tartarie}

Certes, rien ne montre plus clairement le but général de la mission, dont nous rendons compte, que les instructions particulières que le roi donna à l'ambassadeur par l'organe de l'un de ses secrétaires d'Etat. Ces instructions disaient :

«Que depuis longtemps les Anglais faisaient plus de commerce à la Chine qu'aucune des autres nations européennes; que les relations commerciales entre plusieurs de ces nations et les Chinois avaient été précédées ou accompagnées de quelque communication particulière avec le souverain de la Chine; que d'autres avaient eu l'appui des missionnaires qui, par leur science ou par leur habileté dans les arts, s'étaient fait bien accueillir de la cour curieuse et polie de Pékin; et que, bien qu'occupés par les succès de la religion, ces missionnaires n'avaient sans doute pas négligé les intérêts de leur pays, tandis que les négociants anglais restaient sans secours, sans aveu, dans un pays dont l'éloignement permettait qu'on dénigrât le caractère de leur nation, et qu'on y rabaissât son importance, et où même la profession de négociant n'était pas assez estimée pour leur procurer de la sûreté et de la considération. Que, dans ces circonstances, la dignité et la bienfaisance de sa majesté exigeraient qu'elle portât un regard paternel sur ceux de ses sujets qui étaient à Canton; quand bien même le commerce et la prospérité de la nation ne seraient pas intéressés à leurs succès, et qu'elle réclamât pour eux la protection de l'empereur de la Chine, et les égards qu'un puissant monarque avait droit d'attendre d'un autre. Qu'une communication libre avec le peuple le plus singulier, peut-être, qui existe sur le globe, et qui a connu la civilisation et cultivé les arts, depuis une longue suite de siècles, avec moins d'interruption qu'aucun autre, méritait d'être recherchée par la nation anglaise, qui avait vu avec plaisir et loué avec reconnaissance les voyages entrepris par les ordres de son roi et aux frais du gouvernement pour les progrès des sciences, la découverte des pays lointains et la connaissance des mœurs étrangères ; mais qu'en tâchant d'étendre les relations des Anglais avec les Chinois, sa majesté britannique n'avait en vue que les intérêts 


\section{Voyage dans l'intérieur de la Chine et en Tartarie}

de I'humanité, l'avantage réciproque des deux nations, et la protection que le gouvernement de la Chine devait au commerce.

C'est dans le même esprit que le roi d'Angleterre disait dans sa lettre à l'empereur de la Chine:

«L'inclination naturelle d'un prince, grand et bienfaisant, tel que votre majesté impériale, que la providence a placée sur le trône pour l'avantage du genre humain, est de conserver la paix et la sécurité dans les pays soumis à sa domination, et de travailler sans relâche à accroître le bonheur, les vertus et les connaissances de ses sujets, en faisant, autant qu'il le peut, jouir des mêmes bienfaits toutes les autres nations.

«Animée des mêmes sentiments, dès les premiers jours d'un règne, commencé au milieu des horreurs de la guerre, sa majesté britannique, après avoir vaincu ses ennemis dans les quatre parties du globe, leur a accordé la paix aux conditions les plus équitables. Non encore satisfaite depuis, d'avoir, à tous égards, accru la prospérité de ses sujets à un degré dont les temps les plus reculés ne fournissent point d'exemple, elle a plusieurs fois fait armer des vaisseaux et envoyé les hommes les plus sages et les plus intelligents de son royaume à la découverte des régions inconnues. Son dessein n'était alors ni de faire des conquêtes ni d'étendre sa domination; car les pays soumis à sa puissance suffisaient à ses vœux. II n'était pas, non plus, d'acquérir des richesses, ni de favoriser le commerce de ses peuples; mais de connaître toutes les parties habitables de la terre, et la variété de leurs productions; de faire répandre l'instruction, les arts et les agréments de la vie dans les lieux où ils avaient été auparavant ignorés. Après cela, elle a envoyé d'autres vaisseaux chargés d'animaux et des végétaux les plus utiles à l'homme, dans les îles qui en manquaient. Elle a été encore plus ardente à connaître les arts et les mœurs des pays où la civilisation est, depuis une multitude d'âge, perfectionnée par les sages lois et les exemples vertueux de leurs souverains. Elle a senti surtout un vif désir d'être instruite des institutions célèbres établies dans le vaste et populeux 


\section{Voyage dans l'intérieur de la Chine et en Tartarie}

empire de sa majesté chinoise; institutions qui ont élevé cet empire à un point de prospérité qu'admirent toutes les nations voisines.

«Sa majesté britannique, étant maintenant en paix avec tout le monde, croit ne pouvoir pas choisir un moment plus propice pour étendre les liens de son amitié et de sa bienveillance, et proposer à sa majesté impériale d'assurer les avantages qui doivent résulter des relations amicales entre deux nations aussi puissantes et aussi instruites que les Anglais et les Chinois.

L'objet de l'ambassade n'était donc pas de protéger seulement le commerce des Anglais, à Canton. Lord Macartney devait non seulement se rendre en Chine, mais visiter, à son choix, tous les autres pays de cette partie de I'Asie, qu'on peut appeler l'Archipel chinois, et où l'on était à même d'acquérir quelques notions utiles ou importantes. Il avait le pouvoir de traiter, en qualité d'ambassadeur, avec l'empereur du Japon, le roi de la Cochinchine et, en général, tous les princes et souverains dont les États sont situés dans les mers de la Chine.

Enfin, tout étant prêt, et les vaisseaux à l'ancre dans la rade de Portsmouth, l'ambassadeur se rendit dans ce port, au mois de septembre 1792, avec les personnes qui devaient l'accompagner, et qui étaient au nombre d'une centaine, y compris quelques musiciens et quelques ouvriers, et indépendamment des soldats et des domestiques. Ces personnes se trouvaient alors ensemble pour la première fois ; mais elles étaient destinées à composer désormais une espèce de famille, et à s'unir par les liens du devoir et de l'intérêt. Si quelques-unes d'entre elles étaient occupées du seul soin de vivre, et indifférentes à tout autre chose, le reste pouvait être considéré comme entrant dans une carrière ignorée, et commençant une nouvelle existence. Elles avaient quitté leur premier état, leurs anciennes habitudes, leurs plus chers amis, pour s'engager dans une entreprise intéressante, mais périlleuse. Ce n'était pas une troupe d'Argonautes, dévorés de la soif de conquérir une toison d'or : c'étaient des hommes remplis d'une ardente curiosité et du désir de s'instruire. Ils ne songeaient plus qu'à la Chine, tandis que les objets auxquels ils avaient été longtemps attachés, et qui captivaient encore l'attention de ceux dont ils étaient entourés, 


\section{Voyage dans l'intérieur de la Chine et en Tartarie}

semblaient perdre l'intérêt qu'ils avaient eu pour eux. Leurs yeux se fixaient sur une perspective qui s'offrait à l'extrémité de l'horizon, et qui occupait toutes leurs pensées.

Ainsi, abandonnant volontairement l'Europe et ses événements, ils n'éprouvaient d'autre regret que celui que leur inspiraient les affections de la nature, lorsqu'on leur annonça que le vent était favorable, et qu'il était temps de partir. 
Voyage dans l'intérieur de la Chine et en Tartarie

\section{DE UXI È ME \\ P A R T I E}




\section{Voyage dans l'intérieur de la Chine et en Tartarie}

\section{CHAPITRE PREMIER}

\section{Traversée de la Cochinchine aux îles des Larrons, près de Macao.}

Quand la mousson du sud-ouest est régulièrement décidée, le passage de la Cochinchine aux côtes de la Chine est ordinairement rapide et aisé. L'espoir d'être bientôt à la vue du pays qui était l'objet de leur long voyage rendait les passagers plus impatients d'arriver au lieu de leur destination qu'ils ne l'avaient paru lorsqu'ils en étaient encore très loin. Cependant le port de TienSing, où l'ambassadeur se proposait de débarquer, était encore à une distance considérable. Avant de s'y rendre, on résolut de toucher à l'une des îles des Larrons, situées vis-à-vis de Macao, parce que de là, on voulait faire passer des dépêches en Europe, par les occasions qui pouvaient se rencontrer à Canton ou à Macao même.

On voulait, surtout, s'informer de ce qui intéressait l'ambassade, et enfin savoir s'il n'était pas possible de se procurer des pilotes pour la mer Jaune, dont la navigation était entièrement inconnue aux Européens. II n'en était pas de même quant à l'étendue de mer qui sépare la Cochinchine et Macao : aussi, pour la traverser, ne fallut-il point de pilote. On peut pourtant dire que les renseignements qui ont été donnés jusqu'à présent, et sur cette route et sur celle de Macao aux îles de Chu-San, sont très inexacts.

Le jour que l'escadre partit de la baie de Turon, la montagne de TienTcha, ou le nouveau Gibraltar qui forme le port, empêcha les vaisseaux de ressentir beaucoup les effets de la brise de mer. Ils attendirent, en conséquence, celle de terre, qui souffle toujours là, l'après-midi, et dont la direction est du sud quart d'est au sud-sud-est. Elle les porta dans le cours de vingt-quatre heures, à cent milles de Turon. Dans cette route, on reconnut qu'un courant, dont la direction était nord soixante-sept degrés ouest, avait accéléré la marche de trente milles, c'est-à-dire d'un mille un quart par heure. Il est vrai qu'on devait naturellement s'y attendre. La marée va de l'est vers les rivages de la Cochinchine, et monte entre les parcelles, dont 


\section{Voyage dans l'intérieur de la Chine et en Tartarie}

nous avons fait mention dans le dernier chapitre, et une grande île, appelée Hai-Nan. Or, comme l'eau a trop peu de force en se retirant pour contrebalancer le flux constant de l'est, elle est forcée de prendre son cours vers le nord, le long de la côte et dans le golfe de Tunquin. Là, il n'y a d'autre passage qu'un très petit détroit, formé par l'île de Hai-Nan, et une longue et étroite projection du continent de la Chine. Ce passage étant directement ouvert à l'est, l'eau apportée par le flux qui, comme nous l'avons déjà dit, vient constamment de ce côté-là, se trouve renfermée dans le golfe, et s'accumulant immensément, occasionne ces très hautes marées et cette irrégularité dont a parlé sir Isaac Newton.

Le second jour, on s'aperçut d'un petit courant qui fit faire environ huit milles au nord-est ; il était sans doute occasionné par la marée qui refluait de la côte orientale de Hai-Nan, vis-à-vis de laquelle l'escadre se trouva à midi.

Le troisième jour, 19 juin 1793, le courant vint de l'est, et accéléra la route de trente milles: c'était l'effet du flux qui se portait dans le détroit de Hai-Nan, devant l'entrée duquel les Anglais passèrent ce même jour.

Le 20 juin, ils découvrirent une île sur laquelle il y a une montagne en forme de pain de sucre très élevé : c'est l'île que les Européens appellent le Grand Larron. A côté d'elle, il y en a une autre dont les montagnes sont moins pointues et plus basses. Le même jour, ils virent le continent de la Chine, portant nord-nord-est. Quoiqu'il fût trop éloigné pour qu'on pût y distinguer autre chose que des terres hautes et inégales, qui ne paraissaient avoir rien d'extraordinaire, leur aspect fit une agréable impression sur l'âme des Anglais. Ils se crurent dès lors parvenus à un point qui devait faire époque dans l'histoire de leur voyage.

Le 21 juin, l'escadre jeta l'ancre, par douze brasses d'eau, sur un fond vaseux, et sous le vent d'une des îles des Larrons, appelée Chook-Choo : le Grand Larron, éloigné de trois milles, portait ouest-sud-ouest, et Chook-Choo, à la même distance, sud quart d'ouest. On trouva que la latitude du Grand Larron était par les vingt et un degrés cinquante-deux minutes nord, et sa longitude par les cent treize degrés trente-six minutes à l'est du méridien de Greenwich. La latitude de Chook-Choo est par les vingt et un degrés cinquante-cinq minutes nord, et la longitude par les cent treize degrés qua- 


\section{Voyage dans l'intérieur de la Chine et en Tartarie}

rante-quatre minutes est. Ces longitudes sont de quelques milles moins est que la situation communément assignée aux îles des Larrons ; mais elles ont été déterminées d'après une montre marine, dont le résultat était d'accord, à très peu de minutes près, avec plusieurs observations lunaires, faites deux jours auparavant. II est donc à présumer que la détermination en est assez correcte.

Les côtes des îles des Larrons sont composées de rochers noircis par l'action de l'eau salée. L'écume et le frottement des vagues ont tellement corrodé leur surface en plusieurs endroits qu'elles leur ont donné l'air de ruches à miel. On trouve, sur ces îles, diverses sources, dont l'eau n'est point salée, et n'a aucun goût de fer ni d'autre minéral. Le sol paraît de la même nature que le roc qu'il recouvre; et il n'est, en effet, qu'une couche de rocher que l'action réunie du soleil et des pluies ont décomposée et pulvérisée par succession de temps. Le roc consiste en un mélange d'argile, une petite quantité de chaux de fer, et beaucoup de terre vitrifiable et de mica. La mer qui environne ces îles est d'une couleur jaunâtre et vaseuse, et n'a pas grande profondeur. Le fond est de vase et d'argile.

Les îles des Larrons, et les autres îles groupées entre elles et l'extrémité méridionale de la Chine, sont si rapprochées les unes des autres de la grande terre, si brisées et si irrégulières par leur forme et leur position, qu'elles ressemblent à des fragments qui, à des périodes très reculées, ont été détachés du continent et séparés entre eux par la violence des torrents, ou par quelques convulsions de la nature. Ces fragments n'ont maintenant qu'un aspect stérile et désagréable. On y voit bien, en quelques endroits, un peu de verdure. Mais, en général, ils n'offrent à la vue que des rochers pelés, entre lesquels on distingue à peine un arbre ou un arbrisseau. Ils servent de retraite habituelle aux pirates et d'asile momentané aux pêcheurs.

Sir Erasme Gower observe que toutes les îles qu'on voit à l'est du Grand Larron sont plus à pic que celles du côté de l'ouest. Les premières sont hautes, inégales, et la mer a autour d'elles environ vingt brasses de profondeur. Les autres sont assez plates, et semblent former une même terre. L'eau qui les sépare est beaucoup moins profonde qu'à côté des premières. 


\section{Voyage dans l'intérieur de la Chine et en Tartarie}

L'escadre se trouvant sur les confins de la Chine, et l'ambassadeur se disposant à envoyer un message à Macao, deux Chinois, qui avaient accompagné les interprètes et auxquels lord Macartney avait donné passage sur I'Indostan, le prièrent de profiter de cette occasion pour les faire débarquer. Pendant tout le voyage, ils s'étaient conduits avec beaucoup d'honnêteté. L'un d'eux, qui écrivait supérieurement les caractères chinois, s'était rendu très utile en aidant à traduire en langue chinoise les papiers dont l'ambassadeur avait besoin à son arrivée. Ce ministre désira donc de le récompenser de sa peine; mais quoiqu'il n'eût d'autre moyen de subsister que quelques légers secours que lui accordait la cour de Rome, il résista à tous les efforts qu'on fit pour lui persuader d'accepter de l'argent, ou quelque autre espèce de présent. II se croyait lui-même en reste, non seulement parce qu'on lui avait fourni l'occasion de retourner dans son pays, mais à cause des attentions qu'on avait eues pour lui durant le voyage. II était rempli d'estime et de reconnaissance pour la nation anglaise ; et si ses compatriotes adoptaient ses opinions à cet égard, la Chine rendrait à cette nation toute la justice qui lui est due.

L'un des interprètes demanda aussi à quitter le service de l'ambassade. II craignait beaucoup d'être reconnu par le gouvernement chinois, s'il continuait à vivre avec les Anglais; parce que d'après les lois du pays, il était doublement punissable, et pour en être sorti sans permission, et pour avoir accepté de l'emploi d'une nation étrangère.

L'autre interprète, qui était précisément dans le même cas, montra plus de fermeté d'âme que le premier, et prit une résolution toute différente. II se regardait comme engagé à accompagner l'ambassade pendant tout le temps qu'elle durerait, et des réflexions tardives sur le danger qu'il pouvait courir, ne le firent point désister de son entreprise. D'ailleurs, il y avait lieu d'espérer que si l'on découvrait qu'il était Chinois, I'ambassadeur serait en état de le protéger. Il était né dans la partie de la Tartarie dépendante de la Chine, et n'avait point ces traits qui dénotent une origine purement chinoise. Mais comme son nom exprimait en chinois une chose connue, il en prit un autre qui avait la même signification en anglais. II se vêtit en même temps d'un uniforme anglais et mit un chapeau et une cocarde. II pensa devoir prendre 


\section{Voyage dans l'intérieur de la Chine et en Tartarie}

ces précautions pour sa sûreté ; mais il n'en demeura pas moins préparé à tout ce qui pouvait arriver, et disposé à le supporter sans la moindre inquiétude.

Les trois autres Chinois s'embarquèrent à bord du brick, avec les personnes que l'ambassadeur envoyait à Macao. On fit, en même temps, passer les dépêches du gouvernement général des établissements hollandais dans l'Inde à leur résident en Chine, dépêches qui contenaient des ordres pour que ce résident agît de concert avec l'ambassade anglaise. On envoya aussi au procureur général des missions, à Macao, les lettres que lui écrivait, en faveur des Anglais, le cardinal-préfet de la Congrégation de la Propagande. La factorerie anglaise était à Macao, parce qu'aucun vaisseau de la Compagnie n'avait encore paru cette année dans la rivière de Canton.

D'après ce que les commissaires de la Compagnie des Indes anglaise mandèrent à l'ambassadeur, les dispositions de l'empereur de la Chine n'avaient nullement changé. II voulait accorder à l'ambassade une réception convenable à sa dignité ; et il avait donné, à ce sujet, des instructions, répétées aux différents gouvernements des côtes où cette ambassade devait aborder. II avait aussi donné des ordres afin que les mandarins allassent audevant de l'ambassadeur, et qu'il y eût des pilotes, convenablement stationnés, pour recevoir les navires anglais et les conduire en sûreté à TienSing, ainsi que d'autres personnes pour accompagner l'ambassadeur et sa suite jusqu'à Pékin. L'empereur avait terminé ses ordres par ces paroles remarquables :

- Que comme un grand mandarin était venu de si loin pour le visiter, il fallait le recevoir d'une manière distinguée et digne de l'occasion.

Les commissaires, sachant que les étrangers étaient reçus et traités à Canton avec un esprit bien différent de celui qui semblait animer l'empereur, ne doutaient pas que les officiers du gouvernement de cette ville n'eussent jeté un voile sur les intentions de sa majesté impériale à l'égard des étrangers. Ils pensaient, en conséquence, que rien n'était plus nécessaire, et ne pouvait devenir plus avantageux à la Compagnie des Indes, qu'une 


\section{Voyage dans l'intérieur de la Chine et en Tartarie}

communication libre et immédiate entre ses agents et la cour de Pékin, s'il y avait quelque moyen de l'obtenir, dans le cours des négociations qui allaient avoir lieu. L'ambassade, disaient encore les commissaires, ne paraissait nullement agréable à quelques officiers du gouvernement de Canton, lesquels appréhendaient, peut-être, qu'elle n'eût des conséquences fâcheuses pour eux. Ils s'étaient informés, avec inquiétude, des motifs de cette ambassade. Le hoppo, ou principal receveur des revenus et inspecteur du commerce étranger, sachant qu'il avait plusieurs fois mérité d'être repris pour avoir abusé des droits de sa place, ne pouvait penser à l'ambassade sans se rappeler les sujets qu'on avait de se plaindre de lui. Les commissaires pensaient que cet officier avait mis en usage toute sorte d'intrigues pour empêcher le succès de leurs premières démarches; et quand il avait cru trouver un vice dans leur commission, en découvrant qu'ils n'étaient pas envoyés directement par le roi de la Grande-Bretagne mais par la Compagnie des Indes, il n'avait pas laissé échapper l'occasion de les tracasser, et de leur opposer tous les obstacles qui étaient en son pouvoir.

Le foo-yen, ou gouverneur de Canton, avait aussi montré beaucoup de sollicitude pour découvrir l'objet particulier de l'ambassade ; et pensant qu'il pouvait concerner des personnes à qui les commissaires désiraient de le cacher, il les assura que s'ils voulaient lui en faire part, ce secret resterait absolument renfermé entre lui et l'empereur. Les commissaires lui répliquèrent très convenablement qu'ils savaient seulement qu'on était dans l'intention de présenter des compliments à sa majesté impériale, et de cultiver son amitié, mais que si l'on avait quelque autre dessein, il n'était indubitablement confié qu'à l'ambassadeur seul.

Ce fut peut-être aussi dans l'espoir de pénétrer ce dessein supposé et, s'il existait, d'arrêter les progrès de l'ambassade, qu'on pressa plusieurs fois les commissaires d'écrire à l'ambassadeur de s'arrêter à Canton, où tous les vaisseaux étrangers vont, au lieu d'aller à Tien-Sing. On insista même tellement là-dessus, que les commissaires trouvèrent qu'il ne suffisait pas

d'observer «qu'il n'était pas de leur compétence de conseiller à l'ambassadeur de s'écarter des ordres qu'il avait reçus à cet égard, et qu'il n'était peut-être pas en son pouvoir de le faire ». Ils jugèrent encore qu'il était prudent de déclarer que, très probablement, les vaisseaux qu'on ferait 


\section{Voyage dans l'intérieur de la Chine et en Tartarie}

partir de Canton pour aller au-devant de ceux qui portaient l'ambassadeur, ne le rencontreraient pas.

Après avoir tenu un tel langage, il leur fut impossible de requérir des pilotes pour chercher l'escadre vers l'extrémité méridionale de la Chine. Ils demandèrent seulement qu'il y en eût de prêts à Chu-San, dans la province de Ché-Chiang, et à Ning-Hai, dans la province de Shan-Tung, l'un et l'autre de ces ports étant sur les côtes orientales de l'empire. D'ailleurs, il était vraisemblable que les pilotes de ces ports connaîtraient mieux la route du golfe de Pékin que ceux qui résidaient à une plus grande distance. De plus, le port de Chu-San, fréquenté autrefois par les vaisseaux de la Compagnie, ne pouvait pas être manqué aisément: il semblait enfin qu'en prenant des pilotes à Chu-San, on devait assurer, sinon le succès de l'ambassade, au moins celui du voyage, parce que ces pilotes ne seraient pas, comme ceux de Canton, exposés à l'influence et aux intrigues des personnes reconnues pour être contraires au projet des Anglais.

Malgré la jalousie que la factorerie anglaise inspirait aux autres factoreries européennes, quelques-unes d'entre elles, et surtout celle des Hollandais, avaient profité de l'influence nouvelle des Anglais pour échapper aux vexations qu'on faisait ordinairement éprouver à tous les étrangers, au moment où ils passaient de Canton à Macao. La simple notification de l'ambassade avait fait un tel effet sur les principaux officiers du gouvernement de Canton que plusieurs supercheries introduites par le hoppo dans la perception des droits, depuis l'arrivée des commissaires, furent décidément repoussées, sans qu'on éprouvât l'inconvénient ordinaire en pareil cas, c'est-à-dire un délai dans l'embarquement du thé. La crainte qu'avait le hoppo de voir adresser à la cour des plaintes contre lui l'avait rendu depuis peu extraordinairement indulgent et poli.

On voyait aussi que les agents chinois de la factorerie anglaise, se sentant sur un terrain plus ferme qu'auparavant, commençaient à défendre sans crainte les droits de ceux qui les employaient contre l'oppression à laquelle ils avaient été, jusqu'alors, accoutumés à se soumettre. Quel que pût être le résultat de l'ambassade, elle avait toujours produit ce premier avantage, et on était convaincu qu'il y avait désormais une route ouverte, par où les 


\section{Voyage dans l'intérieur de la Chine et en Tartarie}

remontrances contre l'injustice pouvaient aisément parvenir au pied du trône impérial.

Le gouverneur de Canton fut très pressant pour obtenir des commissaires la liste des présents que l'ambassadeur devait remettre à l'empereur ; et il paraît que la cour de Pékin avait montré, à cet égard, une curiosité que le gouverneur désirait de pouvoir satisfaire. II en fit même une condition, en accordant son entremise. II allégua qu'il ne pouvait point envoyer la lettre qui annonçait l'arrivée de l'ambassadeur avec des présents pour l'empereur, sans faire connaître la nature de ces présents.

Les commissaires le satisfirent autant qu'ils purent; mais ils lui dirent qu'ils n'avaient qu'une connaissance imparfaite des choses dont l'ambassadeur était chargé, parce qu'ils avaient quitté l'Angleterre avant qu'on s'y fût procuré une grande partie de ces choses. L'importance qu'on paraissait mettre à savoir quelle était la nature des présents des Anglais doit être imputée, non à l'avidité du grand monarque auquel ils étaient destinés, mais au désir de pouvoir, d'après leur rareté et leur valeur, juger du degré de considération et de respect qu'avait pour lui le prince qui les lui envoyait, la première fois qu'ils communiquaient directement ensemble. Les ouvrages des arts et de l'industrie de l'Europe, par venus à Pékin par d'autres moyens, suffisaient pour y donner une haute idée de ce qu'on devait attendre dans des occasions extraordinaires.

Les commissaires mandèrent aussi que deux marchands chinois de Canton avaient reçu ordre de se tenir prêts à se rendre dans le port où aborderaient les vaisseaux qui portaient l'ambassadeur anglais, et probablement ils étaient chargés de l'accompagner à la cour. Ils devaient, disait-on, non seulement lui servir d'interprètes, mais traiter pour toutes les marchandises qu'il y aurait à vendre dans ses vaisseaux. Mais les commissaires pensèrent que les grands intérêts que la Compagnie avait avec ces marchands pourraient souffrir de leur absence, et ils sollicitèrent le gouvernement pour qu'il ne les écartât point de leurs affaires, l'assurant que l'ambassadeur était déjà suffisamment pourvu d'interprètes, et que la Compagnie n'avait point envoyé de marchandises pour vendre, dans le vaisseau qui suivait l'ambassade, parce que ce vaisseau n'était chargé que de présents destinés à l'empereur. 


\section{Voyage dans l'intérieur de la Chine et en Tartarie}

Indépendamment de ce que ces marchands étaient peu capables de servir d'interprètes, ils retiraient trop de profit du commerce qu'ils faisaient avec les étrangers à Canton, pour se soucier beaucoup de favoriser une mission qu'ils prévoyaient devoir apporter quelque changement à ce commerce, et ils pouvaient au contraire fort bien seconder les intrigues qu'on tramerait contre elle à Pékin. Il se trouva en même temps que ce voyage aurait fait tort à leurs propres affaires: c'est pourquoi ils joignirent leurs instances à la pétition présentée en leur faveur; ils firent des présents considérables à quelquesuns des officiers du gouvernement de Canton, et ils furent dispensés de s'absenter.

Lors des ambassades européennes qui avaient précédé à la Chine celle des Anglais, la cour de Pékin avait quelquefois chargé un des missionnaires dépendant du palais impérial d'aller au-devant de l'ambassadeur et de l'accompagner dans la capitale; mais un changement de système avait récemment eu lieu à Pékin. Depuis deux ou trois ans, on y était instruit de la révolution de France et des principes qui avaient troublé la tranquillité de son gouvernement; et, comme on craignait que ces principes ne pénétrassent dans l'Orient, on avait pris des précautions pour en prévenir l'introduction. Quoiqu'on ne se fût point déterminé à exclure les étrangers de Canton, on les avait astreints à plus de gêne, et on observait leur conduite avec une vigilance redoublée. Les missionnaires étaient toujours reçus en Chine et même, comme astronomes et artistes, encouragés dans la capitale : mais leur correspondance avec toutes les parties de l'Europe était interceptée et examinée. Certes, nulle classe d'hommes n'avait plus d'horreur qu'eux pour la révolution, dans le cours de laquelle on saisit en France les fonds qui avaient servi jusqu'alors à leur faire passer des secours : malgré cela, ils inspiraient encore de la défiance au jaloux et soupçonneux gouvernement de la Chine.

II était donc naturel que, dans l'occasion nouvelle qui se présentait d'employer des agents intermédiaires pour communiquer avec des étrangers, ce gouvernement préférât de se servir de ses propres sujets. Les Portugais de Macao étaient, en quelque sorte, considérés comme tels. D’un autre côté, les rapports intimes qui existaient depuis longtemps entre cette nation et les Anglais portaient ces derniers à croire qu'ils devaient attendre d'elle tous les secours de l'amitié. Mais on fut alors informé, par une voie très sûre, que 


\section{Voyage dans l'intérieur de la Chine et en Tartarie}

l'ancienne politique qu'avaient eue les Portugais, de vouloir écarter de la Chine toutes les autres nations, subsistait dans toute sa force. Cette information ne fut pas sans avantage pour l'ambassadeur. Elle lui apprit de bonne heure que, pour détruire les préjugés qu'on avait contre la nation qu'il représentait, et pour triompher des obstacles qu'on ne manquerait pas de lui susciter, il ne devait compter que sur l'impression que feraient sur les Chinois sa propre conduite et celle des personnes qui l'accompagnaient.

Les bricks étant revenus de Macao, l'escadre partit de Chook-Choo le 23 juin, et fit route avec un vent favorable pour le détroit qui sépare le continent de la Chine de la grande île Formose. Cette île est ainsi nommée par les Européens ; mais ni les Chinois, ni ses propres habitants ne l'appellent que Tai-Van.

Le même jour, l'escadre passa entre deux petites îles, dont l'une, à cause de son aspect fourchu, est nommée les Oreilles d'Ane, et l'autre Lema. Elles sont, l'une et l'autre, stériles, sans culture, et environnées de grands rochers qui s'élèvent au-dessus de la surface de l'eau, et qui semblent, ainsi que les deux îles, composées de dur granit. Leur gisement déterminé, d'après plusieurs observations du soleil et diverses montres marines, est :

$$
\text { Latitude Longitude }
$$

Les Oreilles d'Ane

Lema $21^{\circ} 55^{\prime}$ nord $114^{\circ} 7^{\prime}$ est

$22^{\circ} \gg 114^{\circ} 17^{\prime} \gg$

Le lendemain, 24 juin, les vaisseaux furent à la vue d'un grand rocher très élevé. II est extrêmement blanc; d'après cela, il a été nommé par les Portugais Pedra Branca; et comme ils sont les premiers Européens qui aient navigué dans ces mers, la plupart des noms qu'ils y ont donnés ont été adoptés par leurs successeurs. Pedra Branca est par les vingt-deux degrés dix-neuf minutes de latitude nord, et par les cent quatorze degrés cinquantesept minutes de longitude est. A midi, le thermomètre de Fahrenheit s'éleva à quatre-vingt-quatre degrés, et le baromètre à vingt-neuf pouces soixantetreize points. Pendant les dernières vingt-quatre heures, un courant porta, au nord-est, environ un mille par heure. 


\section{Voyage dans l'intérieur de la Chine et en Tartarie}

Le 25 juin, l'escadre passa le tropique du Cancer. Au coucher du soleil, le ciel fut extraordinairement rouge. Le mercure du baromètre tomba tout à coup, et le vent de sud-ouest souffla avec force. Le lendemain matin, qui était encore le 25 juin - suivant la manière de parler des marins, qui ne comptent les jours que de midi à midi - le lendemain, dis-je, commença par des coups de vent accompagnés de pluie, de tonnerre et d'éclairs. Avant midi, le calme régnait déjà dans l'air ; mais la mer continuait à être agitée. Le thermomètre monta à quatre-vingt-deux degrés, et le baromètre à vingt-neuf pouces soixante-trois points.

Le 26 juin, il y eut encore beaucoup de tonnerre, d'éclairs, et il tomba une pluie presque continuelle. Le vent passa graduellement du sud-est au sud

quart ouest. L'air était si brumeux qu'il ne fut pas possible de faire la moindre observation astronomique de toute la journée. On ne put pas même distinguer les côtes de la Chine, quoique l'escadre fût alors dans la partie la plus resserrée du détroit, et tout au plus à dix lieues de distance de ses côtes et de l'île de Formose, dont la terre est si élevée, ainsi que celle du continent, que dans le beau temps, on voit aisément de l'une à l'autre. Cependant, un peu après le lever du soleil, on vit pendant quelques minutes la partie nordouest de Formose, portant du sud-est quart d'est au sud.

Lorsqu'il tombe de la pluie, les marins chinois quittent leurs vêtements de coton, pour prendre des camisoles et des culottes longues faites avec des roseaux peu serrés, mais placés parallèlement l'un à côté de l'autre. Ils mettent aussi de grands chapeaux rabattus, faits de pareils roseaux; de sorte que la pluie coule sur ces roseaux comme sur les plumes d'un oiseau aquatique. Cet habillement grossier, mais commode, ressemble beaucoup à celui que portent aussi en temps de pluie les habitants de la côte nord-ouest de l'Amérique. Quelques anciens rapports entre ces deux nations peuvent leur avoir fait emprunter cet usage, l'un de l'autre; mais il est encore plus probable que le même besoin les a excitées à avoir recours à la même invention.

S'il est quelque saison où l'on doive espérer d'avoir du beau temps dans le détroit de Formose, c'est vraisemblablement en été et dans le milieu de la mousson. Mais la situation de ce détroit empêche sans doute le calme d'y régner souvent ; car, comme il s'étend du sud-ouest au nord-est et qu'il est 


\section{Voyage dans l'intérieur de la Chine et en Tartarie}

borné de chaque côté par de hautes chaînes de montagnes qui sont dans la même direction, l'effet du vent est accru par la compression qu'il éprouve dans cet étroit canal, lequel reste ouvert, comme un entonnoir, pour le recevoir des deux points d'où les moussons soufflent régulièrement. Les courants suivent invariablement, comme on doit s'y attendre, la direction des moussons. Ainsi, on voit qu'il est impossible aux vaisseaux de naviguer, dans ce parage, avec une mousson contraire.

Dans le journal manuscrit du passage de l'Argonaute dans le détroit de Formose, vers la fin du mois d'avril 1789, on a mis sur le titre que ce vaisseau allait contre la mousson du nord-est. Mais il paraît par le journal même que la mousson était à son terme et que le vent, soufflant de tous les points de l'horizon, était aussi sou vent favorable que contraire. De plus, ce vaisseau, étant petit, pouvait passer en dedans d'une grande partie des îles qui bordent la côte de la Chine, où il mouilla même aussi souvent que le temps l'exigea.

Le 27 juin, l'escadre continua à essuyer des coups de vent, qui venaient presque toujours du côté de l'ouest, avec une forte pluie et une mer agitée dans tous les sens. Dans la nuit, le vent devint variable, et le matin, il passa au nord. La latitude, par computation, différa de seize milles de ce que les observations donnaient à midi ; et la longitude, d'après le chronomètre, était de cinquante milles plus à l'est que celle qu'on avait estimée : d'où l'on inféra que dans les derniers trois jours le courant avait fait quarante-huit milles au nord, soixante-dix degrés est, ou deux tiers de mille par heure. A midi, le thermomètre était à soixante-dix-neuf degrés, et le baromètre à vingt-neuf pouces soixante-treize points.

Pendant toute la journée du 28 juin, le vent fut modéré et variable, mais venant presque toujours de différents points du nord: une grosse lame se déployait vers l'est. Dès que l'escadre fut en dehors du détroit, on vit un courant qui portait à l'ouest, et semblait faire, contre la lame, plus d'un demimille par heure. Le beau temps paraissant assuré, l'escadre fit voile pour les îles qui sont en avant de Chu-San.

Le 29, le temps fut brumeux et désagréable. Le fond s'éleva de cinquantedeux à vingt-deux brasses. On reconnut un groupe d'îles, appelées les Hay- 


\section{Voyage dans l'intérieur de la Chine et en Tartarie}

San, ou les îles Noires. Ce ne sont guère que des rochers pelés. Leur latitude est de vingt-deux degrés cinquante-trois minutes nord, et leur longitude de cent vingt et un degrés vingt-quatre minutes est. Ce groupe n'est qu'à quelques milles du continent de la Chine.

Le 30, le temps fut sombre et brumeux ; la brise souffla modérément du sud-ouest. En gouvernant au nord, on trouva une mer plus profonde. La sonde rapporta graduellement de vingt-deux à trente-deux brasses.

Durant toute la journée du $1^{\mathrm{er}}$ juillet, le temps fut encore sombre, et il y eut beaucoup de bruine. Le vent varia du sud-ouest au sud. On vit un autre groupe d'îles, appelées les Qué-San, auprès desquelles l'escadre mouilla le lendemain, 2 juillet, par neuf brasses d'eau, sur un fond vaseux. La plus haute et la plus méridionale de ces îles portait nord quart d'ouest, à quatre milles de distance des vaisseaux. Cette île ${ }^{1}$ est par les vingt-neuf degrés vingt-deux minutes de latitude nord et, d'après le chronomètre, par les cent vingt et un degrés cinquante-deux minutes de longitude est.

Le lendemain matin, qui était la dernière partie de la journée nautique du 2 juillet, l'escadre leva l'ancre pour se rapprocher de Chu-San. Ce ne fut pas sans peine qu'elle fit cette route, parce que sa marche était gênée par un nombre immense de canots chinois de toute grandeur qu'avait attirés la curiosité de voir des vaisseaux européens. Le Lion en compta plus de trois cents, pressés autour de lui. On en voyait plus loin plusieurs milliers, dont les petits étaient occupés à pêcher, et les autres à charrier différents bois de charpente et diverses autres marchandises. Quelques-uns de ces derniers formaient une rangée et s'avançaient également. Quelques autres étaient amarrés ensemble et portaient des bois d'une grandeur extraordinaire, qui étaient en travers sur les ponts. Tous avaient des voiles de nattes, au lieu de toile, et un équipage beaucoup plus nombreux que celui des bâtiments européens de la même grandeur. Tout, enfin, annonçait bien plus que ce qu'on avait vu jusqu'alors, un grand commerce et une immense population.

\footnotetext{
${ }^{1}$ Les Anglais I'ont nommée le Patchkock.
} 


\section{Voyage dans l'intérieur de la Chine et en Tartarie}

L'Indostan prit, dans un de ces canots, un pilote intelligent. II le fit d'abord passer entre les îles de Qué-San et le continent, gouvernant au nord et vers d'autres groupes d'îles très variées, dont Chu-San est une des dernières. Le seul risque qu'on court en naviguant entre les Qué-San et le continent, c'est de heurter un petit rocher qui est ordinairement couvert lorsque la marée monte ; rocher qui a été vu, pour la première fois, en 1736, par le vaisseau le Normanton. Voici comment on en parle dans le journal manuscrit de ce vaisseau :

«Ce rocher gît au sud-ouest quart d'ouest du Patchkock et en est éloigné de quatre milles. Quand on le découvrit, le reflux de la marée était aux trois quarts ; à quatre ou cinq milles de distance, il ne paraissait pas plus gros qu'une chaloupe renversée, et comme la mer était alors très basse, les hautes marées doivent le couvrir beaucoup.

On peut aisément éviter ce rocher en côtoyant les îles Qué-San, ou du moins en s'en tenant à peu de distance. II n'y a pas le moindre danger à un mille et demi au sud et à l'ouest de ces îles.

Dans la curieuse collection des cartes qu'a publiées M. Dalrymple, on trouve celle de l'une des îles de Chu-San, dessinée par le capitaine Thornton. Dans cette carte, on voit un autre rocher appelé l'Holderness, d'après un vaisseau du même nom, qui y toucha. Il est marqué à plus de trois milles de distance de l'îlot qu'on voit à l'extrémité méridionale de la plus grande île du groupe des Qué-San, conformément aux rapports et aux distances, relevés dans le journal de ce vaisseau. Mais le pilote chinois qui était à bord de I'Indostan ne connaissait aucun écueil aussi éloigné de la côte. Sa véritable position est établie d'après les renseignements qui nous ont été obligeamment communiqués par M. Thomas Fitzhugh, qui passa sur I'Holderness et est maintenant l'un des directeurs de la Compagnie des Indes anglaise. II observe qu'il prit les positions, pendant que l'Holderness était sur le rocher.

«L'extrémité la plus orientale du Museau du Buffle portait nordnord-ouest-nord ; la petite île Qué-San, la plus méridionale, sudest, le pic, qui est au milieu de la seconde Qué-San, sud-est quart 


\section{Voyage dans l'intérieur de la Chine et en Tartarie}

d'est ; le centre de la troisième Qué-San est à la distance d'environ un mille un quart; la partie la plus septentrionale du groupe des Qué-San, nord-nord-est ; la plus grande île du groupe, appelée les Petits Chiens ${ }^{1}$, nord-nord-ouest deux quarts d'ouest.

Les positions qui se trouvent dans le journal de l'Holderness furent estimées quand il eut jeté l'ancre, loin du rocher.

L'escadre suivit sa route entre les îles Qué-San et un petit groupe d'autres îles appelées par les Anglais l'Ours et les Oursons 2, qui sont à l'ouest des premières et très près du continent. San-Man, ou les Petits Chiens, sont un autre groupe d'îles situées au nord et dans le milieu du passage qui conduit à Chu-San. A l'ouest des Petits Chiens, l'eau a cinq brasses de profondeur, et à l'est, sept brasses. De là, en gouvernant nord-nord-ouest, on passe entre plusieurs petites îles ou rochers, environnées d'un fond bourbeux et appelées les Calfats et le Château de Roc, et une petite île qui est à l'est de ces dernières, et qu'on nomme Kin-Sa-Hoia, ou Jacques de Stribord, à l'extrémité méridionale de laquelle sont quelques rochers épars. Dans cette partie de la mer, le fond est très uni. Aussi les Anglais y virent-ils un nombre infini de canots de pêcheurs qui draguaient ou tiraient la seine. Leurs filets s'étendaient d'un canot à l'autre, dans toutes les directions.

L'escadre laissa ensuite le Museau du Buffle à l'ouest, et le Chaudronnier 3 à l'est, et fit voile vers l'île appelée l'Arbre au Sommet. La qualification de cette île serait une distinction suffisante dans un archipel où toutes les terres, quoique entièrement couvertes de verdure, n'ont qu'un très petit nombre d'arbres. II n'y a pas de doute qu'elle ne méritât le nom qu'elle reçut, lorsqu'il y a plus d'un demi-siècle, les Européens, à qui il était alors permis d'aller trafiquer à Chu-San, la désignèrent, pour la première fois, ainsi que celles qui l'avoisinent: mais l'arbre n'y est plus; et cette île maintenant aussi dépouillée que les autres, est connue seulement par sa position sur la carte.

\footnotetext{
1 The Whelps.

2 The Bear and cubs.

3 The Tinker.
} 


\section{Voyage dans l'intérieur de la Chine et en Tartarie}

Au midi de l'Arbre au Sommet et à trois ou quatre milles de distance, on trouve par cinq ou six brasses d'eau un excellent mouillage, où les vaisseaux sont à l'abri de toute sorte de vent. L'Indostan y jeta l'ancre, mais le Lion et le Jackall s'arrêtèrent entre le Laboureur et le Museau du Buffle, et prirent de l'eau sur la première de ces îles, tandis que le Clarence porta à Chu-San M. Barrow, l'interprète chinois et deux autres personnes attachées à l'ambassade. Ils allaient y chercher les pilotes qui devaient les y attendre, pour conduire l'escadre à Tien-Sing.

La plupart des îles de Chu-San ne sont que des montagnes, dont la pente est régulière et le sommet arrondi. II semble qu'elles proviennent d'autant d'angles aigus, dont la pointe originaire a été usée par le temps, et conserve seulement une forme convexe. Quoique ces îles soient très rapprochées, l'eau qui les sépare est très profonde en plusieurs endroits. Leur base est de granit, gris ou rouge, dont quelques parties ressemblent à du porphyre, mais n'en ont pas la dureté.

Certes, ces îles n'ont point été formées par une accumulation lente de terres charriées dans la mer par le grand fleuve vis-à-vis duquel elles se trouvent. C'est ainsi, à la vérité, que sont produites les îles basses et vaseuses qu'on voit à l'embouchure du Pô et de plusieurs autres fleuves. Mais celles de Chu-San doivent plutôt être considérées comme les restes d'une partie du continent, creusée et rudement façonnée en îles, par l'effort des torrents qui ont emporté plus loin dans la mer tout ce qui leur a opposé moins de résistance que le roc.

Quelques-unes de ces îles ont l'aspect le plus attrayant. L'une, surtout, qu'on nomme Pootoo, est représentée comme un véritable paradis terrestre. Ce sont, sans doute, ses beautés auxquelles l'art a, depuis, beaucoup ajouté, qui ont engagé un ordre religieux à y fixer sa demeure. Ces moines, au nombre de trois mille, en sont les seuls possesseurs, et vivent en célibataires. II y a quatre cents temples, auprès de chacun desquels sont des jardins et des maisons qu'habitent les moines. Ce vaste monastère, si l'on peut l'appeler ainsi, est richement doté et célèbre dans tout l'empire.

Pendant l'absence du Clarence, le Lion, mouillé entre le Laboureur et le Museau du Buffle, avait la première de ces îles au nord-ouest quart de nord, 


\section{Voyage dans l'intérieur de la Chine et en Tartarie}

et la dernière au nord-est quart de nord. II y a là un excellent port, à l'abri de tous les vents, et dont le fond est si bon et si solide qu'il fallut toute la force de l'équipage, et même des secours étrangers pour lever l'ancre. La profondeur de la mer est, là, de douze à vingt-deux brasses. La marée y monte d'environ douze pieds, et lors de la pleine lune et des changements de quartier, elle court deux milles et demi par heure. La latitude de ce port est de vingt-neuf degrés quarante-cinq minutes nord, et la longitude de cent vingt et un degrés trente-six minutes est.

L'île du Laboureur est habitée et, en plusieurs endroits, la verdure y est charmante; mais on n'y voit pas un buisson. II n'y a que quelques arbres fruitiers nains, quelques pins et quelques chênes. Les rochers de cette île sont de la même nature que ceux des Larrons. Ils ont seulement de plus que ces dernières quelques veines perpendiculaires de spalt blanc, et blanc et bleu.

Le Lion se procura là, à un prix modéré, des taureaux, des chèvres, de la volaille, et les canots qui pêchaient à l'entour lui portèrent diverses espèces d'excellent poisson. La vue d'un vaisseau tel qu'était le Lion, dont la construction et la grandeur paraissaient si extraordinaires aux Chinois, fit presque cesser tous les travaux de terre et de mer. Son pont et ses entreponts étaient tellement remplis de gens qui venaient les visiter, et il y en avait tant d'autres qui attendaient avec impatience l'instant de venir à bord, qu'il fut nécessaire de congédier promptement les premiers arrivés, afin d'avoir le temps de satisfaire la curiosité des autres. Quelques-uns d'entre eux étant entrés dans la grande chambre du Lion, où l'ambassadeur avait le portrait de l'empereur de la Chine, ils le reconnurent aussitôt et se prosternèrent devant lui baisant la terre à plusieurs reprises et avec une grande dévotion. Lorsqu'ils se relevèrent, ils parurent pénétrés de reconnaissance pour l'étranger qui avait l'attention de tenir dans son appartement le portrait de leur souverain. Quoique les gens de l'équipage finissent par laisser une grande partie des curieux parcourir seuls tous les recoins du vaisseau, aucun d'eux n'abusa de cette liberté, et il ne se commit rien de répréhensible. Très peu de ces Chinois paraissaient avoir cette maladresse, cette grossièreté de mœurs, ou ce manque d'esprit qu'on remarque si fréquemment parmi les classes inférieures des autres nations. 


\section{Voyage dans l'intérieur de la Chine et en Tartarie}

En se rendant à Chu-San, le Clarence entra avec la marée dans le passage de Duffield, où il fut obligé de jeter l'ancre quand le reflux commença. Ce passage est formé par la grande île de Lowang, qui le borne à l'est, et par une autre plus petite île qui est à l'ouest. II n'a pas plus de trois milles de large ; mais la profondeur de l'eau y est de cent à cent vingt brasses et, dans le milieu, on voit plusieurs rochers et deux ou trois îlots. Le Clarence mouilla dans ce passage, à la longueur d'un câble, c'est-à-dire à un quart de mille d'une petite péninsule, environnée d'un banc vaseux qui, à mer basse, est en partie à sec. L'isthme, qui la joint à l'île de Lowang, est couvert par la haute mer. Sur le bord du banc, le mouillage est de quinze brasses sur un fond mou et vaseux.

Les passagers qui étaient à bord du Clarence, voyant que la marée leur laisserait beaucoup de temps avant de revenir favoriser leur route pour ChuSan, voulurent employer ce loisir à faire leur première entrée sur le territoire de la Chine. Mais il ne leur fut pas aisé d'y aborder ; car le rivage de Lowang est environné, dans les endroits où s'étend le banc, d'argile molle, profonde et vaseuse, et partout ailleurs de rochers escarpés. Cependant, ils trouvèrent un moyen de grimper sur ces rochers. Du haut d'une des montagnes voisines, le passage où était le Clarence avait l'air d'une rivière, et la mer qui était audelà ressemblait à un vaste lac, parsemé d'un immense nombre d'îles. La montagne était couverte d'herbe forte, de roseaux, d'arbustes et de diverses plantes qui montraient suffisamment que ce lieu était bien loin de l'Europe. II y avait si peu d'arbres et de bétail qu'à des yeux européens, la campagne avait un air de nudité.

En descendant de la montagne, les Anglais entrèrent dans une petite plaine unie qui avait été dérobée à la mer, et qu'on défendait contre ses eaux par une chaussée de plus de trente pieds de large. La quantité de terrain gagné par cette chaussée ne semblait pas digne du travail qu'elle coûtait. La plaine était cultivée avec beaucoup de soin et couverte en très grande partie de riz, planté par plates-bandes et arrosé par des rigoles qui recevaient l'eau des montagnes voisines. La terre était fumée, non avec de la fiente d'animaux, mais avec des matières qui répugnent davantage à nos sens, et dont on ne se sert pas communément en Angleterre dans les travaux de l'agriculture. On voyait des vases de poterie enfoncés dans la terre pour 


\section{Voyage dans l'intérieur de la Chine et en Tartarie}

recevoir cette sorte d'engrais, ainsi que pour contenir le liquide qui lui est analogue, et dans lequel on fait tremper le grain avant de le semer, parce qu'on imagine que cette opération accélère la croissance de la plante, et empêche les insectes de la piquer, pendant qu'elle est encore très jeune.

Les Anglais rencontrèrent un paysan qui, quoique étonné à leur aspect, ne fut pas assez effrayé pour chercher à les éviter. Il avait un vêtement de coton bleu, fort ample, des demi-bottes, et un chapeau de paille attaché avec une corde par-dessous le menton. II parut sentir qu'un esprit de curiosité animait toujours les voyageurs, et il s'empressa de les conduire dans un village voisin.

En passant devant une métairie, ils rencontrèrent le fermier qui les invita à entrer chez lui et qui, ainsi que son fils, les contemplait avec des yeux étonnés. La maison était bâtie de bois; les montants avaient leur forme naturelle. II n'y avait point de plafond qui cachât le dessous du toit, qui était fortement joint et couvert avec de la paille de riz. II y avait dans les appartements, au lieu de plancher et de carrelage, une terre bien battue, et les chambres étaient divisées par des nattes attachées aux poutres. Deux rouets, pour filer le coton, étaient dans une chambre extérieure; mais les sièges qu'on voyait au-devant restaient vides. II y a apparence qu'ils appartenaient à des femmes qui s'étaient retirées à l'approche des étrangers; car aucune personne de ce sexe ne parut devant eux. Autour de la maison croissaient des touffes de bambou, ainsi que quelques-uns de ces palmiers dont la feuille, naturellement ronde et plissée, sert d'éventail ${ }^{1}$, et devient un objet de commerce.

Le retour de la marée rappela les passagers à bord du brick. Avant qu'ils quittassent Lowang, un des insulaires leur dit que cette île était si considérable et si bien peuplée qu'elle contenait dix mille habitants.

Le Clarence, continuant sa route pour Chu-San, arriva le soir, Iorsqu'il faisait déjà obscur, près d'un long promontoire, appelé la pointe de Kee-To. C'est l'extrémité d'une chaîne de montagnes du continent chinois, montagnes

\footnotetext{
${ }^{1}$ C'est le latanier des Antilles. (Note du Traducteur.).
} 


\section{Voyage dans l'intérieur de la Chine et en Tartarie}

qui paraissent composées de masses de granit. Autour de cette pointe, la marée courait en mascaret et tournoyait avec une telle rapidité qu'elle aurait entraîné un vaisseau moins grand que le Clarence, à moins qu'une forte brise ne l'eût soutenu. A environ cent pas de la pointe, la vase du fond de la mer est portée à la surface en si grande quantité que ceux qui ne savent pas la profondeur qu'il y a en cet endroit ne peuvent s'empêcher de craindre que leur vaisseau n'y touche. Il y a cependant plus de cent brasses d'eau.

Un peu au sud de la pointe, le Clarence trouva un bon mouillage par dixsept brasses d'eau. Ceux qui le montaient jugèrent à propos d'y rester pendant la nuit, attendu que pour arriver à Chu-San, le passage était étroit et rempli d'îles. En conséquence des règlements du vigilant gouvernement de la Chine, l'approche du Clarence était déjà connue à Chu-San. Un bâtiment chinois mouilla près de lui, et un officier vint à bord des Anglais pour leur annoncer que le lendemain matin, sa chaloupe conduirait leur vaisseau dans le port de Chu-San, où l'on pensait qu'il voulait se rendre. Le lendemain, il partit de bonne heure avec la marée et, après avoir passé plusieurs petits détroits, il entra dans le port qu'il cherchait.

Entre les Qué-San et Chu-San, c'est-à-dire dans l'espace d'environ soixante milles de long et trente milles de large, on compte plus de trois cents îles. Un rocher dangereux se rencontre dans la route qui conduit à Chu-San. Ce n'est point l'Holderness, dont nous avons déjà parlé, mais un autre sur lequel I'Indostan toucha à son retour dans le sud. En parcourant les journaux manuscrits des vaisseaux de la Compagnie des Indes anglaise, qui ont été autrefois à Chu-San, on voit qu'en 1704, le Northumberland était le seul à bord duquel on connaissait l'existence de ce rocher. Dans son livre de Log, il est dit qu'il se tint entre la pointe de Kee-To, et l'île du Daim, pour éviter un rocher qui est caché sous l'eau en dehors de l'île de Sarah-Galley, et par le travers duquel les vaisseaux se trouvent, lorsque ce rocher et le pavillon qui est sur la montagne de Chu-San paraissent ne faire qu'un.

La partie du port où le Clarence jeta l'ancre par cinq brasses d'eau était éloignée d'un demi-mille de l'endroit où l'on prend terre, près de la maison du Tsung-ping, ou gouverneur militaire, qui commande à Chu-San. Vue du brick, cette maison portait nord-est quart de nord. De là, aucun des quatre passages qui conduisent dans le port ne paraissait ; de sorte qu'on se trouvait 


\section{Voyage dans l'intérieur de la Chine et en Tartarie}

comme dans un grand lac, environné de montagnes; et il était impossible aux personnes qui étaient sur le pont du Clarence de montrer l'endroit par où le vaisseau était entré. Du nord au sud, le port n'a guère plus d'un mille d'étendue; mais de l'est à l'ouest, il a trois milles. La marée y monte d'environ douze pieds, et il paraît qu'elle est haute vers midi, dans le temps où la lune est dans son plein, ou lorsqu'elle change de quartier. Cependant les marées ne sont pas régulières. Les vents, et les courants occasionnés par une multitude d'îles, influent beaucoup sur elles. Dans le mouillage du Clarence, le flux et le reflux suivaient toujours la même direction, entre trois points du compas, le courant portant constamment entre l'est et le nord-est quart d'est ; et pendant deux jours et deux nuits que ce brick fut dans le port, il eut toujours la proue tournée vers le même côté du rivage. II est parlé de l'irrégularité des marées dans le journal manuscrit du voyage que le navire, le Stringer, fit dans ces mers, en 1708.

«Parmi les îles de Chu-San, dit ce journal, l'irrégularité des marées est telle qu'à deux milles de distance seulement, il y a une différence de deux heures entre les temps où la mer monte.

Parmi ces nombreuses îles, il n'y en a presque point où les vaisseaux de toute grandeur ne puissent trouver un port parfaitement sûr. Cet avantage, et celui d'être au centre de la côte orientale de la Chine et dans le voisinage de la Corée, du Japon, de Léoo-Kéoo et de Formose, attire un commerce considérable dans cet archipel, ainsi qu'à Ning-Poo, ville de la province de Ché-Chiang, dont dépendent toutes les îles Chu-San. Un port seul de cette province expédie, tous les ans, douze vaisseaux pour aller charger du cuivre au Japon.

Bientôt après que le Clarence eût mouillé, quelques officiers civils et militaires se rendirent à bord pour s'informer des motifs qui le conduisaient à Chu-San ; et lorsqu'on se fut expliqué à cet égard, il fut arrêté que les Anglais descendraient, le lendemain, à terre pour être présentés au gouverneur et lui faire leur demande. Les officiers chinois avaient amené, pour leur servir d'interprète, un marchand de leur nation, lequel avait été lié d'affaires avec les agents de la Compagnie des Indes, dans le temps qu'il leur était permis de fréquenter cette partie de la Chine. II parlait encore un peu la langue anglaise. II raconta que, quoique le port de Chu-San eût été interdit aux 


\section{Voyage dans l'intérieur de la Chine et en Tartarie}

Anglais, ils n'y avaient donné aucune véritable raison de mécontentement ; mais que probablement leur exclusion provenait de l'influence des principaux officiers de Canton qui retiraient de grands profits de l'accumulation du commerce étranger dans leur port. Peut-être aussi n'était-elle due qu'à la crainte qu'avait le gouvernement de la Chine d'éprouver quelque funeste effet de la communication illimitée de ses sujets avec des étrangers, dans plusieurs ports de l'empire à la fois.

Le marchand chinois se rappelait avec plaisir les noms de $M$. Fitzhugh et de $M$. Bevan, deux des principaux agents de la Compagnie, à Chu-San et à Ning-Poo; et il conservait l'espoir de voir encore les Anglais faire le commerce dans ces ports. II expliqua pourquoi on n'avait rendu qu'un salut de trois coups de canon au Clarence, qui en avait tiré sept. C'était uniquement parce que les règlements économiques du gouvernement chinois ne permettent point de tirer un plus grand nombre de coups de canon, lorsqu'il ne s'agit que d'un compliment. II dit à cette occasion que la règle des Chinois était de pointer en l'air leurs coups de canon de salut; et il ajouta que si les Anglais avaient eu cette sage précaution, deux Chinois n'auraient point été tués à Canton par les canons d'un vaisseau qui célébrait une réjouissance; accident qui coûta ensuite la vie au canonnier et faillit faire perdre à l'Angleterre le commerce de la Chine. Le gouvernement chinois regarde des canons pointés horizontalement, quel que soit d'ailleurs le motif qui les fait tirer, comme destinés à faire du mal.

Dès qu'on sut que le brick Clarence appartenait à l'ambassade pour laquelle la cour de Pékin avait envoyé des ordres sur toute la côte, afin qu'on lui procurât des secours et qu'on lui rendît des honneurs qui n'avaient jamais eu lieu en pareille occasion, le gouverneur envoya à bord des présents de toute sorte de provisions. Le lendemain, il reçut les Anglais avec beaucoup de politesse. II leur donna un grand repas, les fit assister à des spectacles, et leur fit connaître qu'il espérait qu'une députation en forme qu'il avait envoyée à bord du Lion mouillé, comme nous l'avons déjà dit, à quelque distance, engagerait l'ambassadeur à venir à terre, où l'on lui préparait de grands honneurs. L'ardent désir de paraître bientôt en présence de l'empereur servit de motif pour ne pas accéder à des propositions qui pouvaient occasionner du retard, et pour presser l'envoi des pilotes. 


\section{Voyage dans l'intérieur de la Chine et en Tartarie}

Quant aux pilotes, le gouvernement crut qu'il s'était pleinement conformé aux intentions de la cour, en tenant des marins prêts à conduire l'escadre le long des côtes jusque dans la province qui était au nord de la sienne; parce qu'elle trouverait, après cela, d'autres personnes qui la mèneraient successivement jusqu'à Tien-Sing. Cependant, il est certain que cette manière de côtoyer la Chine pouvait être très ennuyeuse, et même dangereuse pour de gros vaisseaux qui, tirant beaucoup d'eau, courent toujours plutôt risque de heurter des bancs de sable ou des rochers, le long des côtes, qu'en pleine mer. Cette observation fut faite au gouverneur ; mais l'idée de naviguer vers le golfe de Pékin, sans s'arrêter, lui paraissait entièrement neuve. II demanda à y réfléchir jusqu'au lendemain.

Les Anglais, se voyant ainsi obligés de différer leur retour à bord du Lion, allèrent visiter la ville de Ting-Hai, qui est située à un mille du grand village ou faubourg bâti sur le bord de la mer. Pour se rendre à Ting-Hai, ils traversèrent une plaine coupée dans toutes les directions par des ruisseaux et des canaux qui, indépendamment de tout autre usage, sont destinés à séparer les possessions. La plaine est cultivée comme un jardin : on n'y voit pas un seul endroit en friche ; et le chemin, quoique commode, était comme si l'on voulait qu'il y eût le moins de terrain possible perdu pour l'agriculture.

Les murs de la ville sont de trente pieds de haut; et, semblables à ceux d'une grande prison, ils cachent le faîte des maisons qu'ils renferment. Le long de ces murs, et de cent pas en cent pas, il y a des tours carrées en pierre. Les parapets sont garnis d'embrasures et de meurtrières pour les

archers. Mais il n'y a que quelques vieux canons de fer près de la ville. La porte est double et, en dedans, on voit un corps de garde avec plusieurs soldats. Des arcs, des flèches, des piques, des fusils à mèche, rangés en ordre, sont indubitablement destinés à leur usage.

De toutes les villes d'Europe, Venise est celle à laquelle Ting-Hai ressemble le plus; mais elle est moins grande. Presque entièrement environnée et traversée par des canaux, il y a des ponts très élevés et où l'on monte par des marches, comme sur le Rialto. Les rues sont très étroites et pavées en pierres plates et carrées. Mais les maisons, au lieu d'être hautes, 


\section{Voyage dans l'intérieur de la Chine et en Tartarie}

comme celles de Venise, sont très basses et n'ont en général qu'un seul étage. L'ornement de ces maisons se borne presque au toit, dont les tuiles qui couvrent les chevrons sont non seulement jointes avec du plâtre pour que les coups de vent ne puissent pas les faire tomber, mais façonnées de manière à imiter le faîte courbe et les bordures des tentes, ou les couvertures faites avec des peaux d'animaux et d'autres matières flexibles. Cette forme a été, sans doute, préférée, après qu'on s'est servi des matières plus solides afin de rappeler encore l'usage auquel la race humaine avait probablement recours pour s'abriter, avant de savoir construire des maisons régulières.

On voit, sur le faîte de maisons, des figures d'animaux grossièrement faites, en argile, en pierre ou en fer. La ville est remplie de boutiques où sont principalement étalés, avec avantage, des vêtements, des comestibles et des ustensiles de ménage. II y a même des cercueils peints de couleurs très jolies et très variées. La volaille et les plus petits quadrupèdes, même les chiens destinés à être mangés, sont exposés en vente tout vivants. Les poissons le sont dans des vases d'eau, et les anguilles, dans du sable. La quantité d'endroits où l'on vend des feuilles d'étain, et de ces bâtons de bois odoriférant qu'on brûle dans les temples, montre combien ce peuple est superstitieux.

Les personnes des deux sexes portent des robes larges et des culottes longues. Les hommes ont des chapeaux de paille ou de jonc, parce que leurs cheveux sont coupés très courts, ou rasés, à l'exception d'une touffe très mince et longue. Les femmes ont, au contraire, tous leurs cheveux tressés et élégamment noués sur le sommet de la tête, comme on le voit dans quelques statues antiques.

L'industrie et l'activité règnent dans toute la ville; ce qui semblerait ne pas devoir être dans un climat qui n'est pas tout à fait à trente degrés de l'équateur. Mais l'impérieuse nécessité et le désir d'obtenir des récompenses forcent au travail. Personne ne paraît même s'en dispenser. Personne ne demande l'aumône. Les hommes seuls passent d'un air occupé dans les rues. Les femmes restent dans les boutiques, sur leur porte, ou à leur fenêtre.

La plupart de ces femmes, même celles de la moyenne classe, et de la classe la plus inférieure, ont le pied extrêmement petit, ou plutôt mutilé. II 


\section{Voyage dans l'intérieur de la Chine et en Tartarie}

semble que le bout en a été coupé par accident, et que le reste conserve sa grosseur naturelle. Elles le couvrent de ligatures, comme si on leur avait réellement fait une amputation. Certainement, ces femmes souffrent beaucoup, et s'estropient elles-mêmes pour imiter les dames de qualité, dont on a coutume d'arrêter, dès l'enfance, la croissance du bas de la jambe aussi bien que du pied. On laisse l'orteil dans sa position naturelle, et on courbe les autres doigts jusqu'à ce qu'à la longue, ils restent comprimés sous la plante du pied, et ne peuvent plus s'en séparer.

Malgré la flexibilité des membres du corps humain dans un âge tendre, leur disposition à croître doit, quand elle est si cruellement contrariée, occasionner de vives souffrances, et avant que l'ambition d'être admirées s'empare des victimes de la mode, leurs mères ont besoin de beaucoup de vigilance pour les empêcher de se débarrasser des liens qui compriment leurs pieds et le bas de leurs jambes. Lorsque ces liens sont soigneusement portés, le pied conserve une petitesse symétrique. A la vérité, les jeunes personnes sont longtemps obligées de se faire soutenir pour marcher ; et même ensuite, elles ne marchent qu'en chancelant, et n'appuient à terre que le talon.

Mais quoique cette diminution artificielle n'empêche pas entièrement les Chinoises de se servir de leurs pieds, elle doit très certainement influer sur la croissance du reste de leur corps, et nuire à leur tempérament. Quelquesunes des dernières classes parmi les Chinois, lesquelles vivent en général dans les montagnes, et loin des grandes villes, n'ont point une coutume si contraire à la nature ; mais les femmes de cette classe sont regardées par les autres avec le plus profond mépris et on ne les emploie qu'au service le plus abject. Le préjugé, qui donne l'avantage à des pieds mutilés sur des pieds bien formés, est tellement invétéré que l'interprète assura, et plusieurs informations subséquentes confirmèrent, que si de deux sœurs, d'ailleurs parfaitement ressemblantes, l'une avait estropié ses pieds et l'autre les avait naturellement laissé croître, la dernière serait regardée comme dans un état humiliant, indigne d'être associée au reste de la famille, et condamnée à l'obscurité et à toute la bassesse de la servitude.

En formant des conjectures sur l'origine de la singulière mode des dames chinoises, on ne conçoit pas aisément comment les hommes auraient pu l'introduire parmi elles d'une manière violente et soudaine. Si les hommes 


\section{Voyage dans l'intérieur de la Chine et en Tartarie}

avaient été disposés à tenir les femmes constamment renfermées dans leurs maisons, ils pouvaient y réussir sans les priver cruellement de la faculté de se mouvoir. Cette coutume n'est connue ni en Turquie, ni dans I'Indostan, où les femmes vivent bien plus retirées qu'à la Chine. Certes l'opinion, bien plus que le pouvoir, dirige les actions de la race humaine, et une pratique si absurde ne pouvait être maintenue que par les conseils et par l'exemple des personnes qui s'y étaient soumises elles-mêmes. Les hommes l'ont approuvée en silence et encouragée indirectement, comme ceux de I'Indostan approuvent et encouragent, dit-on, la coutume, encore plus barbare, des femmes qui se brûlent après la mort de leurs époux. Mais ce n'est point la violence ou la crainte d'endurer des châtiments corporels qui porte les Indiennes à consommer un si horrible sacrifice : c'est l'horreur et le mépris qui les suivraient si elles s'y dérobaient, et surtout l'idée d'acquérir de la gloire, en remplissant un acte de devoir aux dépens de leur vie. II faut que des siècles aient succédé à des siècles pour mûrir un préjugé qui produit de si funestes conséquences. Mais l'orgueil de la supériorité et la crainte de l'abjection ont souvent suffi pour triompher des dispositions de la nature, et beaucoup de femmes se sont fait une habitude de gêner leur corps et leur âme. Ceux qui se rappellent la mode des tailles minces en Angleterre, et quelles peines on prenait, quelles douleurs on endurait pour exceller en ce genre de beauté, seront peut-être moins étonnés des efforts qu'on fait ailleurs pour des charmes différents. La délicatesse des formes a, sans doute, toujours été l'objet de l'ambition d'un sexe, parce qu'elle a fait l'admiration de l'autre. Cependant, il n'est guère vraisemblable que, comme on le raconte communément à la Chine, ce soit l'exemple extraordinaire d'une femme d'un rang très élevé qui a pu induire toutes les autres à comprimer violemment leurs pieds, pour qu'ils ressemblassent aux siens. Mais le désir de surpasser les autres dans une sorte de beauté peut avoir animé un grand nombre de femmes de tout rang ; et une mode suivie pendant de longs âges a été portée à un excès qui, dans le fait, change son véritable but. Tout ce que peut gagner une femme, en se façonnant les charmes imaginaires d'un pied, bien au-dessous de la grandeur qu'a voulu lui donner la nature, est plus que contrebalancé par le tort qu'elle fait à sa santé et à sa figure ; car la grâce n'est point dans ses pas, ni l'air animé sur son visage. 


\section{Voyage dans l'intérieur de la Chine et en Tartarie}

Tandis que les Anglais étaient occupés à satisfaire l'extrême curiosité qu'excitait en eux tout ce qui les environnait, ils étaient eux-mêmes les objets de l'étonnement de ceux qui les contemplaient. Très peu d'habitants de TingHai avaient encore vu un Européen, ou même quelque autre étranger qui différât beaucoup des Chinois. Ils se rassemblèrent donc en très grand nombre autour des Anglais, à qui le gouverneur avait donné une garde pour les accompagner. Mais le peuple s'approchait, sans paraître avoir rien à craindre des soldats. II était familier, sans laisser échapper des insultes et des moqueries, et sans faire le moindre vacarme. On était alors au mois de juillet, et la foule augmentait encore l'excessive chaleur. Les voyageurs, habillés à l'européenne, de vêtements qui pressaient leur corps et dont quelques-uns étaient serrés par des liens, souffraient beaucoup. Mais la multitude assemblée autour d'eux ayant des habits amples et légers ne paraissait nullement incommodée. Les soldats cherchaient à l'écarter: mais ils s'y prenaient avec douceur ; et s'ils employaient quelquefois les menaces, ils ne paraissaient pas dans l'habitude de se servir contre elle des moyens qui étaient en leurs mains.

Les Anglais cherchèrent un abri contre la chaleur, dans un temple rempli de grotesques et monstrueuses figures des divinités gardiennes de la ville; et bientôt après, ils montèrent dans des chaises à porteur pour se rendre au port. Une nouvelle foule de curieux les accompagnait. Pendant qu'ils étaient en route, ils furent surpris par un ouragan qui faillit renverser leurs chaises, et les força à chercher un abri dans un monastère chinois. Les prêtres s'empressèrent de leur donner l'hospitalité, et de leur faire servir du thé, boisson générale de ces contrées, et dont on fait usage à toutes les heures du jour.

Le lendemain matin, les Anglais se rendirent à la salle d'audience de si bonne heure que le gouverneur n'y était pas encore arrivé. Cette salle, située à l'extrémité d'une cour pavée, était très vaste et environnée de galeries. Le toit en était supporté par plusieurs rangs de colonnes de bois, peintes en rouge et très bien vernissées, ainsi que les poutres et les chevrons. Des lampes et des lanternes de toute forme et de toute grandeur étaient, en grand nombre, suspendues aux poutres et autour des colonnes, par des cordes de soie, ornées de glands de diverse espèce et de diverse couleur. 


\section{Voyage dans l'intérieur de la Chine et en Tartarie}

Quelques-unes de ces lanternes étaient composées de gaze, sur laquelle on avait peint et brodé à l'aiguille des oiseaux, des insectes, des fleurs, des fruits. La forme en bois qui soutenait la gaze était très bien travaillée. D'autres lanternes étaient entièrement de corne, mais si minces, si transparentes, que dans les premiers moments, les voyageurs les crurent de verre. Les Chinois préfèrent la corne au verre pour ces sortes d'ustensiles, parce qu'elle est plus légère, moins chère, moins sujette à se casser et, en cas d'accident, plus aisément raccommodée. Plusieurs de ces lanternes ont deux pieds de diamètre, et forment un cylindre arrondi par les deux extrémités, et dont les bords se réunissent dans le point où est attachée la corde qui le suspend. Chaque lanterne consiste en une seule pièce de corne, dont les joints sont invisibles, par un art qu'ont inventé les Chinois. II est certain que l'immense quantité de lanternes qu'ils emploient dans leurs maisons, dans leurs temples, ainsi que dans leurs réjouissances et dans leurs processions, a dû induire à faire beaucoup d'expériences pour en perfectionner la construction. La corne dont ils se servent, en général, provient des moutons et des chèvres.

Voici quelle est la méthode qu'on observe pour préparer cette matière, suivant ce que nous en avons appris sur les lieux. On plonge les cornes dans de l'eau bouillante, pour leur donner la forme convenable, après qu'elles ont été ouvertes et aplaties ; par ce moyen, elles s'écaillent aisément, ou plutôt se séparent en deux ou trois petites lames très minces. Afin que ces lames puissent se joindre, on les expose à l'effet pénétrant de la vapeur qui les rend extrêmement molles. Les bords des pièces qu'on veut faire joindre sont raclés avec beaucoup de soin, de manière que, quoique ces bords portent l'un sur l'autre, le joint ne doit pas être plus épais que le reste de la pièce. En appliquant immédiatement l'un à l'autre les bords ainsi préparés, et les pressant avec des tenailles, ils deviennent tellement adhérents, qu'ils ne diffèrent en rien des autres parties de la corne ; et de cette manière, on peut préparer des lames de corne d'une grandeur presque démesurée. Quoique ce procédé soit très simple, il est très peu connu ailleurs qu'à la Chine. Peut-être aussi avons-nous oublié, dans la description que nous venons de faire, quelques légères précautions qui peuvent être nécessaires au succès de l'opération. 


\section{Voyage dans l'intérieur de la Chine et en Tartarie}

La salle d'audience fournissait encore un autre objet de curiosité qui frappa les Anglais. Sur plusieurs tables, on avait placé, dans des caisses remplies de terre, des arbres nains, tels que des pins, des chênes, des orangers avec leur fruit. Aucun de ces arbres n'avait plus de deux pieds de haut ; et quelques-uns portaient des marques de décrépitude. On avait semé, sur la terre qui les entourait, de petits monceaux de pierres qui, proportionnellement aux arbres nains, pouvaient être appelés des rochers. Ils étaient corrodés et couverts de mousse, comme s'ils étaient là depuis plusieurs siècles, ce qui servait à augmenter l'illusion et à donner à tout l'ensemble un air d'antiquité.

Cette espèce de végétation rabougrie semble être très estimée des curieux en Chine; car on en trouve des exemples dans toutes les maisons considérables. Une partie du talent du jardinier consiste à savoir la produire, et c'est un art inventé à la Chine. Indépendamment du mérite de vaincre une difficulté, on a, grâce à cet art, l'avantage d'introduire dans des appartements ordinaires, des végétaux qu'autrement leur grandeur naturelle ne permettrait pas d'y faire entrer. Suivant les lois de la nature, les productions végétales atteignent leur état de perfection à différentes périodes, après avoir acquis différentes dimensions, et passé par différents degrés de croissance. Ainsi, le cèdre du Liban emploie plusieurs années à former son tronc haut et robuste avec ses branches horizontales, avant de donner ces fleurs sans couleurs et ces petites graines qui servent à le reproduire et indiquent que sa croissance est parfaite; tandis que l'hysope, qui n'a qu'une tige courte et herbacée, produit ses fleurs et ses graines quelques mois après qu'elle est semée. Quelques arbres se reproduisent de bouture, c'est-à-dire par des morceaux de jeunes branches qu'on a plantés, au lieu d'en semer les graines; et ces morceaux de branches, devenus troncs au terme de croissance fixé à leur espèce, et acquérant la hauteur ordinaire, donnent à leur tour des branches avant d'être adultes ou capables de fructification. Mais, par l'art de rendre nains les grands végétaux, une branche extraite d'un arbre et insérée dans la terre, continue à donner des fruits comme si elle avait été greffée sur un autre arbre, au moment où la sève était propre à la reproduction. 


\section{Voyage dans l'intérieur de la Chine et en Tartarie}

La méthode qu'on emploie à la Chine pour produire des arbres nains est telle que nous allons le rapporter. Quand on a choisi l'arbre dont on veut tirer un nain, on met sur son tronc, et le plus près possible de l'endroit où il se divise en branches, une certaine quantité d'argile ou de terreau qu'on contient avec une enveloppe de toile de chanvre ou de coton, et qu'on a soin d'arroser souvent pour y entretenir l'humidité. Ce terreau reste là quelquefois toute une année, et pendant ce temps-là, le bois qu'il couvre jette de tendres fibres, qui ressemblent à des racines. Alors la partie du tronc d'où sortent ces fibres et la branche qui se trouve immédiatement au-dessus sont, avec précaution, séparés du reste de l'arbre et plantés dans une terre nouvelle, où les fibres deviennent bientôt de véritables racines, tandis que la branche forme la tige d'un végétal, qui se trouve en quelque sorte métamorphosé. Cette opération ne détruit ni n'altère la faculté productive dont jouissait la branche avant d'être enlevée du tronc paternel. Ainsi, lorsqu'elle portait des fleurs et des fruits, elle continue à s'en couvrir, quoiqu'elle ne soit plus sur sa première tige. On arrache toujours les bourgeons des extrémités des branches qu'on destine à devenir des arbres nains, ce qui les empêche de s'allonger, et les force à jeter d'autres bourgeons et des branchettes latérales. Ces branchettes sont attachées avec des fils d'archal et prennent le pli que veut leur donner le jardinier. Quand on a envie que l'arbre nain ait un air vieux et décrépit, on l'enduit, à plusieurs reprises, de thériaque ou de mélasse, ce qui attire des multitudes de fourmis qui, non contentes de dévorer ces matières, attaquent l'écorce de l'arbre et la corrodent de manière à produire bientôt l'effet désiré. Les procédés qu'on emploie dans ces occasions sont quelquefois tenus secrets par les jardiniers, qui varient exprès dans leur manière d'opérer : mais les principes qui les dirigent sont suffisamment expliqués par ce que nous venons de dire. Leurs inventions prouvent plutôt leur adresse et leur patience, que leur méthode ne montre du goût ; car le goût consiste à seconder la nature dans le perfectionnement de ses ouvrages, non à contrarier ses opérations et à mutiler ses productions.

Tandis que les voyageurs s'instruisaient, relativement aux objets exposés dans la salle d'audience, l'arrivée du gouverneur rappela tout à coup leur attention à ce qui les avait attirés en ce lieu. Cet officier était accompagné d'un magistrat civil, distingué par une broderie formant un carré sur sa 


\section{Voyage dans l'intérieur de la Chine et en Tartarie}

poitrine, et sur laquelle on avait représenté, en soie de diverses couleurs, un oiseau imaginaire, qui est le phénix des Chinois. Le gouverneur avait, au contraire, sur sa robe une broderie qui offrait la figure d'un tigre, pour annoncer ses fonctions militaires. Cet animal est l'emblème assez vrai des maux qu'occasionne la guerre; et un oiseau, dans l'ancienne mythologie de l'Europe, annonce la sagesse, qui doit être une des qualités propres de la magistrature. Les deux officiers et quelques-uns de leurs subalternes se placèrent dans des fauteuils, couverts d'écarlate d'Angleterre, et les Anglais s'assirent sur des fauteuils pareils, qui étaient vis-à-vis des autres.

Après les premières civilités, on servit du thé. Ensuite, le magistrat dit un discours, qu'il prononça avec des tons très variés, et accompagna de beaucoup de gestes, d'après quoi on pouvait juger qu'il avait voulu déployer une éloquence qui fut perdue pour la plupart de ses auditeurs. Mais le sens de ses paroles était que l'usage de naviguer de province en province, le long des côtes, avait été de tout temps celui des Chinois, et devait conséquemment être suivi de préférence, dans les circonstances où l'on se trouvait ; que ChuSan n'était qu'un port dépendant du grand port de Ning-Poo, et ne pouvait fournir des pilotes tels qu'on les demandait.

A cela, on répondit simplement que la grosseur et la construction des vaisseaux anglais exigeaient une méthode différente de celle que les Chinois avaient coutume de suivre; et que, puisque Ning-Poo pouvait fournir les pilotes qu'on ne trouvait pas à Chu-San, on allait s'y rendre immédiatement pour les chercher.

Le gouverneur parut aussitôt alarmé de cette intention. II dit que le départ des Anglais pour Ning-Poo ferait croire à l'empereur qu'ils avaient été mécontents de leur réception à Chu-San, ce qui probablement lui ferait perdre sa place et sa dignité. En prononçant ces derniers mots, il montrait du doigt un bouton rouge et rond qu'il portait à son bonnet, et qui annonçait qu'il appartenait à la seconde classe des officiers de l'empire. Les classes des personnes ainsi employées dans l'administration sont au nombre de neuf ; et, hors de là, il n'y a ni rang, ni dignité.

Le gouverneur, ne voulant point courir risque d'être disgracié, entreprit sans tarder de trouver des hommes propres à diriger l'escadre dans la route 


\section{Voyage dans l'intérieur de la Chine et en Tartarie}

qu'elle voulait faire. II donna des ordres pour qu'on cherchât dans la ville des marins connus pour avoir été à Tien-Sing. Aussitôt qu'ils parurent, on examina en particulier leurs connaissances nautiques. Enfin, il y en eut deux qui avaient beaucoup fréquenté le port de Tien-Sing mais qui, depuis quelque temps, avaient quitté la mer. Ils dirent que la navigation de la mer Jaune n'était ni difficile, ni périlleuse, du moins pour des vaisseaux de la grandeur de ceux qui avaient coutume de la traverser ; qu'on trouvait un banc de sable à l'entrée du fleuve Pei-Ho, par où l'on se rend à Tien-Sing, lequel banc de sable empêchait d'entrer dans le fleuve les vaisseaux qui tiraient plus de sept ou huit pieds d'eau : mais, qu'à une journée ou deux de navigation les plus gros vaisseaux pouvaient trouver un port sûr dans l'île de Mi-a-Tau.

A l'instant, les deux marins reçurent ordre du gouverneur de se rendre à bord du Clarence, afin de joindre l'escadre et de la conduire à l'île de Mi-aTau, ou le plus près de Tien-Sing qu'il serait possible. Mais ces hommes étaient établis à Chu-San et y avaient leurs familles, dont ils n'étaient nullement disposés à se séparer. Ils déclarèrent que leur absence nuirait à leurs propres affaires. Ils se prosternèrent devant le gouverneur, en le suppliant de les dispenser d'être employés en cette occasion. Les Anglais ne pouvaient pas parler pour ces hommes sans renoncer, en même temps, à avoir des pilotes, et par là compromettre la sûreté de l'escadre. Le gouverneur déclara que la volonté de l'empereur devait être exécutée, et ne voulut écouter aucune remontrance.

Tandis que les pilotes se hâtèrent d'aller se préparer à ce service inattendu, les voyageurs retournèrent à bord du Clarence, afin de ne point retarder le départ. A peine y étaient-ils que le gouverneur s'y rendit. La curiosité n'avait, sans doute, pas moins de part à cette visite que la politesse. La hauteur des mâts, la manière de placer les voiles au-dessus l'une de l'autre, et la dextérité des matelots en escaladant les haubans captivaient singulièrement l'attention de cet officier. Les navires chinois ont bien quelquefois un hunier de toile au-dessus de leur grande voile; mais cette dernière est toujours faite de nattes, en travers de laquelle on place parallèlement des barres de bambou, bois creux et également remarquable par sa dureté et par sa légèreté. Les matelots montent sur ces barres, quand 


\section{Voyage dans l'intérieur de la Chine et en Tartarie}

il est nécessaire qu'ils aillent au haut des mâts ; mais, en général, ils font les manœuvres sans quitter le pont.

Pendant que le Clarence était dans le port de Chu-San, un des Anglais qui avait mangé à terre trop de fruits acides fut saisi d'un violent colera-morbus. Comme il n'y avait point de médecin, ni de pharmacie à bord, on demanda un médecin chinois pour administrer tout de suite quelque remède au malade qui souffrait cruellement. Bientôt, un docteur parut. Sans faire aucune question sur la nature et la cause de la maladie, il prit le bras gauche du malade avec beaucoup de dignité, et lui tâta légèrement le pouls avec ses quatre doigts. Ensuite, il leva un doigt et continua à presser le pouls avec les trois autres, puis avec deux, et enfin avec un seul, changeant de position à plusieurs reprises, et promenant sa main en avant et en arrière, comme sur un clavier, depuis le poignet jusqu'à l'endroit où le pouls cessait de se faire sentir. Pendant tout ce temps-là, il garda le silence. II ne regardait point le malade ; mais il tenait ses yeux fixés comme s'il avait jugé que chaque maladie devait être indiquée par une différente pulsation de l'artère, et distinguée par un praticien attentif. II déclara que celle pour laquelle on l'avait appelé provenait de l'estomac, ce qui était très évident d'après les symptômes sur lesquels il avait probablement eu des renseignements avant de venir à bord, et qui cédèrent bientôt aux remèdes qu'il administra au malade, à sa propre sollicitation.

Dès que les pilotes furent rendus à bord du Clarence, ce brick sortit du port de Chu-San et, en allant joindre le Lion, il longea I'île de Sarah-Galley où le vent lui manqua tout à coup. II fut en même temps emporté par un mascaret, qui le fit tourner plusieurs fois comme un tourbillon, et avec une extrême impétuosité. Dans ce tournoiement, le beaupré se trouva souvent à quelques pieds seulement d'un rocher qui s'élevait perpendiculairement du sein de la mer. Les pilotes, pour qui cette situation n'était pas nouvelle, furent très utiles en empêchant de prendre l'alarme, et en assurant qu'il n'y avait aucun risque à courir. En effet, la marée écarta bientôt le brick loin du tournant, et il jeta l'ancre la même nuit en dehors de la pointe septentrionale de Lowang. Le jour suivant, il passa le détroit de Gough, et joignit le Lion dans le mouillage que nous avons déjà décrit. 


\section{Voyage dans l'intérieur de la Chine et en Tartarie}

Pendant l'absence du Clarence, la députation de Chu-San et celle du gouverneur général de la province s'étaient rendues auprès de l'ambassadeur. L'une et l'autre avaient apporté des présents de provisions, et invité l'ambassadeur et sa suite aux fêtes qu'on lui préparait à terre. Mais il s'en excusa en alléguant qu'il lui était nécessaire de poursuivre immédiatement son voyage, pour se rendre à la cour de l'empereur. 


\section{Voyage dans l'intérieur de la Chine et en Tartarie}

\section{CHAPITRE II}

\section{Navigation dans la mer Jaune. Entrée de l'ambassadeur dans la rivière qui conduit à Tien-sing.}

La partie de la côte de la Chine que l'escadre avait déjà longée depuis la frontière orientale du Tunquin jusqu'aux îles Chu-San comprend plus d'un millier de milles nautiques, qui ont un sixième en sus des milles anglais ordinaires. Mais il restait encore une bien plus grande étendue de côtes, des îles Chu-San au port le plus près de Pékin, dans le golfe auquel cette capitale donne son nom.

A Chu-San, l'escadre se trouvait aux bornes les plus reculées où la navigation européenne était encore parvenue. La mer qui s'étend de là jusqu'à dix degrés de latitude et six de longitude était entièrement inconnue, excepté à ceux qui habitaient ses bords. C'est dans cette mer que se jettent les eaux du grand Wang-Ho, ou fleuve Jaune. Il entraîne, dans sa longue et tortueuse course, une si grande quantité de limon jaune que c'est à cela qu'il doit l'épithète qui le distingue et qu'il communique à la mer avec laquelle il mêle ses ondes.

La mer Jaune est bornée par la Chine, la Tartarie et la Corée. Ce n'était pas un petit avantage procuré par l'ambassade que d'avoir une occasion de parcourir sans risque une étendue de mer si considérable, sous la direction d'hommes qui y avaient fréquemment navigué. Des deux pilotes pris, dans ce dessein, à Chu-San, I'un resta à bord du Lion, l'autre fut envoyé à I'Indostan. Quoique forcés à ce service, ils se montrèrent empressés à s'en acquitter, autant qu'ils en étaient capables.

Quand un pilote européen arrive sur le pont d'un vaisseau à bord duquel son assistance est requise, il s'empare aussitôt du gouvernail ; et semblable à un dictateur romain, il exerce ses fonctions, tandis que toute autre autorité est suspendue, ou seulement mise en usage pour accroître l'obéissance due à ses commandements absolus. Mais les Chinois pris pour diriger l'escadre 


\section{Voyage dans l'intérieur de la Chine et en Tartarie}

étaient trop étonnés de la nouveauté de leur situation parmi des étrangers pour se mêler de beaucoup de choses. Ils observaient cependant avec beaucoup d'attention les préparatifs pour la continuation du voyage, et toutes les manœuvres des vaisseaux. Chacun d'eux avait apporté une petite boussole: mais ils n'avaient ni cartes, ni instruments pour déterminer les latitudes. Il est vrai que l'expérience locale des pilotes intelligents est regardée comme suffisante, par rapport aux côtes qu'ils fréquentent. Cependant, il n'est pas rare d'avoir à bord des vaisseaux chinois des cartes ou des dessins de la route qu'ils veulent faire, et des promontoires voisins, le tout sculpté ou gravé sur des calebasses, dont la forme répond, en quelque sorte à la figure de la terre. Cette ressemblance peut avoir quelquefois contribué à rendre ces dessins moins erronés ; mais c'est un avantage dû au hasard seul. Ni les astronomes, ni les navigateurs de la Chine n'ont renoncé entièrement à ces notions grossières qui ont longtemps fait croire au genre humain que la terre entière était une surface plane. Ils croient, en même temps, que leur empire est situé dans le centre de cette surface, c'est pourquoi ils l'appellent, avec emphase, l'Empire du Milieu. Suivant eux, les autres pays qui l'environnent sont extrêmement bornés, et situés sur les bords de la terre, au-delà desquels tout doit être précipice et vide affreux.

Cette ignorance de la forme de la terre empêche les Chinois de tenter de déterminer la latitude et la longitude de ses différentes parties par l'observation des corps célestes, et pour les progrès de la navigation. Mais les autres nations, même parmi lesquelles les philosophes ont fait d'importantes découvertes, appliquent rarement ces découvertes à des choses utiles, jusqu'à ce que la grande inventrice des arts sociaux, la nécessité, les porte à faire des efforts extraordinaires. Malgré leur science, malgré la fécondité et la finesse de leur esprit, les Grecs ne sont jamais parvenus au point de déterminer, avec un instrument, la position d'un vaisseau à la mer. Ils se contentaient de pouvoir connaître ce qu'il leur fallait à cet égard, en observant pendant la nuit les étoiles, et pendant le jour quelque partie de la côte de la Méditerranée ou quelqu'une des nombreuses îles dont elle est semée, car ce n'était que dans cette mer qu'ils naviguaient ordinairement. Les Chinois ont le même avantage que les Grecs. Leurs mers ressemblent à la Méditerranée par rétrécissement de leurs limites, et par les nombreuses îles 


\section{Voyage dans l'intérieur de la Chine et en Tartarie}

qu'on y voit de tous côtés. On doit aussi observer que le perfectionnement de la navigation, parmi les Européens, date de la même époque où leurs passions et leurs besoins les forcèrent d'entreprendre de longs voyages sur l'immense océan.

Quant à la boussole, elle est parmi les Chinois d'un usage général. L'aiguille aimantée dont ils se servent excède rarement un pouce de longueur et n'a pas une ligne d'épaisseur. Elle est suspendue avec une extrême délicatesse, et elle est singulièrement sensible ; c'est-à-dire qu'elle paraît se mouvoir pour peu que la boîte où elle est placée change de position vers l'est ou l'ouest, quoique dans le fait la nature de l'aimant et la perfection de la machine qui le contient, consistent en ce que l'aiguille est privée de toute motion, et reste constamment pointée vers la même portion du ciel, quelle que puisse être la rapidité avec laquelle tourne la boîte du compas, ou les autres objets qui l'environnent. D'après ce que M. Barrow a remarqué, cette régularité de la boussole chinoise est l'effet d'une invention particulière. On applique un morceau de cuivre mince autour du centre de l'aiguille, et on le fixe par les bords sur la partie extérieure d'une petite coupe hémisphérique du même métal, laquelle est renversée. Cette coupe reçoit un pivot d'acier qui sort d'une cavité faite dans un morceau de bois rond et très léger, ou de liège, qui forme la boîte de la boussole. La surface de la coupe et celle du pivot sont parfaitement polies, afin d'éviter autant qu'il est possible toute espèce de frottement. Les bords de la coupe sont proportionnément larges, ajoutent à son poids, et font que, d'après sa position horizontale, elle tend à conserver le centre de gravité dans toutes les situations de la boussole, presque en coïncidence avec le centre de suspension. La cavité dans laquelle l'aiguille est ainsi suspendue a une forme circulaire, et n'est guère plus que suffisante pour recevoir l'aiguille, la coupe et le pivot. Au-dessus de cette cavité, il y a une pièce mince de talc transparent qui empêche que l'aiguille ne soit affectée par l'air extérieur, mais permet aisément d'observer son moindre mouvement.

La petite aiguille de la boussole des Chinois a un grand avantage sur celles dont on se sert en Europe, relativement à l'inclinaison vers I'horizon ; ce qui, dans les dernières, exige qu'une extrémité soit plus pesante que l'autre pour contrebalancer l'attraction magnétique. Mais cette nécessité étant différente 


\section{Voyage dans l'intérieur de la Chine et en Tartarie}

dans les différentes parties du monde, l'aiguille ne peut être véritablement juste que dans l'endroit où elle a été construite. Dans les courtes et légères aiguilles, suspendues d'après la manière des Chinois, le poids qui est audessous du point de suspension est plus que suffisant pour vaincre le pouvoir magnétique de l'inclinaison dans toutes les parties du globe. Aussi ces aiguilles n'ont jamais de déviation dans leur position horizontale.

Sur la surface extérieure de la boîte, on voit des lignes concentriques ou cercles proportionnés à la grandeur de cette boîte, qui est rarement de plus de quatre pouces de diamètre. Ces cercles sont distingués par différents caractères. Il y en a huit marqués sur celui du centre, quatre desquels indiquent les quatre points cardinaux, c'est-à-dire l'est, l'ouest, le nord et le sud, et les quatre autres les points intermédiaires. Les mêmes huit caractères signifient aussi les huit divisions naturelles du jour ou du temps, pendant lequel la terre tourne sur son axe en poursuivant sa course autour du soleil. Chacune de ces divisions est conséquemment de trois heures, et les caractères qui les distinguent sont placés presque vis-à-vis de la position où se trouve le soleil dans ces différentes parties du jour; le premier, par exemple, commençant au lever du soleil, est en face de l'Orient. Cette division se trouve parfaitement d'accord avec la première boussole, qu'on dit avoir paru en Europe, au commencement du quatorzième siècle. Ce n'est qu'à mesure que les marins sont devenus plus expérimentés et plus exacts dans leurs observations, que cet instrument a été subdivisé en trente-deux points.

Sur un autre cercle de la boussole chinoise sont tracées vingt-quatre divisions, sur chacune desquelles il y a un caractère qui marque une vingtquatrième partie du ciel, et une vingt-quatrième partie du jour. Suivant cette division, chaque point ou vingt-quatrième partie de la boussole comprend un nombre intégral de quinze degrés, sur les trois cent soixante, par lesquels on est convenu de diviser tous les cercles de la sphère céleste, ce qui probablement a commencé à cette époque reculée où l'on supposait que le soleil faisait sa course apparente dans un espace de trois cent soixante jours.

Les autres cercles, tracés sur la boussole chinoise, contiennent les caractères du cycle de soixante ans, par lequel cette nation règle sa chronologie, ainsi que d'autres caractères, analogues à leur doctrine philosophique et mythologique, doctrine à laquelle ils sont si attachés que la 


\section{Voyage dans l'intérieur de la Chine et en Tartarie}

connaissance de la boussole est aussi familière aux gens qui vivent à terre qu'à ceux qui parcourent les mers.

La nature et les causes des propriétés de l'aimant ont été, dans tous les temps, l'objet de l'attention des Chinois. Leur théorie, à cet égard, comme à beaucoup d'autres, est entièrement opposée à celle des philosophes de l'Europe. Il est certain que lorsque l'aiguille aimantée, suspendue par son centre, tourne une de ses extrémités vers le nord, l'autre regarde le sud. Mais chacune retient ensuite sa polarité ${ }^{1}$, et si on tourne l'aiguille par force, en sens inverse, on la voit, aussitôt qu'elle est en liberté, revenir à sa position première. Ainsi, le pouvoir qui attire cette aiguille peut être supposé résider vers l'une ou l'autre portion de la terre. En Europe, on a pensé que l'aiguille aimantée avait sa principale tendance vers le pôle nord; mais à la Chine, le pôle sud est considéré comme ayant seul le pouvoir attractif. Le nom que les Chinois donnent à leur boussole est ting-nan-ching, ce qui signifie l'aiguille qui montre le sud ; et dans cette boussole, il y a une marque distinctive sur le pôle méridional de l'aimant, comme dans les boussoles européennes, il y en a une sur le pôle septentrional.

L'empereur Caung-Shée, grand-père du souverain qui occupe aujourd'hui le trône de la Chine, avait l'habitude d'écrire ses observations sur différents sujets ; et, ayant accueilli à sa cour de savants missionnaires, il ne fut point inattentif à leurs opinions philosophiques. Voici ce qu'il écrivit à l'occasion de la boussole :

« J'ai entendu des Européens dire que l'aiguille obéissait au nord. Dans nos plus anciennes annales, il est dit qu'elle se tourne vers le sud. Mais comme ni les uns ni les autres n'en expliquent la cause, je ne vois pas qu'il y ait beaucoup d'avantage à adopter une opinion de préférence à l'autre. Les anciens sont les premiers en date; et plus je vais en avant, plus je suis convaincu de leurs connaissances, relativement aux opérations et au mécanisme de la nature. De plus, comme toute action languit et est presque

\footnotetext{
${ }^{1}$ Ce mot n'est pas français, mais comme il est technique, j'ai cru devoir l'adopter.
} ( Note du Traducteur.). 


\section{Voyage dans l'intérieur de la Chine et en Tartarie}

interrompue auprès du pôle nord, il est moins vraisemblable que le pouvoir d'attirer l'aimant vienne de ce côté-là.

Dans les livres mythologiques des Chinois, qui sont la partie fabuleuse de I'histoire de cet empire, on a fait aussi allusion aux propriétés de l'aimant. II y est dit que :

«Sous le règne de Chin-Nong, un rebelle nommé Tchoo-Yoo, dans l'espoir d'échapper à ses ennemis et de les confondre, avait trouvé le moyen de créer à son gré d'épais brouillards et une obscurité profonde: mais, pour en prévenir l'effet, l'empereur inventa une machine consistant en une figure qui était debout sur un chariot et qui avait un bras constamment tendu vers le sud; ce qui mit les troupes impériales en état de poursuivre le rebelle et de le vaincre.

L'empereur Caung-Shée savait fort bien que l'aiguille ne regarde pas toujours directement le nord et le sud, et que sa déclinaison n'est ni la même dans tous les pays, ni invariable dans le même lieu. Mais la sphère de la navigation chinoise est trop bornée pour que l'expérience et les observations qui lui sont dues aient fait former un système sur les lois qui gouvernent la variation de l'aimant. La connaissance de sa polarité générale suffit à tous les besoins qu'en ont les Chinois; et leurs recherches sur la plupart des sujets paraissent avoir été principalement, mais d'une manière trop circonscrite, dirigées vers l'utilité qui pouvait immédiatement résulter d'une pratique suivie.

Bientôt, les pilotes chinois, qui étaient à bord des vaisseaux anglais, s'aperçurent combien la perfection de la boussole leur était moins nécessaire qu'aux hardis navigateurs de l'Europe ; car les commandants du Lion et de I'Indostan, se confiant à cet instrument, s'éloignèrent des côtes et cinglèrent directement vers la haute mer.

L'escadre entra dans la mer Jaune le mardi 9 juillet 1973. Le temps était sombre et nébuleux : une brume épaisse enveloppait I'horizon ; la lame était forte et venait de l'est-sud-est. Le point d'où l'escadre devait compter sa route, en partant de ces parages, était l'île appelée Patch Cock, située par les vingt-neuf degrés vingt-deux minutes de latitude nord, et par les cent vingt degrés cinquante-deux minutes de longitude est. En s'éloignant de l'endroit 


\section{Voyage dans l'intérieur de la Chine et en Tartarie}

où ils étaient mouillés par six brasses d'eau, les vaisseaux emportèrent une si grande quantité de vase que leur sillage laissa pendant près d'un demi-mille une trace d'un brun jaune; ce qui eût pu effrayer des personnes qui n'en auraient pas connu la cause, et leur faire croire qu'on naviguait sur de hauts fonds.

Le mercredi 10 juillet, le temps fut très brumeux, et la lame vint constamment de l'est. Pendant la première moitié de la journée, le vent souffla du nord-ouest et de l'ouest. La seconde moitié fut presque calme. Le matin, on aperçut deux îles, que les pilotes appelèrent Tchin-San et ShooTong-Yeng. Elles portaient nord-ouest quart d'ouest à la distance de huit ou neuf lieues. Le fond était de sable fin, par trente-deux et trente-sept brasses.

Le jeudi 11 juillet, alternativement, vent léger et calme pendant la première partie de la journée. Le soir, la brise se leva du côté du sud : à cinq heures, deux autres îles, petites et rocheuses, furent découvertes à l'ouest, à sept ou huit lieues de distance. Les pilotes dirent qu'elles se nommaient PaTcha-San et Te-Tchong. A midi, on trouva trente-six brasses de fond.

Le vendredi 12 juillet, dans le commencement de la journée nautique, le vent souffla du sud et du sud-est, et fut accompagné d'épais brouillards. Le fond s'éleva presque tout à coup de trente-six à dix-sept brasses : il était de sable gris tacheté de noir. Les pilotes observèrent que l'escadre était, alors, vis-à-vis de la province chinoise de Kiang-Nan et que, dans le voisinage, il y avait de grands bancs dont l'approche était annoncée par le fond sablonneux. Le matin, la brume devint si épaisse qu'il était impossible de voir d'un bout à l'autre du vaisseau. II est difficile d'expliquer pourquoi une mer peu profonde a presque toujours au-dessus d'elle une atmosphère brumeuse: mais c'est toujours ainsi sur le banc de Terre-Neuve, et dans les autres endroits où il y a peu d'eau. L'escadre remarqua un autre fait dont la cause est peut-être non moins inexplicable. Dans les endroits où le fond était le plus élevé, mais cependant couvert d'eau, il parut tout à coup autour des vaisseaux des essaims de ces mouches qu'on appelle des dragons, et quand l'eau devenait plus profonde, ils disparaissaient.

On fit tous les efforts possibles pour que les vaisseaux ne se séparassent pas durant le brouillard. On tira des coups de canon, signal d'usage en pareil 


\section{Voyage dans l'intérieur de la Chine et en Tartarie}

cas. Malgré cela, I'Indostan s'éloigna du reste de l'escadre. Peu après, il rencontra trois grands vaisseaux chinois qui, soit par choix, soit par accident, s'étaient écartés de leur coutume de naviguer le long des côtes. Toute l'escadre trouva que la profondeur de la mer variait si fréquemment et si soudainement que, malgré la présence des pilotes, elle jugea à propos de ne naviguer qu'avec des précautions extraordinaires et quelquefois de s'arrêter même : les sondages ne rapportaient jamais plus de quarante-deux brasses. Lorsqu'on trouvait le plus d'eau, le fond était toujours vaseux ; et le sable indiquait ordinairement les hauts fonds. Les pilotes observèrent que le vent de sud-est était toujours accompagné des plus épais brouillards, et qu'il durait ordinairement quatre ou cinq jours de suite.

Le samedi 13 juillet, le vent souffla du sud-est, l'atmosphère fut épaisse et s'éclaircit par intervalle. On jeta à chaque instant la sonde, pour s'assurer qu'on avait assez de fond.

Le dimanche 14 juillet, le vent resta au sud-est. Le matin, le brouillard se dissipa quelque temps. On aperçut plusieurs oiseaux de terre, des herbes et des bambous qui flottaient sur la mer, et divers autres signes, qui indiquaient le voisinage des côtes. Les jonques chinoises naviguaient en grand nombre dans ces parages, et faisaient différentes routes.

Tandis que I'Indostan était séparé du reste de l'escadre, il rencontra un petit navire de construction européenne. Une jonque chinoise, dans les mers d'Europe, n'aurait pas occasionné plus de surprise, si l'on n'avait pas déjà été prévenu par un avis de Macao, qu'avant que l'escadre arrivât dans les environs, les commissaires anglais avaient envoyé dans la mer Jaune un navire chargé de dépêches pour l'ambassadeur. C'était le brick l'Endeavour, commandé par le capitaine Proctor. Il avait à bord un jeune homme qui parlait l'espagnol et le chinois, et voulait offrir ses services à l'ambassade, en qualité de second interprète.

L'Endeavour appartenait à la Compagnie des Indes anglaise. Conformément au plan suivi par cette Compagnie qui, au milieu de ses entreprises commerciales, s'attache à favoriser les sciences, ce brick avait d'abord été employé, sous le commandement du savant capitaine Mac-Cluer, à faire des découvertes et des observations dans le grand archipel oriental, 


\section{Voyage dans l'intérieur de la Chine et en Tartarie}

compris dans ce qu'on appelle les mers de la Chine. Le capitaine Mac-Cluer était considéré comme un observateur non moins actif qu'intelligent. II avait déjà visité les îles Pelew, ou bien il s'était formé une haute idée de leur climat et de la disposition des habitants, à la lecture de l'intéressante relation publiée par M. Keate, d'après les renseignements fournis par le capitaine Wilson. Décidé à chercher aux îles Pelew le bonheur qu'il considérait, sans doute, comme plus difficile à atteindre dans une société plus nombreuse et plus compliquée, mais plus corrompue, le capitaine Mac-Cluer s'occupa longtemps de son projet, et se pourvut de tout ce qui pouvait lui être nécessaire dans son nouvel asile. En y arrivant, il céda le commandement de son vaisseau au second capitaine, et écrivit aux agents de la Compagnie pour leur rendre compte du parti qu'il prenait. II leur dit, entre autres raisons, qu'il ne se déterminait à ce parti que parce qu'il voulait se distinguer par une conduite dont on avait déjà donné peu d'exemples. Les habitants des îles Pelew l'accueillirent avec joie et avec des distinctions honorables. Ils lui offrirent, en même temps, de lui donner une grande autorité sur eux, ce qu'il refusa, se contentant d'une petite portion de terre pour la cultiver, et aimant mieux se rendre utile à la patrie qu'il adoptait, par les avis que la supériorité de ses connaissances le mettait en état de lui donner, que d'y exercer aucune sorte de commandement. Une telle conduite était certainement plus propre à lui concilier l'attachement constant des insulaires, que l'usurpation d'un pouvoir qui, avec le temps, n'eût pas manqué d'exciter de la jalousie et du mécontentement. Cependant, il n'est pas sûr que quelque accident ne trouble I'harmonie qui subsiste à présent entre la race hospitalière des habitants des îles Pelew et leur nouvel hôte, et qu'il ne change lui-même de disposition, et ne reprenne ces affections qui attachent la plupart des hommes à leurs anciens amis et à leurs habitudes premières.

Le capitaine Proctor confirma, à beaucoup d'égards, l'éloge que le capitaine Wilson a fait des îles Pelew. Loin d'avoir de la férocité dans le caractère, et de voir les étrangers avec horreur, les habitants de ces îles accueillent avec la plus grande bienveillance ceux qui viennent parmi eux, et admettent quelques-uns des principaux au nombre de leur noblesse, ainsi que l'ont éprouvé le capitaine Wilson et le capitaine Proctor. Le dernier, qui a vu quelques parties de la Nouvelle Guinée où les étrangers sont, au contraire, 


\section{Voyage dans l'intérieur de la Chine et en Tartarie}

traités avec inhumanité, attribue une conduite si différente à un esprit de ressentiment excité par des actes de trahison et de cruauté, que se sont sans doute permis quelques aventuriers qui ont abordé sur cette côte; et il ne pense pas que le caractère de ses habitants soit naturellement méchant.

Avant d'entrer dans la mer Jaune, l'Endeavour se rendit à Chu-San, où il prit un pilote comme les premiers qu'on avait offerts à l'escadre. Ce pilote le conduisit le long des côtes avec peu de danger parce que le brick ne tirait que quelques pieds d'eau. II passa près de l'île Tsung-Ming, qui est vis-à-vis du fleuve Kiang. Cette île, loin de ressembler à celles de Chu-San, est entièrement basse, et paraît formée par les terres que charrie le fleuve ; car entre elle et l'embouchure du fleuve, la mer est fort peu profonde. Là, la terre s'accumule bientôt jusqu'au-dessus de l'eau. II n'est pas inutile de remarquer que, dans la carte conservée dans le palais ducal de Venise et qui, pour ce qui a rapport à la Chine, a été, dit-on, tracée d'après les esquisses de Marc-Paul, ce célèbre voyageur du treizième siècle, on ne trouve point l'île Tsung-Ming. Cependant, les îles Chu-San, qui ne sont pas aussi près du sud que celle-là, s'y voient distinctement. II faut qu'à l'époque où le Vénitien voyageait dans ces contrées, cette île fût si petite qu'il ne la crut pas digne d'être remarquée, ou si basse qu'il passa à côté sans l'observer. Si, en effet, elle a crû si considérablement dans l'espace de cinq siècles, elle peut, avant cette époque, avoir éprouvé des changements opposés. II n'est pas difficile de concevoir qu'une terre molle, sortant graduellement de l'embouchure d'une rivière, et déposée jusqu'à l'endroit où le flux s'oppose au courant de l'eau, soit propre à être de nouveau mise en mouvement et emportée par quelque débordement impétueux et soudain, qui triomphe de l'obstacle que la rivière s'est ellemême formé dans son cours ordinaire.

Dans le voisinage de Tsung-Ming et le long des côtes de la Chine, le capitaine Proctor rencontra plusieurs petites jonques ayant des mandarins à leur bord, et croisant par ordre de l'empereur, pour complimenter l'ambassadeur et le conduire dans le port. Mais ces mandarins s'écartaient rarement des endroits où il y avait moins de deux brasses d'eau. Ils ne se doutaient pas que le vaisseau où était lord Macartney tirait deux fois cette quantité, tant ils avaient peu d'idée de la grandeur ou plutôt de la 


\section{Voyage dans l'intérieur de la Chine et en Tartarie}

construction des vaisseaux anglais. Ceux de la Chine, quoique souvent très gros, ont encore un fond plus plat que la plupart des vaisseaux hollandais.

Le Lion cingla à l'est de la route que suivait l'Indostan, et plus près, quoique non pas à la vue de la côte occidentale de la péninsule de Corée qui, de la Tartarie, s'étend droit au sud. D'un autre côté, la péninsule de ShanTung prolonge assez dans l'est le continent de la Chine pour réduire, en cet endroit, la largeur de la mer Jaune à environ quarante lieues.

Le 15 juillet, les deux divisions de l'escadre naviguèrent avec un vent de sud, accompagné d'un épais brouillard, pendant une partie de la journée. Lorsque le temps s'éclaircit, I'Indostan aperçut une petite île en forme de cône, que le pilote dit être nommée Ka-Té-Noo. Le lendemain, il vit la côte escarpée du promontoire de Shan-Tung, ainsi qu'une petite île au midi de cette côte. On remarqua alors qu'un léger courant portait au nord. Là, par le résultat de plusieurs observations de la distance de la lune au soleil, on reconnut que la longitude était de cent vingt-deux degrés quarante minutes est ; la latitude se trouva en même temps de trente-cinq degrés dix minutes nord. De là, le Lion gouverna, en tournant au nord quart d'ouest, jusqu'à ce qu'il parvînt au trente-sixième degré vingt minutes de latitude nord. Le fond s'éleva rapidement depuis quarante jusqu'à seize, quatorze et douze brasses. On trouvait, chaque quart d'heure, une différence de deux brasses, et le fond était sablonneux. Une telle diminution d'eau occasionna naturellement des craintes. Mais elles furent bientôt calmées par les rapports des bricks qui naviguaient toujours en avant et jetaient constamment la sonde. Les assertions des pilotes auraient dû tranquilliser aussi ; mais elles faisaient moins d'effet parce que leur ignorance de la langue anglaise faisait croire quelquefois qu'ils ignoraient leur métier.

Le 16 juillet, l'île que I'Indostan vit au nord-est fut vue par le Lion au nord-ouest, parce que ce dernier vaisseau était plus dans l'est. Toute l'escadre se réunit le mercredi 17.

Le même jour, elle aperçut deux prolongements de terre ou caps, qui, avec lîle dont nous venons de parler, étaient probablement les premières terres reconnues par des vaisseaux cinglant directement du midi vers le golfe 


\section{Voyage dans l'intérieur de la Chine et en Tartarie}

de Pékin. En conséquence, le commandant de l'expédition crut devoir déterminer leur situation avec exactitude, et leur donner des noms.

Les latitudes et les longitudes de ces trois points de terre sont :

\begin{tabular}{lll} 
Latitude & \multicolumn{2}{c}{ Longitude } \\
Cap Macartney & $36^{\circ} 54^{\prime}$ nord & $122^{\circ} 12^{\prime} 122^{\circ} 20^{\prime}$ est \\
Cap Gower & $36^{\circ} 57^{\prime} \gg$ & $122^{\circ} 15^{\prime} 122^{\circ} 23^{\prime}$ » \\
lle Staunton & $36^{\circ} 47^{\prime} \gg$ & $122^{\circ} 9^{\prime} 122^{\circ} 17^{\prime} »$
\end{tabular}

Quand on voit le cap Macartney, portant du nord-nord-est au nord-ouest, on y remarque six sommets très pointus. En dedans de ce cap est une crique où l'escadre découvrit plusieurs bâtiments à l'ancre. Près du cap Gower, il y a un banc de rochers, lequel se prolonge en faisant suite à une langue de terre. Comme le fond était mauvais, les Anglais jugèrent à propos de ne pas s'en approcher. Cependant, ils virent en dedans de la pointe un joli port dont l'entrée était entre le cap Gower et le banc de rochers. Un grand nombre de vaisseaux était à l'ancre dans le port, et on découvrait au-delà une ville d'une étendue considérable.

Le jeudi 18 juillet, le vent souffla presque toujours de l'est, et le temps fut brumeux. L'après-midi, l'escadre passa devant un autre port, qui était spacieux, et où l'on voyait plusieurs grandes jonques. Alors, l'extrémité la plus septentrionale du promontoire de Shan-Tung portait nord quart d'ouest à la distance d'environ huit milles. De là, la pointe de terre la plus haute et la plus prolongée paraissait avoir la forme d'un cône aplati par les côtés, et sur le sommet duquel on avait élevé une pyramide ou une pagode, dont le dôme était très aigu. On comparait familièrement ce sommet à un bonnet de mandarin. Entre le cap Macartney et la pointe, la côte est en général raide, et les montagnes paraissent s'enfoncer fort avant dans le pays. Elles sont entremêlées de superbes vallées, qui s'étendent le long du rivage, et sont entièrement bien cultivées. On voit aussi sur ce rivage des criques propres à mettre en sûreté des petits bâtiments plats, tels que sont ceux des Chinois.

Le vendredi 19 juillet, le vent souffla de l'est-sud-est et du nord. Le temps fut encore brumeux. L'escadre croyant avoir suffisamment dépassé la péninsule de Shan-Tung, et ayant doublé l'extrémité orientale des côtes de la Chine, gouverna ouest quart de nord. A minuit, le brouillard devint si épais 


\section{Voyage dans l'intérieur de la Chine et en Tartarie}

qu'on crut devoir mettre à la cape. Le lendemain matin, le temps s'éclaircit, et les vaisseaux et les bricks se trouvèrent à deux milles d'une petite île rocheuse, portant sud-est deux quarts d'est. Une pointe du continent portait en même temps sud-est deux quarts d'est à cinq milles. II semblait qu'on pouvait trouver là un port commode, du moins pour les navires qui ne tiraient pas beaucoup d'eau. En sondant à trois milles du rivage, on trouva seize et dix-huit brasses d'eau et un fond vaseux.

Le ciel étant alors parfaitement clair, l'escadre fit voile vers l'ouest, dans une ligne parallèle à la côte, dont elle se tenait éloignée de cinq à six milles. Depuis la petite île dont nous venons de faire mention, la pointe de terre la plus occidentale qu'on voit est un sommet en forme de cône, qui termine une chaîne de montagnes inégales, distances de l'île d'environ huit lieues, et portant ouest quart de sud. Une partie de cette côte est rocheuse et stérile, mais en général le sol est uni, bien cultivé et bordé d'une plage sablonneuse.

Aussitôt que l'escadre eut doublé la pointe conique dont nous venons de faire mention, elle en aperçut une autre, ayant auprès d'elle une petite montagne remarquable par une proéminence qu'elle avait sur son sommet. Entre ces deux pointes, on gouverna presque droit à l'ouest, en longeant la côte à deux ou trois milles de distance, et ayant sept ou huit brasses d'eau. Une foule immense de peuple avait monté sur les parties de la côte les plus élevées, afin de voir passer les vaisseaux européens. Au-delà de la dernière pointe, on entra dans une baie profonde, où l'on crut que les pilotes disaient qu'était le port qu'ils avaient désigné, avant de partir de Chu-San, comme propre à recevoir l'escadre. Mais, par le moyen du peuple que la curiosité avait attiré au rivage, on découvrit bientôt qu'on était dans la baie de Ki-SanSeu, et que le port de Mi-a-Tau se trouvait dans une île plus avancée vers l'ouest, de quinze lieues, mais dont la latitude n'était que de quelques milles plus au nord.

La baie de Ki-San-Seu est spacieuse et bien abritée contre tous les vents, excepté ceux qui règnent depuis l'est-nord-est à l'est-sud-est, parce que l'entrée de la baie est dans cette direction. Elle est fermée du côté du nord par un groupe de dix ou douze petites îles et d'un grand nombre de gros rochers, et le continent l'entoure à l'ouest et au sud. Cette baie a au moins dix milles d'étendue de l'est à l'ouest, et presque autant du nord au sud. Elle 


\section{Voyage dans l'intérieur de la Chine et en Tartarie}

contient deux ports ; l'un est derrière une pointe escarpée, appelée Zeu-aTau. Il a quatre brasses d'eau de profondeur, et l'escadre y vit un grand nombre de bâtiments chinois. L'autre port est à l'embouchure de la rivière YaMa-Tao, et couvert par une langue de terre qui s'avance du côté sud-est de la baie.

Le grand nombre de jonques qu'on aperçoit dans presque toutes les baies de cette côte annonce des échanges considérables entre ses habitants et ceux des autres provinces. Non seulement ce commerce attire beaucoup de navigateurs, et conséquemment augmente la population, mais il produit un mouvement, une activité, qu'on ne remarque pas ordinairement parmi les tranquilles, quoique industrieux agriculteurs.

L'embouchure de la rivière Ya-Ma-Tao est traversée par une barre sur laquelle il n'y a que deux brasses et demie d'eau : mais dans la rivière même, il y en a quatre à cinq brasses. Cette rivière a depuis un quart de mille jusqu'à un demi-mille de large. Quoique derrière la baie le pays ne soit pas très montueux, il a un aspect assez stérile et les habitants ont l'air très pauvres.

Entre la pointe de Zeu-a-Tau et l'une des îles qui sont à l'est et forment le groupe dont nous avons fait mention, il y a, pour sortir de la baie, un passage dans une direction nord et sud. Quoiqu'il soit étroit, on y trouve huit, neuf et dix brasses d'eau de chaque côté du rivage : mais en avant des îles du même groupe, qui sont à l'est, il y a de petits bancs de sable, qu'on ne découvre que quand on en est très près, parce qu'ils sont presque de niveau avec la surface de l'eau. - La pointe escarpée, ou le cap de Zeu-a-Tau est l'extrémité d'une petite mais haute péninsule, qui s'étend vers le nord. - Le long du centre de la grande péninsule de Shan-Tung, on voit s'étendre de l'est à l'ouest une chaîne de montagnes, dont les flancs presqu'à pic offrent à la vue des masses de stérile granit.

L'escadre passa la journée du 20 juillet dans la baie de Ki-San-Seu : mais le dimanche 21 , après s'être pourvue de nouveaux pilotes, elle sortit par la passe qui est entre le cap Zeu-a-Tau et les îles, en se tenant plus près du premier que des autres. Un peu à l'ouest de la pointe la plus nord de Zeu-aTau est une baie dans laquelle les Anglais virent entrer plusieurs jonques. 


\section{Voyage dans l'intérieur de la Chine et en Tartarie}

Dans la carte générale de la Chine, qui est maintenant entre les mains d'un personnage illustre et révéré, et qui a été tracée, à grand point avec assez d'exactitude, par les missionnaires du dernier siècle, on a désigné en cet endroit un port commode et sûr.

Après avoir dépassé la pointe est, l'escadre fit deux milles, en se dirigeant vers le nord-nord-ouest; ensuite elle fit voile au nord-ouest quart de nord, puis au nord-ouest, puis à l'ouest, longeant la côte pendant toute la route. Après avoir marché ainsi jusqu'au soir, elle contourna une projecture de terre semblable à celle de l'entrée de la baie de Ki-San-Seu. Là, on vit, comme la veille, les hauteurs couvertes de spectateurs. Les montagnes, qui sont par derrière la côte que l'escadre longea dans cette journée, ont un caractère particulier, et semblent être plutôt l'ouvrage de l'art que de la nature. Leurs flancs paraissent arrondis par le secours de la bêche, et sur leurs sommets, on voit de petits monceaux de terre, qui ont la forme des anciennes sépultures.

Quand les vaisseaux anglais eurent fait le tour de cette dernière pointe, ils en aperçurent une nouvelle, très escarpée et directement à l'ouest de l'autre, et à environ huit milles de distance. La côte qui s'étend entre ces deux pointes forme une espèce de baie, appelée la baie de Ten-Choo-Foo. Elle est ouverte à l'est et à l'ouest, mais en partie abritée au nord, par des groupes de petites îles, semées de distance en distance depuis cinq milles jusqu'à dix lieues loin du rivage. Ces îles paraissent comprendre deux fois autant d'espace que la mer a de largeur en cet endroit, laissant seulement un détroit entre le groupe le plus septentrional et le cap qui est vis-à-vis et qui dépend de la province de Léa-Tung. Parmi les groupes, il y a deux îlots, remarquables par la régularité de leur forme de cônes tronqués et ressemblant à deux verreries, qui s'élèvent du fond de la mer. Ils ont été probablement produits par l'explosion de quelques volcans, dont les matières étaient légères et l'impulsion si modérée, que ces matières sont restées dans le premier endroit où elles sont tombées et, s'amoncelant ainsi graduellement, ont pris la forme régulière que nous venons de décrire. 


\section{Voyage dans l'intérieur de la Chine et en Tartarie}

L'escadre jeta l'ancre par sept brasses d'eau dans la baie de Ten-ChooFoo, et à deux ou trois milles au nord-est de la ville du même nom. Le fond de la mer était mauvais, très dur et rempli de coquillages. On se hâta de dépêcher le Clarence pour aller examiner le port de Mi-a-Tau, indiqué comme un lieu très sûr pour l'escadre. On fit aussi partir un officier chargé d'annoncer au gouverneur de Ten-Choo-Foo l'arrivée des Anglais. La terminaison du nom de Ten-Choo-Foo signifie, dans la langue chinoise, que c'est une cité du

premier ordre et que plusieurs villes moyennes et petites villes dépendent de sa juridiction. Ten-Choo-Foo est bâti sur un terrain élevé et, de dessus le pont des vaisseaux, il paraissait fort grand. Une forte muraille l'entoure.

Tandis que l'Europe était encore barbare, et que les individus se rassemblaient pour la sûreté de leurs personnes et leurs propriétés, les embarras et les dépenses qu'occasionnaient la nécessité d'entourer des villes et de les fortifier introduisirent, vraisemblablement, la coutume de bâtir des maisons à plusieurs étages, afin que les remparts protecteurs eussent le moins d'étendue possible. Mais l'état de la société était sans doute différent à la Chine, quand les fortifications de Ten-Choo-Foo ont été construites, car on y a renfermé une grande quantité de terrains non occupés. L'on croyait alors que le nombre des maisons de cette ville s'accroîtrait à un point où il n'est point encore parvenu, ou bien l'espace qui reste vide était destiné à des exercices militaires, ou à quelque autre objet.

Le port, ou plutôt la baie de Ten-Choo-Foo, reste non seulement à découvert du côté de l'est et de celui de l'ouest, mais elle n'est pas très bien abritée au nord, car les îles de Mi-a-Tau en sont trop éloignées pour arrêter entièrement l'effet du vent et de la grosse mer. Le fond sur lequel les vaisseaux mouillent est, en général, composé de rochers durs et pointus ; et à environ un mille et un quart du rivage, il y a un dangereux banc de rocher, qui est couvert par la haute mer, et s'étend à près d'un mille de l'est à l'ouest. Autour de ce banc, le fond s'élève si rapidement que l'approche en est très dangereuse. Il y $a$, à Ten-Choo-Foo, un bassin où les vaisseaux entrent pour prendre ou déposer leurs cargaisons. Pour y entrer, on passe entre deux chaussées, qui ont entre elles de trente à quarante pieds de distance. Le terrain qui s'étend le long de la côte est parfaitement cultivé, et s'élève 


\section{Voyage dans l'intérieur de la Chine et en Tartarie}

insensiblement jusqu'au pied d'une chaîne de montagnes inégales, stériles, et qui paraissent être de granit.

Le passage entre Ten-Choo-Foo et les îles de Mi-a-Tau se nomme le détroit de Mi-a-Tau. Entre la haute et la basse marée, il y a une différence de sept à huit pieds d'eau. Le cours de la marée montante va vers l'est et droit à la mer, d'où il devrait naturellement venir ; et la marée descendante, qui ne devrait être proprement que le reflux de l'eau vers la mer, se porte au contraire de la mer, droit à l'ouest dans le golfe de Pékin. Cet étrange phénomène n'est point occasionné par la position des îles de Mi-a-Tau qui, en proportion de l'étendue de la mer où elles ne s'élèvent que comme des pointes, sont trop petites pour arrêter le cours ou changer la direction des marées. Mais on peut donner à cet égard une explication plus satisfaisante, en considérant les limites septentrionales de la mer Jaune. Le flux qui entre en venant du sud, dans le passage qui est entre le promontoire oriental de Shan-Tung et la péninsule de Corée, continue à courir avec impétuosité droit au nord, jusqu'à ce que la côte de Léa-Tung lui oppose un obstacle. Alors, il se porte le long de la côte vers l'ouest, et dans le golfe de Pékin, dont il suit la plage unie et sablonneuse en décrivant une ligne courbe, prescrite par la forme du golfe. Enfin, lorsqu'il arrive à Ten-Choo-Foo, il a encore assez de force pour contrebalancer, ou plutôt vaincre, le faible effort du mascaret, qui contourne la projecture des terres de la province de Léa-Tung.

Lorsque le gouverneur de Ten-Choo-Foo fut informé que l'ambassadeur était à bord du Lion, il lui envoya un présent de fruits et d'autres provisions fraîches, et vint lui rendre visite. Cet officier était accompagné d'un grand nombre de personnes. L'une desquelles ayant occasion de lui parler, tandis qu'il passait sur le pont du vaisseau, tomba à genoux devant lui et resta en cette posture tout le temps qu'elle lui adressa la parole. Les Anglais, qui avaient d'abord été étonnés de cette action, le furent encore davantage en voyant que le gouverneur écoutait I'homme agenouillé avec une tranquillité qui montrait combien il était accoutumé à se voir aborder de cette manière.

Cette preuve de l'extrême distance entre les rangs ne semblait pourtant avoir pour cause, ni la hauteur particulière de l'un, ni l'abjection de l'autre. Elle indiquait seulement des formes et des usages établis pour maintenir I'habitude de la subordination. On considère, en Chine, ces formes et ces 


\section{Voyage dans l'intérieur de la Chine et en Tartarie}

usages comme plus propres à prévenir le tumulte et le désordre que ne peuvent l'être dans les autres pays la crainte et les châtiments. Quoique les individus, même égaux en rang, s'y abordent avec beaucoup de cérémonie et de mutuelles démonstrations de respect, il ne s'ensuit pas moins entre eux une conversation libre et familière.

Dans son entrevue avec lord Macartney, le gouverneur de Ten-Choo-Foo montra non seulement de la dignité, mais de l'aisance et de la politesse. L'on vit en cette occasion, ainsi qu'on l'avait déjà observé à Chu-San, que l'air de solennité qu'on $a$, dans plusieurs relations, attribué au caractère général des Chinois, n'était affecté par eux qu'en présence de ceux qu'ils considéraient comme leurs inférieurs.

Le gouverneur invita lord Macartney et sa suite à se rendre à terre, et à participer aux festins et aux spectacles qu'il leur destinait, pour correspondre en quelque sorte, ainsi qu'il le disait, à la réception splendide que son souverain se proposait de faire à l'ambassadeur quand il arriverait à la cour impériale. Mais l'ambassadeur le refusa poliment, ainsi qu'il avait refusé le gouverneur de Chu-San, dont il avait reçu une pareille invitation.

L'éclat de la réception annoncée par l'empereur devait sans doute faire une grande impression sur l'esprit des peuples de la Chine, qui ne regardent le trône qu'avec un respect extraordinaire. Elle devait leur inspirer, pour la nation anglaise, une considération dont les agents que la Compagnie a à Canton ne pouvaient qu'éprouver des effets très avantageux. Tout exigeait en même temps que les individus qui composaient l'ambassade tâchassent, par beaucoup de retenue et de circonspection, de ne pas occasionner des mécontentements dans un pays où le plus petit désordre, la moindre légèreté de conduite, peuvent si aisément offenser. II fallait que partout où ils iraient, ils s'efforçassent de captiver la bonne opinion des Chinois, afin de détruire les préjugés que, suivant ce que contiennent les mémoires de la Compagnie, ce peuple avait conçus contre la morale et les mœurs des Anglais.

En conséquence, lorsque l'escadre fut avancée dans la mer Jaune, et prête, suivant toute apparence, à arriver au lieu de sa destination dans le golfe de Pékin, l'ambassadeur se détermina à faire une note, qui fut 


\section{Voyage dans l'intérieur de la Chine et en Tartarie}

publiquement lue aux équipages et aux passagers de chaque vaisseau. Ce ministre observait dans cette note :

«Que sans la bienveillance des Chinois, l'ambassade ne pouvait accomplir les divers et importants projets dont l'exécution lui était confiée. Que cette bienveillance dépendait beaucoup de l'idée que les Chinois prendraient des dispositions et du caractère de la nation anglaise, dont ils ne pouvaient juger que d'après la conduite des Anglais qui venaient parmi eux. Que l'impression qu'avaient déjà faite sur l'esprit de ce peuple les étourderies commises par quelques Anglais, à Canton, leur était si défavorable, qu'ils les regardaient comme les pires de tous les Européens; que cette impression avait été communiquée à ce tribunal de la capitale, lequel était chargé d'informer l'empereur de tout ce qui concernait les pays étrangers, et de l'aider de ses conseils à cet égard.

«Qu'il était donc essentiel que, par une conduite singulièrement régulière et circonspecte de la part de ceux qui appartenaient à l'ambassade, ou qui avaient des rapports avec elle, on inspirât aux Chinois une nouvelle, mais plus juste et plus favorable idée des Anglais. Qu'il fallait montrer même au dernier officier, soit de terre ou de mer, soit civil, que la nation anglaise était capable, par l'exemple et par la discipline, de maintenir, parmi les inférieurs, la sobriété, l'ordre et la subordination. Que, quoique le peuple de la Chine n'eût pas la moindre part au gouvernement, la maxime invariable des chefs était de défendre le moindre Chinois dans les différends qu'il pouvait avoir avec un étranger, et même de venger son sang s'il y avait lieu; qu'on en avait eu récemment un fatal exemple à Canton, où un canonnier anglais étant devenu la cause innocente de la mort d'un paysan, avait été exécuté, malgré les efforts réunis de plusieurs factoreries européennes qui voulaient le sauver. Qu'on devait conséquemment agir avec beaucoup de précaution et de douceur, dans tous les rapports directs ou accidentels qu'on aurait avec chaque individu, fût-il le dernier du pays.

«L'ambassadeur, qui savait bien qu'il n'avait pas besoin de recommander à sir Erasme Gower de faire tous les règlements que 


\section{Voyage dans l'intérieur de la Chine et en Tartarie}

la prudence pouvait dicter en cette occasion, pour les personnes qui étaient immédiatement sous ses ordres, et qui espérait que le capitaine Mackintosh en ferait de même pour les officiers et l'équipage de l'Indostan, ne doutait pas, non plus, que ces règlements justes, nécessaires et propres à faire estimer le nom anglais et à favoriser les intérêts de la patrie dans des contrées si éloignées d'elle, ne fussent suivis avec joie et avec exactitude; qu'il se flattait aussi que de pareils motifs agiraient sur les personnes attachées à l'ambassade ou à son service.

«Son excellence déclara que, comme elle serait prête à soutenir ceux qui le mériteraient, et à faire un rapport avantageux en leur faveur, elle croirait aussi, en cas de mauvaise conduite ou de désobéissance à ses ordres, devoir en rendre compte avec la même exactitude, et même suspendre ou congédier les fautifs, si l'occasion le requérait. Que si l'on offensait un seul Chinois, ou si l'on commettait un crime punissable par les lois du pays, elle ne se croirait point obligée de s'en mêler, pour tâcher de mitiger ou d'arrêter la sévérité de ces lois.

«L'ambassadeur comptait sur le lieutenant-colonel Benson, commandant de sa garde, pour tenir un œil attentif sur les individus qui composaient ce corps. La vigilance quant à leur conduite personnelle était non moins nécessaire dans les circonstances où ils se trouvaient, qu'elle ne l'eût été, quoique par d'autres motifs, en présence d'un ennemi, en temps de guerre. La garde devait se tenir constamment rassemblée, et s'exercer régulièrement dans toutes les évolutions militaires. Aucun des soldats ne pouvait s'absenter des vaisseaux, ou des endroits qu'on fixerait à terre pour leur demeure, sans la permission de son excellence ou de l'officier commandant.

« On ajouta qu'aucun des ouvriers ou des domestiques ne sortirait du vaisseau, ou de la maison qu'il habiterait, sans la permission de l'ambassadeur ou de M. Maxwel; que son excellence s'attendait que les personnes de sa suite donneraient l'exemple de la 


\section{Voyage dans l'intérieur de la Chine et en Tartarie}

subordination, et la préviendraient lorsqu'elles voudraient s'absenter du vaisseau ou de leur habitation à terre.

«L'ambassadeur enjoignait, de la manière la plus expresse, à toutes les personnes dépendantes des vaisseaux, ainsi qu'à celles de sa suite, à ses gardes, à ses ouvriers, à ses domestiques, de n'offrir, de vendre ou d'acheter, sous aucun prétexte, la moindre espèce de marchandise, sans qu'il en eût préalablement accordé la permission. Qu'une ambassade à Pékin était dans la nécessité d'éviter toute espèce de trafic; et que la Compagnie des Indes avait renoncé aux bénéfices d'un nouveau marché, et à embarquer à bord de I'Indostan des marchandises pour être vendues, parce qu'une ambassade perdrait son importance et sa dignité aux yeux des Chinois, et n'aurait aucun des effets qu'on en attendait, relativement au commerce, si l'on découvrait que les personnes de la suite de l'ambassadeur, ou ayant quelque rapport avec lui, se sont occupées à faire le moindre marché dans l'espoir de gagner ; marché qu'on ne manquerait pas de représenter bientôt comme un système général de trafic. - Son excellence promettait de se relâcher de cette rigueur aussitôt que ses négociations seraient assez avancées pour qu'elle fût sûre du succès de sa mission, et quand la permission qu'elle donnerait à un Anglais de disposer de quelque marchandise, serait considérée comme une faveur accordée à l'acheteur chinois.

«L'ambassadeur saisit cette occasion pour déclarer enfin qu'il était fermement déterminé par le sentiment du devoir que lui imposait sa mission, à surveiller, à découvrir, à punir, autant qu'il serait en son pouvoir, les crimes, la désobéissance à ses ordres, et toute conduite tendant à nuire au succès de l'ambassade, à le retarder, à lui occasionner quelque embarras, ou bien à décréditer le nom anglais. Mais qu'il se croirait heureux, s'il était jamais à même de faire connaître le mérite, de le récompenser, ainsi que de favoriser les intérêts et seconder les vœux des personnes qui l'accompagnaient en cette occasion, autant que ce serait d'accord avec son honneur et le bien public. » 


\section{Voyage dans l'intérieur de la Chine et en Tartarie}

Ceux qui désirent déjà de savoir quel fut l'effet de cette note sur les personnes à qui elle était adressée seront bien aise d'apprendre que, non seulement l'ambassadeur se crut obligé de rendre un compte favorable de leur conduite, mais qu'un mandarin d'un des premiers rangs, lequel accompagna partout l'ambassade, déclara au moment où il se sépara d'elle, que le même nombre de Chinois pris dans les différentes classes de la société, ne se serait pas conduit avec autant de tranquillité et de décence.

Les précautions qui restaient à prendre par l'ambassadeur, avant qu'il entrât en Chine, concernaient en partie la situation de l'escadre en son absence. Le premier objet était de savoir si elle pourrait avoir un asile sûr dans le port de Mi-a-Tau. Lorsque le brick le Clarence en fut de retour, l'officier qui le commandait rapporta qu'un banc de rocher, s'étendant nordest quart de nord et sud-ouest quart de sud, à deux milles en-dehors de l'extrémité est de Chan-San, la plus orientale des îles Mi-a-Tau, formait dans la baie de cette île le seul abri du côté de l'est. Le continent qui s'étend derrière la ville de Ten-Choo-Foo garantissait en partie cette baie du vent de sud, comme l'île même la mettait à l'abri du vent du nord. Elle restait entièrement exposée du côté de l'ouest: malgré cela, le mouillage y était bien préférable à celui en-dehors de Ten-Choo-Foo. Mais le banc de rocher était très dangereux et ne pouvait pas être approché plus près que l'endroit où il y avait neuf brasses d'eau, parce que le fond s'élevait rapidement. Le Clarence jeta l'ancre dans cette baie à un mille du rivage, par sept brasses d'eau, et sur un fond argileux. L'île a environ trois milles de longueur et presque autant de largeur. Elle est bien peuplée, bien cultivée, et on y fait beaucoup de commerce.

L'île au centre du groupe est proprement Mi-a-Tau. Entre elle et la première, il y a une baie dont les issues sont nord et sud, et n'ont pas plus d'un quart de mille de large, mais n'offrant aucun danger. Cette baie est sûre et suffisante pour contenir près de cent vaisseaux, pourvu qu'ils ne tirent pas plus de trois brasses d'eau. Le fond est argileux et conséquemment propre à bien tenir les ancres. Cette île est plus petite que Chan-San; mais il y a proportionnément autant de population et la culture y est aussi bien entretenue. 


\section{Voyage dans l'intérieur de la Chine et en Tartarie}

Kei-San est la plus occidentale de ce petit groupe d'îles. Elle forme avec la dernière, c'est-à-dire Mi-a-Tau, une excellente baie pour les vaisseaux qui ne tirent pas plus de deux ou trois brasses d'eau. Un dangereux banc de rocher est en-dehors de la pointe ouest de l'île, s'étend nord-est et sud-est à un mille, et ne peut être approché à un câble de distance, parce que là on ne rencontre que trois brasses d'eau. Ce rocher doit être laissé à gauche, quand on entre dans la baie qu'il défend du côté de l'ouest. On voit à Kei-San plusieurs villages considérables. Le plat pays est bien cultivé; mais les montagnes sont tout à fait stériles. Vis-à-vis de la pointe escarpée qui est à l'ouest, on trouve six brasses et demie d'eau à un mille du rivage.

Le rapport du Clarence ne laissa point d'espoir de trouver un abri permanent à Mi-a-Tau pour des vaisseaux de la grandeur du Lion et de I'Indostan, et acheva de détruire la confiance qu'on pouvait avoir eue dans les pilotes chinois, qui avaient fait une description si favorable du port de cette île.

Avant de hasarder l'escadre dans le golfe de Pékin, dont le détroit de Mia-Tau peut être considéré comme l'entrée, sir Erasme Gower résolut d'envoyer un officier examiner particulièrement l'embouchure de la rivière qui s'y jette, après avoir passé à Tien-Sing, afin de savoir aisément si les vaisseaux pouvaient s'y risquer, et s'ils trouveraient un port sûr pendant qu'ils seraient obligés de rester dans le voisinage. Le Jackall fut expédié pour prendre ces renseignements. A peine était-il parti qu'un nouveau pilote chinois fut recommandé, comme connaissant parfaitement le golfe de Pékin et la rivière qui conduit à Tien-Sing. C'était un homme d'un aspect vénérable, ayant des manières décentes, et paraissant fort bien entendre la navigation. Il assura qu'il y avait un port excellent, et que les plus grands vaisseaux pouvaient trouver assez d'eau à six milles du Pei-Ho, c'est-à-dire de la rivière Blanche, qui passe à Tien-Sing ; et pour démontrer la vérité de son assertion, il dessina une esquisse du port, avec sa situation relative à la côte septentrionale du golfe et à l'embouchure de la rivière.

La baie de Ten-Choo-Foo, où l'escadre se trouvait alors, était si peu sûre, qu'il n'y avait pas apparence qu'on pût la changer pour une pire, même quand les rapports du nouveau pilote auraient été inexacts. On se détermina donc aussitôt à entrer sans plus de délai dans le golfe de Pékin. 


\section{Voyage dans l'intérieur de la Chine et en Tartarie}

Dans l'après-midi du 23 juillet, le vent étant à l'est, l'air doux et le temps très beau, l'escadre mit à la voile, laissant les îles de Mi-a-Tau à droite. La côte à l'ouest, qui entoure la pointe escarpée de Ten-Choo-Foo, est très plate, et on pouvait à peine la voir de dessus le pont des vaisseaux. Il y a une grande crique dans cette partie de la côte, ou bien une île basse en est tout près, car on vit les mâts de plusieurs jonques en dedans de la terre.

Lorsque, depuis, le Lion quitta le golfe, il découvrit un très grand banc qui s'étend est quart de sud, et ouest quart de nord, à la distance de deux milles, avec trois brasses et demie d'eau dans l'endroit où il est le plus élevé. De là, la pointe escarpée de Ten-Choo-Foo porte est quart de sud à huit ou neuf milles de distance, et l'île de Kei-San, nord quart d'ouest.

Tout le reste du jour du 23 juillet, les sondages furent irréguliers. On trouva alternativement douze, neuf et quinze brasses d'eau, mais plus souvent douze.

Le mercredi 24 juillet, la brise souffla modérément du sud-est, et le temps fut très beau. Vers les trois heures du matin, le fond s'éleva, tout à coup, de quatorze à neuf brasses et, bientôt après, à six et demie. Au même instant, le Clarence qui marchait en avant, tira plusieurs coups de mousquet pour avertir du danger ; et les vaisseaux, faisant un détour, gouvernèrent est-sud-est. On entendait distinctement la lame qui se brisait sur les rochers ou sur les hauts fonds. A six heures du matin, le temps était presque calme. On vit une longue rangée d'îles sablonneuses qui s'élevaient à peine au-dessus de la surface de l'eau. A midi, les extrémités de ces îles portaient, d'après la boussole, de l'ouest quart de nord au nord; le dernier point à la distance d'environ huit milles. Sur la plus orientale de ces îles est un bâtiment très élevé, que le pilote nous dit être destiné à avertir les vaisseaux pendant la nuit, de se tenir loin des bancs de sable, dont ces îles sont environnées.

Le jeudi 25 juillet, le vent souffla du sud et du sud-ouest, mais avec peu de force. Le temps fut beau ; l'escadre, faisant aisément sa route, gouverna à l'ouest, en inclinant un peu au sud-ouest pour éviter les îles basses. L'eau diminua régulièrement depuis quinze à sept brasses. Alors, on vit une autre île basse, qui portait au nord, à la distance d'environ sept milles. De là, on gouverna à l'ouest jusqu'à minuit, lorsque le Clarence fit signal de danger. Le 


\section{Voyage dans l'intérieur de la Chine et en Tartarie}

Lion avait cependant encore six brasses d'eau. Les vaisseaux se tournèrent vers le sud-est, et trouvèrent bientôt une profondeur de dix brasses. Après avoir fait environ quatre milles dans cette direction, ils revirèrent à l'ouestnord-ouest et firent encore quatre milles : mais l'eau diminuant tout à coup jusqu'à six brasses et demie, ils jetèrent l'ancre.

Le lendemain 26 juillet, il tomba beaucoup de pluie jusqu'à midi ; et le soir, il y eut, pendant plusieurs heures de suite, des éclairs et des coups de tonnerre, d'une force dont peu de personnes, à bord du Lion, se rappelaient d'avoir jamais vu d'exemple. Les éclairs couvraient le ciel d'un voile immense de flamme livide, et étaient accompagnés d'éclats de tonnerre qui, en se prolongeant, ressemblaient au feu roulant d'une armée qui tire avec précision. Cependant, la mer n'était aucunement agitée par les secousses de l'atmosphère, et les vaisseaux restèrent tranquillement mouillés sur une seule ancre.

Lorsque l'orage eut cessé, on aperçut le Jackall qui revenait de l'ouest. II était environné d'un nombre immense de vaisseaux chinois, faisant la même route que lui. De dessus le pont du Lion, on ne découvrait point la terre; mais le faîte des arbres et des maisons offraient une perspective singulière ; il semblait qu'ils étaient suspendus dans les airs. Cependant, du haut des mâts, on vit, presque au niveau de la surface de l'eau, une plage sablonneuse, s'étendant du nord-ouest à l'ouest, et à environ quatre lieues de distance du vaisseau.

D'après le rapport du lieutenant Campbell ${ }^{1}$, qui avait été envoyé avec le Jackall pour reconnaître la côte, la rivière Pei-Ho, venant de Tien-Sing, était à quinze milles de distance de l'endroit où l'escadre venait de mouiller. Une barre s'étendant du nord-nord-est au sud-ouest, est au-devant de l'embouchure de la rivière ; et lorsque la mer est basse, il n'y a pas plus de trois ou quatre pieds d'eau par-dessus cette barre, et en plusieurs endroits, elle reste presque à sec. La marée monte de cinq ou six pieds à l'embouchure de la rivière; et lorsque la lune est dans son plein, ou qu'elle change de quartier, la mer est haute vers les trois heures et demie. A cinq ou six milles

\footnotetext{
${ }^{1}$ Maintenant capitaine Campbell.
} 


\section{Voyage dans l'intérieur de la Chine et en Tartarie}

en-dehors de l'embouchure de la rivière, on voit sur la barre un grand bambou, avec quelques autres plus petits, plantés presque en droite ligne jusqu'au rivage, en servant à diriger les vaisseaux qui entrent dans la rivière. II faut alors qu'on longe ces bambous de très près en les laissant à bâbord, c'est-à-dire à gauche. En gouvernant ouest quart de nord, suivant la boussole, et allant droit à un fort, placé sur le côté sud-ouest de la rivière, on prend la meilleure passe. La rivière a environ un tiers de mille de large à son embouchure, et trois brasses de profondeur, quand la mer est basse. En donnant ces détails, le lieutenant Campbell ajouta qu'on disait qu'il y avait, de l'embouchure de la rivière jusqu'à Tien-Sing, trente ou quarante milles, par terre, et le double de chemin par eau ${ }^{1}$.

Quant au port promis par le pilote, on n'en avait pas découvert la moindre trace. On avait seulement vu qu'on pourrait trouver quelque abri contre la grosse mer derrière les îles de sable; mais on n'espérait pas qu'il y en eût contre le vent. La situation de ces îles était exactement conforme à l'esquisse qu'en avait donnée le pilote, et l'on voyait par derrière elles les mâts de plusieurs jonques à l'ancre. Cependant, le peu d'espoir d'y trouver un bon mouillage pour l'escadre empêcha de les examiner. Un léger aperçu des terres qui environnent ce golfe suffisait pour montrer que, vraisemblablement, il n'y avait point un bon port sur les côtes. Un bon port se trouve, en général, entre des masses de rochers, ou au moins entre des monceaux considérables de terre compacte, produits par quelque opération extraordinaire, ou quelque convulsion de la nature, qui en même temps laisse à la mer un passage, que ces exhaussements de terres ou de rochers protègent contre la fureur des vents et des vagues. Mais le pays qu'on voit à l'extrémité du golfe de Pékin est entièrement dépourvu de ces masses solides et élevées, capables de devenir un boulevard derrière lequel les vaisseaux puissent trouver une retraite sûre. Au lieu de ce boulevard, on n'aperçoit qu'une surface basse, unie et formée par le dépôt graduel du sol, que les eaux entraînent des montagnes de l'intérieur du pays. Ce dépôt a comblé toutes les inégalités des endroits où il a eu lieu, et il a formé près de la mer une ligne régulière où l'on ne trouve aucun abri. Sans doute une partie des

${ }^{1}$ [Cf. Reclus, I'Empire du Milieu, carte 'Tientsin et bas Pei-ho'] 


\section{Voyage dans l'intérieur de la Chine et en Tartarie}

eaux tombant des montagnes est rassemblée en ruisseaux qui grossissent, se réunissent et forment des rivières. Mais le mouvement qu'ont acquis ces eaux en descendant des hauteurs est ensuite ralenti proportionnément à l'étendue de plat pays qu'elles traversent. La terre paraît gagner chaque jour sur la mer et, conséquemment, à mesure que l'étendue du plat pays augmente, on peut croire que la rivière perd une partie de la force avec laquelle elle a coutume de charrier et de disperser, dans le golfe, la terre qu'elle a emportée des montagnes. Enfin, cette terre s'est accumulée un peu au-dessous de l'embouchure de la rivière et forme la barre qui la traverse complètement.

Cependant, la barre n'empêche pas la navigation des vaisseaux chinois. II $y$ en a qui portent trois ou quatre cents tonneaux; mais ils ont un fond si plat, et une mâture et des agrès si légers, que plusieurs d'entre eux passèrent par-dessus la barre de la rivière, tandis que le Jackall, qui n'était tout au plus que du port de cent tonneaux, eut beaucoup de peine à les suivre. II est vrai que ce brick était construit pour naviguer avec les vents variables et souvent contraires qui soufflent dans les mers d'Europe, et qu'en conséquence il tirait une double quantité d'eau, c'est-à-dire qu'il s'enfonçait deux fois autant dans la mer que les jonques chinoises d'un port égal au sien. L'inconvénient de perdre l'avantage du vent, lorsqu'il vient par côté, inconvénient auquel sont exposés les vaisseaux européens qui ont un fond trop plat, ne se fait pas beaucoup sentir dans les mers de la Chine, où en général les vaisseaux ne naviguent qu'avec une mousson favorable. En outre, les voiles des jonques chinoises sont faites pour tourner aisément autour des mâts, et forment un angle si aigu avec les côtés des vaisseaux qu'elles les présentent fort bien au vent, malgré le peu de prise que la jonque a sur l'eau.

M. Hüttner, cet étranger dont nous avons fait mention ${ }^{1}$ dans le chapitre second de la première partie de cet ouvrage, accompagna le capitaine Campbell dans son expédition à l'embouchure de la rivière Pei-Ho. Voici ce qu'il rapporta :

1 C'était l'instituteur du jeune Staunton, page de l'ambassadeur. (Note du Traducteur.). 


\section{Voyage dans l'intérieur de la Chine et en Tartarie}

II vit, en entrant dans la rivière, un nombre considérable de jonques chargées d'une multitude d'hommes, dont la plupart étaient sans doute attirés par la curiosité de voir des vaisseaux européens à la voile. Quelquesunes des jonques allaient à la rame; et alors le patron chantait une chanson mélodieuse et, à chaque couplet, les rameurs répondaient en chœur. Non seulement ce chant était un amusement pour eux, mais il leur servait à captiver leur attention et à rendre plus égal le mouvement de leurs avirons.

Le Jackall fut bientôt accosté par un canot, dans lequel il y avait des soldats qui prièrent les Anglais de mouiller pour attendre l'arrivée d'un mandarin chargé de prendre d'eux quelques informations. Ce mandarin ne tarda pas à se rendre à bord avec une nombreuse suite. Dès qu'il sut que le Jackall appartenait à l'ambassade, il fit plusieurs questions sur lord Macartney, et sur les présents destinés à l'empereur. On ne lui fit que des réponses générales. Mais un moment après, il essaya d'obtenir des renseignements plus particuliers en changeant la manière et la forme de ses questions; et il n'employa pas peu d'adresse pour parvenir à son but. Quoique incommodé par le mouvement du brick et par l'odeur du goudron, il resta longtemps à bord, afin d'avoir le temps de s'informer de la grandeur, de la force des vaisseaux qui portaient l'ambassade, et du nombre d'hommes et de canons qu'ils avaient. Pendant ce temps-là, un homme de sa suite écrivait et semblait prendre note de tout ce qui se passait. Le mandarin conclut en déclarant que l'empereur avait donné des ordres pour que l'ambassade fût convenablement reçue, et il offrit de fournir toutes les choses dont elle pouvait avoir besoin.

Le Jackall étant obligé de rester dans la rivière jusqu'à la haute mer du lendemain, le capitaine Campbell et $M$. Hüttner furent invités à se rendre à terre, où on les traita fort bien. On les examina pourtant d'une manière assez incommode, et on répéta les questions qu'on leur avait faites à bord. On leur demanda aussi quelle espèce de nourriture prenaient ordinairement l'ambassadeur et sa suite, et comment voulait voyager son excellence. On observa, en même temps, qu'à la Chine, les personnes d'un rang élevé voyageaient par terre, tantôt dans des chaises à porteur, tantôt dans des voitures à deux roues, ou bien par eau, dans des bateaux commodes et légers, 


\section{Voyage dans l'intérieur de la Chine et en Tartarie}

méthode qu'on préférait toutes les fois qu'elle était praticable. Mais que l'ambassadeur et sa suite feraient ce qui leur conviendrait le mieux.

Les mandarins demandèrent aussi des informations sur les marchandises qu'ils supposaient qu'on portât pour vendre à Pékin, et dirent qu'on pourrait les déposer avec sûreté et les vendre avec avantage dans les quatre églises chrétiennes qu'il y avait dans cette ville. L'idée de trafic était tellement associée avec celle d'Anglais, dans l'esprit des Chinois, qu'ils ne regardaient les hommes de cette nation que comme des vendeurs et des acheteurs de marchandises, et qu'ils avaient beaucoup de peine à croire que ceux qui composaient l'ambassade ne fussent pas des commerçants. Enfin, ils ne pouvaient se persuader que les vaisseaux de guerre ne portaient jamais des marchandises pour vendre, et que dans ceux de l'escadre il y avait très peu de chose, excepté ce qui était destiné à être offert en présent à la cour impériale.

La proposition faite, avec si peu de cérémonie, de convertir des églises en boutiques pour la vente des marchandises, peut paraître singulière à un Européen, mais n'a rien d'extraordinaire pour les Chinois ; car les lieux où ils célèbrent leurs cérémonies religieuses sont employés à des objets d'utilité, quels qu'ils soient, lorsque l'occasion le requiert. La conversation que nous venons de rapporter se tint dans un temple, et quelques-uns des prêtres qui le des servaient se faisaient remarquer dans la foule, par le contraste qu'offraient leurs barbes blanches et leurs robes de soie couleur de rose.

Quand les mandarins furent informés que les vaisseaux anglais ne pouvaient pas passer la barre, ils imaginèrent aussitôt qu'ils étaient d'une grandeur immense, et que les présents qu'ils portaient devaient être proportionnés à cette grandeur. Ils donnèrent ordre de préparer des jonques pour mettre à terre ces présents, ainsi que les passagers et leur bagage. On prépara, près de l'embouchure de la rivière, une maison considérable pour recevoir l'ambassadeur ; et l'on crut qu'il y demeurerait quelques jours pour se reposer des fatigues d'un si long voyage. Les mandarins remarquèrent, en même temps, que son excellence n'avait pas besoin de se hâter de se rendre dans la capitale, parce que l'anniversaire du jour de naissance de l'empereur était encore très éloigné. Ils n'imaginaient pas qu'une ambassade pût être 


\section{Voyage dans l'intérieur de la Chine et en Tartarie}

autre chose qu'une visite, ou un message pour complimenter leur souverain à l'occasion de l'anniversaire de sa naissance, ou de quelque autre solennité.

A peine M. Hüttner était de retour à bord du Lion qu'on vit paraître plusieurs jonques chinoises, chargées d'animaux vivants, de fruits, de légumes et d'autres provisions, en si grande quantité, que les Anglais n'en purent accepter qu'une partie et furent forcés de renvoyer le reste. Peut-être est-il assez intéressant de donner ici l'état des objets envoyés, en une seule fois. Le voici : vingt jeunes bœufs ; cent vingt moutons ; cent vingt cochons ; cent têtes de volaille ; cent canards ; cent soixante sacs de farine ; quatorze caisses de pain; cent soixante sacs de riz ordinaire; dix caisses de riz rouge ; dix caisses de riz blanc ; dix caisses de menu riz ; dix caisses de thé ; vingt-deux boîtes de pêches sèches; vingt-deux boîtes de fruits confits au sucre; vingt-deux caisses de prunes et de pommes; vingt-deux boîtes d'ochras; vingt-deux boîtes d'autres végétaux; quarante paniers de gros concombres; mille giromons; quarante paquets de laitues; vingt mesures de pois en cosse; mille pastèques; trois mille melons musqués; quelques jarres de vin doux et de liqueurs ; dix caisses de chandelles; trois paniers de porcelaine.

Ce fut avec la même abondance et la même générosité que les Anglais reçurent constamment des provisions, sans avoir jamais besoin d'en demander. Certes, I'hospitalité et les attentions de toute espèce, avec lesquelles l'ambassade et l'escadre furent traitées dans toutes les occasions, mais principalement dans la baie de Turon, aux îles Chu-San, à Ten-ChooFoo, et à l'embouchure du Pei-Ho, ne peuvent se rencontrer que dans l'Orient.

Deux des premiers mandarins, l'un civil, l'autre militaire, que la cour avait nommés pour recevoir l'ambassadeur, vinrent, avec une suite nombreuse, lui rendre leurs respects à bord du Lion. II semblait que c'était la première fois qu'ils allaient sur mer, et bien certainement ils n'avaient jamais vu de vaisseau de la construction, de la grandeur et de la hauteur du Lion. Ils ne savaient comment s'y prendre pour escalader le côté du vaisseau. On fit descendre des fauteuils attachés avec des cordes et, par le moyen de poulies, 


\section{Voyage dans l'intérieur de la Chine et en Tartarie}

ils furent hissés sur le pont. Cette manière de monter, aisée, rapide, mais en apparence périlleuse, excita leur crainte, non moins que leur admiration.

Dans l'empressement de remplir leur devoir, en faisant cette prompte visite à l'ambassadeur, les deux mandarins avaient traversé la barre dans la première jonque qui s'était offerte et qui, n'étant pas arrangée pour porter de tels personnages, se trouvait remplie de monde, peu commode et même malpropre. En la quittant, ils en furent encore plus frappés de l'ordre et de l'air guerrier qui régnaient sur le pont du Lion. Quand on les introduisit dans la grande chambre, occupée par l'ambassadeur, ils en admirèrent la capacité, l'élégance, ainsi que toutes les choses commodes qu'on avait pratiquées dans le vaisseau.

Ils complimentèrent l'ambassadeur, et au nom de l'empereur et en leur propre nom, sur ce qu'il était heureusement arrivé, après avoir traversé une immense étendue de mers. Ils lui dirent que la cour impériale les avait chargés d'accompagner l'ambassade; que l'intention de leur souverain était qu'elle fît un voyage sûr et agréable, qu'ils étaient disposés à y concourir : et certes, ils le prouvèrent. Leur conduite mérite qu'on en fasse une mention particulière dans cet ouvrage.

Le mandarin de l'ordre civil était un homme grave, mais non austère. Tout annonçait en lui un esprit droit et solide. II ne s'empressait jamais de parler, et ne se souciait ni de dire rien de brillant, ni de se laisser éblouir par les autres. Le désir de remplir son devoir avec fidélité et avec bienveillance semblait être la seule chose qui l'occupât. II avait été instituteur d'un des enfants de la famille impériale; et on le regardait comme un homme instruit et judicieux. II portait I'honorable distinction d'un globe bleu sur son bonnet. Tous les mandarins ou autres personnes revêtues de quelque autorité, depuis le premier ministre jusqu'au dernier huissier, sont divisés en neuf classes, et portent ainsi de petits globes, ou boutons, sur leurs bonnets ; mais ces globes sont de différente couleur et de différente matière. En outre, les mandarins sont distingués par des habillements particuliers, afin que reconnus du peuple et des étrangers, ils soient sûrs d'obtenir le respect qui convient à leurs personnes, et l'obéissance qui est due à leurs ordres. Le mandarin civil, qui accompagnait l'ambassade, avait aussi le titre de Ta-zhin, c'est-à-dire grand. Son nom de famille était Chow. 


\section{Voyage dans l'intérieur de la Chine et en Tartarie}

Le mandarin militaire, qui accompagnait Chow-ta-zhin, était ce qu'on doit être dans sa profession, simple, franc et brave. Son nom était Van; et comme il avait le même titre que l'autre, on l'appelait Van-ta-zhin, ou Van, le grand. Indépendamment du globe rouge qu'il portait sur son bonnet, il devait à ses services une autre marque d'honneur. Ce n'était, à la vérité, qu'une plume tirée de la queue d'un paon: mais elle lui avait été donnée par l'empereur, avec la recommandation de la porter pendante à son bonnet. On voyait sur son corps plusieurs blessures qu'il avait reçues dans les batailles. La nature l'avait rendu propre à suivre la carrière des armes. II était droit, bien musclé, et d'une taille au-dessus de la médiocre. Sa force, son agilité et ses autres qualités martiales, étaient très estimées dans les armées chinoises, où l'arc et la flèche sont encore en usage et préférés aux armes à feu. II ne se vantait point; mais on s'apercevait quelquefois qu'il sentait le mérite de sa valeur et de ses services. Cependant, loin d'avoir de l'arrogance et de la brutalité, il portait sur son visage un air de bonté naturelle, et ses manières attestaient qu'il aimait à obliger. Sa conversation était enjouée et badine. II écartait volontiers toute réserve, et traitait ses nouveaux amis avec la familiarité d'une ancienne connaissance.

Une troisième personne de grande considération, un homme de race tartare, avait été envoyé comme le principal légat de l'empereur qui, luimême, est d'une dynastie tartare. Mais le légat, naturellement hautain et, en outre, craignant beaucoup la mer, avait attendu à terre l'ambassadeur. Les deux autres envoyés, quoique d'un caractère différent du tartare, n'étaient pas plus disposés à se confier à un élément dangereux ; mais étant Chinois d'origine, comme de naissance, ils se crurent obligés à une obéissance plus stricte, et ils eurent par la suite occasion de s'en réjouir.

Ces deux mandarins furent accueillis à bord du Lion avec beaucoup d'attention et de cordialité. Beaucoup de gêne accompagne ordinairement une conférence, où l'on ne peut s'expliquer que par le moyen d'un interprète: mais il n'y en eut presque pas en cette occasion. La bonne humeur des interlocuteurs et l'ardent désir qu'ils avaient de connaître mutuellement ce qu'ils pensaient la bannirent. Leurs discours ne tenaient en rien de cette réserve qu'ont des étrangers qui se soupçonnent les uns les autres. Quelquefois, avant qu'une phrase fût traduite, les circonstances suggéraient ce 


\section{Voyage dans l'intérieur de la Chine et en Tartarie}

qu'elle devait signifier, et les gestes venaient souvent au secours des paroles. Cependant, l'interprète chinois était si occupé qu'on voulut éprouver le talent de deux personnes ${ }^{1}$ attachées à l'ambassade, auxquelles ce Chinois et celui qui s'était séparé des Anglais à Macao avaient essayé de donner quelque connaissance de leur langue, depuis leur départ de Naples, c'est-à-dire depuis plus d'un an.

L'une de ces personnes s'était attachée à cette étude avec toute l'attention et la constance de l'âge mûr : mais elle eut la mortification de voir qu'elle pouvait à peine entendre quelques-uns des mots que disaient les mandarins, à qui sa prononciation était également inintelligible. L'autre personne qui, étant un jeune homme, avait certainement pris beaucoup moins de peine, mais dont les sens étaient plus actifs et les organes plus flexibles, prouva qu'elle pouvait, au besoin, être un interprète passable. II paraît que plusieurs mots chinois, qui ont une signification opposée, ne diffèrent dans la prononciation que par une légère variation d'accent ou d'intonation ; ce qui peut être saisi bien plus rapidement et plus exactement par ceux qui apprennent la langue dans leur jeunesse que par ceux qui ne commencent à s'y adonner que dans un âge avancé. II y a quelquefois tant de rapprochement dans les inflexions de la voix, en prononçant des mots chinois qui ont différente signification, qu'il n'est pas rare de voir les Chinois euxmêmes, pour éviter des méprises dans la conversation, ajouter aux principaux termes dont ils se servent, les synonymes qui y ont le plus de rapport. La nécessité de s'expliquer ainsi provient d'abord de ce que la langue chinoise a beaucoup de monosyllabes, qui sont moins distincts parce qu'ils admettent moins de combinaisons, et ensuite, de ce que cette langue exclut quelques-uns des sons les plus durs des autres nations, sons qui rendent plus facile à saisir la différence dans la prononciation des mots.

Les deux mandarins s'informèrent si la lettre que l'ambassadeur portait à l'empereur était traduite en chinois, et prièrent instamment qu'on leur fît connaître ce qu'elle contenait. Ils ne firent pourtant point cette demande comme si l'étiquette de la cour impériale exigeait qu'on y accédât. Elle n'était

\footnotetext{
${ }^{1}$ Sir George Staunton et son fils.
} 


\section{Voyage dans l'intérieur de la Chine et en Tartarie}

pas non plus l'effet d'une indiscrète curiosité. II semblait plutôt qu'ils voulaient se conformer à la coutume et se mettre plus à même de remplir le désir qu'ils avaient de recueillir le plus d'informations possibles concernant l'ambassade, pour les transmettre ensuite à leur souverain. Cependant, on pensa qu'il était plus prudent et plus décent de réserver la communication de la lettre du roi d'Angleterre jusqu'à ce qu'au moins l'ambassadeur fût arrivé dans la capitale. Ainsi, on répondit aux deux mandarins que l'original et la traduction de la lettre étaient scellés ensemble dans une boîte d'or, pour être remis aux mains de l'empereur.

Les mandarins témoignèrent beaucoup d'envie de connaître les présents destinés à l'empereur ; et ils en demandèrent formellement la liste, afin de la faire parvenir à sa majesté impériale. La même demande, il est vrai, avait été faite par tous les Chinois qui avaient eu quelques rapports avec l'ambassadeur, ou avec les commissaires à Canton au sujet de l'ambassade. Un catalogue ordinaire des présents qui étaient à bord de l'Indostan n'aurait donné une idée ni de leur qualité, ni de leur valeur intrinsèque et n'aurait pas même pu être compris par aucun effort de traduction. Bien plus: ces présents ainsi annoncés auraient sans doute été confondus avec des objets de pure curiosité qu'on envoie ordinairement pour être vendus et qui, quoique très chers, et même ingénieux, n'en sont pas moins plus brillants que solides. II était donc nécessaire de faire une description générale de la nature des articles que l'ambassadeur était chargé d'offrir à l'empereur ; mais il fallait que, pour rendre les présents plus acceptables, cette description fût un peu dans le style oriental, mesurant leur prix sur leur utilisé, et présentant même comme un mérite, l'omission de splendides bagatelles.

En conséquence, on commença par observer :

«Que le roi de la Grande-Bretagne voulant témoigner à sa majesté impériale de la Chine la haute estime et la vénération qu'il avait pour elle, en lui envoyant une ambassade à une si grande distance, et choisissant un ambassadeur parmi les hommes les plus distingués des contrées britanniques, désirait aussi que les présents qu'il enverrait pussent être dignes d'un prince aussi sage 


\section{Voyage dans l'intérieur de la Chine et en Tartarie}

et aussi instruit que l'empereur de la Chine. Ni leur quantité, ni leur prix ne pouvaient être d'aucune considération devant le trône impérial, abondant en richesses et en trésors de toute espèce. II ne convenait pas non plus d'offrir des bagatelles d'une curiosité momentanée et de peu d'utilité. C'est pourquoi sa majesté britannique avait été soigneuse de choisir seulement des choses qui pouvaient indiquer le progrès des sciences et des arts de l'Europe, et donner quelqu'idée nouvelle à l'âme sublime de sa majesté impériale; ou bien des objets d'une utilité pratique. L'intention et l'esprit dans lesquels on fait les présents, et non les présents eux-mêmes, ont quelque prix entre souverains. »

Quelques-uns des articles étaient décrits de la manière suivante:

«Le premier et le principal est composé de plusieurs parties, dont on peut se servir ensemble ou séparément. II représente l'univers, dont la terre n'est qu'une petite partie. Cet ouvrage est le plus grand effort qu'aient jamais produit, en Europe, la science astronomique et la mécanique réunies. II montre et imite avec une grande clarté, et avec une exactitude mathématique, les divers mouvements de la terre, conformément au système des astronomes européens. II montre aussi les révolutions excentriques ou irrégulières de la lune autour du globe terrestre. Celles du soleil et des planètes qui l'environnent, ainsi que le système particulier de la planète, que les Européens appellent Jupiter, avec ses quatre lunes, tournant constamment autour de lui, et les ceintures attachées à sa surface. On y voit aussi la planète de Saturne avec son anneau et ses lunes; et, enfin, les éclipses, les conjonctions, les oppositions des corps célestes. Une autre partie de la machine indique le mois, la semaine, le jour, l'heure, la minute au moment de l'inspection.

«Cet ouvrage est aussi simple dans sa construction que compliqué et merveilleux dans ses efforts : il n'en reste point d'aussi parfait en Europe. II est calculé pour plus de mille ans; et sera un long 


\section{Voyage dans l'intérieur de la Chine et en Tartarie}

monument du respect qu'inspirent les vertus de sa majesté impériale, dans les parties du globe les plus lointaines.

« Une autre machine tient immédiatement de la première : elle est d'une construction curieuse et utile, et sert à observer plus loin, et mieux qu'on ne l'avait encore fait, les corps célestes, les plus petits et les plus éloignés, parce qu'elle présente leurs mouvements dans une plus grande étendue. Le résultat de ces observations démontre l'exactitude avec laquelle les mouvements des astres sont imités dans la première machine. Les observations se font, non en regardant directement l'objet, comme dans les télescopes ordinaires, dans lesquels les pouvoirs de la vue sont plus limités, mais en apercevant de côté la réflexion de cet objet sur des miroirs; méthode inventée par le grand philosophe Newton, et perfectionnée par un excellent astronome appelé Herschell, qui, par les découvertes qu'ils ont faites dans les sciences, méritent l'un et l'autre que leurs noms parviennent jusqu'à sa majesté impériale de la Chine. Les pouvoirs de la vue, en particulier, ont été étendus, par leur moyen, au-delà de tout ce qu'on avait pu calculer ou osé espérer.

«L'astronomie, non seulement est essentielle pour le perfectionnement de la géographie et de la navigation, mais élève l'âme par la grandeur de son objet et, conséquemment, devient digne de l'attention des souverains: aussi a-t-elle excité la munificence de sa majesté impériale, qui a encouragé l'étude de cette science. Un instrument est ajouté à cet effet, parce qu'il sert à expliquer et à réconcilier le mouvement réel de la terre avec le mouvement apparent du soleil et des autres corps célestes.

« Une autre machine consiste en un globe, représentant le firmament ; le fond en est de couleur d'azur, à l'imitation de celle du ciel : et on y voit toutes les étoiles fixes, placées précisément dans leur position relative. Les étoiles sont faites d'or et d'argent de différente teinte et de différente grandeur, proportionnément à ce qu'elles paraissent être à nos yeux. II y a aussi des lignes d'argent pour marquer les divisions qui distinguent toutes les parties du firmament. 


\section{Voyage dans l'intérieur de la Chine et en Tartarie}

«Pour correspondre à ce globe céleste, il y en a un, représentant les différents continents de la terre, avec les mers et les îles. On y distingue les possessions des divers souverains, les villes capitales, et les grandes chaînes de montagnes. Cet ouvrage est exécuté avec un soin particulier, et comprend toutes les découvertes faites en différentes parties du globe, dans les voyages entrepris à cet effet par les ordres de sa majesté britannique, ainsi que les routes des différents vaisseaux employés dans ces expéditions.

«Plusieurs caisses contiennent des instruments pour connaître le temps, lesquels ont toute la perfection et l'élégance des inventions modernes. Un de ces instruments montre les périodes de la nouvelle et de la pleine lune, avec ses différentes phases, un autre indique l'état de l'air, et annonce les changements dans l'atmosphère. II y a une machine pour pomper l'air, afin de pouvoir faire dans l'espace vide plusieurs expériences curieuses et extraordinaires, qui prouvent combien l'atmosphère est nécessaire à la vie animale, et quels efforts elle a sur les substances inanimées.

« Une autre machine montre les différentes méthodes, que les Européens appellent les pouvoirs mécaniques, et qui ajoutent aux forces naturelles de l'homme et des animaux, avec des inventions pour la démonstration de ces pouvoirs, appliqués à aider et à soulager l'infirmité et l'âge.

«Les autres articles consistent en diverses pièces d'artillerie en cuivre, telles qu'elles servent dans les batailles. II y a des obusiers et des mortiers, qui sont des machines dangereuses avec lesquelles on lance des matières combustibles dans les villes et les forteresses de l'ennemi. On a pensé que ces machines pouvaient paraître intéressantes à un aussi habile guerrier, à un aussi grand conquérant que l'empereur de la Chine. On y a, en même temps, ajouté d'autres armes, telles que des mousquets, des pistolets et des épées tranchantes. Ces armes sont richement ornées et singulièrement précieuses par leurs propriétés ; les mousquets et les pistolets sont très faciles à assurer le point de mire, et les lames des épées coupent le fer sans s'ébrécher. 


\section{Voyage dans l'intérieur de la Chine et en Tartarie}

«Sa majesté britannique, qui est reconnue par le reste de l'Europe comme la première puissance maritime, et est vraiment souveraine des mers ${ }^{1}$, désirait de donner à sa majesté impériale une marque de son attention, en lui envoyant, avec l'ambassade, quelques-uns de ses plus grands vaisseaux; mais elle a été obligée d'en faire employer de moins grands à cause des hauts fonds et des bancs de sable de la mer Jaune, peu connus des navigateurs européens. Toutefois, elle envoie à sa majesté chinoise un modèle du plus grand vaisseau de guerre anglais, armé de cent dix canons d'un calibre considérable. Ce modèle montre jusqu'aux plus petites parties d'un si superbe ouvrage.

« II y a aussi des échantillons des ouvrages que font les meilleurs artistes anglais pour tirer parti des substances argileuses et pierreuses qui se trouvent dans leur pays. Parmi ces échantillons sont des vases d'ornement et d'utilité, dont quelques-uns sont faits à l'imitation de l'antiquité, et d'autres dans le meilleur goût moderne.

«Plusieurs de ces articles doivent, en grande partie, leur solidité et leur beauté aux opérations du feu commun ou terrestre : mais une chaleur qui a bien plus d'intensité et des effets plus soudains et plus étonnants que ceux du feu terrestre est celle qu'on recueille dans les rayons du soleil, par le moyen d'un instrument, qui est au nombre des présents envoyés par le roi d'Angleterre. II consiste en deux corps de verre transparent, dont l'un est d'une prodigieuse grandeur pour un tel ouvrage, et a reçu des mains d'un artiste adroit et patient, une telle forme que, bien placé et bien dirigé, il peut non seulement enflammer des matières combustibles à une certaine distance, mais aussi ramollir et réduire en poudre ou mettre en fusion les pierres les plus dures et les métaux les plus denses, soit or, argent, cuivre ou fer, ou même la matière nouvellement découverte et appelée platine ou or blanc, qui est

\footnotetext{
${ }^{1}$ Quelles sont donc les puissances qui ont reconnu cette souveraineté ? Sir George
} 


\section{Voyage dans l'intérieur de la Chine et en Tartarie}

beaucoup plus difficile à fondre, par le moyen du feu ordinaire, que le reste des métaux connus. Les principales parties de cette machine, étant aussi frêles dans leur composition que la machine entière est puissante et rapide dans ses opérations, sont si rarement sans défaut et si faciles à se casser, lorsque les artistes travaillent à leur donner les derniers degrés de perfection, qu'on n'en voit guère d'une grandeur considérable. L'une des masses de verre de la machine offerte à sa majesté chinoise est la plus grande et la plus parfaite qui ait été fabriquée en Europe.

«On a renfermé, dans des boîtes séparées, les différentes parties de deux lustres magnifiques, c'est-à-dire des cristaux façonnés avec des branches d'or, de manière à pouvoir porter des lumières pour éclairer les grands appartements d'un palais. Ces lustres varient et dans leur forme et dans leurs effets, suivant la disposition des innombrables pièces qui les composent. On y a placé des lampes arrondies qui, d'après une méthode nouvellement inventée, répandent une lumière plus vive et plus étendue que celle que l'art pouvait produire auparavant.

« II y a plusieurs ballots contenant une grande quantité d'articles sortis des manufactures de la Grande-Bretagne, particulièrement des étoffes de laine et de coton, et des ouvrages d'acier et d'autres métaux. On doit espérer que parmi tant de choses, il y en aura quelques-unes qui pourront plaire, soit pour leur utilité, soit comme objets de comparaison avec quelques-unes des productions des grandes manufactures de sa majesté impériale.

«Aux objets qu'on a pu entreprendre de transporter, on a joint plusieurs représentations très exactes de cités, de villes, d'églises, de maisons de campagne, de jardins, de châteaux, de ponts, de lacs, de volcans, d'antiquités, de batailles par mer et par terre, de chantiers où l'on construit les vaisseaux, de courses de chevaux, de combats de taureaux, et de tous les objets les plus curieux, les

Staunton aurait bien dû nous le dire. (Note du Traducteur.) 


\section{Voyage dans l'intérieur de la Chine et en Tartarie}

plus remarquables dans les États de sa majesté britannique, ainsi que dans d'autres parties de l'Europe. II y a aussi les portraits des plus éminents personnages, y compris ceux de la famille royale de la Grande-Bretagne. Ces ouvrages sont en même temps un monument des progrès des arts qui les ont produits.

Non seulement cette description fut traduite en chinois, mais $M$. Hüttner la mit soigneusement en latin, comme on y avait mis la lettre du roi d'Angleterre à l'empereur. On prit cette précaution pour que les missionnaires, attachés à la cour de Pékin, eussent occasion de corriger les erreurs qui pourraient s'être glissées dans la traduction chinoise ; car la manière d'écrire le chinois pour la cour n'est familière qu'à ceux qui fréquentent le palais impérial. Cependant, cette traduction fut assez bien entendue des mandarins Chow-ta-zhin, et Vanta-zhin pour qu'ils en admirassent le contenu.

On fournit un nombre de jonques suffisant pour transporter les présents au-delà de la barre. Après quoi, il fut nécessaire de les faire passer dans des bâtiments d'une autre construction, attendu que les premiers ne peuvent pas remonter la rivière jusque dans les environs de la capitale, et que les autres sont trop faibles pour résister à la lame qui se brise sur la barre, et à tous les accidents qui peuvent agiter la mer. On eut aussi d'autres jonques pour porter, des vaisseaux jusque dans la rivière, les personnes attachées à l'ambassade, ainsi que leur bagage. Là, on trouva des bâtiments prêts à les recevoir. L'ambassadeur avait déjà témoigné l'intention de voyager par mer, parce qu'on lui avait dit que c'était la manière la plus commode.

Quand les jonques chinoises furent assemblées autour de l'escadre, le tout offrit un spectacle assez singulier. C'était un contraste frappant que de voir les hautes mâtures, les cordages compliqués des vaisseaux anglais, au milieu des jonques chinoises, basses, simples, grossièrement faites, mais fortes et spacieuses. Chacune était du port d'environ deux cents tonneaux. La cale des jonques est divisée en une douzaine de compartiments, formés avec des planches de deux pouces d'épais, dont les joints sont enduits d'un ciment de chaux préparé de manière à les rendre imperméables, ou suivant l'expression marine, propres à l'eau. D'après l'observation du docteur Dinwiddie, ce ciment 


\section{Voyage dans l'intérieur de la Chine et en Tartarie}

est composé de chaux et d'huile. On y met aussi quelques raclures de bambou, comme on met du crin dans le plâtre en Angleterre. Cette composition, ajoute le docteur, devient très dure, très tenace, et résiste au feu. Malgré l'huile qu'elle contient, elle est, en effet, incombustible : il n'y a pas de doute qu'elle ne soit préférable au goudron, à la poix, au suif, objets dont on ne se sert jamais dans la construction des vaisseaux chinois, ni pour le bois, ni pour les cordages.

L'avantage qu'il y a à diviser la cale des vaisseaux paraît avoir été bien reconnu à la Chine, car on l'y pratique généralement. De là, il arrive quelquefois qu'un négociant a ses marchandises sans avaries dans un compartiment, tandis qu'un autre a les siennes avariées dans les compartiments voisins, où il se trouve une voie d'eau. Un vaisseau peut toucher sur un rocher et ne point périr, parce que l'eau reste dans la division de la cale qui a été entrouverte; et celui qui charge des marchandises dans plusieurs divisions peut espérer que si l'une fait de l'eau, les autres en seront préservées.

A l'avis d'adopter ce plan de construction dans les vaisseaux marchands d'Europe, on opposera sans doute le préjugé populaire, les dépenses et l'incertitude de réussir dans des expériences nouvelles. On dira aussi que cette méthode occasionnerait une réduction dans la quantité du fret, et que l'arrimage des gros tonneaux et des grandes caisses serait beaucoup plus difficile. Mais il reste à considérer jusqu'où ces objections doivent prévaloir contre la plus grande sûreté du bâtiment, de l'équipage et de la cargaison. Quoi qu'il en soit, l'objection ne peut pas avoir lieu pour les vaisseaux de guerre qui n'ont point de pesants fardeaux à transporter.

Toutes les jonques ont deux grands mâts qui sont également faits d'un seul arbre ou d'une pièce de bois, d'un diamètre beaucoup plus fort en proportion de sa longueur que les mâts des vaisseaux européens. Chaque mât a une grande voile carrée qui est ordinairement de bambou fendu, ou de nattes de paille ou de roseau. Les jonques sont presque également plates aux deux extrémités, à l'une desquelles il y a un gouvernail aussi large que ceux des gabarres de Londres, et attaché avec des cordes qui passent d'un côté de la jonque à l'autre. La boussole est dans une petite jatte placée dans un endroit qui correspond à I'habitacle des vaisseaux européens. On tient une 


\section{Voyage dans l'intérieur de la Chine et en Tartarie}

chandelle souvent allumée à côté de la boussole, avec une assez grande quantité de sable dans la jatte, parce qu'on y met quelques mèches parfumées quand on veut faire une offrande à la divinité qu'on croit présider à la mer. Cette divinité a, en outre, un autel bien fourni de pompons et de mèches, à l'extrémité d'une très petite chambre, autour de laquelle sont les cabanes du capitaine et des matelots. Chacune de ces cabanes n'a que l'espace qu'il faut pour un homme, et on y couche sur une natte et sur un dur oreiller. Les jonques ont ordinairement quarante ou cinquante hommes d'équipage. Tous paraissent prendre un égal intérêt au bâtiment, et participer également aux manœuvres. Aucun ne reçoit, dit-on, de gages fixes, mais ils ont une portion dans le profit du voyage.

Les présents et le bagage furent mis dans une suffisante quantité de jonques; et quoique cette opération se fit en pleine mer, elle ne fut pas accompagnée du moindre accident. Le temps était très beau. Cependant, la saison des orages s'avançait; et il était impossible que l'escadre restât longtemps dans une situation où elle était trop exposée. La Compagnie des Indes désirait que, dès que l'Indostan serait congédié à Tien-Sing par l'ambassadeur, il se rendît à Canton pour y prendre une cargaison, et la transporter en Europe suivant l'usage du commerce. Mais comme ce vaisseau pouvait passer à Chu-San, on pensa qu'il serait avantageux pour lui d'y toucher, parce qu'il pourrait probablement s'y procurer une cargaison à meilleur marché qu'à Canton, si toutefois on pouvait obtenir la permission d'y acheter du thé et de la soie, que recueillent les provinces voisines. L'ambassadeur s'empressa donc d'accorder au capitaine Mackintosh l'agrément de le suivre à Pékin, afin qu'il sollicitât lui-même la permission qu'il désirait. On espérait en outre qu'en s'en retournant au vaisseau, le capitaine Mackintosh pourrait avoir occasion d'observer la manière dont on fabriquait les marchandises qu'il avait coutume de charger en Chine ; manière sur laquelle la Compagnie des Indes désirait avoir des renseignements particuliers.

Après avoir songé à ce qui concernait l'Indostan, on devait nécessairement s'occuper du Lion, et décider, avant que l'ambassadeur le quittât, à quoi on l'emploierait pendant le temps que les affaires publiques retiendraient son excellence à terre. On n'avait pas découvert, dans tout le 


\section{Voyage dans l'intérieur de la Chine et en Tartarie}

golfe de Pékin, un port où ce vaisseau pût hiverner en sûreté. On pensa en même temps que l'endroit où il convenait le moins de le faire demeurer longtemps était un port de la Chine; parce que, malgré toutes les précautions possibles, quelque différend avec les Chinois, ou quelque accident pouvait nuire beaucoup au but général de l'ambassade. La crainte même de quelque trouble pouvait engager un gouvernement tel que celui de la Chine, à exiger le départ prématuré de l'ambassadeur. D'ailleurs, sir Erasme Gower ne croyait pas que la discipline et la santé de son équipage pussent ne pas souffrir de la vie inactive qu'il mènerait pendant un long séjour à terre. En employant, durant cette saison, une partie de son loisir à faire un voyage au Japon, afin d'y sonder les dispositions de la cour, relativement à des liaisons de commerce avec la nation anglaise, sir Erasme pouvait mettre l'ambassadeur en état de déterminer s'il devait s'y rendre lui-même. Ses instructions portaient bien qu'il y irait, mais ce n'était pourtant qu'en cas que cette démarche parût devoir produire un avantage réel ; enfin, si sir Erasme Gower trouvait que les Japonais persévéraient dans leur système d'exclusion, ou même qu'il n'y eût pas une grande utilité à établir des relations avec eux, le compte qu'en rendrait cet officier devait faire éviter l'excédent de dépense qu'aurait pu faire l'ambassade en prolongeant son séjour en Asie.

D'après ces divers motifs, combinés avec l'objet général de sa mission, et conformément aux pouvoirs qu'il avait reçus, l'ambassadeur écrivit à sir Erasme Gower :

«Comme il est impossible que le Lion demeure très longtemps dans la station où il est, en dehors de la barre, qui l'empêche d'entrer dans la rivière Pei-Ho, l'ambassadeur se croit obligé d'exposer à sir Erasme Gower de quelle manière il conçoit que ce vaisseau doit être employé pour le service de sa majesté, pendant le temps que les affaires de l'ambassade la retiendront à la cour de Pékin. - Il est sans doute, je crois, nécessaire qu'il se rende dans le premier port où il pourra se préparer à faire un voyage dans quelques-unes des principales îles des mers de la Chine, après que les malades ne se ressentiront plus des effets de l'insalubre climat des côtes de Java et de Sumatra. - Probablement sir Erasme Gower choisira pour cela les baies de Ki-San-Seu, ou de Chu-San ; 


\section{Voyage dans l'intérieur de la Chine et en Tartarie}

parce qu'il y a là de petites îles sur lesquelles on peut commodément dresser des tentes dans des endroits secs, aérés, favorables aux convalescents, et où, par le secours des mandarins voisins, on peut obtenir des rafraîchissements de toute espèce. L'ambassadeur sait que l'intention du commandant est de payer tous les articles qu'il recevra à bord. Cependant, il est possible que les mandarins se croient obligés, par les ordres généraux de l'empereur relatifs à l'ambassade, de n'accepter aucun paiement pour ce qu'ils fourniront au Lion ; et qu'alors ils en chargent le trésor impérial, et peut-être même avec quelque exagération, soit pour la quantité, soit pour la valeur des objets. Comme il est essentiel que l'ambassade paraisse le moins à charge possible aux Chinois, l'ambassadeur espère que le commandant donnera des injonctions particulières pour qu'on ne reçoive à bord aucune espèce de provisions ou d'autres articles que ceux qui seront pour le compte général, comme absolument nécessaire à l'usage du vaisseau, ou à la santé de l'équipage, et pour qu'on ne laisse pas même approcher du vaisseau tout ce qui y viendra à titre de présent pour des individus.

« L'ambassadeur sait que, malgré la longueur du voyage, l'équipage du Lion n'a presque point encore été attaqué du scorbut; ce qu'on doit attribuer aux fréquentes occasions qu'il a eues de respirer l'air de terre, dans les différents endroits où l'on a abordé ; aux provisions fraîches que le commandant lui a si souvent procurées, ainsi qu'au soin particulier qu'il a constamment eu, d'entretenir la propreté parmi les matelots, et de faire chasser le mauvais air de toutes les parties du vaisseau.

«Pendant qu'on fera les préparatifs nécessaires pour remettre en mer, préparatifs que le commandant peut sans doute confier à l'attention et à l'habileté de ses officiers, l'ambassadeur désire avoir la satisfaction d'être accompagné par lui à Pékin. Peut-être, pendant qu'il y sera, l'empereur pourra, dans quelques audiences, être disposé à faire des questions relativement à la marine anglaise, et alors un homme, aussi expérimenté que l'est le 


\section{Voyage dans l'intérieur de la Chine et en Tartarie}

commandant, donnera à ce prince la plus complète satisfaction. Un des bricks peut rester dans la rivière de Pei-Ho, pour ramener sir Erasme Gower à bord du Lion. Après quoi l'ambassadeur désire qu'il s'éloigne des côtes de la Chine, et ne paraisse en aucune partie de cet empire qu'au mois de mai suivant. - II faut qu'en conséquence, il se rende au port de Jeddo, sur la côte méridionale du Japon, où il pourra délivrer au Cubo, c'est-à-dire au souverain temporel de ce pays, une lettre de l'ambassadeur, à laquelle il est vraisemblable que le Cubo fera quelque attention, puisqu'elle lui parviendra d'une manière si respectable.

«Son excellence ne peut guère indiquer au commandant ce qui doit être le principal objet de son attention, soit dans la route, soit au Japon. Mais, malgré toutes les observations nautiques et des découvertes, dont l'importance occupera sir Erasme Gower, et à l'égard desquelles l'ambassadeur pense comme lui, ce commandant se mettra bientôt à même de juger si les habitants du Japon conservent pour tous les étrangers cette extrême aversion que leur ont autrefois attribuée des personnes, dont les récits pouvaient être dictés par le désir qu'elles avaient d'empêcher les Anglais de chercher encore à faire le commerce dans ces contrées. Le commandant peut aussi avoir occasion de voir jusqu'à quel point les besoins et les fantaisies des Japonais leur rendent agréables les objets de fabrique anglaise; et si dans ce cas ils ont, indépendamment du cuivre, que l'Angleterre retire en abondance de ses propres mines, quelques marchandises ou quelques matières premières propres à être portées en Europe.

« Un grand obstacle s'oppose, en ce moment, à ce qu'on entre dans une négociation particulière avec la cour du Japon. L'ambassadeur n'a pu encore se procurer un interprète japonais. Cependant, il suffit, à présent, d'avoir à bord des hommes qui entendent les deux langues générales de l'orient de l'Asie, le malais et le chinois. Pour la première, on peut se servir du matelot malais, qui est employé à bord du Lion, et qui parle un peu l'anglais, et du matelot anglais qui entend le malais. Quant au chinois, l'ambassadeur veut, en faveur du service public, renoncer à l'agrément qu'il s'était 


\section{Voyage dans l'intérieur de la Chine et en Tartarie}

promis d'avoir auprès de lui un domestique que lui a cédé un des missionnaires de Macao, et qui parle le chinois et le portugais. Ces trois hommes pourront mettre le commandant en état de remplir les objets qu'on a en vue, non seulement à Jeddo, mais aussi dans d'autres pays au midi, où il aura occasion d'aller en quittant le Japon.

« Aussitôt après avoir reçu une réponse du souverain japonais, ou après avoir attendu quinze jours à Jeddo sans la recevoir, soit verbale, soit par écrit, le commandant se rendra à Manille, où il remettra au gouverneur des îles Philippines, qui y fait sa résidence, une lettre de l'ambassadeur. Le port de Cavita, à Manille, est dépeint comme parfaitement bien abrité, et propre à recevoir les plus grands vaisseaux dans toutes les saisons. II est facile de se procurer là toute sorte de provisions, en abondance et à un prix raisonnable: ainsi le Lion pourra y séjourner jusqu'à ce que le commandant juge qu'il est praticable de faire voile plus avant dans le sud ; ce qui, d'après l'expérience de M. Dalrymple, doit être au mois de novembre.

«Pendant que le commandant sera à Cavita, il peut prendre des renseignements utiles sur l'état naturel et civil du pays, sur son commerce et sur le caractère des habitants. II n'est pas invraisemblable que, dans le port fréquenté de Manille, il puisse se trouver quelques personnes qui aient été au Japon, et aient acquis la connaissance de la langue de ce pays. Si une telle personne parle en même temps quelque langue de l'Europe, ou tout au moins le chinois ou le malais, ce sera une acquisition importante, dans le cas où l'ambassadeur ira remplir sa mission à la cour japonaise. II accordera volontiers à une telle personne toute récompense, qui n'excédera pas trop une compensation raisonnable ; et, en conséquence, il souscrira aux conditions que sir Erasme Gower jugera à propos de faire à cet égard.

«En faisant route au sud, aussitôt qu'il sera possible, sir Erasme voudra bien joindre aux observations nautiques qu'il fera pour le perfectionnement de la navigation et de la géographie, la recon- 


\section{Voyage dans l'intérieur de la Chine et en Tartarie}

naissance de l'île de Lalutaya, qui, d'après la relation manuscrite d'un navigateur expérimenté, jointe à ces instructions, paraît avoir un bon port et beaucoup d'autres avantages. Elle est placée à peu près par les dix degrés cinquante minutes de latitude nord, et à environ vingt lieues à l'ouest de la longue île de Palawan. On la trouve dans la carte du voyage de Faveau, ainsi que l'a placée M. Dalrymple. L'île de Cuyo, qui en est voisine, abonde en toute sorte de provisions.

« L'ambassadeur désire que de Lalutaya, le commandant du Lion se rende dans l'île de Magindanao, autrement appelée Mindanao qui, quoique comptée quelquefois parmi les îles Philippines parce qu'elle est située près d'elles, est la plupart du temps sinon toujours indépendante des Espagnols; et son gouvernement est sans cesse en querelle avec cette nation.

«Le sultan de Magindanao s'est autrefois déclaré l'ami des Anglais et, pour les encourager à traiter dans ses États, il leur a cédé l'île de Bonwoot, située dans le voisinage et presque vis-à-vis du principal port de Magindanao. Le commandant aura aussi une lettre de l'ambassadeur pour ce prince; et après avoir demandé une prompte réponse, il ira visiter l'île de Bonwoot, où l'on dit qu'il y a un port commode. II suffit au commandant de rester très peu de jours à Magindanao pour en tirer un parti avantageux, et obtenir tous les renseignements dont il aura besoin. II pourra là se mettre à même de juger s'il est praticable et sûr de poursuivre son voyage jusqu'à Gilolo. Quoique cette île soit une des Moluques, elle n'est point soumise aux Hollandais, et peut, par conséquent, fournir des connaissances très curieuses et très utiles.

«Cependant, comme il est douteux que le terme fixé pour son expédition permette au commandant d'aller jusqu'à Gilolo, et comme les dispositions du souverain de cette île envers les Anglais et tous les autres Européens sont incertaines, l'ambassadeur ne lui adresse point de lettre. II a pourtant et des commissions spéciales pour quelques princes, et des pouvoirs généraux pour traiter au nom de sa majesté avec tous les souverains des mers de la Chine. 


\section{Voyage dans l'intérieur de la Chine et en Tartarie}

Mais si le commandant du Lion peut trouver moyen d'aller à Gilolo, et y découvrir quelques dispositions en faveur des Anglais, il peut y annoncer que son excellence est dans l'intention de visiter ce pays, et d'y établir des relations utiles aux deux nations, si le temps qu'elle sera en Asie le lui permet.

« Il faut qu'en partant de Gilolo, ou bien de Magindanao, sir Erasme Gower fasse voile pour cette partie de la grande île de Célebès, dont les Hollandais ne sont point maîtres. L'avantage qu'il a d'avoir déjà vu cette île doit lui servir beaucoup en cette occasion, et pour faire des observations relatives à la navigation dans le voisinage, et pour connaître l'esprit des habitants. L'ambassadeur engage seulement sir Erasme Gower à en agir à Célebès comme à Gilolo, et à y faire dans les mêmes circonstances, la même déclaration relativement aux intentions de son excellence. Ce ministre lui en dit autant pour l'île de Bornéo, où il espère que le Lion pourra aussi s'arrêter, soit à Bangar, soit à Succédana, soit enfin dans la capitale qui porte le même nom que l'île. Les Anglais ont eu autrefois une factorerie à Bangar; et on croit que dans la ville de Bornéo, il y a encore quelques sujets britanniques qui y résident fixement ou qui y font passagèrement le commerce.

« Rien n'est autant à désirer et n'est plus d'accord avec l'objet général de la mission de lord Macartney que les efforts loyaux et pacifiques qu'on fera pour étendre la consommation des marchandises anglaises dans toutes les parties de l'Asie, d'où il est possible de faire en Europe des retours avantageux; ce qui est éminemment le cas pour Bornéo. La jalousie des trafiquants hollandais peut chercher à s'opposer aux Anglais dans quelques parties de ce vaste pays: mais il en est d'autres, où il paraît vraisemblable qu'on n'aura rien à démêler avec eux.

«Le temps que doit prendre un voyage dans les différents lieux dont nous venons de parler, ainsi que le séjour qu'il peut être nécessaire de faire dans plusieurs ports où le commandant doit s'arrêter, le conduiront probablement jusqu'à l'équinoxe du prin- 


\section{Voyage dans l'intérieur de la Chine et en Tartarie}

temps, après quoi il pourra se rendre à Macao, où l'ambassadeur l'attendra vers le commencement du mois de mai prochain.

«Comme il ne faut omettre rien de ce qui peut être utile, ou donner quelques connaissances nouvelles, l'ambassadeur croit que le commandant pourrait encore tenter d'entrer à Pulo-Lingen, et même qu'il y réussirait, si toutefois cette île se trouvait sur la route que le Lion suivra à son retour dans le nord. Si son excellence ne craignait pas de nuire aux plus importants objets de l'entreprise du commandant, l'intérêt du bien public l'engagerait encore à lui conseiller de visiter, en passant, la partie orientale de l'île de Formose, partie qu'on dit être indépendante des Chinois ; l'ambassadeur lui indiquerait également les îles de Léoo-Kéoo, au midi de la Corée ; et certes, ce serait une grande satisfaction pour lui, si le commandant pouvait acquérir des notions certaines sur ces différents pays.

Les instructions de lord Macartney sont terminées par les observations suivantes :

«L'ambassadeur a, sans difficulté, exprimé ses vœux relativement aux objets que doit entreprendre sir Erasme Gower, et ne s'est point étendu sur les précautions à prendre pour ces objets, parce qu'il sait toute la confiance qu'il doit avoir en la prudence et I'habileté de celui à qui il s'adresse. Forcé par des événements que l'ambassadeur ne peut prévoir, ou des circonstances qu'il ignore, sir Erasme Gower peut s'écarter de la route indiquée dans ses instructions : mais son excellence est persuadée qu'elle aura occasion d'approuver la conduite de ce commandant, et elle ne doute pas que son temps ne soit employé utilement pour le service public.

Sir Erasme Gower répondit que, dès que son équipage serait rétabli en totalité ou en partie, il serait en état de visiter les différents lieux mentionnés dans les instructions de l'ambassadeur ; qu'il examinerait d'abord avec soin la baie de Ki-San-Seu, et que s'il trouvait un mouillage où le Lion pût être en sûreté, il y resterait pour faire traiter ses malades; que s'il en était autrement, il se rendrait nécessairement à Chu-San ; qu'il désirait obtenir une 


\section{Voyage dans l'intérieur de la Chine et en Tartarie}

lettre du gouvernement pour ces deux endroits, afin qu'on lui fournît des provisions fraîches, avec une maison pour loger les malades ou, tout au moins, un endroit où il pût faire planter des tentes pour eux ; que les soins qu'il devait à ces malades l'obligeait de ne point accéder à la proposition flatteuse d'aller à Pékin, qu'il ne les quitterait donc pas, et qu'ensuite il se hâterait de s'occuper des objets qu'il avait à remplir pour l'intérêt public.

On s'adressa aux mandarins pour qu'ils procurassent la lettre qui devait garantir au Lion un accueil favorable. Ils promirent qu'ils l'obtiendraient sans délai du gouverneur de la province. Cependant, lorsque tous les présents et le bagage furent mis à bord des jonques, l'ambassadeur et sa suite se préparèrent à quitter le Lion et l'Indostan. Alors se rassemblèrent à bord des vaisseaux et ceux qui s'en allaient et ceux qui restaient. Tous se rappelèrent les divers agréments qu'ils avaient eus dans le voyage et ils se dirent adieu avec une véritable affection. Les équipages de l'escadre étaient composés d'hommes choisis, qui s'étaient parfaitement bien conduits durant le voyage, et avaient, en conséquence, reçu des marques de la satisfaction de l'ambassadeur. Aussi, au moment où ce ministre entra dans le brick et partit, ils s'empressèrent d'exécuter l'ordre qu'on leur avait donné, de monter sur les vergues, en signe de respect; et les acclamations, les huzza ${ }^{1}$ qu'ils firent $^{\prime}$ entendre, ainsi que le salut des canons des vaisseaux, fut un spectacle nouveau pour les Chinois.

Pour entrer dans la rivière de Pei-Ho, l'ambassadeur et les principales personnes de sa suite s'embarquèrent, le 5 août 1793, à bord des bricks le Clarence, le Jackall et l'Endeavour, tandis que les gardes, les musiciens, les domestiques et les autres personnes attachées à l'ambassade les suivaient dans des jonques qui portaient les présents et le bagage. Favorisés par la brise et par la marée, ils passèrent la barre en peu d'heures. La côte voisine est si basse qu'à peine on la découvrirait, à deux milles de distance, sans les maisons qui y sont bâties. Sur la barre et en dedans, l'eau était trouble et

1 Ce mot se prononce «houra!» C'est une acclamation en usage, non seulement chez les Anglais, mais parmi presque tous les peuples du Nord. (Note du Traducteur.) 


\section{Voyage dans l'intérieur de la Chine et en Tartarie}

vaseuse, quoiqu'en dehors et dans l'endroit où mouillait le Lion, elle fût extrêmement verte et claire. La barre est divisée en un grand nombre de petits bancs de sable, placés en différentes directions, mais si élevés et si rapprochés les uns des autres, que les vaisseaux aussi petits que le Clarence et le Jackall ne peuvent les traverser que quand la mer est haute. Aussitôt qu'on est en dedans de la barre, on trouve trois brasses d'eau, et la rivière a, en cet endroit, environ cinq cents pas de large. Les Anglais la virent presque entièrement couverte de jonques et de bateaux de toute espèce. Près de l'embouchure et sur la rive méridionale, on voit un joli petit village appelé Tung-Coo, avec un port militaire où l'on fit mettre les troupes sous les armes pour faire honneur à l'ambassadeur.

D'après l'idée où étaient les Chinois, que ce ministre voulait, tout de suite, aller à terre, afin de dissiper l'ennui qu'aurait dû lui occasionner un long séjour à la mer, les jonques qui l'accompagnaient laissèrent tomber l'ancre aussitôt qu'elles eurent passé la barre. Malgré cela, son excellence préféra d'aller joindre le yacht qui l'attendait à quelques milles plus haut. A la vérité, la situation de Tung-Coo n'invite pas à y descendre. La terre est basse, marécageuse et couverte en partie de ces longs et utiles roseaux dont l'espèce est connue sous le nom de Arundo phragmites, et qui était en fleur quand les Anglais y passèrent.

De là, il fallut aller contre le courant, ce qui rendit la marche nécessairement lente. Les hauts fonds de cette tortueuse rivière ne laissaient pas, non plus, que de retarder les voyageurs. Quand le vent ou la marée ne les favorisaient pas, un nombre suffisant de paysans chinois traînaient leurs bâtiments avec une corde, et triomphaient ainsi du courant. Bientôt, ils passèrent devant un second village, appelé See-Coo, et le soir, ils arrivèrent à Ta-Coo. La syllabe qui termine les noms de ces trois lieux est, comme on le voit, la même. Elle signifie en chinois qu'ils sont voisins de l'embouchure de la rivière; et les syllabes précédentes indiquent que le premier est à l'est, le second à l'ouest, et le dernier d'une étendue considérable.

Une grande partie des maisons de ces villages, ainsi que de celles qui sont semées en grand nombre sur les bords de la rivière, a des murs bousillés et des toits de chaume. II y en a aussi quelques-unes qui sont vastes, élevées, peintes, ornées, et paraissent être la demeure de la richesse. Mais on n'en 


\section{Voyage dans l'intérieur de la Chine et en Tartarie}

voit point qui indique une médiocre aisance, ni ces gradations multipliées qu'on voit ailleurs entre l'opulence et la pauvreté.

Parmi les personnes qui étaient le long de la rivière, on remarquait quelques femmes, aussi lestes que si leurs pieds n'avaient pas été mutilés. II est vrai qu'on dit que dans les provinces du nord, cet usage est aujourd'hui moins rigoureusement observé qu'autrefois, parmi les personnes de la dernière classe. Ces femmes portent toutes leurs cheveux, qui sont universellement noirs, grands, bien tressés et attachés avec une longue épingle sur le haut de la tête. Les enfants vont presque tous nus. Les hommes sont robustes, bien faits, et ont de bonnes physionomies. Peut-être aussi que quand les Anglais les virent, la curiosité leur donna un air plus animé que de coutume ; et ils étaient assemblés en si grand nombre qu'on pouvait s'écrier avec le poète :

« Combien d'êtres intéressants sont ici rassemblés ! » 


\section{Voyage dans l'intérieur de la Chine et en Tartarie}

\section{CHAPITRE III}

\section{L'ambassade remonte la rivière Pei-ho, pour se rendre dans la capitale de la Chine. Les vaisseaux quittent le golfe de Pé-ché-lée.}

S'il a été difficile et dangereux pour des étrangers sans protection, de voyager dans l'intérieur de la Chine, ceux qui y entraient en ce moment, défendus par le souverain au nom duquel ils venaient, et encouragés par celui à qui ils étaient adressés, n'avaient rien à craindre pour leur sûreté personnelle. Le peuple chinois eut trop peu d'occasions de se mêler fréquemment avec les étrangers pour se familiariser avec eux, et conséquemment se faire et à leurs mœurs, et à leur extérieur. Cependant, la grande civilisation qu'on sait être établie en Chine, dans toutes les classes de la société, et la main de l'autorité prête à retenir les individus disposés à causer du trouble, si par hasard il y en avait eu de tels, ne permettraient pas aux Anglais d'avoir la moindre inquiétude.

Leur petite flotte, composée de bricks anglais et de jonques chinoises, naviguant ensemble pour la première fois, atteignit Ta-Coo dans la soirée du 5 août 1793. Cette ville est, comme nous l'avons observé à la fin du chapitre précédent, située près du Pei-Ho, c'est-à-dire de la rivière Blanche, et la première place un peu remarquable des frontières nord-est de la Chine. L'ambassade y trouva un nombre considérable de yachts, ou grandes berges couvertes, et de canots propres à porter beaucoup, mais construits de manière à passer sur les hauts fonds du Pei-Ho. Tous ces bâtiments étaient destinés à conduire l'ambassade jusqu'à l'endroit où l'on cesse de pouvoir remonter la rivière en se rendant dans la capitale de l'empire.

L'ambassadeur entra aussitôt dans le yacht préparé pour sa réception. II ressemblait un peu à ceux avec lesquels on voyage sur les canaux, en Angleterre et en Hollande. Mais comme il était destiné à faire une plus longue 


\section{Voyage dans l'intérieur de la Chine et en Tartarie}

route que ces derniers, on l'avait construit plus spacieux et plus commode, et on l'avait bien mieux décoré. L'appartement de son excellence occupait la plus grande partie de ce bâtiment. II consistait en une antichambre, un salon, une chambre à coucher et un cabinet. On avait mis dans le salon un siège d'honneur, c'est-à-dire un sofa carré, tel qu'on en voit dans les maisons de tous les premiers mandarins, et sur lesquels ils font placer de grands carreaux et s'asseyent pour donner audience. Une accourse, qui sortait environ deux pieds en dehors du yacht et s'étendait de la poupe à la proue, servait aux domestiques et à l'équipage, sans qu'ils eussent besoin de traverser les chambres. C'était là aussi que se tenaient les matelots lorsqu'ils étaient obligés de se servir de perches pour pousser le yacht, arrêté par quelque banc de sable ou par la vase. L'équipage avait une petite chambre du côté de la poupe ; et dans un coin, on y voyait un petit autel, avec une idole autour de laquelle brûlaient constamment des mèches parfumées. A la suite du yacht étaient plusieurs chaloupes, portant des provisions et des cuisiniers, pour que la table de l'ambassadeur fût toujours bien servie, sans qu'on eût besoin d'aller à terre, ou de s'arrêter lorsque le vent et la marée étaient favorables.

Seize autres yachts, dont plusieurs étaient beaucoup plus grands que celui de lord Macartney, parce qu'ils devaient contenir plusieurs passagers, furent employés à porter le reste de l'ambassade. Les grands yachts avaient quatrevingts pieds de long, et étaient très élevés sur l'eau ; cependant, on les avait construits d'un bois si léger et d'une telle manière, qu'ils ne tiraient pas plus de dix-huit pouces d'eau. Les chambres étaient hautes et bien aérées, quoiqu'elles eussent au-dessus d'elles des dunettes où couchait l'équipage, et par-dessous, des compartiments où l'on serrait toutes les choses nécessaires au bâtiment.

Le principal ornement qui distinguait des autres yachts celui de l'ambassadeur consistait dans de grands carreaux de verre qu'il y avait aux fenêtres, tandis que les panneaux des autres étaient garnis d'une sorte de papier, fabriqué principalement dans la Corée. On mêle dans la composition de ce papier une substance onctueuse, qui le rend plus durable lorsqu'il est exposé à l'air, et fait que la pluie et toute autre espèce d'humidité l'affectent infiniment moins que celui qu'on fait en Europe. L'usage général du verre dans les yachts que l'on s'attache à décorer, et le soin qu'on a d'employer des 


\section{Voyage dans l'intérieur de la Chine et en Tartarie}

matières différentes dans les autres, indique suffisamment qu'à la Chine, le verre est estimé et peu abondant.

Une nombreuse garde de soldats chinois était destinée à accompagner l'ambassadeur à terre, mais on ne put en distribuer qu'une partie à bord des yachts. Quand un Européen descendait sur le rivage, la présence d'un soldat annonçait la protection immédiate du gouvernement. Peut-être aussi le suivait-il pour pouvoir, au besoin, mettre un frein à ses écarts.

Indépendamment des yachts dans lesquels étaient embarqués les passagers, il y avait un pareil nombre de bateaux de transport pour les présents et le bagage. Les Chinois ne manquèrent ni d'activité ni d'attention, en ôtant les objets embarqués dans les jonques de mer, et les mettant dans ce qu'on peut appeler proprement des gabarres de rivières.

Le transport des caisses et des ballots qui contenaient les présents ne demandait pas peu de soin. La direction en fut confiée à la même personne qui avait réussi à le faire passer de l'Indostan dans les jonques, sans qu'ils éprouvassent le moindre dommage. Quoique les matelots dont il se servait ne pussent travailler que dans une jonque à la fois, tous les ballots et les caisses, au nombre des six cents, dont plusieurs étaient très pesants, furent heureusement chargés à bord des gabarres, dans l'espace de deux ou trois jours.

Tandis que cette opération se faisait, les deux mandarins, directeurs du voyage, Chow-ta-zhin et Van-ta-zhin, se rendirent souvent auprès de l'ambassadeur, non seulement pour lui présenter leur respect, mais pour prendre ses ordres, en cas qu'il désirât quelque chose. Ils firent également des visites polies aux principales personnes de l'ambassade. Des mandarins inférieurs surveillaient les différents yachts, pour faire distribuer les provisions et tout ce qui était nécessaire à tous ceux qui composaient la suite de son excellence. Ils allaient ainsi d'un yacht à l'autre, dans des sanpans, qui sont de petits canots couverts, mais dont le fond est trop plat pour qu'ils ne puissent ni tirer beaucoup d'eau ni chavirer.

II y avait dans chaque yacht une table séparée pour les principales personnes de l'ambassade. Elle était ordinairement servie à la mode du pays, et quelquefois avec toute la délicatesse que cette mode comporte. 


\section{Voyage dans l'intérieur de la Chine et en Tartarie}

Quelquefois aussi, on imitait assez gauchement la cuisine anglaise. Les Chinois préparent presque toutes leurs viandes à l'étuvée; mais ils les coupent par petits morceaux carrés, et assaisonnent les sauces avec beaucoup d'épiceries, et leur donnent des goûts très différents. La viande la plus abondante à la Chine est le bœuf et le cochon. La volaille, pareille à celle d'Europe, y est aussi très commune. Parmi les articles les plus chers, et regardés comme les plus délicats, sont les nageoires des requins et les nids d'une espèce particulière d'hirondelle, dont nous avons fait mention dans la première partie de cet ouvrage. Ces deux choses sont très grasses et remplies de jus ; et pour être vraiment bonnes, il faut qu'on les apprête, ainsi que les tortues, avec des sauces très épicées. Voulant sans doute flatter le goût anglais, les mandarins donnèrent ordre de faire rôtir de grosses pièces de viande, comme des coqs d'Inde, des oies, des cochons entiers. Cette manière de cuire la viande ne semblait pas en usage parmi les Chinois, et les cuisiniers chargés de la mettre en pratique s'en acquittaient assez mal.

Ils ne connaissaient pas plus la façon pétrir le pain que celle de rôtir la viande. II n'y avait pas même un seul four dans toute cette partie de l'empire. En général, au lieu de pain, on y mange du riz ou d'autre grain bouilli. Quand on fait bouillir le riz, il gonfle considérablement; et c'est, dit-on, ce qui en facilite la digestion, comme la fermentation de la pâte facilite celle du pain.

On recueille du froment dans plusieurs provinces de la Chine. On y recueille aussi ce grain appelé blé de Sarrasin, dont la farine bien tamisée est parfaitement blanche, et sert aux Chinois à faire des gâteaux qu'on fait cuire à la vapeur de l'eau bouillante. Pour cela, on place les morceaux de pâte roulés, sur un treillis à plusieurs étages, fixé dans une caisse qui n'est ouverte que par le bas. On pose cette caisse au-dessus d'un vase, dont l'eau bout ; la vapeur s'élève à travers le treillis et est à peine suffisante pour former aux gâteaux une croûte fine et molle. Cependant, tels qu'ils sont quand on les coupe par tranches, et qu'on les fait rôtir, ils remplacent fort bien le pain ordinaire. Quelquefois on leur donne plus de goût en y mêlant des graines aromatiques.

On avait envoyé dans chaque yacht des jarres d'une espèce de vin jaune, ainsi que de l'eau-de-vie. Celle-ci paraissait d'une meilleure fabrique que le vin ; car il était en général trouble, d'un goût plat, et devenait bientôt aigre. 


\section{Voyage dans l'intérieur de la Chine et en Tartarie}

L'eau-de-vie était forte, claire, et avait rarement un goût empyreumatique. Dans les provinces septentrionales, on la fait avec du millet; et dans les provinces méridionales avec du riz. Celle qu'on donnait aux Anglais était quelquefois si forte que sa preuve était au-dessus de celle de l'esprit de vin. Les Chinois appellent l'eau-de-vie show-choo, c'est-à-dire «vin ardent ».

On fournit régulièrement aux Anglais des provisions de fruits, tels que des prunes, des poires, des pommes, des raisins, des abricots et des oranges. Les pêches leur étaient présentées comme venant de Pékin, dans le voisinage duquel on s'attache probablement à la culture de ce fruit avec plus de soin que dans les provinces. On fournit également du thé vert et du thé bou en abondance. Le premier venait de la province de Kiang-Nan, et l'autre de celle de Fo-Chien qui, l'une et l'autre, sont à quelques degrés au midi du Pei-Ho. Cependant, le thé était souvent trop frais pour le goût anglais, et on entendait quelquefois désirer du thé de Londres. La province de Fo-Chien produit aussi du sucre candi et du sucre brut, mais point en pains. Quoique le sucre de la Cochinchine, si bien cristallisé, et en forme de gâteaux, soit à très bon marché, il ne paraît pas qu'on en fasse usage dans le nord-est de la Chine.

On accorda amplement tout ce qui pouvait être nécessaire, non seulement aux principales personnes attachées à l'ambassade, mais aux ouvriers, aux soldats, aux domestiques de la suite de l'ambassadeur. Les Chinois déployèrent une grande magnificence et n'épargnèrent rien pour traiter dignement l'ambassade. Plusieurs mandarins étaient chargés de l'accompagner, et leurs salaires furent augmentés à cette occasion. Une foule de Chinois inférieurs fut employée à la servir. Beaucoup de vaisseaux la portèrent, ainsi que les présents et le bagage qui en dépendaient. Partout où les yachts s'arrêtaient, les troupes prenaient les armes, et dans les endroits où elle ne faisait que passer, elle voyait encore qu'on avait fait quelques préparatifs pour lui faire honneur. L'empereur voulut supporter entièrement toute cette dépense extraordinaire, ainsi que celle qu'occasionnaient les provisions de toute espèce qui furent fournies aux Anglais. Ce prince était rempli de cette grande idée que tout l'empire était sa propriété et sa demeure particulière, et que ce serait manquer à l'hospitalité que de souffrir qu'un hôte fût à sa propre charge, ou fût même obligé de défrayer sa suite tandis qu'il 


\section{Voyage dans l'intérieur de la Chine et en Tartarie}

demeurerait chez lui. Or, les Chinois considèrent un ambassadeur comme un hôte qui est venu les visiter.

Les ordres de l'empereur furent strictement exécutés. Une des personnes attachées à l'ambassade avait fait acheter quelques bagatelles pour sa parure ; mais quand elle voulut en rembourser le prix au mandarin qui avait fait cette emplette, celui-ci déclara qu'il n'osait point accepter ce prix, et il en chargea en même temps le compte de l'empereur. Ce que recommande ce prince paraît être, dans toutes les occasions, accueilli avec beaucoup de respect, et suivi avec une ponctualité qui prouve qu'on s'y soustrait rarement sans subir un châtiment égal à l'offense. L'autorité du gouvernement est, dans des occasions particulières, déléguée à de premiers mandarins: les Anglais en eurent la preuve en voyant le chef de leurs conducteurs chasser un officier subordonné qui avait commis une légère faute.

Tandis que le yacht de l'ambassadeur s'arrêtait devant Ta-Coo, il reçut une visite du vice-roi de la province, et il alla le voir à son tour. Ce commandant avait quitté, par ordre de l'empereur, Pao-Ting-Foo, lieu de sa résidence, et éloigné de cent milles de Ta-Coo, pour venir complimenter l'ambassadeur à l'occasion de son entrée sur le territoire chinois, et faire pour lui tout ce qui serait nécessaire. Ce vice-roi était l'homme le plus élevé en dignité que l'ambassadeur eût encore vu en Chine. II avait des manières très aimables. Déjà fort avancé en âge, il avait l'air noble et vénérable. Lorsqu'il reçut l'ambassadeur, il se comporta avec une politesse très attentive, mais sans ces formes contraintes et ces cérémonies particulières qui sont quelquefois employées à la Chine entre les personnes d'un rang inégal, et qu'on croit pouvoir suppléer au sentiment et à l'éducation. II est, par exemple, des formalités minutieuses et fatigantes qu'on trouve décrites dans plusieurs relations, et qu'on dit être observées par les Chinois lorsqu'ils font servir du thé à ceux qui leur rendent visite ; mais elles n'eurent point lieu en cette occasion, et le vice-roi parut les avoir oubliées. Tout ce que nous pouvons remarquer sur la manière dont on servait le thé chez lui, c'est qu'on le mettait dans des tasses couvertes et dont les soucoupes étaient oblongues. En outre, on le faisait infuser dans chaque tasse séparément; les feuilles restaient au fond de la tasse, et le maître de la maison, sinon les convives, 


\section{Voyage dans l'intérieur de la Chine et en Tartarie}

trouvait cette simple infusion préférable au mélange que nous avons coutume d'en faire, avec de la crème et du sucre.

Le vice-roi avait établi sa résidence dans le principal temple de Ta-Coo, consacré au dieu de la mer, dont le voisinage faisait, sans doute, adresser souvent des vœux à cette divinité. Les Chinois lui donnent le nom de ToongHai-Vaung, c'est-à-dire « roi de la mer orientale». On voit plusieurs figures de ce dieu, dans quelques beaux édifices, de porcelaine, placés dans la même enceinte. II est représenté assis sur les vagues, avec fierté, aisance et dignité ; et quoique sa main ne soit point armée d'un trident, pour rassembler les monstres de la vaste et profonde mer, il ne paraît pas avoir moins de sécurité, car d'une main il tient une pierre d'aimant, et de l'autre un dauphin, signe de son pouvoir sur les habitants des eaux. Sa barbe jetée dans tous les sens et ses cheveux épars semblent indiquer qu'on a voulu personnifier en lui le tempétueux élément sur lequel il règne.

La confiance qu'un dieu paraît avoir en une pierre d'aimant montre assez combien la connaissance des propriétés de ce métal est mêlée aux doctrines mythologiques des Chinois, et combien est ancienne l'époque où cette connaissance a été appliquée à la navigation. Ceux qui, d'après plusieurs passages des anciens auteurs, et d'après la facilité avec laquelle des morceaux de fer placés d'une certaine manière, acquièrent des qualités magnétiques, supposent que ces qualités étaient dès longtemps connues en Europe, conjecturent en même temps que le trident de Neptune est moins une baguette magique qu'un emblème du pouvoir qu'a l'aimant de diriger avec certitude la route des navigateurs.

Non loin du Hai-Chin-Miao, ou temple du dieu de la mer, est la salle où siègent les juges de Ta-Coo. Placée au milieu d'une cour spacieuse, elle est de forme hexagone et on y arrive par un large escalier. La couverture en est supportée par des colonnes dont le diamètre est, proportionnément à leur longueur, beaucoup plus considérable que dans aucun ordre d'architecture grecque. Ces colonnes sont de bois vernissé, c'est pourquoi elles ont besoin d'avoir plus de grosseur que des colonnes de pierre, comme des colonnes de fer en exigeraient beaucoup moins. Les règles naturelles et les proportions dans l'architecture doivent nécessairement dépendre autant des matières qu'on emploie que des effets qu'elles sont destinées à produire sur les yeux. 


\section{Voyage dans l'intérieur de la Chine et en Tartarie}

L'hexagone de Ta-Coo était ouvert de tous côtés; ce qui en montrant la douceur du climat était assez bien entendu pour imprimer dans l'âme l'agréable, mais peut-être fausse idée, que la justice est libre et accessible à tout le monde. Là, les Anglais virent six magistrats assis sur des bancs couverts de drap de coton rouge avec des coussins de satin. Cinq d'entre eux n'étaient probablement que les assesseurs du grand juge, et pouvaient servir au besoin à arrêter l'effet de ses caprices ou de ses passions. Les employés du tribunal et l'audience étaient extrêmement nombreux.

Bientôt après que l'ambassadeur fut de retour à bord de son yacht, le vice-roi lui envoya servir un repas somptueux, avec trois autres tables de vingt-quatre couverts chacune, pour les trois personnes qui avaient accompagné son excellence dans sa visite. On ne sait pas pourquoi le vice-roi préféra cette manière de traiter les Anglais à celle de les retenir à dîner avec lui ou de les inviter pour le lendemain. Ce fut sans doute à cause du rang des trois personnes qui accompagnaient l'ambassadeur; car cela ne pouvait provenir, comme dans l'Inde, des opinions religieuses qui empêchent de manger avec des étrangers. Les Chinois ne sont point entichés de ces scrupules. Mais ils ont d'autres coutumes. Rarement, parmi eux, plus de quatre personnes mangent ensemble; et lorsqu'on sert un grand repas dans le même appartement, il y a plusieurs tables différentes. Il est possible que quelque secret motif de délicatesse à l'égard de l'ambassadeur, ou quelques raisons qui avaient rapport aux coutumes anglaises, engageassent le vice-roi à adopter une manière particulière de signaler son hospitalité. II n'en est pas moins vrai que les tables à la charge de l'empereur étaient si bien entretenues qu'elles rendaient ce soin superflu.

L'ambassadeur reçut aussi devant Ta-Coo la visite du principal mandarin du voisinage, dans lequel, comme dans tous les autres Chinois d'un rang élevé, on remarquait moins de préventions et de particularités que dans les classes inférieures. Un esprit exercé est certainement moins l'enfant de l'exemple, ou la créature du climat et du gouvernement, que celui dans lequel rien ne s'oppose à l'influence de ces puissantes causes. On a raison de dire que le peuple est ce qu'on le fait, et les Anglais en eurent continuellement des preuves dans l'effet que produisait sur le commun des Chinois la crainte de la pesante main du pouvoir. Quand ils étaient à l'abri de cette crainte, ils 


\section{Voyage dans l'intérieur de la Chine et en Tartarie}

paraissaient d'un caractère gai et confiant: mais en présence de leurs magistrats, ils avaient l'air d'être extrêmement timides et embarrassés. Cette différence était surtout sensible dans le jeune homme que nous avons déjà dit être venu de Canton dans le brick l'Endeavour, pour offrir de servir d'interprète à l'ambassade. On l'employait quelquefois lorsqu'on s'entretenait avec les mandarins : mais ils lui inspiraient un si profond respect qu'il était rare qu'alors il remplît bien son poste ; et quand il avait à traduire quelques phrases d'une langue européenne en chinois, il ne manquait jamais de changer le style de la conversation, qui convient entre égaux, et de le rendre avec les expressions les plus abjectes dont se servent les gens de la dernière classe. Cependant, non content de cette sorte de précaution, il crut qu'il était encore trop dangereux pour lui de servir des étrangers de quelque manière que ce fût ; et il sacrifia à ses nouvelles craintes le désir qu'il avait de voir, en remplissant l'emploi auquel il s'était voué, la capitale et le souverain de son pays, ainsi que les émoluments qui lui seraient revenus. II s'en retourna donc immédiatement à Canton, dans le même vaisseau qui l'avait apporté.

Tous les arrangements étant faits pour que l'ambassade pût continuer à remonter la rivière, et les ordres de l'ambassadeur étant pris à cette occasion, le signal de mettre à la voile fut donné dans la matinée du 9 août 1793. Aux yachts, dont nous avons déjà parlé, on en joignit un grand nombre d'autres, pour les diverses classes de mandarins ou autres Chinois destinés à accompagner l'ambassade, et dont le nombre égalait au moins celui des Européens qui la composaient. On ne tire jamais le canon, à la Chine, pour donner un signal. Mais on se sert, pour cela, de grandes plaques de cuivre, rondes et avec un rebord, dans la composition desquelles on mêle de l'étain ou du zinc pour les rendre plus sonores, et qui, frappées avec un maillet de bois, font un bruit à rendre sourds ceux qui sont auprès, et à être entendues à une distance très considérable. Cet instrument est nommé par les Chinois loo, mais les Européens qui sont en Chine l'appellent gong, d'après le nom qu'on lui donne dans d'autres parties de l'Orient. On s'en sert généralement sur l'eau. Mais à terre, on emploie ordinairement, pour annoncer l'autorité, et surtout parmi les troupes, deux pièces de bois qui, frappées l'une contre l'autre, produisent un bruit semblable à celui d'une grande crécelle. Il paraît 


\section{Voyage dans l'intérieur de la Chine et en Tartarie}

que les tambours ne sont point en usage dans les armées; mais ils font partie de la musique religieuse qu'on entend dans les temples.

Presque tous les yachts employés pour l'ambassade avaient à bord des Européens et des Chinois. On aurait dû s'attendre qu'un mélange de gens, dont les habitudes, les besoins, le langage étaient si nouveaux les uns aux autres, pourrait produire beaucoup de confusion ; mais il n'y en eut aucune, grâce aux précautions qu'on prit. Dans toutes les occasions, les mandarins étaient attentifs à procurer aux passagers, les choses dont ils avaient besoin. Les soldats chinois, même, et les matelots des yachts, montraient une bonne volonté et un empressement à obliger, faciles à distinguer du simple désir de remplir un devoir et qui prouvaient au moins que les étrangers qui se trouvaient en ce moment avec eux ne leur étaient point désagréables. A la vérité, ces étrangers leur étaient annoncés comme venant de très loin pour complimenter leur souverain; et le dernier des Chinois ne pouvait être insensible à une sorte de satisfaction nationale que lui inspirait cet événement.

La nouvelle de l'approche de l'ambassade se répandit rapidement dans les villes et les villages voisins. On s'en apercevait aisément au nombre de bateaux qui couvraient la rivière. Des multitudes d'hommes étaient assemblées sur le rivage, et attendaient quelquefois très longtemps pour voir passer le cortège, tandis que les femmes, non moins timides que curieuses, le regardaient à travers les portes, ou par-dessus les murs de leurs maisons. Cependant, quelques-unes des vieilles dames trempèrent leurs petits pieds dans la rivière, afin de considérer les étrangers de plus près ; mais les jeunes se tenaient en général fort en arrière. De leur côté, les Anglais étaient continuellement amusés par une succession d'objets nouveaux. Le pays et ceux qui l'habitaient présentaient, presque à chaque moment, quelque chose de différent de ce qu'on voit partout ailleurs. On sentait en général qu'on était très heureux, après avoir fait un si long voyage, d'avoir à contempler un pays qui paraissait intéressant sous tous les rapports.

En remontant le Pei-Ho, l'ambassade ne s'avançait que lentement vers Pékin. Le fleuve est extrêmement tortueux et, par conséquent, la route était extrêmement prolongée. D'ailleurs, le vent qui était favorable lorsqu'on allait dans une certaine direction devenait contraire quand le cours du fleuve forçait 


\section{Voyage dans l'intérieur de la Chine et en Tartarie}

d'en prendre une autre. Toutes les rivières, tous les ruisseaux, tendent sans doute à suivre une ligne droite depuis leur source jusqu'à la mer, et ils ne s'en écartent que lorsqu'ils rencontrent des obstacles, qu'ils n'ont point la force de vaincre. Si ces obstacles sont des rochers ou des éminences de terre compacte, il n'est guère vraisemblable qu'aucun événement subséquent change le lit que les eaux se sont déjà formé ; mais si le cours de ces eaux est à travers un pays presque uni, et que les bords de leur lit soient d'une terre trop molle pour résister à une crue soudaine ou à une rapidité extraordinaire, elles se creusent souvent des routes nouvelles et tortueuses. Tel est le cas du Pei-Ho ; et les inconvénients en sont devenus si considérables qu'ils ont induit le gouvernement à prendre des soins pour contenir cette rivière dans son lit ordinaire. En conséquence, on a amoncelé sur ses bords une grande quantité de terre, dont on se sert pour remplir les brèches qui s'y font de temps en temps. II y a aussi, d'un bout à l'autre, des levées qui ont la forme de coins tronqués, et semblent avoir été faites avec de la vase prise dans le lit de la rivière. A présent ses bords sont plus élevés que les plaines adjacentes. Ces plaines s'étendent à perte de vue, et les sinuosités de la rivière faisaient que les mâts des vaisseaux paraissaient se mouvoir à travers les champs et en différentes directions, tandis que les eaux restaient cachées.

La campagne était parfaitement bien cultivée, et on y voyait en grande quantité le plus haut des granigères ${ }^{1}$, dont la production sert à la nourriture des hommes, celui qui donne le grain communément appelé millet des Barbades. Il s'élève à dix ou douze pieds; et, d'après les calculs les plus modérés, son rapport est de cent pour un.

Le premier jour de leur route, les Anglais crurent que les maisons des villages qu'ils rencontrèrent le long du Pei-Ho n'avaient que des murailles de terre ou de bousillage, comme celles qu'ils avaient vues à l'embouchure de ce fleuve ; mais en les considérant de plus près, ils reconnurent qu'elles étaient bâties de briques mal cuites, ou cuites au soleil. Après que les murs sont faits, on les crépit, ainsi que les toits de tuile, avec une matière mêlée de chaux et ayant une couleur de boue. Sur les bords du fleuve, et même à une

\footnotetext{
${ }^{1}$ Holcus sorghum.
} 


\section{Voyage dans l'intérieur de la Chine et en Tartarie}

très grande distance, on n'a d'autre chaux que celle qui provient des coquillages de mer. On n'y voit des pierres d'aucune espèce : un caillou y est une rareté.

Près de quelques villes et de quelques villages, les voyageurs aperçurent des pyramides de quinze pieds de hauteur et de différentes dimensions quant à la longueur et à la largeur. Elles étaient composées de sacs remplis de sel et arrangés de la même manière qu'on entasse la tourbe dans quelques parties de l'Europe. Les sacs étaient couverts de nattes, qu'on remarquait comme suffisantes pour empêcher que la pluie ne fît fondre le sel. A la vérité, les ondées sont rares et peu fortes dans cette partie de la Chine; et quoiqu'on fût alors au mois d'août, la campagne ne paraissait point souffrir de la sécheresse. On voyait très peu de nuages. Rien n'indiquait une atmosphère humide; mais le soir, il y avait un peu de rosée sur le terrain voisin de la rivière.

Dès que la nuit approchait, les bords de la rivière étaient illuminés avec des lanternes de papier blanc, bleu et rouge, et très agréablement varié. Le différent nombre de lanternes placées sur les mâts des yachts annonçait le rang des passagers qui étaient à bord; et la lumière de ces lanternes, avec celle qui était dans les chambres des yachts, formait, en se réfléchissant, une illumination mobile et colorée, sorte de spectacle que les Chinois aiment beaucoup. La nuit était presque aussi bruyante que le jour, à quoi ne contribuait pas peu les sons du loo, qu'on battait toutes les fois qu'on avait besoin de donner quelque signal. Le bourdonnement menaçant et la fréquente piqûre des maringouins étaient aussi fort incommodes pendant la nuit.

Le second jour, les Anglais virent un vaste enclos qui était le premier qu'ils eussent encore aperçu, et qui ressemblait à ce qu'on appelle en Angleterre un parc de gentilhomme. C'était la résidence du tawhang, c'est-àdire du chef du district. On distinguait sa demeure à sa triple porte, et à deux poteaux de quarante pieds de haut, plantés auprès de la porte, et destinés à porter des marques de dignité et des lanternes qui, la nuit, étaient un ornement utile. L'enclos contenait plusieurs bâtiments, et des arbres de différente espèce. On y voyait aussi beaucoup de moutons et de chevaux. 


\section{Voyage dans l'intérieur de la Chine et en Tartarie}

Jusqu'alors, on n'avait aperçu que fort peu de bétail d'aucune espèce. Quoique le sol soit bas et propre à former des pâturages, les prairies y sont très rares. II n'y a pas un seul coin de terre en friche.

Sur le rivage était un bois de pins très élevés et étendant au loin leurs branches. A l'ombre de ces arbres, on remarquait plusieurs monuments de pierre, érigés à la mémoire des personnes qu'on y avait enterrées. Nul temple n'était bâti auprès de ce cimetière. II semble, cependant, que les dispositions à la gravité et à la piété dans les édifices consacrés au culte public doivent croître à la vue des monuments où reposent les morts; mais des considérations relatives à la santé des vivants ont sans doute engagé les Chinois à avoir soin que les tombeaux soient à jamais séparés des temples.

Une grande partie du rivage opposé au cimetière était couverte de sacs remplis de sel, comme ceux dont nous avons parlé tout à l'heure. La quantité de sel qu'il fallait pour former ces tas nous parut si énorme que M. Barrow voulut la déterminer par un calcul. Le nombre des tas entiers était de deux cent vingt-deux, sans compter plusieurs tas incomplets. Une section transversale contenait soixante-dix sacs. Aucun tas n'avait moins de deux cents pieds de long. Quelques-uns en avaient même six cents. En supposant qu'ils fussent l'un dans l'autre de la longueur de quatre cents pieds, de laquelle un sac occupait deux pieds; il y avait dans chaque tas deux cents sections, ou quatorze mille sacs, et dans les deux cent vingt-deux tas, plus de trois millions de sacs. Chacun de ces sacs contenait environ deux cents livres pesant de sel, et conséquemment il y en avait dans la totalité six cents millions de livres.

Lorsque, sous l'ancien gouvernement de France, plusieurs provinces étaient soumises à la gabelle, c'est-à-dire à l'impôt sur le sel, on calcula avec soin à quoi pouvait s'élever, dans une année, la consommation de cet article, et l'on estima qu'il en fallait beaucoup moins de vingt livres pour chaque individu, malgré les différents usages qu'on en fait. Mais en admettant que l'entière quantité de vingt livres de sel soit consommée par chaque Chinois, les tas dont nous venons de parler suffiraient pendant un an à trente millions 


\section{Voyage dans l'intérieur de la Chine et en Tartarie}

de personnes, sans toucher ni aux tas incomplets, ni aux premiers qu'on avait remarqués sur les bords de la rivière.

Le sel est un objet de revenu considérable pour le gouvernement chinois. Le produit de l'impôt sur cet article dans la province de Pé-Ché-Lée est encore inférieur à celui qu'on retire de plusieurs autres parties de l'empire. Dans plusieurs districts de cette province, et surtout aux environs de la capitale, il y a en abondance une espèce de nitre mal purifié, dont le peuple se sert au lieu de sel marin, ce qui a également lieu dans quelques parties de l'intérieur de I'Inde. Aussi, là, ce nitre mérite plutôt le nom de sel commun, que le sel que produit la mer.

La plus grande partie du sel qu'on transporte sur le Pei-Ho vient des côtes des deux provinces méridionales de Fo-Chien et de Quan-Tung, où on l'extrait de l'eau de la mer. On a, pour cette opération, de grands champs bien unis, bien nivelés, entourés d'un rebord de six pouces de hauteur et dont la surface est argileuse. On y introduit l'eau ou par des écluses, ou avec des pompes à chaîne, jusqu'à ce qu'il y en ait deux ou trois pouces. En été, la chaleur du soleil est assez forte pour évaporer cette eau; et l'évaporation, se faisant lentement et également, laisse de grands cristaux cubiques, qui forment cette espèce de sel connue en Angleterre sous le nom de sel de baye. On voit de ces fabriques de sel à l'embouchure du Pei-Ho ; mais elles ne sont pas très considérables. Sa situation, plus rapprochée du nord, n'est pas aussi favorable que celle des deux autres provinces pour profiter de l'action du soleil. En Angleterre, et même dans quelques-unes des parties méridionales de la France, on emploie la chaleur artificielle pour compléter les procédés nécessaires à l'extraction du sel.

Le sel qui sort des provinces de Quan-Tung et de Fo-Chien, et qu'on transporte sur le Pei-Ho, suffit pour charger annuellement deux milles jonques, du port de deux cents tonneaux chacune. Or, puisqu'un seul objet occupe une si grande quantité de bâtiments, on peut juger du nombre immense qu'il y en a sur le fleuve. Certes, le nombre des villes et des villages qui sont à la vue du Pei-Ho, et les multitudes d'habitants qui couvrent ses bords, ne surprirent pas autant les voyageurs que la quantité de jonques qu'ils rencontraient à chaque instant, montant ou descendant le fleuve, ou bien à l'ancre dans des criques. 


\section{Voyage dans l'intérieur de la Chine et en Tartarie}

Les pyramides dont nous avons fait la description étaient près du port de Tien-Sing, nom qui signifie littéralement, en chinois, «lieu céleste », et qui est en effet mérité par un climat agréable, un sol fertile, un air pur et un ciel serein. Tien-Sing sert d'étape générale aux provinces septentrionales de la Chine. Il est bâti au confluent de deux rivières, et sur une éminence doucement inclinée. Le palais du gouverneur est placé dans un endroit avancé qui domine un vaste bassin, formé par la réunion des deux rivières et presque entièrement couvert de jonques de différente grandeur. La plupart de ces jonques ne passent jamais la barre qui est à l'embouchure du Pei-Ho. Elles ne sont employées qu'au commerce qui se fait par des canaux, ainsi que par de grandes rivières dans tout l'intérieur de l'empire.

L'une des rivières qui se réunissent à Tien-Sing, et sur laquelle l'ambassade devait poursuivre sa route, s'appelait le Pei-Ho, nom qu'elles conservent toutes les deux, quand elles sont réunies. L'autre se nommait Yun-Leang-Ho, c'est-à-dire la rivière portant du grain. Elle doit cette dénomination à la quantité de froment qui sort de la province de Shen-Sée et qu'on envoie par cette rivière, et ensuite par le Pei-Ho, dans les environs de Pékin. Quoique les voyageurs ne fussent pas encore très avant dans la Chine, ils s'aperçurent que les noms de tous les objets qui les avaient frappés dans le pays n'étaient ni des sons arbitraires et vagues, ni des mots d'une origine étrangère, mais avaient une signification qui exprimait la nature et les qualités de ces mêmes objets. Cela seul fait présumer que, dès les temps les plus reculés, la Chine a été possédée par la même race, qui a conservé son idiome original, sans se mêler beaucoup avec les autres nations, et sans prendre leur langage.

Dans l'endroit où les deux rivières se réunissent à Tien-Sing, on a établi, pour la commodité des habitants, un pont de bateaux qui se sépare pour laisser passer les jonques. Le long des quais, il y a des temples et d'autres beaux édifices ; mais le reste n'était composé que de boutiques de détail, et de magasins pour les marchandises ordinaires, avec des cours et d'autres magasins pour les objets de marine. Les maisons particulières n'offrent, du côté de la rue, que des murs sans presque aucune ouverture, parce qu'elles reçoivent le jour par des cours intérieures. Les spectateurs étaient dans la 


\section{Voyage dans l'intérieur de la Chine et en Tartarie}

rue, ou dans les bateaux qui couvraient le côté de la rivière opposé à la ville. II n'y avait que très peu de femmes. Cependant la foule était immense, non seulement depuis le terrain le plus élevé jusqu'au bord de l'eau, mais dans l'eau même, où des curieux s'avançaient pour contempler de plus près les yachts qui portaient les étrangers. Comme ces étrangers ne couraient pas risque d'être incommodés par la foule, rien de semblable à des soldats ou à des connétables ne se mêlait des mouvements du peuple. Cependant, malgré son extrême curiosité, ce peuple conservait beaucoup d'ordre et de décence. On n'entendait pas la moindre dispute; et par un sentiment de convenance mutuelle, les Chinois de la classe inférieure, lesquels portent ordinairement des chapeaux de paille, restaient découverts pendant que l'ambassade passait. Ils aimaient mieux exposer leur tête rasée aux rayons d'un soleil brûlant que d'intercepter la vue des personnes qui étaient derrière eux. L'élévation graduelle des deux côtés de la rivière, jusqu'aux extrémités de la ville, formait de tout l'ensemble un grand amphithéâtre, bordé en outre de têtes qui s'élevaient par rangs, les unes au-dessus des autres. Tous les visages étaient facilement apparents, et la multitude en parut beaucoup plus considérable que celles que les Anglais avaient vues dans les autres parties de la Chine.

La flotte des yachts s'arrêta à peu près dans le centre de la ville, et vis-àvis d'un pavillon où le vice-roi attendait l'ambassadeur. II s'y était rendu par terre, de Ta-Coo, en suivant une route bien plus courte que celle que font faire les détours de la rivière. L'ambassadeur débarqua avec les principales personnes attachées à l'ambassade, et accompagné de tous ses domestiques, ses musiciens et ses gardes. II fut reçu au rivage, et par le vice-roi, et par le légat, dont nous avons déjà parlé précédemment. Un corps de troupes chinoises était aligné derrière eux, suivant un ordre de parade de front, qu'observa le capitaine Parish et que nous allons rapporter.

Trois mandarins militaires, ou principaux officiers.

Une tente avec une bande de musiciens en avant.

Trois longues trompettes.

Une arche triomphale. 


\section{Voyage dans l'intérieur de la Chine et en Tartarie}

Quatre grands étendards verts, avec cinq petits entremêlés avec les grands, et des archers auprès des petits.

Six grands étendards rouges, avec des hommes armés de fusils à mèche, et cinq petits étendards de la même couleur entremêlés avec les grands.

Deux grands étendards verts gardés par des hommes armés d'épées. Tente de musiciens.

Arche triomphale.

Comme il faisait extrêmement chaud, plusieurs de ces militaires portaient des éventails avec leurs armes. Les éventails sont généralement en usage à la Chine parmi les personnes des deux sexes et de tous les rangs. L'emploi, dans une parade militaire, en paraîtra moins surprenant aux personnes qui ont vu quelquefois, dans d'autres parties de l'Orient, des officiers porter des parasols en faisant faire l'exercice à leurs bataillons.

Le vice-roi conduisit l'ambassadeur et les principales personnes de sa suite dans le pavillon, au fond duquel il y avait un endroit obscur, un sanctuaire, où la majesté de l'empereur était supposée résider sans cesse. II était enjoint de témoigner un grand respect à cette majesté ; et quelque singulier que ce fût, on allait y faire une profonde inclination. Lorsque le viceroi seul avait reçu l'ambassadeur à Ta-Coo, il n'avait point été question de ces cérémonies. Sa politesse ne lui avait probablement pas permis de parler tout à coup de cet attribut d'immensité, et de vouloir le faire reconnaître par un étranger, qui n'était point habitué à croire qu'il pût être le partage d'aucun mortel : mais la présence du légat impérial, dont le caractère paraissait très différent du sien, fut très probablement ce qui obligea le digne et vénérable vice-roi à n'omettre aucun des actes accoutumés du respect sans bornes qu'on rend au sublime souverain de l'empire.

Lorsqu'on eut servi le thé, les confitures, et divers rafraîchissements, et qu'on se fut fait des civilités réciproques, le légat annonça à l'ambassadeur que l'empereur était à Zhé-Hol, en Tartarie, lieu qu'il avait coutume d'habiter l'été, et où il voulait célébrer l'anniversaire de sa naissance, qui était le treizième jour de la huitième lune répondant au 17 septembre. II ajouta que c'était là que sa majesté impériale souhaitait recevoir l'ambassadeur. 


\section{Voyage dans l'intérieur de la Chine et en Tartarie}

Indépendamment du désir qu'avait lord Macartney de complaire aux vœux de l'empereur, il fut extrêmement flatté de pouvoir aller en Tartarie, parce qu'il aurait occasion de voir sur les frontières la grande muraille de la Chine, ouvrage dont on assure que le célèbre docteur Johnson disait, dans un enthousiasme de curiosité, que le petit-fils de celui qui l'avait vue avait quelque raison d'en tirer de la vanité.

Le reste de la conversation du légat ne fut pas aussi satisfaisant. II dit qu'après que l'ambassade serait arrivée par eau à Tong-Shoo ${ }^{1}$, à douze milles de Pékin, elle se rendrait directement par terre à Zhé-Hol, où l'on conduirait tous les présents. II n'y avait, sans doute, point à craindre que plusieurs de ces présents se gâtassent dans ce voyage. Mais il était impossible de transporter sans risque, à travers les montagnes et les chemins escarpés de la Tartarie, les objets les plus précieux, les plus curieux, parce qu'ils consistaient en machines délicates, et étaient en partie composés de matières fragiles. On ne pouvait pas, d'ailleurs, en arrivant à Zhé-Hol, présenter à l'empereur tous les présents à la fois. II y avait des machines compliquées, qu'on s'était trouvé obligé de démonter et d'emballer par pièces, afin de pouvoir les embarquer. II fallait du temps pour les remettre dans l'état où elles devaient être. En outre, il semblait nécessaire de les placer une fois dans le lieu où l'empereur faisait sa principale résidence, et d'où elles ne sortissent plus, lorsqu'elles auraient été montées par les ouvriers, sous l'inspection du docteur Dinwiddie et de M. Barrow.

De tels monuments du génie et des connaissances de l'Europe méritaient d'être conservés dans toute leur perfection. Mais le légat était contraire à toutes les mesures qui pouvaient occasionner quelque retard dans les environs de Pékin; et il semblait qu'il désirait d'interdire la vue de cette capitale à toutes les personnes attachées à l'ambassade. II n'avait jamais eu I'habitude de se former de justes notions de la délicatesse des instruments des sciences, ni de les apprécier ; et sans l'interposition du vice-roi, ceux qui composaient une partie des présents de l'ambassade anglaise étaient détruits.

\footnotetext{
${ }^{1}$ [Cf. Reclus, I'Empire du Milieu, carte 'Peking et environs']
} 


\section{Voyage dans l'intérieur de la Chine et en Tartarie}

Enfin, on décida qu'ils seraient déposés auprès de Pékin, dans un palais ordinairement destiné à recevoir des objets du même genre.

Dans le cours de cette discussion, on vit que le légat cachait, sous un extérieur très calme, un caractère méchant. II semblait que tous les étrangers inspiraient à cet homme injuste, et de la jalousie et un profond mépris. Mais ses défauts étaient balancés par l'urbanité et la politesse du vice-roi : lord Macartney eut seulement à regretter que le grand âge et les emplois de ce dernier ne l'eussent pas mis dans le cas d'être chargé, à la place de l'autre, de ce qui concernait l'ambassade.

Dès que l'ambassadeur et les principales personnes de sa suite furent rentrés à bord de leurs différents yachts, le vice-roi leur envoya servir à chacun un magnifique repas, avec du vin, des fruits et des confitures, comme il avait fait à Ta-Coo. Il joignit à cela un présent de thé, de soieries et de mousselines. Quoique ce présent ne fût pas d'une grande valeur, il était accompagné de compliments si obligeants qu'on le reçut de la manière qu'on crut la plus agréable à celui qui le faisait. Le vice-roi envoya aussi un grand dîner et des présents pour les soldats, les musiciens, les ouvriers et les domestiques de l'ambassade.

Parmi les diverses preuves de son attention pour l'ambassadeur, le viceroi fit élever un théâtre, pour le moment, vis-à-vis du yacht de son excellence. Le dehors du bâtiment était peint de couleurs très brillantes, très gaies, très variées; car les Chinois ont un art particulier pour produire des effets extrêmement agréables, par le contraste des couleurs. Le théâtre et les décorations avaient le même avantage. Les acteurs jouèrent successivement, pendant le jour, et des pantomimes et des drames historiques. Ils avaient le costume que portaient les Chinois à l'époque où avaient vécu les personnages qu'ils représentaient. Le dialogue était un récitatif accompagné par plusieurs instruments. Chaque pause était remplie par un grand fracas, dans lequel le loo n'était pas ce qui se faisait le moins entendre. On voyait les musiciens par derrière le théâtre qui, quoique large, avait peu de profondeur. En paraissant pour la première fois, chaque acteur annonçait quel rôle il jouait, et en quel lieu se passait l'action qu'on représentait. L'unité de lieu était sans doute observée, car pendant la durée d'une pièce, la scène ne changeait jamais. Les rôles de femme étaient remplis par des enfants ou par des eunuques. 


\section{Voyage dans l'intérieur de la Chine et en Tartarie}

Un drame attira particulièrement l'attention de ceux qui se rappelaient des scènes à peu près pareilles, qu'ils avaient vues sur le théâtre anglais. La pièce représentait un empereur de la Chine et son épouse, vivant dans la suprême félicité, quand tout à coup leurs sujets se révoltent, la guerre civile s'allume, on combat, et enfin, un général de cavalerie, le plus scélérat des rebelles, triomphe de son maître, le tue de sa propre main, et met en déroute l'armée impériale. L'impératrice, captive, paraît alors sur le théâtre, dans tout l'excès du désespoir que doit lui occasionner la perte de son époux et de son rang, comme la crainte de perdre aussi son honneur. Tandis qu'elle s'arrache les cheveux, et qu'elle fend les cieux de ses cris, arrive le vainqueur. II s'approche d'elle avec respect, la traite avec douceur, compatit à ses infortunes, lui parle d'amour et d'adoration et, semblable à Richard III auprès de lady Anne dans Shakespeare, il parvient, en moins d'une demi-heure, à sécher les pleurs de la princesse chinoise, qui oublie son défunt époux, et consent à donner la main à l'amant qui la console. La pièce finit par la célébration de son mariage et une grande fête.

Pendant que l'ambassadeur était à Tien-Sing, il reçut des nouvelles de l'escadre qu'il avait laissée à l'embouchure de la rivière. Sir Erasme Gower avait reçu un ordre pour obtenir les provisions qu'il demandait, ordre qui était adressé aux mandarins de tous les endroits où la santé des équipages exigerait que l'escadre s'arrêtât. Cependant, comme si l'on avait cru, à TaCoo, qu'il se préparait à retourner en Angleterre, d'où l'on savait qu'il avait été dix mois à venir, on lui offrit des provisions pour un an.

Parmi les passagers embarqués à bord de l'Endeavour pour retourner à Canton étaient non seulement le jeune interprète qui n'osa pas se hasarder à aller à Pékin, mais deux missionnaires, auxquels il manquait une licence pour être reçus dans cette capitale. Ces hommes, voués dès leur jeunesse à la propagation du christianisme dans les pays étrangers, avaient été depuis plusieurs années envoyés de Paris à Macao par les supérieurs des missions, afin qu'ils allassent joindre leurs frères à Pékin. Le moment de leur arrivée à Macao était celui où l'on persécutait les chrétiens dans plusieurs provinces de l'empire. Cette persécution devait son origine à quelques pratiques réelles ou prétendues des prédicateurs européens, ou de leurs prosélytes chinois, pour 


\section{Voyage dans l'intérieur de la Chine et en Tartarie}

occasionner du trouble. La jalousie des prêtres des religions anciennement établies à la Chine, excitant les préjugés et les passions des mandarins, les induit souvent à faire revivre les édits qu'on a rendus contre l'introduction des doctrines et des sectes nouvelles, parce qu'on les croit faites pour porter atteinte à la tranquillité de l'empire.

La persécution ayant donc accru la difficulté qu'avaient les deux nouveaux missionnaires à traverser le pays sans être aperçus, ils furent retenus à Macao par le supérieur du clergé, qui les occupa à instruire de jeunes Portugais qui se destinaient à la prêtrise. Cependant, ils ne perdirent pas de vue leur premier dessein, et cherchèrent avec soin les occasions de l'exécuter. Avant de quitter l'Europe, ils avaient voulu pouvoir devenir utiles à l'observatoire de Pékin, et s'étaient en conséquence attachés à l'étude des mathématiques et de l'astronomie. L'un d'eux avait reçu pendant quelque temps des leçons du célèbre astronome Lalande. Leurs talents et leur science une fois connus de l'empereur ne pouvaient manquer de les rendre recommandables à ses yeux, et de leur valoir à la longue une place dans le tribunal de mathématiques du palais impérial, seul département dans lequel les Européens peuvent être admis. II n'y a à présent d'autres étrangers que des Portugais; et on croit que, par politique, cette nation en exclut ses rivales. II faut avouer, cependant, que cette politique est purement coloniale, et que le cabinet de Lisbonne ne la suggère, ni ne l'encourage, et peut-être même n'en est pas instruit. Mais en supposant qu'elle existe à Macao, ou à Pékin, il est vraisemblable que, comme les deux missionnaires nouveaux n'étaient pas Portugais, les qualités qui les rendaient utiles à Macao et celles qui auraient pu servir à leur avancement à Pékin contribuèrent également à leur faire susciter les obstacles qui les arrêtèrent longtemps dans la première de ces villes. A force de patience et de zèle, ils vainquirent ces obstacles et entrèrent dans la rivière Pei-Ho pour se rendre à Pékin ; mais comme ils ne faisaient pas partie de la suite de l'ambassadeur, et que la permission qu'ils attendaient de la cour n'était point arrivée avant le départ de l'Endeavour pour Canton, ils furent forcés de se rembarquer dans ce navire. Cependant les lecteurs apprendront peut-être avec plaisir que la persévérance de ces hommes pieux fut enfin récompensée comme ils le désiraient, et que non 


\section{Voyage dans l'intérieur de la Chine et en Tartarie}

seulement l'empereur leur accorda la permission d'entrer dans la capitale, mais les prit à son service.

L'ambassadeur reçut à Tien-Sing la visite de tous les officiers civils et militaires, et la foule n'en était pas peu considérable. En cherchant à trouver de la ressemblance entre ces personnes et les Européens, on se rappelait aussitôt ces hommes qui se distinguaient en France, sous le titre de gens de qualité, lorsque la monarchie y subsistait encore. Ils étaient polis et

engageants dans leurs manières, prompts à devenir familiers et communicatifs, mais ils laissaient percer à travers leur urbanité un sentiment d'amour-propre et de vanité nationale qui faisait la base de leur caractère.

Lorsque les cérémonies du jour eurent cessé et que l'ambassadeur fut seul, on vint lui dire qu'un Chinois, qui avait rodé longtemps autour du yacht, demandait à être admis en sa présence. Aussitôt on introduisit un jeune homme, vêtu proprement et avec soin, d'une contenance modeste, et humble dans ses manières. C'était un jeune néophyte, sincèrement converti à la doctrine du Christ, et disciple fervent du missionnaire par qui il avait été arraché au paganisme que professaient ses ancêtres. Dévoué aux ordres de son père spirituel, il remplissait, en ce moment, un emploi qui n'était pas peu dangereux: il portait des lettres à l'ambassadeur, sans la permission des magistrats de la ville d'où il venait, et de celle où il était arrivé. Une telle communication est non seulement défendue avec un étranger, mais très gênée avec les gens du pays.

II n'y a point, à la Chine, de poste établie pour la commodité du peuple. L'empereur seul reçoit continuellement des messagers à cheval, qui lui apportent des nouvelles de toutes les parties de ses vastes États, et qui voyagent avec une célérité presque égale à ce que les Européens peuvent faire de mieux en ce genre. Les dépêches du souverain font en un jour cent cinquante milles. Mais les correspondances ordinaires du gouvernement et celles des mandarins sont portées par des messagers qui vont moins vite. Ceux-ci sont quelquefois chargés des paquets des individus, qui obtiennent cette permission comme une faveur particulière. Mais la circonspecte prévoyance du gouvernement chinois se réserve l'avantage exclusif de donner des nouvelles au peuple, ou de l'en priver, s'il le juge plus convenable. 


\section{Voyage dans l'intérieur de la Chine et en Tartarie}

Les lettres portées secrètement à l'ambassadeur étaient d'un des principaux missionnaires de Pékin, lequel ne paraissait pas borner son attention aux affaires spirituelles. Par la première de ces lettres, datée de Pékin le 7 mai 1793, le missionnaire informait son excellence :

«Que la nouvelle de l'ambassade anglaise était parvenue à l'empereur le 3 du mois de décembre précédent ; que ce prince en avait témoigné une grande satisfaction et avait donné l'ordre immédiat de faire ouvrir le port de Tien-Sing pour la réception des vaisseaux employés en cette occasion. - Que lui, missionnaire, était extrêmement flatté d'apprendre le même jour où il écrivait » (ce qui était pourtant prématuré) « que son excellence approchait de Tien-Sing ; qu'il la priait d'agréer son respect, et qu'il était dans la résolution d'embrasser avec zèle toutes les occasions de rendre service à la Compagnie et à la nation anglaise, ainsi qu'il l'avait promis à messieurs Cox et Mierop, de Canton. - Qu'à la première nouvelle d'une ambassade anglaise, il s'était donné tous les soins possibles pour préparer les esprits à lui faire un accueil favorable, et qu'il espérait n'y avoir pas travaillé en vain. - Qu'enfin, il serait toujours prêt, pendant que son excellence séjournerait en Chine, à lui rendre tous les services qui dépendraient de lui.

La seconde lettre était du même missionnaire, écrite le 6 août, c'est-à-dire peu de jours avant sa réception. L'écrivain mandait à l'ambassadeur :

«Que le gouvernement chinois avait enjoint à un missionnaire portugais (dont il disait le nom) de se rendre promptement à ZhéHol, pour y remplir l'office d'interprète de l'ambassade et diriger l'ambassadeur pour tout ce qui avait rapport aux cérémonies et à l'étiquette. - Que lui (l'auteur de la lettre) croyait devoir prévenir son excellence de se tenir sur ses gardes contre la mauvaise volonté et les desseins dangereux pour la nation anglaise, qu'avait l'interprète nommé; qu'il avait déjà laissé apercevoir dans sa conversation combien il était opposé au succès de l'ambassade ; et que si la cour eût été à Pékin, il aurait espéré (lui l'écrivain) de pouvoir balancer le mal que devaient produire les discours téméraires et mal fondés de l'interprète, et un grand nombre de 


\section{Voyage dans l'intérieur de la Chine et en Tartarie}

lettres de Canton et de Macao, qui contenaient des calomnies multipliées contre l'ambassade, et lui imputaient malignement des projets cachés. Mais qu'il craignait beaucoup qu'on ne réussît à lui nuire à Zhé-Hol, où l'empereur résidait et où lui (l'écrivain) ne pouvait pas se rendre à moins qu'il ne fût appelé par le gouvernement; qu'il avait une extrême envie, ainsi que ses collègues, de témoigner à la nation anglaise combien ils étaient reconnaissants de la protection qu'elle accordait, dans ses établissements de l'Inde, aux missionnaires employés à y propager le christianisme. - Que, comme on avait diverses fois annoncé l'arrivée de son excellence, il avait déjà envoyé trois fois sa première lettre à Tien-Sing.

II concluait en demandant que sa lettre fût tenue secrète, de peur que la connaissance de ce qu'elle contenait n'attirât sur lui le ressentiment des Portugais.

Quoique ces deux lettres pussent avoir été dictées par un esprit de rivalité, d'ambition et d'intrigue, elles servirent à confirmer ce qu'avaient annoncé des personnes désintéressées, à Macao, à l'égard de la jalousie qu'occasionnait l'ambassade. On ne hasarda de faire aucune réponse au correspondant inattendu. II n'était même pas encore temps de prendre des mesures à ce sujet. On avait sans doute bien moins à craindre de l'influence d'aucun Européen, que des dispositions sinistres du légat, et des rapports remplis de prévention qu'il pouvait faire au ministre.

Le soir, le temps étant favorable au départ, plusieurs yachts et autres bâtiments qui dépendaient de l'ambassade, ou y avaient rapport, firent voile jusqu'un peu au-delà de Tien-Sing. A mesure qu'on passait dans cette ville, on remarquait qu'elle était très étendue. Quelques-uns des observateurs jugèrent qu'il n'y avait pas moins de distance d'une de ses extrémités à l'autre, que de Millbank à Lime-house, c'est-à-dire qu'elle était aussi longue que Londres. Les mandarins qui y résidaient assurèrent qu'elle contenait sept cent mille âmes. Le nombre immense de spectateurs que les Anglais y virent rendait ce calcul vraisemblable, même sans y comprendre les personnes du voisinage que le passage de l'ambassade avait pu attirer, mais en songeant à la juste proportion de femmes et d'enfants qui ne s'étaient presque pas mêlés 


\section{Voyage dans l'intérieur de la Chine et en Tartarie}

dans la foule. Les jonques, qui étaient assez nombreuses pour couvrir presque entièrement les eaux de la rivière qui partagent cette cité commerçante, contenaient plusieurs milliers d'hommes. Les hommes qui conduisent ces bâtiments ne sont pas les seuls à qui ils servent d'habitation. Les femmes et les enfants des officiers et des matelots résident aussi constamment à bord. Plusieurs y sont nés, et tous y passent leur vie. Tout rivage leur est étranger; et la terre est un élément sur lequel ils ne se hasardent que rarement.

Les maisons de Tien-Sing qui, ayant des boutiques pour le détail des marchandises ou pour les gens de métiers, étaient ouvertes sur la rue, paraissaient aussi remplies de monde que les jonques. On peut se former une idée des personnes qui logeaient dans les autres habitations, non seulement par le nombre de spectateurs vus dehors, mais par le constant et patriarcal usage de ce peuple, qui rassemble sous un seul toit et dans de petits appartements, toutes les branches et les générations existantes d'une même famille. D'après cet usage conservé par les Chinois émigrés qui sont à Batavia, on trouva, en faisant un dénombrement exact de cette colonie, qu'il y avait dans chaque maison chinoise dix hommes en état de porter les armes.

Les maisons de Tien-Sing sont bâties en briques bleues ou cou-leur de plomb. Il y en a très peu de rouges. Les briques, dont on se sert pour les petites demeures des gens pauvres, sont d'un brun pâle. Ces différentes couleurs ne proviennent point de la nature de la terre, mais des différentes méthodes de convertir cette terre en brique. Les dernières dont nous venons de faire mention n'ont été exposées qu'à la chaleur du soleil, qui les cuit ou les durcit toujours imparfaitement. Les briques bleues ont reçu l'action d'un feu de bois, dans un fourneau, construit exprès, et où la flamme ne peut pas atteindre la surface de la brique. Celles qui, au contraire, sont touchées par la flamme deviennent rouges.

Quand l'argile est préparée et moulée en briques, on a coutume, dans l'Orient, de placer ces briques par rangs les unes au-dessus des autres. Elles sont alors molles et humides et, d'après la nature de la terre argileuse, singulièrement faciles à se coller les unes aux autres. II est donc nécessaire de les tenir séparées par une substance qui, par sa qualité, ne puisse devenir adhérente ni à l'un ni à l'autre rang, sans quoi les différents rangs de briques 


\section{Voyage dans l'intérieur de la Chine et en Tartarie}

ne formeraient, en séchant, qu'une masse solide, incapable d'être employée à l'usage qu'on veut en faire. On prévient donc cet inconvénient en plaçant une couche de paille entre les divers rangs de briques; et cette précaution est si essentielle qu'elle a donné naissance à un proverbe oriental qui a passé dans les langues de l'Occident.

Plusieurs maisons de Tien-Sing ont deux étages ; ce qui est contraire à la mode générale que les Chinois affectent dans leur manière de bâtir. La plupart préfèrent des maisons à un seul étage pour se conformer à la forme originale de toutes les demeures; et ils sont souvent embarrassés quand ils montent un escalier, ou qu'ils sont dans un endroit élevé et qu'ils regardent en bas. Mais l'avantage d'être près des quais et de la rivière, dans une ville de commerce, a donné lieu à ce qu'on considère, dans ce pays-là, comme une duplication de bâtiments sur le même sol.

La jonction de deux rivières navigables, dont l'une passe dans les environs de la capitale, et l'autre communique avec quelques provinces éloignées, doit avoir rendu ce lieu céleste très fréquenté, dès les premiers temps où les Chinois se sont réunis pour former un empire. Les annales du pays, confirmées par la tradition, rap portent qu'un des bras septentrionaux du grand fleuve Jaune se jetait autrefois dans le golfe de Pékin, et continua à suivre ce cours jusqu'à ce que la violence des débordements forma un amoncellement de terre, lequel accru par des efforts prodigieux d'un travail humain, fit passer tout le fleuve dans le lit du bras qui coule vers l'orient, et qui maintenant porte la masse totale des eaux de ce vaste fleuve à travers la province de Kiang-Nan et dans la mer Jaune.

Les anciennes cartes de la Chine présentent le fleuve Jaune divisé en deux bras, mais ces cartes sont si confuses, si incorrectes, qu'on ne voit pas clairement si le bras septentrional se réunissait aux rivières de Tien-Sing, ou s'il allait seul se jeter dans le golfe. Dans le premier cas, l'étendue des eaux autour desquelles la ville est bâtie devait être bien plus considérable qu'elle ne paraît à présent ; aussi est-elle, en effet, représentée comme beaucoup plus grande sur les anciennes cartes, et surtout sur celle de Marc-Paul qui appelle Tien-Sing la Citta Celesta. Tien-Sing avait déjà, en ce temps-là, c'est- 


\section{Voyage dans l'intérieur de la Chine et en Tartarie}

à-dire au treizième siècle, le rang de cité, mais elle ne fut longtemps regardée que comme une ville de peu de conséquence et d'une juridiction bornée, ainsi que l'indique la première terminaison de son premier nom de Tien-Sing-Wee. Partout où une ville très anciennement bâtie subsiste encore, les premières maisons doivent, dans le cours des siècles, avoir souvent fait place à d'autres qu'on $a$, en quelque sorte, construites sur leurs ruines. C'est pourquoi les maisons qu'on y voit à présent ont acquis par une accumulation graduelle, des fondements bien plus exhaussés que ne les avaient celles qui y existaient autrefois. La ville actuelle de Tien-Sing est bâtie sur un terrain élevé, quoique, de chaque côté, la campagne soit fort basse, et présente, comme la mer, une surface plane et uniforme, qui n'est bornée que par l'horizon.

En continuant sa route, l'ambassade ne vit qu'un pays cultivé avec le plus grand soin, ainsi que de l'autre côté de Tien-Sing. La plupart des champs étaient couverts de millet des Barbades, que les Chinois appellent kow-leang, c'est-à-dire le grand blé. Dans toutes les provinces du nord de la Chine, ce grain est à meilleur marché que le riz ; et c'est probablement le premier qu'on y ait cultivé ; car on voit dans les anciens livres chinois que la capacité des mesures était déterminée par le nombre de grains de cette espèce que ces mesures contenaient. Ainsi cent grains remplissaient un choo; et cette mesure était divisée en proportions décimales. Les distances ou les mesures métriques étaient aussi calculées d'après des exemples tirés de la même plante. La paille ou la tige de ce blé est trop raide et trop forte pour qu'on puisse en faire le même usage, auquel cette sorte de matière est employée ailleurs. Mais on en fait quelquefois des nattes grossières, ou des lattes pour recevoir le plâtre sur les murailles ou sur les plafonds. Le bas de la tige et la racine servent de chauffage, excepté quand on en a besoin pour faire des digues dans les endroits où les bords des canaux et des rivières manquent de consistance.

Les bords du Pei-Ho sont, en quelques endroits, revêtus de parapets de granit pour soutenir l'effort des débordements. Dans d'autres, il y a des digues faites aussi avec du granit, extrêmement longues, et garnies d'écluses de distance en distance, pour distribuer avec égalité l'eau dont on arrose les champs voisins. Du sable et de la vase accumulés ont formé, dans quelques 


\section{Voyage dans l'intérieur de la Chine et en Tartarie}

parties de la rivière, des îlots qui la séparent en deux bras étroits et remplis de hauts fonds.

Le millet des Barbades était souvent planté par rangs, et entre ces rangs, il y en avait alternativement d'autres d'une plante qui porte un grain plus petit, et a une tige plus humble. Tantôt c'était le panicum italicum, tantôt le panicum crus galli ${ }^{1}$ qui se trouvaient ainsi abrités par leur grand voisin. Mais après qu'on l'avait cueilli, ils restaient exposés aux rayons du soleil, mûrissaient à leur tour, et tombaient sous la faucille. Quelquefois sur le bord de la rivière, dans des coins où l'on avait par hasard négligé de semer du grain, ou bien tout le long des champs de blé, on voyait une espèce de plante légumineuse qui ressemblait aux haricots. Quelquefois aussi, on voyait des champs de fèves, de blé de Turquie et d'autres plantes dont les grains donnent une huile bonne à manger. Nulle part de mauvaises herbes ne diminuaient les productions utiles, ni ne partageaient avec elles la fertilité de la terre. Chaque champ avait l'air d'un jardin propre et régulier. Le sol avait déjà fourni cette année une première récolte de blé et de légumes pareils à ceux qu'on y voyait. Le froment dans les terrains secs, et le riz dans les terrains humides sont, dit-on, cultivés avec le plus grand avantage.

On ne voit dans ces plaines que peu d'arbres et de bétail. Mais l'œil y est réjoui par la perspective d'innombrables habitations, et l'état florissant d'une culture très soignée. Cependant, la famine se fait quelquefois sentir dans cette partie de la province; et ce désastre est dû tantôt aux débordements qu'occasionnent, dans certaines saisons, les torrents qui tombent des montagnes, tantôt aux ravages des sauterelles. Les vols sont fréquents dans ces occasions, et quoique le gouvernement se donne beaucoup de soins et exerce beaucoup de rigueur pour les arrêter, il ne peut pas parvenir à les empêcher totalement. Mais comme ils sont commis par des hommes qu'aiguillonne la faim et qui cèdent à l'impérieuse nécessité, ils cessent ordinairement au retour de l'abondance.

\footnotetext{
${ }^{1}$ Espèces de millet.
} 


\section{Voyage dans l'intérieur de la Chine et en Tartarie}

Les marées dont le flux avait accéléré la marche des yachts qui portaient l'ambassade cessèrent de se faire sentir à environ trente milles au-delà de Tien-Sing. Quand il n'y avait point de vent, ou qu'il n'y en avait que très peu, on voyait communément les matelots faire usage de deux très larges avirons, placés quelquefois sur le devant du yacht, comme les nageoires pectorales d'un poisson, et quelquefois du côté de la poupe. Il y a même des bâtiments où un seul aviron est à la poupe et l'autre à la proue. Chaque aviron a un petit trou par où on le passe sur un pivot de fer, fixé dans une pièce de bois qui est en dehors du plat-bord. Lorsque les avirons sont une fois en place, on ne les en ôte plus, parce qu'ils font immédiatement au-dessous de la surface de l'eau, un mouvement vibratoire, par le moyen duquel ils écartent l'eau tantôt avec un côté de leur tranchant, tantôt avec l'autre. Lorsqu'on veut ramer avec ces avirons, on a besoin d'y employer plusieurs hommes, et ces hommes paraissent faire ce travail avec plaisir. Les mouvements sont réglés par un air très gai que chante le pilote, et auquel les rameurs répondent en chœur. Ce même air est chanté à bord de tous les bâtiments, et lorsque, dans une nuit paisible, par un beau clair de lune, on l'entend répéter de cent différentes jonques qui suivent différentes directions, on se fait une agréable idée du contentement de cette classe laborieuse qui vit continuellement sur l'eau, et forme une partie considérable de la population de la Chine.

Mais la méthode que nous venons de décrire ne suffisait pas toujours pour faire avancer les yachts, parce que la brise était contraire ou trop faible pour aider à vaincre le courant. Alors on avait recours à un moyen dont on s'était déjà servi à l'embouchure de la rivière. On tirait les yachts avec des cordes. Dans beaucoup d'autres pays, on emploie pour cela des chevaux ou des mulets. Mais à la Chine, non seulement le travail des hommes est celui qui coûte le moins, mais il n'est point épargné, toutes les fois qu'on est sûr de n'en point faire un vain usage. Pour faire remonter les vaisseaux, la principale corde est attachée au haut du grand mât, et elle est jointe à une autre qui part de la proue. La première est extrêmement longue et $a$, vers son extrémité, plusieurs autres cordes attachées en double, et chacune desquelles forme une espèce de bandoulière pour les hommes qui tirent le bâtiment. Souvent ces hommes substituent un morceau de planche à la partie de la torde qui porterait sur leur poitrine, et dont la pression gênerait le 


\section{Voyage dans l'intérieur de la Chine et en Tartarie}

mouvement des poumons. Ainsi arrangés, ces hommes vont en ligne au son d'un air commun, qui les aide à régler leurs pas et à unir leurs efforts, dès lors beaucoup plus efficaces. En outre, cette chanson les distrait, les anime, et leur fait oublier les malheurs de leur condition, pour ne s'occuper que de leur travail.

II y avait environ quinze hommes pour traîner chaque yacht de l'ambassade, et ils étaient au moins cinq cents, employés à ce service, et relevés, alternativement, par un pareil nombre. Tous ces hommes étaient bien musclés, bien faits, mais ils avaient les épaules extrêmement arrondies. En été, ils sont nus depuis la ceinture jusqu'en haut. Aussi cette partie de leur corps est couleur de cuivre ; mais ils sont d'ailleurs fort blancs, comme il est aisé de s'en apercevoir, parce qu'ils se découvrent entièrement quand ils ont besoin d'entrer dans l'eau.

Le pays plat, et quelquefois marécageux, où passe la rivière, est favorable à la production des insectes; aussi y en a-t-il beaucoup dont l'aiguillon est très désagréable. D'autres ne sont incommodes que par leur bourdonnement perpétuel. II y a une espèce de cigale, dont la musique n'est point du genre vocal, mais est produite par le mouvement de deux membranes en forme de petites lames, qui recouvrent l'abdomen de l'insecte. C'est le signal amoureux que fait le mâle pour attirer sa femelle, signal qu'elle ne peut lui rendre, car elle est entièrement dépourvue de ces organes. Ce sol fécond donne naissance à une autre espèce d'insecte, qui n'est guère moins gros d'un colibri.

Une foule d'objets attirait sur le rivage l'attention des voyageurs, et les engageait souvent à quitter les yachts, dont la marche était si lente qu'on pouvait aisément faire des excursions à terre. Mais les Anglais s'aperçurent bientôt qu'ils étaient surveillés avec une jalousie, une suspicion qui surpassaient tout ce qu'ils avaient lu ou entendu raconter de la circonspecte police des Chinois. Ce changement était l'effet des ordres du légat. II était difficile d'attribuer d'inutiles mesures de contrainte à la seule mauvaise humeur; et cependant, on ne pouvait pas y trouver d'autre cause. Enfin, d'après plusieurs mots que les mandarins laissèrent échapper dans leur conversation familière avec l'interprète, celui-ci découvrit que la cour était, depuis peu de temps, très mécontente de la nation anglaise. Voici la seule 


\section{Voyage dans l'intérieur de la Chine et en Tartarie}

explication qu'on put obtenir à cet égard, avec beaucoup de difficultés et de précautions.

Dans une guerre que l'empereur de la Chine faisait au Tibet, son armée éprouva plus de résistance et fit de plus grandes pertes qu'on n'en avait prévu en marchant contre un ennemi tel que celui qu'on croyait avoir à combattre. Aussitôt quelques officiers chinois s'imaginèrent qu'on leur avait opposé des manœuvres européennes et même des soldats européens. Ils dirent qu'ils avaient découvert, parmi leurs ennemis, des chapeaux aussi bien que des turbans; et on conclut que ceux qui portaient ces chapeaux ne pouvaient être que des Anglais. Cependant le gouvernement chinois sema, par politique, des bruits contraires parmi le peuple. II déclara que les Anglais lui avaient fourni des secours. Quoique l'ambassadeur fût convaincu qu'aucun de ces faits n'était vrai, il n'en sentait pas moins que la créance du premier suffisait pour que la cour de la Chine cessât d'avoir des dispositions favorables pour le gouvernement de la Grande-Bretagne, et même aucune confiance en lui.

Quoique l'empereur parût personnellement flatté de l'ambassade, et que les ordres qu'il avait donnés pour sa réception fussent absolus, les ministres, déjà prévenus, pouvaient faire accorder la mission des Anglais avec les hostilités supposées, ainsi qu'avec leur puissance réelle dans I'Inde, et soupçonner que quelque intention perfide était cachée sous une offre de présents et d'amitié. On sait qu'il n'y a pas encore longtemps que de semblables soupçons portèrent la cour ottomane à interdire aux voyageurs anglais le passage de l'Égypte, parce que, dit-elle dans sa proclamation, leurs gens de guerre se déguisent en marchands, lèvent les plans des places étrangères, et font des observations sur leur état de défense, afin de revenir en force les attaquer avec une plus grande certitude de succès.

Ce n'est point une politique rare dans l'Orient, que de préparer une attaque contre une nation étrangère, en lui envoyant une ambassade, en apparence amicale, mais réellement destinée à examiner sa situation.

Le cabinet de Londres connaissait parfaitement les préventions qu'on pouvait chercher à exciter contre les Anglais, à l'égard des vues ambitieuses 


\section{Voyage dans l'intérieur de la Chine et en Tartarie}

que semblait prouver leur agrandissement dans le Bengale ; et il avait indiqué à l'ambassadeur la méthode la plus judicieuse pour écarter tous les soupçons qu'occasionnait une domination si accidentelle et si peu recherchée. Mais il était impossible de prévoir qu'on imputait aux Anglais d'avoir pris les armes contre les Chinois, ce que véritablement ils n'avaient jamais fait. Ce ne fut que l'année suivante, lorsqu'à son retour de Pékin, l'ambassadeur passa à Canton, qu'il apprit, par des dépêches de Londres et de Calcutta, ce qui avait donné lieu à une si fausse assertion.

II y avait eu, quelque temps auparavant, des hostilités entre le gouvernement de Lassa, situé au nord-nord-est de Calcutta, et celui de Napoul, situé au nord-ouest de cette ville, et tous deux au nord de la soubabie ou vice-royauté du Bengale. Napoul touche immédiatement au territoire britannique, qui s'étend jusqu'à l'extrémité septentrionale des plaines de I'Indostan. De ces plaines, à quinze milles de distance seulement, la terre s'élève de sept mille pieds, et du sommet de ces montagnes, comme dit l'ouvrage instructif et élégant du major Rennell, le voyageur étonné regarde avec étonnement la plaine qu'il a laissée derrière lui, et qui ressemble à un immense océan.

A l'ouest du Napoul et à l'est de Bootan est situé le grand Thibet, où les armes anglaises pénétrèrent il y a plus de 20 ans, par des passages fortifiés, et forcèrent le gouvernement du pays à demander la paix. Le Teshoo-Lama, ou chef spirituel et souverain du Thibet, envoya, à cette occasion, un ambassadeur au gouverneur général de Calcutta ; et en revanche, celui-ci fit partir, quelque temps après, une ambassade pour Lassa. Depuis cette époque, il n'y a pas eu le moindre différend entre le gouvernement du Bengale et celui du Thibet. Au contraire, des liaisons amicales les ont rapprochés; des échanges commerciaux se sont faits d'un pays à l'autre, et l'on a eu l'espoir de les voir s'accroître.

Quoiqu'à l'époque de la guerre dont nous venons de parler, l'empereur de la Chine fût disciple de la religion du Lama, et regardé comme son protecteur temporel, il ne se mêla point des affaires du Thibet. Mais bientôt après, il invita le Lama, à la doctrine duquel il paraissait dévotement attaché, à venir à sa cour, pour conférer avec lui sur ses principes religieux. Les relations de Pékin disent que l'empereur accueillit le Lama comme le chef de sa secte, et 


\section{Voyage dans l'intérieur de la Chine et en Tartarie}

le type visible de la divinité qu'il adorait, et qu'il lui rendit des honneurs extraordinaires. Elles parlent aussi des regrets de sa majesté impériale, à la mort du Lama, qui fut emporté par la petite vérole, quelque temps après son arrivée en Chine.

Cependant une perte si soudaine fit naître de violents soupçons au Thibet. On s'imagina que la correspondance et les liaisons du Teshoo-Lama avec le gouvernement anglais du Bengale avaient donné de l'ombrage à l'empereur de la Chine, lequel cédant aux suggestions d'une politique souvent en usage dans l'Orient, avait attiré le Lama à sa cour, avec des intentions toutes différentes de celles qu'il lui avait été témoignées. II est certain que Sumhurlama, frère du Teshoo, fut si effrayé de sa mort, qu'il s'enfuit de Lassa, et emporta d'immenses trésors qui, probablement, servirent a lui faire obtenir la protection du rajah de Napoul. Afin de se mieux concilier l'amitié de ce rajah, il lui fit la description des mines d'or et d'argent des environs de Lassa, et lui confia qu'il y avait d'immenses richesses dans le Poo-Ta-La, c'est-à-dire dans le grand temple bâti près de cette capitale. Séduit par l'espoir de conquérir ces richesses, le rajah fit partir une armée qui, après vingt jours de marche, rencontra les troupes du Thibet assemblées pour s'opposer à son passage. On livra plusieurs batailles. La victoire resta toujours du côté des assaillants ; et la paix fut enfin conclue, à condition que le pays de Lassa paierait au rajah de Napoul un tribut annuel de trois laks de roupies.

Dans les vicissitudes du pouvoir, si fréquentes dans plusieurs parties de l'Orient, Lassa avait déjà été dépendant de Napoul, et sa monnaie portait l'effigie d'un ancien rajah, comme celle de son principal souverain. Le rajah actuel voulut faire revivre cette coutume, et il en fit une clause du nouveau traité qui, ce semble, fut conclu par l'intervention d'un chef dépendant de l'empereur de la Chine, et résidant habituellement à Lassa. Vraisemblablement le vaincu ne se soumit à cette condition que dans le dessein de s'en affranchir dès qu'il pourrait obtenir des secours étrangers. On s'adressa, pour cela, au gouverneur général du Bengale, qui refusa de s'en mêler.

Le rajah de Napoul, enhardi par ses succès à Lassa, envoya des troupes à Diggurah, autre district du Thibet, et pilla les trésors du Lama de cette ville, lequel était aussi un des grands prêtres de la religion de l'empereur. Ces 


\section{Voyage dans l'intérieur de la Chine et en Tartarie}

diverses agressions du rajah contre les chefs spirituels de la foi de sa majesté impériale, et contre les pays qu'elle protégeait, la déterminèrent enfin à les venger. Malgré la longueur et les difficultés de la route que ses troupes avaient à faire, avant d'arriver sur le pays ennemi, elle fit partir soixante-dix mille hommes qui arrivèrent sur les frontières du Thibet en 1791. De là à Napoul, il y a plus de cinq cents milles, et le pays est difficile et inégal. Quelques montagnes du Thibet, qu'on voit des plaines du Bengale, à la distance de cent cinquante milles, dit le major Rennell, sont ordinairement couvertes de neige. Le même officier les croit aussi élevées qu'aucune montagne de notre hémisphère et il ajoute que le pays du Thibet est généralement un des plus hauts de l'Asie, et fait partie de ces contrées où prennent leur source non seulement les rivières de l'Inde et de la Chine, mais celles de la Tartarie et de la Sibérie.

Quoique le Thibet soit situé au midi de la zone tempérée, et par les quarante degrés de latitude nord, son climat est extrêmement rude. Indépendamment des obstacles qu'un tel pays opposait naturellement au passage d'une armée, les montagnes du côté du Napoul étaient fortifiées par l'art. Les troupes du rajah étaient nombreuses et animées par leurs premiers succès. Ce prince n'était peut-être pas sans espoir de secours du côté du Bengale; et il le réclamait en qualité de voisin et d'allié. II avait longtemps, par des avances amicales, essayé de se lier intimement avec les Anglais, et il y avait enfin réussi en concluant un traité de commerce avec eux. II n'était point extraordinaire que des alliés du Bengale, ou dépendants de lui, en obtinssent des troupes pour quelques services particuliers. Vers l'époque même dont nous parlons, les Anglais envoyèrent au rajah de Deringah un petit détachement pour l'aider à rentrer en possession de ses États, situés à l'est du Bengale, et non loin des frontières occidentales de la Chine. Ils fournirent aussi des troupes pour faire cesser les troubles du pays d'Assam, que désolaient une bande de vagabonds du Bengale. Le rajah de Napoul se vanta d'obtenir un pareil secours afin d'encourager son armée, et fit même courir le bruit qu'il l'avait reçu pour intimider ses ennemis.

D'un autre côté, le général de l'armée chinoise écrivit d'un style emphatique au gouverneur général du Bengale, et parlant au nom de son maître : «La fleur de la race impériale, le soleil du firmament de l'honneur, le 


\section{Voyage dans l'intérieur de la Chine et en Tartarie}

joyau resplendissant sous la couronne et sur le trône de l'empire chinois » ; il demandait que « I'on envoyât des troupes anglaises pour s'emparer du rajah et le châtier comme il le méritait ».

Parmi les idées extravagantes qu'avait suscitées aux souverains de la Chine leur autorité illimitée sur tout ce qui les entourait immédiatement était celle d'une monarchie universelle; et on cite, comme un exemple de la modération et du bon sens de l'empereur actuel, sa renonciation à une prétention aussi absurde. Cependant, il est possible que de pareilles notions existant encore dans l'esprit du général des troupes chinoises au Thibet lui fissent croire que le gouverneur du Bengale n'hésiterait pas à accéder à sa demande. La lettre par laquelle il faisait cette demande était écrite dans la langue de l'empereur son maître et ne put point être alors traduite à Calcutta ; mais on sut à peu près ce qu'elle contenait, par une autre lettre de Dhalary-Lama, qui régnait alors au Thibet.

Il est nécessaire d'observer ici que dans l'Indostan, le chaud et le froid ne varient pas dans le cours de l'année d'une manière assez sensible pour occasionner la principale division des saisons, en hiver et en été, comme en Europe. Pendant les premiers six mois de l'année, le temps est extrêmement sec, et durant les derniers six mois, la pluie tombe avec une abondance inconnue dans les autres climats, les rivières débordent, inondent les plaines, détruisent les routes et changent presque entièrement l'aspect du pays. L'année y est donc justement divisée en deux parties qu'on appelle la saison sèche et la saison pluvieuse.

Cette dernière saison, qui survint bientôt après la réception des lettres dont nous venons de parler, rendait long et difficile le voyage de Calcutta à Lassa. En outre, le messager porteur de ces dépêches fut retenu en route par la maladie. Le général chinois ne recevant point de réponse à l'époque où il y avait compté, fut plus aisément disposé à prêter l'oreille au bruit qui s'était répandu dans le pays, et il crut qu'en effet, les troupes anglaises avaient, contre son attente, marché au secours du rajah. Ce qui fortifia encore cette opinion fut la manière vigoureuse dont le rajah se défendait.

II n'était pas absolument impossible que quelques cipayes, déserteurs des troupes que la Compagnie des Indes anglaise entretient dans le Bengale, 


\section{Voyage dans l'intérieur de la Chine et en Tartarie}

connaissant les manœuvres militaires des Européens, et portant même l'uniforme anglais, pussent avoir passé dans l'armée du Napoul, où ils auraient été sans doute recueillis avec joie. La mauvaise saison et l'inégalité du pays augmentaient le danger des assaillants, et rendaient leur succès incertain. L'idée d'avoir de doubles forces à combattre devait ajouter à I'honneur de la victoire et diminuer la honte de la défaite. En conséquence, on dit qu'on manda à Pékin que les troupes anglaises s'étaient jointes au rajah. Les relations intimes qu'avait le général chinois avec la cour, l'éloignement du pays où il était envoyé, les lois de l'empire qui empêchent toute personne employée dans une armée de correspondre sur des objets qui ont rapport à la guerre sans la permission du commandant en chef, l'ignorance générale du peuple de la Chine relativement à toutes les matières politiques, son silence prudent sur de tels sujets, avaient déjà mis ce général à même d'accréditer de pareils mensonges, lorsqu'il commandait une armée contre le Tunquin. Alors, malgré ses fautes et sa déroute, il était parvenu à satisfaire l'empereur et à recevoir la récompense due au mérite et au succès. Sa conduite était également blâmable, comme vice-roi de Canton, où il commettait des injustices, opprimait sans cesse les étrangers, et les haïssait peut-être à cause du mal qu'il leur faisait.

Revenons : on était si peu fondé à accuser les Anglais de soutenir le rajah de Napoul que I'homme qui commandait alors au Bengale, d'une manière si honorable pour lui et si avantageuse pour son pays, se conduisit dans cette affaire, non seulement avec la plus stricte neutralité, mais avec une judicieuse attention pour l'empereur de la Chine. II résolut d'envoyer une députation amicale au rajah de Napoul pour l'assurer que les membres du gouvernement du Bengale désiraient ardemment de le délivrer d'une guerre ruineuse, mais que la correspondance qu'ils avaient entretenue avec les lamas, et les rapports commerciaux qui subsistaient depuis longtemps entre l'Angleterre et l'empire de la Chine leur interdisaient absolument toute espèce d'hostilités contre aucune de ces puissances, lorsqu'ils n'étaient point provoqués par elles. Que ce n'était que par le moyen d'une négociation conciliatoire qu'ils pouvaient le secourir; et que pour l'entreprendre efficacement, il était nécessaire de commencer à correspondre avec les commandants des troupes chinoises et thibétiennes. 


\section{Voyage dans l'intérieur de la Chine et en Tartarie}

Le gouvernement général du Bengale se promettait encore un autre avantage de la députation qu'il envoyait à Napoul. La jalousie que les chefs de ces pays nourrissaient contre les Anglais avait jusqu'alors été cause que ces derniers n'en savaient pas plus sur l'intérieur du Napoul que sur l'intérieur de la Chine. On pensa donc qu'il ne fallait épargner ni peine, ni attention pour tirer avantage d'une occasion si favorable d'acquérir des notions certaines sur la population, les mœurs, les coutumes, le commerce, les manufactures et les productions naturelles d'un pays avec lequel on devait désirer d'entretenir la communication la plus amicale.

Le gouverneur général écrivit immédiatement à Dhalary-Lama :

«Que la Compagnie des Indes anglaise n'avait rien de plus à cœur que de conserver les relations les plus amicales avec toutes les puissances de l'Inde; et que, sentant toute la sagesse de ces principes, il était soigneux de ne point transgresser les lois de l'amitié pour se mêler d'une manière hostile de querelles qui s'élevaient entre les puissances étrangères, excepté quand le besoin de se défendre, ou des attaques non provoquées, l'y obligeaient. Que le gouverneur général avait envoyé au rajah de Napoul une réponse conforme à ces sentiments, lorsque ce rajah lui avait fait demander un secours de troupes. Que Dhalary-Lama ne pouvait pas ignorer que les Anglais étaient depuis longtemps liés d'amitié avec le rajah de Napoul, ainsi qu'avec l'empereur de la Chine, dont la protection s'étendait sur le Lama et sur la Compagnie des Indes anglaise. Que depuis plusieurs années les Anglais faisaient le commerce avec les sujets de l'empereur, et qu'ils avaient en ce moment une factorerie dans ses États. Que par rapport à l'empereur, et sachant que sa majesté impériale avait une grande vénération pour le Lama, le gouverneur général désirait que le pays de ce dernier pût jouir d'une paix durable, et mettre un terme à la guerre qui ne pouvait qu'opérer la ruine et le malheur de ses sujets. Que le gouverneur général se croirait donc heureux si son entremise pouvait contribuer de quelque manière à établir l'harmonie et la paix entre le Lama et le rajah de Napoul, et qu'il était prêt à s'employer comme ami et médiateur. Cependant, que comme la 


\section{Voyage dans l'intérieur de la Chine et en Tartarie}

présente saison des pluies ne permettait pas qu'on fît des démarches pour une telle médiation, il suspendrait l'effet de ses intentions jusqu'à ce que les pluies eussent cessé, et qu'alors il députerait un homme de confiance pour faire connaître tous ses sentiments. Qu'il espérait que par ses soins la paix régnerait de nouveau entre le Lama et le rajah de Napoul, et que leur amitié ne ferait que s'accroître. Que son homme de confiance serait accompagné par quelques cipayes qui lui serviraient de gardes, ainsi qu'à ses domestiques. Que le gouverneur général le prévenait de cela, afin d'empêcher le mauvais effet des rapports mensongers.

Cependant, soit pour profiter de l'occasion, soit pour céder à des circonstances pressantes, les troupes chinoises et thibétiennes voulurent, le plus tôt possible, mettre un terme à la guerre, en attaquant le rajah de Napoul. Elles dédaignèrent et l'inconvénient des pluies, et la médiation offerte; et le rajah désespérant des secours qu'il s'était vainement flatté d'obtenir des Anglais, rendit le butin qu'il avait enlevé et conserva la possession de son ancien territoire.

Dès le commencement de la guerre, le général chinois avait menacé d'exterminer la race du rajah, et de réunir ses États à ceux de la Chine. Si cela était arrivé, l'empire britannique eut été limitrophe de l'empire chinois. Mais soit qu'il craignît qu'un tel voisinage ne fût pas du goût des Anglais, qui pouvaient chercher à l'empêcher, soit qu'il fût satisfait de la gloire qu'il avait acquise, et qu'il se rappelait combien son armée avait souffert dans les premiers combats, il affecta de procurer au rajah le pardon de l'empereur, sous prétexte que son pays était d'une petite étendue, et son peuple d'une tribu étrangère ; et qu'en outre, il consentait à payer un tribut et à livrer les os, les femmes, les enfants et les effets de Sumhur-Lama, premier instigateur de la guerre.

Mais quoiqu'il fût venu pour protéger le pays de Lassa en faveur de Dhalary-Lama, il y établit un chef temporel, auquel il commit le soin de toutes les affaires civiles et politiques. II allégua pour raison de cette conduite que très anciennement le territoire de Lassa avait appartenu au trône impérial, et qu'il lui resterait à jamais. 


\section{Voyage dans l'intérieur de la Chine et en Tartarie}

Ainsi elles font maintenant partie de l'empire chinois, ces contrées qui avaient été jusqu'alors considérées comme appartenant au grand Lama, qui en était le souverain suprême pour tout ce qui concernait les affaires spirituelles, tandis qu'à l'égard des affaires temporelles, l'empereur de la Chine en paraissait seulement le protecteur, en qualité de premier disciple de la foi. D'après ces nouvelles limites il n'y a plus, entre la Chine et les possessions britanniques du côté de l'Indostan, qu'un territoire dont la largeur n'a qu'environ un degré de latitude, et dans une partie duquel se trouvent les États du rajah de Napoul. Les frontières occidentales de la Chine avaient été rapprochées de l'est de l'Indostan, depuis l'année 1773 où le général chinois Akoui soumit entièrement la nation des Miao-Tsée, dont une partie vivait sur le territoire chinois et s'était révoltée, et l'autre habitait un pays indépendant à l'occident de la Chine.

Si les divisions qui ont fréquemment lieu entre les princes qui possèdent les contrées situées sur les limites orientales de l'Indostan engageaient désormais l'empereur de la Chine à y prendre part, comme il en a pris à celles des princes voisins des limites septentrionales, le gouvernement britannique et le gouvernement chinois auraient nécessairement beaucoup d'occasions de discuter et de s'expliquer ensemble; et il leur faudrait beaucoup de précautions pour éviter d'être enveloppés dans les querelles de leurs vassaux ou de leurs alliés.

Les événements arrivés dans le Thibet et à Napoul n'accrurent point les relations entre les frontières de I'Indostan et de la Chine. Le général chinois, vainqueur de Napoul, montra autant de répugnance que les souverains de ce dernier pays, à recevoir un envoyé anglais, et il écrivit au gouverneur général une lettre très polie pour le dissuader d'envoyer la députation annoncée. II lui observa :

«Que comme de la ville où résidait le gouverneur général, jusqu'à Napoul, le voyage était très long, il s'exposerait à de grands embarras en y envoyant quelqu'un. Et pourquoi chercher des embarras inutiles? II espérait que le gouverneur changerait d'intention. Sans doute, ses conseils avaient eu un effet mérité, en engageant le rajah à se soumettre au joug impérial. 


\section{Voyage dans l'intérieur de la Chine et en Tartarie}

II terminait sa lettre en reconnaissant la justice, l'attachement, l'amitié du gouverneur général.

Si une copie de cette lettre était parvenue jusqu'aux mains de l'empereur, elle aurait suffi pour réfuter tous les rapports qu'on avait pu lui faire sur les prétendus secours que les Anglais avaient donnés à son ennemi. Mais l'auteur de la lettre n'était nullement disposé à la transmettre à sa majesté impériale, parce qu'il ne voulait pas avouer la fausseté des bruits qu'il avait semés luimême, et il était peu vraisemblable que l'empereur fût instruit de cette fausseté par un autre canal, puisqu'il n'y avait eu jusqu'alors aucune communication entre les cours de Londres et de Pékin.

Si l'ambassade que le cabinet de Saint-James se proposait d'envoyer en Chine en 1787, et dont nous avons parlé au commencement de cet ouvrage, n'avait pas été suspendue par la mort prématurée de l'homme qui avait été choisi pour remplir la place de ministre plénipotentiaire à la cour de Pékin, sa présence aurait probablement prévenu tous les malentendus à l'occasion de la guerre du Thibet. Peut-être même cette guerre n'eût pas eu lieu. II fallait les agressions répétées du rajah de Napoul pour forcer l'empereur à s'engager dans une entreprise aussi éloignée et aussi incertaine. Quoique sa première guerre contre les Eleutes de la Tartarie se fût terminée par la conquête de leur pays, elle ne lui offrit d'abord que des succès incertains. Ses troupes furent souvent défaites. II périt un grand nombre de soldats. La querelle dura longtemps, et coûta des sommes immenses. Les ministres chinois n'aimaient point la guerre ; et l'âge avancé de l'empereur lui faisait attacher beaucoup moins de prix aux conquêtes. Oui, s'il y avait eu en Chine en 1789 ou 1790, un homme accrédité par le roi d'Angleterre, il aurait pu demander au gouvernement du Bengale d'employer de bonne heure son influence sur le rajah de Napoul, pour qu'il cessât de faire des incursions dévastatrices dans le Thibet. L'empereur eût préféré cette méthode de parvenir sans risque à son but, d'après le même principe qui engagea depuis le commandant de son armée à s'adresser au gouverneur du Bengale. Peut-être aussi serait-il plus avantageux, pour le Bengale, que le Thibet eût conservé son état d'indépendance, plutôt que d'être devenu province d'un autre empire.

Si avant de quitter le voisinage de Canton, lord Macartney eût, par bonheur, été instruit des événements de la guerre du Thibet, il aurait pu 


\section{Voyage dans l'intérieur de la Chine et en Tartarie}

détruire l'effet des faux rapports qu'ils avaient occasionnés ; mais il ignorait encore complètement toutes les circonstances qui servaient de prétexte aux rumeurs injurieuses, semées contre les Anglais; et il fut privé des moyens ordinaires de réfuter la calomnie, c'est-à-dire de pouvoir faire connaître les détails de l'affaire qu'on envenimait. Toutefois l'ambassadeur réussit dans les soins qu'il se donna pour convaincre les deux mandarins que l'histoire qu'on leur avait débitée n'avait aucun fondement. Remplis de confiance en lui, ils ne pouvaient manquer de croire à la vérité de ses assertions ; mais ils n'étaient point autorisés à communiquer directement avec la cour ; et ils craignaient que, prévenu comme on l'était dans cette cour, une déclaration favorable de leur part ne fût attribuée à une vénale partialité pour les nouveaux amis. D'ailleurs, comme ils étaient de race chinoise, ils n'avaient aucune espèce d'influence sur le légat tartare. Une secrète antipathie subsiste toujours entre ces deux nations.

Le légat était le seul à qui il fût permis de correspondre avec le gouvernement, relativement à l'ambassade. L'ambassadeur employa tous les moyens possibles pour captiver sa bienveillance.

II profita des occasions qui se présentèrent pour l'informer de la grande distance qu'il y avait de Calcutta à Napoul et au Thibet; et pour lui représenter de quelles faibles conséquences étaient les relations des Anglais avec ces deux pays, en comparaison de leur commerce à Canton, et par conséquent, combien plus ils mettaient de prix à ce qui avait rapport à ce dernier objet. II fit aussi mention des instructions constamment données au gouverneur général du Bengale, qui lui recommandent d'avoir une attention particulière pour ceux de ses voisins qui sont alliés de l'empire de la Chine ou sous la protection immédiate de cet empire.

Un déni plus formel d'avoir secouru les ennemis des Chinois, lorsqu'il n'y avait point d'accusation avancée, ou même lorsqu'on n'avouait point qu'il y eût réellement lieu de le croire, n'aurait pu servir qu'à renforcer la probabilité du fait, aux yeux d'un homme tel que celui à qui l'ambassadeur avait affaire. Quelque changement qu'opérassent à cet égard les observations de ce ministre, dans l'opinion du légat, elles n'en produisirent que très peu pour tout le reste. Le légat ne montra aucune disposition à rendre justice aux Anglais, ni à l'ambassade. Soit par méfiance, soit par mauvaise volonté, il 


\section{Voyage dans l'intérieur de la Chine et en Tartarie}

refusa d'expédier, par les messagers du gouvernement, les lettres que l'ambassadeur écrivait à sir Erasme Gower ; et cependant il savait bien que l'empereur avait bien voulu faire parvenir, lui-même, à son excellence, un paquet qui avait été porté à Zhé-Hol. II n'y avait pas moyen de faire passer des dépêches sans la permission du légat; et les démarches qu'on fit pour obtenir de pouvoir correspondre avec les commissaires de la Compagnie à Canton furent également inutiles. L'ambassade fut ainsi privée des communications les plus nécessaires,. et n'eut que fort peu d'espoir d'être mieux traitée à l'avenir. Le légat était la créature et l'ami du colao ou premier ministre: d'après la conduite de l'un on pouvait juger des intentions de l'autre.

Telles étaient les circonstances contrariantes dans lesquelles se trouva l'ambassade avant d'arriver dans la capitale. Elle n'allait que lentement contre le courant de la rivière. Dans cette route, on rencontrait à chaque instant de grandes jonques qui revenaient de porter du blé à Tong-Choo-Foo dans le voisinage de Pékin. Elles se hâtaient de s'en retourner avant I'hiver parce que, dans cette saison, la rivière est constamment gelée, quoiqu'elle soit par les quarante degrés de latitude nord. La plupart de ces grandes jonques étaient au service du gouvernement et employées à charrier les impôts levés en nature. Cette manière de percevoir des impôts a, au moins, l'avantage d'empêcher que les individus ne soient forcés de vendre le produit de leur travail au-dessous de sa valeur, afin de payer ce qu'ils doivent à l'État; nécessité où ils pourraient se trouver si les impôts étaient exigés en argent monnayé ou en lingots, qui ont également cours à la Chine.

Une partie des taxes sur le grain est destinée à remplir les greniers construits dans toutes les provinces de l'empire, pour remédier au malheur que la disette fait éprouver aux endroits où l'on ne peut pas tirer des secours des marchés étrangers.

Sur le pont de chaque grande jonque est une longue rangée d'appartements habités par plusieurs familles. On calcula que chacun de ces bâtiments ne contenait pas moins de cinquante personnes ; et qu'entre TongChoo-Foo et Tien-Sing, il y avait au moins mille jonques à grain, ce qui faisait 


\section{Voyage dans l'intérieur de la Chine et en Tartarie}

cinquante mille habitants. Une quantité immense d'autres bateaux, de diverse espèce, descendait ou remontait la rivière, ou était à l'ancre devant les villes bâties sur ses bords; et les personnes qui demeuraient dans ces bateaux étaient au moins au nombre de cinquante mille. Ainsi, sur un seul bras d'une rivière, la population de ces habitations mobiles s'élevait à cent mille personnes.

Dans cette peu profonde rivière, la vase ou l'argile délayée, que remuent les grandes jonques, ou qui se détache de ses bords peu solides, ou enfin, qui est entraînée des montagnes éloignées, reste mêlée à son eau en si grande quantité qu'elle en est à peine potable. Mais on l'éclaircit promptement par le procédé, très simple, que voici :

On met un petit morceau d'alun dans le creux d'un bambou, percé de plusieurs trous. Ensuite, on remue pendant trois ou quatre minutes avec ce bambou l'eau qu'on a puisée dans la rivière. Les particules de terre se mêlant avec l'alun sont précipitées au fond du vase, et l'eau qui est au-dessus reste pure et diaphane. Cette méthode n'est point due à la connaissance de l'attraction particulière de différents corps. Elle est à peine connue des chimistes, dans les pays où la théorie de cette attraction est familière. Les hommes qui n'ont qu'une simple pratique se contentent de faire des essais sur les choses dont ils ont besoin. Les nombreux Chinois, vivant sur les rivières, ont cherché jusqu'à ce qu'ils l'aient trouvé, le moyen de rendre l'eau potable. L'eau du Nil est aussi, dit-on, purifiée par l'alun. La même propriété de ce sel a été découverte en Europe par des ouvriers, employés dans différentes manufactures, où le mélange de l'argile et d'autres terres rendait l'eau mauvaise.

A la Chine, les personnes d'un rang élevé sont si difficiles sur la qualité de l'eau qu'elles en boivent rarement sans qu'elle ait été distillée. Tous les autres Chinois font infuser du thé ou quelques autres végétaux salubres dans l'eau dont ils font usage. Ils la prennent ordinairement chaude, ainsi que le vin et tous les autres liquides. L'habitude a tant d'effet sur les sens que, lorsque les liqueurs spiritueuses ou fermentées sont chauffées, cette nation les trouve plus agréables, comme plus salubres. 


\section{Voyage dans l'intérieur de la Chine et en Tartarie}

II est d'autres pays où l'on croit aussi que les breuvages chauds sont plus sains. Dans le chaud climat de l'Indostan, on a bâti le long de quelques grandes routes des choultries, ou des cabarets, comme on bâtit ailleurs des asiles pieux ; et dans ces choultries, tous les voyageurs trouvent des liqueurs faibles, mais chaudes.

Mais quoique les Chinois aiment à boire chaud, ils savent cependant jouir pendant l'été de l'agréable fraîcheur que produit la glace. Ils s'en servent principalement pour leurs fruits et leurs confitures qui, d'après cela, méritent véritablement le nom de rafraîchissements. \# Dans les jattes qui, à la Chine, sont généralement employées au lieu de plats, on sert des morceaux de glace entremêlés avec des amandes d'abricots et des noix, ou des graines et des tranches de la racine chevelue de lien-wha, qui est le nymphoea nelumbo ${ }^{1}$, et probablement le lotus des Égyptiens. On en présenta souvent à l'ambassadeur et à sa suite dans les déjeuners que lui donnèrent les principaux mandarins.

Quoique le thé soit le breuvage général des Chinois, qu'ils le boivent entre les repas et qu'ils en présentent à ceux qui leur rendent visite à toutes les heures du jour, ils aiment aussi beaucoup, et surtout dans les provinces du Nord, les liqueurs fortes, les liqueurs spiritueuses. Lorsqu'à la Chine la société est animée, et que quelque convive veut se retirer, on essaie de l'empêcher de partir, ou de le faire revenir s'il est déjà parti, en faisant usage des mêmes expédients qui ont lieu en Europe dans les parties de plaisir.

Les mandarins se livrent habituellement aux délices de la table. Ils font divers repas par jour avec des viandes fortement assaisonnées, et chaque repas est composé de plusieurs services. Ils emploient une partie de leurs moments de loisir à fumer du tabac mêlé avec des substances odoriférantes, et quelquefois même avec un peu d'opium, ou bien ils mâchent des noix d'arec.

Quoique les livres d'agrément, tels que les histoires, les romans, les pièces de théâtre abondent à la Chine, la lecture n'y est pas devenue un amusement universel, comme dans toutes les contrées polies de l'Europe. Les 


\section{Voyage dans l'intérieur de la Chine et en Tartarie}

jouissances sensuelles et casanières, plutôt que les exercices du corps et les plaisirs de l'âme, semblent être les principales ressources des Chinois pour remplir les heures où ils n'ont point d'occupations sérieuses.

Les deux mandarins Chow-ta-zhin et Van-ta-zhin passaient une grande partie de leur temps à s'entretenir avec l'ambassadeur et les principales personnes de l'ambassade, par le secours des interprètes. A la vérité, ils faisaient bien moins de questions que de réponses. Les Chinois sont, de tous les hommes, les plus curieux à l'égard des étrangers qui paraissent parmi eux, parce qu'on en voit très rarement, excepté à Canton : mais quant au pays d'où sortent ces étrangers, ils sont très indifférents. Ils ont été élevés dans l'habitude de renfermer leurs idées dans leur propre pays, qu'ils appellent emphatiquement le royaume du centre. Nul Chinois ne songe à le quitter, si ce n'est quelque habitant de la côte, qui est sans fortune, ou quelque marin dont la classe est presque séparée du reste de la société. Les marchandises étrangères que consomment les Chinois ne leur rappellent que Canton, d'où ils les reçoivent comme si elles y étaient fabriquées. Les autres pays, hors l'Asie, sont rarement cités dans leurs livres ou marqués sur leurs cartes informes. Ils ont quelques brillantes descriptions de l'Indostan, et un conte rapporté dans l'ouvrage de l'abbé Raynal 2, se trouve aussi dans les écrivains chinois. Ce conte dit que, dans un certain canton de I'Indostan, le gouvernement était si parfait et le peuple si strictement vertueux qu'une bourse ou un joyau perdu sur un grand chemin était placé, par celui qui le trouvait, dans l'endroit le plus remarquable, afin que le voyageur qui l'avait laissé tomber pût le voir plus facilement en revenant le chercher. Certes, les Chinois n'ont point emprunté ce trait de l'auteur français, ni celui-ci ne l'a pris dans leurs livres ; et cette coïncidence semble devoir faire croire que le conte est fondé sur quelque vérité.

II n'est pas douteux que les personnes qui sont employées dans le gouvernement de la Chine doivent avoir connaissance des pays avec lesquels

\footnotetext{
1 Lis aquatique.

2 Histoire de l'Établissement et du Commerce des Européens dans les deux Indes.
} 


\section{Voyage dans l'intérieur de la Chine et en Tartarie}

il a des relations; de même que les marchands connaissent les lieux avec lesquels leur commerce a des rapports. Mais les autres classes de la société n'ont rien qui les intéresse hors de la Chine; et la masse du peuple serait peut-être peu satisfaite d'entendre raconter, à l'égard des pays étrangers, autre chose que des contes merveilleux, qui ne se passent point chez elle, et des faits qui ne sont point dans la nature.

Quant aux deux mandarins qui étaient à la suite de l'ambassade, ils trouvaient du plaisir à répondre, autant qu'ils en étaient capables, à ce qu'on leur demandait sur leur pays. Quoique leur opinion se ressentît de la partialité nationale, ils semblaient s'attacher à être exacts dans les faits qu'ils racontaient. Chow-ta-zhin, surtout, qui était un homme de cabinet, ne donnait en général des renseignements que d'après les documents publics.

Le légat avait rarement des conversations familières avec l'ambassadeur. On ne jugeait même pas convenable de faire, en sa présence, beaucoup de questions sur la Chine. Quoiqu'il fit la route par terre et avec beaucoup de pompe, il rendait chaque jour visite à lord Macartney. Sa marche était précédée par des soldats ou des domestiques qui annonçaient à haute voix son approche, pour qu'on lui laissât le chemin libre. Sa voiture était une de ces chaises à porteur dont nous avons parlé dans un autre endroit : mais elle était plus ornée de glands de soie. Elle était portée par quatre hommes. Des cordes peu tendues étaient attachées aux extrémités des bâtons de la chaise, et on passait, sous le milieu des cordes, un court bambou dont chaque bout était appuyé sur les épaules d'un des porteurs. Ainsi, il y avait deux porteurs devant et deux derrière, et quatre autres marchaient à leur suite, pour les relever. Des domestiques, portant des parasols et d'autres marques d'honneur, accompagnaient la chaise, qui était, en outre, suivie par plusieurs hommes à cheval.

II est très rare qu'un mandarin, d'un rang élevé, voyage ou sorte jamais de sa maison, sans un train convenable à sa dignité. II est si essentiel, pour les hommes revêtus de quelque emploi, de conserver sans cesse les dehors faits pour inspirer du respect au vulgaire, que si on les voyait passer dans la rue, sans leur suite, on regarderait cela comme une sorte de dégradation. Ils sont, en conséquence, soigneux de conserver l'importance de leur rang, et d'exiger du peuple tous les honneurs qui leur appartiennent. Cette habitude 


\section{Voyage dans l'intérieur de la Chine et en Tartarie}

fait qu'ils sont plus attentifs à rendre aux autres ce qu'ils leur doivent, et principalement aux étrangers de distinction reçus parmi eux.

A chaque ville un peu considérable et à chaque poste militaire, situé sur le bord de la rivière, les troupes étaient rangées en ligne jusqu'à ce que les yachts, qui portaient l'ambassade, eussent passé, et on tirait trois coups de canon pour le saluer. Ces canons étaient des espèces de pétards courts, qui ne servent que pour les saluts. On n'y met qu'une petite quantité de poudre. Ensuite, ils sont plantés perpendiculairement dans la terre, et remplis de terre ou de sable. Après que la cérémonie militaire était achevée, les soldats allaient déposer dans le magasin de leur corps de garde leurs armes et leurs uniformes pompeux, jusqu'à ce qu'il se présentât une nouvelle occasion de les reprendre. Dans l'intervalle, ces soldats ne portent rien qui les distingue. Ils ont le vêtement commun du peuple, et sont employés dans les manufactures ou à la culture des terres. De cette manière, ils se rendent certainement plus utiles en temps de paix ; mais aussi ils ont moins ce courage et cette discipline nécessaires pour la guerre. La paie des soldats et ce qu'on leur accorde en outre valent mieux que ce que gagnent les hommes du peuple. Quelque ombre de ce pouvoir qu'ils exercent en corps, sous leurs officiers, les suit encore alors qu'ils ne sont plus sous leurs drapeaux, et enfin un enrôlement est considéré comme une sorte de préférence. Aussi ne faut-il ni force ni stratagème pour recruter les armées chinoises.

Dans les endroits où le grand chemin était rapproché de la rivière, l'ambassade rencontrait chaque jour quelque poste militaire. Ce chemin était bien fait, mais étroit. On y voyait peu de voitures; et il n'y en avait aucune qui eût plus de deux roues, soit celles qui portaient des voyageurs, soit celles qui servaient à charrier des marchandises. Ni les unes ni les autres n'étaient suspendues sur des ressorts. Les hommes au-dessus du commun voyageaient à cheval, dans des chaises à porteurs, ou dans des palanquins; et les dames allaient, pour la plupart, dans des litières bien fermées, et suspendues entre des chevaux ou des mulets. Mais ces voitures n'étaient employées que pour de petits voyages, ou dans les endroits éloignés des rivières et des canaux.

Semedo dit, dans son histoire de la Chine, qu'autrefois les carrosses étaient très en usage dans cet empire, et que c'est de là que la mode en vint 


\section{Voyage dans l'intérieur de la Chine et en Tartarie}

en Italie au seizième siècle ; mais que les Chinois y ont renoncé depuis, parce qu'ils regardent ces voitures comme embarrassantes et dispendieuses.

Quelques anciens voyageurs parlent de la coutume qu'avaient les Chinois d'appliquer l'invention des voiles à leurs chariots. I Is l'ont en partie conservée. Mais apparemment qu'autrefois elle était usitée dans des parties de la Chine moins fertiles que les bords du Pei-Ho, car Milton dit :

Le Sericanien, dans ses stériles plaines,

Imitant avec art les ailes d'un vaisseau,

Court, à l'aide du vent, sur son char de roseau.

Ces chariots de roseau sont de petites charrettes, ou plutôt de doubles brouettes de bambou, qui ont une grande roue entre elles. Quand il n'y a point assez de vent pour faire marcher la charrette, un homme, qui y est véritablement attelé, la tire en avant, tandis qu'un autre la tient en équilibre et la pousse par derrière. Lorsque le vent est favorable, la voile rend inutile le travail de I'homme qui est en avant. Cette voile consiste en une natte attachée à deux bâtons plantés sur les deux côtés de la charrette. Une si simple invention ne peut servir que quand on veut faire aller la charrette vent arrière ; et elle est vraisemblablement due à quelque individu qui ne voulait avoir ni de compagnon de son travail, ni d'associé à ses profits, ou qui ne pouvait pas en trouver. Des machines compliquées et susceptibles d'être appliquées à d'importants objets prennent ordinairement leur origine dans des pays où l'esprit est excité à faire des efforts, et à chercher des inventions par l'espérance du bénéfice qui provient des découvertes pour améliorer la qualité de quelque article de consommation, ou pour le fournir en plus grande quantité et à meilleur marché que par les méthodes déjà connues.

II ne paraissait point qu'il y eût le moindre défaut de construction dans les ponts placés le long du Pei-Ho. A la vérité, il n'y en avait point qui le traversât et qui pût conséquemment gêner la navigation, mais plusieurs, bâtis en pierre de taille, étaient jetés sur divers courants d'eau qui se réunissaient à la rivière, ou sur des canaux auxquels elle fournissait de l'eau. Les restes d'un pont qu'on voyait en un endroit montraient quelle avait été la violence d'un débordement qui en avait emporté une partie. Non loin de ce pont était un palais considérable, entouré d'un jardin et de beaucoup de terrain, planté 


\section{Voyage dans l'intérieur de la Chine et en Tartarie}

pour l'agrément. Le tout était clos d'un mur et avait une triple porte du côté de la rivière. On dit que ce lieu appartenait à l'empereur et était quelquefois habité par une partie de sa famille. On ne voyait point de propriété particulière de pur agrément. Tous les grands édifices étaient, dit-on, destinés a quelque usage public, ou étaient occupés par des personnes revêtues de quelque emploi. S'il était un homme qui eût reçu une grande fortune de ses pères, mais qui n'occupât aucune place dans le gouvernement, certainement il n'en montrait pas plus d'ostentation, et il jouissait de ses richesses dans l'obscurité.

Depuis leur arrivée en Chine, les personnes qui composaient l'ambassade avaient à peine vu un nuage se mouvoir dans les cieux. Elles n'avaient pas non plus aperçu une seule éminence entre eux et l'horizon. Ce ne fut que le quatrième jour après leur départ de Tien-Sing qu'elles distinguèrent de hautes montagnes bleues du côté du nord-ouest. Ces montagnes annonçaient l'approche de Pékin, au-delà duquel elles étaient situées. Deux jours après, le 6 août 1793, les yachts jetèrent l'ancre à deux milles de cette grande capitale, et à un demi-mille de la cité de Tong-Choo-Foo, où le Pei-Ho cesse d'être navigable, si ce n'est pour des canots. L'ambassade interrompit, pour quelque temps, ses voyages par eau. II y a de Tien-Sing à Tong-Choo-Foo environ quatre-vingt-dix milles.

Les premiers compagnons de voyage de l'ambassade, lesquels étaient à bord du Lion et de l'Indostan, ne restèrent pas longtemps dans le golfe de PéChé-Lée. Mais pendant qu'ils étaient à l'ancre, ils déterminèrent les situations suivantes :

Latitude du mouillage

Longitude d'après la montre marine $38^{\circ} 51^{\prime} 1 / 2$ nord

$117^{\circ} 50^{\prime}$ est

Longitude d'après plusieurs observations du soleil et de la lune, faites le 29 juillet 1793 $118^{\circ} 7^{\prime}$

Longitude prise également le 30

$117^{\circ} 58^{\prime}$ 


\section{Voyage dans l'intérieur de la Chine et en Tartarie}

Moyenne proportionnelle des deux jours $118^{\circ} 2^{\prime} 30^{\prime \prime}$

Variation de la boussole, par amplitude,

le 27 juillet

$1^{\circ} 30^{\prime}$ ouest

le 28 juillet

$1^{\circ} 20^{\prime}$

Latitude des îles de sable, qui sont dans le golfe, et que le vieux pilote nomma Sha-Loo-Poo-Tien : $\quad 39^{\circ} 1^{\prime}$ nord

Longitude des mêmes îles, d'après les montres marines : $118^{\circ} 40^{\prime}$ est

Latitude de l'embouchure du Pei-Ho : 39 40' nord

La hauteur des marées au mouillage était d'environ huit à neuf pieds. Elles fluaient et refluaient irrégulièrement, et de tous les points du compas : mais le principal courant de la marée montante partait du sud-est, et celui du reflux, du nord-ouest.

Le 6 août, premier jour de la nouvelle lune, la marée monta à neuf heures quarante minutes du matin. Elle s'éleva à dix pieds. La pleine mer fut à une heure, et elle resta dans cet état jusqu'à quatre heures après-midi. Le vent soufflait alors modérément de l'est. II n'y eut presque pas de différence dans la marée du lendemain. Ces observations furent faites avec exactitude, pour accéder à la demande d'un astronome célèbre, qui souhaitait que ces faits fussent bien déterminés, pour compléter une Théorie des Marées à laquelle il travaillait.

Le 8 août, les vaisseaux mirent à la voile, et le 12 ils passèrent le détroit de Mi-a-Tau. Ils naviguèrent dans le golfe, en compagnie de plusieurs grandes jonques, de différente grandeur. Quelques-unes avaient quatre grands mâts d'une égale hauteur, et dont aucun n'avait des haubans. Ils étaient fixés dans la contre-quille par une forte et massive carlingue, et appuyés par des jambes de force, qui portaient sur les étambrais. Les voiles étaient les unes de natte, les autres de toile de coton. Les câbles et les cordages étaient, pour la plupart, de chanvre, et paraissaient bien travaillés. Les plus petites jonques passèrent seules le détroit de Mi-a-Tau ; les autres prirent leur route par le nord des îles qui portent le même nom. L'expérience leur avait sans doute appris que c'était le meilleur passage. 


\section{Voyage dans l'intérieur de la Chine et en Tartarie}

A Ten-Choo-Foo, sir Erasme Gower éprouva les bons effets des ordres donnés en sa faveur par le vice-roi de Pé-Ché-Lée. On lui fournit des provisions pour tout son équipage. De là, il partit pour aller examiner la baie de Ki-San-Seu, qu'on appelle quelquefois la baie de Zeu-a-Tau, où il arriva le 15 août. II trouva la baie assez bonne dans toutes ses directions pour qu'un vaisseau y pût hiverner avec sécurité. Elle est très vaste. L'eau a de cinq à neuf brasses de profondeur ; le fond est solide et retient bien les ancres.

Cependant l'aiguade et le bois de chauffage étaient éloignés de la baie. La fatigue qu'occasionnait le besoin d'aller chercher ces objets pouvait devenir funeste à l'équipage du Lion, dont le nombre était diminué et la santé affaiblie. La stérilité des campagnes voisines et la pauvreté des habitants firent douter qu'on pût procurer aux malades et aux convalescents de l'escadre les choses nécessaires à leur rétablissement. D'après cela, on résolut de se rendre à Chu-San, où l'on avait à espérer plus de secours. La saison était favorable, le chemin court ; et la première fois qu'on l'avait fait, on avait trouvé qu'en aucun lieu du monde, la mer n'offrait aussi peu de danger que de Chu-San à la rivière de Tien-Sing. 


\section{Voyage dans l'intérieur de la Chine et en Tartarie}

\section{CHAPITRE IV}

\section{L'ambassade débarque près de Tong-Choo-Foo. Elle traverse Pékin pour se rendre dans un palais qui est au-delà. Elle retourne dans la capitale.}

L'ambassade avait, jusqu'alors, suivi sa route vers la capitale de la Chine, sans fatigue et sans embarras. Les voyageurs n'avaient pu qu'être flattés de trouver, dans tous les objets qui s'offraient à eux, une nouveauté agréable aux yeux, ou intéressante pour l'esprit. L'uniformité même du pays qu'ils avaient traversé était un spectacle d'une étendue à laquelle on peut difficilement trouver ailleurs des objets de comparaison. On peut, d'après une théorie agréable et sacrée, considérer cette vaste plaine comme une partie de ce qu'était la terre dans le premier état de sa formation, conservant encore sa surface égale et féconde, tandis que des bouleversements ont répandu sur le reste l'inégalité et la difformité. Mais ceux qui observent attentivement les opérations de la nature voient que cette partie de la Chine n'est qu'une création subséquente à d'autres points du globe plus élevés, et qu'elle ne consiste qu'en terres d'alluvion, entraînées d'abord par les torrents, qui tombent des montagnes voisines, déposées au pied de ces montagnes, et forçant graduellement la mer à se retirer.

Vers l'extrémité occidentale de l'immense plaine, qui probablement a été formée comme nous venons de le dire, est bâti Pékin, capitale de la Chine. II faut traverser cette ville pour se rendre de Tong-Choo-Foo au palais d'automne de l'empereur, appelé Yuen-min-Yuen, c'est-à-dire le jardin de verdure perpétuelle. C'est là qu'il fallait déposer les présents qui ne pouvaient point être transportés sans danger à Zhé-Hol. L'ambassadeur et sa suite devaient demeurer tout près de ce même palais de Yuen-min-Yuen pendant qu'on ferait les préparatifs nécessaires pour leur voyage en Tartarie.

Comme il ne naviguait point, entre Tong-Choo-Foo et Pékin, des bateaux de la grandeur des yachts, dans lesquels l'ambassade avait jusqu'alors voyagé, les personnes qui la composaient débarquèrent près de la première 


\section{Voyage dans l'intérieur de la Chine et en Tartarie}

de ces villes, et furent logées dans un temple, ou monastère, qu'on avait

préparé pour les recevoir. On mit le bagage et les présents dans deux magasins qu'on construisit exprès, avec des bambous très forts et des nattes d'un tissu tellement serré, que la pluie ne les peut pénétrer. Chacun de ces magasins avait plus de deux cents pieds de long. Ils étaient vis-à-vis l'un de l'autre, et entourés de fortes claies où il y avait des portes aux deux extrémités. Des sentinelles étaient placées tout autour, et des écriteaux, attachés à des poteaux, défendaient à toutes personnes d'approcher avec du feu. Ces grands magasins furent construits en peu d'heures. Tous les effets qui appartenaient à l'ambassade, et qui composaient la cargaison de trente bâtiments, furent mis à terre et emmagasinés en un seul jour. A la Chine, les matériaux et les ouvriers sont toujours prêts dès que l'État en a besoin. II y a aussi une activité et une bonne volonté dans l'obéissance, qui prouvent que la récompense est proportionnée au travail.

Le temple où logèrent l'ambassadeur et sa suite avait été fondé, depuis plusieurs siècles, par un riche dévot, qui avait en même temps laissé de quoi suffire à l'entretien de douze prêtres de la religion de Fo, laquelle est la plus généralement répandue à la Chine. Maintenant, cet édifice sert, au besoin, de choultry ou de caravensera, où logent les personnes d'un certain rang, lorsqu'elles voyagent pour le service public. La divinité la plus remarquable de ce temple est une personnification de la Providence, sous la forme d'une femme, tenant dans sa main un plateau rond sur lequel est peint un œil. Cette figure a de la grâce et de la dignité.

M. Hickey, peintre de l'ambassade et cité dans la première partie de cet ouvrage, a fait du monastère et du temple, où l'on voit cette statue, une description que nous allons copier.

Il est situé sur une hauteur dont la pente est assez douce, à environ un demi-mille de la rivière, et près des faubourgs de Tong-Choo-Foo. Tout autour est une autre muraille, où il y a une petite porte en face de la rivière. Lorsque les Anglais y étaient, cette porte était gardée par des soldats chinois, et il y avait à côté une tente où se tenait une bande de musiciens qui jouaient de leurs instruments toutes les fois que l'ambassadeur ou les principales personnes de l'ambassade passaient devant eux. En entrant par la petite porte, on traverse plusieurs cours et plusieurs bâtiments fort bas, et on arrive 


\section{Voyage dans l'intérieur de la Chine et en Tartarie}

aux édifices particulièrement consacrés aux exercices de la religion. Ceux-ci sont séparés des autres par un mur dans lequel on a pratiqué une entrée, qui a la forme exacte d'un cercle, et dont le diamètre est d'environ huit pieds. En dedans de ce mur, on voit deux temples placés vis-à-vis l'un de l'autre, et ayant entre eux une aire spacieuse. Le devant de chacun de ces temples forme un portique, soutenu par des colonnes de bois, peintes en rouge, vernissées, et d'un très petit diamètre proportionnément à leur longueur. Elles diminuent légèrement depuis la base jusqu'au chapiteau, qui n'a guère d'autre ornement que de la dorure. La base repose simplement à terre, comme dans l'ancien ordre dorique. L'intérieur de ces temples est de toute hauteur, et n'a rien qui cache la charpente de la couverture. On remarque dans ces temples plusieurs statues de divinités mâles et femelles. Quelquesunes sont sculptées en bois et peintes de diverse couleur, mais d'un goût moderne et d'un travail médiocre ; d'autres sont de porcelaine.

La suite nombreuse de l'ambassadeur occupa presque tous les logements du monastère. II n'y resta qu'un seul prêtre pour soigner les lampes du temple, et prendre les ordres de son excellence. Les autres moines se retirèrent dans un monastère voisin; mais ils se rendaient dans le temple lorsque les heures de la dévotion les y appelaient. Les appartements qu'ils avaient cédés aux Anglais étaient frais et agréables malgré la chaleur de la saison. A l'extrémité de chaque chambre était une estrade en planches de plus d'un pied de haut, et telle à peu près qu'on en voit dans quelques corps de garde en Europe. Un gros drap de laine, non tissu, mais travaillé comme le feutre dont on fait les chapeaux, était étendu sur l'estrade, et ce drap, avec un oreiller, formait le lit où reposaient les prêtres. Les autres classes de la société, ou du moins les gens du peuple, en Chine, ne couchent guère d'une manière plus molle, et gardent la nuit une grande partie de I'habillement qui les couvre le jour.

Les logements séparés qui appartenaient aux supérieurs du monastère furent occupés par l'ambassadeur et les principales personnes de l'ambassade. Le reste fut mis dans les autres chambres, où la négligence des

prêtres avait laissé s'introduire des scorpions et des scolopendres. Quelques Anglais, qui n'avaient point voyagé dans le midi de l'Europe, ne connaissaient ces nuisibles insectes que par les descriptions qu'ils avaient lues; et quand ils 


\section{Voyage dans l'intérieur de la Chine et en Tartarie}

en virent pour la première fois dans leur chambre à coucher et sur leurs habits, ils en eurent tant d'horreur qu'il semblait qu'il n'en fallait pas davantage pour leur donner mauvaise idée d'un pays qui produisait de pareils animaux. Mais il y avait moins de danger qu'on ne le croyait; car, quoique ces animaux puissent faire beaucoup de mal, ils en font très peu, même dans les pays où ils abondent le plus; et ils n'en firent aucun dans les circonstances dont nous parlons. La brûlante température, favorable à l'existence de ces insectes, était extrêmement incommode. Le thermomètre de Fahrenheit montait à l'ombre à quatre-vingt-six degrés. Cependant les Anglais se dérobaient à l'excès de la chaleur dans les cours qui séparaient les bâtiments autour des temples, et pour cela, ils tendaient horizontalement des toiles d'un toit à l'autre. Des cordes attachées à ces toiles donnaient aux personnes qui étaient dessous la facilité de les mouvoir dans le sens qu'elles jugeaient convenable, pour introduire l'air dans les endroits d'où le soleil se retirait successivement.

Le lendemain de l'arrivée de l'ambassade à Tong-Choo-Foo, tous les Anglais furent invités à un banquet que donnèrent les mandarins. L'heure à laquelle ce banquet eut lieu fit juger que c'était un déjeuner ; mais la quantité de différentes espèces de viande qu'il y avait en faisait un repas très substantiel. Quoique le thé accompagnât chaque service, il n'était considéré que comme un accessoire. On avait placé les tables dans la partie des nouveaux magasins que ne remplissaient pas les présents et le bagage; car aucun autre endroit couvert n'eût été assez grand pour cela. II paraît, d'après cet exemple, que quand les Chinois veulent traiter quelqu'un avec beaucoup de politesse, l'étiquette consiste non seulement à l'inviter lui-même, mais toutes les personnes de sa suite, quelles qu'elles soient. Donner à manger est une partie si essentielle de leur savoir-vivre qu'ils ne la négligèrent point dans cette occasion, bien que l'hospitalité de l'empereur rendît la leur assez inutile.

Les spectateurs étaient en si grand nombre sur le vaste et sablonneux terrain qui s'étend entre le temple et la rivière, qu'on y avait dressé des échoppes où l'on vendait différentes choses, mais principalement des fruits et des liqueurs. Les haltes étaient ombragées par de grandes toiles carrées que soutenait, dans le milieu, une seule perche plantée dans la terre. Le feu où l'on cuisait les viandes était en plein air ; et il y avait des pompes du côté de 


\section{Voyage dans l'intérieur de la Chine et en Tartarie}

la rivière, pour servir en cas d'accident. Ces pompes étaient construites comme celles d'Europe. On dit aussi que c'est à l'Europe que les Chinois en doivent l'invention, et qu'ils les construisent en partie avec des matières que leur fournissent les Européens. Ils ont commencé à faire usage de ces pompes depuis l'incendie qui eût lieu à Canton, dans le temps où l'amiral Anson y était, et où, par le moyen de ces machines, son équipage arrêta si habilement les progrès du feu. D'autres inventions européennes seront vraisemblablement adoptées en Chine, à mesure qu'on aura plus de relations avec cet empire, et la seule importation de ces articles ajoutera beaucoup au commerce de l'Angleterre.

Ni parmi la multitude assemblée près de Tong-Choo-Foo, ni dans la foule que l'approche de l'ambassade avait attirée ailleurs, depuis son entrée en Chine, on ne remarquait pas un seul homme vêtu en mendiant, ou qui parût vouloir demander la charité. Beaucoup de gens, il est vrai, avaient l'air peu aisés; mais aucun n'était réduit à la nécessité, ou nourri dans l'habitude de demander des secours à un étranger. Disons aussi que la saison n'était point celle qui détruit ou diminue les ressources ordinaires des paysans, et les force quelquefois à avoir recours à des excès criminels pour se procurer de quoi subsister. Mais dans ces temps-là, l'empereur est leur appui. II ordonne d'ouvrir des greniers publics; il remet les impôts à ceux qu'accable l'infortune; il leur accorde des secours pour rétablir leurs affaires. II paraît, aux yeux de ses sujets, remplacer, en quelque sorte, la providence, pour veiller en leur faveur. II sait parfaitement combien la chaîne qui maintient ainsi son pouvoir absolu est plus forte que ne le serait la crainte du châtiment. II est même si jaloux du privilège exclusif d'exercer la bienfaisance envers son peuple, que quelques riches marchands lui ayant une fois proposé de venir au secours d'une province malheureuse, non seulement il rejeta cette offre, mais il en fut très offensé. En même temps, il accepta les dons d'une veuve opulente de la province de Tien-Sing, pour contribuer aux frais de la guerre du Thibet. Mais indépendamment des maux généraux que tout gouvernement sage est attentif à prévenir ou à soulager, des accidents particuliers et le défaut de moyens de subsister sont cause que, dans la plupart des autres pays, on est, en tout temps, affligé par le spectacle d'êtres 


\section{Voyage dans l'intérieur de la Chine et en Tartarie}

humains, dont l'existence dépend des secours précaires de ceux qui ont de quoi secourir l'infortune, quoiqu'ils puissent y être exposés à leur tour.

L'ambassadeur avait, de temps en temps, donné des gratifications aux équipages des yachts et aux autres Chinois employés pour l'ambassade; mais ces largesses n'étaient jamais demandées, et elles étaient faites à l'insu des mandarins. Comme ces mandarins avaient déjà insisté pour mettre sur le compte de l'empereur quelques bagatelles qu'ils avaient achetées pour une ou deux personnes de l'ambassade, quelques Anglais allèrent eux-mêmes dans la ville voisine pour faire des petites emplettes. D'ailleurs, leur curiosité était un motif suffisant pour leur faire prendre ce parti. Des mandarins prirent alors la peine de les accompagner. Van-ta-zhin, surtout, qui était né à Tong-ChooFoo, voulut leur en faire les honneurs. II les fit passer par un grand faubourg qui montre l'accroissement de cette ville depuis la construction des murailles qui entourent ses premiers bâtiments. Ces murailles sont solidement bâties en briques, et plus hautes que les maisons qu'elles renferment, et qu'on a, pour la plupart, construites de bois. La rivière les baigne d'un côté, et ailleurs elles sont défendues par un fossé très large. Les voyageurs ne virent point de canons sur les remparts; mais il y avait quelques mousquets debout auprès des portes. Les principales rues étaient droites, pavées avec de grandes pierres carrées, et avaient des trottoirs de chaque côté. Un tendelet traversait les rues et les abritait contre les rayons d'un soleil brûlant. Beaucoup d'hommes du peuple étaient nus depuis la ceinture en haut. Plusieurs grands magasins contenaient différentes sortes de grains, dont on dit qu'une provision pour plusieurs années est toujours en réserve, pour l'approvisionnement de la capitale. La plupart des maisons avaient des boutiques sur la rue, les unes remplies de marchandises, les autres occupées par des gens de métier ; et, de tous côtés, on déployait une industrie qu'excitait, sans doute, le voisinage de Pékin ; le dehors des boutiques était peint de couleurs très variées et très agréables. Il y avait aussi de la dorure et de riches enseignes avec des écriteaux pour attirer les chalands. Les principales marchandises exposées en vente étaient du thé, des soieries, de la porcelaine venant du midi de la Chine, et des fourrures de différente espèce, dont la plus grande partie est tirée de la Tartarie. Les voyageurs remarquèrent avec plaisir parmi 


\section{Voyage dans l'intérieur de la Chine et en Tartarie}

ces marchandises des draps d'Angleterre; mais il n'y en avait qu'en petite quantité.

L'aspect des Anglais interrompit, pour quelque temps, les occupations du peuple. D'autres Européens, qui pour la plupart étaient des missionnaires, avaient traversé cette ville; mais pour éviter de se faire remarquer, ils s'étaient vêtus de longues robes à la mode du pays, et avaient laissé croître leur barbe comme les Chinois. Les habits courts, les visages rasés de nos voyageurs, formaient un nouveau spectacle. Cependant, celui qui excita le plus de surprise fut un nègre qui servait une des principales personnes de l'ambassade. Il avait été pris à Batavia pour remplacer un domestique qu'on avait renvoyé en Europe. Sa peau, couleurs de jais, sa tête laineuse, les traits particuliers à son espèce, étaient absolument nouveaux pour cette partie de la Chine. On ne se rappelait pas d'y avoir vu rien de semblable. Quelques-uns des spectateurs doutaient qu'un tel être appartînt à la race humaine, et les enfants criaient que c'était un diable noir, fan-quée. Mais son air de bonne humeur les réconcilia bientôt avec sa figure ; et ils continuèrent à le regarder sans crainte et sans déplaisir.

En parcourant les rues, les voyageurs remarquèrent en plusieurs endroits le dessin d'une éclipse de lune qui devait avoir lieu sous peu de temps. Dans ce climat où l'air est pur, et dont les hommes de tout état se tenant presque toujours hors de leurs maisons sont portés à observer ce qui se passe dans les cieux, et s'accoutument aisément à le lier avec les événements terrestres, comme si ces événements en dépendaient, quelques rapports accidentels ont servi à fortifier ces idées, et la vanité de prédire contribue aussi beaucoup à créer la prétendue science de l'astrologie. Les éclipses étant en particulier considérées comme faites pour influer sur les opérations de la nature, et sur les destinées des hommes, les époques où elles ont lieu sont nécessairement devenues un objet d'attention et d'inquiétude. Le gouvernement chinois, toujours attentif à fonder son autorité sur l'opinion que le peuple a de sa sagesse supérieure et de ses soins constants pour maintenir la tranquillité et le bonheur de l'empire, a profité du préjugé sur les éclipses, en se réservant exclusivement la faculté de communiquer au peuple tout ce que la science et les observations astronomiques peuvent apprendre à cet égard. Cette communication se fait ensuite, comme dans l'occasion dont nous venons de 


\section{Voyage dans l'intérieur de la Chine et en Tartarie}

parler, au moment le plus propice et avec une solennité qui accroît encore la vénération du peuple pour ce prévoyant pouvoir dont il reçoit des instructions si intéressantes.

Quant aux éclipses de soleil, il est aisé de concevoir combien la disparition de cet astre au milieu de sa brillante carrière, et les ténèbres soudaines au milieu desquelles il semble que la nature va s'anéantir, doivent paraître terribles à ceux qui ignorent les causes d'un pareil événement, et la brièveté de sa durée. Dès les temps les plus reculés, les habitants de la Chine ont cru que les éclipses de soleil présageaient quelque grande calamité ; et comme on prend beaucoup de peine pour leur persuader que leur prospérité est due à la sagesse et aux vertus de leur souverain, ils croient aussi qu'il y a de sa faute s'il paraît dans les cieux quelque augure funeste. L'empereur a la prudence de régler sa conduite d'après cet incommode préjugé. II n'entreprend jamais rien d'important à l'approche d'une éclipse de soleil. II affecte, au contraire, de se retirer loin de la présence de ses courtisans, et d'examiner avec soin l'administration de l'empire, afin de corriger les erreurs qui peuvent avoir été commises, et pour lesquelles l'éclipse semble avoir été envoyée. II invite en même temps ses sujets à lui dire librement leur avis.

Quelques-uns des mandarins, qui accompagnèrent les Anglais à TongChoo-Foo, connaissaient fort bien la véritable cause des éclipses. Ils savaient aussi qu'il y avait à la cour de Pékin des Européens employés à les calculer ; mais ils croyaient que les Chinois étaient en état de les prédire avec assez d'exactitude. Leur conversation n'apprit pourtant point par quels moyens ils faisaient cette prédiction. Il y a, parmi les Chinois, d'attentifs, de patients observateurs: mais ils ne possèdent pas assez la science du calcul pour parvenir à la solution d'un problème compliqué. Les premières opérations de l'arithmétique ne sont pas généralement connues du peuple. Dans les boutiques où les Anglais achetèrent quelques marchandises, on enregistrait régulièrement les articles vendus, et les divers prix étaient marqués en caractères communs, équivalant aux mots qui expriment les nombres dans les autres langues. Mais cet état n'offrait point une suite de figures distinctes qui pussent s'appliquer aux opérations ordinaires de l'arithmétique, d'après des principes semblables à ceux que les Européens emploient pour les chiffres arabes, et qui leur donnent toujours sur la même ligne, et à mesure qu'ils 


\section{Voyage dans l'intérieur de la Chine et en Tartarie}

sont plus à gauche, une valeur décuple. Les Chinois font leurs calculs par le moyen d'une machine appelée swan-pan, dans laquelle des boules sont enfilées avec des fils d'archal sur différentes colonnes, et arrangées dans le système des chiffres arabes. Les boules représentant les unités sont sur la première colonne à droite, avec une progression décuple pour les autres colonnes de droite à gauche.

La multiplication décimale et la subdivision des quantités et des mesures, dont les Chinois font usage à chaque instant, simplifient beaucoup leurs calculs. Ainsi, par exemple, un leang, qui équivaut à une once d'argent, est divisé en dix chen, le chen en dix fen, et le fen en dix lées. Les subdivisions idéales de l'argent vont beaucoup plus loin, mais toujours, ainsi que les quantités croissantes, dans les mêmes proportions décimales. Un lée, qui fait la millième partie d'un leang, est une monnaie de cuivre dans laquelle il y a beaucoup d'alliage. Elle est de forme circulaire et a, dans le milieu, un trou carré, pour qu'on puisse l'enfiler avec une ficelle; et, par ce moyen, des dizaines simples et multipliées de cette monnaie ont cours. Souvent, on en donne aussi un plus petit nombre sans être enfilé.

Une monnaie d'une si petite valeur convient parfaitement à la dernière classe du peuple, qui s'en sert pour acheter une petite quantité de marchandises, suivant son plaisir ou ses besoins. D'ailleurs, sans ce moyen d'échange, on pourrait quelquefois demander un plus haut prix des objets qu'on vendrait. A la Chine, le thé est comme la bière en Angleterre, vendu dans des tavernes, soit dans les villes, soit sur la grande route, et sur le bord des rivières et des canaux. On ne paie une tasse de thé qu'un lée, et on voit assez ordinairement un voyageur, chargé et fatigué, poser un moment son fardeau, se rafraîchir avec une tasse de thé, et poursuivre ensuite sa route.

Ces lées, appelés collectivement chen, sont, dans le fait, la seule monnaie empreinte qui circule en Chine. Le gouvernement $a$, sans doute, considéré qu'une seule espèce de monnaie peut strictement servir de règle pour tous les prix, car la valeur relative de deux ou de plusieurs métaux pris séparément est sujette à varier, suivant le plus ou moins de la demande qu'éprouvent ces métaux, lorsqu'on veut les employer à d'autres usages qu'à des moyens d'échange, et suivant la quantité qu'on en expose en vente ; de sorte que la monnaie d'un métal devient intrinsèquement plus ou moins précieuse que 


\section{Voyage dans l'intérieur de la Chine et en Tartarie}

celle d'un autre métal, quoique l'empreinte qu'elles portent leur ait originairement donné une égalité relative.

Parmi les Chinois, l'argent est proprement une marchandise. II n'y en a point de monnayé. Les paiements s'y font en lingots, dans la forme qu'ils ont en sortant du creuset où ils ont été affinés, et avec un simple caractère qu'on y empreint pour attester leur poids, qui est communément de dix onces.

La valeur de l'argent varie suivant la plus ou moins grande quantité de ce métal, sortie du trésor impérial. Les piastres d'Espagne sont communes dans toute I'Asie. On a vu, dans la première partie de cet ouvrage, qu'elles étaient connues du pilote de la Cochinchine. Les marchands de Tong-Choo-Foo les connaissaient aussi très bien. L'or est rarement employé dans les relations commerciales : mais on en fait usage pour les objets de parure et pour les meubles. En général, la valeur de l'argent, à la Chine, a été proportionnément plus forte que celle de l'or, excepté lorsque par des demandes extraordinaires, les marchands étrangers en ont fait hausser le prix. La même chose a eu lieu quand l'empereur actuel a employé une grande quantité d'or à décorer les temples du Lama, en Chine et en Tartarie.

A la mort d'un souverain de la Chine, la monnaie qui porte son nom est en quelque sorte dépréciée. La matière qui la compose est d'un si bas aloi qu'on en peut faire fort peu d'usage, et l'ancienne monnaie est commune dans le pays. Quelques Chinois curieux ont des collections de monnaies ; mais il n'y en a aucune assez précieuse pour que des artistes soient tentés de la contrefaire. La série de ces monnaies, correspondant aux souverains dont les annales de l'empire font mention, peut être considérée comme une confirmation de I'histoire de la Chine. Une pareille série a été apportée en Europe ; et quoique incomplète, elle remonte bien au-delà de l'ère chrétienne.

Les histoires de la Chine rapportent, et la tradition confirme, le penchant naturel des empereurs à transmettre à la postérité leur nom et leur gloire par les monuments les plus durables. Mais une politique cruelle a engagé chaque dynastie, au moment où elle est montée sur le trône, non seulement à exterminer les restes de la race de ses prédécesseurs, mais à détruire tous les monuments qui pouvaient rappeler leur mémoire. C'est pourquoi les 


\section{Voyage dans l'intérieur de la Chine et en Tartarie}

édifices qu'on a laissé subsister ne portent aucune trace des souverains qui les ont érigés. Un de ces édifices, qui a l'air très antique, est dans un coin reculé de Tong-Choo-Foo, et semble n'avoir aucune espèce de rapport avec le reste de la ville, dont sa situation l'empêche d'être un ornement. II y est même de si peu d'utilité qu'on ne sait pas avec certitude quelle fut sa destination première. Construit en brique, il ressemble extérieurement à ce qu'on appelle en Europe des pagodes chinoises, et qu'on croit être des lieux consacrés à des exercices religieux. Mais quoique très vaste et parfaitement solide dans le premier et le second étage, l'édifice de Tong-Choo-Foo ne peut pas avoir eu une telle destination. On ne voit, dans ces deux premiers étages, ni porte ni fenêtre. II n'y reste aucun vestige d'escalier, ni aucun autre moyen de monter au troisième étage, où il y a une porte. Les étages, au nombre de onze, sont distingués par une espèce de corniche, ou un rang de briques saillantes qui règne tout autour de l'édifice; et ils sont bien conservés quoiqu'en partie couverts d'herbe et de mousse. On pense, avec assez de vraisemblance, que ce bâtiment fut construit avant la fondation de TongChoo-Foo, même avant qu'on élevât la grande muraille de la Chine, et qu'il était destiné à servir pour une vigie, afin de se tenir en garde contre l'approche soudaine du Tartare ennemi.

On voit à la Chine plusieurs sortes de ces édifices élevés et circulaires, que les Européens nomment pagodes; ils y sont employés à différents usages, mais jamais à aucun culte religieux. Les temples chinois ne sont guère plus hauts que les maisons ordinaires. On en a un exemple dans celui où logea l'ambassade à son passage à Tong-Choo-Foo. La présence des étrangers n'empêchait pas qu'il n'y eût une affluence de dévots. L'interprète chinois qui était zélé chrétien, et même prêtre de l'Église catholique, voyait avec regret les Anglais examiner curieusement les images, et assister aux cérémonies de la religion de Fo ; car il craignait qu'ils ne fussent frappés de la ressemblance qu'il y a entre les formes extérieures de cette religion et celles de l'église romaine.

Cette ressemblance est telle que quelques missionnaires ont conjecturé que les nestoriens avaient autrefois porté en Chine, par la voie de la Tartarie, quelques lueurs du christianisme. D'autres se sont imaginés que l'apôtre Thomas y était allé. Mais le missionnaire Premore pensait, en considérant les 


\section{Voyage dans l'intérieur de la Chine et en Tartarie}

pratiques des sectaires de Fo, que c'était un tour que le diable avait voulu jouer aux jésuites. L'un d'eux observe que la plupart des cérémonies des prêtres de Fo ont tant d'analogie avec celles des catholiques romains, qu'un Chinois qui entrerait dans une église de ces derniers pourrait croire qu'on y adore les divinités de son pays. Sur l'autel d'un temple chinois, on voit souvent, derrière un écran, une statue qui ressemble à celle de la vierge Marie ; on la nomme Shin-Moo, c'est-à-dire la mère sacrée ; elle est assise dans une alcôve, et tient un enfant dans ses bras ; une auréole, qu'on appelle le cercle de gloire, est autour de sa tête, et des cierges brûlent sans cesse devant elle. Les longues et grossières robes des Ho-chaungs, ou prêtres de Fo, et leur ceinture de corde, les font ressembler aux moines de l'ordre de Saint-François. Ils vivent, comme ces derniers, en célibataires, demeurent ensemble dans des couvents, et s'imposent quelquefois des pénitences volontaires et une rigoureuse abstinence.

Les temples de Fo renferment encore plus d'images que les églises chrétiennes; et la plupart ont plus d'analogie avec la religion des anciens Romains qu'avec celle des nouveaux. On y voit une figure de femme qui a beaucoup de rapport avec celle de Lucine; et c'est elle qu'invoquent les jeunes filles qui veulent avoir un époux, et les jeunes femmes qui n'ont point d'enfants. La doctrine de Fo admettant une divinité subordonnée pour chaque genre de vœux que l'esprit humain puisse former, n'a pu manquer de trouver beaucoup de prosélytes parmi les classes du peuple, qui ne sont point contentes du sort que leur promettent les causes et les événements naturels. Le gouvernement ne s'oppose point aux progrès de cette secte, et ne se mêle jamais des opinions particulières. Il ne défend que les croyances qu'il croit pouvoir troubler la tranquillité de l'Etat.

II n'y a point en Chine de religion dominante. Les prêtres d'aucun culte ne sont payés, préférés, ni encouragés par l'État. L'empereur professe une religion ; plusieurs mandarins en ont une autre ; la majorité du peuple en suit une troisième, qui est celle de Fo. Ces hommes, qui sont les plus ignorants, conséquemment les moins capables d'expliquer les phénomènes de la nature, et qui d'ailleurs se trouvent exposés à beaucoup de besoins qu'ils sont hors d'état de satisfaire par des moyens naturels, aiment à supposer un pouvoir 


\section{Voyage dans l'intérieur de la Chine et en Tartarie}

extraordinaire qui opère les choses qu'ils ne peuvent comprendre, et exauce des vœux qui, sans lui, resteraient sans effet.

Nul peuple n'est plus superstitieux que le commun des Chinois. Non seulement des offices habituels attirent dans les temples les prêtres et les femmes, mais tous les disciples de Fo s'y rendent lorsqu'ils sont à la veille de se marier, d'entreprendre un voyage, ou de conclure quelque autre affaire importante. Ils croient qu'alors il est nécessaire pour eux de consulter la divinité tutélaire ; et ils s'y prennent de différentes manières. Quelques-uns mettent, dans le creux d'un bambou, plusieurs petits bâtons consacrés, qui sont marqués et numérotés. Le consultant, à genoux devant l'autel, secoue le bambou jusqu'à ce qu'un des bâtons tombe à terre. On en examine la marque ; et celle qui y correspond dans un livre, que le prêtre tient ouvert, répond à la question qu'on a faite. Quelquefois, les réponses se trouvent écrites sur une feuille de papier collée dans l'intérieur du temple. D'autres jettent en l'air un polygone de bois, dont chaque face a sa marque particulière ; et quand il tombe, la marque qui se trouve en haut est celle qui indique la réponse du livre du destin. Si cette réponse est favorable, celui qu'elle concerne se prosterne avec gratitude, et entreprend avec confiance l'affaire qui l'intéresse. Mais si la réponse est contraire, il jette une seconde fois le bois en l'air. II le jette même, s'il le faut, une troisième, et c'est celle qui décide irrévocablement ce qu'il doit faire. Du reste, le peuple paraît avoir fort peu de considération pour les prêtres. Les temples sont toujours ouverts pour ceux qui désirent d'interroger le sort. Ils le remercient quand ses décrets sont propices à leurs vœux ; mais ils jettent les bâtons consacrés pour savoir ce qu'ils doivent penser de l'avenir, plus souvent qu'ils ne prient pour se rendre le destin favorable, et leur culte consiste plus en actions de grâces qu'en invocations.

Peu de Chinois, dit-on, portent leurs vœux sur d'autres objets que ceux qui ont rapport aux avantages de cette vie. Cependant la religion de Fo professe la doctrine de la transmigration des âmes, et promet le bonheur à des conditions qui, sans doute, se bornaient, dans l'origine, à la pratique des vertus morales, mais qui, depuis, ont été remplacées par des contributions pour l'édification ou la réparation des temples, et l'entretien des prêtres, et par une attention stricte à des règles particulières. Ceux qui négligeront de 


\section{Voyage dans l'intérieur de la Chine et en Tartarie}

remplir ce devoir, disent les prêtres, en seront cruellement punis. Leurs âmes passeront dans le corps des plus vils animaux, et les souffrances qu'elles éprouveront seront proportionnées aux fautes qu'elles auront commises, sous une forme humaine.

Tandis que les Anglais observaient quelques-unes des coutumes religieuses des Chinois, un événement donna occasion à ces derniers d'observer une cérémonie religieuse des Anglais, en voyant les funérailles d'un des leurs, lequel mourut dans le court séjour que l'ambassade fit à TongChoo-Foo. C'était un ingénieux et habile ouvrier en cuivre et en autres métaux. Sorti de Birmingham pour s'établir à Londres, il y vivait honnêtement de son travail lorsqu'il entendit parler de l'expédition qu'on préparait pour la Chine. Il avait appris qu'à Pékin, on avait fait, dans les arts, plusieurs découvertes avantageuses qui n'étaient point connues en Europe; et entre autres celle de faire une espèce de clinquant, qui ne se ternissait pas, ou qui, du moins, durait beaucoup plus longtemps que celui qui était fait suivant les méthodes européennes. Il imagina que s'il parvenait à connaître les procédés des Chinois, il se mettrait en état d'assurer une fortune à sa famille. II ne devait pas espérer de jouir longtemps lui-même du bénéfice que lui procureraient les secrets qu'il découvrirait, car il était d'un âge avancé, d'un tempérament faible et sujet à beaucoup de maladies. Mais il crut que ce ne serait pas trop que d'abréger sa propre vie dans un périlleux voyage, s'il pouvait communiquer à ses enfants des moyens de prospérer.

Pendant le séjour que l'ambassade fit à Madère, lord Macartney voyant que la santé de cet homme avait décliné dans la traversée, le pressa de s'en retourner à Londres. Mais il était affermi dans sa résolution. II continua le voyage, et quoiqu'il fût attaqué de la maladie épidémique qui emporta rapidement plusieurs Anglais jeunes et robustes, il arriva jusqu'à une journée de la capitale, où il se flattait d'obtenir ce qu'il désirait. Mais son tempérament affaibli par la maladie et par la fatigue ne put y résister plus longtemps et il périt, victime de l'affection qu'il portait à ses enfants. C'était un homme probe, d'un caractère tranquille et modeste, et ayant des mœurs très décentes. Aussi fut-il regretté de ses compagnons de voyage de tous les rangs ; et son humble état ne l'empêchera pas d'être cité dans la relation de l'ambassade à laquelle il était attaché. II se nommait Eades. Ses funérailles 


\section{Voyage dans l'intérieur de la Chine et en Tartarie}

furent accompagnées par le plus grand nombre de ses compatriotes qui étaient à Tong-Choo-Foo, et par une foule immense de Chinois. Tout ce qui se pratique dans les enterrements, en Angleterre, fut observé, et la cérémonie se fit avec beaucoup de gravité et de décence, non seulement par respect pour la mémoire du mort, mais par rapport aux Chinois, qui considèrent la moindre légèreté, la moindre inattention, dans ces occasions solennelles, comme une marque de barbarie et d'inhumanité.

Cet Anglais fut enterré au milieu de plusieurs tombeaux chinois entremêlés de cyprès. Le lieu était loin de toute espèce de temple, mais près du grand chemin qui sort de Tong-Choo-Foo. Les cimetières des Chinois ne sont sanctifiés que par la vénération de ceux dont les cendres des pères y reposent. Le peuple conserve ces asiles sacrés avec tout le soin possible. On les visite chaque année pour réparer les brèches, que quelque accident peut y avoir occasionnées, et pour en ôter les herbes qui y ont crû, ou la boue qu'il peut y avoir à l'entour. Les Chinois préfèrent toujours, pour placer leurs cimetières, les endroits où la terre n'est pas propre à la culture, parce qu'alors ces lieux doivent naturellement rester plus tranquilles : cependant, le plus pauvre paysan ne touche point à l'endroit où un peu de terre assemblée annonce que les restes de quelqu'un y reposent, et cet humble monument est respecté jusqu'à ce que le temps et les effets graduels de l'air l'aient mis entièrement de niveau avec le sol qui l'environne.

La campagne qui est autour de Tong-Choo-Foo est plane et fertile jusqu'à plusieurs milles de distance. On fournit à quelques Anglais le moyen de se promener à cheval. Les chevaux de cette partie du pays sont forts et ont les os gros. II paraît qu'on ne prend aucun soin pour en perfectionner la race. Les mulets se vendent plus cher que les chevaux, parce qu'on les nourrit plus facilement, et qu'on peut les faire travailler davantage. Beaucoup de chevaux ont la peau tachetée avec la même régularité que celle des léopards; et cela est même si commun qu'il n'est pas possible de soupçonner qu'on emploie de la fraude pour les faire paraître de cette couleur. Mais on dit que pour avoir des chevaux ainsi marquetés, on se sert, entre autres moyens, de celui de croiser ceux qui sont de couleur opposée. La selle et le reste des harnais des 


\section{Voyage dans l'intérieur de la Chine et en Tartarie}

chevaux chinois sont, pour l'élégance, aussi loin de ceux qu'on fait en Angleterre, que les chevaux eux-mêmes le sont des coursiers arabes.

Les Anglais rencontrèrent plusieurs cavaliers chinois qui, à leur approche, mettaient pied à terre par civilité. C'est, à la Chine, une marque de respect dont un homme ne s'abstient jamais envers ses supérieurs; et la coutume s'en est étendue dans les autres parties de l'Orient. Le gouverneur et les conseillers de Batavia ne manquent point d'exiger un pareil hommage de toutes les personnes qui résident dans la colonie. A la Cochinchine, à Java, à Sumatra, les Anglais remarquèrent, en beaucoup de circonstances, que la Chine donnait le ton aux pays situés dans les environs des mers chinoises. La couleur jaune que porte l'empereur de la Chine est affectée par tous les souverains de l'orient de l'Asie.

On voit quelquefois à la Chine un mélange de coutumes orientales et occidentales. Dans les environs de Tong-Choo-Foo, la saison de la moisson donna aux Anglais occasion d'observer qu'on battait quelquefois le blé avec des fléaux pareils à ceux d'Europe, et que quelquefois on le faisait fouler sous les pieds des chevaux, suivant la manière décrite par les auteurs orientaux. Les Chinois se servent aussi d'un grand rouleau pour séparer le grain de l'épi, et ils emploient ces différents moyens sur des aires élevées, et construites avec de la terre et du sable. Ils ont toujours vanné le blé avec une machine parfaitement semblable à celle qui a été introduite en Europe depuis le commencement de ce siècle. L'invention en est vraisemblablement due à la Chine.

Dans les campagnes que les Anglais parcoururent, la récolte d'automne consiste principalement en maïs et en millet. II y a peu d'enclos, et peu de bétail qui rende les enclos nécessaires; à peine y voit-on quelques pâturages. Les animaux pour le labourage et les charrois, ainsi que ceux qu'on destine à être mangés, sont pour la plupart dans des étables, et l'on ramasse du fourrage pour les nourrir. Des fèves et la paille la plus fine qu'on hache très menue composent la principale partie de la nourriture des chevaux. On laisse souvent pourrir sur la terre les racines du blé et les plus grosses tiges des autres plantes, afin qu'elles servent d'engrais. 


\section{Voyage dans l'intérieur de la Chine et en Tartarie}

Les habitations des paysans sont éparses, au lieu d'être réunies en villages. Les cabanes sont propres et commodes. On n'y voit ni claies, ni portes, ni aucune autre précaution contre les bêtes sauvages et les voleurs. II est vrai que le vol ne s'y commet que très rarement. On ne l'y punit pourtant pas de mort, à moins qu'il ne soit accompagné de quelque dangereuse violence. Les femmes des paysans chinois sont d'un grand secours dans leur famille. Non seulement elles élèvent leurs enfants et ont tous les soins du ménage, mais elles font la plupart des travaux dont on peut s'occuper dans les maisons. Elles élèvent des vers à soie ; elles filent du coton qui, parmi les gens du peuple, est d'un usage général pour les personnes des deux sexes. Enfin, elles font leurs étoffes ; car les femmes sont les seuls tisserands de l'empire. Cependant, la plupart de ces femmes ne manquent pas de nuire à leur santé, ou au moins de s'ôter une partie de leur force, en voulant, à l'imitation des femmes de qualité, sacrifier au préjugé qui fait estimer les petits pieds. Quoique l'opération qu'elles subissent à cet égard ne commence sitôt, ni ne soit suivie avec tant de soin que celle des dames pour qui la beauté doit être un objet plus précieux, elle suffit pour les estropier et les défigurer.

Malgré toute l'utilité dont les paysannes sont dans leur ménage, les maris s'arrogent un empire extraordinaire sur elles, et les tiennent à une si grande distance, qu'ils ne leur permettent pas toujours de s'asseoir à leur table, mais se font servir par elles. Cet empire est, à la vérité, tempéré par les maximes d'une conduite douce envers tous ceux avec qui on a le plus de rapports, maximes qui sont de bonne heure inculquées dans l'esprit des enfants des dernières comme des premières classes de la société. Les hommes avancés en âge vivent au milieu des jeunes gens de leur famille. Ils modèrent, dans l'occasion, leur impétuosité et leur violence. L'influence de l'âge sur la jeunesse est maintenue par les sentiments de la nature, par l'habitude de l'obéissance, par les préceptes d'une morale, d'accord avec les lois du pays, et par les soins continuels et l'art louable qu'emploient les parents à cet effet.

Les vieillards qui n'ont plus la force de travailler communiquent à ceux de leurs descendants qui sont déjà dans l'âge viril, ou au moment d'y entrer, les règles qu'on leur a enseignées dans leur jeunesse et la sagesse qu'ils doivent à l'expérience. Des sentences d'une morale simple sont écrites dans la 


\section{Voyage dans l'intérieur de la Chine et en Tartarie}

chambre où se rassemblent tous les mâles de la famille; et il y a toujours quelqu'un en état de les lire aux autres. Dans chaque maison, on voit un tableau contenant le nom de tous les ancêtres des personnes qui y demeurent. Leurs actions sont souvent rappelées dans la conversation; et leur bon exemple sert à exciter les autres à marcher dans le même sentier. Les descendants d'une même race visitent ensemble, à des temps marqués, les tombeaux de leurs pères. Ce soin commun et d'autres circonstances rapprochent, unissent les parents les plus éloignés. Ils ne peuvent se perdre de vue, et rarement ils cessent de prendre un intérêt réciproque à ce qui les touche. Le fils est obligé de travailler pour l'entretien et le soulagement de son père et de sa mère ; le frère doit prendre soin de son frère et de sa sœur lorsqu'ils sont dans l'infortune; et l'oubli de ces devoirs exciterait une telle horreur qu'on n'a pas besoin de les prescrire par une loi positive. Tout homme réduit à l'indigence, par maladie ou par quelque autre accident, a droit d'avoir recours à ses parents, même les plus éloignés. Les mœurs, bien plus fortes que les lois, et une affection produite et nourrie par une intimité continuelle, assurent des secours à celui qui en a besoin. Ces mœurs, ces coutumes expliquent clairement un fait dont nous avons déjà fait mention, et qui malheureusement paraît extraordinaire aux Européens ; c'est qu'à la Chine, on ne voit jamais des malheureux chercher à exciter la compassion, ou implorer la charité des passants. II faut ajouter que cet avantage n'est point dû au nombre d'institutions publiques de bienfaisance. II ne se réalise point, à la Chine, le vœu de ce monarque persan, qui désirait qu'aucun infortuné ne manquât de trouver du secours dans les hôpitaux. Mais ces établissements sont peu nécessaires dans un pays où la chaîne qui unit les rejetons d'une famille fait que si l'un d'entre eux éprouve des besoins, tous les autres l'aident sans délai et sans lui faire éprouver la moindre humiliation.

Cependant, il arrive rarement que les infirmités des hommes ou la faiblesse des enfants les rendent totalement incapables de payer, par quelque travail, la subsistance qu'ils reçoivent. Dans les manufactures établies dans les maisons, il faut souvent peu de force pour exécuter des choses très essentielles, et dans la campagne, le sol est léger et la culture facile. Dans le voisinage de Tong-Choo-Foo, on laboure avec des bœufs, car il y fait trop froid pour les buffles, mais cette dernière espèce d'animaux est préférée 


\section{Voyage dans l'intérieur de la Chine et en Tartarie}

toutes les fois qu'on peut l'élever. On attèle les bœufs par le cou, et non par les cornes, comme dans le continent de l'Europe.

Plusieurs hommes de Tong-Choo-Foo furent employés à conduire les présents et le bagage de l'ambassade à Hoong-Ya-Yuen, lieu situé au-delà de Pékin, près du palais d'automne de l'empereur. Comme ces objets avaient été jusqu'alors transportés par mer, ou sur la rivière, on n'avait pas fait beaucoup d'attention au poids, mais il fallut enfin les faire charrier par des animaux, ou par des hommes : on ne pouvait, surtout, confier qu'à des hommes ceux des présents qui courraient risque d'être endommagés par le dur mouvement des voitures sans ressorts. Quelques Anglais avaient, en préparant leurs équipages, moins considéré la route qu'ils devaient faire par terre, que celles qu'ils feraient d'abord par mer. En se disposant à se rendre dans un pays lointain, où ils n'étaient jamais allés, ils se pourvurent inutilement de quelques objets qu'ils devaient y trouver, et d'autres dont ils prévoyaient la possibilité de se servir, mais dont ils ne se servirent jamais.

Après avoir fait le calcul des moyens nécessaires au charroi des présents et du bagage, les mandarins furent obligés de commander environ quatrevingt-dix petits chariots, quarante-quatre brouettes, plus de deux cents chevaux, et près de trois mille hommes; observons, en outre, que rien de tout cela ne devait servir ni pour les mandarins eux-mêmes, ni pour les gens de leur suite.

Les plus gros, les plus pesants fardeaux étaient portés par des hommes qui s'arrangeaient de la manière suivante: de chaque côté du fardeau était attaché un long et fort bambou, et si deux hommes ne suffisaient pas pour chaque bambou, on mettait un bambou plus court sous chaque bout des premiers, et alors, les bouts des quatre bambous reposaient sur les épaules de huit hommes ; en ajoutant de nouveaux bambous à ceux-là, la force d'un plus grand nombre d'hommes pouvait être appliquée au fardeau, dans une proportion géométrique, chacun d'eux supportant une égale quantité de poids, en levant et charriant des fardeaux très considérables.

L'ambassadeur, et trois autres Anglais, voyagèrent en chaise à porteur, qui sont, en Chine, les voitures le plus en usage pour les gens d'un rang 


\section{Voyage dans l'intérieur de la Chine et en Tartarie}

élevé, même lorsqu'ils font de longs voyages. D'autres Anglais étaient à cheval, ainsi que les mandarins, dont le principal se tenait à côté de la chaise de l'ambassadeur. Les soldats chinois marchaient à pied et faisaient faire place; les domestiques et les gardes de l'ambassadeur étaient sur des voitures à roues; les chaises à porteur, les chariots, les cavaliers, les présents, le bagage, occupaient un grand espace sur la route. Cette route forme, pour Pékin, une magnifique avenue, et c'est par là qu'arrivent toutes les personnes et les marchandises qui vont des provinces de l'est et du midi dans la capitale. Elle est parfaitement unie ; le centre, d'environ vingt pieds de large, est pavé avec des tables de granit, qu'on y transporte d'une très grande distance, et qui ont depuis six jusqu'à seize pieds de long, et environ quatre pieds de large. De chaque côté est un chemin non pavé, assez large pour les voitures. La route est, en grande partie, bordée d'arbres, et principalement de saules d'une grosseur considérable.

Bientôt les voyageurs passèrent sur un pont de marbre, d'une construction digne de la matière qu'on y avait employée. La perfection d'un tel édifice consiste, sans doute, dans la manière dont il répond au but qu'on s'est proposé en le construisant; et ce pont semble ne laisser rien à désirer à cet égard. II est très large, solidement bâti, et traversant un ruisseau qui ne déborde jamais, il est fort peu élevé au-dessus du niveau du chemin.

En suivant la route, quelques-uns des gardes de l'ambassadeur, fatigués d'être renfermés dans des voitures qui allaient très lentement, prirent le parti de descendre et d'aller à pied : par ce moyen, le peuple qui s'était rendu en foule sur la route pour voir les étrangers, eut occasion d'examiner leur figure, leur air et leur costume. Les joues rouges, les cheveux poudrés de ces gardes, et leurs habits serrés et courts, qui n'empêchaient point de distinguer leurs formes, excitèrent une attention particulière. L'air était brûlant. Le thermomètre de Fahrenheit était à quatre-vingt-seize degrés dans les voitures couvertes. Les gardes qui allaient à pied paraissaient être un peu incommodés de la poussière, du soleil, de la fatigue et de la foule qui les pressait. Plusieurs spectateurs s'en aperçurent, et s'écartèrent pour les laisser respirer plus librement. Mais pour un petit nombre d'autres, ignorants et légers, ils ne furent qu'un sujet de plaisanterie. 


\section{Voyage dans l'intérieur de la Chine et en Tartarie}

On fit halte, pour déjeuner, dans un village qui était sur la route. Le cabaret où l'on entra ne ressemblait point aux nouvelles maisons de ce genre qu'on voit en Angleterre. II n'y avait ni élégance, ni décorations ; mais les appartements, quoique petits, étaient propres et bien aérés. On y servit toute espèce de rafraîchissements. En partant de là, sinon plutôt, les Anglais étaient à tout instant dans l'attente de découvrir cette capitale, qu'on dit être la plus grande ville du monde. Cependant, aucun édifice très remarquable dans les environs, aucune petite maison de plaisance, ne leur annonçaient qu'ils allaient la voir incessamment. Enfin, ils arrivèrent à l'entrée d'un des faubourgs du côté de l'est.

Ils passèrent dans une rue pavée qui était remplie de monde, et où l'on voyait surtout beaucoup d'ouvriers, de marchands et d'acheteurs. Le concours du peuple ne paraissait pas autant avoir été rassemblé pour contempler les étrangers qu'on attendait, que pour vaquer à ses occupations. Amusé un moment par la vue du cortège, chacun retournait bientôt à ses affaires. On fut environ quinze minutes à traverser ce faubourg, après quoi on se trouva devant les murs de la cité de Pékin.

L'arrivée de l'ambassadeur fut annoncée par le bruit du canon. On avait préparé des rafraîchissements en dedans de la porte de la ville, pour toutes les principales personnes de l'ambassade. Près de la porte, les murs étaient revêtus en pierre, ailleurs, ils étaient de brique. Une tour, à plusieurs étages, pour placer une vigie, est élevée au-dessus de la porte. A chaque étage on a peint des embrasures pour du canon, comme on peint quelquefois des sabords sur les côtés d'un vaisseau marchand. En dehors de la porte, on voit un mur demi-circulaire avec une porte latérale. Cet ouvrage est construit d'après les principes des fortifications européennes; et il n'y a pas de doute que ce ne soit une addition moderne. Les murailles de la ville sont d'environ quarante pieds de haut. Le parapet a des créneaux profonds, mais point d'embrasures régulières. II n'y paraît pas, non plus, de canons. On voit seulement dans les merlons, des meurtrières pour les archers. Les murailles ont environ vingt pieds d'épaisseur à leur base, et douze vis-à-vis du terreplein sur lequel le parapet est élevé. Le côté extérieur de ces murailles est, non pas tout à fait perpendiculaire, mais peu incliné, et l'intérieur forme un angle considérable, parce que les rangs de briques y sont placés en forme de 


\section{Voyage dans l'intérieur de la Chine et en Tartarie}

degré les uns en arrière des autres, et ainsi qu'on représente la façade des pyramides d'Egypte. Les murs sont flanqués de tours carrées, qui s'élèvent à environ soixante pas de distance l'une de l'autre, et s'avancent en-dehors de la courtine, qui s'étend de l'une à l'autre, d'environ quarante à cinquante pieds. Plusieurs hommes à cheval peuvent aller de front sur les remparts, où l'on a pratiqué, du côté de la ville, des montées de terre en talus.

L'entrée de Pékin offre un coup d'œil bien différent de celui des villes européennes, où les rues sont souvent si étroites et les maisons si élevées, que du bout d'une rue on croit voir les maisons qui sont à l'autre bout pencher les unes vers les autres, et se réunir. A Pékin, la plupart des maisons n'ont qu'un étage, et aucune n'en a plus de deux. Les rues qui les divisent ont beaucoup plus de cent pieds de large : aussi, ces rues sont aérées, claires et gaies.

La rue où passa l'ambassade n'était pas pavée. On l'avait arrosée pour empêcher qu'il y eût de la poussière. Elle était traversée par un léger et bel édifice appelé par les Chinois Pai-Loo, mot qu'on a traduit pour signifier un arc de triomphe, quoique le monument auquel on l'applique n'ait rien qui ressemble à un arc. Ce monument est en bois, et consiste en trois belles

portes, dont celle du milieu est la plus haute et la plus large. Au-dessus de ces portes, il y a trois toits, l'un au-dessus de l'autre, et très richement décorés. De grands caractères dorés et placés sur les montants et sur les traverses annoncent pour quoi on a érigé le Pai-Loo. C'était pour honorer quelques hommes distingués, ou pour perpétuer la mémoire d'un événement intéressant.

La première rue que suivirent les Anglais s'étend en ligne directe vers l'ouest jusqu'à l'endroit où elle est interrompue par un mur du palais impérial, mur qui fait face à l'est, et qu'on appelle le mur jaune, d'après la couleur d'un petit toit de tuiles vernissées qui le couvre. Là, on aperçoit plusieurs édifices publics qu'on considère comme appartenant à l'empereur, et qui sont aussi couverts en jaune. Ces toits ne sont point interrompus par des cheminées. Les bords et le faîte en sont symétriquement échancrés et forment un feston renversé, dont l'effet est plus agréable que celui que produiraient de longues lignes droites. En outre, ils sont ornés d'une grande quantité de figures, dont quelques-unes imitent des objets réels, et le plus grand nombre n'a de 


\section{Voyage dans l'intérieur de la Chine et en Tartarie}

modèle que dans l'imagination. Le tout resplendissant, comme de l'or sous les rayons du soleil, frappa l'œil des Anglais d'une apparence de grandeur qu'on n'a pas coutume de chercher dans cette partie d'un édifice. On voyait près de la porte d'immenses magasins de riz; et en regardant à gauche le long de la muraille de la ville, on apercevait un bâtiment qu'on dit être un observatoire, érigé par Yong-Loo, l'un des empereurs de la première dynastie. C'est aussi, dit-on, au même prince que Pékin doit ses principaux embellissements.

Sur le devant de la plupart des maisons de cette grande rue sont des boutiques, peintes, dorées, et ornées comme celles de Tong-Choo-Foo, mais avec plus de magnificence. Au-dessus de quelques-unes, il y a de grandes terrasses couvertes d'arbustes et de fleurs. II y a devant les portes beaucoup de lanternes de corne, de mousseline, de soie, de papier; et la forme en est si variée qu'il semble que les Chinois y aient employé tout le pouvoir de leur imagination. En-dehors, ainsi qu'en dedans des boutiques, il y avait beaucoup de marchandises déployées et exposées en vente.

Indépendamment de l'arrivée de l'ambassade, diverses circonstances contribuaient à rassembler la foule dans cette vaste rue. On voyait s'avancer du côté de la porte une suite de personnes, dont conformément aux idées européennes, les vêtements blancs semblaient annoncer la cérémonie d'un mariage ; mais l'aspect d'un jeune homme accablé de douleur montra bientôt que c'était une pompe funèbre. Le corps du mort était dans un très beau cercueil carré, au-dessus duquel était un dais peint de couleurs très gaies et très jolies, et précédé par des drapeaux de soie mélangée. A la suite du cercueil venaient plusieurs chaises à porteur, couvertes de drap blanc, et contenant les femmes de la famille du mort.

A la Chine, la couleur blanche marque l'affliction de ceux qui la portent. Aussi est-elle soigneusement évitée par ceux qui désirent de manifester des sentiments contraires. On ne la voit jamais dans les fêtes nuptiales. Les Anglais virent bientôt une cérémonie de ce genre. La jeune épouse, qui n'a point encore été vue par son époux futur, est portée dans une chaise superbement dorée, ornée de guirlandes de fleurs artificielles, et suivie par des parents, des domestiques, et d'autres personnes qui portent son trousseau, seule dot que les parents donnent en mariage à leurs filles. 


\section{Voyage dans l'intérieur de la Chine et en Tartarie}

La foule n'était pas peu augmentée par les principaux mandarins qui ne sortent jamais qu'avec une nombreuse suite. II y avait aussi des multitudes de peuple autour des gens qui vendaient à l'encan, des empyriques, des diseurs de bonne aventure, des chanteurs, des jongleurs, des conteurs enlevant à leurs auditeurs quelques chen ${ }^{1}$, qui avaient sans doute une autre destination.

L'ambassade fournissait, dit-on, amplement matière aux contes qui captivaient en ce moment l'imagination du peuple: on débitait que les présents qu'elle apportait à l'empereur consistaient en tout ce qui était rare dans les autres pays et inconnu à la Chine. On assurait gravement que parmi les animaux, compris dans ces raretés, il y avait un éléphant pas plus grand qu'un singe, mais aussi féroce qu'un lion ; et un coq qui se nourrissait de charbon. Tout ce qui venait d'Angleterre était supposé différer de ce qu'on avait vu jusqu'alors à Pékin, et posséder des qualités absolument contraires à celles qu'on savait lui être propres. La vue des étrangers qui portaient des curiosités si extraordinaires suspendit, pour un moment, les diverses occupations du peuple. II se pressa en foule pour les voir passer. Les soldats chinois, qui servaient de connétables pour faire reculer les spectateurs, étaient armés de longs fouets, dont ils semblaient vouloir frapper les rangs les plus avancés ; mais ils ne les menaçaient qu'avec une douceur analogue à leur caractère et à cette sorte d'indifférence qu'inspire une autorité qu'on exerce depuis longtemps. Dans le fait, leurs fouets ne frappaient presque jamais que la terre.

Aussitôt que les Anglais furent arrivés auprès de la façade orientale du mur jaune, ils tournèrent à droite, le long de ce mur, et trouvèrent du côté opposé au nord, beaucoup moins de mouvement qu'ils n'en avaient vu dans la première rue ; au lieu de boutiques, il n'y avait que des maisons, dont la façade même était invisible, car un mur fermant une cour, au-devant de chaque maison, empêchait les passants de voir la cour dans laquelle s'ouvrait la porte d'entrée; ce mur s'appelle le mur de respect. L'ambassade fit halte vis-à-vis de la triple porte, qui est presque dans le centre du côté nord du

\footnotetext{
${ }^{1}$ Le chen est une monnaie de cuivre, ainsi qu'on l'a vu plus haut.
} 


\section{Voyage dans l'intérieur de la Chine et en Tartarie}

mur du palais impérial. Ce mur paraissait enclore une grande quantité de terrain, qui n'était point uni, comme tout celui qu'on voyait en dehors du mur. Une partie, au contraire, formait de petites montagnes presque à pic; les grands creux qu'on avait faits en prenant de la terre pour construire ces montagnes étaient remplis d'eau. Au sein de ces lacs artificiels, dont les bords sont irrégulièrement variés, s'élèvent de petites îles, avec plusieurs édifices de fantaisie entremêlés d'arbres. Les principales demeures de l'empereur sont bâties sur des montagnes de différente hauteur ; le tout a presque l'air d'un enchantement. Sur le sommet des plus hautes montagnes, de grands arbres environnent des pavillons, des kiosques, faits pour la retraite et le plaisir. C'est dans un de ces cabinets que s'est passée la scène affreuse qui a mis un terme à l'existence de la race des empereurs qui ont bâti ce magnifique palais.

Vers le milieu du dernier siècle, un homme que la fortune quelque temps sembla favoriser, et qui se crut destiné à devenir la tige d'une nouvelle dynastie, profita de la faiblesse, du luxe de la cour, et de cette indolence qui, plus encore que le luxe, avaient entraîné à leur perte les premières races des empereurs. A la tête d'une armée de Chinois, d'abord rassemblée par l'espoir de rendre le pays plus heureux, et maintenue ensuite par l'appât séduisant du pillage, le rebelle s'avança jusqu'aux portes de Pékin. L'infortuné monarque trop faiblement défendu, et ayant trop peu d'énergie pour oser faire quelque résistance, montra cependant des sentiments assez élevés pour ne pas se soumettre à un ennemi qui avait été son sujet. Déterminé à sauver sa fille unique du déshonneur qui la menaçait, il la poignarda de sa main ; ensuite, il se servit d'une corde pour mettre un terme à sa propre vie. Cette action, comme nous venons de le dire, eut lieu dans un des édifices qui avaient été construits pour des scènes moins sanglantes.

De l'endroit où les Anglais eurent occasion de jeter un coup d'œil à travers la porte de l'enceinte du palais, et d'apercevoir une partie des jardins et des bâtiments, ils virent aussi une rue qui allait droit au nord, et aboutissait aux murailles de la ville. Là, ils remarquèrent un vaste édifice d'une hauteur considérable, lequel renferme une cloche de forme cylindrique, et d'une grandeur prodigieuse. En frappant avec un maillet de bois sur la partie extérieure de cette cloche, on lui fait rendre un son assez fort pour être 


\section{Voyage dans l'intérieur de la Chine et en Tartarie}

distinctement entendu de toute la capitale. Au-delà, mais plus du côté de l'ouest, est une des portes septentrionales dont on perçoit la haute tour, malgré beaucoup de bâtiments intermédiaires.

\# En s'avançant au-delà des portes du palais, droit à l'ouest, et entre le mur jaune et les maisons qui sont dans la partie septentrionale de la ville, on rencontre un lac de quelques acres d'étendue. Les Anglais le virent en automne, et il était presque entièrement couvert de feuilles velues du nymphœa nelumbo, ou lien-wha des Chinois. Indépendamment des autres propriétés que la nature lui a données, la feuille de cette plante $a$, par sa structure et par la manière dont elle pousse immédiatement autour de la tige, l'avantage de défendre du contact de l'eau la fleur et le fruit qui croissent dans son centre. Quelque profondeur qu'ait le lac ou la rivière où croît le lienwha, il n'y a qu'un débordement soudain qui puisse empêcher la tige de cette plante de parvenir jusqu'à la surface de l'eau où ses feuilles s'étendent, se reposent, nagent et quelquefois s'élèvent au-dessus. Le lien-wha, qui résiste au froid rigoureux de l'hiver de Pékin, est très difficilement conservé dans les serres d'Europe; ses feuilles sont aussi belles et aussi odorantes que ses graines sont agréables au goût.

Les Anglais continuèrent à marcher vers l'ouest : on leur montra la maison où demeuraient quelques Russes, et ce qui était plus singulier, ils virent une bibliothèque de manuscrits étrangers, l'un desquels était, dit-on, une copie arabe du Coran. Parmi les spectateurs étaient quelques mahométans, distingués par des bonnets rouges; il y avait aussi des femmes qui, pour la plupart, étaient nées en Tartarie, ou de race tartare. Leurs pieds n'étaient point estropiés comme ceux des Chinoises; et leurs souliers sans pointe et à semelle, d'un pouce d'épais, paraissaient aussi grossiers que ceux des dames chinoises étaient délicats. Quelques-unes de ces Tartares étaient fort bien parées, avaient des traits fort jolis, et un teint relevé par le secours de l'art. II paraissait que la manière de se farder, la plus à la mode, était de mettre beaucoup de rouge sur le milieu de la lèvre inférieure. II y avait des femmes dans des voitures couvertes, et il est bon d'observer qu'on trouve dans plusieurs quartiers de Pékin, des voitures et des chevaux de place. Quelques dames tartares étaient à cheval, et montaient à califourchon comme des hommes. 


\section{Voyage dans l'intérieur de la Chine et en Tartarie}

De tous côtés, on voyait des ouvriers portant leurs outils et cherchant de l'emploi, et des colporteurs offrants des marchandises à vendre. Plusieurs rues étroites avaient une porte à chaque bout, avec des gardes pour rétablir l'ordre, quand il arrive quelque tumulte ; la nuit on ferme ces portes et on ne les ouvre que dans des cas extraordinaires.

L'ambassade passa par une rue qui s'étend du nord au sud, d'un bout à l'autre de la cité tartare: cette rue a presque quatre milles de long, et n'est interrompue que par différents pai-loos, ou portes triomphales. Après avoir passé devant beaucoup de temples, de magasins et d'autres grands édifices, et avoir marché un peu plus de deux heures, depuis l'entrée du côté de l'orient, les Anglais arrivèrent à l'une des portes occidentales. Près de cette porte, et en-dehors de la muraille de la ville, coule le petit ruisseau qui commence là à s'élargir beaucoup, fait ensuite presque tout le tour de Pékin, et va du côté de Tong-Choo-Foo se jeter dans le Pei-Ho. Le faubourg par où les Anglais sortirent du côté de l'occident, étant plus considérable que celui par où ils étaient entrés dans Pékin, ils furent plus de vingt minutes à le traverser.

Les Anglais s'arrêtèrent à l'extrémité du faubourg pour se communiquer réciproquement l'impression que Pékin avait faite sur leur esprit. Ils savaient bien qu'un coup d'œil si rapide ne pouvait pas les mettre en état d'apprécier cette ville, mais à l'exception du palais impérial, tout ce qu'ils venaient de voir ne répondait point à l'idée qu'ils s'étaient formés de la capitale de la Chine. Ils pensèrent qu'un Chinois qui aurait de l'impartialité serait plus satisfait en contemplant les vaisseaux, les ponts, les places, les édifices publics, et le déploiement de richesses de la capitale de la Grande-Bretagne, qu'ils ne l'avaient été en voyant Pékin.

En sortant de Pékin, et marchant droit au nord-ouest, on trouve un chemin de granit, pareil à celui qui y mène quand on vient de Tong-Choo-Foo. Le chemin du côté du nord-ouest conduit à la ville de Hai-Tien ${ }^{1}$, qui n'est point entourée de murailles, et ne contient guère d'autres maisons que celles 


\section{Voyage dans l'intérieur de la Chine et en Tartarie}

qui servent à la vente des marchandises et au logement des ouvriers, près du palais d'automne de Yuen-Min-Yuen. Le palais est un peu au-delà de la ville ${ }^{2}$. Il y a dans cette ville quelques missionnaires italiens que la cour emploie comme artistes : c'est vraisemblablement pourquoi elle les loge auprès d'elle. Les boutiques de Hai-Tien abondent non seulement en choses nécessaires, mais en colifichets et en bagatelles, faits pour amuser les riches et les oisifs des deux sexes.

Il y a même des cages contenant des insectes tels que la bruyante cigale et une grosse espèce de grillon ${ }^{1}$.

Entre la ville de Hai-Tien et le palais de Yuen-Min-Yuen était la maison de plaisance où logèrent l'ambassadeur et sa suite. Cette maison était renfermée dans un enclos de plus de douze âcres. Il y avait un jardin coupé par des sentiers qui allaient en serpentant, un petit ruisseau qui faisait le tour d'une île, un bosquet d'arbres de différente espèce, entremêlés de tapis de gazon et dont le sol était artificiellement inégal ; et enfin, des rochers irrégulièrement entassés.

Les bâtiments consistaient en divers pavillons séparés et construits autour de petites cours. Les appartements étaient beaux et commodes. II y en avait plusieurs ornés de paysages en miniature. Ces tableaux paraissaient dessinés correctement. Les règles de la perspective y étaient observées; mais ce qui prouvait qu'ils étaient l'ouvrages des Chinois, c'est qu'on y avait totalement négligé les effets de la lumière et des ombres. Un lac y était représenté au milieu des arbres et des maisons ; mais un Chinois aurait cru faire une faute en rendant l'ombre d'aucun de ces objets, apparente dans l'eau. La maison avait été occupée par des ambassadeurs des cours étrangères, ou par les premiers mandarins des provinces éloignées, lorsque l'empereur habitait le palais d'automne. Mais depuis quelque temps, elle était vide et avait besoin de réparations.

${ }^{1}$ [Cf. Reclus, I'Empire du Milieu, carte 'Peking et environs']

2 [On trouvera une description de ce palais dans l'article de G. Pauthier, Une visite à Youen-ming-youen, palais d'été de l'empereur Khien-loung, Le Tour du Monde, 18642, pp. 97-113] 


\section{Voyage dans l'intérieur de la Chine et en Tartarie}

Le gouverneur du palais et l'ambassadeur se firent réciproquement beaucoup de compliments et de politesses. Le premier désira de connaître l'opinion de lord Macartney, relativement à la manière dont il fallait placer les présents qui devaient rester dans le palais. On décida que les principaux articles seraient mis de chaque côté du trône, dans une des salles d'audience. L'extérieur de cette salle est magnifique. On y arrive après avoir traversé trois cours carrées, environnées de bâtiments séparés les uns des autres. La salle est placée sur une plate-forme de granit, élevée de quatre pieds au-dessus du niveau de la cour. Son toit avancé est soutenu de chaque côté par deux rangs de colonnes de bois. Le fût de ces colonnes est peint et vernissé, et le chapiteau orné de cartouches et de devises très brillamment colorées, et portant surtout des dragons dont les pieds sont armés de cinq griffes. Les dragons peuvent être représentés sur les maisons et les équipages des princes de la cour de l'empereur, mais avec quatre griffes seulement à chaque pied. Les cinq griffes sont réservées pour l'empereur seul.

Un filet de fil d'archal doré, qu'on peut à peine apercevoir, enveloppe l'entablement de la salle, afin d'empêcher les oiseaux de se percher sur aucune des pointes les plus avancées, qui sont en grand nombre et dans un ordre régulier. L'intérieur de la salle a plus de cent pieds de long, plus de quarante pieds de large, et au moins vingt pieds de haut. Entre la salle et le rang inférieur des colonnes du côté du midi, il y a des panneaux qui, tous, ou du moins la plupart, peuvent être ouverts et fermés à volonté.

Cette salle, spacieuse et bien éclairée, était très propre au déploiement des présents. Il n'y avait d'ailleurs que le trône, quelques grands vases d'ancienne porcelaine, avec une pendule à serinette, jouant douze vieux airs anglais, et faite au commencement de ce siècle, suivant l'inscription qu'elle portait, par Georges Clarke, de la rue de Leadenhall, à Londres.

Le trône, placé dans une espèce de sanctuaire, et ayant quelques marches sur le devant de chaque côté, n'est ni riche, ni pompeux. On voit au-dessus des caractères chinois qui annoncent la gloire et la perfection. II y a des deux côtés des trépieds et des encensoirs, et devant le trône est une petite table,

\footnotetext{
1 Gryllus.
} 


\section{Voyage dans l'intérieur de la Chine et en Tartarie}

ou plutôt un autel sur lequel on fait des offrandes de thé et de fruits, parce qu'en l'absence même de l'empereur, on suppose que son esprit est toujours présent en ce lieu.

Les Anglais y allèrent par hasard dans le temps de la pleine lune, époque d'une grande fête pour les sectateurs de Fo. Parmi les différents noms qui appartiennent à l'empereur en qualité de souverain, il y en a un, non seulement qui a le même son que celui par lequel on désigne quelquefois la divinité en Chine, mais la composition des caractères écrits, qui servent pour l'un et l'autre, et qui est toujours supposée faire quelque allusion à l'objet qu'on veut exprimer, est précisément la même. Cette conformité a, sans doute, pris sa source dans une considération partiale en faveur du pouvoir qui, relativement à l'état moral et à la condition des hommes en Chine, réside presque entièrement dans la personne du souverain. Aux yeux d'un nombre immense de ses sujets, le reste du monde est de très peu de conséquence ; et ils croient que l'empire de ce prince s'étend virtuellement sur la terre entière. D'après ces idées, il est rare qu'ils fassent aucune différence entre ce que lui doivent les autres nations ou les individus étrangers, et les hommages sans bornes qu'ils lui rendent eux-mêmes. Puisqu'ils lui adressent des sacrifices en son absence, il n'est point étonnant qu'ils l'adorent présent. Le ko-téou, ou adoration, comme l'expriment les mots chinois, consiste en neuf prosternations solennelles, à chacune desquelles le front doit frapper la terre. II est difficile d'imaginer un signe extérieur d'une plus grande soumission, d'une plus profonde humilité, et qui annonce une persuasion plus intime de la toute puissance de l'être à qui on rend un pareil hommage.

La cour de la Chine attend ces prosternations de la part des étrangers, comme des sujets et des vassaux de l'empire. Le légat, qui en avait déjà fait mention à l'ambassadeur, commença à le presser de se soumettre devant lui à cet usage, lorsqu'il approchait du trône impérial. Lord Macartney était préparé à répondre à cette demande. Le roi d'Angleterre lui avait donné, en termes généraux, des instructions relatives à des propositions de cette nature. Il connaissait d'ailleurs avec quelle obstination la cour de la Chine exige des cérémonies, qui ne lui rendent peut-être les ambassades si agréables que parce qu'elles sont accompagnées de marques d'humiliation de 


\section{Voyage dans l'intérieur de la Chine et en Tartarie}

la part des puissances qui les lui adressent. C'est dans cet esprit qu'on avait pris soin d'écrire en gros caractères chinois sur les pavillons des yachts et des chariots de l'ambassade: «Ambassadeur portant tribut du pays d'Angleterre ».

Comme il était possible que la signification de ces caractères ne fût point expliquée à lord Macartney, il ne crut pas devoir s'en plaindre formellement, parce que d'ailleurs si on lui avait refusé une satisfaction à cet égard, ce qui ne pouvait manquer d'arriver, il eût été obligé de s'arrêter en chemin, et de terminer sa mission d'une manière aussi fâcheuse que soudaine. Cependant, ces caractères avaient été remarqués. Ils étaient répétés dans la gazette de la cour. Ils devaient être insérés dans les annales de l'empire. Ils pouvaient passer en Europe par le moyen des Russes qui résident à Pékin, et des missionnaires qui s'y rendent des divers pays catholiques. II importait donc que l'ambassadeur fût encore plus attentif à toutes ses actions, de peur qu'on ne les représentât comme peu convenables pour le souverain qu'il avait I'honneur de représenter.

Sous le règne qui précéda celui de l'empereur actuel, de pareilles considérations empêchèrent l'ambassadeur de Russie de se soumettre aux cérémonies d'usage pour approcher le trône chinois, jusqu'à ce qu'on eût fait un pacte, en forme, par lequel on convint qu'en pareille occasion, les Chinois rendraient les mêmes honneurs à ses souverains.

Les Hollandais qui, dans le dernier siècle, se soumirent sans difficulté à toutes les cérémonies qu'on leur prescrivit, parce qu'ils espéraient d'obtenir en retour quelques avantages lucratifs, se plaignirent ensuite d'être traités avec négligence, et renvoyés sans qu'on leur promît la moindre faveur.

On dit que quelques missionnaires résidant à la cour de la Chine y ont montré que la Hollande n'occupait qu'un point sur la carte, et ont observé que sa prépondérance politique était proportionnée à son peu d'étendue. II est possible qu'on ait essayé d'appliquer la même règle à l'Angleterre. Les ministres de la Chine ont jusqu'à présent reçu des renseignements si inexacts, si incertains, si partiaux, sur l'état réel des diverses puissances européennes, que les différents degrés de répugnance que montreraient les ambassadeurs de ces puissances pour les prétentions de supériorité affectées 


\section{Voyage dans l'intérieur de la Chine et en Tartarie}

par la cour de Pékin pourraient y servir de mesure pour juger de leur importance relative. D'un autre côté, l'Europe a aujourd'hui un commerce si étendu, et des communications si fréquentes avec le reste du globe, que le représentant d'une de ces puissances, quelque éloigné que soit le pays où il est envoyé, ne peut y rien faire que les autres regardent comme insignifiant, ou négligent d'observer. Certes, il n'est pas raisonnable de supposer que la prospérité d'une nation ne dépend pas en partie du caractère qu'elle déploie au-dehors et du rang qu'elle y maintient. Si l'on eût oublié ce principe, il y aurait eu lieu d'appréhender que dans les dispositions où étaient alors les ministres chinois, on eût sacrifié sa dignité sans obtenir plus de faveur. Le cabinet de Londres voulait avoir des relations diplomatiques à Pékin pour détruire peu à peu les préventions qu'on avait conçues contre les Anglais depuis leur première apparition sur les côtes de la Chine, préventions qui avaient été fortifiées par les mensonges débités contre eux. A ces préventions, se joignait encore la nouvelle et défavorable impression dont nous avons déjà parlé à l'occasion de la guerre du Thibet.

Malgré I'hospitalité avec laquelle l'ambassade était traitée, et les distinctions et même la splendeur qui l'accompagnaient, on voyait que plusieurs hommes en place, et principalement les chefs tartares, se méfiaient de ses desseins. II semblait qu'ils craignaient que les Anglais n'eussent envie de partager enfin, avec les Tartares eux-mêmes, la domination de la Chine. II n'est point de gouvernement qui haïsse, redoute autant que celui de la Chine, les principes de la Révolution française; et comme ces principes, ainsi que l'ambassade anglaise, venaient de l'Occident, le gouvernement chinois était encore plus éloigné de vouloir étendre ses relations avec cette partie du globe ; et le voisinage de la France semblait devoir nuire à l'Angleterre à une très grande distance de l'Europe ${ }^{1}$.

Quand ces circonstances extraordinaires et défavorables qui ne pouvaient être ni prévues, ni empêchées, n'eussent pas eu lieu, on n'aurait pas pu

\footnotetext{
1 On voit que la passion emporte ici l'auteur, dont l'esprit est en général très calme. Peut-être est-il permis à un Français de douter de la vérité de ces assertions : mais en supposant que les Chinois craignent et haïssent les principes de notre liberté, je demande si les Anglais n'ont pas contribué à les leur faire craindre et haïr ? (Note du
} 


\section{Voyage dans l'intérieur de la Chine et en Tartarie}

s'attendre que des avantages soudains dussent résulter d'une communication directe entre les cours de Londres et de Pékin. Les Anglais n'avaient réellement à espérer qu'un changement en leur faveur dans l'esprit du gouvernement, et de cette partie du public dont les opinions influent insensiblement sur ses supérieurs. Un tel changement ne pouvait donc être que graduel, et cependant il importait à la fois et aux intérêts des possessions britanniques de l'Indostan, et à ceux du commerce, sinon de toute l'Europe, au moins de l'Angleterre. L'ambassadeur ne parut ni découragé, ni inquiet à l'égard du résultat de ses négociations, mais il en était intérieurement affecté.

Un essai pour établir des relations amicales et utiles avec une cour soupçonneuse et repoussante exigeait qu'on levât, dès le commencement, les principales difficultés. Ce n'était qu'en cherchant à cultiver la bienveillance de cette cour, par l'entremise d'agents capables, et par une conduite judicieuse, polie et non abjecte, qu'on pouvait obtenir son estime et sa confiance. II était enfin de la plus grande conséquence que dans cette première ambassade, le représentant du roi d'Angleterre ne voulût point, pour s'assurer personnellement un accueil agréable, accepter des propositions, ou consentir à des actes qui pouvaient blesser la dignité de son souverain et I'honneur de son pays, aux yeux des autres nations. Si, au contraire, cette dignité, cet honneur, étaient respectés la première fois qu'on traitait à la cour de la Chine, les successeurs de l'ambassadeur pouvaient ensuite, sans s'exposer à de fâcheuses conséquences, se conformer aux usages du pays.

Quoique le légat n'ignorât point ce qui s'était passé du temps de l'ambassade russe, il espérait d'après le caractère traitable de l'ambassadeur anglais que, sans y mettre aucune condition, ce ministre accéderait à sa demande. Un tel succès ne lui eût pas fait peu d'honneur aux yeux des ministres qui étaient plus attachés que l'empereur lui-même, à cette antique prétention de supériorité sur toutes les nations. Pour donner plus d'effet à ses sollicitations, le légat employa aussi celles des mandarins les plus intimement liés avec son excellence. Ceux-ci s'acquittèrent de cette commission d'une manière très adroite et très insinuante. Ils commencèrent par des remarques

Traducteur.) 


\section{Voyage dans l'intérieur de la Chine et en Tartarie}

sur les coutumes des différentes nations, et l'avantage que trouvaient les voyageurs à se conformer à ces coutumes dans quelque pays où ils allassent. Parlant ensuite de la manière dont on était présenté à l'empereur, ils citèrent la prosternation comme une cérémonie ordinaire, qu'il serait désagréable de faire avec maladresse, et ils dirent qu'en conséquence, on avait coutume de la pratiquer quelque temps auparavant.

Ils ne furent pas, alors, peu surpris d'entendre citer un fait, attesté par I'histoire, c'est qu'un Européen ${ }^{1}$, revêtu du caractère d'ambassadeur auprès d'un puissant monarque de l'Orient ${ }^{2}$, s'étant soumis à se prosterner devant lui, fut, à son retour parmi ses compatriotes ${ }^{3}$, condamné à perdre la vie, comme ayant dégradé la nation qu'il représentait. On observa encore aux mandarins que, dans les temps modernes, de moindres condescensions avaient été sévèrement réprimées ; qu'on regardait les actions des hommes publics, moins comme les leurs propres, que comme celles des souverains qu'ils représentaient. Que d'après ces principes, un monarque ne devait point s'attendre que les ambassadeurs des puissances étrangères se soumissent à des cérémonies pratiquées par ses propres sujets, et qu'il y avait une distinction juste et nécessaire entre des actes d'hommage et de soumission, et des marques volontaires d'estime et d'amitié.

Dans cette occasion délicate, l'ambassadeur résolut d'employer tous les moyens qui étaient en son pouvoir pour satisfaire aux vœux supposés de l'empereur, sans manquer à son devoir envers son propre souverain. II ne prétendit donc point se dispenser de la cérémonie de la prosternation : mais il offrit de l'accomplir à des conditions qui, sans la rendre moins respectueuse pour la personne de l'empereur, en écartaient le principal inconvénient, c'està-dire empêchaient qu'on ne pût la regarder comme un acte d'hommage et de dépendance du représentant d'un souverain étranger.

Les conditions qu'il proposa étaient qu'un Chinois, d'un rang égal au sien, ferait, devant un tableau où le roi d'Angleterre était peint en habit de

\footnotetext{
1 Timagoras.

2 Le roi de Perse.

3 Les Athéniens.
} 


\section{Voyage dans l'intérieur de la Chine et en Tartarie}

cérémonie, les mêmes prosternations qu'on exigeait du représentant de ce roi, devant le trône impérial.

II était important que cette proposition fût donnée par écrit, et traduite exactement en chinois, de peur que quelque méprise ou quelque mauvaise volonté ne lui fissent manquer son effet. Quoique né en Chine, l'interprète de l'ambassade ignorait absolument le style nécessaire pour le palais impérial ; et en s'occupant du latin et de l'italien pendant plusieurs années qu'il était resté à Naples, il avait perdu l'habitude d'écrire les caractères chinois ; caractères compliqués, dont le nombre ne s'élève pas à moins de quatre-vingt mille. Les missionnaires européens, employés par la cour, entendent la langue, mais ils entreprennent rarement d'écrire, et surtout des papiers officiels, pour lesquels ils emploient un Chinois lettré, auquel ils expliquent verbalement ce qu'ils ont besoin de communiquer.

Le légat, qui ne visait à rien moins qu'à obtenir un consentement pur et simple à ce qu'il proposait, n'était nullement disposé à recevoir des stipulations par écrit, et n'aurait offert ni accordé volontairement aucun secours pour cela. Cependant, ces difficultés pouvaient être surmontées par le moyen des missionnaires européens. Lord Macartney savait que ces missionnaires étaient très disposés à lui rendre visite ; il demanda qu'ils en obtinssent la permission. Il n'y avait pas de doute que quelques-uns d'entre eux ne fussent très nécessaires pour suppléer l'interprète dont la santé était quelquefois dérangée, et expliquer les choses dont les personnes attachées à l'ambassade avaient besoin dans les occurrences les plus ordinaires. En outre, il était vraisemblable que, grâce aux lettres de recommandation, portées à ces missionnaires de la part de leurs supérieurs et de leurs amis d'Italie, il s'en trouverait quelqu'un qui hasarderait de procurer une traduction fidèle des papiers les plus nécessaires à l'ambassadeur, et peut-être aussi de donner beaucoup de renseignements utiles.

Après plusieurs sollicitations, l'ambassadeur vit plusieurs missionnaires : mais ils ne lui furent présentés que d'une manière cérémonieuse, circonspecte, en présence du légat, et ayant à leur tête le jésuite portugais, dont faisaient mention les lettres d'un autre missionnaire que nous avons rapportées plus haut. Ce jésuite semblait avoir tout l'orgueil qu'inspire quelquefois I'habit ecclésiastique, accru en lui par l'honneur d'avoir été 


\section{Voyage dans l'intérieur de la Chine et en Tartarie}

récemment décoré d'un bouton bleu, qui le rendait supérieur à ses collègues, car ils ne portaient que le bouton blanc. Cependant, il était peu propre à servir d'interprète à un ministre britannique: il n'entendait ni la langue anglaise, ni celle qu'on parle le plus généralement dans l'Europe moderne. D'ailleurs, en parlant à ses compagnons, il laissait suffisamment apercevoir combien il était contraire aux Anglais, tandis que les missionnaires des autres pays donnèrent des marques évidentes de bonne volonté et de zèle pour le succès de l'ambassade.

La visite des missionnaires ayant fourni l'occasion de demander que l'ambassade quittât Hoong-Ya-Yuen, pour aller à Pékin, parce qu'on ferait plus commodément dans cette capitale les préparatifs nécessaires pour le voyage de Zhé-Hol, le jésuite encouragea le légat à résister à cette demande, en faveur de laquelle s'étaient réunis tous les autres Européens. Dans une autre entrevue, qui fut la seule que l'ambassadeur pût avoir avec ce Portugais, ce ministre essaya de l'attacher aux intérêts de la nation anglaise. Le jésuite changea en effet de ton, et assura qu'il rendrait service à l'ambassade; ce que promirent aussi pour lui quelques-uns de ses compatriotes, qui étaient des hommes très estimables. Mais les Chinois préférèrent l'interprète de son excellence, parce que comme il était né dans le pays, il avait une prononciation plus agréable pour eux, que l'accent étranger du missionnaire.

Ce dernier voulut se faire un mérite auprès de l'ambassadeur, en persuadant au légat d'écrire à l'empereur pour connaître sa volonté relativement au désir qu'avait son excellence d'aller à Pékin ; sans quoi il prétendait que ce déplacement ne pouvait avoir lieu. Mais le gouverneur du palais de Yuen-Min-Yuen, qui était d'un rang supérieur à celui du légat et avait plus de pouvoir que lui, se mêla de cette affaire; et aussitôt l'ambassade fut conduite à Pékin.

Là, tous les Anglais furent logés dans un vaste palais consistant en plusieurs corps de bâtiments qu'un receveur des revenus et des douanes de Canton avait, dit-on, fait construire avec le produit de ses rapines sur le commerce britannique. Mais ce palais avait été confisqué au profit de la couronne, à cause d'autres rapines exercées depuis sur les Chinois par le même homme, dans un emploi qu'il avait rempli plus près de la capitale. 


\section{Voyage dans l'intérieur de la Chine et en Tartarie}

Ce palais était construit sur le modèle général de ceux des grands mandarins. Un mur de brique très élevé et formant un parallélogramme entourait tout l'emplacement. L'extérieur de ce mur était simple, blanchâtre, et n'avait qu'une porte dans l'un de ses angles, laquelle s'ouvrait sur une rue étroite, et ne promettait nullement les superbes édifices auxquels elle conduisait. Dans toute sa longueur, ce mur supportait le faîte d'un toit, dont le bord reposait sur un autre mur parallèle; et sous ce toit étaient divers appartements pour les domestiques et les offices. Le reste de l'enceinte était divisé en plusieurs cours carrées et de différente grandeur. Dans chaque cour était un bâtiment placé sur une plate-forme de granit et entouré d'une colonnade. Les colonnes étaient de bois, de près de seize pieds de haut, de seize pouces de diamètre à leur pied, et diminuant graduellement de plus d'un sixième. Elles n'avaient ni chapiteau, ni base, suivant la stricte signification de ces termes dans les ordres d'architecture grecque. Elles n'avaient même aucune division du côté de l'entablement ; mais elles étaient unies dans la partie qui supportait la corniche, ainsi qu'en bas, où elles reposaient dans le creux d'une pierre ronde, qui formait un cercle autour d'elles, à peu près comme dans l'ordre toscan.

Entre les colonnes et à environ un quart de longueur, depuis la corniche en bas, on avait sculpté des ornements en bois, qu'on pouvait appeler un entablement, et dont la couleur était différente de celle des colonnes qui étaient toutes peintes en rouge. La colonnade servait de support à cette partie du toit qui s'avançait en courbe jusqu'au-delà de la plate-forme, et se relevait vers les angles. Par ce moyen, on était à couvert dans chaque partie de ces vastes édifices, dans l'ensemble desquels on comptait, au moins, six cents colonnes.

Le principal appartement fut occupé par l'ambassadeur. A côté de cet appartement était une salle construite pour un théâtre particulier et pour des concerts. Il y avait, sur le derrière des appartements particuliers, et tout autour, une galerie pour les spectateurs.

Un seul de ces bâtiments avait plus d'un étage, c'était celui des femmes, lorsque le propriétaire l'habitait. II était situé dans la cour la plus reculée. Le devant consistait en une salle longue et très élevée, avec des fenêtres garnies de papier de Corée, à travers lequel il est impossible de distinguer aucun 


\section{Voyage dans l'intérieur de la Chine et en Tartarie}

objet. Dans le fond était une galerie à la hauteur d'environ dix pieds, laquelle conduisait dans diverses petites chambres, qui n'étaient éclairées que par la salle. Les fenêtres de ces chambres étaient garnies de gaze, montée sur des châssis de bois, et ornée de fleurs, de fruits, d'oiseaux, d'insectes, brodés à l'aiguille ou peints en miniature. Quoique plus petit, cet appartement était plus élégant que la plupart des autres. Il y avait en outre, sur le derrière, une petite cour avec des offices; et tout y semblait fait pour la retraite.

Dans l'une des premières cours était une grande pièce d'eau, au milieu de laquelle s'élevait un pavillon en pierre, représentant exactement un de ces bateaux chinois qui sont couverts. Dans d'autres cours, on avait planté des arbres; et la plus grande offrait une pile de rochers, entassés comme au hasard, mais solidement fixés les uns sur les autres. A l'une des extrémités, il y avait un endroit, préparé pour un petit jardin, qu'on n'avait pas, sans doute, eu le temps d'achever. Le propriétaire de ce palais avait peu joui du fruit de ses rapines; et il était en ce moment condamné à être exécuté pour prix de ses iniquités.

Dans ce palais, on eut bientôt occasion de voir un des missionnaires de Pékin. Bien disposé en faveur de l'ambassade, il consentit volontiers à procurer le traducteur dont on avait besoin ; et, en conséquence, il présenta un jeune chrétien chinois, ordinairement employé par lui, et très propre à remplir cet office. Mais, telle est la crainte habituelle qu'ont les Chinois d'offenser en rien les personnes revêtues de l'autorité, ou de se mêler en aucune manière des affaires d'Etat, telle était, surtout, l'appréhension que ce jeune chrétien avait de déplaire au légat, si son écriture était reconnue, qu'on ne pût pas le déterminer à la laisser paraître. On savait d'ailleurs, bien certainement, qu'un homme né à Canton avait été mis à mort pour avoir écrit une pétition chinoise en faveur des Anglais. Cependant, la difficulté fut surmontée par le moyen du jeune homme, que nous avons déjà dit être attaché à l'ambassadeur en qualité de page, et qui avait non seulement fait assez de progrès dans la langue chinoise, pour servir quelquefois d'interprète, mais pour copier avec une facilité extraordinaire les caractères chinois. II fut nécessaire d'avoir recours à lui pour tous les papiers qu'on eut depuis occasion de présenter dans la même langue. 


\section{Voyage dans l'intérieur de la Chine et en Tartarie}

Les procédés qu'il fallut employer avec le chrétien de Pékin furent un peu pénibles. M. Hüttner traduisit d'abord le mémoire anglais en latin, pour l'interprète de l'ambassade, lequel n'entendait point l'original. Cet interprète expliqua ensuite verbalement le sens du latin dans la langue familière de la Chine, et le nouveau traducteur le rendit dans le style des papiers officiels. Le page mit immédiatement cette traduction au net; et, pour tranquilliser le traducteur, on déchira le brouillon en sa présence.

Le mémoire de l'ambassadeur était adressé à Ho-Choong-Taung Colao, premier ministre de l'empereur. En voici le contenu :

«Sa majesté, le roi de la Grande-Bretagne, en envoyant une ambassade à sa majesté l'empereur de la Chine, a voulu pleinement donner les plus grands témoignages de son estime particulière et de sa vénération pour sa majesté impériale. L'ambassadeur, chargé de faire connaître ces sentiments, désire ardemment de remplir cet objet de sa mission avec zèle et efficacité. II est également prêt à se conformer à toutes les cérémonies extérieures, pratiquées par les sujets de sa majesté impériale, et les principes tributaires qui paraissent à sa cour, non seulement pour éviter les embarras de la nouveauté, mais afin de montrer, par son exemple en faveur d'une des nations les plus grandes et les plus éloignées, la haute et juste opinion qu'inspirent universellement la dignité et les vertus transcendantes de sa majesté impériale.

« L'ambassadeur s'est déterminé, sans hésiter, à agir de cette manière, seulement à une condition dont il se flatte que sa majesté impériale sentira immédiatement la nécessité, et à laquelle elle aura la bonté d'accéder, en donnant des ordres qui préviennent le danger auquel le zèle de l'ambassadeur pour sa majesté impériale l'expose ; car l'ambassadeur souffrirait certainement beaucoup si sa conduite, en cette occasion, pouvait être regardée comme étant, en aucune manière, indigne du rang illustre et sublime qu'occupe, parmi les souverains indépendants, le maître qu'il représente. Ce danger peut être aisément évité, et la satisfaction complète des deux côtés, si sa majesté impériale donne ordre que l'un des offi- 


\section{Voyage dans l'intérieur de la Chine et en Tartarie}

ciers de sa cour, d'un rang égal à celui de l'ambassadeur, accomplisse devant le tableau où le roi d'Angleterre est représenté en grand et revêtu de ses habits royaux, et que l'ambassade a actuellement à Pékin, les mêmes cérémonies qu'accomplira l'ambassadeur devant le trône de sa majesté impériale.

Ce mémoire fut adressé suivant la forme convenable, et remis au légat qui promit de le faire parvenir immédiatement à la cour. II sembla, en même temps, en approuver le contenu. Ni les missionnaires, ni les principaux Chinois à qui il fut communiqué, ne doutèrent nullement que l'empereur n'acquiesçât à la demande de l'ambassadeur. Dans le fait, la réciprocité des cérémonies qu'on exigeait de la part d'un des sujets de sa majesté impériale pouvait se faire sans pompe dans une chambre particulière, et être à peine connue dans l'empire; mais les prosternations de l'ambassadeur devaient avoir lieu dans une fête solennelle, en présence de tous les princes tributaires et des premiers sujets de l'État, et on ne pouvait manquer d'en rendre compte dans les gazettes publiées avec autorité.

Dans cette persuasion, on se prépara immédiatement à se rendre en présence de l'empereur. Ceux des présents qui devaient être conduits en Tartarie furent, ainsi que le bagage de l'ambassade, portés de Hoong-Ya-Yuen à Pékin. Parmi ces premiers objets, il y avait six petites pièces de campagne, en cuivre, d'un beau jet, d'une forme élégante, et placées sur de longues roues. On les avait récemment essayées pour exercer les artilleurs de la garde, afin de les préparer à manœuvrer en présence de sa majesté impériale. Chaque pièce tirait plusieurs coups par minute. Tant de célérité dans les manœuvres militaires, faites par des étrangers, ne plaisait pas beaucoup au légat, qui en fut témoin. II affecta de dire qu'on pourrait en faire autant dans l'armée impériale ; et lui qui, auparavant, avait paru tant désirer que tous les présents fussent conduits à Zhé-Hol à la suite de l'ambassadeur, fut tout à coup d'avis qu'on n'y transportât point les pièces de campagne, parce que l'empereur devait bientôt retourner à Pékin. II y avait parmi le bagage de l'ambassade autant de petits barils de poudre à canon qu'on avait prévu en avoir besoin soit pour les salves, soit pour l'exercice des artilleurs, et des fusiliers de gardes. Cette poudre fut aussi un objet d'inquiétude pour le légat. II demanda qu'elle lui fût livrée, et on la lui livra sur-le-champ, parce 


\section{Voyage dans l'intérieur de la Chine et en Tartarie}

que c'était une chose indifférente. Toute la conduite de ce Tartare décelait une âme tourmentée de la crainte de voir les Chinois prendre une plus haute idée de la valeur anglaise, que de celle de sa nation.

Pour les Chinois, ils admiraient sincèrement un grand nombre d'objets que les Anglais avaient apportés, soit pour présents, soit pour l'usage de plusieurs d'entre eux, et qu'ils avaient déployés pour satisfaire la curiosité de leurs hôtes, et pour tâcher de répandre parmi eux le goût des marchandises anglaises. La plupart des ustensiles d'un usage commun en Angleterre sont également employés à la Chine, et faits dans le pays; mais ceux des Chinois sont, en général, inférieurs et pour la qualité et pour la propreté. La quincaillerie anglaise est extrêmement recherchée en Chine; et si dans la suite des temps les vaisseaux de la Compagnie des Indes ont un libre accès dans le port de Tien-Sing, les manufactures de Birmingham et de Sheffield éprouveront bien plus de demandes par rapport à la consommation que Pékin fera de leurs marchandises.

La ville de Pékin n'est pas aussi grande, proportionnément au reste de la Chine, que l'est Londres relativement à l'Angleterre. La principale partie de Pékin est appelée la cité tartare, parce qu'elle a été rebâtie au treizième siècle, sous la première dynastie tartare. Elle forme un parallélogramme dont les quatre murs font face aux quatre points cardinaux. Ces murs renferment une aire d'environ quatorze milles carrés, dans le centre de laquelle est le palais impérial, qui occupe en dedans du mur jaune, au moins un mille carré. Le tout ensemble n'a qu'environ un tiers de plus que Londres, dans toute son étendue. Mais indépendamment du vaste territoire qu'a acquis la Chine depuis la grande muraille jusque dans le voisinage de la mer Caspienne, ses quinze anciennes provinces sont à la Grande-Bretagne à peu près comme de quinze à un.

Une autre partie de Pékin attenante au mur de la cité tartare est distinguée sous le nom de cité chinoise. Là, logent, pour la plupart, les habitants des provinces que leurs affaires conduisent dans la capitale. Ses murailles, qui tombent presque en ruine, renferment un vaste espace d'environ neuf milles carrés. Cependant, il n'y a que peu de ce terrain occupé par des maisons qui sont peu élégantes, irrégulières et remplies de monde. Le reste du terrain n'est point bâti, et il y en a une partie en culture. C'est là 


\section{Voyage dans l'intérieur de la Chine et en Tartarie}

qu'on a élevé le Sien-Non-Tang, c'est-à-dire l'éminence des vénérables agriculteurs. L'empereur s'y rend tous les printemps et, conformément à l'ancien usage, il prend en main la charrue et la dirige à travers un petit champ pour honorer la profession de laboureur. Tandis que ce monarque est occupé à ce travail, qui dure environ une heure, un groupe de paysans l'accompagne en chantant des hymnes en I'honneur de l'agriculture. Ensuite les princes de la cour et les grands officiers de l'État prennent la charrue à son exemple, et tracent en sa présence plusieurs sillons. Ils sont tous, ainsi que l'empereur, vêtus d'une manière analogue aux travaux du jour. Le produit du champ labouré par leurs mains est recueilli soigneusement, et suivant l'annonce qu'on en fait solennellement, il surpasse en qualité et en quantité ce qu'a rendu, dans la même année, tout autre terrain d'une égale étendue. La célébration de cette fête, qu'on peut avec raison appeler une fête exemplaire, est publiée dans les villages de l'empire les plus éloignés. Elle est destinée à causer de la satisfaction au plus humble paysan, et à le consoler un peu des contretemps que lui occasionnent fréquemment les vicissitudes des saisons, quand il se rappelle que sa profession a été adoptée et ennoblie par son souverain qui se trouve, en effet, incorporé dans la plus utile et la plus nombreuse classe de ses sujets, et semble avoir dès lors un intérêt commun avec eux.

C'est aussi dans l'enceinte de la cité chinoise qu'on a élevé le Tien-Tan, c'est-à-dire l'Éminence du Ciel. Le simple caractère tien, ou ciel, est tracé sur le principal édifice de cette éminence. La forme de l'édifice est ronde, par allusion à la voûte des cieux, qui paraît telle à nos regards. Ainsi, le Tee-Tan, ou Temple de la Terre, est carré, parce que les anciens Chinois croyaient que la terre était un carré parfait.

Dans le solstice d'été, lorsque la chaleur du soleil est à son plus haut degré, l'empereur se rend en pompe sur le Tien-Tan, pour reconnaître le pouvoir de l'astre qui éclaire le monde, et le remercier de sa bénigne influence. Dans le solstice d'hiver, des cérémonies à peu près pareilles sont accomplies dans le Temple de la Terre. II n'y a rien de personnifié dans l'un, ni dans l'autre temple.

Quelques-uns des législateurs de la Chine se sont élevés de la contemplation d'une existence matérielle jusqu'à une première cause, à 


\section{Voyage dans l'intérieur de la Chine et en Tartarie}

laquelle ils ont donné un nom, et d'autres ont ajouté des sacrifices d'animaux à l'hommage qu'il faut lui rendre, comme si c'était un être susceptible d'être flatté par la destruction de la vie qu'il a donnée.

L'adoration solennelle du ciel et de la terre n'a lieu que de la part de l'empereur seul ; et c'est pour sa commodité qu'elle se fait à Pékin, où ce prince paraît dans plusieurs autres grandes cérémonies, inventées par le double intérêt de la politique et de la religion. Ce sont presque les seuls spectacles publics qu'il y a dans cette ville; et on peut un peu les comparer aux fonzioni, ou cérémonies religieuses du pontife de Rome. A d'autres égards, on voit dans la métropole de la Chine peu de ces causes qui contribuent à l'agrandissement des autres capitales.

Pékin est seulement le siège du gouvernement de l'empire. II n'a point de port. II n'est point le rendez-vous du commerce; il n'a point de manufactures. II ne s'y rassemble pas de diète représentative avec un grand nombre d'employés, pour aider, examiner ou réprimer les mesures du gouvernement. Ce n'est pas, non plus, un lieu de plaisir ou de dissipation.

Les principales villes de l'Europe doivent en très grande partie leur opulence, leur grandeur et leur population, à l'affluence de ces hommes qui, grâce à leurs pères ou à la faveur du prince, possèdent des richesses, sans avoir eu besoin de travailler pour les acquérir, et cherchent dans le concours du grand monde des occasions de jouir de leur fortune de la manière la plus agréable. Ils retirent la plus grande partie du revenu net du pays. Délivrés de l'inquiétude de se procurer leur subsistance, ignorant les passions de l'avarice et de l'ambition, presque étrangers aux soins ordinaires de la vie, jamais distraits par les incertitudes qui accompagnent toutes les entreprises, ils composent la partie de la société la plus agréable et la plus instruite. Beaucoup de perfectionnements, et quelques-unes des plus belles inventions dans les sciences, ont été le fruit de leur loisir. C'est principalement parmi eux qu'on trouve ces sentiments purs et élevés, et ces mœurs douces et polies, qui distinguent le caractère des honnêtes gens. Mais, excepté en ce qui concerne les sciences et les beaux-arts, ils sont peu utiles aux autres parties de la société, dont l'industrie assure leur subsistance. Les gens de cette classe, qui comprend les riches et les oisifs parmi la noblesse, et ceux d'un rang inférieur, sont très nombreux dans toutes les parties de l'Europe. Leurs 


\section{Voyage dans l'intérieur de la Chine et en Tartarie}

familles, leurs domestiques, les personnes qui travaillent pour leurs besoins multipliés, ou pour leurs divers amusements, contribuent beaucoup à l'accroissement de chaque capitale. Mais Pékin ne doit presque point à de pareille cause son étendue et sa population. La plupart des hommes y remplissent des postes qui leur sont régulièrement assignés, où ils sont employés auprès de ceux qui les occupent. Exceptés peut-être quelques parents de l'empereur, on n'y voit guère de ces gens dont la seule affaire est de chercher le plaisir et de perdre un temps que d'autres sont dans la nécessité d'employer en remplissant quelque devoir public, ou en travaillant à gagner leur vie.

A la Chine, il y a moins d'inégalité dans les fortunes que dans les conditions des hommes. Les anciennes annales de l'empire attestent que pendant très longtemps les habitants y jouissaient de la terre, ainsi que des autres éléments, presque en commun. Le pays était divisé en petits districts égaux, et chaque district était cultivé en commun par huit familles qui composaient chaque village, et jouissaient de tout le fruit de leurs labeurs, à l'exception d'une partie qu'on réservait pour les dépenses publiques. Ce ne fut qu'à la suite d'une révolution, dont parlent avec douleur toutes les histoires chinoises, antérieures à l'ère chrétienne, que l'usurpateur distribua toutes les terres aux compagnons de ses victoires, allouant seulement aux cultivateurs une petite portion du revenu.

La propriété des terres devint en même temps héréditaire ; mais, dans la suite, les domaines ont été subdivisés en petites parties, par les partages successifs des possessions que chaque père laisse également à tous ses enfants. Les filles ne reçoivent jamais de dot. II est très rare qu'il n'y ait dans une famille qu'un seul fils pour recueillir l'héritage de ses parents, et plus rare encore qu'on y ait des successions collatérales. Les mœurs du pays, ainsi que le vœu de la nature, engagent les hommes à se marier de bonne heure. On y regarde comme une sorte de déshonneur de n'avoir point d'enfants. Les hommes qui en sont privés adoptent ceux des autres, et dès lors, ils leur appartiennent exclusivement. Si l'on se marie avec une femme stérile, on a le droit d'en épouser une autre pendant la vie de la première. Les gens riches peuvent, ainsi que dans la plupart des autres contrées de l'Orient, avoir des concubines, sans qu'on leur en fasse un crime. Les enfants de ces concubines 


\section{Voyage dans l'intérieur de la Chine et en Tartarie}

sont considérés comme ceux de la femme légitime, pour laquelle on leur inspire de bonne heure de grands sentiments de respect et d'affection ; et ils jouissent de tous les droits de la légitimité.

Toutes ces différentes causes contribuent sans cesse à égaliser les fortunes, et peu de personnes accumulent assez de richesses pour que ces causes ne finissent pas par les diviser. En outre, les richesses donnent, en Chine, fort peu d'importance, et point de pouvoir. Lorsqu'on n'y a pas d'emploi, la propriété n'est jamais parfaitement sûre. II n'y a point de ces dignités héréditaires qui peuvent donner de la considération et de la prépondérance. L'autorité que le gouvernement confie pèse plus sur les riches sans protection que sur les pauvres qui ne tentent point la cupidité. Les Chinois remarquent communément que, parmi eux, les fortunes se conservent rarement dans la même famille jusqu'à la troisième génération, soit parce qu'elles sont divisées entre plusieurs héritiers, soit parce qu'on les perd dans des spéculations commerciales, au jeu, ou dans de folles dépenses, soit enfin, parce qu'elles sont extorquées par des mandarins oppresseurs. On ne peut remonter l'échelle de l'ambition que par des études longues et pénibles, et en excellant dans les lettres qui, seules, rendent capables de remplir les emplois publics.

A la Chine, il n'y a proprement que trois classes d'hommes. Les lettrés, parmi lesquels on choisit les mandarins, les agriculteurs, et les artisans, dans le nombre desquels on comprend les marchands. Ce n'est qu'à Pékin qu'on confère les derniers degrés dans les lettres à ceux qui, dans un examen public, montrent qu'ils ont acquis beaucoup de lumières sur les sciences de la morale et du gouvernement, telles qu'elles sont enseignées dans les anciens auteurs chinois, et avec lesquelles I'histoire du pays est intimement mêlée. L'empereur distribue, parmi ces gradués, tous les emplois civils de l'État. Les candidats qui veulent obtenir les derniers degrés sont ceux qui, dans la capitale de chaque province, ont subi avec succès un pareil examen. Ceux qui ont été élus dans les villes du second ordre, c'est-à-dire dans la principale ville de chaque district, deviennent les candidats des capitales des provinces. Ceux qui n'ont pas assez de capacité pour la première ou pour la seconde classe peuvent encore prétendre à des emplois subordonnés et proportionnés au degré pour lequel ils ont réussi. Ces examens se font avec une grande 


\section{Voyage dans l'intérieur de la Chine et en Tartarie}

solennité, et d'une manière qui paraît très impartiale. Les emplois dans l'armée sont également donnés à ceux qui l'ont emporté sur leurs concurrents dans les sciences et dans les exercices militaires.

Les grands tribunaux sont, à cause de la commodité, placés auprès de la porte méridionale du palais impérial de Pékin. C'est à eux qu'on rend exactement compte de tout ce qui se passe dans l'empire. Les affaires du moment sont rapportées par ces tribunaux, aux conseils particuliers de l'empereur, avec des avis motivés. Il y a un corps de doctrine, composé d'après les ouvrages écrits dès les premiers âges de l'empire, confirmé par les législateurs et les souverains successifs, et transmis d'âge en âge avec une vénération toujours croissante. Cette doctrine sert de règle aux jugements des tribunaux, et certes, elle est fondée sur les grandes bases de la justice universelle et sur les principes d'humanité les plus purs.

L'empereur se conforme ordinairement aux avis de ces tribunaux. II y a un tribunal chargé d'examiner les talents et les qualités que les mandarins développent dans leurs emplois, et de proposer le déplacement de ceux qui manquent de capacité ou de justice. Un autre a pour objet la conservation des mœurs et de la morale de l'empire. Les Européens l'appellent le tribunal des cérémonies, parce qu'il les règle, en établissant pour maxime que les formes extérieures contribuent beaucoup à empêcher qu'on ne s'écarte des règles de la morale. Le plus difficile, le plus sévère des tribunaux est celui des censeurs. II examine l'effet des lois subsistantes, ainsi que la conduite des autres tribunaux, des princes, des grands officiers de l'État et de l'empereur luimême. Il y a ensuite divers tribunaux subordonnés, tels que ceux des mathématiques, de médecine, de travaux publics, de littérature et d'histoire. Le tout forme un système régulier, établi à une époque très reculée, conservé avec très peu d'altérations par les différentes dynasties, et repris aussitôt qu'a cessé la puissance de quelques princes dont les caprices ou les passions l'ont écarté. Les changements qui ont été faits par la famille qui occupe actuellement le trône viennent de l'admission d'autant de Tartares que de Chinois dans chaque tribunal. L'opinion des premiers l'emporte, dit-on, toujours sur celle des autres. II est vrai que plusieurs d'entre eux sont des hommes qui joignent à de grands talents beaucoup de force d'âme et des mœurs très polies. Le vieux vice-roi de Pé-Ché-Lée est de race tartare. 


\section{Voyage dans l'intérieur de la Chine et en Tartarie}

Dans le siècle dernier, le jésuite Grimaldi, cité par Gemelli Carreri, prétendait que la population de Pékin s'élevait à seize millions d'âmes. Un autre missionnaire a beaucoup réduit cette estimation, et porté celle de la cité tartare à un million un quart seulement. D'après les meilleurs renseignements fournis à l'ambassade, toute la ville contient environ trois millions d'habitants. Les maisons basses de Pékin semblent ne pouvoir pas suffire à une pareille population: mais il faut peu de place pour une famille chinoise, du moins quand elle est de la moyenne ou de la dernière classe du peuple. Elle n'a jamais d'appartement superflu. Une maison chinoise est ordinairement environnée par un mur de six ou sept pieds de haut. Dans cette enceinte, on trouve souvent une famille de trois générations, avec toutes les femmes et les enfants. Une petite chambre suffit pour les individus de chaque branche de la famille, qui couchent dans différents lits, séparés seulement par des nattes pendues au plafond. II n'y a qu'une chambre à manger commune.

Cette coutume de réunir les différentes branches d'une famille sous le même toit a les plus importants effets. L'autorité et l'exemple des vieillards rendent la jeunesse plus modeste et plus réglée dans sa conduite; et tous ensemble subsistent, comme les soldats en chambrée, avec plus d'économie et d'avantage. Malgré cela, la pauvre classe, qui travaille, est réduite à se nourrir de végétaux; et si elle mange de la viande, c'est très peu et fort rarement. Dans tous les pays, le peuple veut bien, en général, se contenter, pour son travail, d'un salaire proportionné au prix des provisions.

La multitude d'habitants que renferme Pékin n'empêche pas qu'ils n'y jouissent d'une bonne santé. Les Chinois vivent beaucoup en plein air, et ils se vêtissent plus ou moins suivant la température. L'atmosphère de Pékin n'est point humide, et n'engendre point de maladies putrides; et les excès qui les produisent y sont fort rares.

Un très grand ordre est maintenu parmi les nombreux habitants de la capitale. Il est rare qu'on y ait des crimes à juger. II y a une institution qui ressemble assez à celles des anciens dizeniers en Angleterre : chaque dixième marchand est obligé de répondre de la conduite des neuf familles voisines, autant qu'il peut être supposé capable de les surveiller. Dans l'intérieur des 


\section{Voyage dans l'intérieur de la Chine et en Tartarie}

murailles, la police est observée avec une grande exactitude, et il y a autant d'ordre et de sûreté que dans un camp; mais il y règne aussi la même contrainte. Ce n'est que dans les faubourgs que sont tolérées et enregistrées les filles publiques; encore y sont-elles en petit nombre; c'est-à-dire en proportion du peu de célibataires et de maris absents de leurs familles, qui se trouvent dans la capitale.

Nous avons déjà observé que les Chinois qui sont dans l'aisance se marient de très bonne heure. Pour les pauvres, le mariage est une mesure de prudence, parce que les enfants, et particulièrement les fils sont obligés de prendre soin de leurs parents. Tout ce qui est fortement recommandé et généralement pratiqué finit par être considéré comme une sorte de devoir religieux. Les jeunes Chinois se marient donc aussitôt qu'ils ont le moindre espoir de pouvoir faire subsister les enfants qu'ils auront. Cependant, cet espoir n'est pas toujours réalisé ; et les enfants nés sans qu'on ait le moyen de les entretenir sont quelquefois abandonnés par les malheureux auteurs de leurs jours. Ce fut sans doute la plus cruelle, la plus absolue nécessité qui provoqua cet acte barbare et dénaturé, la première fois qu'il fut commis. Mais ensuite, l'âme en fut moins révoltée parce que la superstition vint à l'appui pour en faire un sacrifice à l'esprit de la rivière la plus voisine. Le malheureux enfant est jeté dans cette rivière avec une calebasse attachée au cou, afin qu'il ne se noie pas immédiatement.

Les philosophes de la Chine qui, avec autant d'habileté que d'effet, ont inculqué dans les cœurs les maximes de la pitié filiale, ont laissé en grande partie l'affection paternelle à son influence naturelle, qui ne maintient pas toujours son empire d'une manière aussi efficace que des sentiments fortifiés par des préceptes appris de bonne heure et répétés sans cesse. Ainsi, les Chinois négligent moins fréquemment leurs pères qu'ils n'exposent leurs enfants. Pour fortifier les dispositions à l'obéissance filiale, les lois de l'empire fournissent les moyens de punir la violation de ce devoir, en laissant aux pères un pouvoir absolu sur leurs enfants. L'habitude semble avoir appris à croire que la vie ne devient vraiment précieuse, et le défaut d'attention pour elle, criminel, qu'après qu'elle a duré assez longtemps pour donner à l'âme et aux sentiments le temps de se développer ; mais que l'existence à son aurore 


\section{Voyage dans l'intérieur de la Chine et en Tartarie}

peut être sacrifiée sans scrupule, encore qu'elle ne le soit pas sans répugnance.

On choisit le plus souvent des enfants femelles pour ce cruel sacrifice, parce qu'on regarde leur perte comme un moindre mal. Les filles sont considérées comme appartenant véritablement à la famille dans laquelle on les marie ; au lieu que les fils continuent à vivre dans les leurs, et deviennent le soutien et la consolation de leurs parents. Les enfants sont exposés immédiatement après leur naissance, et avant que leur figure paraisse assez animée, et que leurs traits soient assez formés pour captiver les affections qui naissent dans le sein paternel. Cependant, on a toujours un faible espoir que ces enfants pourront être dérobés à une mort prématurée par les personnes qu'entretient le gouvernement pour recueillir ces innocentes victimes, afin de pourvoir à la subsistance de celles qu'on trouve encore vivantes, et enterrer celles qui ont déjà expiré.

Les missionnaires partagent avec zèle un soin si rempli d'humanité. Ils se hâtent de baptiser ceux qui conservent le moindre signe de vie, afin, comme ils le disent, de sauver l'âme de ces êtres innocents. Un de ces pieux ecclésiastiques, qui n'avait nul penchant à exagérer le mal, avoua qu'à Pékin on exposait chaque année environ deux mille enfants, dont un grand nombre périssait. Les missionnaires prennent soin de tous ceux qu'ils peuvent conserver à la vie. Ils les élèvent dans les principes rigoureux et fervents du christianisme; et quelques-uns de ces disciples se rendent ensuite utiles à leur religion, en travaillant à y convertir leurs compatriotes.

Les conversions s'opèrent ordinairement parmi les pauvres qui, dans tous les pays, composent la classe la plus nombreuse. Les charités que les missionnaires font, autant qu'ils peuvent, préviennent en faveur de la doctrine qu'ils prêchent. Quelques Chinois ne se conforment, peut-être, qu'en apparence à cette doctrine, à cause des bienfaits qu'elle leur vaut ; mais leurs enfants deviennent des chrétiens sincères. D'ailleurs, on a toujours plus d'accès auprès des pauvres ; et ils sont plus touchés du zèle désintéressé des étrangers qui viennent du bout de la terre pour les sauver.

C'est un spectacle singulier, en effet, pour toutes les classes des spectateurs, que de voir des hommes, animés par des motifs différents de 


\section{Voyage dans l'intérieur de la Chine et en Tartarie}

ceux de la plupart des actions humaines, quittant pour jamais leur patrie et leurs amis, et se consacrant pour le reste de leur vie au soin de travailler à changer le dogme d'un peuple qu'ils n'ont jamais vu. En poursuivant leurs desseins, ils courent toute sorte de risques; ils souffrent toute espèce de persécution, et renoncent à tous les agréments. Mais à force d'adresse, de talent, de persévérance, d'humilité, d'application à des études étrangères à leur première éducation, et en cultivant des arts entièrement nouveaux pour eux, ils parviennent à se faire connaître et protéger. Ils triomphent du malheur d'être étrangers dans un pays où la plupart des étrangers sont proscrits, et où c'est un crime que d'avoir abandonné le tombeau de ses pères. Ils obtiennent enfin des établissements nécessaires à la propagation de leur foi, sans employer leur influence à se procurer aucun avantage personnel.

Les missionnaires de différentes nations ont eu la permission de bâtir, à Pékin, quatre couvents, avec des églises qui y sont jointes. II y en a même quelqu'un dans les limites du palais impérial. Ils ont des terres dans le voisinage de la ville; et on assure que les jésuites ont possédé, dans la cité et dans les faubourgs, plusieurs maisons, dont le revenu servait seulement à favoriser l'objet de la mission. Ils ont souvent, par des actes charitables, fait des prosélytes et secouru des malheureux.

Lorsque l'ambassade fut à Pékin, la plupart des missionnaires lui rendirent visite. L'un d'entre eux, Portugais d'un caractère doux et conciliant, était nommé par l'empereur de la Chine, chef des Européens du tribunal des mathématiques; et en même temps le pape lui avait conféré, à la recommandation de la reine de Portugal, le titre d'évêque de Pékin. Les principales puissances catholiques accordent régulièrement de petites sommes pour l'entretien des missionnaires, et ceux-ci par reconnaissance et par attachement national servent, jusqu'à un certain point, d'agents pour les pays où ils sont nés respectivement, et défendent, au besoin, les intérêts de ces pays. Des différences d'opinion ont autrefois divisé les sociétés de missionnaires sur des points particuliers de doctrine; et quelque rivalité subsiste entre ceux d'un certain pays de l'Europe et les autres. Mais la plupart du temps, ils sont réunis par un intérêt commun et une conformité de mœurs, très différentes de celles des Chinois. Dans ces contrées lointaines, tout 


\section{Voyage dans l'intérieur de la Chine et en Tartarie}

Européen est salué par un compatriote, et a droit à son attention et à ses services.

L'un des plus respectables missionnaires, avantageusement connu dans le monde littéraire, par les remarques curieuses qu'il avait publiées sur la Chine, où il résidait depuis sa jeunesse, était devenu si infirme qu'il ne fut pas en état de se transporter chez l'ambassadeur ; mais il lui écrivit pour lui faire part des vœux ardents qu'il formait pour ses succès. II lui offrit tous les secours que ses observations et son expérience le mettaient à même de pouvoir lui donner. II lui fit un tableau de la cour qu'il allait visiter, et l'engagea à espérer qu'il finirait par y obtenir tout ce qu'il désirait. En même temps, il le prévint des difficultés et des délais qu'il éprouverait à toute occasion; parce que, dans cette cour, on ne pouvait rien obtenir sans beaucoup de patience et des efforts réitérés.

Indépendamment des visites des missionnaires, du légat et des principaux Chinois qui avaient accompagné l'ambassade, lord Macartney en reçut, chaque jour, des mandarins des premiers rangs. Les uns venaient chez lui parce que les emplois qu'ils occupaient leur en faisaient un devoir ; les autres y étaient attirés par la curiosité, et plusieurs par les musiciens européens qui, tous les soirs, donnaient concert dans les appartements de l'ambassadeur. Parmi les Chinois qui parurent le plus souvent chez ce ministre, était le premier directeur de l'orchestre de l'empereur. II y venait continuellement, et était si charmé de quelques instruments, qu'il désira d'en avoir les dessins. II ne voulut pourtant pas les accepter en présent ; mais il envoya des peintres qui, après avoir étendu de grandes feuilles de papier sur le plancher, y placèrent les clarinettes, les flûtes, les bassons et les cors de chasse, tracèrent, avec leurs pinceaux, les figures de ces instruments, mesurant toutes les ouvertures, et notant les moindres particularités. Quand cette opération fut achevée, ils écrivirent leurs remarques au bas des dessins, et les remirent au directeur. Celui-ci dit que son intention était de faire faire de pareils instruments, par des ouvriers chinois, et de leur donner des proportions d'après son idée. Un petit nombre de Chinois avait adopté le violon européen ; mais il n'était pas communément en usage à Pékin. On s'y servait d'un autre instrument qui avait la même forme, mais n'était garni que 


\section{Voyage dans l'intérieur de la Chine et en Tartarie}

de deux cordes. Quelques Chinois avaient déjà appris à noter la musique sur du papier rayé.

Beaucoup de personnes se rendirent au palais de Yuen-Min-Yuen, afin de voir les présents qu'on y avait déposés pour l'empereur. Divers ouvriers européens et chinois avaient commencé à ôter de leurs caisses, les parties des machines qui étaient démontées, et les autres articles. Au nombre des spectateurs étaient trois petit-fils de l'empereur, qui admirèrent, avec franchise, ce qu'ils voyaient. Quelques-uns des mandarins semblaient, au contraire, craindre de se livrer à des transports du même genre, et affectaient de considérer ces objets nouveaux comme des ouvrages d'un mérite ordinaire. Cependant, tous les yeux se fixaient sur les vases, qui étaient au nombre des plus belles productions de l'art de $M$. Wedgwood ${ }^{1}$. Chaque Chinois est juge en fait de porcelaine; et ils louèrent universellement ces échantillons de superbes ouvrages qui sortent des manufactures d'Europe.

Il y avait, parmi les présents, un volume de portraits de la principale noblesse d'Angleterre. Afin que l'empereur eût plus d'agrément en parcourant ce volume, un mandarin se chargea de tracer sur les marges, en caractères chinois, le nom et le rang des personnages qui y étaient représentés. Quand ce mandarin en fut à l'estampe représentant un duc anglais, gravé d'après le portrait peint par sir Josué Reynolds, lorsque ce duc était encore enfant, on lui dit que l'original était un ta-zhin, c'est-à-dire un homme d'un rang élevé, et même d'un très haut rang. Le mandarin concevait si peu qu'un enfant possédât, par droit héréditaire, une pareille distinction, qu'il jeta un regard de surprise ; et posant le pinceau avec lequel on trace les caractères chinois, il s'écria qu'il ne pouvait pas mettre une telle inscription à ce portrait, parce que l'empereur savait fort bien distinguer un homme d'un rang élevé d'un enfant.

Pendant le séjour que l'ambassade fit à Pékin, quelques Anglais eurent souvent occasion d'aller au palais impérial, situé dans la campagne, et retournant chaque fois par un chemin différent, ils purent facilement voir la plus grande partie de la capitale. L'ambassadeur se promena aussi dans une

\footnotetext{
${ }^{1}$ Artiste célèbre qui est mort peu avant la publication de la traduction française de cet ouvrage, à la fin du XVIII ${ }^{\mathrm{e}}$ siècle.
} 


\section{Voyage dans l'intérieur de la Chine et en Tartarie}

voiture anglaise, attelée de quatre chevaux tartares, d'une belle taille, lesquels étaient conduits par des postillons choisis parmi les gardes qui avaient autrefois exercé cette profession en Angleterre. C'était un spectacle nouveau pour les Chinois, accoutumés à leurs voitures basses, grossièrement faites, à deux roues seulement, sans ressorts, et ne valant guère mieux que les mauvaises charrettes d'Europe. Quand on eut déballé et monté le superbe carrosse destiné à être offert à l'empereur, il fut extrêmement admiré. Mais il fallut donner des ordres pour en faire ôter le siège ; car les mandarins ayant vu que ce siège si élevé était destiné pour celui qui devait mener les chevaux, ils témoignèrent le plus grand étonnement de ce qu'on proposait de faire asseoir un homme au-dessus de l'empereur, tant la délicatesse de ce peuple est susceptible pour tout ce qui a rapport à la personne de son sublime souverain!

Dans la soirée qui précéda le départ de l'ambassadeur pour Zhé-Hol, un mandarin du premier rang se rendit chez lord Macartney avec un message très gracieux, de la part de l'empereur. Ce prince ayant su que la santé de l'ambassadeur avait été un peu altérée, en demandait des nouvelles, et recommandait à ce ministre de faire le voyage de la Tartarie à petites journées, comme il le faisait lui-même. Il ajoutait que l'ambassadeur et sa suite seraient logés dans les palais qu'on a construits sur la route, pour servir de stations à sa majesté impériale lorsqu'elle se rend à Zhé-Hol.

Le planétaire n'était pas encore achevé d'ajuster, lorsque l'ambassadeur partit pour la Tartarie : le docteur Dinwiddie resta pour surveiller cet ouvrage délicat. D'autres Anglais attachés à l'ambassade restèrent aussi pour diverses raisons à Pékin et à Yuen-Min-Yuen. Quelques-uns furent retenus par des indispositions : de ce nombre était un des jardiniers botanistes. II avait déjà recueilli plusieurs espèces de plantes de la province de Pé-Ché-Lée, et il en conservait une liste que nous allons ajouter à ce chapitre ${ }^{1}$, parce qu'elle peut être intéressante pour les botanistes.

\footnotetext{
${ }^{1}$ Cf. appendice.
} 
Voyage dans l'intérieur de la Chine et en Tartarie 
Voyage dans l'intérieur de la Chine et en Tartarie

\section{TROISI È ME \\ P A R TI E}




\section{Voyage dans l'intérieur de la Chine et en Tartarie}

\section{CHAPITRE PREMIER}

\section{Voyage aux frontières septentrionales de la Chine. Vue de la grande muraille.}

L' Ambassadeur, accompagné par le même nombre de Chinois qu'il avait eu jusqu'alors, et par la plus grande partie des Européens de sa suite, partit de Pékin le 2 septembre 1793.

La plaine où cette capitale est située s'étend très loin au nord et à l'est. Sur la gauche, c'est-à-dire à l'ouest, les montagnes ne sont qu'à peu de distance ; mais sur la droite, la terre, dans une étendue de plusieurs milles, est d'un niveau parfait jusqu'au golfe de Pé-Ché-Lée, et la mer semble s'être retirée du pied des montagnes qu'elle baignait originairement. Des rangs de saules, à l'écorce inégale ${ }^{1}$, d'une grosseur prodigieuse, ombragent le chemin qui traverse la plaine. C'est l'arbre qui semble le plus propre au sol.

Dans cette partie du chemin, l'ambassadeur voyagea dans sa voiture européenne ; et c'était sans doute la première fois qu'une chaise de poste anglaise ${ }^{2}$ roulait sur la route de la Tartarie. L'ambassadeur prit, de temps en temps, avec lui quelqu'un des mandarins. D'abord, ils eurent peur que la voiture, qui était suspendue très haut et qui leur semblait chanceler, ne se renversât; mais quand ils furent certains qu'elle était solide, ils parurent enchantés de son aisance, de sa légèreté, de sa rapidité. Ils admiraient l'élasticité des ressorts et les diverses inventions pour lever et baisser les glaces et les stores, ainsi que pour accroître ou diminuer à volonté le jour que procurent les jalousies.

Le sol adjacent au chemin uni que suivait l'ambassade est comme celui de l'autre côté de Pékin, gras, argileux, et donne en général diverses

\footnotetext{
1 Salix fragilis.

2 Les Anglais appellent chaises de poste des voitures à quatre roues. (Note du Traducteur.)
} 


\section{Voyage dans l'intérieur de la Chine et en Tartarie}

productions. Un champ attira l'attention particulière des Anglais; il était couvert de polygonum, que d'après l'égale hauteur des tiges, ils jugèrent avoir été planté. Bientôt, ils apprirent que les feuilles de cette plante, macérées et préparées comme celles de l'indigo, produisent une couleur bleue, égale à celle de l'indigo, ou qui du moins en approche beaucoup. II serait à désirer que dans les climats où, comme dans celui de Pékin, l'indigo ne croît pas, on fît des expériences pour savoir jusqu'à quel point il serait avantageux de lui substituer la couleur de ce polygonum. On cita en même temps aux Anglais une petite espèce de colutea, dont les bourgeons et les feuilles les plus tendres produisent une substance qui donne une couleur verte.

De tous les végétaux qui croissent à la Chine, il n'en est presque aucun dont les différents avantages qu'on peut en retirer dans le cours de la vie n'aient été découverts, soit à force d'essais, soit par des observations accidentelles qu'a fourni occasion de faire une longue suite de siècles; de sorte que les Chinois ont réussi à avoir chez eux beaucoup d'articles qu'autrement ils eussent été obligés de tirer des autres pays. Par exemple, ils se servent de la graine d'une espèce de fagara au lieu de poivre. Ils n'ont point d'oliviers, mais ils tirent une excellente huile des amandes d'abricot. Ils en ont d'autres plus communes qu'ils extraient des graines de sésame, de chanvre, de cotonnier, de navet, d'une espèce de menthe, et de beaucoup d'autres plantes. On peut dire qu'à la Chine il n'y a pas une herbe inutile. On y fait de la toile avec les fibres de l'ortie morte, et du papier avec l'écorce de différents végétaux, les fibres du chanvre et la paille du riz. Une espèce de momordica s'y mange comme les concombres; une sorte de chardon y sert à relever le goût du riz ; et la boursette ${ }^{1}$ y est parfois mêlée dans les salades. Les Chinois tirent du carthamus leur plus beau rouge, et emploient rarement le vermillon. Le calice du gland leur sert à teindre en noir ; et ils nourrissent le ver à soie avec les feuilles du frêne, comme avec celles du mûrier.

Dans les plaines que traversa l'ambassade en sortant de Pékin pour se rendre à Zhé-Hol, on ne voit indépendamment des diverses espèces de saule,

\footnotetext{
1 Thlaspi, bursa pastoris.
} 


\section{Voyage dans l'intérieur de la Chine et en Tartarie}

que quelques peupliers plantés autour des cimetières, et un petit nombre de frênes et de mûriers qui croissent en différents endroits. Le saule ${ }^{1}$, qui se distingue par ses branches et ses feuilles pendantes, orne les bords des ruisseaux et des rivières. Les Anglais en virent un qui, mesuré à la hauteur d'un homme, avait quinze pieds de circonférence. Le premier jour de leur marche, ils traversèrent, le matin, une rivière étroite, mais assez profonde pour porter de petits bateaux ; il y en avait même une quantité considérable. Le cours de toutes les rivières qui arrosent ce pays va au sud ou à l'est. Les bateaux qui y naviguent portent des marchandises des confins de la Tartane. On charrie d'autres marchandises qu'on tire du même pays ou qu'on y transporte, sur le dos des dromadaires, ou chameaux à double bosse, animaux qui sont plus gros, plus forts, plus rapides que les chameaux ordinaires. Ils sont aussi beaucoup plus velus que ces derniers, et conséquemment plus propres aux climats froids. On les charges souvent avec des pelleteries, la plus riche des productions de la Tartane : mais on les emploie aussi pour des objets d'une moindre valeur qu'on prend dans le même pays. C'est sur le dos de ces animaux qu'on transporte le charbon, qui sert à faire cuire tout ce qui se mange à Pékin. Les moutons que les Anglais virent paître dans ces plaines étaient de l'espèce dont la queue très courte, mais très grosse, pèse plusieurs livres, et est singulièrement prisée par les gourmands de la Chine.

A environ vingt milles de Pékin, le pays qui s'étend vers la Tartarie commence à s'élever. A mesure qu'on monte, le sol change, devient plus sablonneux, et on y voit bien moins d'argile et de terre noire. A quelques milles plus loin, les voyageurs firent halte pour le reste de la journée dans un de ces palais, bâtis pour la commodité de l'empereur, et dont nous avons fait mention à la fin du chapitre précédent. Ce palais était placé sur un terrain irrégulier, au pied d'une jolie colline, laquelle était, ainsi qu'une partie de la plaine, enclose et divisée en parc et en jardins d'agréments qui faisaient un très bel effet. Il y avait des bosquets épais, mais qui ne dérobaient point la vue d'un ruisseau qui coulait à peu de distance. Au-delà de ce ruisseau, quelques éminences étaient plantées d'arbres, et d'autres nues; ces

\footnotetext{
${ }^{1}$ Le saule pleureur.
} 


\section{Voyage dans l'intérieur de la Chine et en Tartarie}

différents objets semblaient être dans leur état naturel, et rassemblés seulement par un hasard heureux. Un jardinier chinois est le peintre de la nature : sans règle et sans science dans ce qu'il invente, il cherche à réunir la simplicité et la beauté.

Au-delà du palais, les montagnes se rapprochent et forment un passage d'environ un mille de largeur. Il y a dans leur voisinage quelques eaux minérales, qu'on appelle les bains de l'empereur, soit parce qu'il les a fait arranger à ses dépens, soit parce que quelqu'un de la famille impériale en a fait usage, ou parce que c'est à lui qu'est censé appartenir tout ce qui n'est point propriété particulière.

Au-delà du passage est une plaine très étendue, où l'on voit plusieurs villages, deux villes du second ordre, entourées de murs et un autre palais impérial. On aperçoit dans les jardins de ce palais quelques traces d'une substance blanche, semblable à la craie, qu'on appelle en termes techniques venant au jour.

Quoique les voyageurs dont nous écrivons la relation eussent visité, dans le cours de leur expédition, une partie des îles d'Afrique, du continent de l'Amérique, des îles de la mer du Sud, et du continent d'Asie, ils n'avaient point encore, depuis leur départ d'Angleterre, rencontré une seule fois, ce qui est si commun dans la province de la Chine où ils étaient alors, une terre pleine de craie. Ils n'avaient pas vu, non plus, de ces cailloux qui ont la forme des nœuds d'arbres, et qui sont en général sur une ligne horizontale dans les lits de craie. Les substances calcaires de diverses espèces qui avaient été vues par eux dans leur long trajet étaient très peu considérables, en comparaison des produits d'un feu volcanique, et des énormes masses de granit, qui se présentaient si fréquemment sur leur route. La dernière de ces matières est rare en Angleterre, et l'autre ne s'y voit point, non plus que sur la route de la Tartarie, où les voyageurs commencèrent à apercevoir beaucoup d'autres substances minéralogiques, semblables à celles de leur pays.

Cependant, la plupart des montagnes, auprès desquelles passèrent les Anglais dans le second jour de leur route, avaient quelque chose de singulier dans leur forme et dans leur position. Elles avaient chacune leur propre base, 


\section{Voyage dans l'intérieur de la Chine et en Tartarie}

et s'élevaient simplement du sein de la plaine, dans laquelle elles étaient semées sans ordre. Paraissant affecter les surfaces unies et semées par des angles, elles étaient arrondies et diminuées par le laps du temps, et conservaient pourtant assez de régularité dans leur forme, pour que l'imagination fût tentée de comparer leurs masses à d'énormes cristallisations.

Les terrains les moins élevés de ces contrées sont, en très grande partie, plantés en tabac. Les Chinois le fument dans des tubes de bambou, et la coutume de fumer est peut-être plus générale parmi eux que dans tout autre pays ; car elle s'étend aux personnes des deux sexes, même à celles d'un âge tendre. Des filles de dix ans, ou encore plus jeunes, que la curiosité faisait sortir des maisons pour voir passer les voyageurs, avaient toujours une longue pipe à la bouche.

Les Européens supposent que le tabac a été porté, de l'Amérique, dans toutes les parties de l'ancien continent. II n'y a cependant aucune tradition qui conserve la mémoire d'une telle introduction à la Chine, ni même dans I'Inde, où l'on cultive et consomme également une grande quantité de tabac. $\mathrm{Ni}$ dans l'une, ni dans l'autre de ces contrées, les usages étranges ne sont adoptés précipitamment. II est possible que le tabac se trouve naturellement ainsi que le gensing, dans quelques endroits des deux mondes.

Les Chinois prennent aussi du tabac en poudre. Un mandarin est rarement sans une petite fiole, très élégante, dans laquelle il tient son tabac; et plusieurs fois par jour, il en met sur le dessus de sa main gauche, entre l'index et le pouce, une quantité à peu près égale à une prise, qu'il porte à son nez et prend avec soin. Ce n'est point la seule substance dont les Chinois fassent usage pour satisfaire ce besoin factice. Ils prennent souvent du cinabre en poudre, au lieu de tabac; de même qu'ils se servent d'opium et d'ingrédients odorants pour fumer.

Le temps où l'ambassade anglaise se rendait de Pékin à Zhé-Hol était la saison où l'on prépare le tabac; opération qui, dans ces contrées, se fait toujours en plein air. 


\section{Voyage dans l'intérieur de la Chine et en Tartarie}

En Amérique, on a besoin de plusieurs bâtiments pour cette sorte de manufacture; mais en Chine, il n'en faut presque point, parce qu'on n'y craint point qu'il tombe de la pluie, et que les feuilles de tabac soient gâtées lorsqu'elles ont été recueillies. On les suspend à des cordes pour les faire sécher, sans aucun abri, et sur les lieux mêmes où elles ont crû. Chaque propriétaire n'a besoin que de sa famille pour l'aider à prendre soin de sa récolte. Ces circonstances servent à faire connaître et combien le climat est peu sujet à l'humidité, et combien les propriétés territoriales sont divisées en petites parcelles. II y a cependant dans cette partie de la Chine quelques terres que des familles tartares ont obtenues à titre de fief et en s'assujettissant à un service militaire. Ces fiefs sont toujours l'héritage du fils aîné : mais ils ne sont pas nombreux, et il n'y en a, dit-on, aucun de bien considérable.

Le troisième jour de leur voyage, les Anglais crurent s'apercevoir que la population diminuait un peu. Le chemin traversait une petite ville entourée de murailles, mais sans canons qui, à la vérité, sont jugés inutiles, parce qu'il n'y a à craindre de ce côté-là aucun ennemi qui ait de l'artillerie. Le principal usage de ces remparts, c'est de servir de halte à ceux qui conduisent, dans la capitale, les tributs et les impôts, recueillis dans les districts voisins, et de rendre plus sûrs les lieux où sont les greniers publics et les prisons. On y met, en conséquence, des troupes en garnison. D'autres troupes sont employées à entretenir les chemins qui sont si raides et si raboteux, en quelques endroits, que lord Macartney fut obligé de descendre de sa voiture et de la faire traîner à vide. Pendant ce temps-là, il se faisait porter en palanquin. Le coup d'œil qu'offrait ce pays était très agréable et très romantique. Des chèvres et des chevaux sauvages paissaient et bondissaient sur les montagnes, et des hommes escaladaient des précipices pour trouver quelques endroits propres à la culture.

Suivant la remarque du docteur Gillan, les montagnes ont, en général, une pente douce en allant vers la Tartarie ; mais du côté de la mer, elles sont presque à pic, présentent souvent un roc nu, et ressemblent à ce que l'on appelle en Suisse les aiguilles des Alpes. Les diverses couches de ces montagnes paraissent être dans l'ordre suivant: la première couche, vue 


\section{Voyage dans l'intérieur de la Chine et en Tartarie}

dans les parties les plus profondes des lits que la rivière avait laissés à sec, était de sable et de pierre vitrifiable; la seconde était de pierre à chaux, rude, grenue, remplie de nœuds, et d'une couleur bleue. La troisième couche était très épaisse, très irrégulière, formée d'une argile durcie, de couleur bleue, et quelquefois aussi d'un brun rouge que lui communique la chaux de fer. En quelques endroits, cette chaux est si abondante qu'elle donne à l'argile une apparence d'ocre, et dans d'autres, la dernière couche pouvait seule paraître. Dans plusieurs parties des environs de la Tartarie, on voit des veines perpendiculaires de spalt blanc, et quelquefois blanc et bleu. Sur le sommet des plus hautes montagnes, des deux côtés de la route, sont de grandes masses de granit; mais aucune ne descend jusqu'au niveau du chemin.

Le pied de quelques-unes de ces montagnes est baigné par une rivière qui coule vers le sud, sur laquelle il y a un pont jeté sur des pierres encaissées dans des claies. De tels ponts sont communs dans cette partie de la Chine, où on les construit avec promptitude et à peu de frais, et où l'ouvrage le plus solide ne résisterait pas longtemps aux torrents qui se précipitent tout à coup du haut des montagnes voisines. Les encaissements sont de différentes dimensions et proportionnés à l'accroissement que prend la rivière quand elle déborde. Des pieux plantés perpendiculairement les retiennent; et le nombre et la force de ces pieux sont proportionnés à la profondeur de la rivière et à la rapidité du courant. Dans les rivières larges, navigables, l'encaissement est discontinué dans le milieu, et on y met de grands bateaux plats. Le tout est couvert de planches, de claies, et de gravier. Lorsqu'on attend l'empereur, on construit quelques ponts pour le moment, de peur que la foule extraordinaire et les pesants fardeaux qui passent sur les autres ne les fassent écrouler.

A mesure qu'ils s'avançaient vers la Tartarie, les voyageurs remarquaient que les villes et les villages qu'ils rencontraient sur la route contenaient presque autant de Tartares que de Chinois; et la différence entre les mœurs et les traits caractéristiques de ces deux nations était moins frappante. Les Tartares sont, en général, plus robustes que les Chinois, mais ils ont moins d'expressions dans la physionomie, et moins de civilité dans les manières. Leurs femmes sont faciles à distinguer des autres, parce qu'elles ont le pied d'une grandeur naturelle. Leur coiffure, ainsi que celle des Chinoises, consiste à placer sur les côtés de la tête et au-dessus des oreilles, des fleurs naturelles 


\section{Voyage dans l'intérieur de la Chine et en Tartarie}

ou artificielles. Quelque pauvres ou quelqu'âgées qu'elles soient, les femmes ne négligent point cette parure. Aussi, la culture des fleurs est régulièrement en usage dans tout le pays. Grâce à une longue pratique et à des expériences multipliées, les jardiniers chinois ont découvert des méthodes pour perfectionner la beauté, la grandeur et le parfum de leurs fleurs, telles que l'anémone, la pivoine, la matricaire et beaucoup d'autres. La tubéreuse leur a été portée par les missionnaires européens.

Les mœurs tartares, moins régulières que celles des Chinois, étaient cause que les voyageurs rencontraient de temps en temps, sur la route, des mendiants, comme on en voit sur celles de l'Europe. Ils ne parlaient point; mais par leur extérieur sale et dépenaillé, et par l'exposition de quelque infirmité naturelle ou accidentelle, ils cherchaient à exciter la commisération des passants.

Dans la matinée du quatrième jour de leur marche, les Anglais aperçurent au loin une ligne proéminente, ou plutôt une marque étroite et inégale, pareille à celles que forment quelquefois, mais plus irrégulièrement, les veines de quartz sur les montagnes de gneiss, en Ecosse, quand on les voit à une très grande distance. La continuité de cette ligne sur le sommet des montagnes de la Tartarie suffisait pour captiver l'attention des voyageurs; et ils distinguèrent en peu de temps la forme d'une muraille avec des créneaux, dans des endroits où l'on ne s'attend pas ordinairement à trouver de pareils ouvrages, et où l'on ne croit pas même qu'il soit possible de les construire.

Tout ce que l'œil peut embrasser, à la fois, de cette muraille fortifiée, prolongée sur la chaîne des montagnes et sur les sommets les plus élevés, descendant dans les plus profondes vallées, traversant les rivières par des arches qui la soutiennent, doublée, triplée en plusieurs endroits, pour rendre les passages plus difficiles, et ayant des tours ou de forts bastions à peu près de cent pas en cent pas; tout cela, dis-je, présente à l'âme l'idée d'une entreprise d'une grandeur étonnante.

Les Anglais furent alors à même de juger, d'après ce qu'ils sentaient, que quelque considérables qu'elles soient, les dimensions de cette barrière destinée à arrêter les Tartares n'étaient pas la seule chose dont eût été 


\section{Voyage dans l'intérieur de la Chine et en Tartarie}

frappée la vue des voyageurs qui l'avaient contemplée avant eux. II est rare que ce qui peut être simplement l'effet d'un travail long et multiplié excite l'étonnement. Mais ce qui cause de la surprise et de l'admiration, c'est l'extrême difficulté de concevoir comment on a pu porter des matériaux et bâtir ces murs dans des endroits qui semblent inaccessibles. L'une des montagnes les plus élevées, sur lesquelles se prolonge la grande muraille, a, d'après une mesure exacte, cinq mille deux cent vingt-cinq pieds de haut.

Cette espèce de fortification - car le simple nom de muraille ne donne pas une juste idée de sa structure - cette fortification a, dit-on, quinze cents milles de long; mais, à la vérité, elle n'est pas également parfaite. Cette étendue de quinze cents milles était celle des frontières qui séparaient les Chinois civilisés et diverses tribus de Tartares vagabonds. Ce n'est point de ces sortes de barrières que peut dépendre aujourd'hui le sort des nations qui se font la guerre. La force des armées triomphe de toute sorte d'obstacles. II n'y a plus de fortifications imprenables, mais elles peuvent ralentir les progrès de l'ennemi. Elles empêchent un pays d'être surpris en temps de guerre par une invasion soudaine; et des murailles fortifiées, qui s'élèvent sur une ligne de démarcation, protègent, en temps de paix, contre les incursions et les attaques partielles des bandits, qui cherchent à piller. Ainsi, tout braves et belliqueux qu'ils étaient, les Romains élevèrent, dans la Grande-Bretagne, plusieurs de ces barrières contres les Pictes sauvages. Toutes les fois qu'un peuple, dans un état social assez avancé pour s'occuper à cultiver la terre, en a dans son voisinage un autre qui n'est que chasseur, et peut être considéré comme tenant de la nature des animaux de proie, le premier oppose des remparts aux dévastations perpétuelles du second. Ce fut la raison qui en fit jadis élever en Egypte, en Syrie, en Médie. Une muraille fut construite par l'un des successeurs d'Alexandre, à l'orient de la mer Caspienne, et l'autre dans le pays de Tamerlan; toutes deux étaient destinées, comme celle des Chinois, à arrêter les hordes errantes des Tartares.

Il est vraisemblable que la plupart de ces murs répondirent quelque temps au but qu'on s'était proposé en les entreprenant, et peut-être même jusqu'à ce que les circonstances, qui avaient exigé la séparation des pays où ils étaient construits, eussent cessé d'exister. Le souvenir de ces travaux les place encore au rang des plus grands monuments des entreprises humaines. 


\section{Voyage dans l'intérieur de la Chine et en Tartarie}

Cependant, soit qu'on les considère relativement à l'étendue du pays qu'ils défendaient, soit qu'on calcule la quantité de matériaux employés à leur construction, ou le travail nécessaire pour triompher des difficultés qu'offraient des lieux où on les a bâtis, tous ces murs ensemble n'égalent pas la seule muraille de la Chine. Elle les surpasse également de beaucoup par la solidité et par la durée. A la vérité, plusieurs des moindres ouvrages en dedans de ces grands remparts cèdent aux efforts du temps, et commencent à tomber en ruines; d'autres ont été réparés: mais la muraille principale paraît, presque partout, avoir été bâtie avec tant de soin et d'habileté que, sans qu'on ait jamais eu besoin d'y toucher, elle se conserve entière depuis environ deux mille ans; et elle paraît encore aussi peu susceptible de dégradation que les boulevards de rocher que la nature a élevés elle-même entre la Chine et la Tartarie.

L'époque où a été commencée la construction d'une barrière artificielle entre ces deux pays n'est point particulièrement déterminée : mais celle de son achèvement est un fait aussi authentique qu'aucun autre de ceux que les annales des anciens États ont transmis à la postérité. Depuis cette époque, qui remonte trois siècles au-delà de l'ère chrétienne, les principaux événements de l'empire chinois ont été mentionnés régulièrement et sans interruption, dans les documents officiels et dans les ouvrages particuliers des écrivains contemporains. Nulle autre part l'histoire n'est autant devenue l'objet de l'attention publique et de l'occupation des savants. Chacune des principales villes de l'empire a une espèce d'université, où l'on confère des degrés à ceux qui ont fait des progrès dans la science de l'histoire et du gouvernement de l'État. Les ouvrages historiques sont multipliés. Les récits des faits récents sont exposés à la correction de ceux qui en ont été témoins ; et les écrits sur les anciens événements, à la critique des auteurs rivaux. D'après tout cela, on ne peut guère avoir de doute sur l'époque d'une entreprise à laquelle ont travaillé plusieurs cent milliers d'hommes; époque rapportée dans les histoires du temps, et citée dans toutes celles des siècles postérieurs.

L'évidence historique dépend d'abord du crédit qu'on accorde aux assertions des écrivains contemporains, et de la manière dont ils s'accordent avec les fastes, les monuments publics, ainsi qu'avec les faits et les 


\section{Voyage dans l'intérieur de la Chine et en Tartarie}

circonstances que les lecteurs sont à portée de connaître ou d'observer. Ces écrivains accrédités confirment, d'après les mêmes principes, la véracité de ceux qui les ont immédiatement précédés. Ainsi, les faits sont tracés et discutés en rétrogradant aussi loin que peut régulièrement conduire la chaîne qui les lie, et jusqu'aux plus anciens événements dont l'authenticité inspire quelque confiance. C'est sur de pareilles bases qu'est fondée la croyance des choses qui n'ont pu frapper immédiatement nos sens. Par exemple, nous n'avons aucun autre moyen de juger que la République romaine a certainement existé; que la bataille d'Actium a été donnée, et qu'un conquérant normand a envahi l'Angleterre.

Pendant les vingt siècles qu'il paraît également certain qu'a subsisté la grande muraille, il y en a seize où elle a suffi pour arrêter les hordes tartares. Mais le torrent qu'entraînait sur ses pas le puissant Gengis Khan rendit toute résistance vaine. Ses descendants ne surent pourtant pas conserver le même avantage, et en moins d'un siècle, les Tartares furent chassés de la Chine. Ce ne fut que trois cents ans après, c'est-à-dire vers la fin du siècle dernier, que la violence des guerres intestines les y fit rappeler; et depuis, ils ont maintenu l'empire dans un état tranquille et florissant.

Indépendamment des moyens de défense que la grande muraille fournissait en temps de guerre, elle était considérée, par les Chinois, même en temps de paix, comme un grand avantage; parce que leurs mœurs réglées et leur vie sédentaire s'accordent peu avec les inclinations inquiètes et vagabondes de leurs voisins septentrionaux; et la grande muraille les empêchait d'avoir aucune communication avec eux. Elle n'est pas même sans utilité pour écarter, des fertiles provinces de la Chine, les bêtes féroces qui abondent dans les déserts de la Tartarie, non plus que pour fixer les limites des deux pays, et empêcher les malfaiteurs de s'échapper de la Chine, et les mécontents d'émigrer.

II paraît que jusqu'à l'époque où la dynastie qui règne maintenant en Chine est montée sur le trône, cet empire a formé peu de projets de conquête. II y subsiste même encore un principe de politique auquel on est très attaché ; c'est de retenir tous les sujets dans les limites du pays. Ceux qui en sortent sans permission s'exposent à être sévèrement punis à leur retour. 


\section{Voyage dans l'intérieur de la Chine et en Tartarie}

La grande muraille de la Chine est devenue d'une bien moindre importance depuis que les territoires qu'elle sépare sont également soumis au même prince. Les Chinois, dont la curiosité cesse quand elle n'est pas excitée par des objets nouveaux, regardent la grande muraille avec une profonde indifférence; et la plupart des mandarins qui accompagnaient l'ambassade semblaient n'y pas faire la moindre attention. Mais un si vaste monument de l'industrie humaine n'a pas manqué d'être remarqué par tous les étrangers qui l'ont vu en entrant en Chine.

Cependant, le premier Européen qui ait parlé de cet empire, Marc-Paul, ne fait aucune mention de la grande muraille. Comme il se rendit par terre à Pékin, on a présumé qu'il avait traversé quel que partie de la Tartarie où la muraille existe à présent; et d'après son silence, un savant italien, qui se propose de publier une nouvelle édition de l'ouvrage de ce voyageur, doute si la muraille était réellement bâtie au treizième siècle, quand le célèbre Vénitien visita la cour du prince tartare qui régnait à la Chine. Mais la simple omission de ce fait de la part d'un voyageur ne suffit pas pour en faire nier l'existence, lorsqu'elle est appuyée par la même espèce de témoignage positif qu'on croit décisif dans toute autre occasion. Elle ne suffirait même pas, cette omission, quand on supposerait que Marc-Paul eût effectivement passé dans l'endroit où s'élève la grande muraille ; et quand même il aurait publié une relation exacte de ses voyages, immédiatement à son retour, au lieu d'en dicter des fragments incohérents longtemps après, loin de sa patrie et privé de ses papiers originaux et de toutes les notes qu'il avait prises sur les lieux. Toutefois, une copie de la route de Marc-Paul, à la Chine, a été tirée de la bibliothèque du doge de Venise, et suffit pour décider la question. D'après cette copie, il paraît que le voyageur vénitien ne traversa point la Tartarie pour se rendre à Pékin. Après avoir suivi la route des caravanes jusqu'à Samarcande et à Cashgar, il tourna droit au sud-est, traversa le Gange et se rendit au Bengale. De là, il dirigea ses pas au sud des montagnes du Thibet, entra dans la province chinoise de Shen-Sée, passa dans celle de Shan-Sée, qui en est limitrophe, et arriva à Pékin, sans avoir vu la grande muraille.

Les voyageurs anglais approchèrent de cette muraille par une montée très raide, et parvinrent à ce qu'on appelle la porte méridionale, pour la distinguer de la porte extérieure qui est plus au nord du côté de la Tartarie. Cette porte 


\section{Voyage dans l'intérieur de la Chine et en Tartarie}

méridionale traverse la route dans l'endroit où elle passe sur le sommet d'une chaîne de montagnes, dont la plupart sont inaccessibles. La porte a été bâtie pour défendre le passage dans une situation très forte. La croupe des montagnes était étroite, et leur descente escarpée. La route suit un défilé au bout duquel est un poste militaire.

Voici les observations du capitaine Parish sur les postes militaires de la Chine : - Les postes militaires sont ordinairement des tours carrées de différentes dimensions ; et il y a toujours une garnison peu nombreuse. II est probable qu'en cas de guerre, ces tours serviraient de rendez-vous aux troupes du voisinage. Elles sont toujours situées à l'entrée des défilés, sur des éminences d'un accès difficile, ou au passage étroit des rivières. Elles varient depuis quarante pieds carrés sur quarante pieds d'élévation jusqu'à quatre pieds carrés seulement, sur six pieds de haut. II est vrai que celles qui n'ont que ces dernières dimensions sont en fort petit nombre: mais les Anglais en rencontrèrent une sur la route de Pékin à la grande muraille. On entre dans les plus grandes tours par un escalier dont les dernières marches sont ordinairement de pierres détachées; cet escalier conduit à une petite arche qui est à mi-hauteur de la tour. La plate-forme seule paraît être destinée à la défense, car il est très rare qu'il y ait des portes sur les côtés. Les parapets des plates-formes sont garnis de créneaux. Les tours sont très fréquemment solides, excepté les plus grandes. Sur le haut de chaque tour, il y a un bâtiment qu'on découvre d'en bas et qui paraît suffisant pour contenir la petite garnison. A l'une des extrémités de ce bâtiment est planté un bâton, au haut duquel flotte un étendard jaune. Ses murs sont quelquefois peints et ornés d'un dragon bigarré.

A côté de la tour, il y a ordinairement une cabane devant laquelle une balustrade rouge soutient quelques lances et quelques mousquets. La cabane sert de baraque ou de corps de garde. Non loin de chaque poste s'élève un pai-loo, c'est-à-dire une porte triomphale et légère, construite en bois, et peinte en noir, en blanc et en rouge. Tout à côté de la porte sont trois, quatre, cinq ou six élévations de maçonnerie, sur lesquelles on a tracé des figures de dragon. Ces élévations contenaient autrefois une composition de matière combustible, et on s'en servait pour donner des signaux ; mais ce ne sont plus, dit-on, que des ornements. Elles diffèrent par leur forme : les unes 


\section{Voyage dans l'intérieur de la Chine et en Tartarie}

sont elliptiques, d'autres hémisphériques ; d'autres ont la forme d'un cône ; et toutes sont posées sur des bases cubiques.

Lorsque l'ambassade passait devant les postes militaires, il en sortait depuis six jusqu'à quinze soldats, qui presque toujours étaient sans armes. Un homme placé au haut de la tour battait sur un loo, tandis qu'un autre mettait le feu à trois petits tubes de fer, placés verticalement dans la terre, pour saluer l'ambassade. Les postes sont à différente distance les uns des autres. Depuis l'embouchure du Pei-Ho jusqu'à Tong-Choo-Foo, il y en a environ quinze, sans compter ceux de Tung-Coo et de Tien-Sing. Cela fait à peu près un par treize milles ; mais sur la route de Pékin en Tartarie, il y en a au moins un de cinq en cinq milles.

Depuis le dernier poste militaire, le chemin suit une étroite vallée dans laquelle serpente une eau limpide. Les montagnes se rapprochent graduellement, et ne laissent guère plus de place qu'il n'en faut pour le chemin et pour la rivière.

Au milieu s'élève une tour avec une porte dans le centre; et une arche est jetée sur la rivière. Ce passage était autrefois fermé par des murs qui s'étendaient depuis la tour jusqu'au sommet de chaque montagne à l'est et à l'ouest, mais ces murs sont maintenant en ruine. Quand les Tartares étaient considérés comme ennemis, des troupes stationnées en ce lieu en défendaient l'approche ; et les restes des ouvrages et des maisons s'y voient encore, ainsi que quelques habitants.

Après avoir passé par une autre porte plus rapprochée des anciennes frontières de la Tartarie, et avoir descendu un défilé presqu'à pic, les voyageurs arrivèrent à Koo-Pé-Koo, lieu où se tenait la forte garnison qui défendait la muraille extérieure dans cette partie. II était environné de plusieurs ouvrages concentriques réunis à la grande muraille.

Lorsque l'ambassadeur arriva sur cette ancienne frontière de la Chine propre, on lui rendit des honneurs militaires. Les troupes furent rangées sur 


\section{Voyage dans l'intérieur de la Chine et en Tartarie}

deux lignes ${ }^{1}$ qui se regardaient. Elles étaient divisées par compagnies, chacune desquelles avait son chef, son étendard et cinq petits drapeaux ; en passant entre ces deux lignes, on voyait des mandarins de chaque côté ; puis de la musique, des tentes, des trompettes, des pai-loos, ou portes triomphales. On comptait douze compagnies de chaque côté; enfin, on apercevait dix petites pièces de campagne de différente forme et de différente construction. La parade des compagnies était :

\begin{tabular}{|c|c|c|}
\hline $\begin{array}{l}\text { Une épée et des } \\
\text { hommes d'épée, cinq de } \\
\text { profondeur. }\end{array}$ & $\begin{array}{l}\text { Le chef, } \\
\text { ordinairement un archer. } \\
\text { Les étendards. } \\
\text { Les cinq petits drapeaux. } \\
\text { Fusiliers et hommes } \\
\text { d'épée, en nombre } \\
\text { presque égal, cinq de } \\
\text { profondeur. }\end{array}$ & $\begin{array}{l}\text { Une épée et des } \\
\text { hommes d'épée, cinq de } \\
\text { profondeur. }\end{array}$ \\
\hline
\end{tabular}

Toute cette troupe était de douze cents hommes. L'intervalle entre chaque compagnie égalait presque la place qu'occupait leur front, laquelle était d'environ sept pas.

Près de Koo-Pé-Koo, il y a dans une partie de la grande muraille quelques brèches qui donnent la facilité de l'escalader et de l'examiner. La négligence dont ces brèches étaient la preuve semblait suffisamment garantir aux Anglais qu'ils n'offenseraient les Chinois, ni ne seraient accusés d'indiscrétion, en satisfaisant la curiosité qu'avait fortement excitée en eux la célébrité de cette barrière, jadis si importante. Toutes les principales personnes de l'ambassade allèrent la visiter, et le capitaine Parish examina particulièrement sa construction et ses dimensions.

Le corps de la grande muraille est une élévation de terre, retenue de chaque côté par un mur de maçonnerie, et recouverte d'une plate-forme de briques carrées. Les murs de côté continuant à s'élever au-dessus de la plateforme, servent de parapets.

Voici ses proportions indépendamment de toute fraction :

\begin{tabular}{|l|l|}
\hline pieds & pouces \\
\hline
\end{tabular}

\footnotetext{
${ }^{1}$ Ces détails sont tirés des papiers du capitaine Parish.
} 


\section{Voyage dans l'intérieur de la Chine et en Tartarie}

\begin{tabular}{|l|r|r|}
\hline Hauteur de l'ouvrage en brique jusqu'au-dessous du cordon & 20 & - \\
Depuis le dessous du cordon jusqu'au haut du parapet & 5 & - \\
Total de la hauteur du mur de brique & 25 & - \\
\hline
\end{tabular}

Le mur de briques est placé sur une base de pierre qui ressort d'environ deux pieds au-delà de ce mur, et dont la hauteur diffère proportionnément à l'irrégularité du terrain sur lequel elle est placée ; mais on n'en voit pas plus de deux assises au-dessus du sol, et ces assises n'ont qu'un peu plus de deux pieds d'élévation.

\begin{tabular}{|l|r|r|}
\hline & pieds & pouces \\
\hline Épaisseur de chaque mur du parapet en haut & 1 & 6 \\
Au cordon & 2 & 3 \\
Profondeur du cordon & - & 6 \\
Avancement du cordon & - & 6 \\
Épaisseur de chacun des murs de côté à leur base & 5 & - \\
\hline
\end{tabular}

Le bas du cordon est de niveau avec le terre-plein de la muraille. Entière épaisseur de la muraille, y compris l'élévation de terre, qui est de onze pieds de large dans toutes ses parties:

\begin{tabular}{|l|r|r|}
\hline & pieds & pouces \\
\hline Au cordon & 15 & 6 \\
Au bas de l'ouvrage en brique & 21 & - \\
Base en pierre & 25 & - \\
\hline
\end{tabular}




\section{Voyage dans l'intérieur de la Chine et en Tartarie}

II y a en quelques endroits un petit fossé au-delà des fondements de la muraille.

\begin{tabular}{|l|r|r|}
\hline & pieds & pouces \\
\hline Relativement aux embrasures, la hauteur des merlons est de & 2 & - \\
La largeur des embrasures, en dehors et en dedans & 2 & - \\
La distance entre elles, prise du centre & 9 & - \\
& & \\
Proportion des meurtrières: & 1 & - \\
Hauteur de l'ouverture & - & 10 \\
Largeur de l'ouverture & 4 & - \\
Profondeur de & 9 & - \\
Distance entre elles & & \\
&
\end{tabular}

Le bas des meurtrières est de niveau avec le terre-plein, et de là il est tellement en talus, qu'on peut découvrir un ennemi à très peu de distance de la muraille. Peut-être croira-t-on que cette position est plus propre à l'usage des armes à feu qu'à celui de l'arc et des flèches.

Les tours jointes à la grande muraille sont éloignées d'environ cent pas l'une de l'autre; mais comme la muraille forme une ligne courbe, la distance, estimée d'après cette ligne, varie et quelquefois s'accroît considérablement. Quand on a eu besoin d'une plus grande force, on les a plus rapprochées. Leurs dimensions, leur construction, leur position relativement à la muraille varient aussi considérablement avec leur situation.

La première tour que le capitaine Parish examina n'avait qu'un étage, de niveau avec le terre-plein de la muraille; et au-dessus de cet étage, un parapet presqu'égal à celui de la muraille. Il y avait trois embrasures ou portes au bas de chaque front, et deux à ceux du parapet de la plate-forme. 


\section{Voyage dans l'intérieur de la Chine et en Tartarie}

Dimensions de cette tour :

\begin{tabular}{|l|r|r|}
\hline & pieds & pouces \\
\hline Longueur de chaque côté du carré à sa base & 40 & - \\
Longueur de chaque côté du même carré en haut & 30 & - \\
Hauteur de la base en pierre & 4 & - \\
Hauteur du mur de brique depuis la base & & \\
$\quad$ en pierre jusqu'au cordon & 28 & 4 \\
Depuis le cordon jusqu'au haut du parapet & 5 & - \\
Hauteur totale & 37 & 4 \\
Largeur des embrasures ou portes d'en bas & 3 & - \\
Leur hauteur & 3 & - \\
\hline
\end{tabular}

Les embrasures du parapet ont les mêmes dimensions que celles de la muraille.

Cette tour a un avancement de dix-huit pieds au-delà de la grande muraille du côté qui fait face à la Tartarie. A sa base, on communique avec la plate-forme de la muraille par une de ses portes, qui est placée exprès un peu en dehors.

La seconde tour examinée par le capitaine Parish diffère beaucoup de la première, par sa forme, par ses dimensions et par sa situation. Elle consiste en deux étages, indépendamment de la plate-forme. Le premier étage est de niveau avec le terre-plein de la grande muraille. La tour est carrée, et presque une masse solide de pierre, entremêlée d'ouvertures en forme de croix, à chaque extrémité desquelles est une grande fenêtre ou porte qui se trouve dans le centre du carré. Par deux de ces portes, elle communique avec le terre-plein de la grande muraille de chaque côté : ainsi cette tour présente deux flancs à la muraille. Il y a outre l'entrée et le centre de la croix, un escalier étroit, formant angle droit avec la direction de la muraille ; et par cet escalier, on communique avec le second étage. Ce second étage ne contient qu'une chambre, formée par trois arches parallèles, dans une situation qui correspond perpendiculairement à l'entrée, et ayant entre elles trois ouvertures cintrées pour la communication. Celles qui sont dans le centre divisent en deux le bâtiment, et sont dans la même direction que la grande muraille; les autres forment des lignes parallèles avec ses côtés. Ainsi, la chambre carrée du second étage consiste en trois arches égales et parallèles, et en trois lignes d'arches de communication, qui laissent quatre pans carrés de maçonnerie vers le centre. Les extrémités des arches parallèles ont des 


\section{Voyage dans l'intérieur de la Chine et en Tartarie}

embrasures, trois desquelles font face à la muraille de chaque côté. Les portes du centre sont vis-à-vis du terre-plein de la grande muraille, les autres flanquent ses cotés dans chaque direction. Les portes des deux autres côtés sont les unes en face du nord, les autres en face du midi.

Le parapet de la plate-forme est garni de douze embrasures, trois desquelles sont de chaque côté. II y a en outre des meurtrières entre les embrasures. Ainsi chaque côté de la tour présente une porte au premier étage, deux au second, trois embrasures avec cinq meurtrières sur la plateforme. On a probablement donné tant de force à cette tour à cause de la proximité de la rivière et de la porte extérieure de la grande muraille. Oui, c'est par rapport à cette porte qu'elle est si singulièrement fortifiée du côté de la muraille que, d'une part, elle défend vers la rivière, tandis que de l'autre, elle protège l'entrée de la porte, en cas que le premier côté soit forcé.

Voici les dimensions de cette seconde tour :

\begin{tabular}{|l|r|r|}
\hline & pieds & pouces \\
\hline Hauteur de la base de pierre & 4 & - \\
Hauteur jusqu'au premier étage & 16 & - \\
Hauteur de l'arche du premier étage & 8 & - \\
Epaisseur de l'arche & 1 & 3 \\
Epaisseur du plancher du second étage & - & 4 \\
Hauteur des arches parallèles & 12 & - \\
Epaisseur des arches parallèles & 1 & 3 \\
Epaisseur du plancher de la plate-forme & - & 4 \\
Hauteur du parapet de la plate-forme & 5 & - \\
Hauteur totale de la tour & 48 & 2 \\
\hline
\end{tabular}




\section{Voyage dans l'intérieur de la Chine et en Tartarie}

\begin{tabular}{|l|r|r|}
\hline & pieds & pouces \\
\hline Longueur de chaque carré de la tour à son sommet & 36 & - \\
Longueur de chaque carré à sa base & 42 & - \\
Dimensions du premier étage : & & \\
Largeur des arches de séparation & 3 & - \\
Longueur de ces mêmes arches & 33 & - \\
Hauteur des arches & 8 & - \\
Largeur des embrasures & 2 & - \\
Hauteur des embrasures & 4 & - \\
Hauteur de l'ouverture pour les portes & 5 & - \\
(Le haut des embrasures est cintré.) & & \\
Largeur de l'ouverture pour l'escalier & 2 & - \\
Hauteur de cette ouverture & 4 & - \\
& & \\
Dimensions du second étage : & & \\
Longueur de chaque côté de la chambre & 28 & 9 \\
Largeur des arches parallèles & 28 & - \\
Longueur des mêmes arches & 12 & - \\
Hauteur des mêmes arches & 5 & - \\
Intervalle entre les arches parallèles & 5 & 7 \\
Largeur des arches de communication & 5 & - \\
Longueur des mêmes arches & 8 & - \\
Hauteur des mêmes arches & 5 & 7 \\
Longueur des pied-droits & 5 & - \\
Largeur des mêmes & 4 & - \\
Largeur de la retraite pour les embrasures & 2 & 6 \\
Profondeur de cette retraite & 8 & - \\
Hauteur de cette retraite & 2 & - \\
Largeur des embrasures & 4 & - \\
Hauteur des embrasures & & \\
\hline
\end{tabular}

Les dimensions des parapets, des embrasures et des meurtrières de la plate-forme sont pareilles à celles de la première tour.

Les embrasures ou portes de chaque chambre, et les retraites pour celles du second étage sont toutes cintrées.

Les encoignures des portes, des fenêtres, des embrasures, et plusieurs des angles saillants, et des escaliers des tours, ainsi que les bases ou fondements sur lesquels sont posées ces tours, et les murailles intervenantes, sont d'un granit gris très dur, et légèrement mêlé de paillettes brillantes.

Le reste de ces bâtiments est construit de briques bleuâtres. Elles sont placées par rangs, d'une brique d'épaisseur chacun, et forment par ce moyen autant de murailles distinctes qu'il y a de briques d'épaisseur. Leurs 


\section{Voyage dans l'intérieur de la Chine et en Tartarie}

dimensions diffèrent suivant la situation dans laquelle elles se trouvent placées. Celles de la façade de la muraille et des tours sont comme suit:

\begin{tabular}{|l|r|r|}
\hline & pieds & pouces \\
\hline Epaisseur des briques & - & $3^{3 / 4}$ \\
Largeur & - & $7 \frac{1}{2}$ \\
Longueur & 1 & 3 \\
\hline
\end{tabular}

Celles qui sont employées dans les terrasses de la grande muraille et des tours diffèrent seulement des premières, en ce qu'elles sont parfaitement carrées. Partout où, pour achever la muraille, les briques ordinaires n'ont pas pu servir, on ne les a point grossièrement taillées à coup de truelle pour les rapetisser, comme font quelquefois de négligents ou ignorants ouvriers, mais on s'est servi d'autres briques, moulées exprès, d'une forme et d'une grandeur convenable. Le ciment ou mortier qui est entre les différentes couches de briques a plus d'un demi-pouce d'épais, et il est presque entièrement composé de chaux d'une blancheur parfaite.

Quoique les briques de la grande muraille aient si longtemps résisté à l'effort du temps et aux influences de l'atmosphère, leur couleur bleue fait d'abord douter si elles ont été cuites autrement qu'au soleil. L'expérience prouve qu'une masse d'argile ou de brique se resserre et diminue quand elle est exposée à l'action du feu, et que plus le feu a de force, plus cette diminution a lieu; mais lorsque cette masse est retirée du feu, elle ne reprend jamais ses premières dimensions. Si donc les briques qui ont servi à la construction de la grande muraille avaient été simplement cuites au soleil,

elles devraient diminuer lorsqu'on les met dans le feu, mais un essai a démontré qu'elles ne diminuaient pas ; d'ailleurs, on voit encore auprès de la grande muraille quelques fourneaux, où vraisemblablement les briques qui la composent ont été cuites.

La grande muraille ne semble pas avoir été construite pour servir de défense contre le canon, puisque les parapets ne pourraient pas résister à la force des boulets ; cependant, le bas des embrasures des tours est semblable à ceux qu'on pratique en Europe pour placer les porte-mousquetons des arquebuses à croc. Ces trous paraissent avoir été faits lorsqu'on a construit la grande muraille, et il est difficile de leur assigner un autre objet que celui de servir pour le repoussement des armes à feu. Les pièces de campagne qu'on 


\section{Voyage dans l'intérieur de la Chine et en Tartarie}

voit en Chine sont, en général, montées avec des porte-mousquetons auxquels ces trous conviennent fort bien et, quoique les parapets ne soient pas faits pour soutenir le choc des boulets de canon, ils peuvent fort bien résister à ces petites pièces. II y avait plusieurs de ces pièces à la parade de Koo-Pé-Koo, et elles étaient toutes montées sur des barres, avec des portemousquetons. D'après ces considérations, il est vraisemblable que la prétention qu'ont les Chinois d'avoir connu très anciennement les effets de la poudre à canon n'est pas sans fondement.

Les détails qu'on vient de lire, et dans lesquels le capitaine Parish est entré avec tant de soin, servent à donner une idée exacte de l'architecture des Chinois, et de la manière dont ils se défendaient, longtemps avant l'ère chrétienne. La vue de la grande muraille prouve non seulement le courage et les vues étendues du gouvernement qui pouvait se livrer à une si vaste entreprise, mais l'état avancé de la société qui fournissait des ressources pour un tel ouvrage, et en réglait les progrès ; et enfin, la vigueur, la persévérance avec lesquelles il fut porté à sa perfection.

La grande muraille continue encore à servir de ligne de démarcation entre la nation chinoise et la nation tartare. Quoique, depuis que ces deux nations sont réunies sous une domination absolue, la seule parole du monarque suffise pour faire obéir tous ses sujets indistinctement, chacune d'elles conserve encore des idées de prétentions et de juridictions locales. 


\section{Voyage dans l'intérieur de la Chine et en Tartarie}

\section{CHAPITRE II}

\section{L'ambassade anglaise arrive auprès de l'empereur de la Chine, en Tartarie, dans le palais où ce prince fait sa résidence pendant l'été.}

A son entrée en Tartarie, l'ambassadeur reçut la visite d'un mandarin militaire, de race tartare. II était attaché au palais. Quoique Van-ta-zhin eût le même rang que lui, à peine osait-il hasarder de s'asseoir en sa présence, tant est grand le respect qu'affectent les Chinois pour les Tartares de la cour! Le dernier des Tartares prend un air d'importance lorsqu'il est sur sa terre natale. L'un d'eux, qui était à la suite des mandarins chinois, devait être puni par leur ordre pour quelques forfaits qu'il avait commis ; mais il résista avec audace, prétendant qu'aucun Chinois n'avait droit d'exercer quelque autorité sur lui lorsqu'il était en-dehors de la grande muraille.

Il y a dans les villages qui sont au-delà de cette muraille quelques familles chinoises et des femmes avec de petits pieds. On ne dit point qu'aucune femme tartare se soit mutilée à l'exemple des Chinoises, quoiqu'à d'autres égards les Chinois soient souvent imités par les Tartares.

A mesure que les voyageurs avançaient dans la Tartarie, ils trouvaient la température plus froide, les chemins plus raboteux, les montagnes moins richement parées. On n'y voit que différentes sortes de pins qui ne sont pas très grands, des chênes rabougris, des deux espèces qu'on appelle chênes d'Angleterre et chênes de Russie, et des trembles, des ormes, des noisetiers, des noyers, diminués au point de ressembler à des arbustes. Tous ces arbres croissent, en général, sur le côté des montagnes, qui fait face au midi. Les autres côtés ne portent guère que des arbrisseaux épineux, avec quelques brins d'herbe brûlée. Les ours, les loups, même les tigres, habitent, dit-on, ces forêts.

Dans les plaines, ou plutôt dans les vallées, abonde cette espèce de lièvre qui, comme quelques animaux des climats froids, de brun ou de rouge qu'il est en été, devient blanc en hiver. Ce lièvre est également remarquable par la 


\section{Voyage dans l'intérieur de la Chine et en Tartarie}

longueur extraordinaire de ses pattes et de ses doigts, qui se joignent quand il s'élance sur la neige, formant une base qui l'empêche de s'enfoncer.

En Tartarie, on se sert rarement de chien pour chasser le lièvre et les autres bêtes fauves; mais on les pousse dans des pièges. Pour cela, plusieurs chasseurs se réunissent, forment un grand cercle, de la circonférence duquel ils s'approchent peu à peu vers le centre, battant les buissons et faisant beaucoup de bruit à mesure qu'ils marchent. Les animaux se trouvent enfin resserrés dans un très petit espace, où ils sont aisément pris.

C'est surtout en Tartarie que le chien devient le fidèle compagnon du paysan. Le chien tartare est d'une petite espèce, ayant une longue queue retroussée, dont le caprice ni la mode ne le privent jamais, et qui penche ordinairement du côté gauche, comme Linnæus remarque qu'est celle du chien domestique. Le chien tartare aboie rarement le jour.

La perspective des pays que traversèrent les Anglais était souvent agréablement romantique, mais très bornée. Celui qui, pour la première fois, est prêt à voyager dans les montagnes, s'attend peut-être à se trouver bientôt sur des terrains qui dominent tout ce qui les environne. Mais il en est presque toujours autrement. Les chemins sont, pour la plupart, au pied des montagnes, non sur le sommet ; et le voyageur est condamné à parcourir le fond des vallées, où il ne trouve qu'un horizon borné et une atmosphère sombre.

Les villages dispersés dans les vallées de la Tartarie offrirent à la vue des Anglais plusieurs personnes attaquées d'une maladie semblable à celle qu'on remarque fréquemment dans les Alpes, et qui y est connue sous le nom de goitre, ou de cou enflé. Les glandes de la gorge commencent à enfler de bonne heure à ceux qui ont des dispositions à avoir cette maladie; et elles acquièrent insensiblement une grosseur énorme. L'enflure commence immédiatement au-dessous de la parotide et, affectant toutes les glandes submaxillaires, s'étend d'une oreille à l'autre. Le docteur Gillan remarqua que près d'un sixième des habitants avaient cette difformité qui, ajoute-t-il, ne paraît pourtant pas telle à ces villageois. Les personnes des deux sexes sont sujettes à cette maladie; mais les femmes le sont plus que les hommes. 


\section{Voyage dans l'intérieur de la Chine et en Tartarie}

Quelles que soient les causes qui l'occasionnent, ces derniers quittent plus souvent les lieux où elles existent.

Ces tumeurs contre nature ne paraissent pas accompagnées d'autres symptômes qui affectent la santé, ou qui empêchent un homme d'user librement de ses facultés physiques; mais l'esprit de beaucoup de personnes qui en sont attaquées est très affaibli, et peut-être qu'aucune d'elles n'est exempte d'un pareil malheur, quoiqu'à un moindre degré. Quelques-unes sont réduites à un état d'imbécillité absolue. Le spectacle de ces idiots, qui ne manque jamais de faire une triste impression sur les hommes qui les voient pour la première fois, est bien loin de produire le même effet sur ceux au milieu desquels ils existent. Les idiots eux-mêmes sont généralement gais, et mènent une vie animale, totalement exempte de pensées et de réflexions. Comme ils ne suivent qu'un pur instinct, ou la seule impulsion des sens, quelque dangereuses que leurs actions puissent être pour les autres, elles sont toujours sans malice et n'excitent aucun ressentiment. Leur personne est considérée comme sacrée; et leurs familles les entretiennent avec un soin particulier.

Quelle que soit la cause qui occasionne des goitres aux hommes, elle n'a aucun effet sensible sur les animaux. On croit communément, et en Europe et en Asie, que cette maladie provient du fréquent usage de l'eau de neige. II est certain que la neige fondue contient un peu plus de terre calcaire que l'eau de pluie, et une très petite portion d'acide nitreux et de sel marin : mais dans les pays découverts, où l'on n'en boit presque pas d'autre, on ne voit point de gens avec des tumeurs goitreuses. Vraisemblablement l'état de l'atmosphère contribue beaucoup à les produire. La partie de la Tartarie où cette maladie est commune a beaucoup de traits de ressemblance avec quelques cantons de la Suisse et de la Savoie.

Les Anglais ne rencontrèrent dans cette route aucune production volcanique. Durant le septième et dernier jour de leur voyage, la chaîne des montagnes était presque parallèle au chemin. Cette chaîne représentait des lignes horizontales, consistant en grands rochers de granit, qui différaient beaucoup les uns des autres par leur grandeur, et étaient arrangés comme les vertèbres d'un quadrupède. Le haut de ces rochers est légèrement tapissé de gazon ; mais leurs flancs restent entièrement dépouillés, parce que la terre 


\section{Voyage dans l'intérieur de la Chine et en Tartarie}

qui les couvrait jadis a été entraînée beaucoup plus bas. A peu près à moitié hauteur de la montagne s'élève un rocher perpendiculaire, ou une antique ruine; car son aspect fit conjecturer aux Anglais qu'il pouvait être l'un ou l'autre. Sa hauteur excède deux cents pieds. Sa forme est irrégulière, et son sommet, beaucoup plus large que sa base, se couronne de grands arbustes. Comme ce rocher se trouvait à une distance considérable des voyageurs, l'un d'entre eux s'écarta du chemin pour aller l'examiner plus particulièrement. II vit que ce n'était ni le reste d'un édifice, ni un rocher entier, mais une énorme masse d'argile durcie, à laquelle était mêlé beaucoup de gravier.

D'une nature plus compacte, sans doute, que le sol qui l'environnait, et qui a cédé à la violence des torrents, cette pyramide renversée est restée comme un monument de la hauteur qu'avait, dans ce lieu même, l'ancienne surface du globe. La base de ce monument montre jusqu'à quelle profondeur la terre a été creusée. Les parties molles et légères, entraînées au pied des montagnes et déposées graduellement, ont formé les plaines unies et fertiles de Pé-Ché-Lée, que nous avons décrites dans le dernier chapitre; et les parties les plus dures, les plus pesantes, bientôt arrêtées dans leurs progrès, constituent la surface des vallées inégales de la Tartarie. Le déplacement d'une couche de sol de deux cents pieds de profondeur, depuis le haut des montagnes jusqu'en bas, et dans une si vaste étendue est, parmi les changements qu'a éprouvés la surface de la terre, l'un des plus grands dont les annales du genre humain fassent mention.

Les inondations soudaines, dont le souvenir a été transmis à la postérité, ne sont point représentées comme ayant produit un effet permanent. Certes, différentes parties du globe indiquent suffisamment les altérations extraordinaires qu'a éprouvées sa surface depuis qu'il est devenu propre à être habité. Le rocher de Gibraltar n'est pas la seule hauteur dans l'intérieur de laquelle on a trouvé des os d'animaux qui doivent avoir vécu et péri avant la formation des montagnes, dont ils sont devenus une partie.

L'élévation de la Tartarie est telle que, dans quelques endroits, elle a quinze mille pieds au-dessus de la mer Jaune. On sait que cette élévation accroît considérablement le froid de l'atmosphère. 


\section{Voyage dans l'intérieur de la Chine et en Tartarie}

Au milieu de ces terrains élevés, et un peu plus loin que la pyramide renversée dont nous venons de faire mention, les montagnes, s'écartant l'une de l'autre, découvrirent aux voyageurs la vallée de Zhé-Hol, où l'empereur de la Chine a un palais et un jardin d'agrément qu'il habite l'été, de préférence à sa capitale. Le palais se nomme le Séjour de l'agréable fraîcheur, et le jardin, le Jardin des arbres innombrables.

L'ambassadeur et sa suite s'avancèrent vers Zhé-Hol dans un ordre convenable. Le chemin qui y conduit se découvre aisément du haut d'une éminence qui est dans le jardin de l'empereur, et d'où ce prince, suivant ce qu'on rapporta ensuite à lord Macartney, eut la curiosité de contempler la marche des Anglais. L'ambassade fut reçue avec des honneurs militaires, et au milieu d'une foule de spectateurs, dont les uns étaient à cheval, les autres à pied. Plusieurs de ces derniers étaient entièrement vêtus de jaune, et coiffés de chapeaux ronds de la même couleur. Quelques enfants avaient aussi ce costume. Tous ces gens-là étaient des lamas inférieurs, ou moines et novices dépendants des temples de la secte de Fo, à laquelle l'empereur était attaché. Mais, malgré l'ordre sacré dont ils étaient membres, et malgré l'habit honorable qu'ils portaient, ils ne paraissaient pas être très respectés de la multitude. Ils ne se comportaient pas non plus de manière à montrer qu'ils eussent eux-mêmes une opinion de leur dignité et qu'ils se souciassent de garder cette bienséance extérieure que tous ceux qui ont quelque rang à la Chine sont très jaloux de conserver.

L'édifice, ou plutôt les édifices destinés à loger l'ambassade, étaient situés près de l'extrémité septentrionale de la ville de Zhé-Hol, qui se trouve entre eux et les portes du palais impérial. Ils étaient sur la pente douce d'une montagne, et avaient différentes cours s'élevant progressivement l'une audessus de l'autre, et se communiquant par des marches de granit. Le tout était suffisamment spacieux et commode. On y pouvait contempler à la fois les montagnes de la Tartarie, la ville de Zhé-Hol, et une partie du parc de l'empereur. La ville de Zhé-Hol ne renferme que des maisons de mandarins, et beaucoup de misérables chaumières remplies de monde. Les rues sont tortueuses, sans pavé et couvertes de poussière. Tout à côté, le palais impérial, les temples, les jardins annoncent la grandeur. Là, entre la magnificence et la misère, on ne connaît point de milieu. 


\section{Voyage dans l'intérieur de la Chine et en Tartarie}

Dans cette partie de la Tartarie, les principales maisons diffèrent peu de celles de la Chine ; et la distribution des appartements et leur ameublement étaient également simples. La grande porte de chaque bâtiment séparé conduit dans une salle communiquant de chaque côté à une chambre, dans laquelle il y a une estrade couverte de drap épais et de coussins, pour qu'on puisse s'y asseoir le jour et y dormir la nuit. II y a aussi des tables vernissées, et quelques chaises pour ceux qui viennent rendre visite. Bientôt après que l'ambassadeur fût arrivé, deux des premiers mandarins se rendirent à son logement pour le complimenter de la part de l'empereur. Un autre mandarin le complimenta de la part du grand colao, ou premier ministre Ho-ChoongTaung.

Le même jour, le légat vint trouver l'ambassadeur et, sans le moindre préambule, sans chercher à se disculper, il lui remit le mémoire cacheté, qui avait rapport à la cérémonie de réception, mémoire dont il avait eu communication à Pékin, et qu'il s'était chargé de faire parvenir au grand colao, ainsi que nous l'avons déjà rapporté. Le légat voulait, en même temps, qu'on crût que ce mémoire était toujours demeuré en sa possession ; mais on savait déjà très bien qu'il l'avait fait passer à Zhé-Hol, et que son contenu y avait été approuvé. Qu'est-ce qui pouvait donc avoir occasionné un changement à ce sujet? II était difficile de l'expliquer, mais les anciennes idées d'orgueil et les prétentions de prééminence l'emportèrent de nouveau ; et I'on soupçonna qu'elles avaient été suggérées par le vice-roi de Canton, qui venait d'arriver à Zhé-Hol, à son retour du Thibet, où il avait commandé l'armée chinoise. II était l'ennemi déclaré des Anglais, et les peignait comme un peuple usurpateur, qu'il était dangereux d'encourager. II eut même, à cet effet, recours au témoignage d'un homme condamné pour ses concussions, de ce même mandarin, que nous avons déjà dit avoir été hoppo, ou receveur général des revenus et des douanes de Canton. Ce coupable fut conduit exprès à Zhé-Hol; et il n'est pas douteux qu'il ne parlât des Anglais conformément aux vues et à l'opinion partiale du vice-roi.

Le colao était, ce semble, persuadé qu'il fallait que l'ambassadeur anglais se soumît à rendre à l'empereur de la Chine l'hommage des vassaux, sans que le gouvernement chinois reconnût l'indépendance du roi d'Angleterre. Ainsi, I'on crut qu'il était expédient de ne pas avouer que le mémoire de 


\section{Voyage dans l'intérieur de la Chine et en Tartarie}

l'ambassadeur avait été transmis à la cour, afin de pouvoir se dispenser de répondre à une proposition trop raisonnable pour être rejetée; et l'on s'attendit que, lorsqu'une fois l'ambassadeur serait en présence de sa majesté impériale, il ferait, sans aucune condition, les prosternements d'usage.

D'après tout cela, l'ambassadeur désira vivement d'avoir une décision sur l'affaire du cérémonial, avant d'être obligé de paraître dans le palais impérial. Le colao désirait de l'y voir sans délai, afin d'apprendre de lui le contenu de la lettre du roi d'Angleterre à l'empereur. Mais quand l'ambassadeur n'aurait pas eu des raisons particulières pour ne point faire cette visite en ce moment, il était trop indisposé pour l'entreprendre. II résolut donc de charger le secrétaire d'ambassade d'aller, à sa place, chez le premier ministre, et de lui porter une copie de la lettre du roi d'Angleterre et le mémoire qu'avait rendu le légat. Les Chinois, qui étaient liés avec l'ambassadeur, craignaient tellement d'être accusés d'avoir écrit ce mémoire, qu'ils prièrent ce ministre de le faire contresigner par le page qui l'avait copié, afin de prouver que c'était son écriture.

L'ambassadeur donna des instructions au secrétaire sur tous les points qu'il pouvait avoir à traiter. L'étiquette de la cour de la Chine ne permettant pas au secrétaire d'ambassade d'avoir, en cette qualité, aucun entretien avec le premier ministre, ni même de s'asseoir en sa présence, il fut nécessaire de faire usage de la commission de ministre plénipotentiaire que lui avait accordée le roi d'Angleterre, pour qu'il pût suppléer l'ambassadeur en cas d'absence ou d'indisposition. En cette qualité, il se rendit chez le colao, qu'il trouva dans un petit appartement du palais impérial.

Quelque grand, quelque puissant que soit un vizir dans un empire despotique, il ne paraît qu'un petit personnage en comparaison du prince luimême, qui croit qu'une très petite partie de sa vaste et magnifique demeure suffit à l'importance relative de la créature de sa faveur. Le vizir de la Chine, qui jouissait presque exclusivement de la confiance de l'empereur, était un Tartare d'une naissance obscure, et tiré par hasard d'un emploi subalterne depuis environ vingt ans. Il était de garde à l'une des portes du palais, lorsque l'empereur passa et fut frappé par sa bonne mine. Ce prince trouvant ensuite qu'il avait reçu de l'éducation, et possédait beaucoup de talent, l'éleva 


\section{Voyage dans l'intérieur de la Chine et en Tartarie}

rapidement aux dignités. On peut dire qu'après l'empereur, il était l'homme le plus puissant de l'empire.

Une si grande élévation, du sein d'une si humble origine, paraîtra peutêtre singulière à ceux qui sont accoutumés à l'ordre et aux gradations régulières des gouvernements mixtes; mais les exemples n'en sont rares ni dans les pays où le monarque peut satisfaire ses volontés et ses caprices sans crainte d'être blâmé, ni dans ceux qui sont divisés par les partis, et où des qualités brillantes et des efforts extraordinaires se font bientôt distinguer. Dans le premier cas, il arrive fréquemment que le prince abandonne à celui qu'il a choisi presque tout l'exercice de son autorité, et qu'il passe sa vie dans l'indolence et les plaisirs sensuels; mais l'empereur de la Chine continua à s'occuper de l'administration des affaires avec une attention infatigable; il partagea avec son vizir, plutôt qu'il ne lui céda, tous les soins qu'exigeait son vaste empire. Ce prince ne se laissait point guider aveuglément par ses avis. Croyant une fois qu'il avait voulu lui faire un mensonge, il le disgracia aussi promptement qu'il l'avait élevé, et le colao rentra pendant quinze jours dans l'obscurité de son premier emploi. Un accident heureux ayant ensuite donné à l'empereur occasion de connaître qu'il n'avait pas eu de justes raisons d'être irrité contre son favori, il lui rendit ses dignités et sa puissance.

Lorsque le colao donna audience au ministre plénipotentiaire, il était assis sur une estrade couverte d'une étoffe de soie, entre deux mandarins tartares et deux mandarins chinois, membres du conseil d'État. Une chaise fut présentée au ministre anglais. Le légat, plusieurs autres mandarins et I'interprète furent obligés de rester debout. Le colao demanda, pour la forme, quel était l'objet de l'ambassade anglaise à la Chine. II fut aisé de le satisfaire sur cela, en lui présentant une traduction chinoise de la lettre que le roi d'Angleterre adressait à l'empereur ; ce qui parut lui être très agréable, ainsi que le contenu de la lettre. Après une courte pause, le ministre lui remit le mémoire de l'ambassadeur, mémoire qu'il feignit de ne pas connaître. Il parut cependant préparé à faire des objections aux propositions contenues dans cet écrit. On lui répondit par les arguments sensibles qu'exigeait un cas aussi simple, et de la manière que l'ambassadeur avait prescrite. Le colao termina la discussion en priant le ministre de faire part de ses raisons à l'ambassadeur, afin qu'il les prît en considération. 


\section{Voyage dans l'intérieur de la Chine et en Tartarie}

II est à remarquer que, pendant toute cette conférence, la salle où elle se tint fut remplie de gens, employés dans le palais, et à qui il était permis d'écouter ce qu'on disait. II semblait qu'en traitant avec des étrangers, à tous égards, si éloignés de la Chine, il n'était nécessaire de rien dérober à la connaissance des Chinois. Peut-être un si grand nombre de spectateurs fut-il cause que le colao affecta un grand air de dignité et de réserve; et par ses manières, et par sa conversation, il semblait vouloir donner à entendre que les civilités qu'il faisait au ministre anglais n'étaient qu'une condescendance de sa supériorité nationale et personnelle. C'était aussi, sans doute, l'orgueil national qui avait fait prendre la résolution d'éviter, s'il était possible, de payer par des formalités pareilles celles auxquelles l'ambassadeur consentait de se soumettre à la cour de l'empereur.

Le lendemain, le légat et deux autres mandarins se rendirent chez l'ambassadeur, et le pressèrent, de la part du colao, de renoncer à ses prétentions. En discutant cette affaire, ils furent dans la nécessité de flotter entre des idées contraires, en représentant le prosternement comme une cérémonie extérieure et insignifiante, quand ils proposaient à l'ambassadeur de s'y soumettre à l'égard de l'empereur de la Chine, et d'une grande importance quand il s'agissait de le faire faire par un Chinois devant le roi d'Angleterre. Ils hasardèrent même de faire entendre à l'ambassadeur qu'un refus absolu pourrait bien ne pas être sans inconvénient pour lui. Mais cette menace indirecte lui fournit occasion de témoigner que le sentiment de son devoir envers son roi l'emportait de beaucoup sur la crainte d'aucun danger. Il déclara qu'il devenait particulièrement indispensable pour lui que la cérémonie fût réciproque, ou qu'un compliment, fait au nom d'un souverain puissant et indépendant, fût distingué de l'hommage des princes tributaires ; parce qu'il savait qu'on avait déjà cherché à confondre ces deux choses, en donnant aux présents anglais le nom de tribut, dans les inscriptions chinoises qu'on y avait mises.

La connaissance que l'ambassadeur avait de cette particularité força les mandarins à sentir la justice de sa proposition ; et à lui demander jusqu'à quel point il pensait que son devoir lui permettait de témoigner son respect à sa majesté impériale, sans se soumettre au prosternement des tributaires ? L'ambassadeur répondit qu'attaché à son souverain par tous les liens du 


\section{Voyage dans l'intérieur de la Chine et en Tartarie}

devoir et de la fidélité, il pliait un genou quand il paraissait en sa présence, et qu'il consentait volontiers à témoigner, de la même manière, son respect envers l'empereur de la Chine.

Les mandarins parurent extrêmement contents de cette réponse, et dirent qu'ils rapporteraient bientôt la résolution de la cour, pour s'accorder sur la cérémonie réciproque, proposée par l'ambassadeur, ou pour accepter I'hommage anglais au lieu du prosternement chinois.

Cependant la conférence qui avait eu lieu au palais entre le colao et le ministre plénipotentiaire anglais se répandit promptement dans Zhé-Hol. Beaucoup de gens, qui ne voyaient dans l'ambassadeur que quelques étrangers isolés, entièrement à la merci de la cour où ils étaient venus, ne pouvaient pas concevoir comment ils osaient proposer des conditions à cette cour, ou hésiter d'obéir à ses volontés. D'autres prédisaient confidemment qu'ils seraient renvoyés sans être admis à l'audience de l'empereur. L'interprète chinois, que son attachement zélé pour l'ambassade rendait extrêmement attentif à tout ce qui la concernait, commença à craindre que quelqu'un de ceux de ses compatriotes qui étaient à la suite des Anglais ne fût tenté de se mal conduire, persuadé que dans les conjonctures où les Anglais se trouvaient, leurs plaintes ne seraient point écoutées. Cependant, ils eurent, au moment même, occasion de faire quelques réclamations relativement aux provisions. Aussitôt on y eut égard ; et les provisions furent fournies avec plus de profusion qu'auparavant.

Tandis que la décision sur le cérémonial était en suspens, divers Anglais firent une petite excursion aux environs de Zhé-Hol. Ils étaient loin d'y être encouragés par les mandarins, qui craignaient sans cesse que quelque imprudence ou quelque indiscrétion de leur part, ou les dispositions qu'a partout la populace à insulter les étrangers, n'occasionnassent des désagréments. Les rigoureuses maximes du gouvernement chinois rendent les mandarins responsables de tout le mal qu'ils sont supposés avoir pu prévenir. D'après cela, ils prirent des précautions pour empêcher les gens du peuple d'entrer dans l'enceinte habitée par l'ambassade, ainsi que pour que les domestiques, les soldats et les ouvriers anglais ne sortissent point sans 


\section{Voyage dans l'intérieur de la Chine et en Tartarie}

permission. Les Chinois, et surtout les gens d'affaires, tels que la plupart des mandarins, ont fort peu d'idée du plaisir qu'on a à se promener dans la campagne pour prendre de l'exercice, ou pour voir les perspectives et la situation du pays. Ils pensent qu'alors on a toujours quelques vues guerrières, et conséquemment suspectes. Cependant, l'ordre général qu'avaient reçu les mandarins de fournir aux personnes de l'ambassade ce qui leur conviendrait et ce qu'elles désireraient ne leur permit pas de leur refuser des chevaux et des guides pour faire leur excursion.

Les Anglais qui entreprirent ce petit voyage furent bientôt rendus sur des hauteurs d'où ils eurent occasion de contempler la vallée de Zhé-Hol, qui suit les sinuosités des montagnes, et est très fertile, mais non pas cultivée avec autant d'art et de soin que les campagnes renfermées dans les anciennes limites de la Chine. Cette vallée est arrosée par une rivière qui, malgré la sécheresse de la saison, était assez considérable, et qui entraînait dans son cours un sable mêlé de beaucoup de parties d'or. Les montagnes adjacentes ne sont ni très élevées au-dessus de la vallée, ni escarpées. Elles consistent, du moins à leur surface, en un mélange d'argile et de gravier. Elles ne présentent ni angles saillants, ni angles rentrants, tels qu'en produisent ces torrents violents qui s'ouvrent des chemins à travers les montagnes; elles n'offrent même aucune chaîne régulière. Mais leur ensemble rappelle une mer en désordre dont les vagues, battues par des vents opposés qui se succèdent rapidement, sont brisées et ont différentes directions.

Certes, ni la forme de ces montagnes, ni les matières qui les composent, n'ont rien qui annonce qu'elles ont été originairement exposées à l'action du feu. Mais elles conservent plusieurs traces qui prouvent que l'eau, les couvrant pendant longtemps, a façonné la surface de cette partie du globe. Elles paraissent avoir été jadis couvertes de bois. Maintenant leurs sommets et les endroits les plus exposés n'ont plus que des productions rabougries. Le bois de haute futaie est rare dans tout ce pays. L'imprévoyance des premières générations, qui n'ont point planté de jeunes arbres à mesure qu'elles coupaient les vieux, est cruellement sentie par leurs descendants.

Les montagnes, ainsi dépouillées d'arbres, ne peuvent plus attirer beaucoup d'humidité. Les plus pauvres habitants ne souffrent point que leurs jardins dépendent du hasard de la pluie. Chacun d'eux a un puits, dont il se 


\section{Voyage dans l'intérieur de la Chine et en Tartarie}

sert pour arroser ses plantations. Les seaux avec lesquels ils tirent l'eau ne sont point faits avec des douves, mais avec des brins d'osier entrelacés avec tant de soin et d'intelligence qu'ils retiennent parfaitement toute espèce de liquide. Les jardins abondent en ail et autres végétaux âpres et aromatiques, qui peuvent servir à relever le goût du millet et des autres grains dont les paysans de ces contrées font leur principale nourriture.

Quand les Anglais furent sur les hauteurs, ils purent aisément contempler plusieurs belles maisons bâties dans les vallées et dans des situations très agréables. Ils crurent d'abord qu'elles appartenaient aux principales familles du pays, ou aux grands officiers de la cour; mais bientôt ils surent que c'étaient différents couvents de lamas, fondés par les empereurs de la dynastie régnante.

En s'en retournant, les voyageurs aperçurent au-delà de la ville de ZhéHol une chaîne de hautes montagnes, et une éminence sur laquelle était une pyramide de terre ou de pierre, renversée et semblable à celle que nous avons déjà décrite dans ce chapitre. Quelques-uns d'entre eux eurent envie d'aller l'examiner: mais les mandarins leur observèrent gravement qu'il y aurait de l'inconvenance à le faire, parce que l'éminence sur laquelle était située la pyramide dominait la partie du jardin impérial consacrée aux femmes du palais, et qu'on pourrait les voir se promener. II y avait cependant trois ou quatre milles de distance d'un lieu à l'autre.

Toute l'ambassade était alors occupée à se préparer à être présentée à l'empereur. On avait annoncé à l'ambassadeur que sa majesté impériale se contenterait de la forme respectueuse avec laquelle les Anglais avaient coutume d'aborder leur souverain. Cette détermination délivra l'ambassadeur de beaucoup d'inquiétude, et mit un terme à la nécessité d'examiner jusqu'à quel point il devait résister ou céder aux vœux de la cour impériale. On avoua tout bas que le bon sens et la générosité de l'empereur, lui-même peut-être fatigué de trop d'adorations, l'avaient bien plus disposé que ses conseillers à dispenser les Anglais de ce cérémonial.

Lord Macartney savait très bien que le triomphe qu'il obtenait contribuerait à irriter davantage ceux des Chinois et des Tartares qui étaient 


\section{Voyage dans l'intérieur de la Chine et en Tartarie}

ennemis des Anglais; mais qu'il augmenterait en général l'estime et la considération du peuple pour une nation en faveur de laquelle on faisait une exception si extraordinaire; et que les conséquences de ces sentiments ne pourraient manquer d'être avantageuses pour elle dans tous ses rapports commerciaux et politiques avec la Chine. Cette déviation d'une règle dont on ne s'était auparavant jamais écarté excita la plus grande surprise, peut-être même des murmures, dans l'âme de ceux qui ne considéraient que le passé ; mais elle confirma l'opinion du vieux missionnaire de Pékin, qui avait annoncé que le prétexte des coutumes, communément et fortement mis en avant par le Chinois, ne l'emportait pas toujours sur la raison, accompagnée de la fermeté et de la persévérance.

Le jour de naissance de l'empereur, à l'occasion duquel beaucoup d'ambassadeurs et de princes tributaires étaient rassemblés à Zhé-Hol, était le 17 de septembre. Mais on choisit le 14 du même mois pour la réception particulière de l'ambassade anglaise.

En attendant, les présents qui avaient été conduits à Zhé-Hol furent transportés au palais; et l'ambassadeur reçut plusieurs messages très polis, qui prouvaient la satisfaction de l'empereur.

Lord Macartney fit aussi une visite particulière au colao, qui l'accueillit avec franchise et affabilité, et lui rendit tous les honneurs dus à son rang, sans qu'il fût plus question des contestations qui avaient eu lieu. Après plusieurs politesses réciproques, et des réponses satisfaisantes à des questions de curiosité que fit Ho-Choong-Taung concernant l'Europe, et particulièrement l'Angleterre, l'ambassadeur entama une conversation dans laquelle il s'efforça de faire sentir au colao la convenance et la loyauté de la conduite passée, et la droiture des intentions futures du roi d'Angleterre à l'égard de la Chine. II insista sur les maximes pacifiques et bienveillantes de son gouvernement, dont le grand objet était l'extension du commerce pour l'avantage général du genre humain. II prit occasion de faire mention de I'Indostan, non comme pour en tirer des arguments favorables, mais comme pour donner quelques renseignements incidentels. II dit qu'après la dissolution de l'empire du Mogol, dans cette partie du monde, quelques provinces maritimes dans le voisinage des colonies britanniques avaient, à l'occasion de leurs dissensions intestines, réclamé la protection des armes 


\section{Voyage dans l'intérieur de la Chine et en Tartarie}

anglaises; et qu'elle leur avait été accordée sans qu'on eût déplacé les princes tributaires qui étaient encore en possession de leurs dignités; mais qu'à d'autres égards, les Anglais ne s'étaient point mêlés des contestations de leurs voisins. Le colao ne lui fit pas la moindre objection qui pût le mettre dans le cas de désavouer plus particulièrement les secours donnés contre les habitants du Thibet.

L'ambassadeur jugea à propos d'user de beaucoup de ménagements et d'expressions adoucies, pour donner une idée de l'importance dont pourraient être, pour la Chine, les liaisons de la Grande-Bretagne avec cet empire, soit en y introduisant les denrées d'Europe, dont la nécessité n'était point sentie à titre d'échange; soit en lui fournissant du coton et du riz de l'Inde, que quelques provinces chinoises sont aussi propres à cultiver; ou des lingots d'argent, dont l'accroissement a quelquefois l'inconvénient de faire augmenter inégalement le prix des objets nécessaires à la vie ; soit enfin relativement au secours d'une force navale pour détruire les pirates de la côte, contre le danger desquels on a une sûre ressource dans la communication intérieure, qui a lieu par les rivières et par les canaux. Telles sont les idées avouées ou affectées qu'a le gouvernement de la Chine sur l'indépendance et la supériorité de cet empire, qu'aucune relation avec les étrangers n'y est admissible sur le pied d'un avantage réciproque. II n'accorde rien que par grâce ou par condescendance.

L'ambassadeur ne voulait pas refuser de négocier même à ce titre ; et le colao lui dit obligeamment qu'ils auraient de fréquentes occasions de se revoir, durant le séjour que son excellence ferait à la cour de la Chine.

L'entrevue se termina comme elle avait commencé, avec beaucoup d'apparence de cordialité et de satisfaction des deux côtés. Bientôt après, l'ambassadeur reçut des messages de civilité, et des présents de fruits et de confitures de la part de l'empereur et du colao.

Les manières d'Ho-Choong-Taung étaient aussi engageantes que son esprit était pénétrant et éclairé. II semblait posséder les qualités d'un homme d'État consommé. Il avait été appelé aux emplois et revêtu de l'autorité par la seule faveur du souverain, comme cela arrive dans la plupart des monarchies; mais il s'y maintenait par l'approbation de ces personnes qui, 


\section{Voyage dans l'intérieur de la Chine et en Tartarie}

par leur rang et leur élévation, ont presque toujours de l'influence dans les gouvernements absolus. Dans ceux de ces gouvernements qui sont en Asie, les princes ne craignent point, comme en Europe, de dégrader leur dignité en s'alliant avec leurs sujets; et le nombre d'enfants que les monarques asiatiques ont de leurs différentes femmes et de leurs concubines occasionne tant d'alliances avec la couronne que l'influence en est diminuée par la concurrence. Cependant, ces sortes de nœuds, ajoutés au pouvoir déjà acquis, l'augmentent et le rendent plus solide.

Une fille de l'empereur était mariée au fils d'Ho-Choong-Taung. Cette circonstance suffit pour alarmer quelques personnes de la famille impériale, ainsi que quelques sujets loyaux qui craignaient que l'ambition du favori n'aspirât à une plus grande élévation. Un homme, indiscrètement zélé, osa présenter un mémoire à l'empereur, pour l'exhorter à déclarer son successeur, parce qu'il croyait que c'était une mesure de sûreté pour prévenir les dissensions qui pouvaient menacer l'empire.

Si le droit de primogéniture prévalait dans l'empire de la Chine, la succession au trône devrait appartenir à un petit-fils de l'empereur, né de son fils aîné, qui est déjà mort; mais les maximes du gouvernement laissent cette succession entièrement au choix du prince régnant, qui peut en exclure, comme on en a vu l'exemple, ses propres enfants et sa famille.

L'avis qu'un sujet avait osé donner au souverain pour l'engager à déclarer son choix irrita singulièrement ce prince. Le conseiller fut arrêté et capitalement puni ; car le tribunal qui le jugea mit sa témérité au nombre des crimes les plus odieux. Cependant l'empereur jugea à propos de publier dans les gazettes de Pékin les raisons qui l'empêchaient de se choisir un successeur. Elles étaient fondées sur le danger d'exciter une ambition prématurée dans une jeune âme, et de faire naître une faction opposée au souverain qui occupait le trône, ainsi qu'on l'avait déjà vu dans la dynastie régnante.

L'empereur avait résolu que l'héritier de sa couronne restât inconnu pendant qu'il la conserverait lui-même. Mais il saisit l'occasion dont nous venons de faire mention pour annoncer à ses sujets qu'ayant déjà occupé le trône pendant un demi-siècle, il renoncerait aux soins du gouvernement s'il 


\section{Voyage dans l'intérieur de la Chine et en Tartarie}

vivait assez longtemps pour compléter la soixantième année de son règne ${ }^{1}$, et qu'alors il exercerait la haute prérogative de nommer la personne la plus digne de lui succéder. Mais que si sa mort avait lieu avant cette époque, l'écrit qui contiendrait le nom de son successeur se trouverait dans un certain appartement de son palais. Cependant, combien sont vaines les précautions que prennent les hommes pour régler les événements qui suivent leur trépas! Yong-Ching, père de l'empereur actuel, en fournit lui-même la preuve. On raconte qu'il ne régna que parce qu'il entra au palais dans les derniers moments de son prédécesseur et qu'il substitua son nom dans le testament destiné à assurer le trône à un autre.

Le jour que l'ambassadeur anglais fut présenté à l'empereur, plusieurs princes de la famille impériale étaient autour de lui ; mais aucun ne paraissait obtenir plus de respect que les autres, ni avoir la moindre préférence sur eux.

L'ambassadeur et les principales personnes de l'ambassade se rendirent dans le jardin du palais de Zhé-Hol avant qu'il fît jour, ainsi qu'on les y avait engagés. Dans le milieu du jardin était une tente spacieuse et magnifique, soutenue par des colonnes dorées, ou peintes et vernissées. La toile ne suivait pas l'obliquité des cordes, dans toute leur longueur, jusqu'aux chevilles qui étaient plantées dans la terre; mais, du milieu de cette longueur, elle tombait perpendiculairement, et le reste formait la couverture. La tente contenait un trône semblable à celui qui a été décrit dans un des chapitres précédents ; et des fenêtres, de chaque côté de la tente, éclairaient particulièrement l'endroit où était le trône. Vis-à-vis du trône, il y avait une grande ouverture, d'où une tente jaune et volante se prolongeait à une distance considérable. L'ameublement de la tente était élégant, mais sans vain éclat et sans embellissements recherchés. Plusieurs petites tentes rondes étaient en face de la grande et il y en avait une oblongue immédiatement derrière. Cette dernière était réservée pour l'empereur, en cas qu'il voulût se retirer en particulier. II y avait un sofa à l'une des extrémités. Le reste était orné de beaucoup de mousquets et de sabres européens et asiatiques. L'une

\footnotetext{
${ }^{1}$ Elle devait arriver en 1796.
} 


\section{Voyage dans l'intérieur de la Chine et en Tartarie}

des petites tentes rondes devait servir à l'ambassade pour attendre l'arrivée de l'empereur. Quelques-unes des autres étaient également pour les divers princes et les représentants des États tributaires qui étaient rassemblés à Zhé-Hol à l'occasion du jour de naissance de l'empereur et qui, lorsque l'ambassadeur anglais fut présenté, se rendirent à la cour pour rendre sa réception plus éclatante. Quelques tentes étaient aussi destinées aux enfants mâles de la famille impériale, et aux principaux officiers de l'État. C'est dans la grande tente que l'empereur, assis sur son trône, voulait recevoir, avec une distinction particulière, l'ambassadeur du roi de la Grande-Bretagne.

Ce n'était pas seulement dans l'intention d'avoir un grand espace pour contenir le concours de personnes assemblées en cette occasion qu'une tente fut préférée à un des grands appartements du palais. En se conformant, à beaucoup d'égards, aux coutumes d'une nation vaincue, mais plus nombreuse et mieux civilisée que la sienne, la dynastie tartare conserve encore une prédilection pour ses anciennes mœurs, et elle les reprend de temps en temps, surtout quand elle est sur le sol de la Tartarie. Une tente mobile est un séjour plus agréable pour un souverain tartare qu'un palais de pierre ou de bois.

Les princes tributaires, ceux de la famille impériale, et les grands mandarins de la cour, formaient un groupe très considérable devant la grande tente ; et chacun était décoré des marques distinctives du rang que lui avait accordé l'empereur.

Plusieurs des courtisans étaient en partie vêtus de drap d'Angleterre, au lieu d'étoffe de soie et de fourrures, seul genre de vêtements qu'ils avaient eus jusqu'alors droit de porter en présence de l'empereur. Comme ces choses n'étaient pas devenues rares, le règlement qui permettait l'usage du drap d'Angleterre à la cour était un honneur qu'on rendait à l'ambassade anglaise ; et l'on eut soin d'en prévenir l'ambassadeur. II est vraisemblable que la consommation de cet article augmentera considérablement, parce que désormais les premiers ordres des mandarins donneront l'exemple d'en porter. C'est à la seule politesse qu'est dû cet avantage, qui ne pouvait pas être demandé dans un traité de commerce. 


\section{Voyage dans l'intérieur de la Chine et en Tartarie}

Les princes étaient décorés du bouton rouge transparent ${ }^{1}$, marque $d u$ premier des neuf ordres, tels qu'ils ont été fixés dans le siècle actuel par l'empereur Yong-Ching. Aucun des grands, rassemblés en cette occasion, ne portait une marque inférieure au bouton rouge opaque, qui distingue le second ordre de l'État. Quelques-uns étaient décorés de plumes de paon placées dans un tuyau d'agate et pendantes à leur bonnet. Cette dignité a trois degrés, distingués par le nombre de plumes. Celui à qui la faveur impériale accorde trois plumes se regarde comme trois fois grand et trois fois heureux.

Chacun de ces personnages avait dans son district un cercle de courtisans qui dépendaient de lui, et il était rempli de l'idée de sa propre importance ; mais devant la tente de l'empereur, tous étaient confondus dans la foule, et leur grandeur se perdait dans la contemplation de la majesté impériale. Suivant l'étiquette, la manière de prouver son respect à l'empereur est de l'attendre très longtemps. Quelques-uns passèrent, pour cela, une partie de la nuit dans le jardin. L'empereur devait y paraître un peu après l'aube. Une heure d'audience, si différente de celles des nations qui, passant par les divers degrés de civilisation, sont parvenues à celui du luxe et de l'indolence, rappelle l'usage journalier de ce peuple qui part pour la chasse aussitôt que les premiers rayons du soleil lui permettent de distinguer et de poursuivre les animaux auxquels il fait la guerre.

Avant l'arrivée de l'empereur, la petite tente de l'ambassadeur fut remplie par une foule de personnes qui se succédaient, et qu'attirait la curiosité ou le désir de faire des politesses à ce ministre.

Parmi ces personnes était un frère de l'empereur, homme d'une taille un peu au-dessus de la médiocre, d'un âge déjà avancé, et très simple dans ses manières. Il y vint aussi deux fils et deux petits-fils de l'empereur. Les premiers étaient des hommes de fort bonne mine, polis et curieux; les autres, jeunes, grands et extrêmement beaux. L'un des tributaires était des environs de la mer Caspienne. Il parlait l'arabe; et connaissant

1 On a déjà vu que les boutons, ou globes, qui distinguent les ordres, se portent au haut d'un bonnet pointu. (Note du Traducteur.). 


\section{Voyage dans l'intérieur de la Chine et en Tartarie}

vraisemblablement un peu plus l'Europe que les autres, il paraissait prendre un plus grand intérêt à ce qui avait rapport à l'ambassade. Mais l'ami particulier et déclaré des Anglais était le respectable vice-roi de Pé-Ché-Lée. II témoigna tant de plaisir en renouvelant connaissance avec l'ambassadeur, et il en parla avec tant d'estime au cercle qui l'environnait, que tous ceux qui composaient ce cercle furent dès lors très prévenus en faveur de son excellence. L'ambassade semblait aussi avoir plus de confiance en présence du vice-roi.

Peu après qu'il fut jour, le son de plusieurs instruments et des voix confuses d'hommes éloignés annoncèrent l'approche de l'empereur. Bientôt il parut venant de derrière une haute montagne, bordée d'arbres, comme s'il sortait d'un bois sacré, et précédé par un nombre d'hommes qui célébraient à haute voix ses vertus et sa puissance. II était assis sur une chaise découverte et triomphale, portée par seize hommes. Ses gardes, les officiers de sa maison, les porte-étendards, les porte-parasol et la musique l'accompagnaient. II était vêtu d'une robe de soie de couleur sombre, et coiffé d'un bonnet de velours, assez semblable, pour la forme, à ceux des montagnards d'Ecosse. On voyait sur son front une très grosse perle, seul joyau ou ornement qu'il parût avoir sur lui.

En entrant dans la tente, il monta sur son trône par les marches de devant, sur lesquelles lui seul a droit de passer. Le grand colao, Ho-ChoongTaung, et deux des principaux officiers de sa maison, se tenaient auprès de lui, et ne lui parlaient jamais qu'à genoux. Quand les princes de la famille impériale, les tributaires et les grands officiers de l'État furent placés suivant leur rang, le président du tribunal des coutumes conduisit l'ambassadeur anglais jusqu'au pied du côté gauche du trône, côté qui, d'après les usages chinois si souvent le contraire des nôtres, est regardé comme la place d'honneur. L'ambassadeur était suivi de son page et de son interprète. Le ministre plénipotentiaire l'accompagnait. Les autres principales personnes de l'ambassade, avec un grand nombre de mandarins et d'officiers inférieurs, se tenaient à l'entrée de la tente, d'où l'on pouvait voir la plus grande partie de la cérémonie.

L'ambassadeur était vêtu d'un habit de velours, richement brodé et orné de la plaque de l'ordre du Bain, en diamants. Par-dessus son habit, il portait 


\section{Voyage dans l'intérieur de la Chine et en Tartarie}

un manteau du même ordre, assez long pour couvrir ses jambes. Le désir de montrer de l'attention pour les idées et les mœurs chinoises, rendait assez important le choix du costume, et est cause que nous en parlons ici. Le respect particulier qu'à cette nation pour tout ce qui tient à l'extérieur influe même sur le système de ses vêtements, dont le but est d'inspirer de la gravité et de la réserve. En conséquence, ils ont la forme la plus opposée à celles qui laissent apercevoir quelque partie du corps. Certes, parmi les nations sauvages, il n'en est peut-être point auxquelles un sentiment intérieur, indépendant de toute espèce de précaution contre l'inclémence de l'air, n'apprenne qu'il est bien de se couvrir quelque partie du corps. Ce sentiment qu'on appelle décence, parce qu'il indique ce qu'il convient de faire, s'accroît en général avec les progrès de la civilisation et le perfectionnement des mœurs, et peut-être n'a-t-il été nulle autre part porté aussi loin que parmi les Chinois qui, dans leurs robes larges et flottantes, cachent absolument la forme de leur corps. II n'y a même à cet égard presque aucune différence entre les vêtements des deux sexes : bien plus, la délicatesse des Chinois s'offense à la vue des ouvrages de l'art qui imitent le corps humain, soit nu, soit couvert seulement des draperies qui suivent et déploient ses contours. Aussi cette délicatesse a retardé, parmi eux, les progrès de la peinture et de la sculpture, du moins en ce qui a rapport à ces sortes de sujets. Elle a aussi obligé les missionnaires à adopter les vêtements du pays, comme étant plus chastes et plus décents que les habits courts et serrés de l'Europe moderne.

Le grand manteau que l'ambassadeur avait droit de porter en qualité de chevalier de l'ordre du Bain était un peu analogue à la mode de s'habiller la plus agréable aux Chinois. D'après les mêmes principes, le ministre plénipotentiaire qui était docteur honoraire ès lois de l'université d'Oxford, prit la robe d'écarlate qui appartient à ce rang; ce qui se trouvait aussi très convenable dans un pays où les degrés en science conduisent à tous les emplois civils.

L'ambassadeur, instruit par le président du tribunal des coutumes, tint avec ses deux mains, et leva au-dessus de sa tête la grande et magnifique boîte d'or, enrichie de diamants, et de forme carrée, dans laquelle était renfermée la lettre du roi d'Angleterre à l'empereur. Alors, montant le peu de 


\section{Voyage dans l'intérieur de la Chine et en Tartarie}

marches qui conduisent au trône, il plia le genou, fit un compliment très court, et présenta la boîte à sa majesté impériale. Ce monarque la reçut gracieusement dans ses mains, la plaça à côté de lui, et dit :

«Qu'il éprouvait beaucoup de satisfaction du témoignage d'estime et de bienveillance que lui donnait sa majesté britannique, en lui envoyant une ambassade avec une lettre et de rares présents; que de son côté, il avait de pareils sentiments pour le souverain de la Grande-Bretagne, et qu'il espérait que I'harmonie serait toujours maintenue entre leurs sujets respectifs.

Cette manière d'accueillir le représentant du roi de la Grande-Bretagne était considérée par la cour de la Chine comme très honorable et très distinguée. L'empereur monte rarement sur son trône pour recevoir les ambassadeurs; et ils ne remettent point leurs lettres de créance dans ses mains, mais dans celles d'un de ses courtisans. Quoique très peu importantes en elles-mêmes, les distinctions accordées aux Anglais étaient regardées par la nation polie des Chinois comme un changement très marqué, en leur faveur, dans l'opinion de son gouvernement, et il fit une heureuse impression sur elle.

Après quelques moments d'entretien avec l'ambassadeur, l'empereur lui donna, pour premier présent, une pierre, appelée par les Chinois pierre précieuse, et qu'ils estiment beaucoup. Elle était de plus d'un pied de long, et on l'avait curieusement sculptée, dans le dessein de lui donner la forme du sceptre, qui est toujours placé sur le trône impérial, et qu'on regarde comme l'emblème de la prospérité et de la paix.

L'étiquette chinoise exigeant qu'indépendamment des présents que les ambassadeurs font au nom de leurs souverains, ils en fassent aussi en leur propre nom, l'ambassadeur anglais et le ministre plénipotentiaire, que les Chinois nommaient l'ambassadeur inférieur, offrirent respectueusement les leurs. L'empereur consentit à les recevoir, et leur en fit d'autres en retour. Ces présents étaient, sans doute, les uns et les autres, moins estimés par celui qui les recevait que par celui qui les donnait ; mais ils étaient également acceptables, quand on considérait qu'ils prouvaient d'une part le respect, et de l'autre la bienveillance et la faveur. 


\section{Voyage dans l'intérieur de la Chine et en Tartarie}

Durant la cérémonie, l'empereur se montra très ouvert, gai et sans la moindre affectation. Loin de s'envelopper d'un air triste et sombre, comme on le représentait quelquefois, il avait l'œil brillant, le regard fixe, et le maintien aisé. Tel il parut du moins pendant tout le temps de son entretien avec l'ambassadeur, entretien que prolongea la nécessité de faire interpréter réciproquement tout ce qu'on disait ; aussi l'entrevue fut-elle extrêmement fatigante.

L'empereur, s'apercevant de l'inconvénient qui résultait du besoin d'avoir recours à un interprète, demanda à Ho-Choong-Taung si quelque personne de l'ambassade entendait la langue chinoise, et ayant su que le page, âgé de moins de treize ans, était le seul qui eût fait des progrès dans cette langue, il eut la curiosité de le faire avancer jusqu'auprès de son trône, et de l'inviter à parler chinois. Soit par ce qu'il dit, soit par sa modeste contenance et par ses manières, cet enfant plut tellement à l'empereur que ce prince tira de sa ceinture une bourse contenant des noix d'arec et la lui présenta.

Les bourses sont les cordons ou les rubans que le monarque chinois distribue à ses sujets, pour récompenser leur mérite: mais le don de sa propre bourse est une faveur particulière, suivant les idées des nations orientales, parmi lesquelles une chose portée par la personne du souverain est regardée comme le plus précieux de tous les dons. La bourse de l'empereur procura au jeune favori l'attention et les caresses d'un grand nombre de mandarins, tandis que d'autres, peut-être, enviaient son bonheur. La bourse impériale n'a rien de magnifique. Elle est tout simplement de soie jaune et a, dans son tissu, la figure du dragon aux cinq griffes, et quelques caractères tartares.

Après que l'empereur eut cessé de parler aux Anglais, quelques ambassadeurs du Pégu, et des Mahométans des environs de la mer Caspienne furent présentés à la droite de son trône. Ils répétèrent neuf fois leurs humbles prosternements, et furent promptement congédiés. On conduisit l'ambassadeur anglais et les trois personnes qui l'accompagnaient, jusqu'à des coussins, sur lesquels ils s'assirent à gauche du trône. Les princes de la famille impériale, les chefs tartares des nations tributaires et les premiers mandarins de la cour, étaient placés suivant leur rang, plus près ou plus loin du trône. Les Anglais étaient à peu près dans le milieu de l'espace qui 


\section{Voyage dans l'intérieur de la Chine et en Tartarie}

séparait le trône de l'extrémité de la tente. Il y avait une table de deux en deux personnes. Aussitôt que tous les convives furent assis, les tables furent découvertes, et on les vit chargées d'un superbe repas. Elles étaient petites, mais chacune avait une pyramide de jattes contenant une grande quantité de viandes et de fruits. On avait placé une table devant le trône, et l'empereur fit honneur aux mets qui la couvraient. On servit aussi du thé ; ceux qui en présentaient les jattes et les tasses à l'empereur tenaient leurs mains élevées au-dessus de la tête, comme l'ambassadeur anglais lui avait offert la boîte d'or qui contenait la lettre de sa majesté britannique.

Ce cérémonial semble d'abord n'avoir pour but que de marquer l'excessive distance qui, dans une monarchie absolue, se trouve entre le souverain et les sujets ; mais quand on le considère attentivement, on est porté à conjecturer qu'il n'a point été originairement imaginé, et ensuite exigé pour le seul plaisir qu'il procure. Il est évident que, pendant qu'on le pratique, non seulement il annonce une inégalité morale, mais il produit une inégalité physique entre celui qui reçoit l'hommage et celui qui le rend. Le premier, quoique supérieur à toute force ouverte, peut fort bien sentir qu'il n'est pas à l'abri de la trahison particulière, et cet esprit soupçonneux qui accompagne souvent un pouvoir sans bornes a sans doute suggéré à celui qui le possède ces

précautions contre les desseins secrets et furieux que peuvent avoir des individus qui l'approchent. Le prosternement, l'agenouillement, l'élévation des mains au-dessus de la tête, rendent certainement plus difficile l'agression des personnes qui sont dans ces postures.

Une chose non moins remarquable que ces cérémonies, c'est le silence solennel qui les accompagne et qui semble être inspiré par une religieuse terreur. II n'y a nulle conversation entre ceux qui sont assis ; nul fracas parmi ceux qui les servent. Ce qui caractérise le plus une telle scène, c'est cette dignité calme, cette pompe tranquille de la grandeur asiatique, que n'ont point encore égalées les raffinements européens.

Cependant, l'attention de l'empereur pour ses hôtes anglais ne diminua pas. Durant le repas, il leur envoya divers plats de sa table ; et quand on eut cessé de manger, il les fit approcher, et leur présenta de sa main un gobelet de vin chinois, assez semblable à du vin de Madère, d'une qualité inférieure. II demanda à l'ambassadeur l'âge du roi d'Angleterre, et quand on le lui eut dit, 


\section{Voyage dans l'intérieur de la Chine et en Tartarie}

il souhaita aussitôt qu'il vécût un aussi grand nombre d'années que lui, et qu'il se portât aussi bien. L'empereur avait déjà quatre-vingt-trois ans ; mais il était d'un tempérament si sain et si vigoureux qu'à peine paraissait-il avoir autant d'années qu'il en avait régné, c'est-à-dire cinquante-sept. A la fin du banquet, il descendit du trône et marcha très droit, d'un pas ferme, et sans la plus légère apparence d'infirmité, jusqu'au siège triomphal qui l'attendait.

Bientôt après que l'ambassadeur fut de retour dans le palais où il logeait, l'empereur lui envoya des présents de soieries, de porcelaine et de thé, pour lui et pour toutes les principales personnes de l'ambassade. Les étoffes étaient, en général, d'un tissu fort et serré et d'une couleur grave, telle que celle dont les hommes font usage en Chine. II y avait des vêtements faits au métier, et décorés, les uns du dragon à quatre griffes ou du tigre impérial, les autres du faisan chinois, brodés en soie d'une couleur plus gaie que celle de l'étoffe. Les premiers de ces vêtements étaient de l'espèce de ceux que portent les premiers mandarins militaires; et les autres semblables à ceux des premiers mandarins civils. La porcelaine consistait en pièces détachées, peu différentes de celles qu'on envoie ordinairement en Europe. Le thé était roulé en boules de différente grosseur. Pour le préparer ainsi, on emploie un liquide glutineux, qui unit les feuilles sans en altérer la qualité ; de sorte qu'elles conservent tout leur parfum. Ce thé vient de la province méridionale de Yu-Nan ; et l'on n'en porte pas communément en Angleterre. Cette espèce de thé est singulièrement estimée en Chine; mais I'habitude a tant de pouvoir sur le goût que les Anglais préféraient le thé auquel ils étaient accoutumés.

Parmi les présents de fruits qu'on envoyait de temps en temps à l'ambassadeur, il y avait des raisins blancs d'une espèce rare. Leurs grains étaient de la grosseur des olives d'Espagne et beaucoup plus oblongs.

A la Chine, presque toute espèce de relation entre les supérieurs et les inférieurs est accompagnée de présents réciproques; mais ceux des premiers sont accordés comme des dons, et ceux des autres acceptés comme des offrandes. Les mots chinois qui répondent à ces termes sont encore employés pour les présents que l'empereur fait aux princes étrangers, ou reçoit d'eux. C'est le style officiel de la supériorité qu'affecte en ces occasions la cour de la Chine, et qui ressemble au ton que s'arrogeait autrefois la chancellerie de 


\section{Voyage dans l'intérieur de la Chine et en Tartarie}

l'empire germanique à l'égard des autres puissances de l'Europe. Mais toutes les fois que l'empereur de la Chine fait mention de lui, et surtout quand il cite en même temps quelqu'un de ses ancêtres ou de ses prédécesseurs au trône, il emploie pour tout ce qui a rapport à sa personne les expressions les plus modestes et les plus humbles, conformément au système des mœurs chinoises. Par un excès de précaution contre l'égoïsme, ces mœurs exigent qu'un homme ne parle jamais de lui que dans des termes très bas, et de ceux à qui il s'adresse, qu'avec les expressions les plus relevées.

La première marque de civilité qui suivit l'envoi des présents de l'empereur fut une invitation adressée à l'ambassadeur et à sa suite, pour aller voir les jardins de Zhé-Hol. Les Anglais se rendirent dans ces jardins de très grand matin, car c'est I'heure où se commencent toutes les affaires dans cette cour si réglée. En se promenant, ils rencontrèrent l'empereur, qui s'arrêta pour recevoir les salutations de l'ambassadeur, et lui dit :

«Qu'il allait faire sa dévotion dans le temple de Poo-Ta-La ; que comme ils n'adoraient pas les mêmes dieux, il n'engageait pas l'ambassadeur à l'accompagner ; mais qu'il avait donné ordre à ses ministres de se promener avec son excellence dans les jardins.

L'ambassadeur, qui pensait que l'empereur lui donnerait une marque suffisante de son attention en le faisant accompagner par un courtisan d'un rang élevé, mais que n'occuperaient point les affaires d'État, fut surpris de voir qu'Ho-Choong-Taung l'attendait dans un pavillon. Le grand vizir de l'empire, celui que tout le peuple considérait comme un second empereur, avait ordre en ce moment de dérober une partie de son temps aux soins du gouvernement, pour tenir compagnie à un étranger dans une promenade de plaisir et de curiosité.

Cette circonstance pouvait contribuer à faire naître une intimité favorable au principal objet de la mission de l'ambassadeur. Mais la satisfaction qu'elle lui occasionna fut bien diminuée par la présence du général du Thibet. Ce général accompagna le colao, comme s'il craignait que l'ambassadeur n'acquît quelque crédit auprès de lui, ou qu'il n'y eût entre eux quelque explication relative à la guerre du Thibet. Le frère du général, lequel était chargé d'une 


\section{Voyage dans l'intérieur de la Chine et en Tartarie}

grande partie de l'administration, était aussi avec Ho-Choong-Taung, ainsi qu'un des autres principaux personnages de la cour ${ }^{1}$.

Ces Chinois prirent la peine de conduire l'ambassadeur et sa suite à travers de vastes terrains plantés pour l'agrément, et ne formant qu'une partie de ces grands jardins. Le reste était réservé pour les femmes de la famille impériale; et l'entrée en était aussi rigoureusement interdite aux ministres chinois qu'à l'ambassade anglaise.

Ils parcoururent une vallée verdoyante, dans laquelle il y avait beaucoup d'arbres, et surtout des saules d'une prodigieuse grosseur. L'herbe était abondante entre ces arbres, et ni le bétail, ni le faucheur n'en diminuaient guère la vigoureuse croissance. Les ministres chinois et les Anglais, étant arrivés sur les bords d'un vaste lac, de forme irrégulière, s'embarquèrent dans des yachts et parvinrent jusqu'à un pont qui traversait le lac dans la partie la plus étroite, et au-delà duquel il semblait se perdre dans un éloignement très obscur. La surface de l'eau était en partie couverte de lien-wah, espèce de lis qui croît aussi à Pékin, et dont nous avons parlé dans le quatrième chapitre de la seconde partie. Quoique dans un climat plus rapproché du nord et dans une saison plus froide que celle où nous l'avions vu dans la capitale de la Chine, il ornait le lac non seulement de ses larges feuilles, mais de ses fleurs odorantes.

L'ambassadeur et ses compagnons descendirent dans un endroit où il y avait plusieurs petits palais, mais pas un seul édifice considérable. On voyait quelques bâtiments sur le sommet des montagnes les plus élevées, et d'autres placés dans les endroits les plus sombres des plus profondes vallées. Chacun de ces bâtiments différait des autres par sa construction, et presque tous avaient, dans leur plan, quelque chose d'analogue à leur situation et aux objets qui les environnaient. Chacun avait une salle publique, avec un trône dans le milieu et quelques appartements sur les côtés. Le tout était orné des ouvrages de l'art qu'avait fournis l'Europe, et des plus rares et des plus curieuses productions de la nature, trouvées en Tartarie. Parmi ces dernières, on remarquait une agate d'une grandeur et d'une beauté extraordinaire. Elle

\footnotetext{
${ }^{1}$ II se nommait Sun-Ta-Zhin.
} 


\section{Voyage dans l'intérieur de la Chine et en Tartarie}

était placée sur un piédestal de marbre dans un des pavillons des bords du lac. Longue de quatre pieds, elle était sculptée en paysage et on y avait gravé des vers composés par l'empereur.

Les meilleurs ouvrages de l'art que fassent les habitants de ces contrées sont des sculptures en bois, lesquelles imitent des objets naturels, groupés avec goût, et exécutés avec vérité et même avec délicatesse. Quelques murs des palais étaient couverts de tableaux représentant la chasse des Tartares. L'empereur y était toujours peint à cheval, galopant, et perçant de ses flèches les animaux sauvages. Cependant ces tableaux ne pouvaient supporter la critique des Européens. Les arbres, quelques parties des paysages, les oiseaux, même les animaux, y étaient dessinés avec exactitude; mais ils péchaient dans tout ce qui a rapport à la figure humaine, dont les spectateurs qui la connaissaient mieux pouvaient plus aisément apercevoir les défauts. $\mathrm{Ni}$ les proportions, ni la perspective, n'étaient observées. Les Chinois, quoique corrects et quelquefois hardis dans le dessin des objets séparés, ne peuvent pas être regardés, dans l'état actuel de leurs arts, comme propres à bien composer et à bien peindre un tableau. Les Anglais virent, dans un appartement, le portrait d'une femme européenne, assez médiocrement peint. Il y avait aussi, dans une chambre à coucher, une belle statue de marbre, représentant un enfant nu, appuyé sur ses genoux et sur ses mains. Quelques animaux, sculptés en pierre, étaient dans un parterre. On voyait, en outre, devant plusieurs bâtiments, de monstrueuses et désagréables figures de lions et de tigres en porcelaine. Les choses qui abondaient le plus dans ces palais, et que les conducteurs admiraient davantage, étaient ces figures d'hommes et d'animaux apportées d'Europe, et qui, par le moyen de rouages et de ressort secrets, produisent des mouvements qui semblent être spontanés. Dans le premier temps où ces machines parurent en Chine, elles furent considérées comme des ouvrages presque surnaturels, et on les vendit à de très hauts prix.

Les Anglais, ayant poussé leur course plus loin, virent des champs où l'on avait rassemblé tout ce que la surface d'un pays peut offrir de plus inégal. Dans les uns croissaient les durs chênes des monts septentrionaux ; dans les autres, les plus tendres plantes des vallées du midi. Là, où se présentait une vaste plaine, on avait entassé des rochers énormes, qui rendaient la scène 


\section{Voyage dans l'intérieur de la Chine et en Tartarie}

plus piquante; et le tout semblait fait pour offrir l'agréable variété et le frappant contraste de la rude et sauvage nature, et de la nature cultivée et embellie.

Les jardins étaient animés par le mouvement et les sons de beaucoup d'oiseaux et de quadrupèdes ; mais on n'y apercevait aucune ménagerie de bêtes féroces. Plusieurs superbes espèces de poissons argentés et dorés se jouaient dans les étangs diaphanes, dont le fond était garni de cailloux d'agate, de jaspe, et d'autres pierres précieuses.

Dans ces jardins, les Anglais ne trouvèrent point de sentiers garnis de gravier, ni d'arbres plantés par rangs, ou rassemblés par touffes. Tout semblait y être fait de manière à éviter un air de régularité et de dessein. II n'y avait rien de longuement aligné, rien qui tournât à angle droit. Les objets naturels semblaient accidentellement épars, et les ouvrages de I'homme, quoique atteignant parfaitement leur but, paraissaient être faits par des mains rustiques, et sans le secours d'aucun instrument.

Quelques-uns de ces embellissements élégants, qu'on a décrits comme ornant les jardins chinois, ne frappèrent point là les yeux des Anglais. Mais les jardins de Yuen-Min-Yuen, situés près de Pékin et d'où sont principalement prises les descriptions de ces ornements, sont, dit-on, plus complets que ceux de Zhé-Hol. II y aurait donc de la présomption à avancer que ce qui est omis dans les uns a été faussement attribué aux autres.

Les Anglais n'eurent point occasion de voir, si tant est qu'elle existe, la ville en miniature, qu'on prétend être bâtie dans la partie des jardins destinée aux femmes de la famille impériale, et où les scènes ordinaires de la vie, le mouvement, la confusion de la capitale sont fidèlement représentés, si l'on en croit les récits d'un missionnaire qui, en qualité d'artiste, a été, dit-on, employé à décorer un lieu semblable à Yuen-Min-Yuen. Toutefois, quoique douteux, ces récits ne sont point improbables. Les femmes du palais, qui vivent séparées du monde, seraient sans doute charmées d'avoir une représentation de ce qui s'y passe, et l'empereur pourrait, sans répugnance, avoir consenti à satisfaire une curiosité que, peut-être, il partageait à beaucoup d'égards. Lorsque lord Macartney était ambassadeur en Russie, il vit, dans un des palais de l'impératrice, à Pétersbourg, l'imitation d'une ville, 


\section{Voyage dans l'intérieur de la Chine et en Tartarie}

avec un certain nombre de boutiques d'ouvriers et de marchands, et la vie du peuple représentée d'une manière assez agréable, pour l'amusement de la cour. Cependant un pareil spectacle devait avoir moins de prix dans un lieu où les femmes sont bien loin d'être, comme celles de la Chine, privées de la vue de ce qui se passe réellement dans le monde.

Pendant plusieurs heures que dura la promenade dans les jardins de ZhéHol, Ho-Choong-Taung eut les plus grandes attentions pour l'ambassadeur, et montra qu'il avait toute la bonne éducation et la politesse d'un courtisan exercé. L'autre ministre ne fut ni moins affable, ni moins prévenant; mais son frère, le général du Thibet, fut constamment froid et repoussant. II ne chercha même pas à cacher les violentes préventions qu'il avait conçues contre les Anglais. II avait, sans doute, eu occasion d'observer à Canton leur esprit hardi et entreprenant, et l'idée des richesses et du pouvoir qui les rendaient capables de rivaliser l'empire chinois n'était peut-être pas ce qui l'offensait le moins. Ce fut en vain que l'ambassadeur tenta de le radoucir, en faisant tomber la conversation sur sa réputation guerrière. II était naturel de s'attendre qu'il serait flatté qu'on lui proposât de voir, comme juge des exercices militaires, un exemple des évolutions européennes, tel que pouvait le lui donner la garde de l'ambassadeur. Mais il répondit d'un ton chagrin qu'il avait déjà vu les évolutions des troupes étrangères, et qu'il ne croyait pas que les Anglais pussent lui offrir rien de nouveau à cet égard. II ne voulait pas non plus reconnaître en eux aucune autre espèce de mérite.

Tandis qu'on parcourait les divers bâtiments des jardins de Zhé-Hol, les Anglais avaient poliment profité des moindres occasions pour témoigner leur approbation à leurs conducteurs, et louer tout ce qui leur avait paru en valoir la peine. Ils ne refusèrent même pas de partager leur admiration pour ces ouvrages de mécanique, dont nous avons déjà fait mention, et qui avaient formé une partie de la superbe et curieuse collection, appelée le Museum de Cox, faite et vue autrefois en Angleterre. Le général du Thibet jugeant, par leurs applaudissements, que ces objets étaient nouveaux pour eux, leur demanda d'un air de triomphe, si l'on pourrait en trouver de pareils en Angleterre ; et il ne fut pas peu mortifié d'apprendre que c'était de là qu'ils avaient été apportés en Chine. 


\section{Voyage dans l'intérieur de la Chine et en Tartarie}

En s'entretenant avec l'ambassadeur, Ho-Choong-Taung lui dit qu'il avait reçu des nouvelles de l'arrivée du Lion et de l'Indostan, à Chu-San. L'ambassadeur saisit cette occasion pour demander que le capitaine Mackintosh, qui avait eu le bonheur de présenter son hommage à l'empereur, eût la permission d'aller rejoindre son vaisseau. Mais le général qui se tenait à côté du colao prit aussitôt la parole, en s'écriant qu'il ne convenait pas qu'on laissât cet officier traverser l'empire chinois. L'ambassadeur jugea à propos de ne pas insister sur cela pour le moment; mais il pressa le colao de lui accorder bientôt un entretien à ce sujet. La multiplicité des affaires, qui pressaient dans ces circonstances, aurait pu servir d'excuse à Ho-ChoongTaung pour refuser l'ambassadeur ; mais il ne fut réellement arrêté que par une indisposition. La fatigue de la promenade qu'il avait faite dans le jardin de Zhé-Hol renouvela quelques maux auxquels il avait été longtemps sujet. En conséquence, il fit prier l'ambassadeur de lui envoyer son médecin anglais, qu'il désirait consulter. Le docteur Gillan accompagna aussitôt le messager dans la maison du colao. Il y trouva rassemblés quelques-uns des principaux médecins de la cour, lesquels paraissaient très inquiets sur la santé de l'illustre malade.

Le colao était attaqué de douleurs violentes ${ }^{1}$ qui affectaient les principales jointures des bras et des jambes. II sentait aussi une vive douleur dans la partie inférieure de l'abdomen; et une tumeur considérable, commençant à l'anneau du muscle oblique extérieur, du côté droit, s'étendait le long du cordon ombilical. II avait souvent souffert de ces incommodités; mais il les avait eues rarement toutes à la fois. Les douleurs articulaires, lombaires et dorsales se faisaient sentir ordinairement au printemps et en automne. La douleur abdominale et l'enflure revenaient plus souvent et duraient moins. L'enflure se montrait et disparaissait quelquefois tout à coup : mais elle était plus forte et plus douloureuse quand le malade avait fait quelque effort particulier.

\footnotetext{
${ }^{1}$ Tous ces détails ont été fournis par le docteur Gillan.
} 


\section{Voyage dans l'intérieur de la Chine et en Tartarie}

Le docteur Gillan apprit toutes ces circonstances du colao lui-même, qui fut surpris du nombre de questions du docteur, parce que les médecins chinois n'avaient pris la peine de lui en faire aucune. Ces médecins tiraient principalement leurs inductions de l'état du pouls, dans la connaissance duquel ils prétendaient qu'était la plus grande science. Suivant eux, chaque partie du corps avait une pulsation qui lui était propre, et qui indiquait quelle était la partie souffrante. Ils considéraient le pouls comme un interprète général de la vie animale, lequel expliquait l'état du corps ; et ils croyaient que, par son seul moyen, la cause et le siège du mal pouvaient être déterminés, sans qu'on eût besoin d'aucune autre information relative au malade.

Après avoir bien examiné le pouls du colao, ces médecins avaient, de bonne heure, décidé que tous ses maux étaient dus à une vapeur maligne, ou à un esprit qui, ayant pénétré dans son corps ou y étant né, passait d'une partie à l'autre, et causait toujours de la douleur dans l'endroit où il se fixait. D'après cette opinion sur la nature et les causes du mal, ils s'occupèrent immédiatement à chasser la vapeur ou l'esprit; et la méthode qu'ils employèrent fut de lui ouvrir, directement dans la partie souffrante, des passages par où il pût s'échapper. L'opération fut souvent répétée; et le malade eut beaucoup à souffrir des profondes piqûres qu'on lui fit avec des aiguilles d'or ou d'argent, seuls métaux dont on peut se servir en pareil cas.

Cependant, la maladie se faisait sentir à l'ordinaire. Mais d'après l'autorité du pouls, c'était entièrement dû à l'obstination de l'esprit, qui demeurait en partie dans le corps, malgré tout ce qu'on faisait pour l'en faire sortir, ou qui après avoir été expulsé d'une partie, se régénérait dans d'autres. Les médecins avaient en vain épuisé toute leur science pour traiter cette maladie. Les premières douleurs revenaient comme de coutume; et lorsque le docteur Gillan fut appelé, elles étaient plus fortes qu'elles ne l'avaient jamais été. Les médecins chinois avaient proposé d'observer la même méthode dans le traitement de l'enflure de la partie inférieure de l'abdomen, parce qu'ils pensaient qu'elle avait la même cause que les douleurs des jointures. Mais le

colao craignant que la piqûre des aiguilles n'offensât quelque partie essentielle, ne voulut pas se soumettre à cette opération ; et certes, il fut très heureux de persister dans son refus. 


\section{Voyage dans l'intérieur de la Chine et en Tartarie}

Ce fut dans ces circonstances que le colao désira de connaître l'opinion du médecin anglais sur sa maladie. Après les premières cérémonies, occasionnées par l'arrivée du docteur Gillan, après qu'on eut emporté le thé, le fruit et les confitures qui avaient été servis, le malade présenta son bras droit au docteur, et ensuite son bras gauche, en les appuyant sur un coussin, afin que le pouls pût être plus attentivement examiné. Le docteur, pour se conformer aux coutumes, aux préjugés du pays, et ne pas choquer le malade et les médecins, par moins d'attention qu'ils n'en croyaient nécessaire à cette formalité préliminaire, tâta le pouls aux deux bras avec beaucoup de gravité, et pendant longtemps. Il dit alors au colao et aux autres Chinois que les médecins d'Europe croyaient rarement qu'il fallût tâter le pouls en différentes parties du corps, parce qu'ils savaient que le pouls de chacune de ces parties correspondait avec celui des autres, et que toutes communiquaient entre elles et avec le cœur, par le moyen de la circulation du sang; de sorte qu'en connaissant l'état ou le pouls d'une artère, l'état de tout le reste était également connu.

Le colao écouta cette doctrine avec étonnement, et les médecins n'en eurent pas moins que lui de ce qui était si nouveau pour eux. Ils furent très déconcertés et très embarrassés dans les observations qu'ils firent sur cela. $A$ la sollicitation du docteur et pour se satisfaire lui-même, le colao mit l'index de sa main droite sur l'artère du bras gauche, et l'index de sa main gauche à la cheville du pied droit, et il trouva, à sa grande surprise, que dans ces

différents endroits la pulsation était simultanée. Il témoigna sa satisfaction de ce qu'une expérience aussi simple et aussi aisée prouvait ce qui venait d'être avancé.

Le docteur lui dit qu'indépendamment du pouls, il était nécessaire de prendre des informations sur les sensations intérieures d'un malade, ainsi que sur ce qui y avait extérieurement rapport, afin de pouvoir juger sainement de l'état de sa maladie. Cette considération engagea le colao à répondre à toutes les questions du docteur. D'après un examen très exact, il parut que ses souffrances avaient deux causes très distinctes. La première était un rhumatisme qui revenait à différentes époques, après s'être d'abord fait sentir dans les montagnes de la Tartarie, où le colao avait été longtemps exposé au froid et la pluie. La seconde fut reconnue pour une hernie complètement 


\section{Voyage dans l'intérieur de la Chine et en Tartarie}

formée. Si le malade s'était laissé piquer dans cette partie, comme le lui avaient proposé ses médecins, il s'en serait suivi les plus dangereuses conséquences.

Le colao pria le docteur de lui donner, par écrit, l'explication de la nature de sa maladie, et la méthode qu'il devait suivre pour la guérir. II lui fit un présent d'une pièce d'étoffe de soie et lui dit que ses idées lui paraissaient claires et raisonnables, et qu'elles étaient si nouvelles et si différentes des notions qu'on avait en Asie, qu'elles semblaient venir d'un habitant d'une autre planète.

Quoique le colao fût promptement guéri de sa maladie la plus pressante, l'ambassadeur fut quelque temps sans pouvoir obtenir une entrevue avec lui. II se détermina alors à lui écrire pour renouveler ses sollicitations à l'égard du départ du capitaine Mackintosh, qui voulait s'empresser d'aller joindre son vaisseau à Chu-San. L'ambassadeur demanda aussi qu'il fût permis aux officiers du vaisseau de vendre leurs pacotilles à Chu-San, et d'en employer le produit à acheter des denrées des provinces voisines, pour former une cargaison.

Il n'y avait à Zhé-Hol aucun missionnaire ami qui pût procurer une traduction convenable de la lettre de l'ambassadeur, comme cela était arrivé en pareil cas à Pékin; mais l'interprète trouva une personne capable de mettre, dans les termes propres, le sens de la lettre, qu'on lui expliqua verbalement, et la traduction fut, comme à l'ordinaire, copiée et attestée par le page.

On ne s'attendait pas à éprouver de nouvelles difficultés relativement à cette lettre ; cependant, il y en eut encore pour la faire remettre. Le légat qui était toujours chargé du principal soin de l'ambassade, l'aurait certainement prise si on la lui eût offerte; il n'eût pas même manqué de promettre de la faire parvenir à son adresse, comme il l'avait promis pour le premier mémoire de l'ambassadeur ; mais il aurait épargné au colao l'embarras d'une lecture.

L'animosité du légat contre les Anglais n'avait point été adoucie par la disgrâce dans laquelle il était tombé, et dont, suivant ce qu'on rapporta à l'ambassade, elle fut l'innocente cause. L'empereur, apprenant que son portrait avait été mis par l'ambassadeur dans la grande chambre du vaisseau 


\section{Voyage dans l'intérieur de la Chine et en Tartarie}

le Lion, fut flatté de cette attention et chargea le légat de lui faire la description de ce portrait, afin de juger s'il était ressemblant. Mais les réponses évasives de cet officier lui faisant bientôt connaître qu'il n'avait pas été à bord, quoiqu'il eût reçu l'ordre d'y aller, il le fit à l'instant dégrader, pour le punir de sa désobéissance ; car c'est un pouvoir que donne la couronne de la Chine, et qui est fréquemment exercé à l'égard de tous les rangs et de toutes les dignités. Le légat fut réduit à changer son bouton transparent pour un bouton blanc opaque, et sa plume de paon pour une plume de corneille, qui pendit à son bonnet. Cependant, protégé par Ho-Choong-Taung, il conserva son autorité et ses emplois.

L'on ne put trouver aucun domestique chinois qui eût le courage d'aller porter la lettre de l'ambassadeur, sans la permission du légat. Nul Européen ne pouvait pénétrer seul dans la maison du colao, et paraître en sa présence ; mais l'interprète chinois, quoique vêtu d'un uniforme anglais, entreprit de se charger du message. Il fut embarrassé, et même insulté en route par la populace ; malgré cela, il parvint jusqu'à la maison du colao, et plaça la lettre en si bonnes mains qu'il fut sûr qu'elle lui serait remise sans délai.

Cependant, la célébration de l'anniversaire du jour de naissance ${ }^{1}$ de l'empereur arriva. L'ambassadeur et sa suite furent invités de se rendre à cette cérémonie, comme à la première, avant le lever du soleil. La fête peut être considérée comme ayant duré plusieurs jours. Le premier fut consacré à rendre un hommage religieux et solennel à la suprême majesté de l'empereur. Cette cérémonie ne se fit point dans une tente ; et il n'y eut point de banquet. Les princes, les tributaires, les ambassadeurs, les grands officiers de l'État et les principaux mandarins furent d'abord assemblés dans une vaste salle, et ensuite on les conduisit dans un édifice reculé, qui ressemblait à un temple. II y avait beaucoup de grands instruments de musique, parmi lesquels étaient des rangs de cloches cylindriques, suspendues à des châssis de bois très bien travaillés. La grandeur des cloches diminuait graduellement d'un bout du rang à l'autre. Des pièces triangulaires de métal étaient arrangées de la même manière, et dans les mêmes proportions. Ces

\footnotetext{
${ }^{1}$ Le 17 septembre.
} 


\section{Voyage dans l'intérieur de la Chine et en Tartarie}

instruments accompagnèrent le chant d'un hymne, lentement exécuté par des eunuques, dont les voix ressemblaient de loin aux sons de I'harmonica. Les chanteurs passaient d'un ton à l'autre quand on frappait sur une cymbale retentissante ; et leur manière d'exécuter plut beaucoup à ceux qui, parmi les Anglais, étaient connaisseurs en musique. L'ensemble de cette musique faisait un très grand effet. Pendant qu'on chantait l'hymne, et à des signaux neuf fois répétés, toutes les personnes présentes se prosternaient neuf fois, à l'exception de l'ambassadeur et de sa suite, qui ne faisaient qu'une profonde inclination. Mais pendant la durée de cet hommage, celui à qui il était adressé resta invisible, à l'exemple de la divinité.

L'impression religieuse qu'on voulait faire sur l'esprit des hommes par cette sorte d'adoration d'un mortel comme eux ne fut mêlée avec rien qui pût y être contraire. On renvoya au lendemain les amusements et la gaieté. Cependant, les Anglais ne crurent point manquer aux convenances en visitant les temples bâtis par l'empereur dans le voisinage du palais. Sun-Ta-Zhin, l'un des courtisans qui avaient conduit l'ambassadeur dans les jardins, lui offrit poliment de l'accompagner dans cette nouvelle promenade. Ce chef tartare avait été récemment élevé au rang de colao, c'est-à-dire de cette première classe de mandarins qui ne sont qu'au nombre de six dans l'empire. Depuis, il avait été employé sur les frontières de la Russie pour terminer quelques différends qui s'étaient élevés entre les Chinois et les Russes. II dit qu'il avait traité à Yachta avec un général russe, décoré d'une plaque et d'un cordon rouge, comme ceux de l'ambassadeur, et qu'il s'était promptement arrangé avec lui. Apprenant que lord Macartney avait été autrefois envoyé à la cour de Russie, il l'interrogea beaucoup sur les richesses, la puissance et les projets politiques de cette cour. En revanche, il répondit très bien à diverses questions de curiosité que l'ambassadeur lui fit à l'égard de la Chine. La conversation devint intéressante et, en partie, confidentielle. Sun-Ta-Zhin était attentif, intelligent ; et la sorte d'intimité qui commença à cette époque entre lui et l'ambassadeur devint ensuite très utile.

Dans l'excursion qu'ils firent ce jour-là, ils visitèrent divers temples. Quelques-uns étaient sur de petites élévations, quelques autres dans la plaine. II y en avait aussi sur le sommet des plus hautes montagnes, auxquels on ne pouvait arriver que par des escaliers taillés dans le roc, et très difficiles 


\section{Voyage dans l'intérieur de la Chine et en Tartarie}

à monter. L'un de ces temples ne contenait pas moins de cinq cents statues dorées, un peu plus grandes que nature, et représentant des lamas morts avec une réputation de sainteté. Quelques-uns de ces saints étaient dans les attitudes contraintes et pénibles que, par une dévotion extraordinaire et par un secret désir d'être admirés, ils avaient voulu garder toute leur vie.

Le plus considérable des temples qu'eût fait construire l'empereur était le Poo-Ta-La, ou grand temple de Fo, consistant en un grand et plusieurs petits édifices. Le principal est d'une forme carrée, et a deux cents pieds sur chaque face. II diffère de tous les autres édifices chinois. Les dehors ressemblent beaucoup à la façade d'un édifice européen. II est très élevé. On y compte onze rangs de fenêtres, ce qui annonce un pareil nombre d'étages. La façade est très belle et bien finie, mais simple et uniforme. Cet édifice $a$, dans le milieu, un carré dans le centre duquel est la chapelle dorée, qu'on appelle ainsi d'après l'or qui y abonde, du moins en apparence. Un vaste corridor en bas et des galeries ouvertes en haut, communiquent aux appartements du carré. Dans le milieu de la chapelle, il y a une estrade entourée d'une balustrade, et élevée au-dessus du pavé. Là sont trois autels, richement ornés, sur lesquels on voit les statues colossales de Fo, de sa femme et de son fils. Derrière l'autel, et dans un endroit obscur, est placé le tabernacle, qu'une lampe solitaire éclaire faiblement, comme si l'on voulait par là inspirer une religieuse terreur. Au moment où les voyageurs approchèrent, le rideau, qui était entrouvert, fut fermé pour dérober aux regards curieux des profanes les reliques que contient ce lieu.

Ils montèrent aussitôt jusqu'au haut de la chapelle, afin d'examiner le toit et l'avancement couverts de plaques qui, comme les statues placées en bas sur les autels, sont, dit-on, d'or massif. L'empereur semble n'avoir rien épargné pour la construction et l'ornement de ce temple. Cependant, on sait qu'à d'autres égards, il n'aime point les prodigalités. Huit cents lamas sont attachés au service du Poo-Ta-La. Sun-Ta-Zhin et les Anglais en trouvèrent plusieurs assis sur le pavé, par rangs, les jambes croisées, chantant lentement et tenant à la main des papiers où il y avait quelques lignes d'écriture tartare, très propre. Quelques-uns de ces prêtres sont consacrés au temple depuis leur enfance. Tous sont employés à pratiquer les cérémonies

extérieures de la religion, et contribuent sans doute à sa magnificence ; mais 


\section{Voyage dans l'intérieur de la Chine et en Tartarie}

on dit qu'il en est peu auxquels une éducation distinguée ou des mœurs très pures aient acquis sur la multitude cette influence qui pourrait contribuer à maintenir la paix et le bon ordre de la société ; et par conséquent remplir le but civil ou temporel des institutions religieuses.

II n'est pas difficile d'expliquer pourquoi la dévotion de l'empereur l'a porté à faire d'aussi excessives dépenses pour les temples de Fo, si l'on en croit quelques-uns de ses courtisans qui prétendent qu'en considérant la durée et la prospérité extraordinaires de son règne, ce prince s'est insensiblement imaginé que la divinité favorite de Fo a daigné s'incarner en sa personne. On sait, il est vrai, que l'enthousiasme accompagne souvent les talents les plus brillants. Quelles que soient les raisons qu'on ait eues d'attribuer au monarque chinois une idée aussi bizarre que celle de croire que Fo existe en lui, il a certainement déployé beaucoup de vigueur et d'étendue d'esprit, ainsi qu'une grande activité de corps et une attention sans relâche dans l'administration de ses États. Aussi a-t-il non seulement conservé les différentes parties de son vaste empire, mais il a soumis un pays qui comprend quarante degrés de longitude à l'occident et qui, par son étendue, non par sa population, égale presque celui dont il avait hérité.

C'est autant par mesure de politique que pour sa propre satisfaction qu'il rassemble de temps en temps, à sa cour, ses grands vassaux, les gouverneurs de ses provinces, les commandants de ses armées, afin de recevoir, de nouveau, leurs serments de fidélité et de déployer devant eux toute la pompe de la grandeur, à laquelle contribuent également leur présence et les ambassadeurs des princes étrangers. II distribue aux premiers et des dignités et des récompenses; et quand ils retournent dans leurs départements, ils emportent dans leur âme la double impression de son pouvoir qui réprime leur ambition et de sa munificence qui assure leur attachement. Le nombre des troupes qui étaient sous les armes à Zhé-Hol le premier jour de la célébration de l'anniversaire de la naissance de l'empereur s'élevait, suivant le calcul du capitaine Parish, à près de quatre-vingt mille hommes. Il y avait environ douze mille mandarins. 


\section{Voyage dans l'intérieur de la Chine et en Tartarie}

Pendant quelques jours, il y eut plusieurs divertissements, auxquels assista l'empereur, environné de toute sa cour. Les spectateurs, eux-mêmes, formaient un spectacle imposant ; mais il y manquait ce lustre particulier qui anime la gaieté et se trouve dans les assemblées composées d'hommes et de femmes. Pour des yeux accoutumés à ces assemblées, celles où l'on ne voit que des hommes paraissent toujours plutôt destinées aux affaires qu'aux plaisirs. Il n'y eut non plus à Zhé-Hol ni chasse, ni tournois, auxquels les courtisans et les étrangers prissent eux-mêmes part; ni même de ces courses et des exercices de cheval, comme il semblait qu'on aurait pu en attendre parmi les Tartares. Les spectacles, les jeux furent entièrement chinois.

Les individus qui excellaient dans quelque talent particulier, les hommes qui, par leur force, leur agilité naturelle ou par une extrême application, s'étaient rendus capables d'exécuter des choses extraordinaires, furent rassemblés en cette occasion. La persévérance de quelques Chinois fait qu'ils sont très habiles dans l'art de sauter et danser sur un fil d'archal, de monter sur une échelle en équilibre, en passant à travers les échelons, ou de se tenir sur d'autres choses légères balancées dans l'air, et enfin d'escamoter si adroitement en détournant l'attention des spectateurs, qu'ils trompent complètement le sens de la vue. Toutes ces choses-là furent faites tour à tour, et plaisaient même à ceux qui en avaient vu de pareilles, quand ils réfléchissaient aux difficultés qu'offrait leur exécution. D'après ce principe, les exercices qui survirent et qui furent ceux des sauts périlleux et des tours de force, eurent aussi leurs admirateurs. Quant à ces jeux qui produisent de l'intérêt parce que deux partis opposés se disputent la victoire, il n'y en eut d'autre que le combat de la lutte, qui est peut-être le plus ancien de tous. Malgré l'embarras de leurs longues robes et de leurs bottes grossières, les combattants cherchaient à soulever leurs adversaires et à les laisser ensuite tomber à plat sur la terre. Ils y réussissaient quelquefois en employant avec beaucoup d'adresse tout l'effort de leurs muscles.

Des habitants des différentes parties des vastes États de l'empereur parurent dans le costume qui leur est propre, et déployèrent tout ce qu'il y a de particulier dans leurs exercices habituels et dans leurs coutumes. Plusieurs d'entre eux dansèrent d'une manière agréable et avec des attitudes 


\section{Voyage dans l'intérieur de la Chine et en Tartarie}

gracieuses. Il y avait aussi quelques chanteurs, et une immense quantité d'instruments de musique. Les musiciens affectaient, pour la plupart, des airs lents et plaintifs, assez semblables à ceux des montagnards d'Ecosse, et ils suivaient, en les jouant, une mesure très exacte. M. Hüttner, très bon juge en musique, trouva que leur gamme était ce que les Européens appelaient imparfaite, et leurs clefs, irrégulières ; c'est-à-dire qu'ils passaient des tons pleins aux tons aigus, et des tons aigus aux tons pleins, excepté quand le son d'une cloche réglait les notes. II observa encore qu'en jouant des instruments, les Chinois montraient qu'ils ne connaissaient point les semi-tons, et qu'ils n'avaient pas même d'idée du contrepoint. Cependant, quelque grand que fût le nombre de leurs instruments, il y avait toujours une certaine mélodie, quoique de temps en temps, quelques-uns jouassent sur une octave basse, tandis que le reste continuait sur la plus haute. Ils approchaient même ainsi de l'harmonie.

Aux musiciens succédèrent plusieurs centaines d'hommes, vêtus de longues tuniques uniformes, couleur d'olive. Ils chantèrent et exécutèrent divers ballets, représentant, avec le secours de lanternes de différentes couleurs, des caractères chinois, qui leur valurent beaucoup d'éloges de la part de l'empereur. S'il eût fait nuit, ces ballets auraient paru beaucoup plus brillants, à cause du contraste ; mais aucun amusement ne pouvait avoir lieu qu'en plein jour, parce que l'empereur qui se lève ordinairement avant le soleil, pour vaquer aux affaires de l'État et à ses dévotions, se retire avant que cet astre se couche.

Après les ballets vinrent les feux d'artifice; et, quoiqu'en plein jour, ils firent un très bel effet. Quelques inventions en ce genre étaient nouvelles pour les spectateurs anglais. Nous allons en citer une. Une grande boîte fut élevée à une hauteur considérable ; et le fond s'étant détaché, comme par accident, on vit descendre une multitude de lanternes de papier. En sortant de la boîte, elles étaient toutes pliées et aplaties; mais elles se déplièrent peu à peu, en s'écartant l'une de l'autre. Chacune prit une forme régulière, et tout à coup, on y aperçut une lumière, admirablement colorée. On ne savait si c'était une illusion qui faisait voir ces lanternes, ou si la matière qu'elles contenaient avait réellement la propriété de s'allumer, sans qu'elles eussent aucune communication extérieure. La chute et le développement des 


\section{Voyage dans l'intérieur de la Chine et en Tartarie}

lanternes furent plusieurs fois répétés, et chaque fois il y eut de la différence dans leur forme, ainsi que dans les couleurs de la lumière qu'elles renfermaient. Les Chinois semblent avoir l'art d'habiller le feu à leur fantaisie. De chaque côté de la grande boîte, il y en avait de petites qui y correspondaient et qui, s'ouvrant de la même manière, laissèrent tomber un réseau de feu, avec des divisions de forme différente, brillant comme du cuivre bruni, et flamboyant comme un éclair, à chaque impulsion du vent. Le tout fut terminé par l'éruption d'un volcan artificiel dans le plus grand genre.

Tous ces spectacles furent exécutés avec avantage en plein air, dans la place qui était devant la grande tente de l'empereur ; et ils furent, en cette occasion, préférés aux plaisirs plus délicats des spectacles dramatiques. Ces derniers, il est vrai, plaisent singulièrement aux Chinois; mais ils ne pouvaient être entendus de beaucoup de Tartares et d'autres spectateurs étrangers, tels que les Anglais. Des personnes choisies, parmi lesquelles étaient l'ambassadeur et les principaux Anglais de sa suite, furent invitées à la représentation d'une pantomime, dans la salle de spectacle appartenant aux dames du palais, laquelle était située sur les limites qui séparent leur jardin particulier et les grands jardins de l'empereur. C'était un édifice petit mais très joli, et à plusieurs étages. Il y avait trois théâtres, l'un au-dessus de l'autre. Vis-à-vis de celui d'en bas étaient des loges profondes pour les hommes, et au-dessus de ces loges des galeries reculées et garnies d'un treillis pour les femmes qui, sans être vues, pouvaient voir tout ce qui se passait sur les divers théâtres. Il est probable qu'elles ne distinguaient rien dans les loges ; car l'empereur voulant satisfaire la curiosité qu'elles avaient de voir quelqu'une des personnes de l'ambassade, envoya chercher, par l'un des eunuques, le page anglais qui était dans la loge de l'ambassadeur, et le fit conduire sur une estrade, où les dames pouvaient le voir.

Au lieu de figures humaines, les acteurs, qui parurent sur le théâtre, prirent la forme d'autres êtres animés, ainsi que des productions inanimées de la terre et de la mer. Ils remplissaient les trois théâtres, formant une sorte d'abrégé du monde, et jouant de manière à faire croire, à quelques-uns des spectateurs, qu'ils représentaient le mariage de l'Océan et de la Terre. Cette pantomime avait plusieurs actes et dura une grande partie de l'après-midi. 


\section{Voyage dans l'intérieur de la Chine et en Tartarie}

Dans les entractes, plusieurs des spectateurs vinrent dans la loge de l'ambassadeur pour le voir et converser avec lui. La plupart étaient des Tartares; car peu de Chinois sont invités à Zhé-Hol. Il y vint aussi deux Musulmans, chefs de quelques hordes de Calmouks qui, mécontents du gouvernement russe, émigrèrent, naguère, en grand nombre, des côtes septentrionales de la mer Caspienne, et se retirant dans la Tartarie chinoise, se mirent sous la protection de l'empereur. Ce prince leur fit un accueil très favorable, et décora les bonnets des deux chefs de boutons de dignité, et de plumes de paon.

L'empereur qui, non seulement dans les occasions importantes, mais dans les circonstances les plus ordinaires, semble être attentif à l'impression qu'il doit produire sur l'esprit des étrangers, aussi bien que sur celui de ses sujets, fit appeler l'ambassadeur et lui dit :

«Que ce n'était que dans des occasions particulières, comme celle que lui offrait ce jour, qu'il assistait à de tels spectacles; que le soin de veiller à la sûreté de ses peuples, et de faire des lois pour leur bonheur, demandait nécessairement tous ses moments.

Cependant, il est certain que ce prince avait mis tant d'ordre dans l'administration des affaires publiques, et fait une si sage distribution de son temps, qu'il lui en restait assez pour cultiver quelques-uns des beaux-arts, sans négliger les intérêts de son empire. II a composé des poèmes qui annoncent, à la fois, de l'imagination, du goût, et l'intention d'imiter la nature. Ils sont moins remarquables pour l'invention que pour les vérités philosophiques et morales, et ressemblent plus aux écrits de Voltaire qu'à ceux de Milton. II remit à l'ambassadeur quelques stances pour le roi d'Angleterre, avec quelques pierres précieuses, qu'il estimait beaucoup, parce qu'elles étaient depuis huit cents ans dans sa famille; mais il les donna comme un gage d'éternelle amitié.

Il aimait aussi beaucoup le dessin et la peinture, et employait soigneusement le peu de missionnaires qui étaient en état de cultiver ces arts. II était très habile à tracer les caractères chinois pour lesquels, comme pour le dessin, on se sert toujours du pinceau. Les papiers copiés par le page de l'ambassadeur méritèrent son approbation; et jugeant qu'il devait 


\section{Voyage dans l'intérieur de la Chine et en Tartarie}

employer son pinceau à autre chose, il envoya chercher les dessins qu'il avait faits des objets chinois, parce que ce prince pouvait juger de leur correction. Le page, qui n'était qu'un dessinateur sans prétention, fut très embarrassé ; mais il choisit des sujets aisés, tels que la feuille et la fleur du nenuphar, plante favorite du pays, et la bourse, que l'empereur avait daigné lui donner. L'idée plut à ce prince, qui lui témoigna sa satisfaction par d'autres présents.

Aussitôt que les fêtes furent terminées, les princes tartares se préparèrent à partir pour retourner chez eux. Ils sont chefs de hordes nombreuses, qui ne dépendent que d'eux, et ils peuvent mettre de grandes armées sur pied. Leurs fiefs sont proprement héréditaires, suivant le droit de primogéniture ; mais depuis peu, il est devenu nécessaire, pour ceux qui en héritent, de recevoir une sorte d'investiture de l'empereur. A la vérité, ce prince ne la refuse que dans des cas très particuliers. Ces princes tartares épousent ordinairement des filles ou des nièces de la famille impériale ; et cette alliance leur donne, à la cour, un rang supérieur. Leur éducation consiste ordinairement à apprendre ce qui a rapport à la guerre et à leurs armes, l'arc et le cimeterre. Malgré cela, quelques-uns d'entre eux connaissent l'histoire et la géographie de leur pays. Ils ont une grande vénération pour l'empereur, qu'ils considèrent comme le descendant de Kublai-Khan, qui envahit la Chine au treizième siècle.

Dès le siècle suivant, la famille de ce conquérant fut chassée du trône, et s'enfuit dans la partie orientale de la Tartarie, possédée par la nation des Mandchous. De leurs mariages avec les filles du pays, les princes expulsés de l'empire chinois devinrent la tige des Bog-Doi-Khans qui, dans le siècle dernier, rentrèrent en Chine, et formèrent la dynastie régnante, dynastie jusqu'à présent extrêmement heureuse. En 1793, ses quatre premiers règnes avaient duré cent quarante-neuf ans, quoique le dernier des quatre ne fût pas encore terminé. Ce sont peut-être les quatre plus longs règnes qui se soient suivis sans interruption à l'exception de ceux des quatre derniers rois de France, qui comprennent une période de cent quatre-vingt-trois ans, encore que le dernier soit mort jeune. 


\section{Voyage dans l'intérieur de la Chine et en Tartarie}

Quoique les quatre souverains de la Chine aient régné sur un peuple qui, lorsque le premier monta sur le trône, était loin d'être entièrement soumis, et qui semble encore un peu étonné de ce joug étranger, leurs règnes ont été non seulement longs, mais d'une prospérité sans exemple. Le premier a commencé par une minorité ; mais il a eu toute la vigueur et l'activité d'une nouvelle dynastie ; et ceux qui ont suivi ont été également remarquables par la sagesse, la fermeté et la vigilance. Le dernier est aussi brillant par les victoires. L'année que les annales britanniques ont appelée le glorieux 1759, fut aussi une année glorieuse pour Chen-Lung. II acheva alors de soumettre les Eleuthes, qui possédaient une grande partie de ce qu'on appelait jadis la Tartarie indépendante.

Maintenant, les frontières des États de l'empereur de la Chine, du côté de la Tartarie, sont reconnues dans les cartes russes. Chacun de ces deux empires contient une surface d'environ quatre millions de milles carrés, ou de près d'un onzième du globe, et égale aux deux tiers de l'Europe. Ces deux grands empires se touchent dans quelques-unes de leurs extrémités, et ils occupent ensemble un cinquième de la terre. Dans le territoire russe est comprise cette vaste et inhabitable étendue de déserts, bornés par la mer Glaciale ; ce qui, conséquemment, fait que la partie habitée se trouve bien moins considérable. Mais dans l'empire chinois, tous les pays conviennent à I'homme, et sont désirables pour lui. La plupart sont situés sous la plus heureuse partie de la zone tempérée, c'est-à-dire par les cinquante degrés de latitude nord. Une petite partie seulement s'étend du côté du midi, entre les tropiques. Tout l'empire peut fournir les plus précieuses denrées, et elles abondent dans plusieurs de ses provinces. Ces provinces sont également riches en production des arts utiles.

L'empereur règle, suivant les saisons, le séjour qu'il fait dans ses différents États : il passe I'hiver en Chine, et l'été en Tartarie. Moukden est la capitale des anciennes possessions de sa famille. Il a beaucoup agrandi et

embelli cette ville, et l'on croit qu'il y a accumulé d'immenses trésors, comme s'il se défiait encore de pouvoir maintenir sa puissance en Chine où, à la vérité, il est considéré comme étranger. En Asie, les hommes ne sont pas autant distingués par le lieu où ils sont nés que par la race dont ils tirent leur 


\section{Voyage dans l'intérieur de la Chine et en Tartarie}

origine. Quoique l'empereur Chen-Lung soit le quatrième, en ligne directe, de la famille qui, dans le siècle dernier, conquit heureusement la Chine, et quoique de ces quatre souverains, les trois derniers soient nés à Pékin, ils sont universellement regardés par leurs sujets, et ils se sont toujours regardés eux-mêmes, comme Tartares. Leurs principaux ministres, leurs serviteurs de confiance, les chefs de leurs armées, la plupart de leurs femmes, de leurs concubines, de leurs domestiques, de leurs eunuques, sont de cette race.

En Chine, tout mâle d'origine tartare reçoit une paie depuis le moment de sa naissance et est inscrit parmi les serviteurs du prince. Ces Tartares forment la garde à laquelle il confie sa sûreté personnelle. Une telle préférence semble être à la fois partiale et impolitique; mais elle fut jugée absolument nécessaire au commencement de la dynastie, lorsque la conquête du pays n'était pas encore achevée, et qu'on ne pouvait avoir que peu de confiance dans la fidélité des vaincus. Cette préférence devint en même temps la source d'un surcroît de mauvaise volonté qui, à son tour, exigea la continuation des mesures qui l'avaient produite. Depuis que les nations tartare et chinoise sont soumises au même souverain, nul changement dans leur état n'a contribué à leur union, ou à surmonter cet éloignement, approchant de l'antipathie, qui doit avoir longtemps auparavant subsisté entre un peuple guerrier, qui cherche sans cesse à envahir, et un peuple civilisé, qui s'efforce toujours d'écarter ses voisins. On dit encore communément dans les provinces de la Chine, où les conquérants sont en plus grand nombre, que demi-douzaine de Chinois ne sont pas rassemblés pendant une heure, sans commencer à crier contre les Tartares.

Les souverains de la dynastie régnante se sont jusqu'à présent conformés aux mœurs, aux lois et au langage chinois, plutôt qu'ils ne les ont exclusivement adoptés. Mais peut-être ne doit-on guère s'attendre que cette dynastie se maintienne assez longtemps sur le trône, pour se confondre entièrement avec les Chinois. Elle a déjà régné presque aussi longtemps qu'ont duré, l'une dans l'autre, celles qui l'ont précédée. Chacune d'elles devait son élévation aux talents et à l'activité qui avaient profité des circonstances favorables; aussi ont-elles presque toujours péri lorsqu'elles n'ont plus su opposer que de l'indolence et de l'incapacité au malheur et à 


\section{Voyage dans l'intérieur de la Chine et en Tartarie}

l'insurrection. Le principe du droit héréditaire, qui a été si longtemps le soutien d'autres trônes, ne paraît pas avoir été gravé dans l'âme des Chinois. Ils ne considèrent que le pouvoir qui, comme base de l'autorité, est d'une durée bien moins stable. Mais les princes tartares de la dynastie actuelle ont continué à maintenir le leur d'une main ferme et vigoureuse ; et le désir de perpétuer la durée et l'uniformité de leur gouvernement les a dirigés dans le choix de leurs successeurs, parce qu'ils ont cru que c'était le moyen le plus certain d'y réussir.

L'empereur Chen-Lung s'était déterminé depuis quelque temps à une mesure qui, dans d'autres pays, pourrait ne pas avoir les mêmes conséquences qu'à la Chine. Il voulait abdiquer la couronne à une époque à laquelle, toute éloignée qu'elle était, son tempérament robuste devait lui faire espérer de survivre. Ainsi, il aura pu, sans risque, placer sur le trône celui qu'il aura choisi pour son héritier, et qui, soit qu'il fût son propre fils, soit qu'il ne le fût que par adoption, aura suivi ses avis et ses exemples ; car il a dû y être excité par les sentiments de l'affection et de la reconnaissance, ainsi que par ceux de la piété filiale qui, en Chine, n'est point affaiblie, même par le trône. II est donc vraisemblable que Chen-Lung aura eu la satisfaction de jouir, dans un autre, de sa dignité et du pouvoir qu'il lui a communiqué, sans en être privé lui-même.

De divers fils qu'a eus l'empereur, il n'y en a plus que quatre vivants, le huitième, le onzième, le quinzième et le dix-septième. Le onzième était gouverneur de Pékin, où il se tenait durant l'absence de son père. Les trois autres étaient à Zhé-Hol ; et de ces trois, les deux plus jeunes promettaient beaucoup. Ils avaient des manières très polies, et aimaient beaucoup à s'instruire sur ce qui avait rapport aux autres pays, et à examiner les inventions et les ouvrages bien faits qui en sortaient.

Le grand âge de l'empereur ne lui permettant plus de faire la chasse aux bêtes féroces dans les forêts de Tartarie, ainsi qu'il avait accoutumé de le faire après la célébration de l'anniversaire de son jour de naissance, ce prince résolut de retourner promptement à Pékin ; et il fut décidé que l'ambassadeur l'y précéderait. 


\section{Voyage dans l'intérieur de la Chine et en Tartarie}

Avant de quitter Zhé-Hol, l'ambassadeur reçut, par les mains du légat, une réponse d'Ho-Choong-Taung à la lettre qui lui avait été adressée quelque temps auparavant. Le colao annonçait qu'il serait permis à l'Indostan de vendre des marchandises et d'acheter des denrées à Chu-San, sous les auspices des principaux mandarins, qui auraient soin d'empêcher que les gens du pays ne se permissent aucune fraude. II disait en outre que, comme I'Indostan avait été en grande partie chargé de présents pour l'empereur, il ne serait assujetti à payer aucun droit de sortie, ce qui était une grâce qu'on n'avait point demandée. Enfin, Ho-Choong-Taung ajoutait qu'il ne convenait pas qu'on permît au capitaine Mackintosh d'aller en ce moment joindre I'Indostan, parce que les affaires de ce vaisseau pouvaient être continuées par les personnes à qui on les avait déjà confiées.

Cette réponse était plus favorable qu'on ne s'y attendait, d'après le canal par lequel elle parvint à l'ambassadeur. Elle n'avait de désagréable que la dernière clause qui, vraisemblablement, était due aux remontrances du général du Thibet, parce qu'il avait été question de cette affaire en sa présence. Son animosité contre la nation anglaise ne semblait pas avoir diminué. Aussi, rien n'était, peut-être, plus à désirer pour les intérêts de cette nation que de voir le général exclu des conseils de l'empereur, et de la viceroyauté de Canton, où il pouvait, non seulement opprimer les Anglais, mais calomnier auprès de la cour leur conduite et leurs intentions.

Le capitaine Parish détermina la latitude de Zhé-Hol par les quarante-un degrés cinquante-huit minutes nord. Tandis que l'ambassade y demeura, le temps fut très sec, et le ciel pur et serein. 


\section{Voyage dans l'intérieur de la Chine et en Tartarie}

\section{CHAPITRE III}

\section{Retour à Pékin. Séjour de l'ambassade dans cette capitale et à Yuen-min-yuen. Observations qui y ont rapport.}

Un très grand nombre d'étrangers ne pouvait pas demeurer longtemps à Zhé-Hol, sans risquer d'y causer de l'embarras. Les principaux de ceux qui s'y étaient rendus à l'occasion de l'anniversaire de la naissance de l'empereur en partirent en même temps que l'ambassadeur anglais, c'est-à-dire le 21 septembre 1793. Ils prirent différentes routes. Parmi ceux qui allaient au Midi, comme lord Macartney, étaient les envoyés du Pégu et d'autres royaumes limitrophes de quelques provinces chinoises.

Des motifs très différents de ceux de l'ambassade anglaise engagent les souverains de ces États à envoyer souvent des personnes pour les représenter à la cour de Pékin. Non seulement leurs possessions sont extrêmement inférieures à la Chine, en étendue et en population, mais la faiblesse et l'incertitude de leur gouvernement, et la fréquence de leurs divisions intestines les rendent peu capables de résister aux forces de ce vaste empire. Ils ne peuvent pas même, au besoin, compter sur le secours d'autres princes, jaloux de maintenir la balance du pouvoir asiatique. C'est donc, en général, par une maxime de prudence politique qu'ils se reconnaissent dans une sorte de vasselage à l'égard de la Chine. Ils rendent hommage et paient tribut à l'empereur, afin d'éviter qu'il ne se mêle plus directement de leurs affaires, et qu'il n'envahisse entièrement leurs États, ce qui ne manquerait pas d'arriver s'ils osaient, par un refus, le provoquer à une lutte trop inégale.

Les envoyés qui faisaient la même route que lord Macartney étaient sous la conduite de quelques mandarins inférieurs. Pendant qu'ils étaient sur le territoire chinois, le gouvernement leur accordait, pour leur entretien, une somme modérée, mais raisonnable. Toutefois, les mandarins comptant sur les difficultés qu'éprouvent toujours les étrangers pour faire parvenir leurs 


\section{Voyage dans l'intérieur de la Chine et en Tartarie}

plaintes à la cour, et espérant qu'ils n'oseront pas l'entreprendre, s'abandonnent au mépris que leur inspirent ces étrangers, et les traitent souvent avec indignité. En outre, ces mandarins recevant eux-mêmes un très petit salaire du gouvernement, se font peu de scrupule de tirer avantage d'une occasion si favorable d'augmenter leurs émoluments en privant frauduleusement les personnes confiées à leurs soins d'une partie considérable de ce qui leur revient; heureusement que ces hommes sont accoutumés à la dureté d'une vie guerrière et que leur âme n'est pas assez délicate pour sentir très vivement les humiliations. Ce qui faisait peut-être le plus de peine aux envoyés du Pégu était la manière toute différente dont on traitait I'ambassade anglaise.

Partout où il y avait des postes militaires, les troupes se mirent sous les armes, comme la première fois que l'ambassade y avait passé. Comme la marche n'était plus gênée par les présents, parce qu'on les avait laissés à Zhé-Hol, on résolut de voyager avec plus de célérité qu'auparavant ; mais de s'arrêter pourtant encore dans quelques-uns des palais impériaux où tout était préparé pour recevoir l'ambassadeur et sa suite. Les chemins nouvellement réparés facilitaient la marche. II y en avait un réservé pour l'empereur seul. Il était parfaitement sec et nivelé. Des citernes creusées à côté servaient à fournir de l'eau pour l'arroser de temps en temps, et empêcher qu'il n'y eût de la poussière. Un autre chemin parallèle, un peu moins large, et balayé avec moins de soin, mais très commode et très sûr, était destiné à la suite de l'empereur ; ce fut sur celui-là que l'ambassade anglaise eut droit de passer. Tous les autres voyageurs, exclus de ces deux routes privilégiées, furent obligés de chercher les autres sentiers qui leur convinrent le mieux.

Quelque peu de temps qui se fût écoulé depuis que l'ambassade avait passé dans cette route pour se rendre à Zhé-Hol, il s'était fait un changement considérable dans la température, et les Anglais trouvèrent un bien plus grand degré de froid qu'on n'en éprouve dans la même saison, et dans une pareille latitude en Europe. Ils en étaient affectés à un point qu'on ressent rarement en Angleterre.

Quand l'ambassade arriva à Koo-Pé-Koo, et que les Anglais furent près de l'endroit où ils avaient déjà visité la grande muraille, quelques-uns d'entre 


\section{Voyage dans l'intérieur de la Chine et en Tartarie}

eux, entraînés par une insatiable curiosité, eurent envie d'examiner encore une fois cet antique boulevard. Mais ils eurent en cette occasion une nouvelle preuve de l'extrême méfiance du gouvernement chinois, ou au moins des personnes qu'il emploie. La brèche où ils avaient passé pour monter sur la muraille était déjà fermée avec des pierres et des décombres, de manière à empêcher qu'ils ne pussent encore l'escalader. Dans toutes les occasions, les Tartares et les Chinois semblaient embarrassés entre la crainte d'offenser, par trop de contrainte, des hôtes qu'ils avaient ordre de respecter, et la crainte plus grande encore de se rendre responsables envers le gouvernement, s'ils souffraient que des étrangers prissent une trop grande connaissance du pays. La principale politique de ces personnes consistait à détourner ces étrangers des objets curieux qu'ils désiraient de voir, en employant des moyens indirects, et leur opposant des obstacles qui avaient l'air d'être purement accidentels; et les Anglais, en partie par prudence, et en partie par égard pour leurs conducteurs, renonçaient fréquemment aux excursions et aux recherches les plus innocentes.

Peu après le départ de Zhé-Hol, un des gardes de l'ambassadeur mourut d'une indigestion, qui lui fut, à ce qu'on croit, occasionnée pour avoir mangé trop de fruit. Sa mort eut lieu dans un des palais de l'empereur. Telle est l'excessive délicatesse de cette nation pour tout ce qui a rapport à son auguste souverain, qu'on ne souffre que personne rende le dernier soupir dans l'enceinte d'une demeure impériale. Les conducteurs de l'ambassade firent donc emporter le corps du garde, dans un palanquin, comme s'il était encore vivant, et l'on ne déclara sa mort que lorsqu'il fut à une certaine distance sur la route.

Une autre personne de la suite de l'ambassadeur souffrait beaucoup d'une dysenterie, et s'arrêta dans un cabaret chinois. Là, elle consulta le médecin du lieu. Ce médecin, joignant à la doctrine du pouls un discours sur les différents tempéraments, attribua malheureusement les souffrances du malade à une humeur froide, et lui fit prendre de fortes doses de poivre, de cannelle et de gingembre dans de l'eau-de-vie distillée ${ }^{1}$ et chaude. Cette

\footnotetext{
${ }^{1}$ Que les Chinois appellent chow-shoo.
} 


\section{Voyage dans l'intérieur de la Chine et en Tartarie}

médecine augmenta tellement les symptômes de la maladie que l'Anglais eut beaucoup de peine à pouvoir arriver en vie à Pékin.

Le retour de l'ambassadeur et de sa suite dans cette capitale fut un événement très agréable pour ceux de leurs compagnons de voyage qu'ils y avaient laissés. Ceux-ci avaient mené, durant l'absence des premiers, une vie extrêmement retirée. Plusieurs missionnaires désiraient de jouir de leur société, presque autant que des exilés désirent de voir leurs compatriotes dans une terre étrangère; et, au commencement, ils les avaient visités presque tous les jours; mais cette intimité contribua peut-être à réveiller l'extrême jalousie des Chinois contre les uns et les autres.

Le long séjour des missionnaires ne les exempta pas de la méfiance générale que tous les étrangers inspirent à cette nation; et rien ne pouvait être plus extravagant et plus dangereux que les desseins qui leur étaient attribués, particulièrement dans les lettres de Macao et de Canton. Les officiers du gouvernement de Pékin résolurent promptement qu'on ne laisserait que le moins qu'il serait possible les anciens Européens communiquer avec les nouveaux. Sous le futile prétexte d'empêcher les

domestiques, qui servaient les premiers, de dérober les effets que l'ambassadeur avait laissés dans son hôtel, on n'en permit l'entrée qu'au seul missionnaire, chargé d'interpréter les Anglais, qui y étaient restés, et de leur procurer les choses dont ils pouvaient avoir besoin.

Le costume des Anglais attirait, autour d'eux, une populace importune, toutes les fois qu'ils se hasardaient à sortir. Ils n'étaient accompagnés ni par des mandarins d'un rang propre à les faire respecter, ni par des interprètes chinois qui pussent leur expliquer ce qu'ils voyaient et ce qu'ils entendaient. II est vrai que l'étendue de l'hôtel où ils demeuraient leur permettait de prendre assez d'exercice pour qu'ils ne souffrissent pas de cette gêne. D'ailleurs, plusieurs d'entre eux allaient fréquemment à Yuen-Min-Yuen, où l'arrangement des machines et des autres principaux présents exigeait leur surveillance.

Le docteur Scot, qui avait été laissé à Pékin pour prendre soin de divers soldats et domestiques malades, fut extrêmement attentif auprès d'eux. 


\section{Voyage dans l'intérieur de la Chine et en Tartarie}

D'autres circonstances lui fournirent une nouvelle occupation. En Chine, comme ailleurs, non seulement les besoins de l'homme sont ce qui excite son industrie, mais ses inventions perfectionnent quelquefois les objets qu'il est obligé de se procurer. Les vêtements que les Chinois portent immédiatement sur leur corps, ainsi que ceux dont ils se parent, sont en général d'une couleur obscure, et n'exigent ni qu'on les renouvelle, ni qu'on les lave fréquemment. Ils sont quelquefois d'une étoffe qui n'admet point cette dernière opération. Les vêtements blancs de toute espèce ne se portent que pour le deuil. L'étiquette veut même qu'ils ne soient jamais trop propres, parce que ceux qui sont en deuil ne doivent prendre aucun soin d'euxmêmes, afin de mieux paraître accablés par la douleur.

Les Européens ont besoin, pour leur santé et pour leur propreté, de changer et de laver souvent les vêtements qui approchent le plus de leur corps. L'ampleur des habillements des peuples asiatiques, quoique exigeant fréquemment qu'ils en mettent une plus grande quantité pour se garantir de l'inclémence de l'air, permet en même temps qu'ils les portent plus longtemps sans inconvénient. Leurs tables vernissées ne peuvent être ni pénétrées par I'humidité, ni gâtées par la poussière ; aussi ne les couvrent-ils jamais avec une nappe. Ils ne se servent pas non plus de draps de lit. Ils n'ont point adopté l'usage du linge; et la plupart ne font usage de toile de coton blanc que dans très peu d'occasions. Pour laver la toile grossière dont ils se servent, ils la font tremper dans une eau alcaline, qui la dégage sans danger des malpropretés qu'elle contracte quand ils la portent. L'alcali avec lequel ils composent cette lessive est fait avec un fossile blanc, qui se trouve en abondance dans les environs de Pékin. Ils n'en emploient presque jamais d'autres, excepté pour se nettoyer la peau ; et à cet égard, ils font usage de beaucoup de préparations cosmétiques.

Cependant l'alcali des Chinois est trop âcre pour le linge fin, et il en détruit promptement le tissu. Afin de remédier à cet inconvénient, le docteur Scot se procura une suffisante quantité d'huile, et avec l'alcali chinois, il fit de très bon savon pour la consommation de ses compagnons et pour la sienne.

II est vraisemblable que l'usage général du linge, auquel l'Europe doit l'exemption des maladies lépreuses, sera adopté par les Chinois, à mesure que s'accroîtront leur commerce et leurs relations avec les Européens. La 


\section{Voyage dans l'intérieur de la Chine et en Tartarie}

lèpre est la seule des maladies pour laquelle il y a des hôpitaux régulièrement établis en Chine; car on l'y regarde comme trop contagieuse pour souffrir que les personnes qui en sont affligées aient aucune communication avec le reste de la société.

L'usage du savon s'établira bientôt après celui du linge, parce qu'il en est la suite nécessaire. Les ingrédients pour faire du savon, et la plupart des autres objets demandés pour l'usage des Anglais, furent fournis aux dépens du gouvernement chinois; cependant, il fallut toujours expliquer très particulièrement aux mandarins ce qu'on voulait en faire.

Ces mandarins ne refusaient jamais verbalement ce que les Anglais désiraient ; mais, dans le fait, ils ne l'accordaient pas toujours. Quelquefois, ils prenaient l'alarme, comme si ce qu'on leur demandait avait quelque but dangereux. Un des peintres de l'ambassade les pria une fois de lui procurer un chevalet afin d'y placer la toile dont il devait se servir pour faire le portrait d'un missionnaire. Les mandarins ne concevant pas la nature d'un chevalet, quelque simple que cela fût, crurent probablement que ce pouvait être quelque partie d'un appareil de mathématiques, duquel on voulait se servir pour faire des mesurages ou des plans de fortifications, ou pour dessiner les remparts de la capitale; et on ne put absolument les engager à donner des ordres pour faire faire un pareil instrument.

Quelques personnes de l'ambassade désirèrent de se pourvoir à leurs dépens, des choses dont elles avaient besoin. Mais elles étaient veillées de près. Le prix des articles achetés leur fut rendu; et ceux qui les leur avaient vendus furent punis corporellement. II est vrai que l'hospitalité chinoise, qui veut que les étrangers soient affranchis de toute espèce de dépense, servit de prétexte à cette rigueur ; mais tout cela n'était pas totalement étranger à un système de précautions dictées par la jalousie.

A cette jalousie politique et remplie de prévention se joignirent les alarmes et une jalousie d'une autre espèce. Elles furent cependant excitées très innocemment. Dans une des cours de l'hôtel de l'ambassadeur étaient des rochers artistement entassés dans le goût chinois, et faits pour servir de décoration, mais qui pouvaient servir aussi pour monter sur le mur formant l'enceinte de l'hôtel. De là, on pouvait quelquefois apercevoir les femmes des 


\section{Voyage dans l'intérieur de la Chine et en Tartarie}

maisons voisines. On dit que durant l'absence de l'ambassadeur, quelques Anglais se promenèrent sur le mur de l'hôtel, par désœuvrement, non par aucun motif d'indécente curiosité. Ce fait fut regardé comme très peu convenable; et tout le voisinage en fut scandalisé. Mais dès qu'on s'en plaignit, la promenade cessa.

Ce fut à cette époque qu'il se répandit à Pékin un bruit confus sur la contestation passagère, qui eut lieu à Zhé-Hol, à l'occasion de la cérémonie de la réception. Quelques politiques en conclurent que non seulement l'ambassade se bornerait là, mais qu'on ne permettrait pas même à l'ambassadeur de retourner dans la capitale; et qu'ainsi que les envoyés du Pégu, qui quittaient la Tartarie en même temps que lui, il serait obligé de continuer sa route sans s'arrêter. L'arrivée de l'ambassadeur à Pékin mit fin à ces conjectures.

On lui rendit, à son entrée, les honneurs accoutumés, et il reçut la visite des principaux mandarins, dont plusieurs avaient attendu son arrivée à son hôtel. Cependant lord Macartney sentait qu'il convenait de fixer un terme à son ambassade. La résidence permanente du ministre d'une cour étrangère, en Chine, était une chose inouïe dans le pays. La maxime d'après laquelle on considère les ambassadeurs étrangers comme des hôtes qu'il faut défrayer aux dépens du trésor public pendant tout le temps qu'ils séjournent dans le pays engageait naturellement à abréger ce séjour. La dépense extraordinaire qu'occasionnait à l'empereur la manière splendide dont il traitait les Anglais était une raison de plus pour qu'ils songeassent à se retirer ; car, en restant longtemps, ils auraient abusé de I'hospitalité avec laquelle ils étaient reçus. C'eût été, sans doute, trop blesser l'orgueil et les préjugés de la nation chinoise, que de lui proposer, tout à coup, dans une première mission diplomatique, de renoncer à ses anciens principes à l'égard des envoyés des souverains étrangers, et de souffrir que l'ambassadeur anglais vécût à ses propres frais, pendant qu'ils seraient encore sur le territoire de la Chine. Lord Macartney résolut donc de partir après la grande fête du commencement de l'année chinoise, c'est-à-dire en février. Durant cet intervalle, il devait avoir le temps de s'occuper de tout ce qu'il pouvait raisonnablement espérer d'obtenir ou demander. 


\section{Voyage dans l'intérieur de la Chine et en Tartarie}

Cependant, ce ministre apprit qu'il devait s'attendre à recevoir bientôt quelque proposition relative à son départ. Les Anglais qu'on avait laissés à Yuen-Min-Yuen, pour monter les machines qui y avaient été portées en présent furent pressés de finir leur ouvrage de peur d'être obligés de le laisser incomplet. Le docteur Dinwiddie y était presque constamment pour diriger les ouvriers qui ajustaient les parties compliquées du planétaire. $M$. Barrow allait aussi dans ce palais et y séjournait même de temps en temps, afin de veiller à l'arrangement des autres présents.

M. Barrow eut fréquemment occasion d'observer l'intelligence et la dextérité des ouvriers chinois. Deux d'entre eux descendirent les deux magnifiques lustres de cristal envoyés à l'empereur, afin de les placer dans une situation plus avantageuse. Ils les séparèrent par pièce, et les remontèrent en peu de temps sans difficulté et sans se tromper, quoique le tout fût composé de plusieurs milliers de petits cristaux, et qu'ils n'eussent jamais rien vu de semblable. Un autre Chinois tailla fort bien un étroit morceau du bord d'un vase courbe de cristal, afin de remplacer dans le dôme du planétaire un autre morceau qui avait été cassé dans le transport. Les ouvriers anglais avaient en vain tenté de tailler ce verre avec un diamant, suivant la ligne courbe qu'il devait avoir. Le Chinois ne fit point connaître sa méthode ; mais on dit qu'il réussit en commençant par tracer une ligne avec un fer chaud sur la pièce qu'il voulait séparer.

L'invention de ce Chinois est d'autant plus singulière qu'il n'y a dans tout l'empire d'autre manufacture de verre que celle de Canton, où au lieu de mettre en fusion du sable et d'autres ingrédients avec les procédés nécessaires pour les convertir en verre, on se contente de faire fondre les morceaux de verre cassé qu'on a ramassés, et de leur donner de nouvelles formes, suivant les usages auxquels ils peuvent être destinés.

Les Chinois ont très vraisemblablement droit à l'honneur de ne devoir qu'à eux-mêmes l'invention des instruments nécessaires dans les premiers et les

plus utiles arts de la société. Le voyageur savant et attentif aura sans doute observé, relativement aux outils les plus communs, tels, par exemple, le rabot et l'enclume que, soit dans I'Inde, soit en Europe, et dans les temps 


\section{Voyage dans l'intérieur de la Chine et en Tartarie}

anciens comme dans les temps modernes, ils ont été fabriqués précisément de la même manière, différant rarement, excepté peut-être dans la qualité des matières qui les composent, et dans le plus ou moins de perfection du travail, mais dénotant toujours une origine commune, et n'étant en général qu'une imitation servile les uns des autres. Dans la Chine seule, les outils les plus communs ont quelque chose de particulier dans leur construction. C'est souvent, à la vérité, une légère différence ; mais elle indique clairement que, plus ou moins propres à remplir le même objet que ceux des autres pays, les uns n'ont point servi de modèle aux autres ; ainsi, le dessus de l'enclume qui, partout ailleurs, est plat et un peu incliné a, en Chine, une forme convexe.

Ce fut dans les forges qu'on trouve près de Pékin, en se rendant à ZhéHol, que les voyageurs observèrent cette enclume. Là, un autre objet attira aussi leur attention. Les soufflets dont les forgerons se servent en Europe sont placés verticalement. Le vent est en partie produit par le poids de la machine, qu'en conséquence, on rend très lourde. Mais elle est ouverte ou soulevée par le bras d'un homme, qui est obligé de vaincre la difficulté que lui offre le poids qui produit le vent, et pendant cette opération, le souffle est discontinué. Mais les soufflets des Chinois se placent horizontalement. L'homme qui souffle n'est aidé dans aucun temps, par le poids de la machine, mais aussi il n'en est jamais accablé. C'est assurément un avantage que de n'avoir qu'un travail égal et jamais excessif. Le soufflet est fait comme une boîte, à laquelle une porte mouvante est si bien adaptée que quand on la retire en arrière, le vide qu'on produit dans la boîte fait que l'air entre avec impétuosité par une ouverture d'une espèce de valvule, et en même temps le vent sort par une autre ouverture qui lui est opposée. Le même effet est continué quand la porte est poussée en avant ; l'espace se trouve diminué, l'air est comprimé, et une partie sort par la même ouverture. Lorsqu'au lieu d'une porte mouvante, un piston est adapté à la boîte, l'air est comprimé alternativement entre le piston et les deux extrémités de la boîte et, par conséquent, forcé de sortir continuellement. On fait mouvoir, très aisément, ce soufflet double ou perpétuel, qui produit deux fois autant d'effet que les soufflets ordinaires. Peut-être la description de cette invention chinoise n'est pas très intelligible; mais on en a porté un modèle en Angleterre, pour le soumettre à l'examen des curieux. 


\section{Voyage dans l'intérieur de la Chine et en Tartarie}

Le rabot chinois est, ainsi que l'enclume, distingué par quelques petites particularités, qui montrent qu'il n'a point eu de modèle. II diffère non seulement dans la manière dont on y fixe le ciseau, mais aussi dans celle dont on s'en sert. Ailleurs, les bouts du rabot servent de manche; et c'est en tenant ces bouts qu'on pousse l'outil sur la surface du bois, afin de la rendre unie ; mais à la Chine, le rabot est garni de manches particuliers, qui font que le même travail se fait peut-être avec plus d'aisance.

L'histoire des temps les plus reculés, où subsistait l'empire chinois, attribue les inventions les plus utiles dans la société aux premiers monarques du pays. Il est bien plus probable qu'elles ne sont que le résultat graduel des efforts de plusieurs individus obscurs qui, dans le cours de leurs travaux, sentant le besoin de ce secours mécanique, cherchèrent à se le procurer. Les historiens qui sont venus ensuite, n'en pouvant point connaître les vrais inventeurs, ont remplacé leurs noms par ceux des princes qui encouragèrent ces arts. Cependant, il y a lieu de croire que, non seulement les inventions de première nécessité, mais celles de décoration et d'ornement, ont été connues des Chinois dès la plus haute Antiquité. Les annales de l'empire l'attestent, et l'on ne peut manquer d'en être convaincu, quand on considère le progrès naturel de ces inventions, et l'état des artistes chinois en ce moment.

Un art nouvellement découvert s'exerce grossièrement, même avec le secours des outils, et cela continue assez longtemps. Mais l'art arrivant ensuite à sa seconde période, est perfectionné, et l'artiste est déjà à même de se servir de tous les outils et de toutes les machines qui peuvent y être employés. La dernière période de la perfection est celle où l'artiste est devenu si adroit qu'il peut faire son ouvrage avec peu d'outils, ou des outils grossiers, et avec peu ou même point de secours. Tel est, en Chine, l'état avancé du potier, du tisserand, de celui qui travaille l'ivoire et les métaux précieux, et de la plupart de ceux qui pratiquent les arts mécaniques en usage dans le pays. De semblables progrès sont, sans doute, le dernier effort de l'art, et la plus forte preuve qu'on le possède depuis très longtemps.

II n'est pas surprenant que l'art de faire la poudre à canon, et celui de l'imprimerie, aient été découverts par les Chinois longtemps avant d'être 


\section{Voyage dans l'intérieur de la Chine et en Tartarie}

connus en Europe. Quant au premier, il est vraisemblable que, dans tous les pays où la nature crée en abondance du nitre ou du salpêtre, qui est le principal ingrédient dont on se sert dans la composition de la poudre à canon, les propriétés inflammables de cette substance doivent être d'abord observées ; et quelques expériences, fondées sur l'observation, conduisent à la composition qui produit de si prompts et si violents effets. Le salpêtre est une production naturelle et constante de la Chine et de I'Inde ; et là aussi, la connaissance de la poudre à canon semble avoir existé dans les siècles les plus reculés, dont I'histoire fasse mention. Les Chinois l'ont employée, de tout temps, à des choses utiles. Ils s'en servent pour faire sauter des rochers, et écarter les grandes masses de terre qui les gênent. Elle est en même temps un des objets de leurs amusements, car ils font beaucoup de feux d'artifice. Ils l'ont aussi, dès longtemps, employée comme moyen de défense, en minant les passages de l'ennemi, et le faisant sauter. Mais ils ne s'occupaient pas à diriger sa force avec des tubes de métal, comme l'ont fait les Européens, bientôt après qu'ils l'ont eu découverte. Cependant, il n'est pas décidé que cette invention appartienne à ceux qui en ont profité, et l'on ne peut pas marquer précisément, dans l'histoire, l'époque où elle a commencé à être mise en pratique. Quoiqu'à l'imitation de l'Europe, elle ait été nouvellement introduite dans les armées de l'Orient, on y préfère encore quelquefois d'autres manières de combattre.

Pour l'art de l'imprimerie, dont les effets sont si importants en Europe, il est évident que, comme son objet est de multiplier les copies d'un même écrit, il n'a pu être cherché que dans une société où il y avait beaucoup de lecteurs. Le nombre de ces lecteurs a dû sans doute aussi s'accroître partout où l'art de l'imprimerie a été introduit. Mais là où ce nombre était déjà devenu très considérable par d'autres causes tendant à augmenter les classes polies et lettrées de la société, les différents essais, entrepris pour satisfaire leur goût, ont dû naturellement produire une invention aussi simple que l'art de l'imprimerie des Chinois.

Cet art consiste seulement à tailler en relief, sur du bois dur, la forme des caractères écrits; à enduire ces caractères d'une substance noire et glutineuse, et à y appliquer successivement différentes feuilles de papier, afin que les caractères restent imprimés sur chaque feuille de ce papier qui, lui- 


\section{Voyage dans l'intérieur de la Chine et en Tartarie}

même, est une invention préliminaire très ingénieuse. L'art de graver, pour le plaisir des hommes riches et puissants, avait été porté à un si haut degré de perfection chez plusieurs nations de l'Antiquité, que l'invention de l'imprimerie, telle que nous venons de la décrire, et approchant de si près de la gravure, devait naturellement la suivre partout où le nombre des lecteurs était assez grand pour que l'inventeur fût sûr d'être récompensé. Depuis les premiers siècles, l'état de la société, en Chine, rend le nombre des lecteurs prodigieux. Là, ce n'est point comme dans le reste du monde, où la valeur et les talents militaires, réunis quelquefois à une éloquence naturelle, sont originairement le fondement de la puissance et de la grandeur, tandis que les lettres n'y ont guère jamais servi que d'amusement. A la Chine, l'étude de la morale écrite, de I'histoire et de la politique, est la seule route par où l'on puisse acquérir, non seulement du pouvoir et des honneurs, mais toute espèce d'emploi dans l'État. Ainsi, la nécessité de multiplier les copies des livres écrits pour toutes les personnes des clases mitoyennes, ainsi que des premières classes, dans le plus populeux des empires, fut ce qui, très naturellement et de bonne heure, donna naissance à l'art de l'imprimerie, tel qu'on l'y pratique encore.

Le papier dont on se sert pour les livres, à la Chine, est trop faible pour pouvoir être imprimé des deux côtés. La planche gravée sur laquelle on applique le papier pour en recevoir l'empreinte contient ordinairement des caractères pour deux pages. Quand le papier est imprimé, on le plie en mettant le blanc en dedans. Le pli forme la marge extérieure qui, par ce moyen, se trouve double; et contre l'usage des relieurs européens, on coud ensemble tous les bords des feuilles, et on relie ainsi le volume. Lorsque l'édition est achevée, les planches ou formes sont rassemblées, et on indique ordinairement, dans la préface, l'endroit où elles sont déposées, en cas qu'on ait besoin d'une seconde édition de l'ouvrage.

L'on a quelquefois pensé, en Europe, que des caractères mobiles étaient une invention préférable à celle des Chinois. Mais si chaque caractère est considéré comme une lettre dans un alphabet, des caractères mobiles peuvent être difficilement employés dans l'impression d'une langue qui, ainsi que la langue chinoise, a un nombre immense de caractères. Dans une imprimerie européenne, le compositeur distribue les vingt-quatre lettres de 


\section{Voyage dans l'intérieur de la Chine et en Tartarie}

l'alphabet. II sait tout de suite où il doit les prendre. II les distingue d'un coup d'œil. Ses mains acquièrent l'habitude de les atteindre rapidement sans qu'il les regarde, comme les doigts apprennent à connaître les touches d'un clavecin sans que les yeux s'y portent.

Mais si le clavecin avait plusieurs milliers de touches, il est évident qu'on n'acquerrait pas une pareille habitude et que les touches ne pourraient pas toutes être à la portée de la main. La pratique serait également impossible en imprimant avec quatre-vingt mille caractères mobiles, car c'est le nombre des différentes lettres qui constituent la langue chinoise. Les artistes de la Chine ne se sont point occupés à former des caractères mobiles et séparés, pour chacun des traits élémentaires dont les lettres sont composées, comme on l'a entrepris il y a quelques années en Allemagne. Il est cependant possible qu'une telle pratique eût pu réussir, malgré la difficulté qu'offre la petitesse du caractère nécessaire pour chaque trait particulier; difficulté qui a été surmontée par un ingénieux et savant artiste, en imprimant la langue persane au Bengale, de laquelle, il est vrai, les caractères ne sont pas tous nécessairement si petits. II est encore une autre difficulté ; c'est celle d'unir dans l'impression, avec des caractères séparés, les différents traits d'une lettre chinoise; ce qui n'est pas nécessaire dans l'impression des langues européennes, où les lettres d'un même mot se touchent rarement.

II est des ouvrages où les mêmes lettres sont répétées, comme, par exemple, dans les calendriers et les gazettes; et alors les Chinois se contentent d'avoir des caractères séparés, et de les insérer dans les formes où ils sont nécessaires.

On publie fréquemment des gazettes à Pékin, sous l'autorité du gouvernement. Les diverses nominations aux emplois, les grâces accordées par l'empereur, tous les actes publics, l'affranchissement des impôts dans les districts qui ont éprouvé la disette ou quelqu'autre calamité générale, les récompenses de services extraordinaires, les ambassades envoyées, les tributs payés à l'empereur ; voilà ce qui forme une partie considérable des nouvelles publiques. Les détails domestiques de la maison du prince et de sa vie privée sont rarement, ou plutôt ne sont jamais mentionnés dans les gazettes; mais on y trouve les événements singuliers, les exemples de longévité, et quelquefois la punition des fautes commises par les mandarins. 


\section{Voyage dans l'intérieur de la Chine et en Tartarie}

On y rapporte même quelques exemples des femmes adultères qui sont punissables, quoique le crime ne soit pas regardé comme capital ; mais on en parle peut-être pour détourner les autres de l'envie de les imiter. Quand la Chine était en guerre, ses victoires et la soumission des rebelles étaient annoncées dans les papiers publics. En tout autre temps, les nouvelles du monde se bornent à la Chine.

Indépendamment des ouvrages classiques des Chinois, qui sont excessivement multipliés, la littérature légère du pays donne beaucoup d'occupation à la presse. L'Orphelin de la Chine, perfectionné sans doute en Angleterre par un poète dramatique très estimable, peut être considéré comme une preuve avantageuse de l'art de la tragédie parmi les Chinois; et I'Histoire agréable, dont, grâce aux soins d'un savant et ingénieux prélat, il a paru, depuis plusieurs années, une traduction anglaise, montre que leurs romans sont d'un genre simple et intéressant. Le zèle du christianisme a engagé les missionnaires à procurer aux lecteurs sérieux de la Chine plusieurs ouvrages en langue chinoise, à l'appui des préceptes que prêchent ces religieux.

Malgré la vigilante police des magistrats chinois, des livres désapprouvés par eux sont secrètement imprimés et répandus dans l'empire. II n'est ni aisé de prévenir, ni de découvrir toujours les opérations d'un commerce qui, avec du papier et de l'encre, n'a besoin que de quelques planches et d'un couteau pour y graver des caractères. Les livres ainsi publiés furtivement sont principalement ceux qui blessent la décence et enflamment l'imagination de la jeunesse. On ne dit point qu'il y en ait eu contre le gouvernement. Cependant, les mandarins affirmèrent aux Anglais que, depuis des siècles, il y avait, à la Chine, une secte dont les principes avaient pour base la haine de la monarchie, et qui se nourrissait de l'espérance de la renverser. Les assemblées de cette secte se tenaient dans le plus grand secret, et personne n'en avouait la connaissance ; mais une sorte d'inquisition était établie pour les découvrir. Ceux qu'on soupçonnait d'en être membres étaient enlevés et séparés de la société. Ils se voyaient traités à peu près comme les personnes accusées de judaïsme l'étaient autrefois dans quelques royaumes catholiques.

Les ouvrages politiques, moraux et historiques des Chinois ne contiennent point des idées abstraites de liberté qui puissent les conduire à prétendre à 


\section{Voyage dans l'intérieur de la Chine et en Tartarie}

l'indépendance. On dit que, lorsque les Français ont voulu étendre les principes de la démocratie, la déclaration des droits de l'homme a été traduite dans un des langages de l'Indostan, et y a même été répandue. II n'est pourtant pas vraisemblable qu'elle cause quelque fermentation parmi les Indous dont l'esprit est tranquille, soumis, résigné, et la constitution faible et délicate; mais il pourrait en être tout autrement avec les Chinois qui sont plus susceptibles d'impressions fortes et plus disposés aux entreprises. C'est une race très hardie. Leur climat, plus septentrional que celui de l'Inde, contribue à les rendre intelligents et résolus. Ils sont plus agriculteurs que manufacturiers, et comme tels, plus propres à se sentir animés d'un esprit audacieux. Plusieurs d'entre eux ne sont pas très satisfaits de leur condition, qui met perpétuellement leur fortune et leur personne à la merci des mandarins. Les punitions corporelles auxquelles tout homme est sujet à l'instant où un magistrat fait le moindre signe, et quelquefois les seules appréhensions de ces punitions sont, lorsqu'elles n'avilissent pas l'âme, capables d'exciter l'impatience et l'indomptable ressentiment. A la Chine, des preuves manifestes d'innocence ne suffisent pas toujours d'appui à l'individu qui a recours au pouvoir supérieur. La maxime de maintenir la subordination empêche, en général, qu'on ne rende justice à l'opprimé. Cependant, les vexations énormes et multipliées produisant, enfin, le tumulte et le désespoir, excitent l'attention du gouvernement ; et le magistrat est déplacé, et souvent puni avec la plus grande sévérité.

Mais si, en se permettant des injustices contre le peuple, il est la plupart du temps sûr de l'impunité, il se voit traité avec la plus inexorable rigueur, dès qu'il commet la moindre faute contre le gouvernement. II vit aussi dans la crainte de devenir fréquemment responsable des événements qui sont hors de sa portée. D’après le principe général qui veut qu'un magistrat veille sur les mœurs du peuple, il est, dans beaucoup de circonstances, considéré comme criminel pour n'avoir pas prévenu des crimes qu'il n'était pas en son pouvoir de prévenir. Ainsi, les mandarins savent qu'une bonne conduite ne les empêche pas toujours d'être disgraciés, et ils sentent tout le chagrin d'une dangereuse incertitude. 


\section{Voyage dans l'intérieur de la Chine et en Tartarie}

Certes, il est toujours le plus solide le gouvernement où, comme en Angleterre ${ }^{1}$, la plus grande partie des sujets savent qu'ils sont intéressés à sa conservation. II ne paraît pas que les Chinois pensent généralement ainsi à l'égard du leur. Sans raisonner sur le droit de changer ceux qui les gouvernent, plusieurs d'entre eux se plaisent à regarder un pareil changement comme propre à améliorer leur condition. Ils sont en même temps enclins à prendre part aux révoltes qui ont fréquemment lieu, tantôt dans une province, tantôt dans l'autre. On empêche les assemblées, parce qu'on craint toujours qu'il ne s'y passe quelque désordre. L'on a pris les plus grandes peines sous la dynastie régnante pour inspirer aux Chinois de l'attachement pour la personne de leur souverain; mais cet attachement cesse dès qu'ils éprouvent quelque calamité qu'ils lui imputent d'avoir occasionnée, ou de ne pas s'efforcer de soulager; et alors, oubliant le droit qu'il a au trône qu'il remplit, droit qui est ailleurs garant de la sûreté des monarques, ils sont toujours emportés par le désir de l'engager à céder ce rôle à un autre.

La maxime générale d'obéir au prince, maxime inculquée par les moralistes chinois, pourrait bien ne pas tenir dans toutes les âmes contre la nouvelle doctrine de droit sacré et du devoir de résister à l'oppression. Mais le soupçonneux gouvernement de la Chine, prévoyant l'avidité avec laquelle des notions d'égalité seraient adoptées, particulièrement par de jeunes esprits des classes inférieures de la société, que doit naturellement enflammer cette lumière flatteuse et nouvelle, a commencé de bonne heure à prendre des mesures pour en arrêter l'introduction.

Jusqu'à présent, le plus solide fondement de la sûreté et de la tranquillité de l'empire a été le système patriarcal, lequel ainsi que nous l'avons observé plus haut, a continué d'être suivi par tous les individus des générations successives, vivant toujours sous les vieillards de leurs familles. La prudence et l'expérience de ces vieillards, en dirigeant les intérêts de leurs enfants,

\footnotetext{
1 Nous ne pouvons nous empêcher d'observer que, toutes les fois qu'il s'agit de la France ou de l'Angleterre, l'auteur de cet ouvrage montre beaucoup de partialité. II ne déguise ni son admiration pour le gouvernement de son pays, ni son antipathie pour celui des Français. (Note du Traducteur.).
} 


\section{Voyage dans l'intérieur de la Chine et en Tartarie}

tend à détourner d'eux les funestes conséquences des événements qui pourraient provoquer le mécontentement et la déloyauté; et comme ils se défient de toute innovation, ils leur donnent l'exemple de se résigner au lot qui leur est échu dans le partage de la vie. Le sentiment naturel de respect pour l'âge, réuni à l'affection qu'inspirent les parents, s'enracinant de bonne heure, et se fortifiant par l'idée des services reçus chaque jour, lient les âmes d'une manière plus douce, mais souvent plus efficace que toute la force des lois.

L'art de l'imprimerie, pratiqué, sans doute, dès les premiers temps de l'empire, a contribué à le conserver jusqu'à ce jour, dans un état presque uniforme. C'est cet art qui a répandu universellement, et établi dans tous les rangs, des principes de justice invariables, et des règles de morale, qui sont autant de barrières contre la fougue des passions humaines, et s'opposent au penchant des hommes dans la plénitude du pouvoir.

A chaque changement dans le gouvernement des contrées qui sont voisines de la Chine, mais dont les mœurs et les usages sont bien différents des siens, le succès, semblable à un torrent, entraîne tout ce qui se rencontre devant lui, et efface tous les premiers arrangements de la société ; mais en Chine, les institutions et les opinions survivent aux ravages des conquêtes et des révolutions. Le souverain peut être détrôné, toute sa famille disparaître ; mais les mœurs et la condition du peuple restent les mêmes. Le trône est appuyé par des maximes que propage la presse. C'est par elle que les vertus du possesseur de ce trône sont peintes à tous ses sujets. Elle lui donne l'immense avantage de diriger leurs sentiments comme il le juge convenable. Ses palais, ses jardins, sa magnificence, n'inspirent point d'envie contre un prince qu'on représente comme doué des qualités les plus transcendantes, et occupé à travailler, sans relâche, au bonheur de son peuple.

Les cérémonies extérieures, destinées à l'honorer, ne sont point de vaines formalités. Elles contribuent à inspirer au peuple des sentiments de respect et de dévouement pour lui. Le jour de l'anniversaire de sa naissance, tous les mandarins qui résidaient à Pékin, revêtus de leurs robes de cérémonies, se rassemblèrent à midi dans le grand palais de cette capitale, et firent, devant 


\section{Voyage dans l'intérieur de la Chine et en Tartarie}

le trône, les prosternements accoutumés. Du bois de santal et du bois de rose brûlaient à côté ; et des viandes et des liqueurs y furent présentées comme si, quoique absent, l'empereur pouvait jouir de ces offrandes.

M. Barrow fut présent lorsqu'on observa les mêmes cérémonies à YuenMin-Yuen ; et il apprit que la même chose avait eu lieu dans toutes les parties de l'empire, et que ceux qui se prosternaient étaient très attentifs à se tourner du côté de la capitale.

Tous les premiers jours de la nouvelle et de la pleine lune, l'encens et les offrandes sont également présentés par les officiers qui résident dans les différents palais de l'empereur.

Ces palais sont en grand nombre dans l'empire. Celui de Pékin forme le centre de la cité tartare. Quoique cette capitale soit bâtie au milieu d'une plaine poudreuse, d'où les montagnes de la Tartarie ne sont vues que de loin, le mur qui environne le palais, les bâtiments qui en dépendent et les jardins renferment un abrégé de toutes les diverses espèces de sites, que la main de la nature a créés en se jouant sur la surface du globe. Des montagnes et des vallées, des lacs et des rivières, d'horribles précipices et des pentes douces, ont été réunis dans un lieu où la nature n'avait pas voulu les placer ; cependant, ils y sont avec des proportions si exactes, et tant d'harmonie, que sans l'aspect uniforme de la campagne environnante, le spectateur douterait si ce sont des productions réelles ou d'heureuses imitations de la nature. Ce monde en miniature a été créé par l'ordre et pour le plaisir d'un seul homme ; mais il a fallu y employer le pénible travail de plusieurs milliers de bras.

Les temples de Pékin n'égalent point ses palais. La religion de l'empereur est nouvelle en Chine ; et ses cérémonies y sont pratiquées avec bien moins de pompe qu'en Tartarie. Les mandarins, les lettrés, parmi lesquels sont choisis les magistrats qui gouvernent l'empire, et qui occupent le premier rang de la société, révèrent, plutôt qu'ils n'adorent Confucius, et se rassemblent pour honorer sa mémoire, dans des édifices très propres, mais d'une construction simple. Les classes nombreuses et inférieures du peuple sont moins en état de fournir aux moyens de construire de grands et superbes édifices pour le culte public, qu'elles n'y sont naturellement portées. En outre, leur principale attention est dirigée vers leurs dieux domestiques. 


\section{Voyage dans l'intérieur de la Chine et en Tartarie}

Chaque maison a son autel et ses déités. Les livres de mythologie contiennent des images de celles qu'on croit veiller sur les personnes et les propriétés, et présider aux objets extérieurs, dont l'effet peut être sensible. Lui-Shin est, suivant les Chinois, l'esprit qui préside au tonnerre ; et dans son emblème, la violence de ce météore auquel rien n'est capable de résister, la rapidité de l'éclair que rien ne peut surpasser, et leurs effets réunis, sont représentés par une figure monstrueuse qui s'enveloppe de nuages. Sa bouche est recouverte par un bec d'aigle, symbole des dévorants effets du tonnerre; et ses ailes en peignent l'extrême vélocité. D'une main, il tient un foudre, et de l'autre une baguette, pour frapper sur diverses timbales dont il est environné. Ses serres d'aigle sont quelquefois attachées à l'axe d'une roue, sur laquelle il tourne au milieu des nuages, avec une rapidité extraordinaire. Dans l'original, d'où cette description est tirée, le pouvoir qu'a cet esprit redoutable est indiqué par le spectacle d'animaux frappés de mort et couchés sur la terre, de maisons abattues et d'arbres déracinés.

Dans les environs de Pékin, les jardins de Yuen-Min-Yuen occupent un terrain qui, suivant M. Barrow, a au moins douze milles de circuit. Cet Anglais fut, de tous ceux qui composaient l'ambassade, celui qui vit le mieux ces jardins. Ainsi, nous allons citer ce qu'il en dit: Yuen-Min-Yuen est un lieu délicieux. Tout ce que la nature a de grand et d'agréable y est séparé, rapproché ou arrangé avec tant d'intelligence, que son ensemble n'offre ni embarras ni désordre dans la variété des objets. II y règne, au contraire, un accord et des proportions qui produisent des effets très naturels. On ne voit, dans aucune partie de ces jardins, de plaines rondes, ovales ou carrées, avec du gazon taillé bien ras. Les Chinois sont singulièrement habiles dans l'art d'agrandir aux yeux l'étendue réelle d'un terrain, en disposant les objets destinés à embellir sa surface. Pour cela, ils placent, sur le devant de l'endroit d'où doit être pris le point de vue, des arbres hauts et vigoureux, du vert le plus foncé. Ceux qu'ils plantent plus loin sont graduellement moins élevés et d'un vert plus clair. En général, la perspective est terminée par des groupes d'arbres dont l'espèce et la couleur du feuillage sont variées, et qui ne déploient pas leur vigueur à la même époque. Souvent ces arbres paraissent vieux et rabougris, croissent avec difficulté à travers des rochers, tantôt 


\section{Voyage dans l'intérieur de la Chine et en Tartarie}

comme s'ils y étaient nés, tantôt comme s'ils y avaient été rassemblés à dessein. L'effet de cette apparente difficulté, et de cette demi-vue, est aussi très bien entendu des Chinois. A Yuen-Min-Yuen, on a construit une légère muraille qui, vue de loin à travers les branchages d'un bosquet, ressemble à un édifice magnifique. Les pièces d'eau ne sont point entourées d'un talus comme les glacis d'une fortification, mais leurs bords sont, en divers endroits, garnis de rochers artificiels qui paraissent y avoir été posés par la nature.

Les seules choses qui ne soient pas pittoresques dans les paysages des Chinois sont la forme étudiée et la couleur brillante de leurs bâtiments. Cependant, leurs toits onduleux ne méritent point la première partie de ce reproche, et leur projecture jette une ombre douce sur les colonnades qui les soutiennent. Quelques-unes de ces hautes tours, que les Européens appellent des pagodes, sont très favorables à la perspective ; et en conséquence, on les place dans des situations élevées.

Malgré la juste idée que les Chinois se sont formée de l'art d'orner les jardins, et le goût avec lequel ils savent faire ressortir tous les objets qu'ils y placent, non seulement ils ignorent totalement les principes de la perspective et du clair-obscur, mais ils sont insensibles à leurs effets, comme le prouvent tous les ouvrages sortis de leur pinceau. Lorsque les Anglais exposèrent divers portraits, peints par les meilleurs artistes de l'Europe, et destinés à être offerts à l'empereur, les mandarins observant la variété des teintes, occasionnées par la lumière et les ombres, demandèrent sérieusement si les originaux de ces portraits avaient un côté du visage d'une couleur différente de l'autre. Ils regardaient l'ombre du nez comme un grand défaut de la peinture ; et quelques-uns d'entre eux croyaient qu'elle y avait été placée par accident.

Un missionnaire italien, nommé Castiglione, et excellent peintre, était attaché à la cour de Pékin. II reçut ordre de l'empereur de lui faire divers tableaux; mais on lui enjoignit en même temps d'imiter la manière de peindre des Chinois, non celle de l'Europe, qui était considérée comme peu naturelle. Aussi, dans les ouvrages qu'il a faits pour décorer le palais, on voit des maisons au-dessus des maisons, dans un ordre régulier, jusqu'au haut du 


\section{Voyage dans l'intérieur de la Chine et en Tartarie}

tableau. Les figures du devant et celles du fond sont de la même grandeur et bravent la nature et les sens. II a peint aussi une suite de figures chinoises occupées à différents métiers. Ces tableaux sont admirables par la touche et le coloris; mais le défaut d'ombres fait qu'ils sont sans effet. Toutefois les Chinois les préfèrent à tous les chef-d'œuvres de peintures qu'on peut leur porter d'Europe.

Les Chinois semblent considérer les ombres comme des circonstances accidentelles, qui ne doivent pas être transportées de la nature dans un tableau, parce qu'elles le privent de l'uniformité du coloris et d'une partie de son éclat. Quant à la représentation des objets, à différente distance, ils préfèrent de les voir dessinés, non comme ils paraissent à l'œil, diminuant par degrés à mesure qu'ils s'éloignent, mais d'une grandeur prescrite par le jugement, qui corrige les erreurs de la vue ; erreurs qui sont pourtant nécessaires à la beauté et à l'ordre du paysage.

Le mauvais effet des tableaux, exécutés d'après les principes chinois, doit produire le découragement de l'art. Aussi les maisons sont ornées non de tableaux, mais de tablettes, contenant des sentences morales, peintes sur du bois ou sur de l'étoffe de soie, avec beaucoup d'art et de délicatesse. Les Chinois estiment mieux ces tablettes que les ouvrages des meilleurs maîtres. Quoique les peintres chinois pèchent dans le groupé des figures, et dans tout ce qui concerne la composition et l'ordonnance d'un tableau, ils réussissent dans le dessin des objets individuels. Ils dessinent, surtout, avec bonheur, les sujets d'histoire naturelle. Ils les rendent non seulement d'une manière très correcte, mais avec les traits, les attitudes de la nature, et avec une telle exactitude qu'un peintre chinois compte quelquefois le nombre d'écailles des poissons qu'il veut représenter. Leur coloris est extraordinairement brillant ; et cet éclat est d'autant plus surprenant, qu'il n'est dû qu'à la patience et au soin qu'ils emploient dans la lévigation des mêmes ingrédients, avec lesquels on fait les couleurs en Europe ${ }^{1}$. Quelques estampes ont été copiées par eux

\footnotetext{
${ }^{1}$ Le docteur Sparrmann, célèbre par ses voyages et par ses connaissances en histoire naturelle, m'a montré, dans le cabinet de l'académie de Stockholm, un volume de poissons, peints à la Chine. Ils sont peints avec tant de vérité qu'ils ont l'air d'être vivants; et il $y$ en a dont les couleurs sont si brillantes qu'on croirait qu'on y a
} 


\section{Voyage dans l'intérieur de la Chine et en Tartarie}

et coloriées avec un art qui a été admiré des meilleurs juges. Un homme connu, à Londres, par son goût, possède une copie coloriée et faite en Chine, d'une étude de sir Josué Reynolds, et il a cru qu'elle méritait d'entrer dans la précieuse collection de ses tableaux.

M. Barrow observe qu'on a parlé, depuis très longtemps, du talent d'imiter des Chinois ; mais que les principales causes qui arrêtent les progrès des arts parmi eux sont le peu de communication qu'ils ont avec les autres nations, et le défaut d'encouragement de la part de leur gouvernement, dont la politique est de s'opposer au luxe, et de soutenir le travail, surtout celui de l'agriculture. II ajoute que leur talent pour la sculpture est encore très défectueux à l'égard des formes, des attitudes et des proportions. Ils ont, il est vrai, l'art de se servir très délicatement du ciseau pour tailler la pierre, le bois et l'ivoire; mais leurs productions sont contournées et peu naturelles. Ils font souvent la figure humaine sans les proportions nécessaires, et leur aversion pour l'anatomie en est en partie cause. Ils ne réussissent pas mieux à représenter le lion. II y en a deux en bronze devant l'une des portes de la salle d'audience de Yuen-Min-Yuen. Le métal a été fondu par petits morceaux, qui ont ensuite été ajustés d'une manière très ingénieuse, quoiqu'il y en ait plus de cent dans la composition de chaque statue. Mais ces statues ressemblent si peu à l'animal qu'on a voulu qu'elles représentassent qu'on peut presque les prendre pour des chevaliers armés, avec des perruques comme on les portait du temps du roi Charles ${ }^{1}$.

Le lion peut être considéré, par les Chinois, comme un être imaginaire. II n'y en a point dans leur pays. On n'y en a jamais porté, ni pour en faire présent à l'empereur, ni pour les montrer en payant comme objet de curiosité. Les statues des lions qu'ont les Chinois sont probablement faites d'après quelques mauvais dessins où était représenté cet animal, que sa force supérieure et la générosité qu'on lui attribue ont fait connaître bien plus loin qu'il n'a voyagé.

appliqué de légères feuilles d'or, d'argent ou de nacre. (Note du Traducteur.).

${ }^{1}$ Charles II. 


\section{Voyage dans l'intérieur de la Chine et en Tartarie}

Le plus gros et le plus puissant des quadrupèdes, l'éléphant, se trouve, comme une suite de la grandeur, dans les palais impériaux, où il ne mérite pas moins d'entrer par rapport à la force et à la docilité qui peuvent le rendre utile, que pour sa taille énorme et sa forme singulière. C'est le seul quadrupède qui a une trompe; mais cette conformation se trouve fréquemment dans les insectes et, entre autres, dans la mouche commune, qu'on cite quelquefois comme en état de vaincre l'éléphant même.

Des éléphants mâles et femelles sont transportés en Chine des environs de l'équateur; et il en naît quelques-uns au nord du tropique. Quelque pudiques que soient ces animaux, on a découvert, à cette occasion, qu'ils s'unissent de la même manière que les autres quadrupèdes. Leur conformation des deux côtés paraît, il est vrai, s'opposer à leur union ; mais il est des circonstances où la nature triomphe de cet obstacle. Les éléphants de la Chine sont plus petits et d'une couleur plus claire que ceux de la Cochinchine. Ils sont granivores, puisqu'on ne leur donne ordinairement que du riz et du millet; mais dans l'état sauvage, ces animaux, ainsi que la girafe, le chameau et la chèvre, se nourrissent plus souvent des feuilles et des bourgeons des arbres et des arbustes que de graines, de paille ou $\mathrm{d}^{\prime}$ herbe ${ }^{1}$.

Les officiers de la maison de l'empereur et les domestiques des palais de ce prince sont tous, ou du moins la plupart, des êtres qui, avant d'arriver à l'âge de puberté, ont été privés des moyens de devenir hommes, ou qui, s'ils ont eu le temps de le devenir, ont depuis cessé de l'être. Ce ne sont, sans doute, que les fureurs d'une excessive jalousie qui ont suggéré l'idée de mutiler un sexe pour en faire un sûr gardien de l'autre; et il n'y a que l'extrême abus d'une autorité illimitée qui a pu exécuter un dessein si cruel et si dénaturé. Mais d'autres motifs ont ensuite contribué à augmenter le

\footnotetext{
1 On peut ajouter le rhinocéros aux animaux que cite ici l'auteur, et rappeler l'ingénieuse et judicieuse observation d'un voyageur célèbre; c'est que la corne du rhinocéros et les longues dents de l'éléphant ne leur ont été données, par la nature, que pour qu'ils puissent toujours trouver à se nourrir dans les immenses forêts où ils vivent. Lorsque les arbres ne leur fournissent point assez de jeunes branches et de bourgeons, l'un de ces animaux se sert de sa corne et l'autre de ses longues dents pour fendre, en une multitude de lattes, le tronc des arbres les plus mous, et par ce moyen, ils peuvent aisément les brouter. (Note du Traducteur.)
} 


\section{Voyage dans l'intérieur de la Chine et en Tartarie}

nombre de ces êtres dégradés. N'appartenant à aucun sexe, méprisés et détestés de tous deux, sans espérance d'avoir jamais de postérité, incapables de chérir et d'être chéris, ne ressemblant enfin à personne, ils peuvent être supposés plus propres à porter les chaînes factices de la servitude, et à s'attacher, à se dévouer sans réserve au prince qui les emploie. Commençant par être des domestiques abjects, et ne prétendant à aucune importance, ils sont les prompts et serviles ministres des amusements et des plaisirs secrets de leur maître, et ils parviennent, en rampant, à la familiarité et à la faveur. Ensuite, ils acquièrent quelquefois beaucoup de crédit et d'autorité, ainsi que l'attestent un grand nombre d'exemples cités dans les annales de la Chine. Quand ils sont revêtus du pouvoir, ils se vengent sur le genre humain de la dégradation de leur être, et ils ont souvent occasionné des calamités qui ont mis l'empire à deux doigts de sa perte. Plusieurs fois, ils ont presque tous été chassés de la cour. Dans le temps de la minorité de Caung-Shée, aïeul de l'empereur régnant, Chen-Lung, on renvoya près de six mille eunuques; mais leur nombre a augmenté depuis, et à présent ils occupent tous les emplois inférieurs, du moins dans les palais de Pékin et de Yuen-Min-Yuen.

II leur suffit, pour être propres à remplir ces emplois, d'avoir subi l'opération qu'on pratique quelquefois dans certaines parties de l'Europe, et qui en perfectionnant la voix, ôte la faculté de devenir père. Mais pour garder les femmes de la cour, et pour pouvoir même approcher de leurs appartements, il faut être ce que les Turcs appellent, sans aucun égard à la couleur, un eunuque noir, c'est-à-dire un être qui a perdu toutes les marques de son sexe.

Les lecteurs seront peut-être surpris quand ils apprendront que l'opération qu'on fait pour cela est, quoique très délicate, exécutée même sur des Chinois adultes, sans compromettre leur vie. Un tel fait est d'autant plus extraordinaire que l'art de la chirurgie est si peu connu en Chine qu'on n'y fait pas même usage de la saignée, et que l'anatomie y est non seulement ignorée, mais en horreur. On doit cependant remarquer qu'à la Chine on guérit de toute sorte de maladies accidentelles, plus rapidement que dans la plupart des contrées de l'Europe, et qu'elles y sont même accompagnées de moins de symptômes dangereux. On a aussi observé que les habitants de I'Indostan guérissaient constamment et avec promptitude des blessures les 


\section{Voyage dans l'intérieur de la Chine et en Tartarie}

plus terribles. Les chirurgiens ont été souvent surpris de la facilité avec laquelle se rétablissaient quelques cipayes, blessés au service des Anglais. Sans doute la pureté de l'air de la Chine et de l'Inde est dans ces sortes d'occasions plus propice que le coelum nebulis foedum dont parle Tacite, dans sa description de la Grande-Bretagne; mais la manière de vivre contribue aussi beaucoup à former le tempérament, et le plus ou moins de dispositions qu'ont les chairs à s'enflammer et à se corrompre lorsqu'il y a, comme on dit d'une manière technique, solution de continuité. Ni les Chinois, ni les Indous ne sont enclins à aucune sorte d'excès. Les Indous de la plus nombreuse et dernière classe peuvent manger de toute espèce d'animaux, excepté du bœuf. Malgré cela, et ces Indous et le peuple chinois, consomment moins de viande et boivent moins de liqueurs spiritueuses et de liqueurs fermentées que les habitants de l'Europe, du moins ceux du Nord.

Ceux qu'on rend eunuques à la Chine peuvent subir l'opération depuis la première enfance jusqu'à l'âge de quarante ans. On dit que, dans ces occasions, on se sert non du fer, mais de ligatures ointes d'une liqueur caustique. Souvent, on voit, peu de jours après l'opération, le malade sortir comme s'il ne lui était rien arrivé. Lorsqu'un adulte est ainsi transformé en eunuque noir, sa barbe commence bientôt à tomber, et insensiblement, il ne lui en reste plus ; en même temps, il se flétrit, et en peu d'années, son visage est sillonné comme celui de

La Sorcière ridée, au dos courbé par l'âge ${ }^{1}$.

Cette précoce vieillesse des eunuques chinois s'accorde avec ce qu'observe Chrysostôme, en parlant de l'eunuque Eutrope :

«Quand il a ôté son fard, dit-il, son visage paraît plus laid et plus ridé que celui d'une vieille femme.

Claudien remarque qu'il n'y a presque point d'intervalle entre la jeunesse et la décrépitude des eunuques. Le principal gardien des femmes de YuenMin-Yuen en était la preuve. Quoiqu'il n'eût pas plus de trente ans, il ne se montrait jamais sans que son visage fût peint, sa personne bien composée,

\footnotetext{
${ }^{1}$ L'expression du poète anglais est, littéralement, à l'âge double.
} 


\section{Voyage dans l'intérieur de la Chine et en Tartarie}

sa parure très riche; et il portait à sa ceinture beaucoup de glands et de colifichets. II avait au moins six pieds de haut; et il était robuste, mais mal fait et tout dégingandé. II n'y avait point de petite fille qui eût la voix plus faible et plus glapissante que la sienne.

Si un homme, désirant de sortir de la classe des plébéiens, se soumet à devenir eunuque, il est aussitôt reçu et employé dans le palais ; ce qui lui donne les avantages et l'importance d'un homme de qualité. Soit qu'il porte un balai ou un paquet de clefs, il ne retranche rien de son titre. Peu d'eunuques cependant sont décorés d'un bouton à leur bonnet, parce que le bouton est proprement la marque distinctive des mandarins civils et militaires.

Les eunuques du palais ont souvent plus d'influence que d'autorité avouée; et on sait que quelquefois leurs insinuations ont fait disgracier des premiers mandarins qui leur avaient déplu. Sachant tout ce que peuvent leurs rapports et leurs mensonges dans le cours de leur service familier auprès du souverain, ils portent l'effronterie jusqu'à traiter avec indignité des personnes mêmes de sa famille. Un prince d'environ dix-huit ans, qui était petit-fils de l'empereur, se trouvait un jour à Yuen-Min-Yuen, parmi ceux qui regardaient les présents apportés d'Angleterre, lorsqu'un eunuque le fit sortir, en disant qu'il lui convenait mieux d'aller à l'école, que de faire le paresseux dans cette salle.

II y a dans le palais une école où les princes sont instruits, principalement dans les langues chinoise et tartare-mandchou, ainsi que dans l'histoire, les coutumes et les cérémonies des deux nations.

On croit que l'occupation des eunuques, dans l'intérieur du palais, a beaucoup diminué à mesure que l'empereur est avancé en âge. L'impératrice reconnue était morte depuis quelque temps, lorsque l'ambassade anglaise arriva en Chine, et l'empereur avait traité avec beaucoup de légèreté la proposition qu'on lui avait faite de se marier de nouveau. Plusieurs autres compagnes de sa jeunesse ont aussi cessé de vivre.

A la mort d'un empereur, toutes ses femmes sont, dit-on, conduites dans un bâtiment particulier qui est dans l'enceinte du palais, pour y passer le 


\section{Voyage dans l'intérieur de la Chine et en Tartarie}

reste de leurs jours, séparées du monde entier. On nomme ce bâtiment le palais de chasteté.

Il y a, en Chine, quelques religieuses païennes, qui font vœu de rester vierges ; et quoique ce soit contraire aux maximes générales de politique et de morale adoptées dans l'empire, on a, pour ces filles, l'admiration qu'inspirent ordinairement les personnes qui, à force de persévérance, réussissent à exécuter des choses difficiles.

A l'avènement d'un nouvel empereur, les principaux personnages du pays conduisent leurs filles dans son palais, afin qu'il choisisse ses femmes parmi elles. Les familles de celles qui sont acceptées en acquièrent beaucoup d'honneur et de crédit. Indépendamment de ces femmes réservées pour l'empereur, d'autres sont présentées pour femmes ou pour concubines aux princes de son sang. Les concubines sont considérées, en Chine, sous le même point de vue que les servantes de l'Écriture.

Les missionnaires attachés au palais, sachant combien leur état est précaire, et avec quelle facilité on peut réveiller le soupçon contre des hommes qui tendent à changer la religion et les opinions de l'empire, craignent plus de déplaire à un eunuque qu'à un mandarin ; car le premier est toujours plus insolent, plus capricieux et plus sujet que l'autre à céder à de vils sentiments de malice et de vengeance. Chaque missionnaire s'efforce de se maintenir dans les bonnes grâces de toutes les personnes de la famille impériale, et de celles qui vivent à la cour. Ils ont auprès d'elles beaucoup d'humilité ; ils leur rendent de petits services en exerçant pour elles les arts, qui sont à leur portée ; et quelquefois, ils leur présentent des objets d'Europe, qui sont en leur possession, et dont ces personnes peuvent avoir fantaisie ; encore sont-ils alors très attentifs à les remercier de I'honneur qu'elles leur font d'accepter ces objets. Les missionnaires ne parlent jamais qu'à genoux aux princes du sang.

Quelques missionnaires restaient constamment auprès des Anglais qui dirigeaient l'arrangement des présents à Yuen-Min-Yuen, afin de leur servir d'interprètes, et d'apprendre à connaître la nature et l'usage des instruments qu'on déposait dans ce palais. 


\section{Voyage dans l'intérieur de la Chine et en Tartarie}

Ces Anglais étaient parfaitement bien traités à Yuen-Min-Yuen. Un mandarin les visitait tous les jours pour leur demander s'ils étaient satisfaits et s'ils désiraient d'avoir autre chose que ce qu'on leur avait fourni.

Un d'entre eux allait ordinairement à Pékin trois fois par semaine. Un cabriolet était toujours à ses ordres. Quelquefois, un mandarin et son domestique l'accompagnaient; mais il était souvent maître d'aller seul. Chaque matin, il recevait un message pour savoir s'il irait ce jour-là à la cité.

Les instruments et les différentes machines étant enfin montés et mis en ordre, et tous les présents arrangés de la manière la plus avantageuse, en différentes parties de la salle d'audience et des deux côtés du trône, tous les Anglais qui étaient à Yuen-Min-Yuen, s'apprêtèrent à retourner à Pékin. Mais le principal eunuque du palais déclara qu'il avait reçu un ordre de l'empereur pour faire changer l'arrangement des présents, et les placer à l'une des extrémités de la salle d'audience, parce que, quand ils seraient là, sa majesté pourrait les voir de son trône, sans être obligée de tourner la tête. Tel fut le motif qu'on allégua pour ce nouvel arrangement ; et comme si c'eût été une affaire très importante, on se dispensa, à cette occasion, de suivre la coutume d'interrompre, dans le palais, toute sorte de travaux, trois jours avant, et trois jours après l'anniversaire du jour de la naissance de l'empereur.

Très peu de temps après le retour de l'ambassadeur à Pékin, on annonça que l'empereur approchait de Yuen-Min-Yuen, et l'on avertit son excellence que, conformément à l'étiquette, on s'attendait qu'elle irait à quelques milles au-devant de sa majesté impériale. L'ambassadeur était alors très affecté d'un rhumatisme, qui l'avait souvent tourmenté depuis son arrivée en Chine. Les mandarins qui s'aperçurent à quel point il souffrait en ce moment, et combien peu il lui était impossible d'agir comme à l'ordinaire, lui proposèrent de rendre le voyage moins fatigant en le faisant à deux reprises, et de partir la veille de l'arrivée de l'empereur, pour aller coucher dans son ancienne demeure, près de Yuen-Min-Yuen, parce que le lendemain, il n'aurait que très peu de chemin à faire. Ce plan rendit praticable la marque d'attention qu'on désirait de l'ambassadeur. En conséquence, il passa la nuit à la campagne avec toute sa suite d'Anglais et de Chinois. Le lendemain, ils furent tous 


\section{Voyage dans l'intérieur de la Chine et en Tartarie}

debout avant le lever du soleil. Ils suivirent un chemin parallèle à celui qui était exclusivement réservé pour l'empereur, et qu'en séparait un fossé peu profond. Tous les deux étaient illuminés avec des lanternes de diverses couleurs, et suspendues chacune à trois bâtons plantés obliquement dans la terre et formant un triangle.

L'ambassadeur et sa suite arrivèrent après deux heures de marche au lieu du rendez-vous général. Ils furent conduits dans un salon spacieux, où l'on avait préparé des rafraîchissements. Après en avoir profité, ils se rendirent dans l'endroit où devait passer l'empereur, et où il pouvait remarquer l'attention respectueuse des Anglais. Ils étaient placés sur une hauteur verdoyante à gauche du chemin et, de chaque côté d'eux, on voyait une multitude de mandarins, de gardes et de porte-étendards. Plusieurs de ces derniers, en attendant l'approche de l'empereur, avaient mis leurs étendards roulés en travers du chemin destiné à ce prince, comme s'ils avaient voulu empêcher que personne tentât d'y passer. Les deux côtés de la route étaient bordés de troupes dans un espace de plusieurs milles, et aussi loin que l'œil pouvait atteindre. Tout auprès de la route était une tente qu'on avait préparée pour l'ambassadeur, parce que, comme on était informé de son indisposition, on voulait qu'il fût à son aise en attendant l'empereur. Divers escadrons de cavalerie, avec des archers armés de leurs arcs, de leurs carquois, précédaient le monarque. Bientôt après parut un palanquin, ou plutôt une chaise telle que celle que nous avons décrite dans le chapitre précédent, mais couverte de drap d'un jaune brillant, et ayant des portières garnies de glaces. Elle était portée par huit hommes, à côté desquels huit autres marchaient, pour être prêts à les relever en cas de besoin. A la suite de la chaise étaient des troupes de cavalerie en uniforme jaune, des soldats armés de piques, d'autres qui portaient des boucliers, et d'autres des étendards. L'empereur était dans la chaise. Aussitôt qu'il aperçut l'ambassadeur, il s'arrêta, et lui envoya un message gracieux, en lui faisant dire qu'il le priait de se retirer sans délai, parce que le froid et l'humidité du matin étaient contraires à la maladie dont il avait appris que son excellence était incommodée.

Derrière la chaise de l'empereur, il y avait une voiture à deux roues, grossièrement faite et sans ressorts, différant très peu, pour la construction, 


\section{Voyage dans l'intérieur de la Chine et en Tartarie}

des plus mauvaises voitures de campagne, mais couverte de drap jaune, et vide, comme si elle était destinée à servir de temps en temps à l'empereur. Quand on compare une telle voiture avec les carrosses légers, commodes et élégants portés en présent à l'empereur, il ne paraît pas vraisemblable que le préjugé national résiste longtemps à l'évidence d'une commodité et d'un agrément si supérieur; et un jour viendra peut-être où les carrosses anglais seront en Chine un article d'importation, comme les montres et le drap.

La voiture de l'empereur était immédiatement suivie d'une chaise, dans laquelle était le grand colao Ho-Choong-Taung. Tandis que l'empereur était occupé à envoyer son message du côté du fossé où était l'ambassadeur, plusieurs mandarins franchirent ce fossé et se jetèrent à genoux pour rendre hommage au premier ministre. On remarqua qu'aucun autre ministre, ni même aucun des princes de la famille de l'empereur ne marchait à sa suite, ni ne paraissait sur la route. La distinction en était d'autant plus grande pour celui qui s'y trouvait. Peut-être aussi que quelque arrangement avait exigé, ou quelque accident occasionné, que l'empereur se séparât ainsi de ses courtisans.

L'ambassadeur, dont l'excursion était inutile à l'empereur, retourna sans délai à Pékin, tandis que ce prince poursuivit sa route droit à Yuen-Min-Yuen. Il était impatient de contempler les présents que l'ambassadeur y avait déposés avant d'aller à Zhé-Hol. Il les examina avec bien plus d'attention qu'un homme qui n'aurait pas voulu prendre la peine de tourner la tête pour les voir ${ }^{1}$. II parut très satisfait de la plupart de ces présents, et donna ordre qu'on distribuât de l'argent aux ouvriers qui avaient travaillé à les arranger. Quelques-uns des instruments et des machines furent essayés en sa présence. On observa, avec le télescope, des objets éloignés; et l'on fit fondre des métaux dans le foyer de la grande lentille de Parker. L'esprit philosophique de l'empereur ne manqua sûrement pas de remarquer que, grâce à l'industrie européenne, la même matière, le verre, était propre à opérer des effets aussi divers qu'extraordinaires.

\footnotetext{
${ }^{1}$ On a vu plus haut ce que disait l'eunuque de Yuen-Min-Yuen.
} 


\section{Voyage dans l'intérieur de la Chine et en Tartarie}

Un modèle du Royal Souverain, vaisseau de guerre de cent dix canons, captiva longtemps l'attention de l'empereur. II s'adressa aux Anglais qui étaient présents, et leur fit plusieurs questions concernant les diverses parties de ce modèle, et la marine anglaise en général. Mais il était aisé de s'apercevoir que les interprètes avaient une grande difficulté à expliquer beaucoup d'expressions techniques; inconvénient qui abrégea très certainement le nombre des questions du monarque. Cependant, la curiosité qu'il témoigna en cette occasion, et l'empressement qu'il eut de converser avec de simples particuliers, prouva que l'appréhension de n'avoir que des entretiens imparfaits et ennuyeux par le moyen des interprètes l'empêcha, bien plus que l'étiquette de la cour ou aucune indifférence pour l'Europe, de communiquer fréquemment et personnellement avec l'ambassadeur.

Quant à ce qu'étaient, à cette époque, les sentiments de ce prince à l'égard des Anglais ou de leur ambassadeur, la situation de ce dernier ne lui permettait presque pas de pouvoir le découvrir. Cependant, il avait quelque raison de se flatter que, depuis l'arrivée de l'ambassade, la jalousie conçue contre sa nation, à l'occasion de la guerre du Thibet, avait insensiblement disparu du cœur de l'empereur. En outre, les amis de l'ambassadeur étaient persuadés que le général qui avait commandé les troupes chinoises dans cette guerre et qui, depuis, avait été vaincu dans une autre, allait perdre la vice-royauté de Canton, où la haine qu'il portait aux Anglais le rendait très peu propre à avoir des relations avec leur factorerie.

D'un autre côté, il était assez probable que l'empereur pouvait avoir balancé entre les représentations opposées qui lui avaient été faites relativement aux Anglais. Mais c'était la première fois que quelques-uns d'entre eux paraissaient à sa cour ; et l'on avait observé que des préventions conçues contre des absents étaient souvent affaiblies quand ils se montraient, et même insensiblement détruites. Certes, les Anglais s'étaient déjà fait des amis parmi les grands officiers et les mandarins, quoique leurs efforts pour cela n'eussent pu être que momentanés. Ce fut par le moyen de ces amis que l'ambassadeur apprit qu'il s'était tenu à la cour un conseil, à l'occasion de la lettre du roi de la Grande-Bretagne, et qu'on y avait aussi discuté la manière dont il convenait d'agir envers ses sujets. On sut que le premier ministre avait fait appeler, à ce conseil, le général du Thibet, et l'ancien hoppo de Canton, 


\section{Voyage dans l'intérieur de la Chine et en Tartarie}

déjà déclaré coupable, et que, sous prétexte qu'ils étaient en état de juger de la conduite et des intentions des étrangers faisant le commerce de la Chine, il avait voulu avoir leur témoignage et leur avis. Mais, dans le fait, le colao n'avait employé ce moyen que pour fortifier son opinion, et triompher des dispositions favorables de l'empereur. Quand le but immédiat de l'ambassadeur eût été d'obtenir quelque avantage particulier pour sa nation, c'eût été probablement en vain, puisqu'il avait contre lui les suggestions du colao et de ses adhérents. II sentit encore mieux qu'il convenait d'envoyer, sans tarder, au colao le message dont nous avons parlé au commencement de ce chapitre, afin de lui annoncer que, dès que le premier jour ${ }^{1}$ de l'année chinoise serait passé, il demanderait à l'empereur la permission de quitter Pékin.

Au lieu de répondre directement à ce message, le colao fit inviter l'ambassadeur à aller le voir le lendemain à Yuen-Min-Yuen, où il avait quelques lettres anglaises à lui remettre. Cette invitation étant connue de toute l'ambassade, les divers Anglais qui y étaient attachés se sentirent vivement émus dans l'attente de recevoir, enfin, des nouvelles des amis qu'ils avaient dans leur patrie. Ceux-mêmes qui étaient immédiatement engagés dans la négociation oublièrent un moment toutes les considérations politiques, et jouirent d'avance de la satisfaction qu'ils croyaient devoir les attendre à Yuen-Min-Yuen. Lorsqu'ils y arrivèrent, quelques lettres anglaises leur furent, en effet, remises; mais elles étaient écrites de Chu-San par les personnes qui étaient à bord du Lion et de l'Indostan. Le principal mandarin de Chu-San, animé par un motif d'honnêteté et de politesse, avait inséré dans les paquets de l'empereur, des lettres adressées aux étrangers qui étaient à sa cour. Des motifs tout différents avaient dirigé la conduite des mandarins de Canton, quoique ce fût de ce dernier port qu'on attendît les lettres les plus intéressantes, les plus importantes, celles qui venaient d'Europe.

La défiance qui s'était emparée de l'âme du colao à l'égard des desseins des Anglais le rendait impatient de connaître le contenu des lettres adressées de Chu-San à l'ambassadeur. Ces lettres étaient de sir Erasme Gower.

\footnotetext{
${ }^{1}$ En février.
} 


\section{Voyage dans l'intérieur de la Chine et en Tartarie}

L'ambassadeur dit au colao que sir Erasme lui mandait qu'il était dans I'intention de partir immédiatement de Chu-San; mais que I'Indostan ne pouvait pas mettre à la voile jusqu'à ce que le capitaine l'eût rejoint. Lord Macartney remit, en même temps, les lettres dans les mains du colao, afin d'écarter les doutes qu'il pouvait avoir sur la fidélité de cette explication.

En apprenant que le départ du Lion était résolu, Ho-Choong-Taung parut inquiet. II dit :

«Qu'il espérait que ce vaisseau n'avait pas encore mis à la voile et qu'il attendrait que l'ambassade eût le temps de se rembarquer ; que dès que l'empereur avait appris l'indisposition de l'ambassadeur, et la mort de quelques personnes de sa suite, il avait remarqué combien les hivers de Pékin étaient rudes pour les étrangers, et que craignant que le séjour de cette ville ne fût nuisible à la santé des Anglais, et sachant en outre que le voyage par terre était très incommode et très fatigant, il avait pensé qu'il leur convenait de partir avant que les rivières et les canaux fussent gelés, ce qui arrivait quelquefois de bonne heure et subitement.

Le colao ajouta :

«Qu'il croyait que son excellence désirait d'attendre la fête de la nouvelle année ; mais que cette fête n'était qu'une répétition de ce qui avait eu lieu à Zhé-Hol.

II était évident que cette sollicitude affectée pour la santé de l'ambassade cachait tout autre motif ; mais l'ambassadeur crut qu'il fallait répondre sur le même ton. II observa que les Anglais étant eux-mêmes nés dans un climat plus septentrional que celui de Pékin, ils craignaient moins les effets du froid que ne pourraient raisonnablement les craindre d'autres étrangers; et qu'ils avaient pris des précautions contre quelque degré de froid auquel la capitale de l'empire pût être exposée. Passant ensuite à d'autres considérations, l'ambassadeur observa

« combien il serait affligé de quitter sitôt une cour où il avait été si bien accueilli ; que les intentions de son souverain étaient qu'il y restât assez longtemps, aux propres frais de sa majesté britannique, pour avoir de fréquentes occasions, et non aussi peu 


\section{Voyage dans l'intérieur de la Chine et en Tartarie}

qu'il en avait eues jusqu'alors, de renouveler les témoignages de son respect à l'empereur, et de cultiver et cimenter l'amitié qui avait si heureusement commencé entre les deux nations. Que dans cette vue, le roi son maître lui avait recommandé de faire connaître combien il serait charmé que l'empereur pût accorder, avec les coutumes de l'empire, l'envoi d'un ou plusieurs de ses sujets, comme ambassadeurs en Angleterre, et qu'en ce cas, on aurait soin de leur fournir des vaisseaux convenables pour l'allée et pour le retour.

Lord Macartney poursuivit en disant

« que tandis qu'il était à Zhé-Hol, le colao avait eu la bonté de lui donner la flatteuse espérance d'avoir plusieurs entrevues avec lui ; et que, quoiqu'il le désirât vivement, son prompt départ l'en priverait nécessairement.

L'ambassadeur essaya alors d'expliquer, en termes généraux, ce qu'il aurait bien mieux aimé pouvoir dire dans une de ces entrevues vainement promises. Mais il eut soin d'écarter tout ce qui pouvait avoir la moindre apparence de plainte, et il usa de toute sorte de précautions et de patience, de peur de nuire aux intérêts qui lui étaient confiés, ou d'affaiblir l'impression que l'ambassade avait déjà faite en faveur de son pays.

Le colao sut parfaitement dissimuler tous ses sentiments, et n'entra dans aucune discussion sur les objets que l'ambassadeur lui avait communiqués, mais il parla encore du départ et conclut en disant :

«Que l'empereur n'avait d'autre motif, en proposant ce départ, que l'intérêt qu'il prenait au bien-être de l'ambassade, et qu'à tout autre égard son séjour lui serait très agréable.

Rien ne pouvait être plus flatteur que les expressions dont se servit HoChoong-Taung, lorsqu'il parla, en son propre nom, à l'ambassadeur. Quoique natif de la Chine, l'interprète, qui n'était point accoutumé au langage et aux dissimulations de sa cour, conclut que l'ambassadeur était absolument maître de rester à Pékin aussi longtemps qu'il le jugerait convenable. 


\section{Voyage dans l'intérieur de la Chine et en Tartarie}

Le colao laissa sortir l'ambassadeur sans le prévenir, en aucune manière, que la réponse de l'empereur à la lettre du roi d'Angleterre était déjà prête, et qu'il se proposait de la lui remettre le lendemain; ce qui, suivant l'usage du pays, devait être regardé comme un congé. Cependant, à peine l'ambassadeur fut de retour à Pékin qu'il reçut un avis particulier sur cela. L'après-dîner, les mandarins Chow-ta-Zhin et Van-ta-Zhin lui rendirent visite et lui apprirent qu'il recevrait le lendemain un message du colao Ho-ChoongTaung pour l'inviter à se trouver avec lui au palais de Pékin. Feignant ensuite de n'être pas sûrs de ce qu'ils allaient dire, ils ajoutèrent qu'il paraissait probable que la réponse de l'empereur à la lettre du roi d'Angleterre lui serait remise ; et que dans ce cas, ils lui conseillaient de demander la permission de retourner, sans délai, auprès de son souverain. II était évident qu'on leur avait recommandé de donner ce conseil. Aussi, durant toute la conversation, furent-ils dans un embarras extraordinaire, et lorsqu'ils conseillèrent à l'ambassadeur de prendre congé, ils parurent accablés.

Le lendemain, le légat vint de bonne heure auprès de l'ambassadeur pour le prévenir que le colao désirait qu'il se rendît, aussitôt qu'il lui serait possible, dans la grande salle d'audience du palais de Pékin, où il l'attendait.

Quoiqu'indisposé, l'ambassadeur ne voulut point manquer ce rendezvous; et bientôt il partit avec une suite convenable, traversa une grande partie de la cité tartare, et arriva au palais. Entré dans l'enceinte du palais, il fut conduit à travers des cours spacieuses, et le long de canaux d'eau stagnante sur lesquels on a construit des ponts de granit, ornés de balustrades de marbre ; et quand il fut auprès de la salle d'audience, il trouva la réponse de l'empereur contenue dans un grand rouleau de papier couvert d'une étoffe de soie jaune, et placée dans une chaise de cérémonie, entourée de rideaux de la même couleur. La lettre fut ainsi portée dans la salle par l'escalier du milieu, tandis que le colao et les autres Chinois, qui s'étaient jusqu'alors tenus auprès de la lettre, montèrent, ainsi que l'ambassadeur et sa suite, par les deux escaliers de côté. La salle d'audience ne forme qu'un seul bâtiment, mais il y en a tout autour un assez grand nombre d'autres. Bâtie en bois, sur des fondements de granit, elle est spacieuse, magnifique, et ornée en dedans et en dehors de dorures et de peintures extrêmement 


\section{Voyage dans l'intérieur de la Chine et en Tartarie}

brillantes, et variées de la manière la plus heureuse. La réponse fut placée dans le milieu de la salle, d'où elle devait être ensuite envoyée à l'hôtel de l'ambassadeur.

On n'annonça point le contenu de la lettre, mais tout ce qu'il pouvait y avoir de gracieux ou de favorable n'était probablement dû ni au colao, ni à ses adhérents qui, en refusant obstinément les présents d'usage que leur offrit l'ambassadeur, montrèrent clairement, suivant les mœurs orientales, qu'ils lui étaient contraires. Malgré cela, dans la conversation qui suivit, relativement aux objets que désirait d'obtenir la Compagnie des Indes anglaise, Ho-Choong-Taung demanda un mémoire sur ces objets; et, sans s'engager à l'appuyer, il promit qu'on le prendrait incessamment en considération. II n'était pas au moins sans avantage que ces objets fussent connus, et pussent servir de réponse aux assertions si sou vent faites à la cour. Ces assertions portaient que les étrangers, quelques indignes qu'ils fussent, jouissaient, à Canton, de tout ce qu'exigeaient la justice et l'humanité; mais que l'ambassade anglaise avait des desseins secrets, dangereux pour le gouvernement. D'après cela, l'ambassadeur s'empressa de présenter une note contenant ses demandes.

Cependant, il semblait qu'une partie de la cérémonie du jour où lord Macartney fut reçu par le colao était de lui montrer la beauté du palais impérial de Pékin. Le colao se préparait à le conduire partout, avec la même politesse qu'il avait eue en l'accompagnant dans les jardins de Zhé-Hol ; mais l'indisposition de l'ambassadeur l'obligeant à se retirer, il laissa le ministre plénipotentiaire et quelques autres Anglais auprès du colao, qui les conduisit dans un grand nombre d'édifices séparés, construits sur un plan régulier, et semblables à ceux qu'ils avaient déjà vus dans les autres palais impériaux, mais d'un style plus relevé et d'une plus grande magnificence. Tous ces édifices étaient destinés à servir dans les grandes occasions et à déployer toute la pompe du trône. Les appartements particuliers de l'empereur, placés dans l'intérieur du palais, ne furent montrés que de loin.

Le même soir, la réponse de l'empereur à la lettre du roi d'Angleterre fut portée en cérémonie à I'hôtel de l'ambassadeur. En même temps, on envoya différentes caisses contenant les présents de l'empereur pour sa majesté britannique. Ces présents étaient sans doute choisis parmi les productions les 


\section{Voyage dans l'intérieur de la Chine et en Tartarie}

plus précieuses et les meilleures manufactures de l'empire. Il y avait aussi des présents pour l'ambassadeur et pour toutes les personnes de sa suite. En donnant quelques faibles marques de sa générosité aux moindres domestiques de l'ambassade, l'empereur eut l'attention de ne pas oublier les absents. Les officiers et les équipages qui avaient porté l'ambassadeur en Chine eurent part à sa générosité.

Jusqu'alors, il n'avait été prescrit rien de positif pour le départ de l'ambassade; et d'après la dernière déclaration faite à Yuen-Min-Yuen de la part de l'empereur, on pouvait en conclure que la cour n'emploierait point, à cet égard, des commandements absolus. Mais il eût été difficile, et sans doute inutile, de prétendre résister aux volontés du colao. Cependant l'ambassadeur n'avait encore eu que fort peu de temps pour traiter de l'objet de sa mission, et il désirait beaucoup de demeurer quelque temps de plus, dans l'espérance de rendre le gouvernement plus favorable à cet égard. Dans ces circonstances, le même homme qui l'avait déjà prévenu en secret qu'il recevrait la réponse de l'empereur et qui, connaissant parfaitement la cour de Pékin, savait aussi un peu que les vexations qu'éprouvaient le commerce et les négociants étrangers, à Canton, étaient toujours croissantes, écrivit ce qui suit :

«Les Chinois ne regardent une ambassade que comme une visite qui vient avec des présents, à l'occasion de quelque fête solennelle, et qui ne doit demeurer dans le pays que pendant la durée de ces fêtes. En conséquence, parmi les nombreuses ambassades qui leur ont été envoyées dans le siècle dernier et dans le siècle actuel, il n'en est aucune qui ait passé ce terme. Sous le présent règne, l'ambassadeur de Portugal fut congédié au bout de trente-neuf jours, quoique sa nation soit la plus favorisée de celles qui fréquentent la Chine.

« Les Chinois ne savent presque pas ce que c'est que de faire des traités avec les pays étrangers. Lorsqu'on veut négocier quelques affaires avec eux, il faut les y préparer par une ambassade de compliment, et ensuite on doit suivre les négociations peu à peu, car on peut obtenir beaucoup d'eux avec du temps et des ménagements ; mais rien avec précipitation. 


\section{Voyage dans l'intérieur de la Chine et en Tartarie}

« II est vrai que les exactions des officiers inférieurs et des autres personnages qui traitent avec les étrangers, à Canton, s'étaient accrues graduellement; et à moins que l'autorité ne les réprimât, elles pouvaient avec le temps devenir si excessives, qu'on eût été dans l'alternative, ou de renoncer entièrement au commerce de la Chine, ou d'envoyer une ambassade pour faire des remontrances à cet égard. Plutôt c'eût été, mieux cela eût valu. Si l'ambassade anglaise fût arrivée avant que la révolution de France eût fait craindre au ministère et aux tribunaux chinois la plus légère innovation, elle eût eu moins de difficultés à remplir entièrement le but qu'elle se proposait. Mais cette mission a fait une telle impression dans tout l'empire, que malgré des oppositions momentanées, elle aura des conséquences avantageuses pour les Anglais ; et désormais, l'oppression n'ira pas plus loin.

«Tels sont le caractère et l'usage du gouvernement chinois, que quoique d'abord contraire à toute proposition nouvelle, parce qu'il craint qu'on ne lui surprenne des concessions injustes, ou des règlements nuisibles, il souffre qu'on lui présente une seconde fois la même demande; et alors n'étant plus effarouché par une idée de nouveauté, il la prend sérieusement en considération. Ce moment peut être accéléré par les lettres qu'un souverain écrira à l'autre. II faut envoyer ces lettres par les vaisseaux qui viennent annuellement en Chine : cela ne paraîtra point déplacé, à présent que les relations ont commencé d'une manière convenable.

Cette lettre était terminée par le conseil de ne pas persister à vouloir demeurer plus longtemps à Pékin.

Un événement que l'ambassadeur venait d'apprendre, mais que l'auteur de cette lettre ignorait encore, servit d'appui aux avis qu'elle contenait. L'un des Chinois, amené de Naples, lequel s'était séparé du Lion près de Macao et qui, après avoir repris l'habillement de son pays, était venu joindre sa famille à Pékin, porta à lord Macartney une lettre d'un des commissaires de la Compagnie, à Canton. Dans cette lettre, datée du mois de juillet 1793, le commissaire faisait mention des événements politiques qui avaient rapport à l'Angleterre jusqu'au mois de janvier précédent. II disait qu'il était très 


\section{Voyage dans l'intérieur de la Chine et en Tartarie}

probable qu'une rupture avait eu lieu entre les Anglais et les républicains de France et de Brabant. II ne paraissait point invraisemblable que des étrangers, réunis sous les pavillons français et belge, pussent entreprendre d'enlever quelques-uns des navires anglais qui partiraient séparément de la Chine pour retourner en Angleterre, à moins que des vaisseaux de guerre n'arrivassent à temps pour les faire partir tous ensemble, et les convoyer en sûreté.

Dans ces circonstances, l'ambassadeur ne pouvait rendre à la Compagnie un service plus essentiel et plus à propos que de ramener avec lui, sous l'escorte du Lion, tous les navires anglais qui partiraient de Canton, la saison suivante. Comme les derniers navires en chargement sont rarement prêts avant le mois de mars, l'ambassadeur pouvait, en attendant, essayer d'exécuter lui-même sa mission au Japon; mais il fallait pour cela avoir le bonheur de trouver encore sir Erasme Gower à Chu-San, ce qu'il ne crut pas impossible, si le gouvernement voulait aussitôt dépêcher une lettre à sir Erasme. Le désir qu'avait le colao de voir partir l'ambassade devait l'engager à ne pas retarder l'envoi de la lettre.

L'ambassadeur se détermina donc à annoncer à Ho-Choong-Taung qu'il avait l'intention d'aller joindre immédiatement sir Erasme Gower à Chu-San, et à le prier de faire expédier, sans le moindre délai, la lettre qu'il écrivait à ce commandant ; parce qu'autrement, il courrait risque de le manquer.

Cette résolution fut très satisfaisante pour le colao, et tout prouva qu'elle avait été sagement prise. L'étiquette chinoise exigeait que l'ambassade cessât au moment où elle reçut la réponse de l'empereur et les présents de congé. Dès lors, il ne devait plus y avoir de communication avec sa majesté impériale. Il était en même temps aussi peu convenable à la dignité d'un ambassadeur de prolonger son séjour lorsqu'il sentait que sa mission cessait d'être agréable, qu'il l'eût été à un hôte ordinaire de rester au-delà du temps pour lequel il avait été invité.

Les relations avec l'empereur, dont le terme supposé était ce qui causait le plus de peine à l'ambassadeur, furent cependant continuées, ainsi qu'on le verra dans les pages suivantes; elles le furent même d'une manière plus 


\section{Voyage dans l'intérieur de la Chine et en Tartarie}

intime, et par une voie plus favorable que tandis qu'il restait environné d'une nombreuse cour.

Un si prompt déplacement parut très fâcheux à quelques Anglais attachés à l'ambassade, lesquels s'étaient arrangés pour passer l'hiver à Pékin. Jugeant de la température, par la latitude de cette ville, qui n'est que de quelques minutes au-dessous du quarantième degré de latitude nord, ils ne songeaient pas aux violents effets que la grande chaîne des hautes montagnes de la Tartarie, éternellement couvertes de neige, produit sur cette capitale, où pendant les mois d'hiver, le thermomètre est ordinairement la nuit à moins de vingt degrés, et le jour beaucoup au-dessous du point de la congélation.

Les habitants de Pékin sentent moins le froid, non seulement parce qu'ils en ont I'habitude, mais parce qu'ils se couvrent en raison de son intensité. Leurs vêtements consistent alors en fourrures, en étoffes de laine et en toiles de coton piquées. Ils ne sont point accoutumés à voir le feu ; il n'y a d'autres cheminées dans Pékin que celles qui sont dans les cuisines des grands hôtels. Le feu sur lequel les Anglais comptent principalement pour ne pas souffrir de la rigueur du froid ne pouvait pas bien remplir leur but, dans des maisons construites de manière à laisser entrer l'air extérieur de presque tous les côtés. Cependant, il y a des poêles dans les principales maisons, et ils sont chauffés en dehors des appartements, avec du charbon de terre qui se trouve en abondance dans les environs de Pékin. Ces poêles sont placés ordinairement sous des estrades, où l'on s'assoit le jour, et où l'on dort la nuit.

Le plus mauvais temps, à Pékin, doit être regardé comme assez doux par les Tartares, parce qu'ils sortent d'un climat plus rigoureux ; mais les autres étrangers s'y trouvent, dit-on, moins bien l'hiver que l'été, quoiqu'alors la chaleur y soit excessive. Pour l'une et l'autre saison, il semble nécessaire d'être acclimaté.

Plusieurs personnes de l'ambassade furent malades à Pékin ; et toutes ne se rétablirent pas. Le corps humain semble plus fait pour supporter l'air le plus chaud que le plus froid, et pour vivre sous l'équateur, plutôt que près du pôle. 
Voyage dans l'intérieur de la Chine et en Tartarie 


\section{Voyage dans l'intérieur de la Chine et en Tartarie}

\section{CHAPITRE IV}

\section{L'ambassade quitte Pékin. Voyage à Han-Choo-Foo, fait en partie sur le canal impérial}

Lorsque lord Macartney eut résolu de tâcher de joindre le Lion à Chu-San, il eut autant d'impatience de partir de Pékin qu'il avait d'abord eu d'envie d'y prolonger son séjour. Un autre motif contribua à lui faire hâter son départ. Le Pei-Ho et les autres petites rivières du nord de la Chine doivent une partie de leurs eaux aux neiges qui fondent en été, sur le sommet des montagnes de la Tartarie. Tandis que les neiges continuent à fondre, les rivières sont profondes et propres à la navigation; mais vers la fin de l'automne, où les rayons obliques du soleil ont moins d'effet sur la terre, et où la fonte des neiges cesse, les rivières deviennent tout à coup si basses et leur cours se ralentit tellement, qu'elles ne peuvent plus porter que des bateaux petits et peu commodes, même avant que le froid ait changé en glace leurs eaux faibles et paresseuses.

Les mandarins qui accompagnaient l'ambassade, sachant bien qu'en Chine, les voyages par terre étaient extrêmement incommodes et fatigants, surtout en hiver, hâtèrent tous les préparatifs, afin de pouvoir être à temps de s'embarquer sur le Pei-Ho, pendant qu'il était encore navigable.

Il fut décidé que l'ambassade se rendrait à Han-Choo-Foo, capitale de la province de Ché-Kiang, dont Chu-San forme une partie ; parce que si, quand elle serait à Han-Choo-Foo, on apprenait que sir Erasme Gower l'attendait encore à Chu-San, on pourrait aller le joindre en peu de jours, sinon, se rendre directement à Canton, afin de s'y embarquer pour l'Europe. Les mandarins Chow-ta-Zhin et Van-ta-Zhin étaient constamment restés auprès de l'ambassade, à laquelle ils étaient extrêmement utiles. 


\section{Voyage dans l'intérieur de la Chine et en Tartarie}

Lord Macartney demanda qu'ils continuassent à l'accompagner jusqu'au moment de son embarquement; et quoiqu'ils fussent particulièrement attachés à la province de Pé-Ché-Lée, on n’hésita pas à les lui accorder.

Les doutes et les soupçons que les ennemis des Anglais avaient inspirés au colao et qu'ils avaient même tenté de faire parvenir jusqu'à l'empereur, procurèrent à l'ambassadeur un avantage plus grand encore que celui d'avoir auprès de lui les deux premiers conducteurs de l'ambassade. Le gouvernement chinois crut, ce semble, qu'il fallait qu'un homme digne de la plus grande confiance fût chargé d'accompagner ces étrangers suspects, pendant le long voyage qu'ils allaient faire dans l'intérieur de l'empire, afin de veiller sur leur conduite, et de découvrir, s'il était possible, quels étaient leur caractère et leurs desseins. Le choix tomba sur le colao Sun-ta-Zhin, dont nous avons parlé dans un des chapitres précédents. Lorsqu'il avait été envoyé sur les frontières pour traiter avec les agents de la Russie, il s'était acquitté de cette mission d'une manière très satisfaisante pour la cour; aussi le jugea-t-on le plus propre à remplir une mission nouvelle à l'égard d'autres étrangers. Il avait des manières ouvertes et engageantes, et ne paraissait pas fait du moins pour adopter la haine et les préventions du légat. Le choix d'un homme de ce rang pour accompagner l'ambassade fut considéré par les Chinois comme un honneur qu'on lui rendait, et ce fut de cette manière qu'on l'annonça à l'ambassadeur.

Dans la matinée du 7 octobre, Ho-Choong-Taung se rendit avec d'autres colao dans un des pavillons qui sont en dedans des portes de Pékin, afin de se séparer de l'ambassadeur avec les cérémonies d'usage. On dit à ce dernier plusieurs choses flatteuses de la part de l'empereur; et les ministres qui représentaient ce prince observèrent toute l'étiquette de la civilité chinoise. Ils dirent qu'ils espéraient que l'ambassadeur était satisfait du traitement qu'avait reçu l'ambassade, pendant son séjour parmi eux ; et ils l'assurèrent que rien ne serait oublié pour rendre son voyage agréable jusqu'au port où il devait s'embarquer ; et, en effet, on lui tint parole.

On mit sur une table deux tuyaux de bambou, couverts d'un drap jaune, et contenant des rouleaux de papier jaune, semblable à du vélin. L'un des rouleaux contenait la liste des présents de l'empereur, et l'autre une réponse aux dernières demandes de lord Macartney. Les dispositions des hommes qui 


\section{Voyage dans l'intérieur de la Chine et en Tartarie}

avaient été consultés sur cette réponse, et la promptitude avec laquelle on l'avait faite, ne donnaient pas lieu de croire qu'elle fût favorable ; mais quand même on eût eu quelque espoir qu'elle pût l'être, il eût certainement été détruit par le silence qu'Ho-Choong-Taung garda à ce sujet; car s'il eût accédé aux demandes de l'ambassadeur, il eût voulu se faire mérite de le lui annoncer. En présence de l'ambassadeur, les deux rouleaux furent attachés avec des rubans jaunes sur les épaules d'un mandarin du cinquième ordre qui, pendant cette opération, se tint constamment à genoux. On le fit ensuite monter à cheval pour porter les deux rouleaux jusqu'à l'endroit où l'ambassade devait s'embarquer.

La distance des rangs, en Chine, est tellement marquée, que les deux mandarins qui, depuis longtemps, accompagnaient l'ambassade, et qui n'étaient point d'un ordre inférieur, s'agenouillèrent pour prendre congé du colao. Quoique l'interprète eût été annoncé comme secrétaire de l'ambassade pour la langue chinoise, il était toujours obligé de se tenir debout devant le même colao ; et une fois, l'orgueilleux général de l'armée du Thibet le força de l'interpréter à genoux.

Après s'être séparé des ministres de l'empereur, l'ambassadeur, avec sa suite ordinaire d'Anglais et de Chinois, sortit de Pékin par une des portes du côté de l'est, et fut salué avec les honneurs accoutumés. II marcha ainsi droit à Tong-Choo-Foo, afin de s'y embarquer sur le Pei-Ho.

L'air était alors bien moins chaud que la première fois que l'ambassade avait passé sur la magnifique chaussée par laquelle on sort de la capitale ; aussi, aucun Anglais ne se trouva trop pressé par la foule qui couvrait le chemin. Certes, il n'est pas nécessaire qu'il y ait des étrangers pour que ce chemin soit continuellement rempli de monde. Indépendamment du nombre immense de personnes employées à porter des provisions à Pékin, ou à en emporter des marchandises, la foule d'hommes qui accompagne toujours les mandarins qui y arrivent ou qui en partent, et les lentes processions, particulièrement celles des funérailles, occupent souvent toute la largeur de la route. 


\section{Voyage dans l'intérieur de la Chine et en Tartarie}

On ne laisse enterrer personne dans l'enceinte de la ville; et la cérémonie de porter les morts en terre cause autant d'embarras aux portes de cette capitale que le charroi des provisions pour les vivants. Quels que soient l'état et la fortune d'un Chinois qui n'est point dans les emplois publics, il ne vit point habituellement avec éclat, et réserve ses principales dépenses pour les fêtes solennelles, ou les événements particuliers qui arrivent dans sa famille. Suivant les mœurs du pays, la mort d'un parent est certainement un des plus grands événements. Les sentiments d'affection et de respect qu'on avait pour ce parent tandis qu'il était vivant ne s'éteignent point tout à coup dans l'âme de ceux qui le perdent. C'est une satisfaction, une consolation même, que de rendre des devoirs superflus aux mânes de ceux qu'on regrette. Les vœux de la nature sont, à cet égard, confirmés et fortifiés par la morale et les lois de l'empire. Toute institution tendant à maintenir l'habitude du devoir des enfants envers ceux à qui ils doivent le jour est sanctifiée par un précepte qu'on ne peut jamais négliger sans s'exposer à l'infamie.

Le premier convoi funèbre que les Anglais rencontrèrent en sortant de Pékin était précédé par plusieurs instruments qui exécutaient une musique solennelle. Ensuite venaient des personnes portant diverses enseignes. II y avait des étendards en soie, et des planches peintes, avec des caractères et des devises qui indiquaient le rang et les titres de celui qui n'était plus. Immédiatement en avant du cercueil marchaient les parents mâles, qui étaient soutenus par des amis, occupés à empêcher qu'ils ne se livrassent aux excès de la douleur, à quoi leur air semblait annoncer qu'ils étaient disposés. On portait au-dessus des pleureurs des parasols avec de longs rideaux. Lorsqu'un convoi se trouvait vis-à-vis d'un temple ou d'un cimetière, plusieurs personnes étaient occupées aussitôt à brûler des morceaux de papier rond, couverts de légères feuilles d'étain. Suivant l'opinion populaire, ces feuilles, comme le denier qu'on offrait à Caron pour passer le Styx, doivent, dans les premiers instants d'une nouvelle existence, être employées à acheter les choses nécessaires à la vie.

Quoique, d'après leur doctrine philosophique, les Chinois lettrés excluent toute idée contraire à la raison, et n'admettent pas même l'existence des êtres qui n'ont point de rapport avec nos sens, ils cèdent souvent à l'usage ; et se conforment, dans la pratique, aux notions des faibles et du vulgaire. 


\section{Voyage dans l'intérieur de la Chine et en Tartarie}

Parmi beaucoup d'autres superstitions, le peuple a celle d'être très scrupuleux sur le temps et le lieu où il doit enterrer les morts. Le délai occasionné par ces difficultés a souvent retenu longtemps les cercueils des riches loin de leur dernier asile. On en voit ainsi beaucoup dans des maisons et dans des jardins où, en attendant, on élève un appentis pour les mettre à l'abri du mauvais temps. Mais la nécessité force les pauvres à vaincre leurs scrupules, et à porter promptement, et sans de grandes cérémonies, les restes de leurs parents dans leur dernière demeure.

Quelque différent que soit le sentiment qui agite l'âme des Chinois à l'occasion du mariage, ils le célèbrent, à la vérité, d'une manière brillante et dispendieuse, mais avec beaucoup moins de pompe qu'ils n'en mettent dans leurs funérailles. La magnificence qui accompagne la célébration du mariage doit vraisemblablement son origine aux parents des époux. Ce sont eux qui ont pu naturellement désirer de donner de l'éclat à une union de leur choix. Ils ont voulu y mettre une solennité qui contribuât à en rendre les liens plus sacrés et plus durables. Mais l'impulsion qui réunit les deux sexes n'a jamais eu besoin du secours des fêtes publiques. Le mystère sert beaucoup mieux l'amour et est préféré pour ses solennités.

Les Chinois ne regardent le célibat d'aucun sexe comme une vertu. La constance est la seule sorte de chasteté qu'ils recommandent. Cependant les règles de la décence extérieure sont maintenues chez eux par l'exemple et les leçons de toutes les personnes qui ont de l'éducation et de la politesse. Quelque ressemblance qu'on trouve entre le paganisme de la Chine et celui de l'Indostan, le premier semble n'avoir emprunté de l'autre aucune de ces figures obscènes, sculptées quelquefois jusque sur le dehors des temples indiens, et représentées comme l'emblème des premiers desseins de la nature.

Un des Anglais attachés à l'ambassade eut, en partant de Pékin, le temps d'examiner un petit temple ouvert, situé sur l'un des côtés de la chaussée. II n'avait pu prendre ce soin, dans l'empressement où l'on était en approchant de cette ville. Une figure sculptée, qu'il trouva dans le temple, lui parut représenter le lingam des Indous, ou leur dieu des jardins. Ce n'était, cependant, qu'une simple colonne, élevée perpendiculairement sur le dos d'un 


\section{Voyage dans l'intérieur de la Chine et en Tartarie}

lézard grossièrement fait. La colonne n'était, sans doute, là que pour porter une inscription chinoise qui en couvrait presque tout un côté.

Si, d'après les expressions libres qu'on trouve fréquemment dans quelques-uns des écrivains les plus élégants de l'Antiquité, et d'après les tableaux indécents qu'on a découverts parmi d'anciennes ruines comme, par exemple, à Pompeïa, ainsi que d'après les restes du culte obscène, pratiqué dans une partie obscure même du pays, et les usages effrontés de quelques tribus sauvages, si, dis-je, on doit inférer que la décence n'est un sentiment ni naturel, ni nécessaire, il faut avouer que c'est au moins un heureux artifice de la société, parce que quoiqu'elle n'exclue pas toujours le vice, elle cache sa turpitude, et ajoute au charme et à la délicatesse des jouissances naturelles. Dans la pratique de cette vertu factice, les Chinois ont précédé et surpassé la plupart des nations.

A son arrivée à Tong-Choo-Foo, l'ambassade fut très bien accueillie dans le même temple où elle avait logé quelques jours, la première fois qu'elle avait passé dans cette ville. Les principaux mandarins de Tong-Choo-Foo rendirent visite à l'ambassadeur, et le soir, la ville fut illuminée avec des très jolies lanternes. Les Anglais trouvèrent les troupes sous les armes devant le temple. Elles avaient différents habits uniformes. II y en avait de très singuliers et très pittoresques, mais qui semblaient plutôt faits pour paraître sur le théâtre que pour aller au combat. Des gilets et des jupons piqués, des bottes de satin avec des semelles de papier très épais, ont un mélange de grossièreté et de mollesse peu fait pour une vie guerrière. Mais le temple pouvait se passer de leur secours. II était bien en sûreté sous la protection plus puissante du Men-Shin, esprit qui le gardait, et dont la figure était peinte sur la porte d'entrée. Des dessins de la même espèce, et auxquels on attribue le même pouvoir, sont collés sur les portes d'entrée et les portes intérieures de la plupart des maisons chinoises.

Le peuple chinois, sachant à combien de maux il est exposé, cherche de tous côtés ce qu'il croit pouvoir l'en préserver. Les âmes, une fois ouvertes à la crédulité, acceptent avidement les secours surnaturels qu'une religion nouvelle leur offre contre la violence du pouvoir, ou les calamités de la 


\section{Voyage dans l'intérieur de la Chine et en Tartarie}

nature. La propre religion des Chinois n'a rien d'exclusif ; et ils auraient, en grand nombre, embrassé le christianisme, s'ils avaient pu l'accorder avec leurs autres préceptes. Les jésuites, qui voulaient permettre à leurs néophytes de pratiquer leurs anciennes cérémonies dans les demeures de leurs ancêtres, auraient bien mieux réussi que les antagonistes qui les condamnaient; car le principal reproche qu'un païen de la Chine fait à présent à ces antagonistes, c'est de négliger leurs aïeux. Les sacrifices de troupeaux, de volaille, d'huile, de sel, de farine, et d'encens, dont fait mention le Lévitique, sont connus et pratiqués par les Chinois. Ils ont aussi leurs lares et leurs pénates, comme les Romains ; et en faisant des offrandes à chaque nouvelle lune, ils rappellent l'expression du poète latin :

Coelo supinas si tuleris manus nascente luna

Puisque les Chinois ont un si grand penchant pour toutes les religions, il n'est pas surprenant que les Anglais aient trouvé, dans le temple de Fo, un prêtre étranger à la secte de cette divinité. II était disciple de Lao-Koun, dont la doctrine diffère peu de celle d'Epicure. Ce Lao-Koun disait que vivre heureux était le premier but de l'homme, et qu'une indifférence absolue pour tous les événements était le plus sûr moyen d'atteindre ce but ; qu'il ne fallait pas vainement réfléchir sur le passé, ou s'inquiéter de l'avenir, parce que la plus sage occupation était de jouir des moments passagers de la vie.

A ces maximes qui, quand elles seraient vraies, ne pourraient guère être praticables, les prêtres ont joint beaucoup de rites et de prétentions, qui ont un but opposé; mais ils ont été obligés de le faire, pour acquérir de l'ascendant sur le peuple. Ils prétendent pouvoir prédire l'avenir, et fournir des moyens de se garantir du mal. Ils ont leurs sectateurs et leurs temples, et portent un habillement qui les distingue des autres. Mais, d'ailleurs, ils sont réunis avec toutes les autres sectes, contre la religion simple et naturelle, ou plutôt la raison-morale de Confucius.

Indépendamment des divinités que nous avons dit, dans un autre chapitre, être dans le temple de Tong-Choo-Foo, on y remarque les statues de la paix et de la guerre, de la tempérance et de la volupté, de la joie et de la mélancolie, avec des figures de femme, représentant la fécondité et le plaisir. Devant ces statues, on voit tantôt un seul, tantôt plusieurs vases de 


\section{Voyage dans l'intérieur de la Chine et en Tartarie}

bronze, dans lesquels les prêtres et les dévots brûlent des mèches parfumées et du papier couvert de feuilles d'étain.

Tandis que les principales personnes de l'ambassade achevaient de visiter le temple et la ville de Tong-Choo-Foo, les Anglais et les Chinois de leur suite arrangeaient tout ce qu'il fallait pour l'embarquement. Les yachts étaient déjà prêts sur le bord de la rivière. L'ambassadeur eut la satisfaction de voir que, pour qu'il pût descendre commodément la rivière, on avait tout préparé avec le même soin, la même attention, que lorsqu'il l'avait remontée. Les présents donnés par l'empereur n'étaient pas de nature à causer tant d'embarras que ceux qu'on lui avait portés ; et il fallut peu de temps pour embarquer tout le bagage dans les bateaux. Un de ces bateaux fut chargé des voitures de l'ambassadeur, qu'on avait démontées exprès. II y avait, parmi ces voitures, un très beau carrosse de cérémonie, que l'ambassadeur avait voulu offrir, en son nom, à l'empereur, et qu'il avait, en conséquence, inséré dans la liste des présents remis aux mandarins. Trouvant ensuite qu'il convenait mieux d'offrir quelque chose de sa propre main, il présenta au monarque deux montres enrichies de diamants. Cependant le carrosse était déjà à Yuen-Min-Yuen. L'empereur l'y ayant vu à son retour de Zhé-Hol, le renvoya avec un message poli, attendu qu'il n'acceptait point deux fois des présents d'un particulier.

L'ambassade ne s'arrêta pas plus de vingt-quatre heures à Tong-ChooFoo. Les eaux du Pei-Ho étaient déjà basses, et continuaient à diminuer. Si on avait attendu quelques jours de plus, elles n'auraient pas pu porter les yachts ; et il eût été également incommode de voyager par terre ou dans de petits bateaux.

Les yachts, dont on se servit dans cette occasion, étaient de la construction la plus légère possible, mais commodes pour les passagers. II n'y avait point, au-dessus des chambres, de logement pour le domestique, et on ne pouvait mettre que très peu de bagage à fond de cale. Ils avaient soixante-dix pieds de long, et quinze de large, avec un fond plat ; ils tiraient à peine dix pouces d'eau. Malgré cela, la rivière était si basse que le second jour du voyage, il fallut, en quelques endroits, les faire passer de force. Indépendamment de la cause du décroissement des eaux, citée au commencement de ce chapitre, il y en a une autre qui n'est pas si constante, mais qui avait lieu en cette occasion. La sécheresse avait été si considérable que, 


\section{Voyage dans l'intérieur de la Chine et en Tartarie}

depuis le mois de juillet, il était à peine tombé une ou deux fois de la pluie pour remplacer ce que l'évaporation faisait perdre à la rivière. Depuis cette époque, il avait été rare de voir un nuage. Le temps de la moisson est si peu pluvieux qu'on bat communément le grain sur une aire, dans le milieu du champ même où on l'a recueilli.

Le thermomètre de Fahrenheit qui, au mois d'août, n'était presque jamais sur le Pei-Ho au-dessous de vingt-quatre degrés, ne s'élevait pas à cinquante lorsque les Anglais y repassèrent ${ }^{1}$. La campagne qui avait été, en très grande partie, couverte de kowleang, ou grand millet, offrait une moisson de millet d'une autre espèce. Sa tige courte bornait moins la vue; et comme les voyageurs s'éloignaient des montagnes, situées à l'occident de Pékin, ils avaient en perspective une plaine immense, fertile, bien cultivée et remplie de villages.

Les yachts avaient encore fait fort peu de chemin, lorsque Van-ta-Zhin se rendit à bord de celui de l'ambassadeur pour lui apprendre que le colao Sunta-Zhin venait de recevoir une lettre de l'empereur, et qu'il désirait de lui en faire part. Lord Macartney s'aperçut en même temps que le yacht de Sun-taZhin s'approchait très vite du sien; et voulant lui épargner la peine d'en sortir, il se rendit immédiatement à son bord. II commença par rappeler à ce nouveau compagnon de voyage les civilités qu'il en avait reçues dans le PooTa-La et dans les jardins de Zhé-Hol; et il lui en renouvela ses remerciements. Après quoi, il lui dit qu'il s'était regardé comme très heureux, en apprenant qu'il avait été nommé pour lui faire I'honneur de l'accompagner dans le voyage de Chu-San.

Le colao reçut l'ambassadeur avec beaucoup de marques de considération, et témoigna le plus grand contentement d'avoir été choisi en cette occasion. II lut ensuite une partie de la lettre de l'empereur, laquelle disait :

«Qu'il fallait que Sun-ta-Zhin se chargeât particulièrement du soin de l'ambassade ; qu'on traitât avec beaucoup d'attention et toutes les distinctions convenables l'ambassadeur et sa suite, dans leur voyage à Chu-San, où Sun-ta-Zhin les mettrait en sûreté à bord de 


\section{Voyage dans l'intérieur de la Chine et en Tartarie}

leurs vaisseaux ; mais que si ces vaisseaux étaient déjà partis, il accompagnerait l'ambassade de la même manière, et pour le même objet, jusqu'à Canton. »

II était naturel de supposer que Sun-ta-Zhin ne communiquerait pas ses instructions particulières qui, peut-être, étaient renfermées dans la même dépêche. Mais il en dit assez pour faire entendre qu'on n'avait pas fait partir la lettre par laquelle l'ambassadeur mandait à sir Erasme Gower de l'attendre à Chu-San. La lettre écrite en anglais avait été remise ouverte au ministre. Celui-ci ne put point trouver à Pékin, parmi ceux qui n'appartenaient pas à l'ambassade, quelqu'un en état de lui traduire cette lettre. Quoique tout dût lui prouver que la lettre contenait ce que l'ambassadeur lui avait dit, et qu'il fût difficile d'imaginer quelle nouvelle indiscrète ou quelles injonctions dangereuses l'ambassadeur aurait pu donner alors à sir Erasme Gower, le colao Ho-Choong-Taung eut de tels soupçons à cet égard qu'il retint la lettre.

Cependant, Sun-ta-Zhin fut bientôt convaincu de la franchise avec laquelle l'ambassadeur lui expliqua la lettre, ainsi que de la nécessité de cette dépêche, et il écrivit à l'empereur pour qu'elle lui fût envoyée sans délai. Bientôt après, l'ambassadeur prit congé de lui, et se retira dans son yacht où, au bout d'une demi-heure, Sun-ta-Zhin lui rendit visite. La conversation devint alors plus libre. Le colao, apprenant que lord Macartney avait demeuré trois ans en Russie, il parut qu'il ne pouvait pas deviner quelles affaires publiques avaient exigé de si longues négociations. Sa surprise mit l'ambassadeur dans le cas de lui donner une explication des coutumes des nations européennes, à l'égard des relations pour lesquelles les divers souverains ont habituellement des ambassadeurs à la cour les uns des autres; ce qui entretient une bienveillance réciproque, et prévient les jalousies que pourraient occasionner des malentendus accidentels.

Les questions de Sun-ta-Zhin ne paraissaient pas moins être l'effet de sa curiosité personnelle que du désir de communiquer à l'empereur tout ce qu'il pourrait recueillir dans la conversation de lord Macartney, relativement aux Anglais et aux autres nations européennes qui trafiquent en Chine. On

\footnotetext{
${ }^{1}$ Au commencement d'octobre.
} 


\section{Voyage dans l'intérieur de la Chine et en Tartarie}

pouvait juger, d'après la correspondance journalière de l'empereur, combien l'ambassade captivait son attention ; et l'ambassadeur s'apercevait aisément qu'en s'entretenant familièrement avec ce prince, par l'organe du loyal Sunta-Zhin, il réussissait mieux à détruire les préventions du gouvernement chinois contre les Anglais, et conséquemment, il avançait davantage vers le principal but de sa mission, que ses conférences gênées ne l'avaient permis durant son séjour à la cour. Les visites réciproques de l'ambassadeur et de Sun-ta-Zhin furent fréquemment répétées. Au premier signal, leurs yachts s'abordaient, et le Chinois et l'Anglais passaient aisément de l'un à l'autre. Dans ces occasions, Sun-ta-Zhin lisait souvent des passages des lettres que lui écrivait l'empereur, et qui contenaient quelques expressions gracieuses pour l'ambassadeur et sa suite, à l'occasion du compte que Sun-ta-Zhin lui avait rendu de leur manière de se conduire et de leurs dispositions. Il est probable que ce Chinois avait découvert que le portrait que le légat avait fait d'eux était noirci à dessein ; et une telle méchanceté suffisait pour engager une âme comme la sienne à parler des Anglais d'une manière aussi favorable que l'exigeaient ses propres observations et son opinion.

Non seulement Sun-ta-Zhin avait l'âme remplie d'une générosité naturelle, mais son goût pour la littérature contribuait à corriger les préjugés étroits et nationaux qu'avaient pu lui inspirer et son éducation, et les maximes, et les sentiments des personnes avec lesquelles il vivait. II avait toutes les connaissances qu'on peut puiser dans les livres chinois et tartaresmandchous. Parmi tous les mandarins qu'avait eu occasion de voir l'ambassadeur, il était le seul qui voyageât avec une bibliothèque. Poli dans ses manières, il croyait, cependant, qu'il lui était nécessaire d'user de tous les privilèges attachés à son rang. II avait le titre de colao, et il était, de plus, décoré du manteau jaune, qui ressemble à un spencer ${ }^{1}$, et qu'il portait pardessus sa robe. Ce manteau est maintenant la plus haute distinction connue en Chine; et il imprime à celui qui le porte un caractère en quelque sorte sacré. Le clergé de Zhé-Hol, pauvre, ignorant, et très irrégulier dans ses

\footnotetext{
${ }^{1}$ On sait que le spencer n'est qu'un gilet qu'on porte par-dessus l'habit. II me semble que les Anglais auraient pu emprunter des Chinois une manière de se vêtir plus commode et moins bizarre. (Note du Traducteur.)
} 


\section{Voyage dans l'intérieur de la Chine et en Tartarie}

mœurs, ne peut conséquemment être respecté, et ne retire aucun avantage d'être entièrement vêtu de jaune; mais une partie d'habillement de cette couleur procure à tout autre homme le respect et la considération de tous les rangs.

Quoiqu'honorés du titre de grands, Chow-ta-Zhin et Van-ta-Zhin évitaient de se trouver chez l'ambassadeur lorsque Sun-ta-Zhin lui rendait visite, parce qu'ils étaient obligés de se tenir debout en sa présence. L'interprète ayant une fois voulu hasarder de s'asseoir devant lui, il le fit aussitôt rentrer dans le devoir.

Les mandarins inférieurs et les gardes qui accompagnaient l'ambassade n'osaient point, comme auparavant, tenter d'empêcher les principaux Anglais de faire des excursions à terre. II est vrai que ceux-ci étaient très attentifs à ne commettre aucune indiscrétion, et à ne point retarder la marche des yachts. D'ailleurs, de Tong-Choo-Foo à Tien-Sing, le pays n'était pas nouveau pour eux, encore que la différence des saisons et des cultures en eût un peu changé l'aspect. Les champs étaient brûlés par une longue sécheresse. Mais comme, en quelques endroits, le lit de la rivière était élevé au-dessus de la campagne voisine, parce que l'eau déposait continuellement de la terre dans le fond, et parce qu'on construisait sans cesse de nouvelles levées pour empêcher les débordements, cette campagne s'arrosait avec peu de difficultés, et on avait pour cela pratiqué des écluses sur les bords de la rivière, comme on l'aurait fait dans les murs d'un canal élevé.

Dans les endroits où la rivière était de niveau avec la campagne, les cultivateurs employaient quelquefois une plus fatigante manière d'arrêter l'eau. Deux hommes se plaçaient vis-à-vis l'un de l'autre sur deux hauteurs un peu avancées dans la rivière et, tenant chacun deux cordes attachées à un panier, ils balançaient ensemble longtemps et avec force ce panier; et lorsqu'ils avaient assez d'élancement, ils jetaient l'eau dans un réservoir creusé à côté de la levée. Ensuite, ils la conduisaient par des rigoles dans les endroits qu'ils voulaient arroser. Quelquefois, on se sert d'une longue perche placée en travers de la fourche d'un poteau, qui tourne sur un pivot. II faut qu'un bout sorte beaucoup plus que l'autre pour quelle serve de levier; et alors, on attache au bout le plus court un seau qu'on fait plonger dans la rivière, et qu'on lève ensuite pour le vider dans le réservoir; malgré la 


\section{Voyage dans l'intérieur de la Chine et en Tartarie}

pesanteur de l'eau, il ne faut pour cette opération qu'une légère force appliquée à l'autre extrémité de la perche.

Les habitants des rives de Pei-Ho ont l'air très pauvres, à en juger par leurs maisons et par leurs vêtements. Mais leur bonne humeur prouve qu'ils ne manquent pas des choses les plus nécessaires à la vie, et qu'ils ne regardent pas leur état comme l'effet de quelque injustice exercée envers eux, sentiment qui ne laisse pas ordinairement l'homme tranquille. Leur pauvreté n'est pas non plus due à la stérilité des champs que cultive leur industrie; mais leur population est trop nombreuse pour que chaque famille ait une assez grande portion de terre pour pouvoir se procurer toutes les commodités de la vie. On en réserve fort peu pour élever des animaux. Les Chinois sont sans doute convaincus de ce qu'affirme Adam Smith :

« C'est qu'un champ médiocrement fertile, qui rapporte du blé, produit de quoi nourrir plus d'hommes que le meilleur pâturage de la même étendue où l'on élève des animaux; car, si sa culture exige plus de travail, ce qui reste après avoir ôté la semence et payé les frais d'exploitation est aussi beaucoup plus considérable.

Les Anglais virent quelques coins de terre où l'on faisait paître des moutons. Mais on en fait venir de la Tartarie un bien plus grand nombre, ainsi que beaucoup de gros bétail. Les animaux de cette dernière espèce, élevés en Chine, sont nourris avec de la paille de blé, coupée par petits morceaux. Le peuple ne mange que très peu de viande qu'il mêle avec les végétaux pour leur donner un peu de goût. Le lait, le beurre, le fromage, principale ressource de la vie pastorale, sont peu connus des Chinois. Quand l'ambassadeur et les principales personnes de sa suite désirèrent d'avoir du lait, il ne fut pas très aisé de trouver un homme qui s'entendît à soigner les vaches. Cependant, il s'en présenta un, et il fut mis, avec deux vaches et le fourrage nécessaire, dans un bateau qui survit les yachts.

Dans cette saison, la plus grande partie de la récolte de kow-leang ${ }^{1}$ était déjà serrée. La première opération qui suit celle de la moisson est de fouiller à la houe les racines de kow-leang; et comme dans tout ce qu'ils font, les 


\section{Voyage dans l'intérieur de la Chine et en Tartarie}

Chinois sont extrêmement méthodiques, et qu'ils connaissent, par expérience, les avantages qui résultent de la division du travail, cette opération est régulièrement exécutée de la manière suivante : un homme s'avance en ligne directe et enlève de chaque côté, à coups de houe, un rang de racines. Un second marche ensuite, et dégage ces racines de la terre qui y est adhérente; et enfin, un troisième s'occupe à rendre la terre meuble dans l'espace qui est entre les rangs. Par ce moyen, un seul buffle suffit pour y traîner la charrue. Les racines de kow-leang sont quelquefois brûlées sur le sol, et l'on en étend ensuite les cendres. Mais quand le chauffage est rare, on emporte ces racines pour les brûler dans les maisons.

La terre étant dans un état de culture continuel, les charrues de la construction la plus simple suffisent pour tout ce qu'on a besoin d'en faire. Quand le sol est très léger, des hommes et des femmes s'attachent euxmêmes à la charrue, et labourent. Cette charrue n'a pas besoin de coutre, attendu qu'il n'y a point d'herbe à séparer. Le soc qui ouvre la terre est terminé en courbe : ce qui fait le même effet que l'ais qui, dans les charrues d'Europe, sert à retourner la terre. Cette partie du soc chinois est quelquefois de fer, et plus souvent de cette espèce de bois qu'à cause de sa dureté, on nomme bois de fer.

Après trois jours de navigation, les yachts arrivèrent dans l'endroit jusqu'où remonte la marée. Le reflux, accélérant le courant de la rivière, les porta le lendemain à Tien-Sing. Là, le légat qui, jusqu'alors, avait voyagé avec l'ambassade, mais qui, intimidé par la présence de Sun-ta-Zhin, ne s'était aucunement mêlé de la diriger, s'en sépara enfin, ou plutôt disparut sans prendre congé et sans mettre les Anglais dans le cas de le remercier des services qu'il savait bien lui-même ne pas leur avoir rendus.

Ce fut aussi là que l'ambassade prit une nouvelle route. Au lieu de suivre le même bras du Pei-Ho jusqu'à la mer, elle tourna à droite, vers le sud, et passa devant l'embouchure de la rivière When-Ho qui, comme le Pei-Ho, vient des montagnes de la Tartarie, et tombe dans le grand bassin de Tien-Sing.

\footnotetext{
${ }^{1}$ Grand millet.
} 


\section{Voyage dans l'intérieur de la Chine et en Tartarie}

Les yachts furent trois heures à traverser la multitude de jonques qui étaient à l'ancre dans ce bassin, et ils entrèrent dans la rivière Yun-Leang-Ho, dont il a déjà été question. Sur les bords de cette rivière, les faubourgs de la Cité Céleste ${ }^{1}$ occupent un grand espace. On y avait construit un pavillon pour recevoir l'ambassadeur, et placé, dans l'endroit où il devait débarquer, une porte triomphale. Une collation de fruits et de confitures l'attendait dans le pavillon. La foule des spectateurs n'était pas moins grande cette fois-ci que la première fois qu'il passa à Tien-Sing.

Derrière la ville de Tien-Sing s'étend une plaine vaste et sablonneuse, couverte de petites tombes dont le nombre est incalculable. C'est le cimetière public; et les limites n'en sont si reculées que parce que le respect que les Chinois ont pour les morts les empêche d'ouvrir une fosse dans l'endroit où la moindre trace indique qu'il y en a eu une première.

Le Yun-Leang-Ho se nomme aussi Eu-Ho, c'est-à-dire «la précieuse rivière ». Son cours, auprès de Tien-Sing, est entre deux chaussées extrêmement élevées, et inclinées, du côté de l'eau, comme un glacis. Sur le haut de chacune de ces levées, qui ont plusieurs milles de long, est un très joli chemin, garni de gravier, et ombragé par des rangs de grands saules, de hauts peupliers, de trembles et d'arbres fruitiers, principalement des pruniers. Le long des levées, la campagne est cultivée comme un jardin. II y a surtout beaucoup de légumes.

Le courant était si fort que pour le vaincre, il fallut employer dix-huit ou vingt hommes à tirer chaque yacht. Malgré cela, on ne faisait pas plus d'un mille par heure. Mais l'aspect charmant de la campagne dédommageait un peu de la lenteur de cette navigation. Dans d'autres endroits, la rivière s'élargissait d'environ quatre-vingts pieds, et le courant opposait alors moins de résistance.

D'après une tradition, conservée par les marins qui naviguent sur le YunLeang-Ho et les habitants qui sont sur ses bords, cette rivière était jadis deux fois plus profonde qu'elle n'est à présent. Une partie du fleuve Jaune suivait alors son cours, et tombait dans le bassin de Tien-Sing. Mais maintenant, tout

\footnotetext{
${ }^{1}$ Signification du nom de Tien-Sing.
} 


\section{Voyage dans l'intérieur de la Chine et en Tartarie}

ce grand fleuve va se jeter dans la mer Jaune à plus de cent milles de distance de la Cité Céleste.

Les postes militaires de Yun-Leang-Ho ne sont séparés que de quelques milles. Les soldats qui y sont stationnés doivent protéger le commerce intérieur des provinces et les voyageurs contre les voleurs et les pirates. Un soldat chinois porte l'épée du côté droit et la pointe tournée en avant ; et il la tire du fourreau en mettant sa main droite en arrière.

Le sol que les Anglais virent, en partant de Tien-Sing, est sablonneux. Mais on ne peut le creuser à un pied de profondeur sans trouver l'eau en abondance. L'on y voit, à peu de distance les uns des autres, des canaux de différente grandeur. Quelques-uns portent leurs eaux à la rivière, et d'autres y prennent naissance.

Tandis que les Anglais remontaient le cours du Yun-Leang-Ho, il y eut une différence remarquable entre la hauteur du thermomètre pendant la nuit et celle où il était dans le milieu du jour. Quelquefois, au lever du soleil, la liqueur ne s'élevait guère au-dessus de quarante degrés de l'échelle de Fahrenheit et, à midi, elle approchait de quatre-vingts. Ces vicissitudes commencèrent à affecter la santé de quelques Anglais; mais la maladie d'un petit nombre de gardes était causée par trop de plénitude, et par le défaut d'exercice.

En passant près des quelques villages, les voyageurs virent des femmes assises devant leur porte, occupées à filer du coton au rouet. Quelques-unes travaillaient à la moisson ; et on ne pouvait guère les distinguer des hommes par la délicatesse de leurs traits ou de leur teint. Suivant M. Hickey, qui, dans le cours de sa profession, observa particulièrement les formes du corps,

« la personne de ces femmes est entièrement le contraire de ce qu'on considère en général comme beauté ou élégance dans leur sexe. Leur tête est grosse et ronde, et leur petite stature ne paraît pas avoir plus de six fois la longueur de la tête. Leur taille est entièrement cachée par leurs robes amples. Elles portent de grandes culottes qui vont depuis la hanche jusqu'au bas de la jambe ; et de la cheville au bout du pied, tout est couvert de liens. 


\section{Voyage dans l'intérieur de la Chine et en Tartarie}

Les femmes dont les formes sont plus élégantes ne sont probablement pas exposées aux rudes travaux de la campagne. Une coutume qui subsiste, dit-on, en Chine, doit rendre la beauté rare dans les classes inférieures. On assure que les jeunes filles, distinguées par leur figure ou par les grâces du corps, sont, dès l'âge de quatorze ans, achetées à leurs parents, pour l'usage des gens riches ou puissants. Les principales personnes de l'ambassade virent, par hasard, quelques-unes de ces femmes ; et d'après la blancheur et la délicatesse de leur teint, la beauté et la régularité de leurs traits, ils jugèrent qu'elles avaient droit d'être admirées. Celles qui ne paraissent pas ordinairement dans la foule, mais que la curiosité faisait sortir de leurs maisons pour voir passer les étrangers, étaient quelquefois obligées de se retirer à cause des huées des hommes, qui semblaient leur reprocher de s'exposer à la vue des Barbares.

Après avoir parlé des petits yeux qu'on attribue, en général, aux Chinois des deux sexes, M. Hickey ajoute :

«La plupart des hommes ont le nez court et retroussé, les os des joues gros, la bouche grande et le teint brun et sale. Tous, sans exception, ont les cheveux noirs, et si épais, si forts, qu'auprès d'eux, ils comparent ceux des Européens au poil des plus petits animaux. Les Chinois portent souvent des moustaches, et laissent croître sur leur menton un brin de barbe qui descend très droite.

Les Anglais remarquèrent que la saison de la moisson occasionnait une gaieté générale parmi les Chinois des deux sexes. Ils paraissaient bien sentir qu'ils travaillaient pour eux-mêmes. Beaucoup de paysans sont propriétaires des terres qu'ils cultivent. On ne voit point parmi eux de ces fermiers spéculateurs qui cherchent, par des monopoles et des combinaisons, à tirer un grand parti de leur récolte, et à triompher, par leurs richesses, du pauvre cultivateur, jusqu'à ce qu'ils l'aient enfin réduit à l'état de simple manœuvre. Les avantages qui résultent du voisinage de la rivière consolent un peu les paysans de l'oppression des mandarins, qui les obligent fréquemment de traîner, pour un mince salaire, les bateaux qu'emploie le gouvernement.

La rivière serpentait dans une plaine riche et bien cultivée, qui n'avait de bornes que l'horizon. Là, le kow-leang et les autres espèces de millet 


\section{Voyage dans l'intérieur de la Chine et en Tartarie}

semblaient, comme sur les bords du Pei-Ho, être la principale production. Les maisons de presque tous les villages étaient entourées d'une épaisse clôture de tiges de kow-leang, destinées, sans doute, à être employées contre le froid, qui s'approchait rapidement, quoiqu'on ne fût encore qu'à la mioctobre.

Les villages sont quelquefois aussi grands que des villes européennes; mais quand ils ne sont pas entourés de murailles, les Chinois n'en font pas grand cas, et ils ne les comprennent point dans l'un des trois ordres de leurs cités.

Quoique les yachts remontassent lentement le cours de la rivière, les voyageurs n'étaient presque jamais une demi-heure sans découvrir quelque nouveau village. La plupart des maisons de ces villages ne sont faites que de bousillage, ou de masses de terre imparfaitement cuites au soleil, et moulées entre des planches, qu'on y laisse attachées, jusqu'à ce que ces murs aient assez de solidité pour supporter un toit. Quelquefois, les murs sont simplement d'osier, avec un crépi d'argile. Les toits sont, en général, de chaume et quelquefois de gazon. Les appartements sont divisés par des treillis, et tapissés de large papier, sur lequel on voit des figures de divinités ou des colonnes de sentences morales. Chaque maison a tout autour d'elle un espace vide, entouré de claies, ou de tiges de kow-leang ; tout cela est fait avec un ordre, une propreté qui attestent l'industrie du propriétaire, et suffisent pour que le spectateur trouve moins désagréable les matériaux grossiers qui composent ces demeures.

Les villes sont entourées de murailles, plus hautes, pour la plupart, que les maisons qu'elles renferment. Ces murailles forment, en général, un carré, dont les quatre côtés font face aux quatre points cardinaux. Les portes sont distinguées par les noms de porte de l'est, de l'ouest, du nord ou du sud, suivant leur position, et le nom est gravé sur une pierre au-dessus de la porte. Les rues sont ordinairement étroites, et il n'y a dans les villes aucune espèce de place, ou de grand espace vide. Les vastes édifices y sont en petit nombre, et consacrés à des usages publics, ou habités par les principaux mandarins revêtus de l'autorité. Les lois somptuaires de la Chine règlent les demeures aussi bien que les vêtements des gens riches. Suivant une maxime de cet empire, laquelle est bien loin d'être universellement adoptée ailleurs, 


\section{Voyage dans l'intérieur de la Chine et en Tartarie}

plus le palais du riche est spacieux, plus la cabane du pauvre est rétrécie ; et plus les établissements du premier sont splendides, plus la condition de l'autre devient misérable; parce que, plus on emploie de travail à fournir aux superfluités, moins il en reste pour se procurer les choses nécessaires à la vie.

Les maisons sont, en général, d'une construction simple, et n'ont qu'un étage. Les fondements sont de pierre de taille ou de granit, qu'on tire des montagnes les moins éloignées. Les briques qui servent à construire ces maisons sont d'une terre choisie, et cuites dans les fourneaux chauffés avec du bois ou du charbon de terre. Les toits sont en tuiles, faites avec le même soin que les briques. Ils ont des rangs de tuiles concaves, et des rangs de tuiles convexes, qui forment autant de sillons où toutes les tuiles sont bien liées avec du mortier d'agile.

Le mélèze est ordinairement le bois qu'on emploie dans la construction des maisons. Il croît sur des montagnes qui sont trop froides et trop escarpées pour admettre un autre genre de culture. Les fenêtres sont petites, et garnies de papier au lieu de vitres. Les Chinois ne font point entrer du fer dans la construction de leurs maisons : à peine y a-t-il un clou. Le rez-dechaussée n'est point planchéié, mais carrelé avec de grands carreaux de marbre ou de briques.

Les édifices publics et élégants sont entourés d'un rang de colonnes de mélèze, parallèle aux murs extérieurs, ce qui forme un péristyle tout autour du bâtiment. Le toit repose alors sur le mur, et il y a un avancement qui est soutenu par les colonnes. Dans les maisons particulières, il y a quelquefois un double et même un triple toit élevé de quelques pieds seulement au-dessus de l'autre.

Tous les édifices publics et la plupart des palais ont leurs principales portes et leurs fenêtres tournées vers le sud. Les bâtiments publics les plus remarquables sont, dans chaque ville, une salle d'audience où l'on entend ceux qui ont à se plaindre, et où l'on administre la justice ; un collège, où les étudiants sont solennellement examinés et reçoivent les premiers degrés; des temples pour le culte public de diverses sectes; des greniers, où l'on 


\section{Voyage dans l'intérieur de la Chine et en Tartarie}

tient du grain en réserve pour les temps de disette; enfin, une bibliothèque publique.

Les maisons ordinaires ont des façades sans colonnes; et devant celles où il y a des boutiques, on plante deux longs poteaux, peints, dorés, et portant des planches avec de grands caractères d'or, et des peintures analogues aux marchandises qu'on vend. Les caractères sont pour les passants lettrés, et les peintures pour les ignorants. L'intérieur des maisons a peu d'ornements; et les ameublements sont fort simples. Chaque meuble ou ustensile de bois est peint en rouge et vernissé.

Dans les grandes rues et dans une partie des faubourgs des villes que traversèrent les Anglais, on voyait le mouvement, l'activité du commerce, qui est dû en partie à la proximité de la rivière de Yun-Leang-Ho, où l'on voit sans cesse passer des bateaux. II y en a aussi à l'ancre devant les villages, ainsi que devant les villes.

Chaque ville est mise sous la protection de certaines étoiles ou constellations, dont les Chinois comptent vingt-huit. Mais ils ont, en outre, une division d'étoiles qui répondent aux signes du Zodiaque, et qu'ils appellent les douze demeures du Soleil. Il n'est pas surprenant que, sous un ciel aussi pur que celui des Chinois, dès les premiers moments où la société a commencé à se civiliser, où un plus petit nombre de combinaisons civiles, une plus petite population donnaient moins d'occupation à chaque individu, et où avec un travail bien moins pénible, I'homme obtenait de la terre de quoi suffire à sa subsistance, il n'est pas surprenant, dis-je, que ce peuple ait employé une partie de son temps à contempler les astres brillants qui l'éclairaient.

Les Chinois n'ont point emprunté des autres nations ce qu'ils savent de ces astres, ainsi que le prouvent les noms par lesquels ils les distinguent, nom qui sont analogues aux coutumes et aux événements de leur pays. On trouve encore quelques-unes de leurs anciennes monnaies, sur lesquelles sont des caractères indiquant les demeures du soleil. Par l'observation, ils parvinrent, en peu de temps, à connaître le véritable nombre de jours de l'année solaire, ainsi que d'autres périodes et phénomènes des cieux. Mais ils tombèrent promptement dans les illusions de l'astrologie, dont les prophéties 


\section{Voyage dans l'intérieur de la Chine et en Tartarie}

et les promesses magnifiques leur firent perdre le goût des travaux patients et réglés de la science astronomique. Leurs astrologues prétendent savoir prédire toutes les variations de la température dans les diverses saisons de l'année suivante; et ils ne manquent pas de les publier dans leurs almanachs, ainsi qu'on a coutume de le faire dans ceux d'Europe. Ils y marquent, de plus, les jours heureux et les jours malheureux pour toutes les entreprises possibles. L'attachement du peuple pour ces absurdités est fortifié par le moindre rapport de l'événement avec la prédiction, tandis que toutes les fois que cet événement et cette prédiction ne s'accordent pas, on l'impute non à l'infaillibilité de l'art, mais à l'ignorance de celui qui le pratique. On consulte beaucoup de nouveaux oracles, afin de voir s'ils se rencontreront avec la première prédiction. Ainsi, ce qui devrait mettre un terme à la crédulité des dupes de ces impostures ne sert qu'à accroître l'occupation de ceux qui en font leur emploi. Ils en retirent beaucoup de profit, pendant qu'elles coûtent aux autres et de l'argent, et de l'inquiétude. C'est un impôt volontaire mis sur la superstition.

Il n'y a, en Chine, aucune taxe légale qui ait rapport à la religion. La religion prescrit cependant des cérémonies qui prennent nécessairement du temps; et elle ordonne des offrandes qui occasionnent de la dépense. Ces offrandes ont lieu les jours de la nouvelle et de la pleine lune, au printemps et en automne, ainsi qu'au commencement de l'année. Dans cette dernière occasion, surtout, on dépense beaucoup. II s'effectue aussi quelque bien. Des liaisons interrompues se renouvellent; des amis brouillés se réconcilient; tout date d'une nouvelle époque. Le plus pauvre villageois se prépare dans les mois précédents à rendre un moment sa vie agréable, après en avoir si longtemps traîné le fardeau. Cependant les Chinois n'ont point de jours fixés pour un repos périodique. Aussi, on doit en conclure que le travail ordinaire du peuple n'est pas souvent interrompu.

Les Chinois sont, en général, plus propres à supporter un travail modéré avec peu d'interruption que la plupart des Européens d'une classe inférieure. On leur donne de bonne heure de meilleures et de plus saines habitudes. Ils restent plus longtemps sous la direction de leurs parents. Ils sont, pour la plupart, sobres ; ils se marient jeunes ; ils sont moins exposés aux tentations 


\section{Voyage dans l'intérieur de la Chine et en Tartarie}

du libertinage, et moins sujets à contracter des maladies qui corrompent les sources de la vie. Leur manière de vivre est plus régulière et plus uniforme.

On estime, d'après l'autorité des faits et de l'observation, que malgré le luxe empoisonneur auquel s'abandonnent les Européens riches, et malgré les maladies que leur occasionnent le trop de bonne chère, le défaut d'activité et le vice, ils vivent, en général, dix ans de plus que les hommes d'une classe inférieure ; parce que ceux-ci sont usés avant le temps, par la fatigue, et que leur pauvreté les empêche de se procurer tout ce qui est nécessaire à leur subsistance et à leur entretien. Ils sont, en outre, plus exposés aux inclémences de l'air et aux accidents, et moins précautionnés contre leurs effets, ainsi que plus sujets aux maladies dont ils ont moins le temps et les moyens de se faire guérir.

Les Chinois n'ont point de dimanche, ni même de division qui ait quelque rapport avec les semaines. Leurs temples sont ouverts chaque jour pour recevoir les dévots. II y a eu de ces dévots qui ont fait quelques dons peu considérables pour l'entretien du clergé. Mais aucune terre n'est sujette à la dîme ecclésiastique. Sous le dernier règne, le gouvernement a substitué un impôt sur les terres à celui de la capitation, comme plus proportionné aux facultés des individus. Il y a aussi une taxe sur la plupart des marchandises d'importation, et sur toutes les choses de luxe; mais les droits étant confondus avec le prix de chaque article, le consommateur s'en aperçoit rarement. Un droit de transit est aussi perçu sur les marchandises qui passent d'une province à l'autre. Chaque province de la Chine peut être comparée à un royaume d'Europe, et est distinguée par quelques denrées ou par quelques manufactures particulières. Les envois qu'on fait de ces denrées et des produits de ces manufactures forment le grand commerce de l'intérieur de l'empire, et portent les droits à une somme considérable. Les présents des tributaires et des sujets de l'empereur, et la confiscation des biens des coupables opulents sont comptés dans l'énumération des ressources du trésor public. Les impôts, tels que celui qui est sur le riz, sont reçus en nature. Les

différentes espèces de grains, qui servent à la subsistance des classes les plus pauvres de la société, sont exemptes d'impôts. Tel est, par exemple, le froment, auquel les Chinois préfèrent toujours le riz. 


\section{Voyage dans l'intérieur de la Chine et en Tartarie}

Lorsqu'en remontant le Yun-Leang-Ho, les Anglais arrivèrent près de SanChoo, ils aperçurent des champs de blé-froment, les premiers qu'ils eussent vus depuis qu'ils étaient en Chine. Le blé n'avait encore qu'environ deux pouces de hauteur; mais, quoique la terre où il était semé fût sèche et sablonneuse, et qu'il n'y eût pas eu de pluie depuis trois mois, il poussait très bien. II était proprement semé dans les trous, faits à la houe, méthode qu'on a dernièrement essayée dans quelques parties de l'Angleterre. Celle de semer le blé en le jetant au loin n'est que très accidentellement employée par les Chinois. Ils ont trouvé qu'elle faisait perdre une très grande quantité de grain, et que la récolte en diminuait de beaucoup; parce qu'alors on voit des endroits où le blé pousse par touffes, tandis qu'il y en a d'autres qui restent presque vides. Les semailles à la houe occupent les femmes et les enfants des cultivateurs à un travail qui n'exige que très peu de force. Une des personnes de l'ambassade calcula que ce qu'on épargnait en Chine, en semant le grain dans des trous, au lieu de le jeter au loin, suffirait pour nourrir tous les sujets de la Grande-Bretagne en Europe.

Les Chinois ne tracent jamais des sillons dans leurs champs. Ils sèment leur grain sur une surface unie. Quelque avantage qu'il puisse y avoir à faire écouler les eaux de la pluie, par des sillons, dans un terrain qui n'a point de pente, c'est une erreur que de croire que la récolte sera augmentée si l'on étend la surface du sol par la courbe que forme la hauteur des sillons; puisque les plantes qui croissent perpendiculairement ne peuvent pas être en plus grande quantité sur une courbe que sur sa base. D'ailleurs, il y a une perte de terrain réelle dans le fond des sillons, attendu que les plantes qui y croissent sont toujours faibles, chétives et languissantes.

Le cultivateur chinois n'est point inattentif dans la direction qu'il donne aux rigoles où il sème son grain, ainsi qu'on peut en juger d'après les règlements solennels faits pour la cérémonie du jour où l'empereur laboure un champ. Ces règlements portent :

«Qu'il doit avoir le visage tourné vers le midi, prendre la charrue de la main droite et tracer un sillon dans cette direction.

Cependant, la meilleure exposition dépend des circonstances locales. Dans quelques parties de l'Angleterre, où les sillons étaient tracés de l'est à l'ouest 


\section{Voyage dans l'intérieur de la Chine et en Tartarie}

pour semer de l'herbe, on a remarqué que le côté exposé au sud était toujours plus vert, plus fourni, et que I'herbe y croissait plus vite que sur le côté qui faisait face au nord. Peut-être que si I'on en faisait l'expérience, on trouverait la direction nord-ouest et sud-est préférable, parce que les vents froids et piquants qui retardent tant la végétation dans la Grande-Bretagne soufflent rarement de cette partie, au printemps et en été. Le côté le plus large de la hauteur que forment les sillons étant exposé au nord-est, d'où soufflent les vents froids et destructeurs, abriterait, en grande partie, le côté opposé. Quand les sillons sont directement tracés vers le nord-est, ces vents piquants pouvant frapper toute l'étendue d'un champ de blé, nuisent à la racine de la plante aussi bien qu'à sa tige.

Les Chinois emploient la farine de froment non seulement pour des gâteaux cuits à la vapeur de l'eau, ainsi que nous l'avons dit dans un chapitre précédent, mais aussi pour faire de ces pâtes qu'on appelle en Europe vermicelli, et qu'on aime beaucoup en Chine.

Chaque chaumière chinoise a son jardin potager; et autour des chaumières, on voit quelques cochons, de la volaille, et surtout des canards. Quand les Chinois tuent ces canards, ils les fendent, les salent, les font sécher, et en envoient beaucoup dans les grandes villes où ils sont un objet de commerce. L'art de faire éclore les œufs des canards, par une chaleur artificielle, est, dès longtemps, pratiqué par les Chinois. Certes, ils n'ont pu l'apprendre de l'autruche, qui pond ses œufs dans le sable pour que le soleil les fasse éclore ; car cet oiseau n'est point naturel à la Chine ; mais peut-être l'ont-il appris du crocodile, dont une petite espèce se trouve dans les rivières du midi de l'empire.

Dans la partie du pays que traversaient les Anglais, on voyait, à côté des champs de froment, beaucoup de coins de terre où croissait du blé-sarrasin qui était en fleur. Cette espèce de blé est employée aux mêmes usages que l'autre grain, et produit une farine extrêmement blanche et fine.

Les voyageurs avaient le temps de faire beaucoup d'excursions dans la campagne, car leurs yachts remontaient très lentement le cours de la rivière, qui coule au nord-est. Les mandarins employaient un assez grand nombre d'hommes à traîner les yachts; mais le salaire que leur accordait le 


\section{Voyage dans l'intérieur de la Chine et en Tartarie}

gouvernement n'était point proportionné au travail, et plusieurs paysans l'abandonnaient quand ils trouvaient l'occasion de s'échapper sans être aperçus. II arrivait souvent qu'on les changeait pendant la nuit, afin de surprendre plus facilement ceux qu'on voulait forcer de servir. Un chef les suit ordinairement comme un commandeur de nègres dans les Antilles et, le fouet à la main, il hâte leurs pas, et les empêche de déserter.

Le 18 octobre, l'ambassade entra dans la province de Shan-Tung. Tous ses conducteurs provinciaux furent remplacés par d'autres destinés à les mener à Han-Choo-Foo. L'après-dîner, les yachts passèrent à la vue de deux villes devant lesquelles, comme devant toutes celles qui étaient situées sur les bords du Yun-Leang-Ho, il y avait à l'ancre un grand nombre de jonques et de barques.

Ce jour étant celui de la pleine lune, les Chinois employèrent la nuit à leurs cérémonies religieuses. Les coups de canon se succédaient continuellement; une musique bruyante se faisait entendre; plusieurs centaines de loos étaient frappés à la fois ; on tirait des feux d'artifices, et on brûlait des mèches parfumées; tout cela continua depuis minuit jusqu'au lever du soleil.

Cette partie de la province de Shan-Tung forme une vaste plaine des deux côtés de la rivière. On y voit croître non seulement du froment et du millet, mais du tabac, et surtout la plante annuelle qui porte le coton. Ce dernier article est la principale production du pays, ainsi que de la province de KiangNan qui le borne au midi. On ne néglige pas non plus la culture des cotonniers dans les parties du nord où les gousses peuvent parvenir à leur perfection avant que les rigueurs du froid ne se fassent sentir. II n'est pas rare, dans ces contrées, de voir le cultivateur enlever des sommités de feuilles du cotonnier, afin d'accroître le nombre de gousses et hâter leur maturité. L'expérience a prouvé de même dans les Indes occidentales, que les roses poussaient en plus grande quantité, et étaient plus promptement écloses lorsqu'on avait fouetté les branches du rosier.

La Chine ne produit pas assez de coton pour la consommation de ses habitants, car les Chinois de l'un et de l'autre sexe, dans les classes inférieures, ne portent absolument que des étoffes de coton. Bombai fournit à 


\section{Voyage dans l'intérieur de la Chine et en Tartarie}

la Chine une immense quantité de cet article. On le vend à Canton pour des piastres qui, dans le cours du commerce, sont données pour des lettres de change sur l'Angleterre, et les piastres retournent ainsi aux Chinois pour le thé, les soieries et les porcelaines qu'on porte en Europe. Près des champs de cotonniers, on en voit d'autres couverts d'indigo, dont la couleur sert à teindre les étoffes de coton qui servent au commun des Chinois, dans toute l'étendue de l'empire.

Le 22 octobre, les yachts s'arrêtèrent devant Lin-Sin-Choo, ville du second ordre, près de laquelle est une très belle pagode à neuf étages. Ta est le nom que les Chinois donnent à ces édifices. Ils sont en grand nombre dans les parties de la Chine où il y a des montagnes, sur le sommet desquelles elles sont souvent placées. Les pagodes ont, en général, depuis cent vingt jusqu'à cent soixante pieds de haut, ce qui fait quatre ou cinq fois le diamètre qu'elles ont à leur base. Le nombre de leurs étages ou galeries est presque toujours impair, c'est-à-dire de cinq, de sept ou de neuf. Ces galeries diminuent à mesure qu'elles sont relevées, et chacune est couverte d'un toit avancé.

A Lin-Sin-Choo, les yachts quittèrent le Eu-Ho qui, depuis sa source située à l'occident, coule jusque-là dans une direction nord-est, et y est réuni au canal impérial qui va au sud. Ce canal, l'ouvrage le plus grand et le plus ancien en ce genre, va de Lin-Sin-Choo à Han-Choo-Foo, et suit une ligne irrégulière d'environ cinq cents milles de longueur. II passe non seulement sous des montagnes et dans des vallées, mais à travers des rivières et des lacs. II doit avoir été commencé ou achevé à Lin-Chin-Foo, et comme, par sa situation peu élevée, la pagode qu'on voit auprès n'a pu être destinée à servir pour une vigie, comme on suppose qu'est l'objet de ces sortes d'édifices, il est possible qu'elle ait été construite comme un monument de l'entreprise ou de l'achèvement de ce canal, ouvrage aussi utile à la nation chinoise que fait pour attester son génie.

Ce genre d'ouvrage diffère beaucoup des canaux d'Europe, lesquels se prolongent ordinairement en ligne directe, et sont étroits et sans courant. Celui de la Chine fait beaucoup de sinuosités dans son cours. II est d'une largeur inégale, même quelquefois très considérable, et ses eaux sont rarement stagnantes. 


\section{Voyage dans l'intérieur de la Chine et en Tartarie}

La terre qui sépare cette rivière artificielle du Eu-Ho a été creusée jusqu'à la profondeur de trente pieds, afin que les eaux de la première pussent s'épancher facilement dans l'autre. Leur cours est ensuite modéré par des écluses qui traversent le canal dans les endroits où on l'a jugé nécessaire ; mais il est rare qu'elles soient à moins d'un mille de distance l'une de l'autre, l'eau n'ayant que peu de courant dans beaucoup d'endroits. Les écluses de ce canal n'ont point de portes comme celles d'Europe. Elles sont d'une construction simple, faciles à ouvrir et à fermer, et n'exigent qu'un entretien fort peu coûteux. Elles consistent en quelques planches qu'on pose séparément l'une au-dessus de l'autre, dans la rainure de deux solides piliers de pierre, avancés des deux côtés du canal, et n'ayant entre eux que l'espace nécessaire pour le passage des plus gros bateaux. II n'y a que peu d'endroits où le canal soit parfaitement de niveau. Les écluses qui le traversent, et d'autres qui sont sur ses bords, servent à régler la quantité d'eau qu'il doit avoir. II faut une certaine adresse pour que les bateaux qui passent par les écluses n'éprouvent pas quelque accident. En conséquence, il y a sur le devant de chaque bateau un très grand aviron, par le moyen duquel un homme de l'équipage le gouverne fort bien. Pendant ce temps-là, d'autres hommes, placés sur les piliers et tenant des coussins de peau, rembourrés de crin, empêchent que le bateau n'éprouve quelque avarie, si dans la rapidité du passage, il heurte contre ces piliers.

De légers ponts de bois sont jetés sur les piliers, et on les retire très aisément quand des bateaux ont besoin de passer. Les écluses ne s'ouvrent qu'à des heures marquées; et alors tous les bateaux qui se sont rassemblés dans l'intervalle passent en payant un léger péage, qui est employé à l'entretien des écluses et des bords du canal. La diminution de l'eau, occasionnée par l'ouverture des écluses, n'est pas très considérable. Chaque fois qu'on les ouvre, elle ne baisse guère que de quelques pouces, et elle est bientôt remplacée par les rivières et les ruisseaux qui viennent s'y jeter des deux côtés. Cependant, il y a des endroits où les écluses sont à une distance considérable l'une de l'autre, et où le courant est très rapide ; là, l'eau baisse quelquefois de plus d'un pied ou deux. Le canal passe dans les lits de plusieurs anciennes rivières, auxquelles il ressemble par l'irrégularité de sa 


\section{Voyage dans l'intérieur de la Chine et en Tartarie}

profondeur, les sinuosités de son cours, et sa largeur dans les endroits où il n'y a point d'écluses.

Partout où le pays peut fournir au canal une suffisante quantité d'eau, sans pourtant lui en donner en trop grande abondance, il y a des écluses qui, placées sur ses bords, servent à l'y introduire comme à l'évacuer au besoin. Cela est ainsi du côté du sud: aussi les écluses transversales y sont en plus petit nombre. On n'y en rencontre jamais plus de six par jour.

L'ambassade n'était pas encore loin de Lin-Sin-Choo, lorsqu'il arriva un fâcheux accident, dont elle fut le témoin et la cause. Plusieurs milliers d'habitants des villes et des villages voisins s'étaient rassemblés sur les bords du canal pour voir passer les étrangers, et beaucoup de ces curieux étaient montés sur de grands bateaux, placés sur le bord du canal. La poupe avancée d'un de ces bateaux, étant surchargée par la foule, se brisa et plusieurs personnes tombèrent avec elle dans le canal. Quels que fussent les cris et les dangers de ceux qui se débattaient dans l'eau, sans savoir nager, ils ne parurent pas détourner un instant l'attention des spectateurs qui étaient en sûreté, occupés à contempler les yachts. Aucun canot n'alla porter des secours à des malheureux qui pouvaient se noyer. Un seul s'avança de leur côté ; mais l'homme qui le conduisait parut plus empressé de ramasser le chapeau d'une de ces victimes de leur curiosité, que de la sauver elle-même. Quelque sacrés que soient, en Chine, les nœuds qui lient les enfants à leurs parents, quelque tendres que soient leurs affections, les sentiments d'humanité de la multitude alors assemblée n'étaient pas assez forts pour qu'elle parût alarmée du péril qui menaçait des infortunés, et qu'elle songeât à les secourir, ou pour empêcher le plus insensible des êtres d'aimer mieux, dans un pareil moment, profiter d'un misérable chapeau que de sauver la vie à un homme.

Dans la soirée du 23 octobre, les yachts arrivèrent à Tong-Whang-Ho. Cette ville est maintenant éloignée du fleuve Jaune; mais une partie de son nom semble avoir quelque rapport avec ce fleuve qui, soit par l'effort de l'art, soit par accident, peut en avoir été autrefois approché.

Près des murs de Tong-Whang-Ho étaient rangés trois cents soldats, nombre ordinaire des troupes qui, dans chaque ville où il y avait garnison, se 


\section{Voyage dans l'intérieur de la Chine et en Tartarie}

rassemblaient pour honorer le passage de l'ambassade. II était alors nuit. Chaque spectateur avait une lanterne à la main; et les différences des mousselines qui couvraient ces lanternes produisaient sur l'eau un effet très agréable. Quand une ville était traversée par le canal, les soldats étaient rangés de chaque côté. Quelquefois, I'on s'attendait que l'ambassadeur débarquerait ; et au premier signal, ces soldats tombaient à genoux pour le recevoir. Aux yeux d'un voyageur européen, un pareil spectacle ressemblait à celui d'une troupe de pèlerins demandant la bénédiction.

Depuis que les Anglais étaient partis de Tien-Sing, tout le pays qu'ils avaient traversé n'était qu'une immense plaine, remplie de villes, de villages, de chaumières et de champs bien cultivés. On n'y voyait pas la plus petite éminence; le sol n'offrait pas l'apparence d'une seule pierre. C'était une continuation de la plaine vaste et uniforme de Pé-Ché-Lée, produite sans doute par des causes d'une même nature, et formant avec elle une portion du globe, laquelle diffère, dans sa composition et par son aspect, de presque toutes les autres.

Ce fut près de Tong-Whang-Ho que les Anglais aperçurent, pour la première fois depuis leur départ de Pékin, quelques terrains élevés et un pays montueux, s'étendant du côté de l'est. Peu après, les sommets des montagnes furent visibles du sud- ouest. Le nom de la province orientale de Shan-Tung signifie, suivant les caractères chinois qui le composent, «les montagnes orientales ». Une chaîne de montagnes de granit, dont la direction est de l'est à l'ouest, depuis le promontoire qui est vis-à-vis de la Corée, comme nous l'avons dit précédemment, s'étend dans toute la longueur de la province vers celle de Pé-Ché-Lée, en s'abaissant graduellement, et forme les vastes et remarquables hauteurs de Shan-Tung. Ces substances solides doivent, au moins, avoir existé depuis la création du globe ; et si jamais elles ont été une île, que ne séparait du continent qu'un étroit canal, ce canal doit, dans le laps du temps, avoir été comblé par le dépôt graduel des terres de ces montagnes, qui restent maintenant dépouillées, tandis qu'un pareil dépôt ayant eu lieu de l'autre côté, a formé la grande et fertile plaine qu'on y voit.

Le 25 octobre, les yachts arrivèrent dans la plus haute partie du canal impérial, laquelle se trouve vers les deux cinquièmes de sa longueur. Là, la rivière Luen, la plus considérable de celles qui fournissent de l'eau à ce canal, 


\section{Voyage dans l'intérieur de la Chine et en Tartarie}

s'y jette avec rapidité, et avant d'y aboutir, son cours forme avec lui une ligne transversale. Une forte muraille renforce le bord occidental du canal ; et les eaux du Luen, frappant avec violence contre cette muraille, se partagent et vont, la moitié, vers le nord et la moitié, vers le sud. Si la cause de cette division n'était pas expliquée d'une manière générale, on aurait l'air de raconter une merveille, quand on dirait que plusieurs baguettes jetées à la fois dans cette partie de la rivière sont bientôt séparées, et suivent des directions diamétralement opposées.

C'est sans doute de ce point élevé que celui qui conçut l'idée du canal vit, avec l'œil du génie, la possibilité de former cette communication importante entre les différentes parties de l'empire chinois, en mesurant de là I'inclinaison du terrain au nord et au sud, et en réunissant les différentes eaux fournies par les hauteurs qui sont de chaque côté. II sentit qu'il fallait en même temps empêcher, par les écluses, la perte des eaux, suppléer à la diminution qu'occasionnerait nécessairement l'ouverture des écluses pour le passage des bateaux, par l'abondante rivière de Luen, plus élevée que la plus haute partie du canal, et faire en sorte que, se divisant proportionnément, elle coulât de deux côtés différents. Près de ce lieu est placé un temple d'une architecture très élégante, et bien décoré, appelé Luen-Whang-Miaw, c'est-àdire le «temple jaune de la rivière de Luen ».

Les Anglais n'avaient pas encore fait beaucoup de chemin dans la partie méridionale du canal, lorsqu'ils arrivèrent dans le voisinage de l'endroit où le fameux oiseau-pêcheur de la Chine, le leu-tze, est élevé dans l'art de fournir à son maître une grande quantité de poisson. Le leu-tze est une espèce de pélican, ressemblant au cormoran ordinaire; mais ayant été présenté au docteur Shaw, il l'a caractérisé de la manière suivante: «Pélican ou cormoran brun, avec le plumage de la gorge blanc; le dessous du corps blanchâtre et tacheté de brun ; la queue ronde, l'iris bleue, et le bec jaune. »

Dans un vaste lac, situé à l'est du canal, et tout près de ses bords, on voit des milliers de petits bateaux et de radeaux, qui servent à la pêche qu'on fait avec le leu-tze. Sur chaque canot ou radeau, il y a dix ou douze de ces oiseaux qui plongent à l'instant où leur maître leur fait un signe. On ne peut 


\section{Voyage dans l'intérieur de la Chine et en Tartarie}

voir sans étonnement les énormes poissons que ces oiseaux prennent et rapportent dans leur bec. Ils sont si bien instruits qu'on n'a besoin de leur mettre au cou ni anneau, ni cordon pour les empêcher d'avaler quelque partie de leur proie. Ils ne mangent que ce que leur maître leur donne pour les encourager et les nourrir. Le canot dont se servent les hommes qui font cette pêche est extrêmement léger. II est quelquefois charrié jusqu'au lac avec les oiseaux par les hommes qui doivent s'y embarquer.

La partie occidentale du lac est une haute chaussée qui la sépare du canal, dont l'eau est bien plus élevée que celle du lac. Cette chaussée s'étend dans toute la longueur du lac. Il a fallu, pour la faire, une immense quantité de terre, qui n'a sans doute été rassemblée qu'avec beaucoup de travail et de dépense. Cette terre est, de chaque côté, revêtue de murailles de pierres ; et pour que la chaussée ne fût pas trop pressée par le poids de la colonne d'eau du canal, on a pratiqué, de distance en distance, des écluses par où l'eau surabondante est versée dans le lac ou sur les terrains bas, et quelquefois même dans les fossés, creusés au milieu de la chaussée pour servir de réservoirs.

Ces fossés supposent une connaissance, au moins pratique, des lois de I'hydrostatique; car on y entretient ordinairement l'eau à une hauteur moyenne entre le niveau de celle du canal et le niveau de celle du lac, c'està-dire entre le terrain élevé et le terrain bas. Par ce moyen, la pression qui se fait contre la double chaussée est divisée, et chaque partie a besoin d'une moindre force pour résister. La colonne d'eau du réservoir balance une colonne d'égale hauteur dans le canal, et la profondeur de l'eau du lac empêche que celle du réservoir effectue aucune pression, excepté par la partie de la colonne qui se trouve au-dessus du niveau de ce même lac.

Le soin qu'on a eu de faire un fossé dans le milieu de la chaussée a produit un autre avantage. II a fallu aller chercher au loin beaucoup moins de terre. II paraît, par les cartes que les jésuites ont tracées du pays où passe le canal, qu'une grande partie de ce pays consistait autrefois en lacs et marais, dont plusieurs ont été desséchés, et sont maintenant, ainsi que tout le haut de la chaussée, régulièrement cultivés. 


\section{Voyage dans l'intérieur de la Chine et en Tartarie}

Plusieurs centaines d'acres de terre autour du lac sont encore marécageux, et couverts de lien-wha, dont nous avons déjà parlé dans cet ouvrage [Cf. plus haut, et plus haut]. Les Chinois ont toujours fait si grand cas de cette plante, qu'ils ont fini par la regarder comme sacrée. Cependant leur vénération pour elle ne les engage pas à n'en faire qu'un objet d'inutile ornement : ils la mettent au nombre des choses qui servent à leur nourriture. Leurs étangs sont en général couverts de lien-wha qui, lorsqu'ils sont en fleur, forment un coup d'œil très agréable. Les graines de cette plante ont à peu près la forme et la grosseur du gland, et un goût plus délicat que l'amande. Pour les servir, on les fixe par le bas sur une substance qui a la forme d'un cône renversé. L'été, on coupe les racines par tranches, et on les sert avec de la glace. On les confit aussi au sel et au vinaigre pour les manger I'hiver.

C'est avec cette racine que les Egyptiens préparaient, dit-on, leur colocasia. Mais la plante ne croît plus dans ces contrées; et quelques naturalistes en concluent qu'elle n'y a jamais été indigène, mais que les habitants I'y cultivaient avec beaucoup de soin. Les anciens Romains tentèrent en vain plusieurs fois de la naturaliser en Italie par le moyen de graines qu'ils apportaient d'Egypte. Les essais qu'on a fait dans les temps modernes pour la faire croître en Europe ont rarement réussi, même avec le secours d'une chaleur artificielle. En Chine, elle croît souvent spontanément, et on la fait venir facilement en plein air, soit qu'on en transplante des racines, soit qu'on en sème des graines. Les Chinois distinguent plusieurs variétés de cette espèce de lys.

Les voyageurs qui n'avaient encore vu qu'un côté du canal avec une chaussée, trouvèrent bientôt qu'il y en avait des deux côtés. Quoiqu'il y ait de modernes et moins grands exemples d'un pareil ouvrage, c'était un curieux spectacle que cet immense volume d'eau forcé par I'humaine industrie de se resserrer dans un étroit canal, plusieurs toises au-dessus de son premier lit, et de couler ainsi en l'air jusqu'à une distance très considérable, où elle rencontre un terrain qui est à son niveau.

Dans toute la partie où le canal est ainsi élevé, la chaussée est soutenue par des murs de marbre gris et commun pour lesquels on s'est servi d'une espèce de mortier. Ces murs ont environ douze pieds d'épaisseur, et les grands blocs qui les recouvrent sont liés avec des crampons de fer. Là, le 


\section{Voyage dans l'intérieur de la Chine et en Tartarie}

canal n'est en effet qu'un aqueduc très élevé au-dessus du sol, et partout où ce sol est desséché, il y a beaucoup de villages. Le terrain qui environne l'aqueduc est inondé une grande partie de l'année. Les Anglais y virent du riz, dont la tige s'élevait au-dessus de l'eau. Dans beaucoup de plat pays du centre et des provinces méridionales de l'empire, on cultive du riz ; car c'est la principale nourriture de tous ceux des Chinois qui ne sont pas assez pauvres pour être forcés de manger des espèces de grains moins chères. Une grande partie des champs voisins du canal est très propre à la culture du riz qui, depuis le moment où on le sème jusqu'à celui de sa maturité, a besoin que la terre où il croît soit légèrement submergée. Plusieurs rivières, dont quelques-unes sont très grandes, traversent les diverses provinces de la Chine, et débordent tous les ans. Alors les eaux déposent un limon qui fertilise le sol, comme les débordements du Nil fertilisent l'Egypte. Les sources du fleuve Jaune et du Kiang ne sont pas très éloignées de celles du Gange et du Burumpooter, et se trouvent parmi les montagnes qui bornent I'Inde au nord, et la Chine à l'ouest. Là, des torrents de pluie périodique grossissent souvent et prodigieusement ces rivières, quoiqu'en même temps, il ne tombe pas une goutte d'eau dans les plaines qu'elles traversent.

Quelques jours après que le limon a été déposé sur les plaines de la Chine, on se prépare à semer le riz. On commence par entourer un coin de terre d'une petite chaussée d'agile. Ce terrain est ensuite labouré ; et on y fait passer légèrement une herse droite, garnie par-dessous d'un rang de dents de bois, et traînée par un buffle. Le grain qui a été déjà trempé dans du fumier délayé avec de l'urine est semé très épais, et on inonde aussitôt le terrain, soit par des canaux qui y conduisent l'eau d'une source plus élevée, soit par une pompe à chaîne, dont l'usage est aussi familier aux cultivateurs chinois que celui de la houe. En peu de jours, on voit le riz pousser au-dessus de l'eau. Dans cet intervalle, si le reste du terrain, destiné à être cultivé, est trop compact, on le laboure ou on rompt les mottes à coups de houe, et on le nivelle avec la herse. Aussitôt que le riz a sept ou huit pouces de hauteur, on l'arrache avec sa racine, on en coupe les sommités, et chaque racine est plantée séparément, quelquefois dans de petits sillons tracés avec la charrue, et quelquefois dans des trous faits avec un bâton pointu. Les racines sont mises à six pouces l'une de l'autre. On inonde aussi ce champ. 


\section{Voyage dans l'intérieur de la Chine et en Tartarie}

Pour arroser facilement les champs de riz, et régler la quantité d'eau qu'on veut leur donner, on les divise par de petites levées d'argile; et par une rigole qu'on fait sur chaque levée, on porte l'eau à volonté dans toutes les parties du champ. Quand le riz approche de sa maturité, l'eau a déjà disparu, soir par l'évaporation, soit parce que la terre l'a absorbée ; et la plante couvre entièrement le terrain sec.

La première récolte de riz se fait à la fin de mai ou au commencement de juin ; mais c'est principalement dans les provinces méridionales qu'elle est aussi hâtive. L'instrument dont on se sert pour couper le riz est une petite faucille dentelée comme une scie. On ne se sert ni de charrettes, ni d'animaux pour emporter les gerbes hors du champ. Mais on en attache deux à chaque bout d'un bambou, qu'un homme charge sur son épaule, et on les porte ainsi dans l'endroit où le grain doit être séparé de la paille. Cette dernière opération se fait non seulement avec le fléau dont on a coutume de se servir en Europe, ou en faisant, à la manière des autres Orientaux, promener du bétail sur l'aire où le riz est étendu ; mais aussi en le frappant contre une planche posée de champ, ou contre un cylindre échancré à cet effet, et dont le derrière et les côtés sont beaucoup plus hauts que le devant, afin que le grain ne se répande pas au loin. Après l'avoir vanné, on le porte au grenier.

Pour dégager les grains de riz de la pellicule qui les enveloppe, on a un grand vase de terre, ou une pierre creusée comme celle dont on se sert ailleurs pour filtrer l'eau; et après qu'on l'a fixée dans la terre et qu'on y a mis le grain, on pile ce grain avec une autre pierre de forme conique, et attachée à l'extrémité d'un levier. II est, par ce moyen, dégagé de sa pellicule ; mais, à la vérité, quelquefois imparfaitement. La pierre est souvent agitée par un homme qui pèse avec ses pieds sur l'extrémité du levier. On emploie encore un autre moyen. On passe le grain entre deux pierres aplaties et de forme circulaire. Celle qui est par-dessus est la seule qui tourne; mais il faut qu'il y ait assez de distance entre les pierres pour que le grain soit dégagé de sa pellicule sans être écrasé. La première opération se fait en grand, avec des moulins à eau. Alors l'axe de la roue a plusieurs bras qui pèsent en tournant sur l'extrémité des leviers, et les soulèvent de la même manière que lorsqu'on y pèse avec le pied. Quelquefois vingt leviers sont 


\section{Voyage dans l'intérieur de la Chine et en Tartarie}

soulevés par la même roue. La paille de riz hachée sert à nourrir le peu de bétail qu'emploient les cultivateurs chinois.

Les travaux de la première récolte étant achevés, on s'occupe, sans tarder, à préparer la terre pour l'ensemencer de nouveau. On arrache d'abord le chaume, qu'on met en petits tas et qu'on brûle ; après quoi, on en répand les cendres sur toute la surface du champ. Les procédés que nous avons décrits sont ensuite renouvelés. La seconde récolte se fait ordinairement en octobre, ou au commencement de novembre. Le grain est préparé comme la première fois, mais le chaume n'est plus brûlé; on le retourne avec la charrue, et on le laisse pourrir dans la terre. Ce chaume et le limon qu'apportent les débordements sont les seuls engrais que reçoivent les terres où les Chinois cultivent le riz. Les terres fertilisées par le refoulement des eaux dans le voisinage de la mer, par le débordement des rivières, ou par des canaux, sont non seulement propres à la culture du riz, mais à celle du sucre. II faut pourtant, lorsqu'on y plante des cannes à sucre, avoir la précaution d'en ôter l'eau aussitôt qu'elles commencent à pousser.

Content de deux récoltes de riz ou d'une récolte de sucre dans une année, le cultivateur chinois laisse ordinairement reposer sa terre jusqu'au printemps suivant ; alors il recommence ses travaux. Ainsi, de génération en génération, des récoltes successives sont faites sur le même sol, sans qu'on ait la moindre idée de la nécessité de laisser la terre en jachère pendant une année.

La grande élévation du canal impérial, dans la partie où naviguaient alors les yachts, a permis de placer beaucoup d'écluses sur ses bords. Elles sont toutes sur des arches en pierre, et servent à verser le superflu de l'eau dans les marais voisins. Mais bientôt les voyageurs furent dans une autre partie du canal, et dans une situation toute différente. On ne voit là ni montagne, ni éminence saillante. C'est encore une plaine immense à la vue ; mais cette plaine s'est tellement élevée par degrés au-dessus de son premier niveau, que le canal est creusé au moins à vingt pieds au-dessous de la surface du sol.

L'eau qui se perd dans cette partie est remplacée par celle que l'on tire de l'immense lac de Wée-Chaung-Hoo, qui est à côté et sépare la province de 


\section{Voyage dans l'intérieur de la Chine et en Tartarie}

Shan-Tung de celle de Kiang-Nan. La situation du canal, en cet endroit, rappela à lord Macartney le grand canal de Russie qu'il connaissait très bien. Ce dernier canal court de même en certains endroits, parallèlement au lac Ladoga, dont il est séparé par une grande chaussée, mais qui lui fournit quelquefois de l'eau.

De dessus la hauteur, la perspective du lac de Wée-Chaung-Hoo était extrêmement agréable au lever du soleil. On voyait ses bords couverts de maisons de bois, et le terrain qui s'élevait par derrière orné de pagodes. Le lac était presque entièrement couvert de bateaux qui se croisaient dans toutes les directions, et employaient toutes les manières de naviguer qu'on doit aux perches, aux avirons, aux pagayes et aux voiles. La pêche est une des principales occupations des habitants des bords de ce lac. Ils emploient pour pêcher différentes méthodes ; mais celle des filets est peut-être la plus générale. Ils en ont une autre très singulière. Ils attachent sur le bord d'un canot une planche peinte en blanc, et lui donnent une inclinaison qui forme avec l'eau un angle d'environ quarante-cinq degrés. Lorsqu'il fait clair de lune, le canot où l'on a attaché la planche peinte est tourné de manière que les rayons de la lune frappent sur cette planche, et lui donnent l'apparence d'une eau mobile. Le poisson est alors tenté de s'y élancer comme dans son élément, et le pêcheur tirant aussitôt une corde, le fait tomber dans le canot. Toutes les manières de prendre du poisson sont employées avec avidité par les Chinois, qui essaient par-là de se dédommager de la rareté de la viande des animaux terrestres.

Quant aux animaux d'une grande espèce, les Chinois des dernières classes ont très peu d'occasions d'en goûter, à moins qu'ils ne meurent par accident ou par maladie. Dans ce cas, l'appétit d'un Chinois surmonte tous les scrupules: que l'animal mort soit un bœuf ou un chameau, un mouton ou un âne, il le mange également. Ce peuple ne connaît point de distinction entre la viande propre et la viande malpropre. II peut bien aisément concevoir l'horreur et le dégoût qu'une nation, accoutumée à se nourrir sans cesse de végétaux doit sentir la première fois qu'on lui propose de mettre à mort un être sensible, dans le dessein de se gorger de sa chair ; mais lorsqu'il s'est fait à cette idée, il ne regarde la préférence donnée à une espèce d'animaux sur l'autre que comme un objet de goût ou de fantaisie. 


\section{Voyage dans l'intérieur de la Chine et en Tartarie}

Les quadrupèdes qui peuvent trouver à subsister autour des habitations, tels que les cochons et les chiens, sont ceux dont on mange le plus, et on les vend dans les marchés.

Ceux des Chinois qui ne sont pas assez opulents pour être délicats satisfont leur appétit avec toute sorte de choses. Quelquefois même la vermine qui dévore les gens malpropres est à son tour dévorée par eux.

Les oiseaux aquatiques sont très recherchés par les Chinois, et ils en prennent sur le lac de Wée-Chaung-Hoo d'une manière assez plaisante. Ils laissent flotter sur l'eau des jarres vides et des calebasses, afin que ces objets deviennent familiers aux oiseaux. Alors, un homme entre dans le lac avec une jarre ou une calebasse sur sa tête, et s'avançant doucement vers un oiseau, il lève son bras, saisit l'oiseau et le tire par-dessous sans faire le moindre bruit pour ne pas épouvanter les autres. II continue cette chasse jusqu'à ce qu'il ait rempli son havresac. Cette invention ne doit pourtant pas paraître très extraordinaire, car elle est exactement la même que celle qui, suivant Ulloa, est en usage dans l'Amérique méridionale, parmi les naturels des environs de Carthagène, et des bords du lac Cienega de Tesias.

En Chine, des individus gagnent souvent leur vie par des moyens qui ne pourraient pas être adoptés en grand, ou dans le dessein d'acquérir un profit très considérable ; mais ces individus ne portent pas leurs vues au-delà d'une subsistance modérée. L'art de suivre un plan étendu pour gagner de l'argent, et d'inventer de nouvelles méthodes pour fournir à beaucoup de monde une espèce de marchandise particulière, ne sont connus en Chine que dans les grandes villes ou dans les villes maritimes. Cependant, dans tous les villages, il y a des gens qui essayent d'accumuler des richesses, en profitant des besoins des habitants des environs. Partout, il y a des boutiques où l'on prête sur gage. La loi accorde aux prêteurs un très gros intérêt. L'usage de ces prêts annonce sûrement une grande imprévoyance de la part de la multitude, ou une grande incertitude de succès dans ses entreprises. Mais la facilité de la culture, et l'abondance des récoltes, quand il ne survient pas quelque calamité, mettent souvent les paysans, tout pauvres qu'ils sont, en état de supporter le fardeau de ces emprunts. 


\section{Voyage dans l'intérieur de la Chine et en Tartarie}

Dans quelques endroits où passe le canal impérial, le lac et les marais rendent la culture presque impraticable. Là, cependant, il n'y a pas un coin desséché où l'on ne voie de petites chaumières. Les habitants se nourrissent principalement de la pêche; et le voisinage du canal les met à même d'échanger une partie de leur poisson pour se procurer les autres objets dont ils ont besoin.

A ces marais sans culture, les Anglais virent bientôt succéder un pays dont la perspective était superbement variée. Il y avait de riches plaines, de petites hauteurs, des coteaux plus élevés, des chaînes de montagnes entremêlées de vallées; et partout, des villages bien bâtis et très rapprochés les uns des autres. La population était très nombreuse, et chaque coin de terre cultivé. Quelques champs étaient couverts de palma-christi ${ }^{1}$, dont la graine sert, aux Antilles, à faire I'huile qui porte le nom de cette plante ou celui d'huile de castor, et qu'on emploie dans la médecine. Mais les Chinois l'ont rendue propre à être mangée ; et il est rare qu'ils s'en servent comme remède.

Cependant, à côté du palma-christi, la plus grande partie du pays était couverte de coton, dont les gousses s'ouvraient et étaient prêtes à être cueillies. Le canal s'élargissait en cet endroit, et le courant y était si rapide qu'il faisait plus de deux milles par heure. Divers bras en étaient détachés, et sur ces bras, ainsi que sur le canal même, et sur des lacs éloignés, on voyait voguer plusieurs bateaux.

Le canal passe ensuite à travers un pays bas, sujet aux inondations, et coupé de lacs et de marais. Quelques petits villages mal construits, quelques saules et des champs de riz sont là les seuls objets qui frappent la vue. Mais bientôt, une suite de villes et de jolis villages, une immense quantité de vaisseaux de toute espèce, et une nombreuse population annoncent les approches du fleuve Jaune où le canal épanche ses eaux avec un cours modéré, en conservant toujours sa direction vers le sud.

Les Anglais virent dans ce voisinage plusieurs très grandes barques qui attendaient la saison suivante pour être chargées des revenus impériaux qu'on transporte dans la capitale de l'empire. D'autres barques préféraient aussi de s'arrêter en ce même endroit, parce que c'est une espèce de point 


\section{Voyage dans l'intérieur de la Chine et en Tartarie}

central qui, ayant une communication régulière avec chaque partie de l'empire, est plus propre à l'échange des marchandises.

Le 2 novembre, les yachts qui portaient l'ambassade arrivèrent dans la partie du canal où il se réunit au fleuve Jaune. Nous l'avons déjà remarqué : ce fleuve doit son nom à la couleur du limon qu'il charrie et qui y est mêlé en si grande quantité qu'il ressemble plus à de la terre délayée qu'à de l'eau. Du côté où est l'embouchure du canal, ainsi que sur la rive opposée, est une ville très étendue et très peuplée. Là, le canal a environ trois quarts de milles de large, et forme un excellent port.

Ni ce canal, ni aucun autre en Chine n'est entretenu aux frais et pour le profit de quelques individus. II est sous l'inspection et la direction immédiate du gouvernement, dont la politique est de maintenir une communication facile entre les diverses parties de l'empire, parce qu'elle favorise le commerce et l'agriculture du pays, et par conséquent, augmente les revenus de l'État, et les ressources du peuple.

L'extrême rapidité qu'a le fleuve Jaune dans l'endroit où les yachts et les barques de l'ambassade devaient le traverser rendait nécessaire, suivant la coutume des Chinois, un sacrifice à la divinité du fleuve, afin de s'assurer un passage heureux. Dans ce dessein, le pilote, entouré de tout son équipage, se plaça sur le devant du yacht, et tenant dans sa main un coq, destiné à servir de victime, il lui arracha la tête, la jeta dans le fleuve, et consacra le bâtiment en arrosant, avec le sang de l'oiseau, le pont, les mâts, les ancres, et les portes des appartements, et y attachant quelques plumes du même animal. Alors plusieurs grandes jattes remplies de viande furent rangées sur le pont en ligne transversale. Au-devant de ces jattes, on avait placé une coupe remplie d'huile, une de thé, une de liqueur spiritueuse, et une quatrième de sel. Le pilote s'inclina trois fois profondément, en tenant ses mains élevées, et en marmottant quelques paroles, comme pour invoquer la déité. Pendant ce temps-là, on battait avec force le loo ; des mèches allumées étaient élevées vers le ciel ; du papier couvert de feuilles d'étain ou d'argent était brûlé, et l'équipage faisait partir un grand nombre de pétards. Le pilote, s'avançant vers la proue, fit des libations au fleuve, en y versant les coupes qui 


\section{Voyage dans l'intérieur de la Chine et en Tartarie}

contenaient l'huile, le thé et la liqueur ; après quoi, il y jeta celle où était le sel. La cérémonie étant achevée, on emporta les jattes de viande, dont l'équipage se régala. Ensuite, les yachts furent lancés avec confiance à travers le courant du fleuve. Aussitôt qu'on l'eut passé, le pilote remercia le ciel par trois inclinations profondes.

Indépendamment des offrandes journalières, et des adorations qui se font à l'autel placé du côté gauche de la chambre, côté que les Chinois regardent comme le plus honorable, on fait des sacrifices solennels, tels que celui que nous venons de décrire, afin d'avoir un vent favorable ou d'écarter un danger imminent.

Pour que les Chinois fassent des sacrifices, dans l'intention d'apaiser les vagues irritées ou de se les rendre propices, il suffit, sans doute, que la même chose ait été pratiquée par leurs ancêtres. Mais l'origine de cette coutume est plus difficile à expliquer; et la coutume même ne prouve pas que ceux qui l'ont inventée fussent très éclairés. Quelques considérations peuvent faire présumer que l'usage de s'adresser à des êtres invisibles pour leur demander des secours a été fondé sur un principe commun, partout où il a eu lieu.

Aussitôt qu'un homme a eu acquis un pouvoir absolu sur plusieurs autres hommes, et que ce pouvoir a été également senti, soit en présence de celui qui en était revêtu, soit en son absence, on a jugé nécessaire de chercher à obtenir sa bienveillance, en lui offrant tout ce qui semblait devoir lui être plus agréable. Ainsi, le souverain, et en son absence, son palais, son trône, ou la principale demeure du lieu, ont reçu des dons qu'on croyait pouvoir le flatter ; car telle était la ressource du faible pour se ménager l'amitié du puissant ou éviter ses injustices. Si le souverain aimait l'or, les entrailles de la terre étaient creusées pour le satisfaire. S'il préférait de se livrer aux plaisirs déréglés et sanguinaires de la table, plaisirs auxquels on dit que les princes et les conquérants des premiers âges étaient très adonnés, de sanglants sacrifices étaient préparés et offerts à son autel.

On savait que les événements moraux qui influaient sur le bonheur du peuple dépendaient de la volonté du souverain, et que ceux de ses sujets qui vivaient loin des lieux où il se tenait, et qui ne pouvaient le voir, n'en 


\section{Voyage dans l'intérieur de la Chine et en Tartarie}

sentaient pas moins le poids de son autorité. De là, on conclut que les événements physiques étaient également soumis à un être personnifié, quoique invisible, et dont on pouvait acquérir la protection et la faveur par les mêmes moyens qui étaient pratiqués dans la conduite morale du monde.

Les offrandes ou les sacrifices étaient faits quelquefois par une classe d'hommes revêtus du titre de ministres de l'autel ; et ces hommes retenaient, pour leur usage particulier, la plus grande partie des sacrifices offerts. Ainsi, lorsque les dévots devinrent sacrificateurs, ils suivirent l'exemple des prêtres, et après avoir présenté solennellement le sacrifice à la divinité, ils le retinrent pour le manger, consacrant seulement à l'objet de leur culte quelques petites, mais importantes parties de l'offrande, telles, par exemple, que l'huile et le sel. Comme lorsqu'on jetait beaucoup d'huile dans l'eau, les vagues irritées s'apaisaient, cette propriété servit sans doute à confirmer la puissance surnaturelle de la déité à laquelle on s'était adressé, et de la satisfaction que lui causait l'offrande. Quant au sel, il était considéré comme nécessaire pour donner du goût à la plupart des aliments et, par conséquent, on supposait qu'il ne pouvait manquer d'être agréable.

Il paraît que les causes qui ont dirigé d'autres nations dans la nature de leurs sacrifices, ont aussi influé sur les Chinois. Par exemple, lorsqu'une volaille était offerte en sacrifice par les juifs, la loi du Lévitique recommandait : «Que le prêtre l'apportât sur l'autel, lui arrachât la tête et la brûlât sur l'autel ; qu'il fît couler le sang de la volaille sur l'autel, qu'il lui ôtât le jabot et les plumes, et qu'il la jetât ensuite derrière l'autel. » Ces mêmes juifs recommandaient : «De ne point souffrir que le sel du contrat fait avec leur dieu manquât aux viandes des sacrifices. »

Les auteurs profanes font mention de l'huile et du sel comme d'une chose commune dans les sacrifices des anciens Européens. Virgile peint Enée versant de l'huile sur les victimes égorgées :

...Oleum fundens ardentibus extis.

Ovide met, parmi les oblations des premiers Italiens, ... Puri lucida mica salis.

Et Horace n'oublie pas, dans les offrandes qu'on fait aux Pénates irrités le 


\section{Voyage dans l'intérieur de la Chine et en Tartarie}

..Saliente mica.

Mais les Chinois ne croient pas que leurs offrandes suffisent pour leur faire traverser le fleuve Jaune. Ils font aussi beaucoup d'efforts pour vaincre la violence du courant et atteindre le rivage sans accident.

Le vent était favorable lorsque les yachts de l'ambassade passèrent. Ils étaient toués par de légers canots à la voile, et en outre, ils se servaient de leurs grandes voiles et de leurs larges avirons. Quelques-uns traversèrent le courant sans beaucoup dériver ; mais d'autres furent entraînés à une distance considérable de l'entrée du canal où ils devaient aborder, et il fallut les faire haler avec une corde pour les y conduire ; ce qui fut très fatigant.

Parmi les fleuves de l'ancien continent, il n'en est guère qui traverse une plus grande étendue de pays et porte plus d'eau à la mer que le fleuve Jaune. M. Barrow, dont le journal, ainsi que celui de l'ambassadeur, a servi à cet ouvrage plus souvent que nous ne l'avons cité, essaie de donner une idée juste du fleuve Jaune.

« Les sources du fleuve Jaune, dit-il, sont dans deux lacs, situés au milieu des montagnes de cette partie de la Tartarie, désignée sous le nom de Ko-konor. Ces lacs sont à peu près par le trentecinquième degré de latitude nord et par le dix-neuvième degré de longitude à l'ouest de Pékin. Après avoir serpenté dans cette partie de la Tartarie, et fait d'abord vers l'est environ deux cent quarante milles, puis vers le nord-ouest cent milles, et de nouveau vers l'est deux cent cinquante milles, grossi par les eaux de diverses rivières qu'il reçoit dans son cours, le fleuve entre dans la province de Shen-Sée. Là, courant vers le nord dans une direction parallèle à la grande muraille, il la traverse par le trente-neuvième degré de latitude, et entre dans le pays des Tartares-Ortoos qu'il sépare de celui des Tartares-Monguls. Continuant dans une direction septentrionale jusqu'au quarante-neuvième degré de latitude, il parcourt un espace de quatre cents milles. Les hauteurs de la Tartarie lui livrent en abondance leurs eaux tributaires, et la province de Shen-Sée lui en fournit de toutes les parties de I'horizon. Parcourant ensuite deux cents milles vers l'est, il traverse 


\section{Voyage dans l'intérieur de la Chine et en Tartarie}

encore la grande muraille, et tournant au sud, il fait quatre cents milles dans cette direction, sépare les provinces de Shen-Sée, et entre dans la province de Ho-Nan, par une latitude parallèle à celle où il prend sa source. De là, après avoir reçu les eaux d'un grand lac, il traverse la partie septentrionale de la même province et celle de la province de Kiang-Nan, en faisant droit à l'est cinq cent soixante milles, et il verse l'immense volume de ses eaux dans la mer à laquelle il donne son nom.

«La longueur du cours de ce fleuve a deux milles cent cinquante milles. L'endroit où le traverse le canal impérial n'est éloigné de la mer que de soixante-dix milles. II n'a guère là qu'un mille de large, et dans le milieu du courant, la profondeur est de neuf à dix pieds. Cependant, quoique le pays soit très plane, le courant du fleuve est si rapide qu'il fait sept ou huit milles par heure. II est vrai que jamais la rapidité d'une rivière ne dépend de la pente d'une partie du pays qu'elle traverse, mais de l'impétuosité de sa chute, lorsqu'elle est encore près de sa source, et de l'étrécissement du canal dans lequel elle est ensuite forcée de couler, ou bien de l'accroissement soudain de ses eaux dans le même canal : cette vérité est démontrée par les observations que le major Rennel a publiées sur le cours du Gange.

«Pour éviter toute possibilité d'exagération, supposons que dans l'endroit où les Anglais traversèrent le fleuve Jaune, il n'eût que trois quarts de mille de large, une profondeur moyenne de cinq pieds, et un courant de quatre milles par heure; de là, il s'ensuit que ce fleuve verse chaque heure, dans la mer Jaune, un volume d'eau égal à 418176000 pieds cubes, ou 2563000000 gallons $^{1}$; ce qui fait onze fois plus d'eau que le Gange n'en fournit à la mer des Indes.

«Pour pouvoir se former quelque idée de la quantité de limon mêlée aux eaux du fleuve Jaune, on fit l'expérience suivante. Dans l'endroit où le courant était de sept ou huit milles par heure, et où

\footnotetext{
110252000000 pintes, mesure de Paris. (Note du Traducteur).
} 


\section{Voyage dans l'intérieur de la Chine et en Tartarie}

le fleuve avait neuf pieds de profondeur, on prit un gallon et troisquart d'eau, mesure commune. Cette eau déposa un sédiment qui, lorsqu'il fut compact et pressé en forme de brique, forma une masse de deux pouces et un tiers cubes. Ce sédiment était composé d'un limon argileux très fin et d'une teinte jaunâtre ; et lorsqu'il fut sec, on le réduisait facilement en poudre impalpable, en le pressant entre les doigts.

«Martini observant combien le fleuve Jaune paraît trouble, et ne se doutant pas du peu de matière colorée qu'il faut pour teindre un grand volume d'eau, estime que dans la saison des pluies le limon que charrie ce fleuve forme un tiers de son volume.

«Quelques-uns des voyageurs qui ont parcouru l'Egypte ont également cru que la quantité de limon mêlée aux eaux du Nil dans le temps où ce fleuve déborde formait un vingtième de son volume. Mais le docteur Shaw, observateur bien plus exact, ayant fait évaporer une quantité donnée d'eau du Nil, trouva que le résidu n'était que la cent vingtième partie de la masse première.

«Suivant la méthode observée pour estimer la quantité de limon contenu dans les eaux du fleuve Jaune, il parut que le limon ne formait que la deux centième partie du volume des eaux. II est vrai que, par la nature de l'expérience, il doit s'être perdu une quantité considérable de limon.

«Cependant, d'après la proportion dont nous venons de faire mention, le fleuve porte chaque heure dans la mer Jaune 3420000000 pouces cubes, ou 2000000 pieds cubes de terre ; ce qui fait 48000000 par jour, et 17520000000 par an.

«Supposé que la profondeur moyenne de la mer Jaune soit de vingt brasses ou de cent vingt pieds (et les Anglais la trouvèrent rarement aussi profonde), la quantité de terre charriée par le fleuve Jaune, si elle était accumulée, suffirait pour former jusqu'à la surface de la mer une île d'un mille carré dans l'espace de soixante-dix jours. En portant plus loin ce calcul, un observateur curieux trouvera en combien de temps la mer Jaune peut être 


\section{Voyage dans l'intérieur de la Chine et en Tartarie}

comblée par le limon seul que le fleuve y dépose successivement. Ainsi, en admettant que cette mer s'étend au nord du fleuve, et comprend les golfes de Pé-Ché-Lée et de Lea-Tong, la somme des milles carrés qui composent cette étendue est d'environ 125000 qui, multipliés par le nombre de 70 jours, nécessaires pour remplir un mille carré, doit faire 8750000 jours, ou 24000 ans.

« D'après ce calcul, on suppose que la quantité de terre portée par le fleuve Jaune est sans cesse la même; mais cela peut n'être point ainsi. Toutefois, le cours de ce fleuve est d'une très grande longueur; il se précipite avec une excessive rapidité des montagnes de la Tartarie, et entraîne tout ce qu'il rencontre devant lui. De fréquentes crues, occasionnées par de fortes pluies, augmentent sa vélocité comme son volume, et le font déborder dans les pays plats où il passe, et qui ne sont composés que d'un sol léger et sans aucune compacité. II est donc possible qu'il charrie encore, pendant des siècles multipliés, une aussi grande quantité de terre que celle qu'il charriait au passage de l'ambassade anglaise. »

Tandis que les yachts qui portaient les Anglais s'avançaient vers le fleuve Jaune, il y eut une correspondance suivie entre l'empereur et le nouvel et respectable conducteur de l'ambassade. Sur la représentation de ce dernier, la lettre adressée à sir Erasme Gower, et retenue par Ho-Choong-Taung, fut, par l'ordre exprès du monarque, envoyée à Chu-San. Sun-ta-Zhin fit souvent part à l'ambassadeur des expressions flatteuses qu'employait l'empereur, en parlant de lui dans ses dépêches. L'ambassadeur était particulièrement informé que ces expressions n'étaient dues qu'aux rapports favorables de Sun-ta-Zhin, relativement à la conduite et aux dispositions des Anglais. Ce Chinois déclara que, d'après les observations les plus attentives, il était convaincu que l'ambassadeur n'avait réellement d'autre intention que celle de procurer à sa patrie des avantages commerciaux, que les nations européennes considéraient comme un objet très important, bien qu'aux yeux d'un homme d'État chinois cet objet fût de peu de conséquence, et ne méritât pas tous les embarras d'une expédition aussi lointaine que celle qu'il avait occasionnée. Sun-ta-Zhin ajouta qu'il n'apercevait, dans les sentiments et 


\section{Voyage dans l'intérieur de la Chine et en Tartarie}

dans les mœurs des Anglais, rien dont la communication pût avoir le moindre danger pour le peuple avec lequel ils désiraient avoir des relations.

Les gracieuses expressions de l'empereur étaient quelquefois accompagnées de présents de choses confites, qu'il choisissait sur sa table et envoyait, suivant la manière des Orientaux, comme des marques de son attention particulière.

En répondant aux lettres de Sun-ta-Zhin, l'empereur lui manda :

«Qu'il avait conçu lui-même une haute estime pour l'ambassadeur et pour sa nation, malgré les divers soupçons qu'on avait eus sur eux; qu'il était déterminé à protéger leur commerce, auquel l'ambassadeur paraissait prendre un si vif intérêt ; qu'il avait, à la vérité, refusé d'accéder à des demandes particulières, mais que ce n'était pas parce qu'il les regardait précisément comme dangereuses en elles-mêmes, mais parce qu'elles auraient fait introduire des nouveautés qu'il ne croyait pas prudent d'adopter, au moins tout à coup, à l'âge avancé où il était. Que quant aux affaires de Canton, le détail de ce qui concernait cette province éloignée avait été presque entièrement à la discrétion du vice-roi qui, officiellement consulté sur la réponse, ne s'était nullement soucié de dicter l'abolition des pratiques qu'il avait permises. Mais que pour donner une marque de son attention aux vœux des Anglais à cet égard, l'empereur avait fait un changement dans le gouvernement de cette province, et y avait nommé une personne de son sang, laquelle était douée de sentiments extraordinaires de justice, et d'une bienveillance particulière envers les étrangers ; qu'il avait écrit à ce nouveau vice-roi, qui n'avait point encore quitté son premier gouvernement de Ché-Kiang, dont le Chu-San faisait partie, et lui avait recommandé, dans les termes les plus forts, de revoir les règlements du port de Canton, et de mettre un terme aux vexations dont se plaignaient les Anglais.

Sun-ta-Zhin dit en outre à l'ambassadeur qu'on pourrait peut-être imaginer que, par amitié pour son excellence, il était porté à donner l'interprétation la plus favorable aux dépêches de l'empereur; mais que les 


\section{Voyage dans l'intérieur de la Chine et en Tartarie}

expressions dont il s'était servi dans les principales choses qu'ils avaient dites étaient celles de l'empereur lui-même. II ajouta ensuite que, comme le nouveau vice-roi de Canton résidait encore à Han-Choo-Foo, capitale de la province de Ché-Kiang, il lui présenterait l'ambassadeur qui, par ce moyen, aurait la confirmation de tout de qu'il venait d'entendre.

Les lettres qu'écrivait l'empereur et celles que lui adressait Sun-ta-Zhin étaient mises dans un sac ou un panier plat, qu'un homme à cheval portait, attaché autour de son corps. Au bas du sac étaient suspendues des clochettes dont le bruit annonçait à chaque station l'arrivée du messager, qui y était changé ainsi que le cheval. La distance entre les stations était de dix ou douze milles.

Aussitôt que les yachts de l'ambassade entrèrent dans la province de Kiang-Nan, elle reçut de la part du vice-roi une marque d'attention que les autres commandants avaient négligée. Les hommes qui traînaient les yachts lorsque les Anglais remontèrent le Pei-Ho à leur arrivée en Chine, ainsi que ceux qui leur avaient servi de la même manière à leur retour, étaient vêtus de simple toile de coton bleue, et quelquefois ils ne portaient que les haillons de la pauvreté. Mais dans la province de Kiang-Nan, ils parurent avec un uniforme neuf, bordé de rouge, et ils étaient coiffés d'un bonnet pointu, sur le sommet duquel était un bouton rouge et plat. Lorsque ces hommes étaient changés, l'uniforme passait à ceux qui les relevaient. Cet uniforme était à tous égards mieux assorti aux yachts et aux barques de l'ambassade. D'une jolie construction, commodes pour les passagers, portant le pavillon impérial, ornés des banderoles et d'autres décorations navales, accompagnés d'une musique bruyante, mais agréable quand elle était entendue de loin, les yachts de l'ambassade étaient au nombre de quarante, et marchaient en ordre à la suite l'un de l'autre. II est vrai qu'ils n'allaient pas très vite, surtout quand la brise soufflait du sud-ouest; mais cette même brise rendait la température extrêmement agréable. En même temps, un ciel nuancé de couleurs grisâtres ne laissait passer que la quantité de rayons du soleil qu'il fallait pour que l'air fût encore plus doux.

La scène était encore embellie par la vue des autres bâtiments qui naviguaient et se croisaient sur le canal ; par la perspective des villes et des villages bâtis sur ses bords; par les laboureurs qui cultivaient leurs champs 


\section{Voyage dans l'intérieur de la Chine et en Tartarie}

ou recueillaient leur moisson; par les postes militaires déployant leurs étendards et tirant, à l'approche de l'ambassade, leurs canons pour la saluer ; enfin, par un nombre immense de spectateurs, accourus sur les bords du canal pour voir passer les étrangers.

Au sud du fleuve Jaune, les yachts allaient beaucoup plus vite, parce qu'à partir de ce fleuve, le canal impérial a un courant beaucoup plus rapide : c'est pour cela qu'on a augmenté dans cette partie le nombre des écluses. Plus loin, le canal passe sur les bords du lac Pao-Yng ; mais il est beaucoup plus élevé que ce lac, et une chaussée, semblable à celle que nous avons décrite, l'en sépare. Il se fait dans le lac Pao-Yng une pêche considérable, pour laquelle on emploie principalement l'oiseau dont nous avons déjà parlé, le leu-tze ou cormoran-pêcheur de la Chine, lequel dans une langue scientifique peut être distingué des autres espèces sous le nom de Pelicanus sinensis. On élève sur le lac Pao-Yng un très grand nombre de ces oiseaux, et on en envoie dans toutes les parties de l'empire.

Au-delà du lac, le pays est si marécageux qu'il est impossible de le cultiver comme les autres. Le lien-wha y croît spontanément et en abondance. Dans les endroits ainsi submergés, les Chinois déploient un nouveau genre d'industrie. Ils font des radeaux ou des claies de bambou, qu'ils chargent d'une couche de terre, et laissent flotter sur l'eau; ensuite, ils y cultivent plusieurs espèces de végétaux. Ainsi, à bord des vaisseaux, on se procure une petite quantité de jardinage, en semant les graines dans de la terre arrosée, ou bien dans des morceaux de flanelle montés sur des châssis, et humectés avec soin. C'est, par exemple, de cette manière qu'on a promptement du sénevé ; ce qui est extrêmement agréable aux personnes qui sont depuis longtemps en mer.

Indépendamment de la méthode employée par les Chinois pour se procurer des récoltes sur l'eau, ils ont beaucoup d'autres moyens de tirer parti des lacs, des rivières et des canaux. Ils cultivent des végétaux qui croissent dans le fond des eaux, et particulièrement le lien-wha ; ils prennent, de beaucoup de manières, les oiseaux qui se tiennent sur l'eau, et les poissons qui sont au-dessous, ainsi que les autres animaux qui rampent dans 


\section{Voyage dans l'intérieur de la Chine et en Tartarie}

le fond; ils fertilisent les terres par l'arrosement; ils ont, par eau, une communication peu chère et aisée, entre les différentes parties de l'empire, et de cette manière, ils laissent à l'agriculture beaucoup de terrain qu'il faudrait pour les grandes routes, et beaucoup de travail qu'exigerait leur entretien. Ils épargnent encore davantage de terrain, puisqu'ils n'ont pas besoin d'en employer en pâturages ou à la culture du fourrage qu'il leur faudrait, s'ils étaient obligés d'avoir des animaux pour porter les voyageurs et les marchandises : aussi on peut, sans exagération, dire qu'en Chine le produit des eaux est égal à celui des terres, proportionnément à leur étendue.

La partie marécageuse de la province de Kiang-Nan était, de tous les pays que les Anglais avaient vus en Chine, celui qui avait l'air le plus pauvre et le moins propre à être habité. Après avoir vu ravager leurs habitations et le produit de leur industrie par des inondations extraordinaires, ou par d'autres calamités inattendues, les Chinois quittent quelquefois ces sortes de pays, et vont former des colonies en Tartarie, malgré la prévention générale qu'ils ont contre les Tartares. Quoiqu'un grand nombre des premiers mandarins et la plupart des vice-rois des provinces soient nés en Tartarie, ou issus du sang tartare, et que quelques-uns d'entre eux aient des mœurs polies et un caractère très respectable, les Chinois considèrent les Tartares, en général, comme des barbares. Pour justifier leur opinion à cet égard, ils citent un fait que le peuple raconte depuis quatre siècles: c'est que quand les TartaresMonguls s'emparèrent de Pékin pour la première fois, ils plantèrent des tentes pour eux, et logèrent leurs chevaux dans les palais des empereurs chinois.

Dans le milieu du plat pays que traversaient les Anglais, il y avait une ville du troisième ordre. Le haut de ses murailles n'était guère au-dessus du niveau du canal, qui formait en cet endroit un aqueduc de vingt pieds de haut et de deux cents de large. Le courant de l'eau faisait trois milles par heure. On peut juger par là de la force des levées qui contiennent l'eau, et de l'immensité de travail qu'il a fallu pour les construire.

Bientôt les yachts se trouvèrent devant une jolie ville, où toutes les maisons qui bordaient le canal étaient à deux étages, et peintes en blanc. Les habitants étaient mieux vêtus, et les femmes plus belles et plus jolies que la plupart de celles que les Anglais avaient vues au nord. 


\section{Voyage dans l'intérieur de la Chine et en Tartarie}

Un peu au-dessus de cette ville, le canal cesse d'avoir du courant. Comme le terrain s'élève du côté du sud, il a été nécessaire de creuser à vingt pieds de profondeur pour conserver le niveau dans un espace de sept ou huit milles anglais. A l'extrémité de cette partie du canal, les voyageurs virent une ville du premier ordre, qui semblait être d'une haute antiquité. Une partie des murailles et des maisons était en ruine, et couverte de mousse, d'herbe et de ronces.

Cette ville paraissait, cependant, faire un grand commerce. II y avait à l'ancre au moins mille vaisseaux de différentes grandeurs. Une garnison, d'environ deux mille hommes, était sous les armes, et avait ses drapeaux et sa musique, comme si l'on allait la passer en revue. La campagne des environs était plane, bien cultivée, et couverte de riz et de mûriers.

Ces arbres ne semblent pas beaucoup différer des mûriers communs d'Europe. On élague continuellement leurs branches, afin que les jeunes scions poussent plus promptement, car les feuilles des scions sont plus fines, plus tendres, et plus nourrissantes pour les vers à soie, que celles des grosses branches. Quelques-uns de ces arbres portent des mûres blanches, et d'autres, des mûres rouges. On les cultive avec le plus grand soin. On les plante par rangs bien alignés, et à dix ou douze pieds de distance les uns des autres. Au pied de chaque arbre, on rapporte une couche de terre argileuse, humectée mais non inondée, et d'environ un pied au-dessus du sol. Les arbres sont fréquemment élagués et étêtés, parce qu'on veut faire pousser constamment de jeunes branches et des feuilles tendres. On pense que les feuilles des mûriers noirs sont plus nourrissantes que celles des mûriers blancs. Les Chinois ne connaissent point l'art de greffer les arbres; mais quelques grosses branches de leurs mûriers sont couvertes de gui. Pour que les plantations de mûriers n'occasionnent aucune perte de terrain, on sème du riz dans l'espace qui reste entre les arbres et l'on arrose par le moyen des sillons.

Les vers à soie sont nourris dans de petites chaumières qu'on construit exprès au milieu des plantations de mûriers, afin qu'ils soient éloignés de toute espèce de bruit ; car les Chinois pensent que le seul aboiement d'un chien suffit pour nuire à ces insectes. Cependant, les habitants des villes en 


\section{Voyage dans l'intérieur de la Chine et en Tartarie}

élèvent quelques-uns et, pour cela, ils achètent des feuilles de mûrier des cultivateurs de cet arbre.

Les œufs des vers à soie sont déposés sur du papier, et conservés jusqu'au temps où on veut les faire éclore. Quand cette époque est arrivée, on humecte avec un peu d'eau le papier qui contient les œufs; et peu de temps après les vers éclosent. La température du climat suffit pour cela. Les Chinois ne connaissent ni l'usage, ni la nature du thermomètre: la seule expérience les guide. Quand ils veulent faire éclore les œufs des vers à soie plus tôt que de coutume, ils emploient la chaleur artificielle. On fait toujours suffoquer les insectes avant de dévider la soie. Pour la dévider, on met les cocons dans un panier ou dans un vase percé de plusieurs trous, et on les expose à la vapeur de l'eau bouillante, de manière qu'ils puissent en être bien imprégnés. Lorsque les cocons sont dévidés, on mange les chrysalides des vers à soie ; on mange aussi, dans le même pays, et le ver de terre, et la larve de quelques insectes. Mais, en cela, les Chinois ne doivent pas paraître absolument étranges, puisque les colons des Antilles mangent, avec délices, une grosse chenille ${ }^{1}$ qui se trouve sur une espèce de palmier.

Trois jours après avoir traversé le fleuve Jaune, les yachts arrivèrent sur les bords de la rivière Yang-Tsé-Kiang, qui parut aux Anglais au moins égale au fleuve, sinon plus considérable que lui. Elle avait, en cet endroit, environ deux milles de large.

Les sources de cette rivière sont dans les mêmes montagnes d'où sort le fleuve Jaune, et dans son cours, il est un endroit où elle se rapproche assez de lui pour n'en passer qu'à quelques milles. Voici comment M. Barrow décrit cette rivière.

« Le Yang-Tsé-Kiang a deux bras qui, après s'être séparés, s'éloignent l'un de l'autre de quatre-vingts milles, et font vers le sud, dans une direction parallèle, environ soixante-dix milles. Ils se réunissent ensuite entre le vingt-sixième et le vingt-septième

\footnotetext{
${ }^{1}$ On l'appelle, aux Antilles, le ver palmiste; mais on ne le mange qu'aux Iles-du-
} 


\section{Voyage dans l'intérieur de la Chine et en Tartarie}

degré de latitude nord, précisément sur les limites les deux provinces de Yu-Nan et de Sé-Chuen. Courant ensuite vers le nord-est à travers la dernière de ces provinces, le Yang-Tsé-Kiang reçoit les eaux des nombreuses rivières de cette province et de celle de Quée-Choo. Elle fait, dans cette direction, environ six cents milles ; puis elle entre dans la province de Hoo-Quang, par le trente et unième degré de latitude nord. Elle fait plusieurs sinuosités dans cette dernière province, et ajoute à ses eaux celle de divers lacs ; car ils abondent dans cette partie de la Chine. En sortant de la province de Hoo-Quang, la rivière passe entre les provinces de HoNan et de Kiang-Sée, et ses eaux abondantes, tournant un peu de l'est vers le nord, coulent mollement vers la province de Kian-Nan, et se versent dans la mer qui borne la Chine à l'est, par le trentedeuxième degré de latitude nord. Depuis la province de Hoo-Quang jusqu'à l'embouchure de la rivière, il y a environ huit cents milles ; ce qui fait que depuis sa source, cette rivière parcourt au moins deux mille deux cents milles anglais. Dans l'endroit où les yachts de l'ambassade la passèrent, le courant ne faisait pas plus de deux milles par heure; mais la rivière était plus profonde que le fleuve Jaune.

Ainsi, ces deux grandes rivières prennent leur source dans les mêmes montagnes; passent, dans un endroit presque l'une auprès de l'autre ; s'écartent ensuite de quinze degrés de latitude, finissent par se jeter dans la même mer à deux degrés l'une de l'autre. Elles embrassent, dans leur cours, une étendue de pays de plus d'un millier de milles de longueur, qu'elles contribuent à fertiliser et à enrichir, mais auquel leurs débordements nuisent quelquefois. Ce pays comprend dans ses limites la plus grande étendue de l'ancien empire chinois, et est situé dans cette partie de la zone tempérée qui, en Asie comme en Europe, a vu naître les hommes les plus célèbres, et exécuter les actions les plus brillantes dont I'histoire fasse mention.

Vent. (Note du Traducteur.) 


\section{Voyage dans l'intérieur de la Chine et en Tartarie}

Pour joindre le canal, qui se prolonge de l'autre côté du Yang-Tsé-Kiang, les yachts furent obligés de côtoyer un peu la rive septentrionale de cette rivière. Là, la face du pays était entièrement changée. Au lieu de plaines, de lacs et de marais, le terrain s'élevait graduellement depuis le bord de la rivière, et était enrichi de plantes, dont les espèces, variant ainsi que les couleurs, étaient entremêlées d'arbres, de temples et de pagodes. II y avait dans la rivière plusieurs îles bordées de buissons, et des rochers qui paraissaient au-dessus des eaux. Les vagues de la rivière roulaient comme celles de la mer; et l'on dit qu'on y voit quelquefois des marsouins. Les Anglais n'y virent que des jonques à l'ancre.

Tandis que les voyageurs traversaient le Yang-Tsé-Kiang, leur attention fut presque entièrement captivée par une île, située dans le milieu de cette rivière, et appelée Chin-Shan, ou la Montagne d'Or. Cette île, dont les bords sont très escarpés, est couverte de jardins et de maisons de plaisance. L'art et la nature semblent s'être réunis pour lui donner une perspective enchanteresse. Elle appartient à l'empereur, qui y a bâti un très grand et très beau palais, ainsi que divers temples et pagodes, placés dans la partie la plus élevée de l'île.

Le terrain, qui est au midi du Yang-Tsé-Kiang, s'élève par degrés à une telle hauteur qu'il a fallu, en quelques endroits, creuser jusqu'à quatre-vingts pieds pour trouver le niveau et faire passer le canal.

C'est dans la campagne des environs que croît l'arbuste qui fournit cette espèce particulière de coton, dont on fait l'étoffe connue en Europe sous le nom de nankin. Le duvet qui enveloppe les graines est ce que dans la langue du commerce les Anglais appellent coton-laine. Ce duvet est ordinairement blanc ; mais dans la province de Kiang-Nan, dont Nan-Kin est la capitale, il a cette même couleur de jaune rouge qu'il conserve lorsqu'il est filé et tissu. On croit que la couleur et la qualité supérieure du coton de Kiang-Nan est due à la nature particulière du sol ; et on assure que l'espèce en dégénère, à l'un et à l'autre égard, quand on la transplante dans une autre province, quelque peu de différence qu'il y ait entre les climats de cette province et celui de KiangNan. 


\section{Voyage dans l'intérieur de la Chine et en Tartarie}

Dans plusieurs parties du Kiang-Nan, des ponts solides traversent le canal. Quelques-uns sont construits d'un granit rougeâtre qui contient beaucoup de spalt ; d'autres sont d'un marbre gris et commun. Les arches de quelques-uns de ces ponts sont en cintre plein; dans d'autres, elles ont une forme elliptique, et l'extrémité de l'ellipse est précisément au haut de l'arche. Il y en a quelques-uns qui sont en fer à cheval, dont la partie la plus large est au haut de l'arche. Les pierres employées dans la construction des arches d'un pont chinois ne sont point carrées, et ne laissent point au haut de l'arche un espace triangulaire rempli par ce qu'on appelle la clef. Au contraire, les pierres sont taillées en formes de coins, proportionnément à la courbe de l'arche; de sorte que, quand elles sont placées, elles se trouvent toutes parfaitement adhérentes.

Pour passer sous un pont, il faut baisser les mâts ordinaires des yachts et des barques; et on en élève d'autres, consistant en deux longues perches, qui se joignent par le haut, et s'écartent en bas, suivant la largeur du bâtiment, comme les deux côtés d'un triangle isocèle. Ces mâts sont élevés par le moyen de deux verrous de fer qui passent dans les bouts de perches, et dans deux poteaux, chacun desquels est d'un côté du vaisseau, et a une entaille propre à recevoir le bout des perches. Ce double mât est promptement baissé pour passer sous un pont; mais il y a des ponts assez élevés pour qu'on y passe à la voile.

Ces ponts sont nécessaires dans cette partie pour établir une communication entre les deux bords du canal qui sont presque entièrement couverts de villes et de villages. La hauteur des arches et les marches par lesquelles on y monte empêchent d'y faire passer des voitures à roues ; mais le nombre de ces voitures est très petit, et on s'en sert rarement, parce que les marchandises les plus pesantes et la plupart des passagers vont par les rivières et les canaux, dont le pays est coupé dans tous les sens.

On a pratiqué, sous un pont, une communication entre le grand canal et un autre canal auquel il fournit de l'eau ; et cette communication ne gêne ni les gens qui passent sur le pont, ni ceux qui tirent la corde des barques.

Les rues de la cité de Sou-Choo-Foo sont divisées, comme celles de Venise, par des canaux qui partent tous du principal canal; et sur chacun de 


\section{Voyage dans l'intérieur de la Chine et en Tartarie}

ces canaux, on a construit un élégant pont de pierre. La flotte des yachts et des bateaux qui portaient les Anglais fut près de trois heures à traverser les faubourgs de Sou-Choo-Foo pour arriver jusqu'aux murs de la ville, près desquels il y avait un nombre immense de bâtiments qu'on avait mis à sec. Dans un seul chantier, on en voyait seize qu'on construisait à côté l'un de l'autre, et qui tous étaient du port de deux cents tonneaux. Le canal passe sous les murs de la ville par différentes arches, assez semblables à celles qu'on voit dans les murailles de Batavia.

La ville de Sou-Choo-Foo paraît extrêmement grande et extrêmement peuplée. Les maisons y sont bien bâties et agréablement décorées. Les habitants qui, pour la plupart, sont vêtus de soie, ont l'air d'être riches et heureux. Cependant, on dit qu'ils sont fâchés que la cour n'habite plus NanKin, qui, située dans leur voisinage, était autrefois la capitale de l'empire. Certes, il n'y a que de grandes considérations politiques qui aient pu engager le souverain à préférer la province septentrionale de Pé-Ché-Lée, sur les confins de la Tartarie, à la partie de ses États où tous les avantages du climat, du sol et des productions ont été prodigués par la nature, et où la nature ellemême a été perfectionnée par le talent et l'industrie. Les voyageurs ont appelé Sou-Choo-Foo le Paradis de la Chine ; et un dicton, commun parmi les habitants de cette ville, est : «Que le ciel est au-dessus d'eux, mais que sur la terre, ils ont Sou-Choo-Foo ».

Les Anglais trouvèrent les femmes de Sou-Choo-Foo plus belles, plus jolies, et vêtues avec plus de goût que la plupart de celles qu'ils avaient vues dans le nord de la Chine. Sans doute que dans les provinces du nord la nécessité de cultiver un sol moins fertile, de partager et les plus rudes travaux des hommes et les grossiers aliments qui servent à leur nourriture, et de n'avoir que très peu de temps pour soigner leurs personnes, contribuent à noircir leur teint, à grossir leurs traits et à les défigurer, bien plus que les rayons du soleil ne noircissent et ne défigurent celles qui n'habitent qu'à trente degrés de distance de l'équateur. Les dames de Sou-Choo-Foo portent quelquefois sur le devant de la tête un petit bonnet de satin noir, qui forme une pointe entre les deux sourcils, et est enrichi de brillants. Elles ont aussi des pendants de cristal ou d'or. 


\section{Voyage dans l'intérieur de la Chine et en Tartarie}

A peu de distance de Sou-Choo-Foo est le superbe lac de Tai-Hoo, environné d'une chaîne de montagnes pittoresques. Ce lac fournit beaucoup de poisson aux habitants de Sou-Choo-Foo; et en outre, il est pour eux un lieu de rendez-vous public et d'amusement. Beaucoup de canots, qui servent aux promenades de plaisir, sont conduits par une seule femme. Chaque canot a une chambre très propre; et on prétend que celles qui les conduisent exercent plus d'une profession. Le lac de Tai-Hoo sépare la province de KiangNan de celle de Ché-Kiang, dont l'ambassade approchait déjà la capitale.

Au-delà de Sou-Choo-Foo, on voyait des plantations de mûriers, très étendues et semblables à une forêt. II y avait aussi, parmi les mûriers, quelque arbre à suif. Du fruit de cet arbre, qui est le croton sebiferum de Linnæus, les Chinois retirent une espèce de graisse végétale avec laquelle ils font une grande partie de leur chandelle. Ce fruit ressemble beaucoup, extérieurement, aux graines du lierre. Dès qu'il est mûr, la capsule s'ouvre et se divise en deux, ou plus fréquemment en trois parties qui, en tombant, laissent à découvert autant de noyaux, chacun desquels est séparément attaché à l'arbre et couvert d'une substance charnue et de la blancheur de la neige; ce qui fait un très beau contraste avec les feuilles de l'arbre, lesquelles, dans cette saison, sont d'un rouge tenant à la fois du pourpre et de l'écarlate. On écrase les noyaux et on les fait bouillir dans de l'eau pour en extraire la substance charnue ou graisseuse, et les chandelles qu'on fait avec cette substance sont plus fermes que celles de suif, et n'ont aucune espèce d'odeur. Cependant, elles n'égalent ni la bougie, ni les chandelles de blanc de baleine.

Cette dernière substance est inconnue en Chine, ainsi que l'animal qui la produit. On n'y connaît guère non plus l'art de blanchir la cire, et celle qu'on y blanchit s'emploie en emplâtre ou en onguent.

La bougie qu'on voit en Chine se fait avec la cire produite par l'insecte qui se nourrit sur le troène, et que nous avons décrit dans le chapitre de la Cochinchine. Cette cire est naturellement blanche et si pure qu'elle ne donne point de fumée; mais on en ramasse si peu qu'elle est rare et chère. Les chandelles à bon marché sont faites de suif ordinaire ; mais elles ont trop peu de consistance pour qu'on s'en serve sans les revêtir d'une légère couche de suif végétal ou de cire. On en peint aussi quelquefois la surface en rouge. 


\section{Voyage dans l'intérieur de la Chine et en Tartarie}

Les Chinois se servent de différentes matières pour faire des mèches. Celles qu'ils emploient dans leurs lampes sont de trois sortes: d'amiante, qui brûle sans se consumer ; d'armoise ${ }^{1}$, ou d'une espèce de chardon ${ }^{2}$, qui sert aussi pour les armes à feu. Mais pour les chandelles, ils se servent d'un bois léger et inflammable qui, percé par l'extrémité d'en bas, est posé sur une pointe de fer fixée sur le haut du chandelier qui, au lieu d'être creux, est plat. Ainsi, cette pointe soutient la chandelle sans qu'on ait besoin de bobèche. L'esprit économique des Chinois leur fait considérer que cette forme de leurs chandeliers remplit aussi l'objet, qui n'est connu ailleurs que des plus pauvres classes du peuple, et qu'elles cherchent à obtenir en se servant de ce qu'on appelle un binet. Par ce moyen, on croit qu'il y a un dixième de différence dans la consommation de la chandelle.

L'arbre à suif a été, dit-on, transplanté à la Caroline, et y réussit aussi bien qu'en Chine. C'était presque la seule espèce d'arbre qui ombrageât les bords du grand canal, dans la partie où l'ambassade anglaise était alors. Là, le canal était sans aucun courant, et si large qu'un pont de pierre, qui le traversait, n'avait pas moins de quatre-vingt-dix arches.

De Sou-Choo-Foo à Han-Choo-Foo, c'est-à-dire dans une étendue d'environ quatre-vingt-dix milles, le canal impérial continue à avoir une largeur de soixante à cent toises, et ses bords sont revêtus de murailles de pierre. Tout le pays qu'il traverse dans cette partie est non moins beau que riche.

Les yachts s'arrêtèrent dans un village près de Han-Choo-Foo pour recevoir le nouveau vice-roi de Canton, lequel vint, dans son bateau, faire la première visite à Sun-ta-Zhin et à l'ambassadeur.

Le vice-roi Chaung-ta-Zhin paraissait avoir un caractère doux et des mœurs aimables. Il se prévalait peu, et de l'avantage d'être parent de l'empereur, et du poste qu'il occupait comme gouverneur général des deux provinces de Quang-Tung ${ }^{3}$ et de Quang-Sée. II confirma les assurances

\footnotetext{
${ }^{1}$ Artemisia.

2 Garduus marceus.

3 C'est la province que les Européens appellent Canton.
} 


\section{Voyage dans l'intérieur de la Chine et en Tartarie}

données par Sun-ta-Zhin, relativement aux dispositions et aux ordres de l'empereur en faveur des Anglais ; et il parla de la bienveillance qu'il avait luimême pour eux.

Le lecteur observera que les noms des Chinois, cités dans cet ouvrage, sont tous d'une syllabe, indépendamment des additions de qualités ou de titres. Chaque mot de la langue chinoise est également monosyllabique. Les additions sont d'autant plus nécessaires qu'un nom ne renferme aucune distinction en faveur de la famille de celui qui le porte. II n'y a pas plus de cent noms de famille connus dans toute l'étendue de l'empire, et l'expression des cent noms est souvent employée comme un terme collectif pour toute la nation chinoise. Cependant, les individus prennent à différentes époques ou dans différentes circonstances des surnoms qui expriment quelque qualité ou rappellent quelque événement. Chaque nom de famille est porté par des personnes de toutes les classes; cependant, l'identité de ces noms indique quelque rapport. Tous ceux qui les portent peuvent fréquenter la maison de ceux qu'ils croient leurs communs ancêtres.

Un Chinois épouse rarement, ou plutôt il n'épouse jamais une femme qui porte son nom de famille; mais les fils et les filles de deux sœurs mariées à des hommes d'un nom différent se marient souvent ensemble. Ceux de deux frères qui portent le même nom ne le peuvent pas.

En Chine, les noms n'annoncent jamais aucune distinction ; il n'y existe point de noblesse héréditaire; et cependant, chacun y fait beaucoup d'attention à sa généalogie. Celui qui jusqu'à une époque reculée peut citer ses ancêtres comme s'étant distingués par leurs vertus privées, ou par des services publics, et par les honneurs qu'ils ont en conséquence obtenus du gouvernement ; celui-là, dis-je, est plus respecté que des hommes nouveaux. Ceux qu'on croit être les descendants de Confucius sont toujours traités avec une considération particulière. Les empereurs leur ont même accordé quelques privilèges. L'ambition d'une origine illustre est si générale, que les empereurs ont souvent donné des titres aux aïeux morts d'un homme de mérite.

On ne néglige, en Chine, aucun moyen pour exciter à faire de bonnes actions, et empêcher qu'on en fasse de mauvaises; et l'on emploie 


\section{Voyage dans l'intérieur de la Chine et en Tartarie}

également l'espoir de la louange et la crainte du blâme. II y a un registre public, nommé le livre du mérite, dans lequel on inscrit tous les exemples frappants d'une conduite estimable; et dans les titres d'un homme, on mentionne particulièrement le nombre de fois que son nom a été inséré dans ce livre. D'un autre côté, celui qui commet des fautes est dégradé, et il ne suffit pas qu'il se borne à ne porter que son titre réduit ; il faut encore qu'il joigne à son nom le fait pour lequel il a été dégradé.

Ces règlements sont faits principalement pour les mandarins auxquels l'empereur ne confie l'autorité que pour qu'ils l'emploient à faire le bonheur du peuple. Si l'on abuse de cette autorité, et que le peuple souffre une plus grande somme de maux que celle qui est nécessairement attachée à la nature de la société, c'est en grande partie parce qu'un homme ne possède pas des facultés physiques assez étendues pour empêcher que ses délégués trompent sa vigilance, et pervertissent même ses intentions, à moins que le peuple n'ait le pouvoir d'exercer sur eux une certaine censure.

Indépendamment des honneurs qu'il tenait de l'empereur, le vice-roi Chaung-ta-Zhin avait reçu des habitants de la province de Ché-Kiang le plus flatteur de tous les titres. Pour le récompenser de les avoir gouvernés avec équité et avec bienfaisance, ils l'avaient surnommé le second Confucius.

Le vice-roi entra avec Sun-ta-Zhin et l'ambassadeur, à Han-Choo-Foo, le 9 novembre 1793. 


\title{
Voyage dans l'intérieur de la Chine et en Tartarie
}

\author{
CHAPITRE V \\ Voyage à Han-Choo-Foo, \\ et de Han-Choo-Foo à Chu-San.
}

Un bassin vaste et irrégulier termine le canal impérial dans les faubourgs de Han-Choo-Foo. II est accru par les eaux d'un lac situé à l'occident de la ville. Ce lac fournit aussi beaucoup d'eau à un canal qui entoure la ville, et duquel sont détachés plusieurs autres canaux qui passent dans les principales rues.

Han-Choo-Foo est bâtie entre le bassin du canal impérial et la rivière de Chen-Tang-Chaung qui va se jeter dans la mer à un peu plus de soixante milles à l'est de cette ville. Quand la mer est haute, la largeur de la rivière se trouve augmentée de quatre milles, vis-à-vis de Han-Choo-Foo ; et dans les moments du reflux, on voit une jolie plage d'environ deux milles de large, et s'étendant à perte de vue. Par le moyen de cette rivière, Han-Choo-Foo reçoit des provinces méridionales et y envoie une grande quantité de marchandises. Pour embarquer ces marchandises, ou pour les décharger, on se sert de chariots à quatre roues, qu'on place à la suite l'un de l'autre, et qui forment une chaussée qu'on prolonge ou qu'on raccourcit suivant la distance qu'il y a des vaisseaux au rivage.

Il n'y a point de communication par eau entre la rivière et le canal impérial. Toutes les marchandises qui viennent du côté de la mer et remontent la rivière, ainsi que celles qui descendent par les lacs et les rivières de Ché-Kiang et de Fo-Chen, doivent être d'abord débarquées, lorsqu'on veut les faire passer dans le nord; et c'est ce qui rend Han-Choo-Foo l'étape générale entre les provinces méridionales et les provinces septentrionales de l'empire.

La population de Han-Choo-Foo est immense; car on prétend qu'elle égale presque celle de Pékin. Cependant, la ville n'a, en apparence, rien de grand que les murailles qui l'entourent. Les maisons sont basses. Il n'y en a point qui ait plus de deux étages. Les rues sont étroites et pavées avec de 


\section{Voyage dans l'intérieur de la Chine et en Tartarie}

grands quartiers de pierre dans le milieu, et de petites pierres plates sur les côtés. Toutes les maisons des principales rues ont des boutiques ou des magasins sur le devant; et plusieurs de ces magasins ne sont point inférieurs aux plus brillants de ceux qu'on voit à Londres dans le même genre. On fait à Han-Choo-Foo un commerce très étendu et très actif de soieries ; on y vend aussi beaucoup de fourrures et de large drap d'Angleterre. II est difficile de passer dans les rues à cause de la foule qu'il y a. Ce n'est pas seulement ainsi parce que les habitants se rassemblent pour voir les étrangers, ou dans quelqu'autre occasion extraordinaire, mais parce qu'ils vont où les appellent leurs affaires. Dans les magasins et les boutiques, on voit des hommes et point de femmes. Les satins brodés et tout ce qui concerne les manufactures de soieries occupent une immense quantité de femmes à Han-Choo-Foo. La plupart des hommes y sont vêtus d'une manière agréable et paraissent dans l'aisance.

En Chine, la forme des vêtements est rarement changée par la mode ou le caprice. L'habillement qui convient à l'état d'un homme et à la saison de l'année où il le porte est toujours fait de la même manière. Les femmes mêmes n'ont guère de nouvelles modes, si ce n'est peut-être dans l'arrangement des fleurs et des autres ornements qu'elles mettent sur leur tête. Elles ont en général un réseau de soie qui leur tient lieu de linge ; et elles portent par-dessus, une veste et de grands caleçons de soie qui, lorsqu'il fait froid, sont garnis de fourrures. Elles mettent en outre, par-dessus leur veste, une longue robe de satin, rassemblée avec grâce autour du corps, et nouée avec une ceinture. Ces différentes parties de leurs vêtements sont de couleur différente ; et le goût de celle qui les porte se déploie dans le choix et le contraste de ces couleurs. Quoique les dames chinoises mettent l'embonpoint au rang des beautés d'un homme, elles le regardent comme un grand défaut dans leur sexe, et elles s'efforcent de conserver la finesse et la délicatesse de leur taille. Elles laissent croître leurs ongles, mais elles ne conservent, de leurs sourcils, qu'une ligne arquée et très mince.

Les Anglais apprirent à Han-Choo-Foo que le Lion avait mis à la voile du port de Chu-San le 16 octobre, parce que sir Erasme Gower n'avait point reçu la lettre de l'ambassadeur, quoique sur les représentations de Sun-ta-Zhin, 


\section{Voyage dans l'intérieur de la Chine et en Tartarie}

l'empereur la lui eût fait envoyer. Si cette lettre eût été expédiée quand on la remit au colao Ho-Choong-Taung, le 4 du même mois, elle serait certainement arrivée à Chu-San avant le départ de sir Erasme, et elle eût empêché qu'il ne suivît les premières instructions que lui avait données l'ambassadeur, lorsqu'il croyait séjourner plus longtemps à Pékin ; instructions qui, comme nous l'avons déjà rapporté, enjoignaient à sir Erasme Gower de faire un voyage d'observation, et de ne revenir dans le voisinage de Canton qu'au mois de mai.

Cependant, avant cette époque, la crainte de la mousson du sud-ouest qui s'approchait pouvait engager les vaisseaux de la Compagnie à risquer de partir de Canton pour se rendre en Europe sans convoi, plutôt que d'être obligés d'attendre jusqu'à l'année suivante ; de sorte qu'il semblait que c'était en vain que l'ambassadeur s'était empressé de quitter la capitale de la Chine. Mais ce ministre eut pourtant quelque espoir de pouvoir exécuter le projet qui I'intéressait si vivement, celui de convoyer avec le Lion, jusqu'en Angleterre, la riche flotte qui était alors à Canton. Dans une lettre écrite la veille de son départ de Chu-San, sir Erasme Gower mandait à l'ambassadeur que, se trouvant inopinément avoir besoin de diverses choses pour son équipage, et surtout de drogues de pharmacie, que les Chinois ne pouvaient lui procurer, il prenait le parti de diriger d'abord sa route vers la rivière de Canton, parce qu'il espérait que la factorerie anglaise lui fournirait ce qui lui manquait. II ajoutait qu'ensuite il remettrait immédiatement à la voile pour exécuter les ordres qui lui avaient été donnés par son excellence. Les soupçons qui avaient été ailleurs si contraires aux desseins de l'ambassadeur n'existaient point dans le cœur de Sun-ta-Zhin et du vice-roi. Une lettre pour retenir le Lion fut à l'instant envoyée aux commissaires de la Compagnie à Canton, afin qu'ils la fissent parvenir à sir Erasme Gower, si cela était encore possible.

L'Indostan était resté à Chu-San, où il attendait le capitaine Mackintosh. Le nouveau vice-roi de Canton ne voulut point, comme l'ancien, empêcher que cet Anglais allât joindre son vaisseau. On décida, en même temps, que la plupart des personnes de l'ambassade qui avaient passé sur ce vaisseau s'y

embarqueraient à Chu-San, et qu'on y chargerait aussi les présents de l'empereur pour le roi d'Angleterre, comme on y avait chargé, en se rendant en Chine, les présents du roi d'Angleterre pour l'empereur. II fallait, en 


\section{Voyage dans l'intérieur de la Chine et en Tartarie}

conséquence, que l'ambassade se partageât, et que ceux qui la composaient prissent deux routes différentes. L'ambassadeur résolut de se rendre directement à Canton avec la plus grande partie de sa suite. Le vice-roi Chaung-ta-Zhin, qui devait aller prendre possession du gouvernement de cette province, hâta son départ, afin d'accompagner les Anglais. D'un autre côté, Sun-ta-Zhin consentit, avec la même honnêteté, à mener à Chu-San le colonel Benson et les autres personnes qui devaient joindre l'Indostan.

Les arrangements qu'il fallut faire ne retinrent les voyageurs que peu de jours à Han-Choo-Foo. Quelques-uns d'entre eux profitèrent de cette occasion pour écrire à leurs amis en Europe; parce qu'ils pensèrent que l'Indostan pouvait avoir trouvé une cargaison à Chu-San, et ferait voile directement pour l'Angleterre, tandis que le Lion serait peut-être parti de Canton avant l'arrivée de l'ordre que l'ambassadeur lui avait donné d'y rester. Cependant, on songea aussi que si son départ avait eu lieu, sir Erasme Gower serait obligé de naviguer contre la mousson du nord-est en passant le détroit de Formose pour se rendre aux îles du Japon. Alors il y avait apparence que, comme sa marche dans le détroit serait nécessairement lente, l'Indostan l'y rencontrerait. En conséquence, l'ambassadeur remit au capitaine Mackintosh une lettre pour sir Erasme Gower, pareille à celle qu'il lui avait déjà adressée sous le couvert des commissaires de la Compagnie, à Canton.

Tandis qu'on s'occupait à Han-Choo-Foo des préparatifs du départ, Vanta-Zhin, avec sa bonté ordinaire, invita M. Barrow et quelques autres Anglais, à faire une promenade sur le lac de See-Hoo, situé à peu de distance à l'occident de la ville. En même temps, il se pourvut d'une barque très élégante et d'un bateau qui était à la suite, et dans lequel on devait préparer le manger des voyageurs. Le lac était rempli de poisson, dont une partie servit à leur dîner. II y avait beaucoup d'endroits peu profonds ; mais l'eau était extrêmement diaphane, et le fond couvert de gravier. On voyait un nombre immense de canots, dans lesquels étaient des gens qui faisaient des parties de plaisir. Mais il n'y avait que des hommes. Les femmes de ce canton ne paraissent jamais dans ces sortes d'occasions.

Le lac forme une superbe pièce d'eau de trois ou quatre milles de diamètre, et environnée au nord, à l'est et au sud de montagnes pittoresques, entre la base desquelles et les bords du lac est un terrain étroit mais uni, dont 


\section{Voyage dans l'intérieur de la Chine et en Tartarie}

on a tiré le parti le plus agréable. On y voit des maisons charmantes, et des jardins de mandarins, ainsi qu'un palais appartenant à l'empereur, et des temples et des monastères pour les ho-chaung, ou prêtres de Fo. Des ponts de pierres d'une forme légère et bizarre, mais très jolie, sont jetés en grand nombre sur les différents bras du lac, réunis aux ruisseaux qui tombent des montagnes.

Sur le sommet de ces montagnes, on a bâti des pagodes, l'une desquelles attira l'attention de nos voyageurs. Elle est située sur le bord d'une péninsule très élevée, qui s'avance dans le lac. Cette pagode s'appelle le Lui-Foong-Ta, c'est-à-dire le temple des vents foudroyants. II y reste quatre galeries entières, les unes au-dessus des autres; mais le haut est presque entièrement brisé. On distingue cependant encore une espèce d'ordre régulier dans les corniches en ruine qui forment une double courbe. La mousse, I'herbe et les ronces croissent sur ces ruines. Mais on n'y voit point de lierre, qui, en Europe, couvre ordinairement les masures. II n'y en a même dans aucune partie de la Chine. Les cintres et les moulures de la pagode sont peints en rouge, et les murailles en jaune. Elle n'a maintenant qu'environ cent vingt pieds de haut. On assure qu'elle a été bâtie du temps de Confucius, qui vivait il y a plus de deux mille ans.

Dans les bois, croissant sur le haut des montagnes et dans les vallées, il y a plusieurs milliers de tombeaux, qui sont bâtis comme des maisons. Ils ont environ de six à huit pieds de hauteur, et sont, pour la plupart, peints en bleu. Le devant est garni de piliers blancs, et ils forment de petites rues. Les tombeaux des Chinois d'un rang élevé sont à part, sur le penchant des montagnes, bâtis sur des terrasses de forme demi-circulaire; et ils ont des murailles de pierre avec des portes de marbre blanc, où l'on écrit les noms, les qualités et les vertus de ceux dont ils renferment les restes. De plus, les terrasses sont quelquefois ornées d'obélisques. Ces monuments de grandeurs passées sont environnés de différentes espèces de cyprès, dont la couleur sombre et mélancolique semble avoir été choisie partout pour parer les scènes de douleur. Cependant, l'if des cimetières ne croît ni en cet endroit ni dans le reste de la Chine. Mais plusieurs tombeaux y sont ombragés par une espèce de tuya pleureur, ou de bois des Indes, aux branches longues et pendantes, qu'on ne connaît point en Europe. II y a, dans les environs du lac, 


\section{Voyage dans l'intérieur de la Chine et en Tartarie}

des tombeaux de toute espèce de forme, en pierre, en terre ou en bois. Ce lieu paraît être l'un des grands cimetières de Han-Choo-Foo. Malgré cela, on rencontre des tombes dans tous les environs de cette ville. II y en a dans les champs, dans les jardins, à côté des grands chemins et sur les bords du canal impérial.

II ne se passe guère de nuit sans qu'on visite le cimetière des environs du lac. Des Chinois s'y rendent avec des torches, pour honorer les cendres de leurs parents. Ils décorent leur tombe de banderoles d'étoffe de soie ou de papier peint ; ils y sèment des fleurs et ils y brûlent des parfums.

Il arriva à Han-Choo-Foo un événement qui, bien que de peu de conséquence en lui-même, sert à prouver combien les Chinois ont de facilité à prendre l'alarme sur tout ce que peuvent faire les étrangers. Lorsque l'ambassade se partagea, on commit une erreur dans la distribution du bagage. Une partie de celui qui devait être transporté directement à Canton fut mis à bord des barques qui étaient à l'ancre dans le petit canal qui conduit à Chu-San. Pour rectifier l'erreur, trois Anglais, avec un mandarin et son domestique, se rendirent de bon matin à bord de ces barques. Ils firent, à cheval, le tour de la partie orientale de la ville, et traversèrent une jolie plaine, située sur le bord de la rivière. Là, ils montèrent dans des chariots couverts de tapis, garnis de coussins de soie, rembourrés de coton, et traînés par trois vigoureux buffles, lesquels étaient attelés de front. Les buffles étaient conduits par le moyen d'une corde, qui passait dans le cartilage de leur museau, de la même manière qu'on a coutume de conduire les chameaux. Le charretier sautant sur le buffle du milieu, partit à toute course, et les buffles s'élançant dans la rivière, sans la moindre difficulté, allèrent aussi loin qu'ils trouvèrent le fond. Alors les voyageurs s'embarquèrent dans un canot, qui les porta sur la rive opposée, où ils montèrent en chaise et firent environ un mille pour se rendre au canal de Chu-San.

Là, les Anglais firent le changement nécessaire dans la distribution du bagage, après quoi ils reprirent le chemin de leurs yachts qui étaient encore mouillés dans le grand bassin. Quand ils eurent passé la rivière, ils marchèrent droit à la ville, se proposant de la traverser, parce que c'était le chemin le plus court pour aller au bassin. Mais le mandarin qui les conduisait avait résolu de leur faire faire encore le tour des remparts, attendu qu'il ne 


\section{Voyage dans l'intérieur de la Chine et en Tartarie}

jugeait pas convenable qu'on permît à des étrangers de traverser la ville, ce qu'ils avaient pourtant déjà fait avec Van-ta-Zhin. II envoya, en secret, un messager dire qu'on fermât les portes, afin d'empêcher les Anglais d'entrer. La sentinelle obéit ; et lorsque les voyageurs se présentèrent, on leur dit que le gouverneur de la ville avait les clefs. Comme l'heure où l'on a coutume de fermer les portes le soir était encore éloignée, l'ordre du mandarin, communiqué à l'officier qui était en dedans de la porte, ne manqua pas d'occasionner quelque confusion, et une partie de la garnison prit aussitôt les armes. Le bruit en parvint bientôt jusqu'à Van-ta-Zhin, qui rit beaucoup de voir que trois Anglais avaient pu causer de l'effroi dans l'une des plus grandes et des plus fortes cités de l'empire chinois.

Ceux des Anglais qui allaient à Chu-San, étant en plus petit nombre, et plus tôt prêts que les autres, partirent le 13 novembre 1793. Ils avaient à leur tête le respectable Sun-ta-Zhin, qui dit affectueusement adieu à l'ambassadeur et à ses principaux compagnons. Depuis le premier instant où ce colao les avait connus à Zhé-Hol, sa conduite envers eux avait été remplie de bienveillance; et la manière avantageuse dont il en parlait, fit beaucoup d'effet auprès de l'empereur. Aussi il est probable que si, à leur arrivée en Chine, ils avaient été sous ses auspices, et qu'il eût été chargé, au lieu du légat, de rendre compte de ce qui les concernait, l'ambassadeur aurait rencontré moins d'obstacles, soit pour accomplir l'objet de sa mission, soit relativement à son séjour.

Sun-ta-Zhin eut aussi beaucoup d'attention pour les voyageurs qu'il accompagna à Chu-San : voyant que les barques qu'on avait fournies au colonel Benson, au capitaine Mackintosh, et aux autres Anglais n'étaient pas assez commodes, il prit soin de leur en faire donner d'autres dès le lendemain de leur embarquement sur le petit canal.

Le premier jour de leur route, ils passèrent dans un pays découvert entièrement, et parfaitement bien cultivé. Le capitaine Mackintosh le compare aux jardins potagers des environs de Londres, et pense qu'il est encore plus fertile, et a beaucoup moins de coins de terre oisifs.

Il observe qu'au lieu d'une carrière creusée sous la terre, il vit un rocher solide, de trois cents pieds de hauteur au moins, lequel était tout uniment 


\section{Voyage dans l'intérieur de la Chine et en Tartarie}

taillé sur les côtés, et d'où l'on tirait des pierres de toute forme et de toute grandeur. Cet énorme rocher est dans le voisinage d'une grande ville, des plus beaux édifices de laquelle il doit, sans doute, avoir fourni les matériaux. Le capitaine Mackintosh vit aussi des ponts qui, au lieu d'avoir des arches cintrées, n'avaient que des colonnes réunies par des pierres, dont quelquesunes étaient de trente pieds de long, et qui avaient été également tirées du grand rocher. Des pierres pour la construction d'autres grands édifices sont portées de ce rocher en différents endroits.

En citant des exemples de l'attention particulière des Chinois à ne pas laisser inoccupé le plus petit terrain susceptible de culture, le capitaine Mackintosh remarque que les vignes dont ce pays abonde sont, en général, plantées sur les bords des canaux; et comme les pampres s'étendent, on les soutient avec des échalas qu'on plante dans l'eau, à cinq ou six pieds du bord. Par ce moyen, tout cet espace forme une treille sans qu'on ait besoin d'autre terrain que celui qu'occupe le pied de la vigne. Tous les raisins qu'on recueille en cet endroit se mangent, et l'on n'en fait jamais de vin.

Il y a de fortes raisons pour qu'on ne laisse point les terres sans culture, puisque celles qu'on néglige sont confisquées au profit du souverain, et concédées par lui à de nouveaux fermiers qui ont envie de les cultiver. C'est une tenure à peu près semblable à celle de quelques mines du comté de Derby, en Angleterre, lesquelles sont exploitées par des entrepreneurs.

Dans la route de Han-Choo-Foo à Chu-San, les eaux d'un canal passent quelquefois dans un autre canal beaucoup plus bas; et deux fois les barques de nos voyageurs furent lancées d'un canal dans l'autre, avec une prodigieuse vélocité. Ce passage n'est point pratiqué par le moyen d'écluses. Mais il y a, à l'extrémité du canal supérieur, une forte digue en pierre qui est de niveau avec la surface de l'eau. Le bord de la digue est garni, du côté que frappe le courant, d'une pièce de bois arrondie ; l'autre côté forme un talus, d'environ quarante-cinq degrés d'inclinaison, et descendant de près de dix pieds, où se trouve le fond de l'autre canal. Ce dernier conserve son niveau, autant que le terrain le permet, et ensuite ses eaux sont versées dans un autre, par le moyen d'une seconde digue, pareille à celle que nous venons de décrire. 


\section{Voyage dans l'intérieur de la Chine et en Tartarie}

En passant d'un canal élevé dans celui qui est au-dessous, le bateau étant une fois monté sur la pièce de bois qui borde la digue, coule par son propre poids jusqu'au bas du talus. Pour empêcher les barques de plonger dans le canal, et d'être submergées, il y a à la proue des planches étroites qui forment une espèce de balustrade, et qu'on garnit d'épaisses nattes.

Pour faire remonter de grandes barques du canal qui est en bas dans celui d'en haut, il faut employer près de cent hommes qui poussent les barres d'un ou deux cabestans placés sur les culées de la digue. Une corde qui passe derrière la poupe de la barque se roule autour des cabestans, et par ce moyen la barque est tirée en haut en moins de temps que par les écluses; il est vrai qu'il faut employer plus d'hommes ; mais en Chine, c'est une force qui est toujours prête, qui coûte peu, et qu'on préfère constamment à toutes les autres.

$\mathrm{Au}$ bout de trois jours de marche, les voyageurs qui se rendaient à ChuSan arrivèrent à Loo-Chung, ville où ils quittèrent leurs barques pour entrer dans des jonques du port d'environ soixante tonneaux, très bien arrangées pour des passagers, et construites pour naviguer sur la mer. Elles étaient alors mouillées dans une rivière où la marée montait jusqu'au-delà de LooChung.

Rien ne pouvait être plus agréable et plus romantique, dit le capitaine Mackintosh, que les pays que virent les Anglais en se rendant de Loo-Chung à Nim-Po, ville située près de Chu-San. Nim-Po est sur le bord d'une rivière aussi large que l'est la Tamise, entre Londres et Woolwich, et qui serpente à travers de très fertiles vallées, entourées de collines de différente forme et de différente hauteur, et de montagnes excessivement élevées.

En débarquant à Nim-Po, Sun-ta-Zhin présenta les Anglais aux principaux mandarins du district, à qui il recommanda d'avoir pour ces étrangers une attention particulière. En même temps, il donna des ordres pour que I'Indostan fût exempt de payer les droits accoutumés, qui sont très considérables pour les vaisseaux étrangers. II ordonna aussi qu'on permît au capitaine Mackintosh et à ses officiers d'acheter, franc de droits, tout ce qu'ils jugeraient propre à composer une cargaison pour l'Europe. II déclara que l'exemption des droits devait également avoir lieu dans le port de Chu-San, et 


\section{Voyage dans l'intérieur de la Chine et en Tartarie}

même dans celui de Canton; ce qui fut, en effet, du moins pour ce qui concernait les taxes payables à l'empereur.

Le capitaine Mackintosh désirait vivement de recevoir Sun-ta-Zhin à bord de son vaisseau, qui mouillait dans la rade de Chu-San. II voulait le traiter d'une manière distinguée; ce que ce respectable mandarin méritait à tous égards, et qui lui eût été sans doute agréable. Mais étant déjà un peu indisposé, craignant l'odeur d'un vaisseau anglais 1, et, d'ailleurs, voulant s'en retourner promptement, il quitta les Anglais près de Nim-Po, après leur avoir fait de très beaux présents, au nom de l'empereur. II prit congé du colonel Benson et du capitaine Mackintosh en leur serrant la main à la manière anglaise, afin de leur donner une marque de cordialité et de bienveillance. Le lendemain, ils arrivèrent à bord de I'Indostan. II y avait presque huit jours qu'ils étaient partis de Han-Choo-Foo, éloigné de Chu-San d'environ cent cinquante milles.

Le vice-roi, l'ambassadeur et les autres Anglais quittèrent Han-Choo-Foo bientôt après le départ des voyageurs qui allaient à Chu-San. Pour se rendre à Canton, on s'embarque sur la rivière Chen-Taun-Chaung, qui coule du sudouest. Tandis que l'ambassade traversait la ville pour se rendre au lieu où elle devait s'embarquer, on porta devant elle, pour la première fois, des parasols de cérémonie, ce qui est une grande marque d'honneur. On avait rassemblé sur le bord de la rivière plus de deux mille hommes de cavalerie tartare, habillés superbement, portant différents uniformes. Ils avaient tous l'air très guerrier.

Le capitaine Parish observe qu'en Chine, la cavalerie porte l'arc, qui paraît être l'arme la plus estimée. Cet arc est fait d'un bois élastique et renforcé par deux cornes, dont la racine se joint dans le milieu de l'arc, d'où elles s'étendent vers les extrémités, et forment chacune une courbe distincte. II est garni d'une corde de fils de soie fortement tordus ensemble. La force de l'arc varie depuis soixante jusqu'à cent livres. Les flèches sont emplumées et parfaitement bien faites. Leur bout est garni d'une douille et d'une pointe

\footnotetext{
${ }^{1}$ L'odeur du goudron, qui n'existe pas dans les vaisseaux chinois.
} 


\section{Voyage dans l'intérieur de la Chine et en Tartarie}

d'acier qui ressemble au fer d'une lance. Les Chinois et les Tartares font grand cas de leur adresse à se servir de cette arme.

Quand ils veulent tirer une flèche, ils prennent l'arc de la main gauche et le tiennent un peu obliquement. Ils font passer la corde par derrière un anneau d'agate, qu'ils ont au pouce de la main droite, la première phalange duquel est pliée en avant, et retenue dans cette position pour presser la jointure du milieu de l'index. La corde est tirée jusqu'à ce que le bras gauche soit tendu, et que le droit passe derrière l'oreille droite. Alors on écarte l'index du pouce, ce qui fait échapper la corde de derrière l'anneau d'agate, et partir la flèche avec une force considérable.

Les cavaliers tartares et chinois ont un casque de fer, qui a la forme d'un entonnoir renversé. La crête qui répond au tuyau de l'entonnoir est haute de six ou sept pouces et se termine comme une lance. Le casque est orné d'un gland rouge. Le cou du cavalier est couvert d'une étoffe de drap piquée et garnie de fer. Cette pièce s'étend tout autour du visage. Ils portent une veste et des culottes de drap également piquées et garnies de fer. La veste descend un peu au-dessous de la taille, et les culottes vont jusqu'à mi-jambe. Cet uniforme a les inconvénients d'une armure sans en avoir les avantages. Les officiers ont des casques de fer poli, garnis en or, et dont la crête est beaucoup plus élevée que celle des soldats. Leur vêtement est bleu ou couleur de pourpre garni en or, et leurs bottes sont de satin noir.

Il y a d'autres troupes, qui ne sont armées que d'une épée, et dont I'uniforme est appelé I'habillement des tigres. Cet habillement, ajusté aux formes du corps, est jaune, et marqué de raies d'un brun foncé. Le bonnet couvre presque entièrement le visage, et représente une tête de tigre. Ils portent un bouclier de bambou, sur lequel est peinte une hideuse tête de tigre ou de dragon, avec une gueule et des dents énormes; et ils mettent beaucoup d'importance à l'effet que peut faire cette figure. De chaque côté des troupes qui étaient en parade sur le port de Han-Choo-Foo, on avait élevé un trophée en bois peint, orné de festons en soie ou en coton d'une très brillante couleur. Les mandarins militaires se tenaient sous ces trophées. La musique était sous des tentes. II y avait beaucoup de trompettes qui paraissent être les instruments militaires qui conviennent le mieux. Elles 


\section{Voyage dans l'intérieur de la Chine et en Tartarie}

sonnèrent, comme à l'ordinaire, à trois reprises différentes pour saluer l'ambassade.

Toutes les troupes saluèrent aussi l'ambassadeur lorsqu'il passa pour entrer dans la barque qui lui était destinée. Ces barques étaient très pointues du côté de la proue et du côté de la poupe.

Leur fond était plat, et elles avaient environ douze pieds de large et soixante-dix pieds de long. Elles avaient des voiles de toile de coton, tiraient très peu d'eau et naviguaient fort bien. Celle qu'on avait préparée pour lord Macartney était moins bien décorée que celle du vice-roi ; mais ce dernier ne voulut point souffrir cette différence ; et il dit qu'elle lui ferait bien plus de tort à lui qu'à l'ambassadeur.

Le nombre de bateaux de toute espèce était immense dans cette partie de la rivière; mais malgré cela, il n'y avait point de confusion. Les matelots étaient extrêmement adroits. On voyait plusieurs grands bateaux conduits par un seul homme qui ramait, allait à la voile, gouvernait et fumait sa pipe dans le même temps. D'une main, il tenait la bouline, de l'autre la barre du gouvernail, et avec son pied, il faisait mouvoir un aviron qu'à chaque coup il poussait aussi loin qu'il aurait pu le faire avec la main.

Le vent étant favorable, les barques remontèrent assez loin contre le courant de la rivière, sans avoir besoin d'être traînées avec une corde. L'ambassadeur passa devant un poste militaire, près duquel il y avait une douzaine de canons, de deux à quatre livres de balle, lesquels étaient grossièrement et pesamment faits. L'épaisseur du métal égalait le diamètre du calibre. Ils paraissaient fort peu en état de servir; malgré cela, on les conservait avec beaucoup de soin, et ils étaient chacun sous un toit de bois.

Bientôt la rivière devint plus étroite, et passa dans un défilé, formé par deux chaînes de hautes montagnes, sur les flancs desquelles étaient plusieurs ravins, séparés l'un de l'autre par des avancements de rochers pelés. Une chaîne de montagnes de granit commence à Han-Choo-Foo, et s'étend vers le sud. Les portes et le pavé de la ville sont tirés de ces montagnes.

Les petites vallées situées entre les montagnes où se trouvaient les voyageurs étaient soigneusement cultivées et très pittoresques. A cette perspective, en succéda une toute différente. On voyait d'un côté de la rivière 


\section{Voyage dans l'intérieur de la Chine et en Tartarie}

une plaine immense, bien cultivée, et couverte de diverses productions, et de l'autre, des montagnes escarpées dont le pied était baigné par la rivière, et qui semblaient plus hautes qu'aucune de celles qu'on voit en Angleterre. Le châtaignier aux larges feuilles et l'arbre empourpré qui produit le suif croissaient en abondance dans ce canton, et formaient un contraste avec le vert noir du superbe mélèze, et le vert brillant du camphrier aux branches étendues et au feuillage touffu. Nous avons déjà dit que les voyageurs avaient vu quelques jeunes camphriers dans le jardin botanique de Batavia.

Le camphrier est la seule espèce de laurier qui croisse en Chine, et il y vient assez haut pour qu'on le mette au nombre des arbres qui fournissent le plus beau et le meilleur bois de charpente. On s'en sert pour les bâtiments de toute espèce, ainsi que pour les mâts de vaisseau; et il est d'un trop haut prix pour qu'on en emploie aucune autre partie que les branches, à faire la drogue qui est connue sous le nom de camphre.

Cette substance s'obtient en faisant bouillir dans de l'eau les branches, les bourgeons, les feuilles, comme nous l'avons expliqué dans la première partie ; et alors elle surnage comme de l'huile, ou bien elle s'attache sous une forme glutineuse à un bâton avec lequel on remue constamment l'eau où l'on la fait bouillir. On mêle cette masse glutineuse avec de l'argile et de la chaux, et on la dépose dans un vase de terre qu'on couvre d'un autre vase de même grandeur, et qu'on a soin de bien luter. Ensuite, on place le premier vase sur un feu modéré; le camphre se sublime à travers la chaux et l'argile, et s'attache aux parois du vase supérieur, où on le trouve en gâteau dont la forme est déterminée par celle du vase même.

Cependant, ce camphre est moins pur et plus faible que celui qu'on trouve sous une forme solide parmi les fibres de l'arbre, comme on trouve la térébenthine dans différentes sortes de pins ${ }^{1}$. Au Japon, et dans la grande île de Bornéo qui a peu de population, on coupe et on fond l'arbre qui produit le camphre, pour pouvoir recueillir en nature cette substance précieuse, de même que les sauvages du Mississipi abattent d'autres arbres dans la seule intention d'en avoir le fruit. Le camphre de Bornéo et du Japon est pur et si

\footnotetext{
${ }^{1}$ Le térébinthe, le mélèze et quelques autres. (Note du Traducteur.)
} 


\section{Voyage dans l'intérieur de la Chine et en Tartarie}

fort qu'il communique aisément et son odeur et ses propriétés à d'autres huiles épaissies qu'on fait alors passer pour du véritable camphre. Cette drogue, ainsi falsifiée, est vendue par les Chinois à un prix bien au-dessous de celui qu'ils paient eux-mêmes le véritable camphre du Japon et de Bornéo.

L'arbre à suif croît, en général, sur le bord de la rivière, et le camphrier à une certaine distance. On voit aussi une immense quantité de thuyas ${ }^{1}$ qui s'élèvent à une prodigieuse hauteur, dans la vallée où est bâtie la ville de Yen-Choo-Foo.

Au-delà de cette ville, la rivière était si basse que, quoique les barques des Anglais tirassent moins d'un pied d'eau, les hommes qui les conduisaient avaient besoin d'employer toute leur force pour les faire avancer. II fallut même prendre des paysans pour ôter, du milieu de la rivière, les cailloux couverts de limon verdâtre, afin de faire un canal artificiel pour le passage des barques. Ces cailloux n'étaient guère que des fragments de quartz et de pierre vitrifiable.

Durant cette lente navigation, les barques furent jointes par deux jeunes et jolis hommes qui, curieux de voir l'ambassadeur, le suivaient depuis HanChoo-Foo. Ils étaient eux-mêmes honorés du même titre par le roi de l'île de Leoo-Kéoo. Leur habillement était composé d'une espèce de shawl 2 très fin, d'une superbe couleur brune, et garni, à la manière chinoise, d'une fourrure de peaux d'écureuils. Cette étoffe se fabrique dans leur pays. Ils portaient des turbans de soie élégamment plissés, l'un couleur de pourpre et l'autre jaune. Ils ne paraissaient avoir sur le corps ni linge ni toile de coton. Ces jeunes gens avaient le teint très brun, mais une figure intéressante. Ils étaient bien élevés, et conversaient avec facilité. Ils venaient d'arriver à Han-Choo-Foo pour se rendre de là à Pékin, où leur chef envoie, régulièrement tous les deux ans, des délégués pour porter le tribut et rendre hommage à l'empereur. Ils avaient débarqué à Emouy, port de la province de Fo-Chen, et le seul qui soit

\footnotetext{
1 Arbor vitae.

2 On prononce chal.
} 


\section{Voyage dans l'intérieur de la Chine et en Tartarie}

ouvert à ces étrangers. Ils parlaient le chinois, mais ils avaient, en outre, une langue particulière.

Ils dirent qu'ils ne se rappelaient pas d'avoir jamais vu aucun vaisseau européen aborder dans leurs îles; mais que s'il y en allait quelqu'un, il y serait bien accueilli, parce que l'entrée n'en était point défendue aux étrangers. Ils ajoutèrent que leur ville capitale était très étendue et très peuplée ; et qu'à peu de distance il y avait un beau port, capable de recevoir les plus grands vaisseaux. Le thé qu'ils recueillent est, suivant eux, très inférieur à celui de la Chine. Ils ont plusieurs mines de cuivre et de fer, mais point de mine d'or ou d'argent.

D'après la position géographique des îles de Leoo-Kéoo, elles devaient naturellement dépendre des Chinois ou des Japonais. Les derniers les ont regardées avec indifférence, mais les autres, après leur avoir envoyé une ambassade pour leur faire connaître leur force et leur situation, ont fait un armement qui est allé les soumettre et leur imposer un tribut. Lorsque le souverain de ces îles meurt, son successeur reçoit l'investiture de ses États de l'empereur de Chine. 
Voyage dans l'intérieur de la Chine et en Tartarie

$$
\begin{gathered}
\text { QUATR I ÈME } \\
\text { PARTIE }
\end{gathered}
$$




\section{Voyage dans l'intérieur de la Chine et en Tartarie}

\section{CHAPITRE PREMIER}

\section{Voyage de Han-choo-foo à Canton. Passage du Lion et de l'Indostan de Chu-san à Canton.}

Peu de temps après avoir vu les envoyés de Leoo-Kéoo, l'ambassade continua sa route. La rivière, s'éloignant un peu des montagnes, s'élargissait et devenait plus profonde. Dans les vallées situées le long de la rivière, on voyait beaucoup de cannes à sucre qui étaient presque mûres, et avaient environ huit pieds de haut. Ces cannes n'étaient plantées que depuis un an ; mais comme elles avaient la même grosseur que celles des Antilles, avec moins de nœuds, elles devaient contenir beaucoup de suc. Les nœuds des cannes à sucre des Antilles ne sont éloignés les uns des autres que d'environ quatre pouces : ceux des cannes de la Chine le sont de six.

Les plantations des cannes à sucre, en Chine, appartiennent à divers individus et ont très peu d'étendue; et les dépenses qu'exige l'établissement d'un moulin sont trop considérables pour qu'il y en ait sur chaque plantation. L'extraction du vesou et la fabrication du sucre est, dans ce pays-là, une entreprise dont ne se mêle point celui qui cultive les cannes. Les fabricateurs du sucre se transportent dans les plantations avec l'appareil qui leur est nécessaire, mais que les planteurs des Antilles regarderaient comme insuffisant et digne de leur mépris. II n'est pas difficile de voyager en Chine avec cet appareil, parce qu'il est peu de plantations où l'on ne puisse se rendre par eau.

Là, quelques bambous et quelques nattes suffisent pour construire, momentanément, une sucrerie. A l'extrémité du bâtiment, on place une grande chaudière de fer sur un fourneau ; et dans le milieu, deux cylindres ou 


\section{Voyage dans l'intérieur de la Chine et en Tartarie}

rouleaux, montés verticalement ${ }^{1}$. Ces rouleaux sont quelquefois de bois dur et plus souvent de pierre. Quand ils sont de bois, on taille, à six ou huit pouces du haut, des dents obliques qui s'engrainent les unes dans les autres ; et quand ils sont de pierre, on y met des collets de bois, également garnis de dents. Au haut de l'axe d'un des cylindres, lequel est plus long que l'autre, sont attachés deux leviers assez courbes pour pouvoir tourner en s'écartant des rouleaux ; et à l'extrémité de ces leviers, on attache deux buffles qui, en tournant comme dans un moulin ordinaire, écrasent les cannes qu'on met entre les cylindres, et le suc ou le vesou coule par un tuyau jusque dans la chaudière.

Les cannes, privées de leur suc, sont le chauffage par le moyen duquel on fait bouillir ce suc, jusqu'à ce qu'il acquière assez d'épaisseur pour pouvoir se cristalliser.

Celui qui fabrique le sucre cherche à s'arranger avec plusieurs planteurs à la fois, afin que sa petite manufacture, placée dans le centre de leurs diverses plantations, puisse leur servir sans qu'il soit obligé de la transporter. Durant le temps de la fabrication, les domestiques et les enfants du planteur s'occupent à charrier les cannes au moulin.

On plante les cannes à sucre par rangs très bien alignés, et on a grand soin de chausser les racines. En Chine, comme aux Antilles, les hommes qui travaillent aux champs dans le temps de la récolte des cannes deviennent gras et bien portants. Plusieurs esclaves chinois et d'autres paresseux se cachent et vivent au milieu des cannes lorsqu'elles deviennent mûres. On trouve sous les racines des cannes un gros ver blanc que les Chinois font frire dans I'huile, et mangent comme une chose très délicate.

Près des cannes à sucre, les Anglais virent plusieurs bosquets d'orangers. II y $a$, en Chine, une très grande quantité d'espèces d'oranges; quelquesunes sont plus petites que celles du Portugal ; d'autres, aussi grosses que les plus grosses des Antilles; mais les plus douces, les plus remplies de jus, sont les oranges d'un rouge foncé. On les préfère à toutes les autres ; et il est aisé

\footnotetext{
${ }^{1}$ Aux Antilles, où les moulins à sucre sont perfectionnés, ils ont trois cylindres au lieu de deux. (Note du Traducteur.)
} 


\section{Voyage dans l'intérieur de la Chine et en Tartarie}

de les distinguer, non seulement par leur couleur, mais parce que la pulpe ne tient à l'écorce que par quelques légères fibres.

On servait à nos voyageurs beaucoup d'espèces de fruits. Leur dessert était ordinairement composé de raisins, d'oranges, de pommes, de poires, de châtaignes, de noix, de grenades, de melons et d'une espèce de dattes.

Les Chinois n'ont point plusieurs fruits qu'on voit en Europe, tels que des groseilles, des framboises, des olives ; mais ils en ont beaucoup d'autres que l'Europe ne produit point. Ils ont, par exemple, le sée-chée, et le lée-chée. Le sée-chée est un fruit rougeâtre, mou, d'une forme aplatie, et dont la peau est très unie. Sa pulpe, légèrement acide, renferme un noyau : il est de la grosseur d'une petite orange, et il semble que sa rondeur s'est aplatie par son propre poids. Le lée-chée n'est pas plus gros qu'une cerise, et a la peau remplie d'une espèce de duvet épineux. Sa pulpe est acide, et contient un noyau, dont la grosseur est considérable, proportionnément à celle du fruit. On confit le lée-chée, et alors il est assez doux.

II est des pins qui portent de grosses pommes, dont les Chinois aiment beaucoup les pépins. On sait que les Italiens en font aussi grand cas. Toutes les montagnes trop escarpées, ou trop pierreuses pour qu'on les cultive, sont entièrement plantées de pins de toute espèce, mais principalement de mélèzes, parce qu'on en préfère le bois pour bâtir.

Nos voyageurs virent pour la première fois l'arbuste qui produit le thé. II croissait comme une plante commune, et semée au hasard sur les côtés et sur le haut des levées, qui séparaient les jardins et les bosquets d'orangers. Cependant, cet arbuste est régulièrement cultivé à la Chine. On le sème par rangs, à la distance d'environ quatre pieds l'un de l'autre, et l'on a soin de sarcler les mauvaises herbes dans le champ où il croît. Rarement le cultive-ton dans les terrains bas et marécageux, parce que ces terrains sont réservés pour le riz; mais on en sème en très grande quantité sur les collines et dans les pays montueux, surtout dans la province de Fo-Chien. On l'empêche de devenir très haut, afin d'avoir la facilité de cueillir les feuilles, qu'on ramasse d'abord au printemps, et ensuite deux fois dans le cours de l'été. 


\section{Voyage dans l'intérieur de la Chine et en Tartarie}

Les longues et tendres branches de cet arbuste croissent depuis la racine, de sorte qu'à proprement parler, il n'a point de tronc. II est touffu comme le rosier, et quand les pétales de la fleur s'épanouissent, elles ressemblent assez à la rose.

Tous les renseignements que prirent les Anglais concernant l'arbre à thé leur confirmèrent que sa qualité dépendait du sol où il croissait, et de l'âge auquel ses feuilles étaient recueillies, ainsi que de la manière dont on les préparait. Les plus grandes et les plus vieilles sont les moins estimées, et servent à la consommation des dernières classes du peuple. On les vend souvent sans leur avoir donné toutes les préparations nécessaires, et Iorsqu'elles conservent encore ce goût herbacé, qui est commun à la plupart des plantes fraîchement cueillies ; mais il disparaît bientôt, et le parfum, le goût le plus essentiel qui les caractérise, se conserve longtemps tout entier.

Les jeunes feuilles sont soumises à beaucoup de préparation avant d'être exposées en vente. Chaque feuille passe d'abord par les doigts d'une femme, qui la roule et lui donne la même forme qu'elle avait sur l'arbre avant de se déployer. Ensuite, on la place sur un plat de terre ou de fer, le plus mince que puisse le faire un Chinois. On dit avec assurance dans le pays qu'on ne les met jamais sur du cuivre ; et il est certain qu'on voit très rarement en Chine des ustensiles de ce métal, qui est principalement employé pour la monnaie.

Le plat de terre ou de fer est placé sur le feu où le reste d'humide que contenaient les feuilles se dissipe; et, en se desséchant, elles se roulent davantage. La couleur et le goût âpre du thé vert viennent, dit-on, de ce que les feuilles ont été cueillies de bonne heure; c'est comme les fruits qui ne sont pas mûrs, ils ont de la verdeur et de l'âpreté.

On met le thé dans de grandes caisses, doublées de minces feuilles de plomb, et de feuilles sèches de quelques grands arbres. II est trop vrai que le thé est alors foulé dans les caisses par les pieds nus des Chinois, comme la vendange est pressée par les sabots ${ }^{1}$ des vignerons européens; mais le jus du raisin est ensuite purifié par la fermentation. Malgré l'opération mal propre

1 L'auteur aurait dû dire aussi par les pieds nus ; car c'est communément ainsi qu'on foule la vendange. (Note du Traducteur.) 


\section{Voyage dans l'intérieur de la Chine et en Tartarie}

des emballeurs chinois, les personnes du premier rang, en Chine, n'aiment pas moins le thé que les gens du peuple, et mettent beaucoup de soin à le choisir. Le thé d'une bonne qualité est plus cher à Pékin qu'à Londres. On le roule quelquefois en boules, comme nous l'avons déjà dit. On en tire aussi fréquemment un extrait noir et très fort. On attribue au thé beaucoup de vertus; et l'usage en est général dans toute l'étendue de l'empire.

Il n'est pas douteux que de l'eau chaude, dans laquelle on aurait fait infuser quelque autre plante aromatique, pourrait être aussi agréable à des personnes fatiguées et transpirant souvent avec violence, ainsi qu'à des estomacs qui digèrent mal. Une des meilleures qualités du thé, peut-être, c'est de plaire assez à ceux qui prennent l'habitude d'en boire à chaque instant, pour leur ôter, en grande partie, le goût des liqueurs fermentées et enivrantes. En Chine, le pauvre fait infuser plusieurs fois les mêmes feuilles de thé.

Cette plante est cultivée dans plusieurs provinces de la Chine; mais rarement plus au nord que trente degrés au-delà de l'équateur. Elle réussit mieux entre ce parallèle et la ligne qui sépare la zone tempérée de la zone torride; mais on la trouve aussi dans la province chinoise de Yun-Nan, qui est encore plus au sud.

L'ambassadeur se procura plusieurs pieds de cette plante ainsi que d'autres qu'on cultive en Chine ; et il les envoya au Bengale, où il savait que divers cantons étaient très propres à leur culture.

On consomme en Chine une si immense quantité de thé, que quand l'Europe cesserait tout à coup d'en demander, le prix n'en diminuerait presque pas dans les marchés de la Chine. Mais cela dérangerait peut-être un peu ceux des cultivateurs qui sont habitués de fournir aux négociants de Canton celui qu'on exporte.

Une plante semblable au thé était alors en fleur sur les flancs et sur le sommet des montagnes, où le sol n'était guère composé que de fragments de pierre pulvérisée par l'action du soleil et par la pluie. Les Chinois nomment cette plante cha-whaw, ou fleur de thé, parce que, comme nous venons de le dire, elle ressemble en effet au thé, et parce que ses pétales ainsi que les 


\section{Voyage dans l'intérieur de la Chine et en Tartarie}

fleurs entières du jasmin d'Arabie, sont quelquefois mises dans les caisses de thé pour augmenter le parfum.

Le cha-whaw est le camellia sesanqua des botanistes. Elle porte une noix, dont on extrait de I'huile aussi bonne que la meilleure huile de Florence. C'est ce qui fait qu'on multiplie beaucoup cette plante ; d'ailleurs, la culture en est facile, et elle vient dans des endroits où il ne pourrait guère croître d'autres plantes.

En continuant leur navigation sur la rivière, les Anglais virent plusieurs excavations faites dans les montagnes voisines, pour en tirer le pé-tun-tsé, qu'on emploie dans les manufactures de porcelaine. Cette matière est une espèce de granit fin, ou un composé de quartz, de spalt et de mica ; mais le quartz paraît y être en plus grande quantité qu'aucune des autres parties. II paraît, d'après plusieurs expériences, que cette matière est la même que la pierre de Growan des mineurs de Cornouailles. Le mica qui se trouve dans ce granit, en Chine et en Angleterre, contient quelques parties ferrugineuses, et alors il ne peut pas servir pour la porcelaine. Le granit peut être moulu plus fin par les moulins perfectionnés en Angleterre, et ensuite mieux cuit que dans les manufactures imparfaites des Chinois. Aussi peut-on donner la porcelaine qui en provient à meilleur marché que le pé-tun-tsé préparé, quelque peu coûteuse que la main-d'œuvre soit en Chine.

Le kao-lin, ou la principale matière qu'on mêle au pé-tun-tsé, est aussi l'argile de Growan. Le wha-shé des Chinois est la pierre savonneuse des Anglais; et il est démontré que le shé-kan est le gypse. Un manufacturier chinois raconta que la pierre incombustible qu'on appelle asbeste entrait aussi dans la composition de la porcelaine.

Non loin de la route que les Anglais suivaient pour se rendre à Canton, il y avait une ville non murée et appelée Kin-Té-Chin, où trois mille fourneaux pour cuire de la porcelaine étaient, dit-on, allumés tous à la fois, ce qui faisait que, pendant la nuit, la ville avait l'air d'être toute en feu.

Le génie ou l'esprit du feu est la principale divinité qu'on adore en cet endroit; et certes, ce n'est pas sans quelque raison. Le succès de la fabrication de la porcelaine est incertain, attendu que les Chinois n'ont pas une méthode exacte pour régler le degré de chaleur dans les fourneaux. Aussi 


\section{Voyage dans l'intérieur de la Chine et en Tartarie}

quelquefois tout ce que ces fourneaux contiennent ne forme qu'une masse inutile. Les Chinois qui fabriquent de la porcelaine auraient besoin d'avoir le thermomètre de $\mathrm{M}$. Wedgwood, fondé sur la propriété qu'a l'argile de se resserrer en proportion du degré de chaleur auquel elle est exposée, propriété observée par ce physicien, et dont nous avons déjà parlé dans cet ouvrage.

Après que l'ambassade eut navigué quelques jours sur la rivière de ChenTang-Chaung, et presque pour la première fois depuis qu'elle était en Chine, le temps devint humide et sombre. Il y avait assez longtemps que les voyageurs avaient quitté l'Angleterre, pour être surpris de voir en novembre un jour s'écouler sans que le soleil parût. Tandis qu'ils avaient été sur le canal impérial, ils avaient eu quelquefois un temps orageux, mais très rarement de la pluie. La température devint aussi extrêmement froide sur la rivière de Chen-Tang-Chaung, quoique sa latitude soit à moins de trente degrés de la ligne équinoxiale. Mais le pays est rempli de montagnes, où les vents se trouvant pressés dans d'étroits passages, en deviennent plus violents et plus froids. En outre, on était alors dans le temps du changement de la mousson, lequel est sans cesse accompagné de beaucoup de tonnerre, de vent et de pluie ; et ces tempêtes se font sentir jusque dans les provinces de l'intérieur de la Chine. Le matin, de bonne heure, le thermomètre de Fahrenheit n'était quelquefois qu'à quarante-huit degrés.

A Chan-San-Shen, la rivière cessa entièrement d'être navigable. C'est dans une chaîne de montagnes qui environnent cette ville que la rivière prend sa source. De là, elle ne parcourt pas plus de deux cents milles. Elle passe d'abord dans un pays montueux et peu fréquenté, et elle n'a de communication avec aucun chemin considérable, aucune autre rivière, ou aucun grand canal, jusqu'à ce qu'elle arrive à Han-Choo-Foo. Les Anglais virent, sur cette rivière, naviguer moins de bâtiments que dans aucune autre partie de l'empire, où ils avaient voyagé par eau : la navigation en est aussi beaucoup moins commode. Malgré cela, dans le pays qu'elle traverse, le coin de terre le plus reculé est bien cultivé et bien peuplé. Au-dessous de HanChoo-Foo, la rivière est beaucoup plus large et couverte de vaisseaux de toute espèce, qui vont dans la mer Orientale, ou qui en reviennent. 


\section{Voyage dans l'intérieur de la Chine et en Tartarie}

Une autre rivière prend sa source au sud des mêmes montagnes qui sont derrière la ville de Chan-San-Shen; et il fut décidé que l'ambassade s'y embarquerait, après avoir fait par terre le chemin qu'il y a de l'une à l'autre. La grande route de Pékin à Canton passe à Nan-Kin, ancienne capitale de l'empire; mais la nécessité d'aller à Han-Choo-Foo, ville entre laquelle et Canton les relations par terre sont rares, obligea nos voyageurs de traverser des pays où peut-être jamais aucun autre Européen n'avait passé. Aussi eurent-ils une occasion très favorable de connaître le véritable état de quelques provinces de l'intérieur.

Les visites amicales que se rendaient mutuellement le vice-roi et l'ambassadeur furent souvent répétées, soit lorsqu'ils étaient dans leurs barques, soit pendant le jour où l'on fit les préparatifs du voyage par terre. La dignité du vice-roi, comme gouverneur de deux grandes provinces, et I'honneur d'être parent de l'empereur faisaient qu'aucun sujet en Chine ne pouvait être au-dessus de lui et n'avait droit à des formes d'un plus profond respect de la part de toutes les autres classes de Chinois. Mais sa bonté naturelle semblait éviter toute apparence de supériorité. II voulut absolument faire asseoir en sa présence Chow-ta-Zhin et Van-ta-Zhin qui par ce moyen, purent assister à ses entrevues avec l'ambassadeur. L'interprète chinois même ne fut soumis devant lui à aucune gêne.

Le vice-roi entretint, comme Sun-ta-Zhin, une correspondance presque journalière avec l'empereur, et il dit souvent à l'ambassadeur des choses flatteuses de la part de ce prince. Dans les entretiens du vice-roi avec lord Macartney, il fut souvent question des oppressions auxquelles les étrangers, et surtout les Anglais étaient soumis à Canton. Sa bienfaisance le disposait à écouter des représentations à cet égard ; et Chow-ta-Zhin, qui avait acquis sa confiance, et sur l'attachement de qui l'ambassadeur avait raison de compter, se chargea de lui mieux expliquer en particulier l'objet des plaintes des Anglais, et de le presser pour qu'il leur rendît justice. Il était également avantageux que tout ce qui avait rapport à cette affaire se trouvât dans les lettres que le vice-roi écrivait à l'empereur durant le voyage, et ne fût point mêlé avec d'autres détails. 


\section{Voyage dans l'intérieur de la Chine et en Tartarie}

Le vice-roi et l'ambassadeur furent bientôt informés que tout était prêt pour continuer leur route. Cependant, les préparatifs avaient d'abord éprouvé quelques difficultés. II avait rarement passé, par ce chemin, autant de voyageurs à la fois. II n'était pas aisé de trouver pour eux un assez grand nombre de chevaux, dans un pays où l'on ne s'en sert point pour les travaux de l'agriculture ; où les classes inférieures voyagent à pied, et les autres dans des palanquins portés par des hommes. Les gardes de l'ambassadeur, avec leurs pompons rouges et leurs armes brillantes, étaient considérés comme des hommes qui avaient droit à se faire porter. Les Chinois croyaient même devoir fournir quelque espèce de voiture pour tous ceux qui appartenaient à l'ambassade.

Faute de chevaux, on se procura des chaises, auxquelles on attacha des bambous, afin de pouvoir les faire porter par des hommes. Mais beaucoup de ces hommes avec leurs haillons, leurs chapeaux de paille, et leurs sandales, étaient si maigres et avaient l'air si faible auprès de ceux qu'ils portaient, que plusieurs de ces derniers, rougissant du contraste, quittèrent leurs voitures et continuèrent la route à pied.

Le chemin traversait d'abord un pays très élevé; ensuite des vallées étroites et des champs marécageux et remplis de riz, au milieu desquels une chaussée était élevée entre deux murailles de pierre, et couverte de gravier fin, qu'on avait tiré des montagnes voisines. Comme il n'y avait aucune espèce de voiture à roues dans le pays, la chaussée était étroite mais unie et bien nivelée.

Au sud du chemin, on voyait plusieurs hautes montagnes en pain de sucre, et détachées les unes des autres. Elles étaient couvertes d'herbe et d'arbrisseaux; et leur forme était si régulière, leur pente si également graduée depuis leur sommet jusqu'à leur base, qu'elles avaient moins l'air d'être l'ouvrage de la nature que celui de l'art. Ces montagnes étaient composées de pierre à chaux bleue et d'une qualité commune. Au-delà de ces montagnes, il y avait des carrières d'où l'on tirait de superbes pierres blanches et brillantes. C'était du quartz dans son état le plus pur ; les Chinois s'en servaient au lieu du pé-tun-tsé, dans leurs manufactures de porcelaine. 


\section{Voyage dans l'intérieur de la Chine et en Tartarie}

Dans ce petit voyage par terre, et loin de toutes les grandes routes, les Anglais ne firent pas un seul mille sans voir un village; et, à l'exception des endroits où il n'y avait que du roc vif ou des hauteurs inaccessibles, ils ne remarquèrent pas un coin de terre qui ne fût en culture. Les villages n'étaient point entourés de murailles ; mais il y avait des barrières aux extrémités.

II paraissait qu'on avait dépouillé les rochers de la terre qui les avait anciennement couverts, afin de la placer dans des endroits où elle pût plus facilement nourrir des plantes. Là où les montagnes ne sont pas tout à fait perpendiculaires, la pente régulière est convertie en terrasses placées les unes au-dessus des autres, et toutes supportées par des murs de pierre. Par ce moyen, toute la montagne est cultivée jusqu'au sommet. Ces terrasses ne sont point employées à un seul genre de culture. On y voit du grain, des légumes, des ignames, des patates douces, des oignons, des carottes, des navets et plusieurs autres plantes potagères. On a creusé un réservoir sur le sommet de la montagne. L'eau de la pluie y est rassemblée, et ensuite on la conduit par des canaux dans les différentes terrasses qui sont au-dessous. Dans les endroits trop hauts, trop escarpés, trop stériles pour les plantes délicates, ou qui exigent beaucoup de soin, on cultive, avec succès, la camellia sesanqua, diverses espèces de sapin, et particulièrement le mélèze.

Les Chinois regardent les engrais pour leurs terres comme un objet si important que des multitudes de vieillards, de femmes et d'enfants, incapables de faire beaucoup d'autre travail, sont constamment occupés à chercher des immondices dans les rues, dans les grands chemins et sur les bords des canaux et des rivières.

Ils ont un panier attaché devant eux, et portent à la main un petit râteau de bois avec lequel ils ramassent les excréments des animaux, et tout ce qui peut servir pour fumier. Mais, après la fiente des oiseaux, le fumier que préfèrent les fermiers chinois est celui que préféraient aussi les fermiers romains, ainsi que nous l'atteste Columelle. Ce sont les matières qu'on emporte la nuit hors de Londres, et dont on fait, dans le voisinage de cette ville, le même usage qu'ils font eux-mêmes, comme nous l'avons déjà observé en parlant de la visite que firent quelques Anglais aux cultivateurs de l'île de Lowang. 


\section{Voyage dans l'intérieur de la Chine et en Tartarie}

Cet engrais est mêlé, en petite quantité, avec une portion de terre grasse, et on le met en gâteaux qu'on fait sécher au soleil. Ces gâteaux alors sont un objet de commerce, et on les vend aux fermiers qui ne les emploient jamais dans un état compact. Le premier soin est de construire de grandes fosses pour contenir non seulement ces gâteaux, mais toute espèce de fiente, toute sorte de matières végétales, telles que des feuilles, des racines, des tiges de plantes, du limon des canaux, des débris d'animaux, même la barbe et les cheveux que ramassent les barbiers.

On mêle avec ce fumier le plus d'urine qu'il est possible, ou bien on y verse de l'eau, afin de le délayer ; et c'est lorsqu'il est dans une fermentation putride qu'on le répand sur la terre labourée. En différentes parties d'une ferme, près des chemins et des sentiers, on place de grands vases enterrés jusqu'au bord, pour les laboureurs ou pour les passants qui peuvent avoir besoin de s'en servir. A côté des grandes routes et dans le voisinage des villages, il y a de petites maisons où sont des réservoirs construits avec assez de solidité pour que ce qu'ils reçoivent ne puisse pas se perdre dans la terre, et on jette de temps en temps de la paille par-dessus, afin d'empêcher l'évaporation. Enfin, les Chinois mettent tant de prix au principal des ingrédients qui constituent leurs engrais, que le plus cassé, le plus impotent vieillard n'est jamais regardé comme tout à fait inutile à la famille qui le nourrit.

Cependant, la quantité d'engrais rassemblée par ces différents moyens est encore insuffisante pour les terres qui sont en culture à la Chine, et qui font une très grande partie de l'étendue de l'empire.

En conséquence, on en réserve d'abord ce qui est nécessaire pour se procurer des légumes et des herbes potagères, ainsi que pour accélérer la croissance des fleurs et des fruits.

Parmi les végétaux qu'on cultive le plus généralement et en plus grande quantité est une espèce de chou ${ }^{1}$ appelé par les Chinois pe-tsai, ou herbe blanche. II est d'un goût délicat, ressemble un peu à la laitue pommée d'Angleterre, et les Chinois ainsi que les étrangers qui sont en Chine l'aiment 


\section{Voyage dans l'intérieur de la Chine et en Tartarie}

beaucoup. Dans le voisinage de toutes les villes bien peuplées, on voit des acres entiers couverts de ces choux. Le matin, on a quelquefois de la peine à passer à travers l'immense quantité de petites charrettes à bras et de brouettes qui en sont chargées, et encombrent les portes de Pékin et de HanChoo-Foo.

Cette espèce de chou semble mieux réussir dans les provinces septentrionales qu'ailleurs. Les habitants de ces provinces en salent pour leur consommation pendant l'hiver, et pour en envoyer dans les provinces du sud, où ils sont échangés contre du riz.

Du riz, des choux et un peu d'ail ou d'oignon, au lieu de viande, avec un breuvage de thé commun, sont souvent tout ce qui compose les repas des paysans et des ouvriers chinois.

Le cultivateur chinois qui veut semer des graines les met auparavant tremper dans du fumier liquide, jusqu'à ce qu'elles gonflent et que la germination commence à se manifester. II prétend que l'expérience lui a appris que cette précaution accélère la croissance des plantes et les empêche d'être dévorées par les insectes cachés dans la terre où on les a semées. Peut-être est-ce cette méthode qui est cause qu'en Chine les navets ne sont jamais attaqués par la mouche qui leur est si funeste ailleurs. Le fermier chinois verse également son engrais liquide sur les racines des plantes et des arbres fruitiers, afin de hâter leur croissance et d'augmenter leur vigueur. L'auteur romain $^{1}$, déjà cité dans ce chapitre, rapporte qu'une semblable pratique avait beaucoup amélioré les pommes et les raisins d'Italie.

Le grand objet de l'agriculture chinoise, la production du grain, s'obtient en général avec peu d'engrais, et sans laisser jamais la terre en jachère. II est vrai qu'en Chine, il y a quelque plante, telle qu'une espèce d'épidendron qui végéterait même dans l'air. D'autres qui sont bulbeuses, ou qui ont beaucoup de suc, croissent bien, les unes dans le sable, et les autres dans l'eau. Mais malgré ces exceptions, la terre vierge est plus propre à la végétation. Quelle que soit la théorie de l'art de l'agriculture, sa pratique

\footnotetext{
${ }^{1}$ Brassica.
} 


\section{Voyage dans l'intérieur de la Chine et en Tartarie}

demande qu'on rende la terre meuble, ou qu'on lui donne la consistance la plus convenable à la plante qu'on veut faire croître. Le point où l'on veut mettre la terre s'obtient souvent par le moyen des engrais, produits en général par un mélange de substances animales et végétales qui ont éprouvé une fermentation putride. Alors, il se forme un mucilage qui, indépendamment des autres changements qu'il peut produire, donne une qualité nouvelle au sol avec lequel il se trouve mêlé, rend l'argile plus friable, donne de la consistance aux terres légères et sablonneuses, et les maintient les unes et les autres dans le degré nécessaire de chaleur et d'humidité.

Quelquefois un mélange de terre remplace avec succès le fumier dont on manque. Ainsi, la marne, qui est une composition de terre calcaire et d'argile, et ne peut produire seule aucune végétation, convient parfaitement bien pour amender certaines terres; ainsi, une addition de sable et d'eau est très propre à faciliter la végétation des terres fortes et argileuses.

Les Egyptiens connurent de bonne heure les avantages de donner au sol le juste degré de consistance qu'il doit avoir. En conséquence, ils répandaient régulièrement une certaine quantité de sable sur les terres où le Nil avait déposé un limon trop riche et trop gras. En pareille circonstance, le sable de mer est le meilleur. Le sel qui est si bien connu pour ses qualités antiseptiques, et qui, employé en grande quantité, peut nuire à la fertilité de toute espèce de sol, produit des effets contraires alors qu'on en répand avec ménagement sur des substances animales ou végétales; or, comme le sable de mer contient quelques parties de sel, il facilite la fermentation nécessaire à la végétation.

Par des pratiques semblables à celles que nous venons de décrire, les Chinois suppléent au défaut d'engrais. Ils travaillent avec une attention infatigable à donner au sol le juste degré de consistance qu'exige la plante qu'ils veulent lui faire produire. Ils transportent constamment de la terre d'un champ dans un autre. Ils mêlent du sable au sol qu'ils trouvent trop gras, et de l'argile ou des terreaux argileux à celui qui leur paraît trop meuble. Lorsque leurs terres ont le degré de consistance nécessaire, leur premier soin

\footnotetext{
${ }^{1}$ Columelle.
} 


\section{Voyage dans l'intérieur de la Chine et en Tartarie}

est d'empêcher qu'elles ne deviennent sèches et arides, et que la filtration des sucs nourriciers n'y soit arrêtée. Presque tout leur pays étant traversé par des rivières ou par des canaux, ils peuvent s'y procurer de l'eau en abondance. Ils n'ont besoin que de trouver le moyen de conduire dans leurs champs celle qui leur est nécessaire. Ainsi, ils font constamment leur récolte sans jamais laisser leurs terres en jachère, et quelquefois sans y mettre aucun engrais.

En Chine, l'arrosement des terres est réduit en système, et considéré comme un des premiers principes de la science de l'agriculteur. Indépendamment des méthodes que nous avons déjà dit être employées par les cultivateurs chinois, pour élever l'eau et la conduire dans leurs plantations, il en est une autre plus efficace, plus ingénieuse, c'est leur pompe à chaîne.

La machine qui porte ce nom, et qui est maintenant si perfectionnée et si commune à bord des vaisseaux de guerre anglais, diffère principalement de la pompe chinoise, en ce qu'elle est cylindrique, et que celle de la Chine est carrée. La plupart des nations orientales paraissent s'être servi, depuis un temps immémorial, de la machine appelée roue égyptienne; et cependant elle fut inconnue à l'Europe, jusqu'au moment où les Sarrazins l'introduisirent en Espagne, dans un état imparfait, et sous une forme grossière. Ce n'était presque rien, que quelques paquets de foin attachés à une corde qui tournait sur une roue. Une partie de la corde restant dans l'eau, chaque paquet de foin prenait une certaine quantité de ce fluide et le versait au haut de la roue.

La pompe chinoise consiste en un tronc de bois creux, et qu'une planche sépare dans sa longueur en deux compartiments égaux. Des morceaux de bois carrés, aplatis, et d'une dimension proportionnée à la cavité du tronc, sont attachés à une chaîne qui tourne sur une petite roue ou sur un cylindre, placé à chaque extrémité du tronc, par conséquent chacun de ces morceaux de bois élève, à mesure que la chaîne tourne, un volume d'eau égal aux dimensions de la cavité du tronc, et c'est ce qui fait qu'on les nomme les leviers.

Le pouvoir qui fait mouvoir cette machine s'applique de trois manières différentes. Si l'on veut lever une grande quantité d'eau, on prolonge l'axe 


\section{Voyage dans l'intérieur de la Chine et en Tartarie}

des cylindres sur lesquels tourne la chaîne, et on y met plusieurs bras de bois. Ces bras ont la forme d'un $T$, et sont arrondis et polis de manière qu'on puisse y appuyer aisément le pied. L'axe tourne sur deux poteaux, fixés par une pièce de bois qui traverse de l'un à l'autre. Alors, des hommes montant sur les bras de l'axe, et s'appuyant sur le chevron qui joint les poteaux, communiquent à la chaîne un mouvement de rotation, et les morceaux de bois carrés élèvent constamment un grand volume d'eau. L'on se sert de la pompe à chaîne pour dessécher des marais, pour transporter l'eau d'un étang dans l'autre, et pour élever l'eau des canaux et des rivières sur de petites hauteurs.

La seconde manière de faire mouvoir la pompe, c'est d'atteler un buffle ou tout autre animal à une grande roue horizontale, dont les dents s'engrainent avec celles de l'axe du cylindre sur lequel tourne la chaîne. Les Anglais ne virent employer cette méthode qu'à Chu-San.

Enfin, lorsque la pompe est petite, on la fait mouvoir avec la main. On adapte alors, à l'extrémité de l'axe, une simple manivelle, telle que celle qui fait tourner la pierre d'un émouleur. C'est la méthode la plus généralement suivie dans toute l'étendue de l'empire. Chaque paysan chinois possède sa pompe portative, comme un instrument qui ne lui est pas moins utile que la bêche ne l'est aux paysans européens. Une immense quantité d'ouvriers est sans cesse occupée à faire de ces pompes.

Dans le petit voyage que firent les Anglais pour se rendre de la ville de Chan-San-Shen à la rivière, ils ne virent pas, ainsi que nous l'avons déjà remarqué, un seul coin de terre où ne se déployât l'industrie du cultivateur. En beaucoup d'endroits, le sol était d'une qualité médiocre; mais alors on redoublait d'efforts pour le fertiliser. Sur les terrasses des montagnes, on labourait la terre, non avec la charrue, mais avec la houe. Les champs y sont extrêmement propres : on y voit jamais une mauvaise herbe. L'on dit que, dans quelques provinces, les Chinois se servent d'une charrue à roue; mais celle qu'ont eu occasion d'observer nos voyageurs est de la plus simple structure. Un seul buffle la traîne, et un homme la conduit. Elle n'a qu'un manche et point de coutre, attendu que, comme en Chine il n'y a point de prairies, et conséquemment point de racine d'herbe à couper, le coutre y est inutile. 


\section{Voyage dans l'intérieur de la Chine et en Tartarie}

A la Chine, les auberges sont communes sur les grandes routes. Mais comme le pays des environs de Chan-San-Shen est très peu fréquenté, il ne se trouva point dans la ville où l'ambassade arriva le soir un seul cabaret propre à la recevoir. Cette ville est située sur les bords de la rivière sur laquelle les Anglais devaient s'embarquer le lendemain. La maison où I'on a coutume d'examiner les jeunes lettrés du district, lorsqu'ils veulent prendre leurs degrés, fut choisie pour loger nos voyageurs, et on l'arrangea pour cela assez commodément.

L'examen des étudiants chinois se fait, dit-on, toujours en public. Le nombre des auditeurs, ainsi que la présence du gouverneur et des principaux magistrats du district qui y président, doivent empêcher les juges de montrer de la partialité. On fait aux candidats quelques questions verbales, et on leur en donne par écrit, comme dans les collèges anglais. La récompense de ceux qui réussissent n'est pas bornée aux simples honneurs de l'université, car ces honneurs deviennent les degrés qui conduisent à tous les emplois, à toutes les dignités de l'État. Ceux mêmes qui n'obtiennent point le grade qu'ils ambitionnent ont cependant acquis assez d'instruction pour pouvoir s'occuper utilement dans la société, et ajouter à la masse générale des connaissances.

Une manière d'avancement si ouverte à toutes les classes tend à les réconcilier avec le pouvoir auquel tous les individus ont droit de parvenir. Les jeunes gens nés de parents riches ont sans doute plus de facilité et de meilleures occasions de s'instruire que les enfants des pauvres ; malgré cela, le génie a quelquefois la force de triompher des obstacles et, quoi qu'il en soit, la possibilité du succès flatte toujours ceux mêmes qui ne peuvent pas l'obtenir. La persuasion où l'on est aussi, que l'autorité a été acquise par le mérite, fait qu'on est plus disposé à la respecter et à lui obéir, à moins qu'elle ne soit accompagnée de trop d'abus. Mais quand ces abus ont lieu, le savoir et le talent ne suffisent pas toujours pour sauver ceux qui les commettent.

Certes, un tel système de gouvernement promet de grands avantages à la société, et ne peut manquer de les lui procurer, que quand l'envie de faire le mal l'emporte sur la force des principes et sur la crainte d'être découvert en les sacrifiant. Les Chinois pauvres, qui n'ont pas le moyen de faire entendre 


\section{Voyage dans l'intérieur de la Chine et en Tartarie}

leurs plaintes et de faire connaître leur opinion sur leurs administrateurs iniques, sont presque entièrement à la merci de ces administrateurs. Les étrangers qui ont affaire à eux ne peuvent pas non plus se soustraire à leurs vexations; c'est pourquoi l'ambassadeur profita de toutes les occasions que lui fournirent et ses liaisons avec le vice-roi, et les intentions honorables de cet officier, pour lui faire sentir la nécessité de protéger les étrangers qui trafiquaient à Canton, et de mettre un frein aux exactions du hoppo ${ }^{1}$ et des autres officiers chinois qui avaient des rapports avec le commerce. Le vice-roi était réservé dans ses promesses, mais il semblait sincèrement disposé à faire tout le bien qu'il pourrait.

Dans une nouvelle visite que le vice-roi fit à l'ambassadeur, il lui dit qu'il s'attendait bien que plusieurs officiers de la province qu'il allait gouverner prendraient beaucoup de peine pour lui donner des préventions contre la nation anglaise; mais qu'il pensait que non seulement la justice due aux Anglais, mais l'honneur même de son pays exigeaient qu'on changeât de conduite envers eux. II ajouta que, cependant, quelque considérable que fût l'autorité qui lui était confiée, et quelque bien appuyé qu'on le crût, sa situation n'était pas sans difficultés. Indépendamment des employés de Canton, lesquels, poursuivit-il,

« ont intérêt à empêcher qu'on écoute des plaintes qu'ils ont euxmêmes occasionnées, et qui sont accoutumés à traiter les étrangers avec non moins de mépris que d'injustice, les Anglais ont aussi des ennemis à la cour ; et dans le nombre de ces ennemis, est mon prédécesseur même, qui peut considérer toute réforme de ma part comme une censure de sa conduite, et un reproche indirect d'avoir toléré l'injustice. Mais il est encore une considération plus importante pour moi : c'est la manière sèche et hautaine dont le premier ministre, Ho-Chaung-Taung, a refusé d'accéder aux demandes de l'ambassadeur. J'ignore comment l'ambassadeur présentera ce refus à la cour d'Angleterre, mais s'il s'efforçait d'exciter le ressentiment de cette cour, tout ce qui

\footnotetext{
${ }^{1}$ Receveur général des douanes et des revenus de Canton.
} 


\section{Voyage dans l'intérieur de la Chine et en Tartarie}

pourrait faire connaître ce ressentiment rendrait excessivement criminelle aux yeux du gouvernement chinois la moindre preuve de faveur que je donnerais aux Anglais. Ainsi, je désire de savoir parfaitement sur quoi je dois compter à cet égard.

L'ambassadeur n'était pas très certain qu'une pareille appréhension vînt du vice-roi seul. Elle pouvait partir d'une source plus élevée. Mais quoi qu'il en fût, elle montrait que les armées des Anglais dans l'Inde, et les forces de mer qu'ils avaient partout ailleurs, étaient reconnues assez puissantes pour exiger quelques ménagements même de la part de l'orgueilleux empire de la Chine.

L'ambassadeur avoua au vice-roi qu'il avait eu quelques doutes sur les dispositions de la cour, ou plutôt des ministres de Pékin, à l'égard de son pays. Mais que d'après ce que lui avaient dit, des sentiments de l'empereur, celui qui l'avait accompagné à Han-Choo-Foo ${ }^{1}$, et le vice-roi lui-même, il comptait sur des assurances aussi solennelles et pensait qu'on aurait une attention particulière pour les intérêts des Anglais qui trafiquaient en Chine ; qu'il avait déjà mandé à la cour de Londres quelle était sa confiance à ce sujet, en écrivant d'Han-Choo-Foo, pour rendre compte de sa négociation, et qu'il ne doutait pas que son gouvernement n'eût confiance dans les promesses qui lui avaient été faites.

Le vice-roi demanda alors à l'ambassadeur s'il pouvait l'autoriser à annoncer que, pour preuve de la continuation des dispositions favorables du roi d'Angleterre, ce prince écrirait bientôt à l'empereur de la Chine, et enverrait un nouveau ministre, si l'empereur consentait à le recevoir ; que, toutefois, ce ministre serait envoyé sans la pompe et les dépenses qu'avait dû coûter la présente ambassade, et simplement comme un témoignage de l'amitié durable de sa majesté britannique.

A cette proposition inattendue, lord Macartney hasarda de répondre que, probablement, le roi d'Angleterre ne ferait point difficulté d'écrire à l'empereur pour lui accuser la réception de ses présents, et le remercier de l'accueil qu'il avait fait à l'ambassade; que c'était une chose différente de 


\section{Voyage dans l'intérieur de la Chine et en Tartarie}

l'objet de cette ambassade. Que cependant, il espérait que tout s'arrangerait avec le temps ; mais que la distance qu'il y avait de la Grande-Bretagne à la Chine, et l'incertitude des voyages par mer, l'empêchaient de dire à quelle époque une nouvelle ambassade arriverait.

Le vice-roi termina la conversation en annonçant qu'il allait, sans tarder, expédier un courrier pour rendre compte de la conférence qu'il venait d'avoir avec l'ambassadeur, et qu'il espérait que ce qu'il manderait, en outre, satisferait pleinement l'empereur.

Les voyageurs étaient à peine embarqués qu'un vent violent, mêlé de pluie, retarda, ou plutôt arrêta leur marche. Après que la pluie eut cessé, son effet continua sur la rivière qu'elle avait grossie; et le courant étant favorable, les barques naviguèrent avec rapidité. Quand elles furent près de la ville de Koang-Sin-Foo, le temps devint encore froid, sombre et pluvieux. Le pays offrait une perspective sauvage. De chaque côté de la rivière, on voyait d'énormes masses de rochers nus, prodigieusement élevés, et ressemblant à ceux qui avaient paru exagérés dans les tableaux chinois. Ces rochers étaient d'une pierre rouge et noirâtre ; et on en avait pris plusieurs blocs pour bâtir.

La rivière était alors si large et si profonde que les barques couvertes, dont on s'était servi lorsqu'il y avait peu d'eau, furent changées pour des yachts plus grands et plus commodes.

Toutes les fois que le vent contraire, les sinuosités de la rivière, ou quelque autre circonstance retardaient la marche de l'ambassade, plusieurs Anglais quittaient les yachts pour aller à pied le long des bords de la rivière ou des canaux, ou bien ils traversaient la campagne pour examiner ce qui s'offrait à leur vue, et faire toutes les observations dont ils étaient capables. Deux d'entre eux qui, chaque jour, avaient coutume de faire quelques excursions, furent une fois rudement arrêtés par un mandarin, accompagné

\footnotetext{
${ }^{1}$ Le colao Sun-ta-Zhin.
} 


\section{Voyage dans l'intérieur de la Chine et en Tartarie}

de quelques soldats insolents. II ordonna aux Anglais de retourner à bord, et les menaça de les y envoyer par force, s'ils ne s'empressaient d'obéir.

Chow-ta-Zhin et Van-ta-Zhin, informés de cet événement, ordonnèrent aux soldats de se coucher à plat ventre, et les firent tenir par quelques militaires, en ordonnant à d'autres de les frapper avec une latte de bambou ; châtiment qu'on inflige ordinairement en Chine, pour de légères offenses. Mais les Anglais qui avaient été maltraités obtinrent la grâce des soldats. Cependant Chow-ta-Zhin porta des plaintes au vice-roi contre le mandarin qui était le principal offenseur, et qui, dans cette occasion, n'avait agi par aucun autre motif que pour le seul plaisir d'abuser de son autorité contre des étrangers qu'il avait sans doute cru sans protection. Les pauvres paysans du district où commandait cet homme n'avaient sans doute guère d'espoir d'en être traités avec douceur ; mais le vice-roi mit un terme à ses duretés, en le privant de son emploi ; et il lui fit, de plus, infliger une punition corporelle.

Quelque avilissante que puisse paraître à un Européen la punition du bambou, il ne faut que se plaindre légèrement pour la faire infliger aux individus qui ne sont point au rang des mandarins. Un vice-roi a non seulement le pouvoir de dégrader les bas officiers, mais de faire infliger, sans un jugement en forme, à des officiers inférieurs, une punition qui n'est point capitale. La plupart des Chinois sont tellement accoutumés à leur condition, qu'ils ne considèrent dans ces sortes de châtiments que la douleur qu'ils peuvent leur causer.

Le principal objet du gouvernement est de maintenir la tranquillité et le bien-être général, et il semble se soucier peu des précautions qu'exige la sécurité personnelle des individus. Quand un homme est accusé d'un crime qui mérite la mort, on assemble une cour de justice pour le juger ; mais on ne convoque point de jury pour examiner le fait. Les juges mettent peu d'importance aux preuves orales, à moins qu'elles ne soient fortifiées par des circonstances particulières, et par des documents écrits. Cependant, lorsque l'accusation n'est pas très grave, le prévenu est admis à se justifier par un serment solennel, accompagné de cérémonies religieuses.

La question est quelquefois employée pour arracher à un accusé l'aveu de son crime et le nom de ses complices. Ce moyen est très impolitique de la 


\section{Voyage dans l'intérieur de la Chine et en Tartarie}

part de ceux qui le mettent en usage, parce que ni la prudence, ni l'innocence ne peuvent mettre à l'abri du soupçon et de l'accusation, ni conséquemment empêcher de souffrir un mal pire que la mort, pour découvrir un crime incertain.

Il est rare qu'une peine capitale soit infligée sans que l'empereur ait confirmé la sentence. Mais cette confirmation n'est pas toujours nécessaire. La sentence est exécutée par ordre du vice-roi, dans les cas extraordinaires comme, par exemple, lorsqu'il y a rébellion ou sédition.

Ordinairement, tous les criminels condamnés à mort sont transférés à Pékin, où leur procès est revu par le grand tribunal institué pour cela. Les coutumes de l'empire, qui supposent le souverain doué des plus grands principes d'humanité, exigent qu'il prenne l'avis du conseil pour savoir s'il peut, sans danger pour l'État, éviter de faire exécuter les sentences de mort.

L'exécution de tous les criminels se fait dans le même temps; et le nombre est rarement de plus de deux cents, ce qui semble bien peu dans un empire si vaste et si peuplé. Le plus souvent, une amende, un emprisonnement, le fouet, l'exil, sont les peines qu'on inflige. II faut, pour être puni de mort, avoir commis quelque crime contre l'État, ou contre l'empereur, ou avoir versé le sang ; ce qui n'admet ni pardon, ni commutation de peine. Il n’y a même en Chine aucune distinction entre le meurtre prémédité, et I'homicide involontaire. Le vol n'y est jamais puni de mort, à moins qu'il ne soit commis avec violence et avec cruauté. La modération du châtiment semble annoncer que le crime est rare ; et il l'est, en effet, excepté dans les temps de famine, temps où la sévérité des peines n'arrêterait pas davantage les coupables.

Quelque louable et prévoyante que soit l'attention du gouvernement chinois, quelque sages et bienfaisants que soient ses règlements, il se borne à tirer des secours de ses propres provinces pour celles qui ont des besoins ; et ces mesures, n'étant pas toujours fidèlement exécutées, ne peuvent avoir un effet aussi sûr que la vigilance intéressée et judicieuse des spéculateurs européens, qui ne manquent pas d'apporter des provisions là où elles manquent. Aussi la famine se fait plus souvent sentir dans une province chinoise que dans aucun pays d'Europe. 


\section{Voyage dans l'intérieur de la Chine et en Tartarie}

Parmi les divers supplices capitaux connus des Chinois, ils regardent celui de la corde comme moins infâme que la décapitation. La perte d'une partie du corps est pour eux une honte excessive. Le supplice du cha, qu'on appelle en Europe la cangue, est ordinairement infligé pour les crimes les moins graves. Ceux qu'on punit de ce supplice sont obligés de porter une grande table dans laquelle il y a trois trous, l'un pour passer le cou, et les autres pour passer les mains. C'est une espèce de pilori ambulant; et le coupable y est quelquefois condamné pour des semaines et des mois entiers. S'il a assez de force, on le fait promener dans cet état ; mais ordinairement, il préfère de rester appuyé contre une muraille ou contre un arbre; et alors, si l'un des valets du magistrat civil s'imagine que le malheureux coupable s'est reposé trop longtemps, il le force de se lever en le frappant d'un fouet fait avec des courroies de cuir.

On cite quelques exemples de coupables auxquels on a permis de mettre quelqu'un à leur place pour subir la peine qu'ils avaient méritée. La loi, dont les principes sont raisonnables et justes, ne permet sûrement pas un pareil abus ; mais ses dispensateurs peuvent le tolérer ; et la piété d'un fils peut, en Chine plutôt qu'ailleurs, le porter à souffrir un châtiment pour l'épargner à son

père.

L'administration des prisons de la Chine est, dit-on, parfaitement bien entendue. Les coupables et les hommes emprisonnés pour dettes sont dans des lieux séparés. II ne leur est pas permis d'avoir de communication, parce qu'on pense qu'il est impolitique et immoral d'associer le crime avec l'imprudence et l'infortune. Les deux sexes sont également renfermés à part. L'emprisonnement pour dettes n'est que précaire. Mais si après qu'un débiteur a livré à ses créanciers tout ce qu'il possédait, ils ne sont point encore satisfaits, on le condamne à porter publiquement un joug sous le cou, pendant un certain temps, afin d'engager sa famille à payer ses dettes, et à mettre un terme à sa honte, si toutefois elle en a les moyens. Si le débiteur s'est rendu insolvable en jouant, ou par quelque autre preuve d'inconduite, il subit une punition corporelle, et l'exil en Tartarie.

En Chine, il est des cas où un homme peut se vendre lui-même ; comme, par exemple, pour payer ce qu'il doit à la couronne, pour assister son père dans la détresse ou, s'il est mort, pour le faire enterrer d'une manière 


\section{Voyage dans l'intérieur de la Chine et en Tartarie}

convenable. Si celui qui s'est vendu sert son maître d'une manière irréprochable, il est en droit de demander sa liberté au bout de vingt ans. S'il se conduit mal, il reste esclave pendant toute sa vie, ainsi que les enfants qu'il peut avoir vendus avec lui.

Lorsque les débiteurs de l'empereur le sont frauduleusement, on les étrangle; mais s'ils ne le sont que par suite d'infortune, on se contente de vendre leurs femmes, leurs enfants, et tout ce qui leur appartient, et de les envoyer eux-mêmes dans les nouveaux établissements chinois, en Tartarie.

En Chine, les intérêts de l'empereur sont toujours le premier objet. II n'y a point de propriété qui puisse être sûre contre ses droits. La préférence ainsi donnée à celui qui possède un pouvoir illimité peut être considérée comme la conséquence notoire de ce pouvoir. On peut aussi justifier, jusqu'à un certain point, cette préférence en considérant que celui qui est le plus exposé à la fraude doit avoir les moyens les plus efficaces pour s'en garantir, et punir ceux qui la commettent.

Les différends entre les individus, relativement à leurs propriétés, n'occupent pas beaucoup de place parmi les affaires de la Chine. Le désir de rendre justice n'y a pas fait multiplier les formes et les plaidoiries. Des années n'y sont pas remplies par la décision d'un procès, pendant la durée duquel on ne peut donner que peu d'attention à d'autres objets. De quelque manière qu'il finisse, on le perd bientôt de vue; et on passe à d'autres affaires et à d'autres considérations.

La propriété, quelle qu'elle soit, est dans une tenure trop simple à la Chine pour que le droit qu'on y a, occasionne beaucoup de contestations. II n'y a ni douaires, ni substitutions. Les causes des dissensions sont détruites chez les Chinois par le peu de commerce qu'ils ont avec les étrangers ; par l'uniformité de leurs principes, de leurs coutumes, de leurs idées; par l'espèce de communauté dans laquelle vivent la plupart d'entre eux, et surtout par l'union qui existe dans les familles, si différentes que celles qui, ailleurs, sont livrées aux plus grandes querelles, par les prétentions exclusives des individus. Les salles des tribunaux chinois sont plus remplies de gens qui vont solliciter que de plaideurs. 


\section{Voyage dans l'intérieur de la Chine et en Tartarie}

Des hommes de talent, des lettrés, se chargent quelquefois de défendre la cause de ceux qui sont jeunes, ignorants ou incapables; mais il n'y a point d'hommes qui s'enrichissent à faire le métier de procureurs ou d'avocats et qui, par ce moyen, parviennent aux dignités.

On cherche à rendre les juges impartiaux, en ne les élevant jamais à cet emploi dans la province où ils sont nés. Mais si ce n'est pas par affection qu'ils penchent en faveur d'une des parties, ils peuvent être entraînés par le poids des présents. Des présents sont offerts par un inférieur à un supérieur, et par un plaideur à un juge : c'est une coutume générale en Chine, comme dans la plupart des autres contrées de l'Orient. Ainsi, les juges sont payés par les deux parties; et si chacune d'elles est également riche et également libérale, il est possible que le jugement de leur procès soit prononcé avec équité. De même que dans les tribunaux judiciaires d'Angleterre, il règne de l'impartialité, malgré les honoraires réguliers que les juges reçoivent des différents plaideurs.

Les grandes dépenses qu'exigent les procès peuvent donc devenir un moyen d'oppression dans les mains de celui qui est à la fois opulent et inique. Mais, ce qu'il y a de pire, c'est que parmi les Chinois, on n'a point déterminé la somme des honoraires, ou plutôt les présents que doit recevoir un juge. On s'attend même que ces présents seront toujours proportionnés aux facultés de celui qui les fait. S'il était vrai, comme le croient quelques juges chinois, que ces dons fussent une rétribution nécessaire de leur place, sans qu'ils pussent avoir aucune influence sur la décision d'un procès, cela pourrait bien être un frein pour les riches, obligés de faire beaucoup de ces dons, et alors leurs voisins pauvres seraient un peu moins exposés à leurs vexations. Mais dans le fait, l'argent est le grand mobile des jugements dans les tribunaux chinois; et communément, le droit s'y trouve au fond de la plus longue bourse. Les dispensateurs de justice n'y reçoivent pas des salaires qui les mettent à l'abri de la tentation, et qui puissent rendre l'acceptation des présents aussi inutile que déplacée.

L'argent que les Européens ont porté en Chine depuis un siècle a occasionné une grande augmentation dans le prix de tous les articles de consommation, et a détruit la proportion qui existait entre les appointements de plusieurs officiers du gouvernement et les dépenses qu'ils sont obligés de 


\section{Voyage dans l'intérieur de la Chine et en Tartarie}

faire. Les relations des anciens missionnaires disent qu'en Chine, on vivait autrefois presque pour rien; mais aujourd'hui, il y a beaucoup de choses de première nécessité qui n'y sont pas à meilleur marché qu'en Angleterre.

Dans toutes les difficultés qui ont lieu entre les Tartares et les Chinois, la partialité a occasion de se manifester ; et l'on ne doit guère s'attendre que la balance de la justice soit tenue d'une main ferme entre le conquérant et le vaincu. Mais dans les provinces méridionales, c'est un mal qui se fait très peu sentir. On n'y trouve guère d'autres Tartares, que ceux qui sont élevés aux premiers emplois et, conséquemment, ils n'ont pas beaucoup d'occasions de témoigner de la préférence aux individus de leur nation. II n'y avait pas un seul Tartare établi dans le voisinage de Koang-Sin-Foo, ville où le mauvais temps retint les Anglais pendant toute une journée.

La campagne autour de la ville était inondée, et presque entièrement remplie de plantations de riz. Beaucoup de moulins à riz, établis sur la rivière, montraient que ce grain était plus fréquemment réduit en farine dans cette province que dans celles du nord, où les Anglais n'avaient pas vu un seul de ces moulins. Il y avait beaucoup de gens occupés à pêcher, et d'autres qui ramassaient les graines de l'arbre à suif, qui étaient déjà mûres et commençaient à s'ouvrir comme les gousses du cotonnier.

Pour ne pas abandonner leurs yachts, les voyageurs dirigèrent leur course un peu au nord-ouest ; et bientôt ils entrèrent dans cette vaste étendue de pays plat et marécageux, où se trouve le lac Po-Yang, le plus grand, sans doute, qui se trouve dans l'empire chinois. A plusieurs milles, tout autour de ce lac, la campagne n'est qu'un désert marécageux, couvert de joncs et de roseaux, et entièrement sous l'eau pendant la plus grande partie de l'année. On n'y voit pas un seul village; pas même de traces d'habitation, si ce n'est quelque misérable et solitaire hutte, habitée par quelque pêcheur, et dont on ne peut approcher qu'avec un canot. Les malheureux qui se fixent là vivent du produit de leur pêche et des végétaux qu'ils cultivent sur des radeaux de bambou.

Le lac Po-Yang et le pays qui l'environne peuvent être appelés l'égout général de la Chine. Les rivières courent s'y jeter de tous les points du 


\section{Voyage dans l'intérieur de la Chine et en Tartarie}

compas. Ce lac fournit de l'eau à plusieurs canaux, dont on a eu soin de fortifier les bords pour que les vaisseaux y fussent en sûreté dans le temps des tempêtes et des débordements. Les vagues du lac s'élèvent quelquefois si haut, que les marins chinois les regardent comme aussi dangereuses que celles de la mer. On voit dans le Po-Yang quelques îles de sable qui s'élèvent à peine au-dessus de la surface de l'eau et sont couvertes d'humbles cabanes de pêcheurs.

Après avoir rassemblé les eaux de plusieurs rivières, le Po-Yang verse les siennes dans le Yang-Tsé-Kiang, et le rend plus considérable.

Dans le pays marécageux qui s'étend à plusieurs milles au sud du PoYang, et que traversèrent nos voyageurs, les demeures et les ressources des habitants sont les mêmes qu'à l'orient de ce lac. Chaque habitant paraît avoir un endroit où il pêche seul. Cet endroit est divisé par petits compartiments, où l'on nourrit et engraisse les poissons. Il y a de ces poissons qui ressemblent à de petites sardines. On les sale, on les fait sécher, et ils deviennent un objet de commerce dans toute l'étendue de l'empire. Indépendamment des différentes manières que nous avons déjà dit être en usage pour prendre le poisson en Chine, il en est une qui est également employée : c'est celle d'étendre un filet sur quatre morceaux de bambou, et de le suspendre à une longue perche.

Les oiseaux aquatiques abondent dans cette contrée, et sont une partie de ses ressources. On se sert de divers stratagèmes pour les prendre, mais comme ils ne sont jamais épouvantés par l'explosion des armes à feu, ils sont très peu farouches. Même le corbeau commun à gorge blanche se laisse approcher à deux ou trois pas avant de prendre sa volée.

A mesure que nos voyageurs s'éloignaient du lac Po-Yang, et qu'ils passaient de la province de Kiang-Nan dans celle de Kiang-Sée, la campagne devenait plus fertile, et son aspect plus agréable. La population accoutumée reparaissait.

La marche des yachts était lente, parce qu'ils avaient besoin de vaincre le courant rapide d'une rivière qui venait du sud-ouest. Aux marais des environs du Po-Yang succédèrent de vastes plantations de cannes à sucre. Comme 


\section{Voyage dans l'intérieur de la Chine et en Tartarie}

elles étaient dans un sol sablonneux et beaucoup plus élevé que la rivière, il fallait, pour les arroser, porter l'eau à une hauteur à laquelle on ne pouvait parvenir par les moyens que nous avons déjà dit être employés en Chine. Mais le besoin suggère des ressources. On a inventé une machine aussi ingénieuse qu'utile, peu chère, et facile à employer.

Deux poteaux de bois dur sont solidement plantés dans le lit de la rivière, et forment une ligne transversale avec ses bords. Ils supportent l'axe d'une grande roue dont les jantes sont d'un diamètre différent; celles le plus près du bord de la rivière ayant environ quinze pouces de moins que les autres. Malgré cela, elles plongent également dans l'eau, tandis que le haut de la roue se trouve au-dessus du niveau de la terre. L'axe a environ dix pieds de long, et la roue y est attachée par seize ou dix-huit rayons, ou bras, qui partent obliquement de chaque extrémité de l'axe, et se croisent vers les deux tiers de leur longueur. Là, ils sont renforcés par un cercle concentrique, et ils vont ensuite aboutir à la roue. Les bras de l'extrémité de l'axe qui est en dedans, c'est-à-dire du côté du bord de la rivière, soutiennent les jantes qui sont en dehors ; et ceux qui partent de l'extrémité de l'axe qui est en dehors supportent les jantes qui sont en dedans. Entre les bords de la roue et les bras qui se croisent, il y a des claies qui servent de godets ou de palettes et, recevant l'impulsion du courant, font tourner la roue.

De chaque côté de la roue sont attachés de petits tubes de bois qui ont une inclinaison d'environ vingt-cinq degrés vers I'horizon, ou vers l'axe de la roue. Ces tubes sont fermés par le bout extérieur, et ouverts par l'autre, de sorte qu'en passant dans l'eau, ils se remplissent; mais quoique le mouvement de la roue change leur position relative, ils se retrouvent assez inclinés pour ne verser l'eau que lorsqu'ils sont tout à fait en haut. Alors ces tubes se vident dans une large gouttière qui est soutenue par des poteaux, et par le moyen de laquelle on conduit l'eau dans les plantations qui en ont besoin.

A l'exception de l'arbre ou de l'axe de la roue et des deux poteaux qui le supportent, tout le reste de la machine est de bambou. Les jantes de la roue, les bras, les godets et même les cordes sont faits avec des bambous, soit dans toute leur longueur, soit coupés par morceaux, ou fendus en lattes très minces. II n'y entre ni écrous, ni clous, ni chevilles de fer. Les diverses parties 


\section{Voyage dans l'intérieur de la Chine et en Tartarie}

en sont liées ensemble par des cordages de bambou. Ainsi, avec très peu de dépense, on construit une machine qui, sans exiger ni travail, ni soin, porte l'eau à une très grande hauteur, et entretient un réservoir proportionné aux besoins de l'agriculteur.

Les roues de ces machines ont depuis vingt jusqu'à quarante pieds de diamètre, suivant la hauteur des bords de la rivière, et le point où l'on veut élever l'eau. Une de ces roues peut aisément porter vingt tubes de quatre pieds de long et de deux pouces de diamètre. Chacun de ces tubes contient les six dixièmes d'un gallon, et par conséquent, vingt tubes contiennent douze gallons. Un courant d'eau d'une rapidité modérée suffit pour faire faire à une roue quatre tours par minute. Ainsi, on peut élever quarante-huit gallons d'eau dans la courte période d'une minute, deux mille huit cent quatre-vingts gallons dans une heure, et soixante neuf mille cent vingt gallons, ou plus de trois cents tonneaux dans un jour.

La machine dont nous venons de faire la description surpasse, à beaucoup d'égards, toutes celles du même genre. La roue persane, aux jantes de laquelle sont attachés des seaux mobiles, et qui est si commune dans le midi de la France et dans le Tyrol, approche de la roue chinoise; mais elle est beaucoup plus coûteuse, d'une construction moins simple et d'une invention moins ingénieuse. Dans le Tyrol, on élève aussi l'eau avec une roue, dont la circonférence est garnie de godets ; mais cette roue est très inférieure à la roue chinoise et à la persane.

Le bambou est une plante également curieuse, utile et belle. C'est proprement un roseau creux et garni de nœuds. On dit qu'il réussit mieux dans les terrains légers, situés dans le voisinage d'une eau courante, que dans les autres. II atteint bientôt toute sa croissance, c'est-à-dire que dans dix-huit mois, il s'élève à environ vingt pieds de haut. II a le double et rare avantage d'être également léger et solide. Sa tige se resserre, et le diamètre en diminue à mesure qu'elle croît, ainsi qu'on le voit dans quelques espèces de palmiers. Les branches du bambou sont en petit nombre, et d'un vert léger et brillant; ses feuilles sont longues et étroites.

On trouve quelquefois dans le creux du bambou une substance singulière qui, suivant la relation d'un savant voyageur, est regardée, dans quelques 


\section{Voyage dans l'intérieur de la Chine et en Tartarie}

pays, comme un remède, et qu'un chimiste ingénieux a prouvé être de la nature du caillou.

Les Chinois comptent plus de soixante espèces de bambou, et peut-être les emploient-ils à un plus grand nombre d'usages. Non seulement ils s'en servent pour bâtir, soit à terre, soit sur l'eau, et pour faire presque toute sorte de meubles, mais ils le réduisent en pâte pour fabriquer le papier, et de plus, ils mangent avec plaisir les jets qui commencent à pousser.

On voit beaucoup de bambous dans la province de Kiang-Sée, sur les bords de la rivière où les Anglais naviguaient. II y a aussi de grands camphriers qui croissent un peu plus loin de la rivière, et qui sont quelquefois mêlés avec un arbre encore plus grand, un figuier que les Chinois appellent yang-shoo, et qui étend horizontalement ses branches assez loin pour couvrir presque un demi-âcre de terre.

Les vallées qu'on voit entre la rivière et les montagnes ne sont pas très spacieuses. Mais quand tout le pays n'eût formé qu'une plaine, il n'aurait pas pu être plus peuplé. La province de Kiang-Sée a beaucoup de manufactures de poterie commune et de très belle porcelaine. En quelques endroits, la rivière baigne le pied des montagnes, du haut desquelles d'énormes masses de rocher ont souvent roulé dans l'eau. L'impétuosité du courant qui passe sur ces rochers a souvent occasionné des accidents, dont le souvenir engagea les matelots chinois qui conduisaient les yachts des Anglais à faire un sacrifice pareil à celui que nous avons décrit, en parlant du passage du fleuve Jaune.

Au-delà des rochers, la surface de l'eau était unie, et les voyageurs la virent presque entièrement couverte de petits bateaux, dans chacun desquels il y avait un ou deux cormorans. Ces canots sont si petits et si légers que les pêcheurs les portent souvent sur leurs épaules, d'un lac à l'autre, ainsi que l'oiseau qui leur sert à prendre le poisson. Quelquefois, les pêcheurs n'ont point de canot, et ils se mettent, avec leurs oiseaux, sur de petits radeaux qui ne sont composés que de cinq bambous attachés ensemble.

Au passage de l'ambassade anglaise, dans cette province méridionale, le froment commençait à pousser, et on en voyait des champs à côté des plantations de hautes cannes de sucre qui ne devaient pas tarder à être bonnes à passer au moulin. Dans cette province, les femmes de la dernière 


\section{Voyage dans l'intérieur de la Chine et en Tartarie}

classe sont affranchies du préjugé des petits pieds, et elles sont si robustes et si accoutumées au travail que les paysans des autres provinces vont souvent chercher dans le Kiang-Sée ce qu'ils appellent une femme laborieuse.

On voit souvent un cultivateur de cette province tenir d'une main la charrue, à laquelle sa femme est attelée, et de l'autre main semer le blé. A la vérité, la terre est meuble, et la charrue d'une construction et d'un bois très léger ; mais la tâche imposée à la femme paraît bien peu convenable à des yeux européens, surtout n'étant pas également partagée par les deux sexes. Les femmes du Kiang-Sée sont distinguées des filles, en ce que ces dernières laissent tomber leurs cheveux du devant de la tête jusque sur leurs sourcils, et que les autres relèvent tous les leurs sur le sommet de la tête.

Dans la province de Kiang-Sée, les biens sont affermés pour trois, cinq ou sept ans et, d'après le contrat, la ferme cesse à l'expiration d'un de ces termes, si le fermier ou le propriétaire le désirent. En général, le propriétaire partage la récolte avec le cultivateur. Ce dernier a sa moitié entière, et l'autre paie sur la sienne l'impôt dû à l'empereur, impôt qui est censé devoir être toujours le même, soit que la récolte ait été abondante, soit qu'elle ait été mauvaise. Mais dans ce dernier cas, on fait quelques représentations, et on obtient la remise d'une partie ou de la totalité de l'impôt. L'empereur doit, diton, avoir cinq pour cent sur la valeur de la récolte ; mais comme l'estimation est entièrement à la discrétion des officiers de la couronne, on la fixe ordinairement au-dessus du prix courant, et par ce moyen, l'impôt s'élève à un dixième de la totalité du produit.

La rivière, dont les yachts des Anglais avaient si longtemps remonté le courant, devint peu profonde et cessa bientôt d'être navigable. Elle prenait sa source entre deux chaînes de montagnes froides et stériles qui, durant les mois d'hiver, sont souvent couvertes de neige. II y a quelques parties de terrain sans la moindre trace de verdure, parce que ce sol n'est qu'une espèce de sable noir, ou de pierre décomposée. Dans un endroit où le côté de la montagne est à pic, on découvre diverses veines de quartz, horizontalement et parallèlement rangées, entre des couches de terre argileuse. 


\section{Voyage dans l'intérieur de la Chine et en Tartarie}

Les Anglais furent obligés d'entreprendre un second voyage par terre, de la même manière que le premier. Les préparatifs étant faits dès le même jour du débarquement, nos voyageurs se mirent en route le lendemain de bonne heure, et arrivèrent bientôt au pied des montagnes qui séparent la province de Kiang-Sée de celle de Quan-Tung.

Ces montagnes forment une chaîne qui s'étend presque tout à fait de l'est à l'ouest, et forme une ligne transversale avec les autres montagnes que nous avons dit commencer auprès de Han-Choo-Foo et s'étendre vers le sud. La base des montagnes, entre le Kiang-Sée et le Quan-Tung, est de granit recouvert d'une couche de pierre calcaire et graveleuse.

Bientôt les Anglais commencèrent à escalader la plus haute de ces montagnes, le sommet de laquelle était confondu avec les nuages qui l'environnaient. Quelques-uns des voyageurs crurent voir que deux de ces nuages restaient immobiles, et étaient séparés par un espace régulier. Mais quand ils eurent parcouru, en montant, un grand espace de terrain auquel on a fait faire beaucoup de sinuosités pour qu'on puisse y passer à cheval, ils virent avec étonnement que ce qu'ils avaient pris pour deux nuages immobiles n'était que le sommet d'une montagne, dans laquelle on a creusé un passage très profond. Quelque difficile que soit encore ce passage, il l'est beaucoup moins qu'il ne l'était avant que le sommet de la montagne fût partagé. Aussi la statue du mandarin qui a fait exécuter cet ouvrage occupe une place dans l'un des temples des environs. II y a dans le passage un poste militaire.

La montagne est couverte de plantations d'arbres jusqu'au sommet, d'où l'œil découvre une vaste et riche perspective. Une descente douce, régulière, et de plusieurs milles de longueur, s'offre de chaque côté; et un pays presque entièrement couvert d'une brillante verdure, et au milieu duquel sont semés des villages, des villes et des maisons de fermier, est, pour nous servir de l'expression de M. Barrow, mis aux pieds du spectateur, tandis que des plaines d'une étendue immense, et des montagnes qui s'élèvent à l'horizon, terminent la vue.

Cependant, du côté du nord, on aperçoit un espace stérile et désert. En comparaison de l'énorme hauteur d'où les Anglais voyaient les collines qui 


\section{Voyage dans l'intérieur de la Chine et en Tartarie}

s'élevaient dans la plaine, elles ne leur paraissaient que comme autant de gros tas de foin; et plusieurs montagnes éloignées ne semblaient pas plus considérables. La ville de Nan-Gan-Foo, d'où les voyageurs étaient partis récemment, avait l'air d'un monceau de tuiles et la rivière qui y passe était alors, à leurs yeux, comme une ligne brillante.

La montagne qui est si élevée au-dessus de tous les objets qui l'environnent a encore bien plus d'élévation au-dessus de la surface de la mer. Elle est de mille pieds au moins plus haute que les sources du KanKiang, c'est-à-dire de la rivière sur laquelle l'ambassade avait navigué depuis les environs du lac Po-Yang. Le courant de cette rivière est si rapide qu'on estime qu'elle a vingt pieds de pente par mille, dans un cours d'environ trois cents milles en ligne directe, ce qui fait six mille pieds. Or, ce nombre et les mille pieds d'élévation au-dessus de la source de la rivière sont bien ce que la montagne a au-dessus du niveau du lac Po-Yang.

Ce lac fournit un immense volume d'eau à la rivière de Yang-Tsé-Kiang qui, avec un courant très rapide, traverse ensuite trois cents milles de pays, pour aller se jeter dans la mer Orientale. Depuis le lac jusqu'à la mer, le Yang-Tsé-Kiang a au moins mille pieds de chute. Ainsi, la montagne a huit mille pieds d'élévation au-dessus de la mer.

Le chemin de la montagne était rempli de paysans qui portaient de grandes jarres d'huile à Nan-Gan-Foo, d'où on devait la faire passer par eau dans les provinces plus septentrionales. Les voyageurs virent aussi sur la montagne quelques chevaux extrêmement petits, vifs et lestes. Ils n'avaient pas le devant du corps très joli, mais ils étaient, d'ailleurs, bien faits; et ils avaient les jambes aussi fines et aussi sèches que celles d'un cerf.

Nan-Choo-Foo, située à dix-huit milles du passage de la montagne, est une ville frontière de la province de Quan-Tung. En y arrivant, les voyageurs trouvèrent des barques qu'on avait préparées pour les transporter, eux et leur bagage. Ces barques étaient couvertes et commodes, mais petites et assorties au peu de profondeur que la rivière a près de sa source.

Cette rivière, appelée le Pe-Kiang, fait environ deux cent soixante milles, avant d'arriver à Canton. De là, elle parcourt encore à peu près quatre-vingts 


\section{Voyage dans l'intérieur de la Chine et en Tartarie}

milles de pays, et se jette dans la mer méridionale de la Chine. C'est près de cette mer que les Européens lui ont donné le nom de Bocca-Tigris.

Au nord de Canton, la rivière court longtemps entre deux chaînes de montagnes calcaires, dont quelques-unes s'avancent jusque sur ses bords, tandis que d'autres en sont inégalement reculées, de sorte qu'on y voit et des plaines étroites et des plaines spacieuses. Les hauteurs sont d'abord raides, escarpées, et couvertes d'arbres de l'espèce du camellia sesanqua et des mélèzes, qui croissent quelquefois dans des endroits où il ne faut pour les planter que peu de travail et peu de soin. Le sol n'est, en grande partie, que du sable, mêlé d'un peu d'argile, et tient de la nature du granit qu'il recouvre.

Il y a de petites vallées où l'on voit, de loin en loin, quelques jolies maisonnettes environnées de morceaux de terrain en culture, et qui n'ont d'accès que du côté de la rivière. On a élevé dans la rivière beaucoup de tas de pierres qui, soutenus par des pieux, forment des espèces de digues, où il y a des ouvertures par où l'eau passe avec une extrême vélocité. Les pêcheurs placent, vis-à-vis de ces ouvertures, des paniers d'osier, garnis en dedans de morceaux de bois, dont les pointes convergentes permettent au poisson d'entrer, et l'empêchent ensuite de rétrograder.

Dès que nos voyageurs furent vis-à-vis des montagnes qui étaient moins escarpées, ils virent que, de l'un et de l'autre côté de la rivière, on avait planté du tabac sur les flancs obliques de ces montagnes; chose contraire à la méthode ordinaire des agriculteurs chinois, qui élèvent des terrasses partout où il y a de la pente. D'autres montagnes avaient le plus stérile, le plus horrible aspect. On n'y apercevait pas la moindre végétation. Des rochers très élevés, et présentant toute espèce de formes bizarres, menaçaient de leur chute les bateaux qui passaient au-dessous d'eux. Cinq de ces énormes masses, qui sont les plus remarquables, ont été nommées par les Chinois les cinq têtes de cheval ; l'une, surtout, est facile à distinguer, parce qu'elle a, près de son sommet, quelques couches de pierre de différentes couleurs.

D'autres montagnes de cette partie de la Chine sont remplies de mines de charbon, qu'on a ouvertes depuis peu de temps sur le bord de la rivière. On les exploite par un canal qu'on a fouillé jusqu'auprès de la mine, et par ce moyen, le charbon est chargé dans des barques à mesure qu'on la fouille. Ce 


\section{Voyage dans l'intérieur de la Chine et en Tartarie}

charbon est mou, gras, friable, facile à se réduire en poussière, et semblable à celui qu'on appelle en Angleterre charbon de culm.

Comme les Chinois ne font point leur feu dans des cheminées ouvertes et garnies de grilles, mais bien dans des poêles fermés, ils purifient ordinairement le charbon avant de l'employer; et pour cela, on creuse des puits très profonds dans les environs des mines. D'après l'esprit d'économie qui règne parmi les Chinois, et que leur immense population rend peut-être nécessaire, la poussière même du charbon n'est point perdue. II y a des gens qui gagnent leur vie à ramasser cette poussière, à la mêler avec une pareille quantité de terre molle ramassée dans les marais, et à en faire des briques qu'on fait sécher au soleil pour être transportées dans les districts où il ne se trouve point de charbon.

Aussitôt que la rivière fut plus large et plus profonde, les barques de l'ambassade furent remplacées par des yachts plus grands et plus commodes. Le volume d'eau était accru par la jonction d'une autre rivière considérable, venant du nord-ouest. Au confluent de ces deux rivières est bâtie la ville de Chau-Choo-Foo, dont les environs sont très agréables et très romantiques. $\mathrm{Au}$ passage des Anglais, les plaines étaient couvertes de riz et de tabac, et les terrains élevés portaient des cotonniers et des sesanqua.

Les canots qui naviguent d'une partie de la ville de Chau-Choo-Foo à l'autre bord sont conduits par des femmes qui, pour la plupart, jeunes, proprement mises, montrent clairement l'envie d'attirer l'attention des étrangers. Nous avons déjà observé que la même coutume règne sur le lac Tai-Hoo, où il se trouve beaucoup d'hommes éloignés de leur famille.

A Chau-Choo-Foo, le commerce de deux rivières navigables occasionne un grand concours d'étrangers. Les fragiles femelles qui conduisent les canots et cherchent à plaire à ces étrangers n'ont point embrassé leur double occupation après avoir quitté leurs parents, ou pour avoir été abandonnées par eux à cause de leur inconduite. Les parents n'attachent quelque prix à la chasteté de leurs filles que parce qu'elle peut contribuer à leur faire trouver un époux riche ; et lorsqu'ils n'ont pas cet espoir, ils ont peu de répugnance à 


\section{Voyage dans l'intérieur de la Chine et en Tartarie}

leur donner un métier qui leur fournit l'occasion d'en faire un autre plus lucratif.

Les Chinoises, surtout celles des dernières classes, sont élevées presque dans le seul principe d'obéir à leurs pères et à leurs époux. Elles sont instruites à ne considérer dans leurs actions que le bien ou le mal qui peut avoir rapport à eux, sans avoir aucune idée de la vertu en elle-même. De leur côté, les hommes n'estiment la chasteté que lorsqu'elle contribue à leur satisfaction particulière. II en est peut-être autrement parmi les premières classes des Chinois ; car il y a souvent, en effet, une plus grande différence entre la façon de penser des personnes d'un rang différent dans le même pays, qu'entre des personnes du même rang et de différents pays.

Les femmes chinoises, de quelque rang qu'elles soient, restent, pour la plupart, privées de l'avantage de lire, et de pouvoir acquérir des connaissances par l'observation. Leur ignorance, leur inexpérience, leur retraite, leur crainte de ceux qu'elles considèrent comme leurs supérieurs, les empêchent de devenir les amies et les compagnes habituelles du loisir de leurs époux. Le goût même qu'inspirent les charmes de leur personne diminue insensiblement, et l'on a moins d'horreur pour des crimes contre nature, lesquels, quoique justement condamnés par les moralistes chinois, ainsi que tous les désirs impurs et pervers, sont rarement punis par les lois, ou plutôt ne le sont jamais, surtout quand les mandarins les commettent.

Partout où les femmes ne font point partie de la société des hommes, on ne peut trouver ni une délicatesse de goût et de sentiment, ni la prévenante douceur et les grâces d'une conversation élégante, ni le raffinement et le jeu des passions; et dès lors, les hommes, plus libres dans leurs mœurs, sont sujets à se livrer à de grossières plaisanteries et à des allusions déplacées. La politesse extérieure des Chinois est très cérémonieuse. Elle consiste en divers mouvements du corps, en inclinations de tête, dans la manière de plier le genou, de tendre la jambe, de joindre et d'écarter les mains. Toutes ces choses sont considérées en Chine comme la perfection d'une bonne éducation; et les peuples qui les ignorent n'y sont guère plus estimés que des barbares. 


\section{Voyage dans l'intérieur de la Chine et en Tartarie}

Cependant, après leurs premières civilités, les Chinois deviennent aisés et familiers. Ils parlent aux étrangers sans timidité et sans contrainte. Ils se présentent même avec un air de confiance, et comme des hommes supérieurs qui croient que leurs mœurs et leurs manières sont exemptes de défauts. Cette habitude de confiance en eux-mêmes vient de ce qu'ils sont persuadés qu'ils surpassent leurs voisins en toute espèce de mérite.

Dans le milieu des siècles où l'Europe était plongée dans l'ignorance et la barbarie, lorsque les Tartares-Mongouls n'avaient point encore conquis la Chine, et que le Vénitien Marc-Paul y voyageait, les Chinois avaient déjà atteint le plus haut degré de leur civilisation ; et ils étaient, à cet égard, bien supérieurs et à leurs conquérants et aux Européens du même siècle. Mais comme ils n'ont plus fait de progrès, tandis que les nations d'Europe ont perfectionné chaque jour leurs mœurs, leurs arts et leurs connaissances en tout genre, ils sont maintenant regardés par les Européens avec moins d'admiration qu'ils ne l'ont été par les premiers voyageurs qui en ont parlé. Dans les relations que des Chinois eurent avec l'ambassade anglaise, ils sentirent eux-mêmes quelques-uns des avantages que les Anglais avaient sur eux.

Peut-être aussi que le mélange des Tartares-Mandchous a nui aux Chinois. Ils se sentent jusqu'à un certain point dégradés sous le joug de l'autorité la plus absolue, dont un prince puisse être revêtu, pendant que les Tartares croient, en quelque sorte, partager la puissance de leur souverain sur le peuple conquis, et se consolent par là d'être écrasés du poids de cette puissance. Ainsi, les domestiques d'un grand seigneur en Livonie, ou les nègres qui servent dans la maison d'un colon de la Jamaïque, quoique esclaves eux-mêmes, se regardent comme bien supérieurs, les uns aux paysans, et les autres aux nègres qui travaillent à la terre.

D'après un principe à peu près semblable, la plupart des habitants de la province maritime de Canton, considérant que les étrangers qui viennent dans leur pays ne sont point protégés par le gouvernement, affectent quelquefois une sorte de supériorité sur eux.

Cependant, quelques jours avant que les yachts qui portaient l'ambassade arrivassent à Canton, les Anglais eurent occasion de s'apercevoir de 


\section{Voyage dans l'intérieur de la Chine et en Tartarie}

l'influence de leur vaste commerce en Chine. Ils entendaient fréquemment des Chinois essayer de prononcer des mots anglais. Une grande partie des bateaux qui descendaient la rivière étaient chargés de marchandises destinées pour l'Angleterre.

La rivière était couverte, en beaucoup d'endroits, de grands radeaux composés de bois de charpente qui n'était presque que du mélèze et du camphrier, et qu'on conduisait dans les provinces du centre et du nord de l'empire, où le terrain est trop uni et trop bien cultivé pour produire beaucoup de bois. Les radeaux sont quelquefois liés ensemble, et ont alors plus de cent pieds de long. On y met divers mâts, afin de pouvoir remonter à la voile contre le courant, toutes les fois que la brise est favorable. Quand il en est autrement, ils sont traînés par les conducteurs qui construisent de petites cabanes, et vivent sur ces radeaux. Ils y cultivent en même temps des végétaux et y élèvent plusieurs espèces d'animaux domestiques. On y voit des troupes d'enfants sortir des cabanes, comme des abeilles sortent du sein d'une ruche. Les conducteurs ont aussi tout ce qu'il leur faut pour pêcher, et ils s'y servent de leurs grands filets aussi facilement que s'ils étaient dans des bateaux.

Les Anglais remarquèrent d'un côté de la rivière un immense rocher de marbre gris et commun, d'environ six cents pieds de haut. Dans une vaste crevasse, à laquelle on ne peut arriver qu'avec un bateau, est un temple habité par les ho-chaung, ou prêtres de Fo. Ils y adorent plusieurs chefs ou héros, ainsi que des vertus et des passions personnifiées. Le temple consiste en plusieurs appartements creusés dans le roc, les uns au-dessus des autres, et d'une hauteur considérable.

Au-dessus de ces excavations est une seconde crevasse, où les voyageurs virent une énorme masse de stalactites qui paraissaient être au moins du poids d'une tonne, et avaient un nombre immense de ramifications. Plusieurs montagnes des environs étaient taillées perpendiculairement jusqu'au bord de la rivière. On en avait tiré beaucoup de grosses pierres pour la construction des pagodes, des ponts et des plates-formes sur lesquelles sont élevés les temples et les palais chinois. Les carrières sont souvent sur les bords des rivières, parce qu'il y a plus de facilité pour le transport des pierres. 


\section{Voyage dans l'intérieur de la Chine et en Tartarie}

Une plaine, qui s'étendait jusqu'aux bornes de l'horizon, succéda enfin à la double chaîne de montagnes, au milieu de laquelle la rivière coulait depuis sa source. Son lit était déjà plus large ; et bientôt les voyageurs rencontrèrent la marée montante qui venait du sud. Le pays était entrecoupé de larges canaux, destinés à la navigation, et d'autres plus petits qui servaient à l'arrosement des terres. Le riz était la principale culture. II y avait aussi quelques plantations de mûriers. Tout annonçait la fertilité, l'industrie et une grande population.

A mesure que les voyageurs approchaient de Canton, ils voyaient le long de la rivière des pépinières remplies de plantes curieuses. Ils remarquèrent aussi plusieurs maisons de campagne appartenant aux principaux marchands chinois. L'ambassadeur était attendu dans l'une de ces maisons par les commissaires de la Compagnie, par divers autres Anglais, et par quelquesuns de leurs amis chinois.

Le vice-roi était allé devant pour faire préparer à Canton la réception de l'ambassadeur. II envoya aux Anglais de grandes et magnifiques barques, ornées de glaces, de peintures et de dorures: c'est dans ces barques que l'ambassade arriva à Canton le 19 décembre 1793. Les honneurs extraordinaires que le vice-roi fit rendre à lord Macartney, et les égards particuliers qu'il eut pour lui ne furent point une inutile et vaine parade. Ils apprirent aux habitants de Canton à considérer que les Anglais n'étaient plus dénués de protection, et qu'ils méritaient d'être respectés.

Presque toutes les personnes attachées à l'ambassade eurent, à Canton, le plaisir de voir enfin réaliser leurs espérances trop longtemps déçues, et de recevoir des nouvelles de leurs amis. Ils surent aussi que le gouvernement français avait déclaré la guerre à la Grande-Bretagne. Cette nouvelle fut cause que l'ambassadeur eut encore plus de satisfaction, en apprenant que sir Erasme Gower qui, après avoir reçu de Canton tout ce qui lui était nécessaire, était parti pour le nord, avait été ensuite joint par le messager des commissaires de la Compagnie avant qu'il eût fait beaucoup de chemin et que, conséquemment, le vaisseau de guerre le Lion était mouillé dans le Bocca-Tigris. 


\section{Voyage dans l'intérieur de la Chine et en Tartarie}

Ce vaisseau était parti de Chu-San le 18 octobre. Pendant sept semaines qu'il avait demeuré dans ce port, son équipage était presque entièrement guéri de la dysenterie qui l'avait longtemps tourmenté. Indépendamment de l'avantage de respirer l'air de terre et d'y prendre de l'exercice, il avait eu celui d'un régime frais et sain. On lui avait fourni de la viande, et particulièrement des volailles, ainsi que des végétaux, à un prix très raisonnable. Les provisions n'étaient un peu chères que lorsque les employés du gouvernement se mêlaient des achats, parce que comme ils exigeaient une rétribution des vendeurs, l'acheteur était toujours obligé de supporter le surhaussement.

A Chu-San, les fruits de toute espèce étaient abondants et très bon marché. Le thé y était moins cher que dans aucune partie de la Chine. Un mois avant que le Lion en partît, il y eut une tempête affreuse. Les éclairs étaient si bas qu'ils rasaient la bouche des canons, et si forts, si multipliés que personne ne put demeurer sur le pont. Pendant toute la durée de l'orage, le vent était au nord, c'est-à-dire opposé à ce qu'il avait été depuis plusieurs mois; et les marins regardèrent la tempête comme l'effet du combat des deux moussons. Cependant, le vent repassa au sud-ouest. Ensuite, il fut variable jusqu'à la fin de septembre, quand une forte brise de nord-est se leva, et devint peu à peu assez modérée. Dès lors, la nouvelle mousson fut établie pour le reste de la saison.

En partant de Chu-San, sir Erasme Gower désirait de poursuivre la route que l'ambassadeur lui avait tracée à Tien-Sing. Mais il fut obligé de se rendre dans la rivière de Canton, ainsi que nous l'avons déjà dit. Cependant, ne soupçonnant point le changement de circonstances qui devait nécessairement changer sa destination, il était déterminé à retourner le plus promptement possible vers le nord-est.

A son départ de Chu-San, on lui rendit tous les honneurs que méritait le bon ordre qu'il avait maintenu dans son équipage. Le Lion quitta les îles de Chu-San, et passa le détroit de Formose avec rapidité et sans danger ; et le 23 octobre, il mouilla près des îles des Larrons.

Dans celle qu'on nomme l'île Samcock, sir Erasme Gower trouva assez d'eau pour la consommation de son équipage. Dans la partie la plus élevée de 


\section{Voyage dans l'intérieur de la Chine et en Tartarie}

cette île est un monceau de rochers de granit, d'où l'on voit aisément toutes les passes qui conduisent aux différentes îles des Larrons. Les pilotes chinois regardent de là pour découvrir les vaisseaux qui doivent entrer dans leurs ports. La latitude de l'île de Samcock est de vingt-deux degrés neuf minutes nord; et sa longitude, déterminée d'après neuf observations de distance du soleil à la lune, est de cent douze degrés quarante minutes à l'est du méridien de Greenwich.

De l'île Samcock, sir Erasme Gower envoya demander aux commissaires de la Compagnie, à Canton, les drogues de pharmacie et les autres articles dont il avait besoin, et qui lui furent fournis en très peu de jours. II dirigea de nouveau sa course vers le détroit de Formose. Mais il fallait qu'il naviguât contre la mousson du nord-est, qui était déjà dans toute sa force.

Le 4 novembre, il essuya, non loin de Pédra-Branca, un violent coup de vent. Le mauvais temps dura pendant tout l'intervalle que le Lion resta à la mer. La lame courte, inégale, s'élevait à chaque instant. Les voiles étaient sans cesse déchirées et on les remplaçait avec difficulté. Pendant plusieurs jours, le Lion s'efforça de longer les côtes de la Chine, sans pouvoir avancer d'un mille. Il gouverna alors sur l'île Formose, où il y avait moins de courant contre lui, et il fit un peu de chemin; mais il trouva encore un temps si tempétueux qu'il eut deux mâts de hune cassés. II retourna alors aux îles des Larrons pour y chercher un abri, s'y réparer, et se mettre en état de faire de nouveaux efforts pour passer le détroit de Formose.

Des pirates qui infestaient cette partie des côtes de la Chine avaient récemment enlevé plusieurs jonques chinoises, et pillé les îles voisines. L'usage de ces pirates est de réduire à l'esclavage tous les hommes jeunes et robustes qu'ils prennent, d'égorger les autres, de couler à fond les jonques, et de brûler les maisons après avoir ôté tout ce qui leur paraît valoir quelque chose.

Le 21 novembre, le Lion rencontra un brick qui, après avoir été examiné, fut reconnu pour être le vaisseau auquel appartenaient cinq hommes que les Anglais avaient trouvés, le mois de février précédent, sur l'île volcanique d'Amsterdam. Sir Erasme Gower, ayant déjà appris à Canton la nouvelle de la guerre entre la France et l'Angleterre, s'empara du brick, qui était de bonne 


\section{Voyage dans l'intérieur de la Chine et en Tartarie}

prise puisqu'il était de l'Île-de-France, et y avait été armé ${ }^{1}$. Ainsi, le brick fut tout à coup dans l'impossibilité de retourner à l'île d'Amsterdam pour y prendre Perron et ses compagnons, avec la cargaison de peaux de veaux marins qu'ils avaient apprêtée ; et si jamais ces malheureux sortent de cette île solitaire et désolée, ils le devront au hasard qui conduira sur cette côte quelque vaisseau, dont le commandant voudra bien les tirer de leur exil.

Avant que le Lion eût achevé de se réparer, sir Erasme Gower reçut la dépêche de lord Macartney. Ainsi, dès qu'il fut prêt à remettre à la voile, au lieu de combattre de nouveau contre la mousson, il se rendit directement dans le Bocca-Tigris.

Le capitaine Mackintosh arriva aussi à Canton plutôt qu'il ne s'y attendait. II avait trouvé les mandarins et les habitants de Chu-San parfaitement bien disposés à obéir aux ordres de l'empereur, relativement au privilège que le capitaine et les officiers de l'Indostan avaient d'acheter une cargaison dans ce port. Le thé et les soieries étaient bien moins chers là qu'ailleurs. Mais les négociants de Chu-San n'étaient point préparés. Ils n'avaient point assez de marchandises propres aux Européens pour charger un vaisseau tel que I'Indostan, qui portait douze cents tonneaux. Ils ne pouvaient pas non plus acheter toutes les marchandises qui étaient à son bord, et qui convenaient mieux à une plus grande ville. C'est pourquoi ils demandèrent du temps pour se procurer la plupart des articles qu'ils n'avaient pas; mais le capitaine jugea à propos de se rendre à Canton, où il devait jouir, pour ce voyage, du même privilège et des mêmes exemptions qu'à Chu-San.

II quitta cette ville avec un regret que partagèrent les habitants ; car ses officiers et son équipage avaient été très attentifs à ménager les Chinois ; et la satisfaction avait été complète de deux côtés.

\footnotetext{
${ }^{1}$ Si la conduite de sir Erasme Gower est conforme aux lois de la guerre, elle n'en est pas moins contraire aux plus saints devoirs de I'humanité. L'estimable et bienveillant Perron avait reçu les Anglais avec cordialité ; et pour prix de cet accueil, les gens de l'équipage du Lion lui volèrent une partie de ses peaux de veaux marins. Ensuite, le capitaine de ce vaisseau, profitant des renseignements que Perron lui a donnés luimême, lui enlève son navire, et expose ce Français et ses quatre compagnons à périr de désespoir et de misère, dans une île déserte. (Note du Traducteur.)
} 


\section{Voyage dans l'intérieur de la Chine et en Tartarie}

L'Indostan eut, ainsi que le Lion, une mousson favorable pour se rendre à Canton. Mais le vent était si tempétueux dans le détroit de Formose que le capitaine Mackintosh dit n'avoir jamais vu un plus mauvais temps que celui qu'il essuya dans cette courte traversée. 


\section{Voyage dans l'intérieur de la Chine et en Tartarie}

\section{CHAPITRE II}

\section{Séjour de l'ambassade anglaise à Canton et à Macao.}

La ville et les faubourgs de Canton sont situés, en grande partie, sur la rive orientale de la rivière de Pé-Kiang. L'ambassade anglaise fut logée sur la rive occidentale. Elle occupa divers bâtiments séparés, spacieux et commodes. Quelques-uns de ces bâtiments étaient meublés à l'anglaise et avaient des fenêtres vitrées et des cheminées à grille. Quoique Canton soit dans le voisinage du tropique, le solstice d'hiver y fit trouver aux Anglais l'usage des cheminées très agréable. Leurs logements étaient environnés d'un vaste jardin, où il y avait des parterres et des pièces d'eau. D'un côté était un temple, et de l'autre, un édifice très élevé, du haut duquel on voyait la rivière, l'endroit où mouillaient les vaisseaux, la ville et une très grande partie de la campagne.

Comme port de mer et ville frontière, Canton se ressent beaucoup du mélange des étrangers avec les gens du pays. Les factoreries des différentes nations de l'Europe, qui y font le commerce, ont de belles maisons alignées sur le bord de la rivière, en-dehors des murs de la ville, et sur chacune desquelles flotte le pavillon de sa nation. Ces maisons contrastent avec celles des Chinois, et sont un ornement pour l'ensemble de Canton. Le grand nombre d'étrangers qu'on voit dans les faubourgs, et dont on charge ou l'on décharge les vaisseaux, leurs différents langages, leurs vêtements, leurs manières, tout enfin, pourrait faire douter à quelle nation cette partie de la ville appartient, si l'on n'en était pas prévenu d'avance.

Le voisinage des factoreries étrangères est rempli de magasins où l'on dépose soit les marchandises d'Europe avant de les livrer aux marchands chinois, soit les marchandises chinoises avant de les embarquer. Le devant de chaque maison est une boutique, et les boutiques d'une ou de plusieurs rues sont louées aux étrangers. Tous les achats se font par des individus appartenant aux vaisseaux ou par les agents des compagnies européennes. 


\section{Voyage dans l'intérieur de la Chine et en Tartarie}

Mais les grands objets d'importation et d'exportation sont presque entièrement confiés aux derniers. II n'y a jamais eu de leur part le moindre exemple de fraude, mais on en a vu plus d'un dans les marchés faits par les autres. La probité, la ponctualité, le crédit de la Compagnie des Indes anglaise, surtout, ainsi que de ses agents, sont si bien reconnus par les marchands chinois, que leurs marchandises sont toujours reçues d'après la facture, et les balles à leur marque passent, sans examen, dans le commerce, d'un bout à l'autre de l'empire.

Ces agents sont divisés en supercargues et en écrivains. Ils sont assez heureux pour avoir des émoluments qui les mettent à l'abri de la tentation. II leur est alloué, sur les affaires qu'ils traitent, une commission proportionnée à la place qu'ils occupent. Leurs mesures sont toujours réglées à la pluralité des voix, et on écrit régulièrement les raisons de ces déterminations. Ils sont accoutumés de bonne heure à avoir de l'ordre, de la candeur et de l'exactitude, qualités qui caractérisent un honorable marchand ; et ils sont, en même temps, éloignés de cette avarice et de ces inclinations basses, qui peuvent dégrader une si utile profession.

L'on porte de Canton diverses espèces de marchandises, mais la principale, celle en comparaison de laquelle les autres ne sont presque rien, est le thé. Jadis, les Anglais achetaient moins de thé que la totalité des agents des autres nations européennes. Plusieurs des directeurs de la Compagnie anglaise ne manquèrent pas d'observer que la plus grande partie du thé, porté ainsi dans divers pays de l'Europe, passait ensuite en contrebande dans les ports d'Angleterre ; et que ce qui excitait à faire cette contrebande était l'impôt considérable que le Parlement britannique avait mis sur le thé. Non seulement le thé était le principal objet de contrebande, en Angleterre, mais il occasionnait et facilitait l'introduction clandestine d'autres marchandises.

La contrebande était portée à un tel point que, dans un rapport que fit à ce sujet à la chambre des communes un membre très estimable, élevé aujourd'hui au rang de pair, il dit :

«Que les pratiques illicites qu'on emploie pour priver l'État de ses revenus se sont accrues au degré le plus alarmant; que ces 


\section{Voyage dans l'intérieur de la Chine et en Tartarie}

pratiques s'exercent sur les côtes et dans diverses parties du royaume, avec une violence et des outrages qui, non seulement menacent d'anéantir les revenus de l'État, mais sont excessivement nuisibles à un commerce loyal et régulier, très pernicieuses pour les mœurs et la morale de la nation, et incompatibles avec un bon gouvernement.

Dans le même temps, un homme très habile, qui est maintenant teneur de livres de la Compagnie des Indes, fit une note des faits relatifs à la contrebande, note qui est imprimée dans l'appendice de cet ouvrage. On présenta cette note avec un plan pour procurer à la Grande-Bretagne l'avantage de l'importation de tout le thé consommé par les sujets de ce royaume et de ses dépendances. Ce fut ce qui occasionna la loi, généralement connue sous le nom d'acte de commutation, qui mit un terme à tous les maux indiqués dans le rapport cité plus haut, et fit employer un nombre considérable de matelots et de vaisseaux, à aller chercher, pour le conduire en Angleterre, le surcroît de thé que la cessation de la contrebande obligea les agents de la Compagnie d'acheter à Canton.

L'état de l'augmentation annuelle des achats de thé et des ventes des marchandises anglaises à Canton se trouvera aussi dans l'appendice.

Indépendamment des supercargues et des écrivains de la factorerie anglaise, il y avait à Canton, lorsque l'ambassade y arriva, trois commissaires de la Compagnie ${ }^{1}$. Ils avaient été envoyés par la Compagnie, non seulement pour annoncer en forme, au gouvernement chinois, l'ambassade de la Grande-Bretagne et pour préparer sa réception, mais pour examiner et régler l'administration des affaires de la Compagnie à Canton et à Macao. Ceux qu'emploie la Compagnie joignent aux qualités qui les rendent propres à remplir leur place, l'avantage d'une belle éducation. Le premier des commissaires était un homme très savant; et un autre était connu, dans le monde littéraire, par ses voyages et par son esprit.

\footnotetext{
1 MM. Jackson, Irwine et Brown.
} 


\section{Voyage dans l'intérieur de la Chine et en Tartarie}

Les trois commissaires donnèrent à l'ambassadeur un ample détail des torts qu'on faisait aux intérêts de la Compagnie à Canton, et des désagréments personnels auxquels ses agents étaient exposés. Par ce moyen, lord Macartney fut à même d'ajouter aux représentations qu'il avait faites au vice-roi pendant le voyage de Han-Choo-Foo à Canton. Le vice-roi était parfaitement disposé à faire cesser tout véritable sujet de plainte. II publia bientôt deux édits contre les fraudes qu'éprouvaient les étrangers en traitant leurs affaires commerciales, et contre les insultes qu'on leur faisait essuyer. Des coupables furent punis conformément à ces édits.

Cependant, on ne pouvait pas s'attendre qu'il y aurait tout à coup une réforme complète des abus les plus invétérés. Les préjugés et les intérêts de plusieurs Chinois concouraient à faire des efforts pour empêcher la cessation de ces abus. Le hoppo, c'est-à-dire le principal receveur des revenus de Canton, était alarmé à cause de ses exactions accoutumées. II savait les torts qu'il avait fait subir aux étrangers, et sa haine, son mépris pour eux égalaient son injustice. Habile et artificieux, il était secondé par la plupart des autres officiers du gouvernement de Canton, et par des particuliers qui adoptaient ses préjugés, profitaient de ses rapines, ou craignaient son ressentiment.

La lettre de loi avait besoin de secours contre de tels obstacles, pour pouvoir être mise à exécution ; et il n'était pas bien certain qu'on pût mettre au nombre des vertus du vice-roi une fermeté capable de résister aux artifices et aux faux rapports des personnes qui l'entouraient. Les étrangers n'osaient guère tenter de l'approcher, à cause de la supériorité de son rang, et plus encore par rapport à la différence des mœurs, et au défaut de moyens de communication. A la vérité, il était vraisemblable que, durant le séjour de l'ambassadeur à Canton, ses compatriotes n'auraient point occasion de se plaindre. Son intimité avec le vice-roi, la facilité avec laquelle il pouvait le voir dans tous les temps, et lui faire parvenir, par le moyen d'un interprète intelligent et fidèle, les représentations de la factorerie, sans que le haut rang de cet officier ni la crainte de la vengeance d'aucun des oppresseurs, l'engageassent à affaiblir ses représentations; tout, enfin, semblait être garant de la justice et de la tranquillité dont devaient jouir toutes les personnes que le commerce attirait dans le pays. 


\section{Voyage dans l'intérieur de la Chine et en Tartarie}

Comme il était vraisemblable qu'après un voyage au Japon et à la Cochinchine, l'ambassadeur retournerait à Canton, on devait croire que les Anglais seraient également respectés en son absence, et que les réformes introduites, acquérant la force de l'habitude, le vice-roi pourrait plus aisément les maintenir.

L'ambassadeur n'ignorait pas que le seul motif de sauver la précieuse flotte des vaisseaux revenant de la Chine, s'il était effectivement nécessaire de les convoyer, pouvait lui servir d'excuse pour retourner en Angleterre, dans cette saison, et sans avoir fait tous les efforts qui étaient en son pouvoir pour remplir les divers objets de sa mission dans l'Orient.

Pendant que lord Macartney fut à Canton, le vice-roi et lui se rendirent souvent et réciproquement visite. L'ambassadeur vit aussi fréquemment les agents de la factorerie anglaise ; et la familiarité de ces rapports prouva aux Chinois que la classe dont étaient tirés les agents de la Compagnie et les occupations auxquelles ils étaient employés n'avaient rien d'avilissant aux yeux de leurs compatriotes, et qu'ils étaient même faits pour vivre en société avec les personnes des premières classes.

Le vice-roi n'était pas très jaloux de l'orgueil et des prétentions du rang. II était le premier qui, dans cette place éminente, eût permis aux marchands chinois de Canton, de s'asseoir en sa présence et qui eût même consenti à manger avec les agents de la factorerie anglaise ; car cet officier voulut bien assister à un repas que la factorerie donna à l'ambassadeur.

Les dispositions favorables du vice-roi à l'égard des Anglais furent peutêtre fortifiées par l'opinion qu'il avait conçue de leur science et de leurs talents. Le hasard contribua à lui inspirer cette opinion. La coutume de fumer, comme de prendre du tabac en poudre, est générale à la Chine, et s'étend jusqu'aux personnes du plus haut rang. Le vice-roi ayant besoin d'allumer sa pipe, dans un moment où ses domestiques n'étaient point autour de lui, l'ambassadeur tira de sa poche une fiole phosphorique, l'ouvrit, et eut bientôt allumé une mèche qu'il présenta au vice-roi. Celui-ci parut très étonné de voir qu'un homme pût porter du feu dans sa poche, sans courir aucun risque. Lord 


\section{Voyage dans l'intérieur de la Chine et en Tartarie}

Macartney lui expliqua le phénomène en termes généraux, et lui fit présent de la fiole qui n'avait pas peu de prix aux yeux de ce Chinois.

Cet incident, de peu de conséquence, donna lieu à une conversation sur d'autres sujets curieux; et il fut alors aisé de voir combien les Chinois, quoique très intelligents et très adroits dans leurs arts particuliers, sont loin des nations européennes pour ce qui concerne beaucoup de sciences utiles et philosophiques.

L'ambassadeur n'était point fâché d'avoir occasion de faire connaître quelques-unes de ces modernes découvertes des Européens, et surtout celles qui étaient plus propres à frapper l'imagination; comme, par exemple, la méthode de s'élever dans les airs avec le secours d'un ballon rempli de gaz; la machine pneumatique et l'opération par laquelle on rend la vue aux personnes qui ont la cataracte.

Le docteur Dinwiddie fit des leçons sur l'électricité et sur d'autres parties de la physique expérimentale. II eut pour auditeurs non seulement les agents de la factorerie, mais aussi les Chinois qui entendaient un peu l'anglais, et qui furent enchantés de plusieurs expériences, encore qu'ils n'en comprissent pas toujours l'explication, et qu'ils n'entendissent qu'imparfaitement le langage du professeur. La supériorité reconnue des connaissances des Européens devait nécessairement leur attirer de l'admiration, de l'estime, et conséquemment un meilleur traitement de la part des Chinois.

Le docteur Gillan fut très utile à plusieurs mandarins, en leur prescrivant des remèdes propres à leurs maladies; et quelques-uns de ceux qui remplissaient les premiers emplois vinrent à Canton pour le consulter.

En Chine, l'état de la médecine est très peu avancé. II n'y a point d'école publique ou particulière, où cet art soit enseigné. Un jeune homme qui désire de devenir médecin n'a d'aucun moyen d'acquérir des connaissances que de s'attacher, en qualité d'apprenti, à quelqu'un qui exerce cette profession. En l'accompagnant chez ses malades, il a occasion de voir quelle est sa manière de les traiter, et il acquiert la science et les secrets que le maître veut bien lui communiquer. 


\section{Voyage dans l'intérieur de la Chine et en Tartarie}

Les émoluments de la profession sont ordinairement proportionnés à la science du praticien. Le nombre de pièces de cuivre qu'il faut pour faire la valeur de six sous sterling est le prix que les gens du peuple accordent aux médecins. Ce que donnent les mandarins est, peut-être, le quadruple de cette somme.

Les mandarins du premier rang ont un médecin qui fait partie de leur maison, réside auprès d'eux, et les accompagne dans leurs voyages. Les médecins de l'empereur, ainsi que la plupart de ses domestiques, sont eunuques. En Chine, l'art de guérir n'est point, comme en Europe, divisé en différentes branches. Le même homme est à la fois médecin, chirurgien et apothicaire.

La chirurgie a fait, parmi les Chinois, encore moins de progrès que la médecine et la pharmacie. En cas de fracture compliquée et de gangrène, l'amputation est absolument inconnue, et une mort prompte devient la suite de ces accidents. Il y a sûrement, en Chine, des personnes estropiées, mais il faut qu'elles soient en bien petit nombre, ou qu'elles vivent très retirées, car les Anglais n'en virent pas une seule dans la route qu'ils firent depuis l'extrémité septentrionale jusqu'à l'extrémité méridionale de l'empire.

La mortalité occasionnée par la petite vérole confluente, et la remarque qu'on avait faite qu'elle n'attaquait jamais qu'une seule fois la même personne, engagèrent les Chinois à exposer des jeunes gens à cette maladie, lorsqu'elle paraissait moins maligne. Le succès de cette méthode les conduisit enfin à la pratique de l'inoculation. Les annales de la Chine en font mention, pour la première fois, à une époque qui répond au commencement du dixième siècle de l'ère chrétienne.

Voici quels sont les procédés ordinaires de l'inoculation chinoise. Quand la petite vérole se déclare dans quelque district, les médecins du lieu recueillent soigneusement, dans les pustules d'une bonne espèce, une quantité de virus qui a acquis le degré de maturité nécessaire. Ensuite, ils le font sécher, le réduisent en poudre, et le mettent dans un vase de porcelaine bien fermée, de manière qu'il ne soit pas exposé au contact de l'air extérieur. Par ce moyen, le virus conserve ses propriétés pendant plusieurs années. 


\section{Voyage dans l'intérieur de la Chine et en Tartarie}

Quand la personne qu'on veut inoculer a été bien préparée en prenant des médecines ordinairement apéritives, et en observant pendant quelque temps un régime exact, on choisit un jour heureux pour répandre un peu de poudre variolique sur du coton fin, qu'on introduit dans les narines. Les Anglais attachés à l'ambassade ne peuvent pas dire si la cécité ou les yeux faibles sont plus communs à la Chine qu'ailleurs; mais si cela est, on le doit probablement, en grande partie, à l'insertion du virus dans un endroit si rapproché du nerf optique, auquel l'inflammation qu'il occasionne peut se communiquer.

En Chine, il n'est pas permis à un médecin de saigner une femme enceinte, et il peut encore moins pratiquer l'art des accouchements. Les deux sexes semblent être d'accord pour croire qu'il y aurait à cela de l'indélicatesse. II y a des livres pour l'instruction des sages-femmes, avec des dessins qui représentent l'état et la position de l'enfant à toutes les périodes de la grossesse. II y a aussi une multitude de prescriptions pour tous les cas possibles, et à ces prescriptions sont mêlées beaucoup de pratiques superstitieuses.

Plusieurs charlatans qui exercent la médecine en Chine font comme ceux des autres pays. Ils profitent de l'obscurité qui enveloppe leur art, et de l'ignorance et de la crédulité du peuple pour gagner de l'argent, en vendant des remèdes de leur composition, et des secrets merveilleux. Ils distribuent des avis à la main, dans lesquels ils vantent l'efficacité de leurs remèdes, et copient des attestations de gens qu'ils ont guéris. Mais il était réservé à la secte des Tao-tses ${ }^{1}$ de prétendre hardiment posséder un secret médicinal pour ne point mourir.

Ceux qui possèdent toutes les jouissances de la vie n'ont d'autre vœu à former que de pouvoir les conserver toujours. Aussi divers souverains de la Chine se sont, dit-on, flattés que le remède des disciples de Lao-Koun avait la vertu qu'ils lui attribuaient. Ils se sont mis, pleins de santé, entre les mains de ces religieux empiriques, et ont pris de fortes doses de leur fameux breuvage de l'immortalité. Cette liqueur n'est pas composée d'ingrédients

\footnotetext{
${ }^{1}$ Les disciples de Lao-Koun, dont on a parlé plus haut.
} 


\section{Voyage dans l'intérieur de la Chine et en Tartarie}

innocents, mais probablement d'extrait de pavot et d'autres substances qui, occasionnant une exaltation momentanée, font croire qu'elle a des effets vivifiants. Encouragés par cette idée, les souverains qui ne voulaient point mourir ont répété l'usage du remède qui les a bientôt plongés dans la langueur et dans l'affaiblissement, et ils sont souvent, à la fleur de leur âge, devenus victimes de l'imposture et de la folie.

Personne, en Chine, ne professe les sciences qui ont rapport à la médecine. Le corps humain n'y est jamais disséqué, à moins que ce ne soit en particulier. On y publie, il est vrai, des livres et des dessins où l'on démontre la structure de ses parties intérieures; mais ils sont extrêmement imparfaits et peut-être qu'on les consulte moins souvent pour observer la forme et la situation de chaque partie, que pour trouver le nom de l'esprit sous la protection duquel elle est.

Il est douteux qu'en Chine I'histoire naturelle et la chimie soient, comme sciences, plus perfectionnées que l'anatomie. Il y a cependant plusieurs traités sur des objets particuliers qui dépendent de l'une ou de l'autre. Les Chinois possèdent aussi une encyclopédie très volumineuse, contenant beaucoup d'observations et de faits relatifs à ces deux sciences; mais le peu de recherches que les Anglais de l'ambassade ont eu le temps et l'occasion de faire pendant leur court séjour en Chine ne leur ont fait apercevoir aucune trace d'un système général, d'après lequel les observations et les faits séparés fussent rapprochés et comparés, les propriétés des corps déterminées par l'expérience, les arts qui ont des rapports entre eux conduits vers le même but, des conséquences tirées par analogie, des règles déterminées, enfin, des principes établis pour constituer une science. II est même des sciences pour lesquelles les Chinois n'ont pas de nom. Leurs livres sont remplis de procédés particuliers et de méthodes qui leur servent beaucoup pour les arts mécaniques et ceux qui ont des rapports avec la chimie ; et il est vraisemblable que ces livres seraient très utiles à un homme qui aurait le double avantage d'entendre la langue dans laquelle ils sont écrits, et de n'être point étranger aux matières dont ils traitent.

Aussitôt qu'un art ou une manufacture produisent l'effet général qu'on s'en était proposé, il est rare que l'inventeur chinois soit excité par sa 


\section{Voyage dans l'intérieur de la Chine et en Tartarie}

curiosité, ou facilité par son opulence, à essayer de faire de nouveaux progrès pour donner à ses ouvrages plus d'élégance ou d'utilité.

L'usage qu'on fait des métaux pour les choses ordinaires a engagé les Chinois à les chercher dans les entrailles de la terre, où ils ont trouvé tous ceux qu'on appelle des métaux parfaits, à l'exception de la platine. Peut-être qu'ils ne savent point employer la méthode la moins chère et la moins longue de séparer les métaux précieux des substances hétérogènes parmi lesquelles ils sont trouvés, ni même de convertir le minerai des autres en métal. Mais toutes les fois qu'ils le veulent, ils réussissent parfaitement à dégager les métaux de toute espèce d'aloi, ainsi qu'à les mêler dans les proportions qui leur conviennent.

Les Chinois estiment plus l'or à cause de sa rareté qu'à cause de son usage. Ils ont, dit-on, des mines d'or ; mais l'exploitation en est rarement permise. On en ramasse de petits grains parmi les sables des rivières et des torrents qui le charrient des montagnes dans les provinces de Yu-Nan et de Sé-Chuen. Cet or est pâle, mou et ductile. Quelques mandarins et beaucoup de femmes du premier rang portent des bracelets de ce métal, non seulement comme ornement, mais parce qu'on s'imagine que c'est un préservatif contre beaucoup de maladies. Les ouvriers chinois réduisent l'or en feuilles sous leur marteau, et ensuite ils le collent avec de la gomme sur du papier qu'on brûle dans les temples, ou bien ils s'en servent pour décorer les statues de leurs divinités.

Ceux qui font le velours et les diverses étoffes de soie emploient de l'or dans leur tissu et dans leur broderie. On en fait aussi à Canton des colifichets que les Chinois ne portent pas, mais qu'on vend en Europe comme des ornements orientaux.

Indépendamment de l'usage qu'on fait de l'argent dans le paiement des autres marchandises, quand il passe suivant son poids, on le convertit en fil, comme l'or, et on l'emploie dans les manufactures d'étoffes de soie et de coton.

Pour le métal des cloches, les Chinois mêlent au cuivre une plus grande quantité d'étain qu'on n'a coutume d'en mettre ailleurs. Aussi, leurs cloches sont plus sonores, mais plus fragiles que celles d'Europe. Leur cuivre blanc, 


\section{Voyage dans l'intérieur de la Chine et en Tartarie}

qu'ils appellent pe-tung, ressemble à l'argent, et a le grain très serré. II reçoit un beau poli. On s'en sert comme de l'argent pour faire plusieurs sortes d'ustensiles très propres. D'après une analyse exacte, il paraît qu'il entre dans la composition de ce métal du cuivre, du zinc, un peu d'argent et, de temps en temps mais pas toujours, quelques parties de fer et de nickel.

Le tu-te-nag des Chinois est, à proprement parler, du zinc extrait d'une riche calamine. On mêle la calamine avec de la poussière de charbon, et on la met dans une jarre de terre qu'on expose à un feu lent. Le métal, s'élevant alors en forme de vapeur, est recueilli dans un récipient ordinaire, et ensuite condensé dans l'eau.

La calamine d'où l'on extrait ce zinc contient très peu de fer, et point de plomb ni d'arsenic, substances qui sont si communes dans la calamine d'Europe, et contribuent non seulement à ternir les compositions qu'on en fait, mais l'empêchent de prendre un aussi beau poli que le pe-tung des Chinois.

Le docteur Gillan apprit à Canton la manière dont les ouvriers du pays font leur pe-tung. Ils réduisent le cuivre en feuilles extrêmement minces ; ensuite, il le font chauffer au point de le ramollir et de le mettre presque en fusion ; et dans cet état, ils en suspendent les feuilles au-dessus de la vapeur de leur plus pur tu-te-nag ou zinc, placé dans un vase exposé à un feu très ardent. La vapeur pénètre ainsi les feuilles de cuivre bien chauffées, et s'y fixe tellement qu'elle ne se dissipe, ni ne se calcine aisément dans la fusion qu'elle doit ensuite éprouver. On laisse refroidir le tout lentement, et on voit qu'il a acquis une couleur plus brillante et un grain plus serré, que quand il est préparé suivant la méthode des Européens.

Le minerai de fer n'est pas bien travaillé dans les fourneaux des Chinois, et le métal qu'ils en retirent n'est ni si uni, ni si malléable, ni si ductile que le fer anglais. Les ouvrages qu'ils forgent sont extrêmement cassants, grossièrement faits, et sans aucun poli. Mais ils excellent dans l'art de couler le fer ; et ils en font des plaques beaucoup plus minces que celles qu'on voit ordinairement en Europe.

Une grande partie de l'étain qu'on porte en Chine y est réduite en feuilles les plus minces possibles. Après quoi, on attache ces feuilles avec de la 


\section{Voyage dans l'intérieur de la Chine et en Tartarie}

gomme sur des carrés de papier qu'on brûle devant les idoles. Le mélange de l'étain et du vif-argent est employé par les ouvriers de Canton à faire de petits miroirs avec des glaces qu'on souffle dans le pays, mais qui ne proviennent que des débris du verre porté d'Europe. Les grains de verroterie, et les boutons de verre de différente forme et de différente couleur, portés par les Chinois des classes supérieures, se fabriquent en grande partie à Venise, et sont au nombre des restes du commerce étendu, et presque exclusif, que les Vénitiens faisaient jadis en Orient.

Les Chinois font beaucoup d'usage de lunettes, qu'ils attachent autour de la tête. Les ouvriers de Canton les font avec du cristal, qu'ils coupent en lames. Pour couper ce cristal, ils se servent d'une espèce de scie, formée de deux ou plusieurs fils de fer très fins et tordus, et qu'ils attachent, comme la corde d'un arc, aux deux extrémités d'un morceau de bambou flexible. Ils défont un des bouts du fil d'archal, afin de le passer autour du cristal, dans l'endroit où ils veulent le diviser. Le cristal est déjà placé entre deux pivots, et par ce moyen, on le scie de la même manière qu'un horloger européen scie de petits morceaux de métal. Un petit vase, rempli d'eau, reçoit la poudre de cristal que fait tomber la scie et qui, mêlée avec l'eau, humecte souvent et le fil d'archal et la rainure qu'il fait dans le cristal. La poudre de cristal, semblable à celle du diamant, aide à couper et à polir la matière dont elle provient.

Les ouvriers qui font ces lunettes ne connaissent aucun principe d'optique, pour pouvoir donner au verre les degrés de convexité ou de concavité qui le rendent propre à suppléer aux divers défauts de la vue. Mais ils laissent les acheteurs choisir les lunettes qui leur conviennent le mieux.

Le peu de lapidaires qui taillent des diamants à Canton se servent de spalt, qu'ils mêlent en très petite quantité avec du granit gris. Les voyageurs, prenant le tout pour du granit seul, doutèrent si la pierre sur laquelle pouvait agir le granit était véritablement un diamant.

Les artistes chinois sont excessivement adroits à imiter les ouvrages d'Europe. Ils raccommodent des montres et en font même quelquefois. Ils copient des tableaux, et colorient des gravures avec beaucoup d'art. Ils fournissent aux étrangers des bas de soie faits au métier ou tricotés dans le 


\section{Voyage dans l'intérieur de la Chine et en Tartarie}

pays. Nous disons aux étrangers, car les Chinois ne portent des bas d'aucune espèce, excepté pourtant quelques jeunes gens qui aiment beaucoup, en secret, à imiter les modes européennes. Ces magots, qui se balancent et qu'on fait à Canton, sont tenus en équilibre par le moyen du vif-argent. Les Chinois emploient aussi ce métal comme les Européens, et le croient spécifique contre certaines maladies. Mais les gens du peuple ont, à cet égard, un préjugé : ils s'imaginent qu'il détruit le pouvoir d'un sexe et rend l'autre stérile. Cependant la grande population du pays semble prouver que ce remède y est rarement employé, ou que ces effets lui sont faussement attribués.

L'on observe effectivement qu'à la Chine, les mariages sont aussi féconds que précoces, à quoi, sans doute, contribue beaucoup l'établissement du système patriarcal, dont nous avons déjà parlé dans cet ouvrage, système qui est certainement contraire au vice et aux excès de toute espèce. L'exposition même des enfants prouve qu'il y a trop de population, relativement aux moyens de subsistance. La population de la Chine n'est point sujette à diminuer beaucoup par la guerre. Les anciennes provinces de la Chine n'ont fourni que très peu d'officiers, et point de soldats, pour la conquête de la Tartarie occidentale et la guerre du Thibet.

Le célibat est rare en Chine, même parmi les militaires de profession. Quelquefois, une excessive sécheresse et, quelquefois, des inondations extraordinaires occasionnent la famine dans des provinces particulières; et la famine est suivie de maladies. Mais la population est bien rarement diminuée par des causes morales, telles que l'émigration ou la navigation étrangère. Les manufactures, soit par le travail qu'on y fait, soit par la vie sédentaire qu'on y mène, ne sont pas toujours favorables à la santé : elles sont souvent situées dans des endroits où l'air est stagnant et insalubre ; et le séjour des villes, où elles se trouvent, expose les ouvriers à plus d'inconduite ; mais en Chine, le nombre de ceux qu'occupent ces établissements n'est que fort peu considérable, en comparaison de celui des cultivateurs. En général, la population des Chinois semble n'avoir d'autres bornes que celles que peut y mettre la nécessité de subsister, et de telles bornes sont certainement plus reculées à la Chine que dans tout autre pays. 


\section{Voyage dans l'intérieur de la Chine et en Tartarie}

Toute la surface de l'empire est, à très peu d'exceptions près, employée à produire de quoi nourrir l'homme. Il n'y a que fort peu de pâturages, et point de prairies, ni de champs cultivés en avoine, en fèves, ou en navets pour nourrir aucune espèce de bétail. On n'y voit guère d'autres maisons de plaisance que celles qui appartiennent à l'empereur. Les chemins n'occupent pas beaucoup de terrain : ils sont étroits et en petits nombre. L'eau y est le principal moyen de communication. II n'y a point de communaux. L'on n'y laisse point de terre en friche par négligence, par caprice, ou pour l'amusement des grands propriétaires; et les terres labourables n'y demeurent jamais en jachère.

Le sol, sous un soleil qui l'échauffe et le fertilise, donne presque toujours deux récoltes par an, parce que la culture est adaptée à la qualité du terrain, et qu'on supplée à ses défectuosités par le mélange d'autres terres, par les engrais, par l'arrosement, et par toute espèce de soins et d'industrie. Le travail de l'homme y est très peu détourné de ces soins et de cette industrie, pour être employé à servir le luxe des gens opulents et puissants, ou à des choses inutiles. Les soldats mêmes y sont occupés à l'agriculture, excepté dans les courts intervalles où ils montent la garde, où ils font l'exercice, et où ils ont quelque service extraordinaire.

Les moyens de subsistance sont aussi accrus en Chine, parce qu'on y mange de beaucoup plus d'espèces d'animaux et de végétaux que dans tout autre pays; et même dans la préparation de leurs aliments, les Chinois mettent beaucoup d'ordre et d'économie.

En considérant l'influence de ces différentes causes, on ne sera peut-être pas surpris de voir avancer que chaque mille carré, en Chine, contient l'un dans l'autre, plus de trois cents habitants, ce qui excède d'environ un tiers le nombre de ceux qu'il y a, aussi par mille carré, dans les contrées les plus peuplées de l'Europe. On se rappelle, il est vrai, que l'une des Antilles a fourni un plus grand exemple encore de population.

Chow-ta-Zhin, qui était un homme habitué aux affaires et à l'exactitude, qui n'avançait les faits qu'avec précaution, et ne parlait ordinairement que d'après des documents officiels, voulut bien, à la sollicitation de l'ambassadeur, lui fournir un état des habitants des quinze anciennes 


\section{Voyage dans l'intérieur de la Chine et en Tartarie}

provinces de la Chine. Cet état, tiré des bureaux de la capitale, est imprimé à la fin de cet ouvrage et nous y avons ajouté, pour la satisfaction de nos lecteurs, la quantité de milles carrés et d'acres de terre qui se trouvent dans chaque province ${ }^{1}$.

L'étendue de ces provinces est déterminée par des observations astronomiques, ainsi que par l'estimation. Elles contiennent plus de douze cents mille milles carrés, c'est-à-dire plus de huit fois l'étendue de la France. Le nombre des habitants est régulièrement pris dans chaque division d'un district, par un dizenier, ou par chaque dixième chef de famille. Ces relevés sont rassemblés par des officiers qui résident si près des lieux où on les a faits qu'ils peuvent en corriger les erreurs majeures; et ensuite, on les dépose tous dans le grand registre de Pékin.

Quoique l'état général soit strictement le résultat de ces différents relevés qui, pris séparément, semblent si fort exempts d'erreur, le nombre des hommes portés dans cet état est si prodigieux qu'on a de la peine à le croire exact. Les calculs mêmes absolument certains, mais immenses dans leurs résultats, tels, par exemple, que l'évaluation de l'énorme distance des étoiles fixes, inspirent nécessairement du doute aux hommes dont l'esprit n'est pas habitué à ces sortes de matières.

Après toutes les déductions raisonnables, pour les erreurs accidentelles et les exagérations partiales que peuvent contenir les relevés de la population chinoise, le résultat en est encore immense; et c'est un grand et curieux spectacle offert à l'esprit, qu'une si nombreuse partie de la race humaine, liée par un grand système de politique dans un si vaste pays, se soumettant tranquillement à un seul souverain, uniforme dans ses lois, dans ses mœurs, dans son langage, mais différant essentiellement, à cet égard, de toute autre nation, et ne désirant de communiquer avec le reste du monde, ni ne formant aucun dessein contre lui.

Il fut impossible aux Anglais de se procurer aucun renseignement exact sur la population de la Tartarie chinoise. Aucun Chinois ne va au-delà de ZhéHol, excepté quelques officiers qu'y appelle le service militaire, ou ceux qui y

\footnotetext{
${ }^{1}$ [Appendice I].
} 


\section{Voyage dans l'intérieur de la Chine et en Tartarie}

sont bannis pour la vie. Les Chinois regardent encore ce pays comme étranger pour eux. On croit que, par-delà Zhé-Hol, il est très peu peuplé.

Les revenus publics de la Chine propre s'élèvent, dit-on, à un peu moins de deux cents millions d'onces d'argent, qui font à peu près soixante-six millions de livres sterling, c'est-à-dire quatre fois autant que les revenus de la Grande-Bretagne, et trois fois autant que ceux de la France avant la révolution. Le produit des impôts sert à payer, dans les lieux mêmes où ils sont perçus, tous les officiers civils et militaires, ainsi que toutes les dépenses ordinaires et extraordinaires. On prend ces sommes dans le trésor particulier de chaque province, et le surplus est remis au trésor impérial à Pékin. Suivant ce que nous avons pris en nombre rond d'un état ${ }^{1}$, fourni par Chow-ta-Zhin, ce surplus s'éleva, en l'année 1792, à la somme de 36614328 onces d'argent, ou 12204776 livres sterling. Dans les cas d'insurrection, ou dans d'autres occurrences qui exigent des dépenses extraordinaires, on met des taxes additionnelles sur les provinces adjacentes, ou qui ont des rapports avec ce qui occasionne les dépenses.

Les occasions de commettre des abus dans l'administration des immenses revenus de la Chine ne sont pas très négligées, ainsi qu'on peut en juger par les fréquentes confiscations que l'empereur fait subir à ceux qui se rendent coupables de ces abus. On assure que la plupart des départements publics sont très corrompus et très oppresseurs, et que leurs membres acquièrent des fortunes considérables, malgré la modicité de leurs salaires.

Parmi les tableaux qui sont dans l'appendice, il y en a un qui contient les appointements qu'accorde l'empereur aux principaux officiers du gouvernement, à ceux qui perçoivent les revenus, et à ceux qui sont nommés par l'administration de la justice 2. Quant à ces derniers, il faut observer que, quoiqu'il y ait dans chaque ville un principal juge chargé de l'instruction des procès criminels, toutes les affaires civiles sont jugées par le gouverneur ou le

\footnotetext{
${ }^{1}$ Cet état se trouve dans l'appendice II.
}

2 [Appendice IV]. 


\section{Voyage dans l'intérieur de la Chine et en Tartarie}

sous-gouverneur de la place. II n'y a point de tribunal particulier ou de juge légal, établi pour ces sortes d'affaires.

Pour ce qui concerne les impôts, les Chinois peuvent être considérés comme plus favorisés que beaucoup de nations européennes, en supposant, toutefois, que l'argent représente la propriété, et qu'il ait la même valeur en Chine qu'en Europe, relativement aux denrées de première nécessité ; car si tout le revenu était réparti en capitation, chaque Chinois ne paierait que cinq schellings, tandis que par un calcul pareil, les habitants de l'I rlande paieraient huit schellings; les Français en payaient seize avant l'établissement de la république ; et les Anglais en paient au moins trente-quatre.

Les Anglais ne purent apprendre rien de certain sur les revenus de la Tartarie. Indépendamment de ce que l'empereur retire des domaines particuliers qu'il a dans cette partie de ses États, les princes tartares lui paient un tribut, qui augmente fréquemment à proportion de leur richesse. Toutes les marchandises qui viennent de la Tartarie, ou qui la traversent pour entrer en Chine, comme les cuirs et les fourrures, paient un droit léger en passant la grande muraille. Mais les marchandises qui sortent de la Chine pour entrer en Tartarie sont affranchies de tout droit.

Les informations relatives à l'armée chinoise furent fournies par Van-taZhin, qui était un officier distingué, et dont les rapports étaient pleins de candeur, quoique peut-être faits avec moins de soin et d'exactitude que ceux de Chow-ta-Zhin.

Van-ta-Zhin assura qu'en y comprenant les Tartares, la totalité de l'armée soldée, en Chine, s'élevait à un million de fantassins, et à huit cent mille hommes de cavalerie. D'après les observations que l'ambassade anglaise eut occasion de faire sur les garnisons des cités de différent ordre, et sur les postes militaires qui étaient toujours à une petite distance l'un de l'autre, il lui parut qu'il n'y avait rien d'exagéré dans le calcul de l'infanterie ; mais elle rencontra peu de cavalerie. S'il y en avait réellement huit cent mille hommes, ils devaient être, en grande partie, en Tartarie, ou bien ils servaient dans des lieux éloignés de la route de l'ambassade.

Une grande partie des troupes, surtout parmi la cavalerie, est composée de Tartares. Les principaux officiers, ceux qui ont la confiance de l'empereur, 


\section{Voyage dans l'intérieur de la Chine et en Tartarie}

sont de la même nation. De quelque nation que soit celui qui se présente pour servir, il n'est reçu que quand il jouit d'une bonne santé, et qu'il est robuste et bien fait. La paye d'un cavalier chinois est de trois onces ${ }^{1}$ et de trois dixièmes d'once d'argent, et de quinze mesures ou rations ${ }^{2}$ de riz par chaque mois lunaire. Un cavalier tartare a sept onces d'argent et vingt mesures de riz pour le même laps de temps. Un fantassin chinois a une once et six dixièmes d'once d'argent, et dix mesures de riz. Un fantassin tartare a deux onces d'argent et dix mesures de riz.

L'empereur fournit à tous les soldats les armes, l'équipage et l'habit. Indépendamment de leur paye et des rations qu'on leur accorde, ils obtiennent des gratifications de l'empereur, dans des occasions particulières, comme lorsqu'ils se marient, ou qu'il leur naît des enfants mâles. A la mort de leurs parents, le prince leur fait un présent de consolation; et quand les soldats eux-mêmes meurent, un pareil don est accordé à leur famille.

La vie militaire est plus faite pour un Tartare que pour un Chinois. L'éducation dure, les mœurs grossières, l'esprit actif, les inclinations vagabondes, les principes relâchés et la conduite irrégulière du Tartare sont plus propres à la guerre que les habitudes calmes, réglées et les goûts domestiques, moraux et philosophiques du Chinois. La Tartarie semble plus faite pour produire des guerriers et la Chine des lettrés. Les derniers sont principalement versés dans les sciences de la morale et de la politique du gouvernement, qui se trouvent souvent réunies dans la contemplation et dans les ouvrages de leurs législateurs et de leurs philosophes. Quelques-uns de leurs principaux écrivains ont réussi à parer leurs leçons d'une manière si instructive et si agréable, qu'elles ne font pas moins de plaisir à un Chinois, que n'en peuvent faire à un Anglais les réflexions d'un Johnson dans son Rambler ou dans son Rasselas.

\footnotetext{
${ }^{1}$ L'once chinoise pèse plus que l'once européenne.

2 On n'en sait pas le poids.
} 


\section{Voyage dans l'intérieur de la Chine et en Tartarie}

Après les études qui enseignent à l'homme à régler sa vie et sont liées avec elle, l'étude que les Chinois estiment le plus est celle de l'histoire des événements de leur pays, qui est pour eux le monde entier; histoire qui comprend aussi celle des mouvements célestes qu'on a eu occasion d'observer en même temps. A l'égard des événements, nous avons déjà fait mention de la constance et de la régularité avec lesquelles chaque fait est rapporté par les Chinois, et soigneusement transmis à la postérité, avec peu de mélange de ces événements surnaturels qui ont décrédité les anciens monuments historiques de la plupart des autres nations.

Quant aux mouvements célestes, rien n'est si propre à exciter la curiosité et l'admiration, que la vue du firmament azuré et semé d'étoiles qu'une atmosphère pure permet aux habitants de la Chine de contempler presque toujours. Les vicissitudes des jours et des nuits, de l'été et de l'hiver, et les différentes phases de la lune, sont trop frappantes pour ne pas fixer l'attention des classes ignorantes ainsi que des classes instruites de la société. Le berger en gardant son troupeau, le cultivateur en labourant son champ, ont eu de fréquentes occasions de consulter les cieux. Ils ont observé ses rapports entre leurs mouvements, l'état de la température et la période des productions de la terre. Il était à la fois si utile et si satisfaisant de pouvoir déterminer ces rapports d'une manière exacte, et de régler le retour des saisons, qu'on fit divers efforts pour y parvenir et pour former des systèmes d'astronomie et de chronologie.

La succession des idées ou des événements humains était trop incertaine et trop irrégulière pour servir à mesurer le temps qui, conséquemment, ne put être réglé que d'après les révolutions constantes des corps célestes. La première division du temps fut sans doute prise de l'intervalle qui est entre le lever et le coucher du soleil; la seconde le fut des changements dans les apparences de la grandeur et de la forme de la lune; et la dernière du retour du soleil dans le voisinage des mêmes étoiles fixes.

On imagina d'abord que la dernière période d'une année était égale à douze révolutions complètes de la lune; mais en suivant une telle division, pendant environ seize ans, on trouva que la saison qui avait été fixée pour l'été arrivait en hiver. Alors, on imagina l'intercalation d'un mois pour corriger 


\section{Voyage dans l'intérieur de la Chine et en Tartarie}

le calendrier et faire correspondre les calculs des mouvements respectifs des corps célestes.

Dans un climat favorable à l'astronomie, la balance des heures au-delà du nombre de jours durant lesquels le soleil paraît retourner vers les mêmes étoiles fixes, et se mêler avec elles, peut avoir été bientôt déterminée, et a occasionné l'addition d'un jour à chaque quatrième année, afin de maintenir la régularité dans le calcul du temps à l'égard du retour des saisons. Mais plusieurs siècles doivent s'être écoulés avant qu'on ait découvert une période dans laquelle les différences du retour du soleil et de la lune sont si exactement calculés, qu'à sa fin les nouvelles et les pleines lunes reviennent, non seulement le même jour, mais à une heure et demie du temps précis où elles paraissaient quand la période a commencé. La connaissance de cette période, qu'on nomme cycle, n'a pu s'acquérir que par une multiplicité d'observations très exactes.

Plusieurs révolutions des deux grands flambeaux des cieux se sont complétées; des conjonctions sans nombre ont passé, avant qu'on ait reconnu que leur retour avait lieu le même jour à la fin de dix-neuf ans. La petite différence qui se trouve entre les périodes de ce cycle fut en partie diminuée par l'invention d'une autre période de soixante ans, et de sept cent vingt révolutions de la lune. L'on supposa d'abord qu'avec l'intercalation de vingt-deux lunaisons, cette période mettait une parfaite coïncidence entre les positions relatives du soleil et de la lune ; mais suivant cette période même, on fit constamment reculer un peu chaque nouvelle année ; ce que les Chinois corrigèrent ensuite de temps en temps.

Ce cycle remplit un double but : il servit d'ère pour la chronologie, et de période régulatrice pour l'année luni-solaire. Chaque année du cycle est distinguée par l'union de deux caractères pris dans l'arrangement d'un nombre inégal de mots placés dans différentes colonnes, et d'une telle manière que les deux mêmes caractères ${ }^{1}$ ne peuvent se rencontrer de nouveau qu'au bout de soixante ans. La première colonne contient une série de dix mots ; la seconde une série de douze qui, dans le fait, sont les mêmes

\footnotetext{
${ }^{1}$ On a déjà vu que chaque mot était rendu par un seul caractère.
} 


\section{Voyage dans l'intérieur de la Chine et en Tartarie}

qui indiquent les douze heures ou divisions du jour, chacune desquelles est le double d'une heure européenne. Le premier mot de la première colonne, joint au premier mot de la seconde colonne, marque la première année du cycle, et cela continue ainsi jusqu'à ce que la première série soit épuisée. Alors, le onzième mot de la seconde série se trouve combiné avec le premier de la première série pour marquer la onzième année du cycle ; et le douzième mot de la seconde série, joint avec le second mot de la première, sert à indiquer la douzième année. Le troisième mot de la première série est joint dans une progression régulière, avec le premier mot de la seconde série pour marquer la treizième année ; et en continuant de cette manière, le premier caractère de la première série et celui de la seconde ne peuvent se retrouver ensemble qu'au bout de soixante ans, lorsque la première année du cycle recommence.

L'année chrétienne de 1797 répond à la cinquante-quatrième année du soixante-huitième cycle chinois; ce qui démontre que le commencement de ces cycles est de deux mille deux cent soixante-dix-sept ans antérieur à la naissance du Christ. Pour combattre cette assertion, dont les registres publics et les annales de l'empire attestent la vérité, il faut supposer que ces registres et ces annales ont été falsifiés, et qu'en établissant le cycle, on l'a antidaté. Mais on serait aussi peu fondé à dire cela, qu'à prétendre que la première olympiade est reculée de plusieurs siècles au-delà du temps où les jeux olympiques ont commencé.

Les habitants de la péninsule de l'Inde emploient également le cycle de soixante ans pour marquer plusieurs de leurs époques. Les Siamois s'en servent aussi. L'année solaire des Indous a commencé au solstice d'hiver, et celle des Chinois commence encore ainsi, d'où l'on peut inférer qu'il y a eu quelque communication entre ces deux peuples. L'histoire dit en effet que les Chinois naviguaient jadis le long des côtes, ou du moins sans s'éloigner beaucoup de la terre, depuis Canton jusque dans la mer Rouge et le golfe Persique.

Les annales chinoises ne se bornent point à relater les événements politiques. Elles parlent aussi de ce qui paraît d'extraordinaire dans les cieux, et des changements naturels qui ont lieu dans le pays. Elles font mention de plusieurs conjonctions des planètes; l'une desquelles, suivant le célèbre astronome Cassini, n'a point eu lieu à l'époque fixée par les Chinois ; mais un 


\section{Voyage dans l'intérieur de la Chine et en Tartarie}

écrivain non moins estimable, l'éloquent et savant Bailly, a soutenu que le calcul de Cassini était erroné. Certes, l'authenticité de l'observation est compatible avec l'inexactitude de l'indication du temps où elle a eu lieu. Le calcul de ce temps doit nécessairement participer de l'imperfection du calendrier qui était alors en usage. Si l'époque précise de l'éclipse était assignée d'une manière correcte, elle pourrait faire soupçonner qu'on l'a calculée longtemps après pour prouver la haute antiquité de la nation qu'on supposerait avoir fait de telles observations.

A en juger par l'état où l'astronomie est à présent en Chine, il est très vraisemblable que si jamais les Chinois ont été capables de prédire les éclipses, ce ne pouvait être que par des observations longues et répétées, et non par le calcul. L'on rapporte, il est vrai, que deux astronomes furent sévèrement punis pour avoir négligé de prédire une éclipse de soleil qui eut lieu vers midi, le premier jour de la nouvelle lune de l'année 2155 avant l'ère chrétienne. Mais on dit qu'il doit y avoir quelque erreur dans ce récit; car cette éclipse n'était point visible en Chine, quoiqu'elle le fut sous d'autres méridiens que celui de Pékin.

Les Chinois ont, dit-on, possédé trois ans avant la naissance du Christ, un traité de la clepsydre, et un traité sur les cadrans solaires. Le dernier de ces ouvrages enseigne à trouver la latitude d'un lieu quelconque, et à tirer une méridienne; connaissance que ne possédaient pas à cette époque, les Romains eux-mêmes; car pendant longtemps, on n'eut à Rome d'autre moyen de déterminer le milieu du jour qu'en observant le moment où le soleil se trouvait entre le palais où siégeait le sénat et la tribune. On s'y servit même, plusieurs années, d'un cadran solaire calculé pour une autre latitude, parce qu'on s'imaginait qu'il convenait également dans tous les lieux. On accuse les Chinois de tomber encore dans une pareille erreur.

Les annales de la Chine rapportent un événement dont les personnes qui composaient l'ambassade anglaise trouvèrent la tradition encore subsistante dans le pays. Le grand fleuve Jaune surmonta ses bords, et cette inondation causa un ravage affreux parmi les habitants des contrées voisines. Le nom de celui qui entreprit d'étancher les eaux et de contenir dorénavant le fleuve dans son lit, ainsi que diverses particularités concernant ce même homme, la méthode qui suivit pour son opération, le temps qu'il employa, tout enfin est 


\section{Voyage dans l'intérieur de la Chine et en Tartarie}

détaillé, d'une manière si bien circonstanciée que cette relation porte le plus grand caractère de vérité.

Pendant qu'il travaillait à dessécher la terre, l'entrepreneur traça une carte des pays que traversait le fleuve, carte qui existe encore dans le Shoo-King, l'un des livres sacrés des Chinois. L'antiquité de cette carte grossière est prouvée par la division du fleuve, laquelle subsistait alors. Le fleuve Jaune, en arrivant dans la province de Kiang-Nan, comme nous l'avons déjà observé, se séparait en deux bras égaux, l'un desquels tournait aussitôt vers le nord, et se jetait dans le golfe de Pé-Ché-Lée, pendant que l'autre avait la même direction que suit aujourd'hui tout le fleuve. L'histoire de la Chine ne fait mention d'aucun déluge général.

Quelque peu avancés que soient maintenant les Chinois dans la science astronomique, ils ont quelques idées des cercles imaginaires des cieux, tels que l'écliptique qu'ils nomment la voie jaune, le cercle équinoxial, et la ligne méridienne. Les constellations ne sont point représentées chez eux par des images fantastiques, mais les étoiles qui les composent sont réunies, sur leurs cartes, par des lignes. Ils ne connaissent que cinq planètes, nombre égal à celui des substances élémentaires, qu'ils supposent entrer dans la composition de tous les corps. Ces substances sont le feu, l'eau, la terre, le bois et le métal ; et à chacune d'elles, suivant les Chinois, préside une des cinq planètes.

Peu de Chinois semblent avoir quelque idée du mouvement de la terre, mais ils s'imaginent que le soleil se meut parmi les étoiles fixes. Ils distinguent dans la voie jaune quatre points principaux pour marquer les quatre saisons. Le jour, comme celui des anciens Egyptiens, est divisé en douze heures, chacune desquelles équivaut à deux heures européennes. La première heure chinoise commence à onze heures du soir.

Ces portions de temps sont mesurées avec assez d'exactitude, par le moyen d'un flambeau, fait avec la moelle d'un arbre particulier, flambeau qui brûle avec tant de régularité, qu'étant divisé en douze parties égales, chacune se consume exactement dans la douzième partie de vingt-quatre heures. Les Chinois ont aussi appliqué au même objet le mouvement graduel du sable et la chute des liquides. 


\section{Voyage dans l'intérieur de la Chine et en Tartarie}

Les Chinois emploient quelquefois des moyens fatigants et très peu ingénieux pour exécuter diverses choses utiles à la société. A Pékin même, la meilleure manière qu'on ait pour annoncer l'heure est de frapper avec un maillet sur une grosse cloche, le nombre de coups qui répond à celui des heures ; et il faut pour cela qu'un homme veille le progrès du temps, tel qu'il est réglé d'après quelqu'une des méthodes dont nous venons de parler.

Quelques caractères de la langue chinoise expriment bien les nombres, mais les Chinois n'en ont pas d'autres pour les rendre d'une manière abrégée, comme les chiffres arabes qu'emploient les Européens et qu'ils n'ont adoptés que pour éviter l'inconvénient d'écrire constamment les nombres avec des lettres alphabétiques.

Sans l'usage des chiffres arabes, ou de quelques autres figures abrégées, il serait difficile et ennuyeux, quand bien même cela serait praticable, d'exécuter les opérations de l'arithmétique qui exigent des positions particulières de simples signes. A la vérité, les Chinois ont moins besoin de ces signes, attendu qu'ils font leurs calculs sans écrire, par le moyen de leur swan-pan ${ }^{1}$. Cependant, quand il faut qu'ils expriment des nombres dans leurs écrits, ils ont recours à leurs caractères, chacun desquels signifie un nombre entier, indépendamment de sa position relative. Cette méthode est moins fatigante, sans doute, que celle d'écrire les nombres avec les lettres alphabétiques; mais elle n'égale nullement l'expression concise des mêmes quantités en chiffres arabes. La multiplication et la division de toutes les quantités, par proportions décimales, facilitent les calculs des Chinois, et les empêchent de chercher des méthodes plus abrégées.

Dans les premiers degrés de l'État social, quand les besoins pressants des hommes excitent leur invention, aucune circonstance locale n'a mis les Chinois dans la nécessité de considérer avec attention la nature des lignes et des surfaces, et de tirer des conséquences de la considération de leurs propriétés. Les débordements ordinaires des rivières de la Chine n'étaient ni assez considérables, ni les eaux ne restaient assez longtemps sur les terrains

\footnotetext{
1 On a déjà vu que c'est une machine où il y a plusieurs boules enfilées dans des fils
} d'archal. 


\section{Voyage dans l'intérieur de la Chine et en Tartarie}

adjacents, pour exiger qu'on calculât leur étendue et leur profondeur ; ce qui, dit-on, avait lieu en Egypte, où l'on croit que la géométrie a été inventée. $\mathrm{Ni}$ dans les temps anciens, ni dans les temps modernes, les Chinois n'ont eu, comme les autres nations, assez de communication avec le reste du genre humain ${ }^{1}$ pour imiter ses exemples, ou emprunter ses découvertes. On cite des princes de la Chine, lesquels ont fait de grands progrès dans les mathématiques, sous les missionnaires attachés à la cour; mais ni la politique du gouvernement, ni celle des missionnaires eux-mêmes, ne leur auraient permis de répandre ces sortes de connaissances dans le public, quand bien même leurs occupations religieuses leur en auraient laissé le temps. Ils savaient trop bien que le peuple aurait eu moins d'admiration pour ses chefs et pour la prédiction solennelle des éclipses, si la science qui fournit les moyens de les prédire avait été généralement connue; ils n'ignoraient pas, enfin, que les missionnaires dont on a besoin pour la composition des almanachs eussent été alors remplacés par des Chinois. Les Chinois dépendent véritablement, à cet égard, du savoir des autres nations.

L'importation toujours croissante des marchandises étrangères dans les ports de la Chine a créé un autre genre de dépendance, que plusieurs des hommes d'État de cet empire, et surtout les Tartares, considèrent comme un mal, et cherchent à faire cesser, en aggravant, auprès de la cour de Pékin, tous les inconvénients et les embarras occasionnés par l'admission du commerce étranger.

II a fallu prévenir, autant qu'il était possible, les accidents qui pouvaient nuire à la continuation des relations commerciales avec la Chine; et c'est sans doute un des motifs qui ont engagé les nations que ces relations intéressent, à les laisser entre les mains de compagnies privilégiées. II ne peut s'établir à Canton d'autres marchands européens, que ceux qui sont

1 Ceci est un peu contradictoire avec ce que l'auteur vient de dire plus haut de l'ancienne navigation des Chinois jusqu'au golfe Persique et dans la mer Rouge. Pour moi, je suis convaincu que les Chinois ont eu, jadis, beaucoup de rapports avec les Egyptiens et avec d'autres peuples de l'Antiquité ; mais il serait trop long de rapporter ici les raisons qui fondent mon opinion. (Note du Traducteur.) 


\section{Voyage dans l'intérieur de la Chine et en Tartarie}

munis de commissions de leurs souverains. Puisqu'en effet, malgré toutes les précautions, la bonne foi, l'exactitude, la patience des agents de compagnies, le commerce européen ne s'est maintenu en Chine qu'avec beaucoup de difficultés, il est à croire que, lorsque ces qualités ne pourraient pas être invariablement l'apanage d'individus qui ne seraient pas guidés par l'expérience, ou qui n'agiraient pas d'après des principes stricts et uniformes, il s'élèverait des disputes, on tenterait d'employer la fraude, et il surviendrait des événements dont profiteraient les ennemis des étrangers pour les faire entièrement chasser. Les restrictions qu'on a mises au commerce étranger en Chine n'ont pas toujours subsisté. Elles n'ont eu lieu qu'à la suite de quelques mécontentements de la part du gouvernement chinois, relativement à l'inconduite prétendue des Européens dans les ports, qui étaient autrefois tous également ouverts aux étrangers.

Les relations des voyages en Chine, au seizième et au dix-septième siècles, avant et depuis la conquête des Tartares, parlent de l'arrivée des vaisseaux, des passagers et des marchandises d'Europe dans différents ports de la Chine, et ne disent point qu'ils éprouvassent la moindre vexation de la part du gouvernement, ni des particuliers. Mais depuis cette époque, les plaintes, souvent mal fondées, et exagérées par des magistrats oppresseurs ou des individus intéressés, et transmises à la cour de Pékin contre les Anglais et les autres étrangers qui n'y avaient point d'amis pour défendre leur cause, ont non seulement fait mettre des restrictions à leur commerce et surveiller leur conduite, mais occasionné du dégoût aux agents européens qui étaient sur les lieux, et nui aux intérêts de leurs commettants.

Ces faits peuvent être ajoutés aux solides arguments que le président des directeurs de la Compagnie des Indes, cité au commencement de ce chapitre, a avancés pour faire proroger la charte de la Compagnie, et qu'il a soumis au ministre, sous l'inspection particulière duquel les intérêts britanniques prospèrent, en Asie, depuis plusieurs années.

Certes, la question de savoir si la charte de la Compagnie des Indes devait être renouvelée était d'une très grande importance, et a été considérée avec impartialité : mais la décision en était très délicate. Les opinions populaires d'Adam Smith sont contraires à toute espèce de monopole. Mais sa théorie 


\section{Voyage dans l'intérieur de la Chine et en Tartarie}

est fondée sur des principes qui ne peuvent pas être mis en pratique dans la circonstance particulière dont il s'agit ici.

II faut convenir, sans doute, avec ce savant écrivain, que quand on fait le commerce dans des pays peu éloignés, dont les habitudes, les préjugés, les besoins sont bien connus de tous les négociants, et où l'on peut entretenir des relations avec des capitaux bornés, les efforts séparés et l'émulation d'un grand nombre de personnes doivent donner à ce commerce la plus grande étendue dont il soit susceptible; et ces efforts, cette émulation ne peuvent avoir lieu que quand le commerce est entièrement libre. Mais il en est autrement pour une branche de commerce éloignée qui, pour être avantageuse à l'Etat, a besoin d'exporter, pendant un certain temps, les produits de ses manufactures à perte, et de faire des avances considérables pour les retours. Un tel commerce doit être exclusivement confié à un corps de marchands, lequel peut pour longtemps mettre dehors de grands capitaux, et qui, dans ses rapports avec le gouvernement, n'a pas moins en vue le bien public que son avantage particulier.

Les membres de ce corps, quels que puissent être les succès de leurs entreprises, partagent entre eux un profit modéré, qui n'excède que de très peu l'intérêt ordinaire de l'argent. Ils ne retirent, d'ailleurs, aucun bénéfice auquel n'ait droit toute personne qui, aux mêmes conditions, veut entrer dans leur corps, et surtout si elle a l'option d'envoyer des marchandises pour son compte particulier. Ce corps semble ne devoir pas être un juste objet de jalousie pour le reste de la société. II joint à l'avantage d'un commerce ouvert, l'administration utile d'une compagnie privilégiée; et en cas qu'il fasse des profits extraordinaires, il doit les partager avec l'État, qui le protège à très grands frais. Un tel établissement promet plus d'utilité au public que le hasard d'un commerce avantageux fait par des individus, qui pourraient bien s'enrichir, mais qui ne garantiraient aucune rétribution au gouvernement, pour l'indemniser de ses dépenses et des risques qu'il courrait pour eux.

La méthode de faire le commerce par le moyen de compagnies, plutôt qu'individuellement, est tellement assortie aux idées des Chinois, et leur paraît si nécessaire pour la sûreté de toutes les affaires mercantiles, ainsi que pour la tranquillité de ceux qui les font, qu'ils ont établi parmi eux une société de hongs, c'est-à-dire de marchands, qui sont responsables les uns pour les 


\section{Voyage dans l'intérieur de la Chine et en Tartarie}

autres envers le gouvernement et envers les nations étrangères. II leur est permis de lever une taxe sur les marchandises qu'ils ont à vendre, afin de subvenir aux frais que peut leur occasionner leur société.

Cette taxe est cependant une augmentation du prix d'achat, et doit nécessairement retomber presque toujours sur le consommateur.

Dans tous ce qui n'est pas opposé à leur propre intérêt, les marchands chinois sont favorablement disposés pour les agents des compagnies européennes; mais ils osent rarement se charger des justes remontrances des étrangers. Habitués à redouter la pesante main du pouvoir arbitraire, les marchands chinois sont toujours d'un caractère timide et circonspect. Quelquefois, ils ont supprimé les représentations de leurs amis étrangers ; et quelquefois, ils les ont présentées d'une manière si faible et si insignifiante, et ils ont pris, au nom de ces étrangers, un ton si suppliant et si abject, qu'ils n'ont fait qu'exciter le mépris des mandarins, et les encourager à redoubler d'injustice et de mauvais traitements.

Les commissaires sentant l'avantage qui résulterait de la facilité de communiquer leurs sentiments par la voie des agents de la Compagnie sur lesquels ils pourraient compter, prirent beaucoup de peine pour encourager l'étude de la langue chinoise dans la factorerie. La connaissance du langage des pays où l'on fait le commerce ne peut manquer d'être très utile, parce qu'elle met à l'abri des fraudes auxquelles les étrangers sont ordinairement exposés. Il est certain qu'en Chine, surtout, le crime redoute d'être découvert. L'oppresseur désire que ses torts ne soient point publiés; et un concussionnaire avide peut être retenu par la crainte d'entendre bientôt des plaintes exprimées dans un langage clair et ferme.

II était très difficile à un étranger d'apprendre le chinois, même à Canton, ville de la Chine. Un jargon particulier y est parlé par toutes les classes des habitants, excepté par les mandarins, qui ne sont jamais nés dans les provinces où ils remplissent quelque emploi, et à qui l'on ne peut s'adresser, soit verbalement, soit par écrit, que dans le langage général de l'empire.

Nous avons déjà dit, au commencement de cet ouvrage, qu'il était défendu aux maîtres de langue chinoise de l'enseigner aux étrangers. Cette 


\section{Voyage dans l'intérieur de la Chine et en Tartarie}

défense fut un des griefs dont l'ambassadeur se plaignit au vice-roi, qui pouvait à peine croire une assertion, d'après laquelle il semblait que le gouvernement et les marchands de Canton avaient l'intention décidée d'empêcher les étrangers de traiter leurs propres affaires, et d'apprendre à se mettre bien en état de suivre les lois et les coutumes du pays.

On doit être encouragé à apprendre le chinois en voyant plusieurs habitants de Canton qui, excités par l'avantage de trafiquer avec les factoreries étrangères, se sont rendus capables de se faire entendre dans les langues européennes, pour les choses ordinaires. Cependant, ils ont à vaincre un obstacle, auquel ne sont pas exposés les étrangers qui apprennent le chinois. Le son de diverses lettres de la plupart des alphabets, telles que $B, D$, $R$, et $X$, est absolument inconnu dans la langue chinoise. L'organe de la parole, dans un Chinois, n'est point encore accoutumé à prononcer ces lettres. En s'efforçant d'en articuler une, il en fait presque toujours entendre une autre, à laquelle son organe est habitué. Au lieu de la lettre $R$, il prononce $\mathrm{L}$ mouillée, ce qui occasionne quelquefois des méprises assez bizarres. Par exemple, un Chinois qui veut vendre du riz offre une marchandise que très peu de personnes voudraient acheter ${ }^{1}$.

La différence entre les tons et les accents des mots qui se ressemblent presque par le son, mais qui varient considérablement par le sens exige sans doute une grande délicatesse d'oreille pour être saisie, et beaucoup de souplesse dans l'organe de la voix pour être rendue exactement. Pour réussir à bien faire cette distinction, un étranger doit les apprendre dans l'âge où ses organes sont encore prompts et flexibles. Cependant, on est puissamment aidé à prendre chaque mot dans son véritable sens, par la contexture de la phrase dans laquelle il est placé. Un Anglais, par exemple, n'est jamais embarrassé dans la conversation pour savoir si l'on veut parler du soleil ou d'un fils, quoique dans sa langue la prononciation de ces deux mots soit la même.

1 Des poux. En anglais, le mot qui signifie du riz se prononcerait comme celui qui signifie des poux, si l'on mettait un L à la place d'un R. (Note du Traducteur.) 


\section{Voyage dans l'intérieur de la Chine et en Tartarie}

Les Chinois, ainsi que nous l'avons déjà observé, font aussi fréquemment usage des synonymes dans leurs entretiens, afin d'éviter qu'il n'y ait de l'incertitude dans le sens de leurs mots. Cependant, si dans une discussion épineuse, il reste encore quelque doute sur la signification d'une expression particulière, on a recours au meilleur moyen de se faire entendre; on trace avec un doigt en l'air ou de quelque autre manière, la forme du caractère, et on détermine tout d'un coup ce qu'on veut exprimer.

Celui qui apprend le chinois n'est point embarrassé par une multitude de règle minutieuses de grammaire, de conjugaison, de déclinaison. II n'est point dans la nécessité de distinguer les substantifs, les adjectifs et les verbes, ni l'accord du genre, du nombre et du cas. Le chinois fournit la preuve que la construction laborieuse et le mécanisme compliqué des langues grecque et arabe, ne sont nullement nécessaires, ni pour la communication complète des idées dans toutes les circonstances de la vie, ni même pour les grâces de l'élocution et l'harmonie des vers. Le commencement ni la terminaison des mots ne sont point altérés, comme dans le grec, où les verbes seuls en offrent plus de mille exemples pour distinguer les temps de l'action qu'on veut exprimer, ou les cas dans lesquels on veut placer les choses dont on fait mention. Un très petit nombre d'articles désignent le passé, le présent et le futur ; et l'on n'emploie point d'auxiliaire, ni l'on ne change la terminaison ${ }^{1}$ quand le temps peut être compris avec certitude. Un Chinois qui veut déclarer son intention de partir demain ne dit jamais qu'il partira demain, parce que le mot demain suffit pour indiquer que le temps de son départ est au futur.

Le pluriel est marqué, dans le chinois, par l'addition d'un mot sans lequel le nombre des personnes et des choses est toujours censé être au singulier. Ni la mémoire, ni l'organe de la voix ne sont fatigués par la prononciation de plus de sons qu'il n'en faut nécessairement pour exprimer la différence des idées. La langue chinoise est entièrement monosyllabique. Une seule syllabe exprime toujours une idée complète. Chaque syllabe peut être rendue avec une consonne européenne, précédant une voyelle que suit quelquefois une lettre mouillée. Un tel ordre de mots écarte la dureté des sons qu'occasionne

\footnotetext{
${ }^{1}$ Je suis obligé de faire ici quelque léger changement pour appliquer au français les
} 


\section{Voyage dans l'intérieur de la Chine et en Tartarie}

le rapprochement des diverses consonnes, et rend le langage aussi doux, aussi harmonieux que l'est l'italien, à cause de la rareté des consonnes et de la fréquence de ses terminaisons par voyelles.

Il est probable que les premiers mots qu'a fait entendre l'homme n'étaient que des exclamations ou de simples sons monosyllabiques. Les noms ou les sons par lesquels il distinguait d'abord les autres animaux, lorsqu'il avait besoin de les désigner en leur absence, étaient des essais d'imitation des sons qu'ils faisaient entendre eux-mêmes. Dans le chinois, par exemple, le nom d'un chat ressemble encore assez au cri de cet animal. De même qu'en parlant, on essaya naturellement d'imiter les sons ou la voix des objets, quand cela se put, on essaya aussi, en écrivant, d'en dessiner une grossière figure.

Il est à remarquer que, dans la plupart des langues, les mots radicaux, séparés des lettres serviles qui marquent leurs inflexions suivant leur conjugaison ou leur déclinaison, sont monosyllabiques. Dans la composition des mots, une partie de leur racine est conservée pour désigner la signification et l'étymologie qui devient ainsi polysyllabique. Mais les grammairiens chinois sentant les inconvénients qui résultent de la longueur et de la complication des sons, bornent tous leurs mots à des sons simples, même lorsqu'ils expriment des idées combinées; et si en écrivant, les caractères composés rendent des idées compliquées, ils conservent une partie au moins de la forme de chaque caractère désignant une idée simple.

Il y a, dans la langue chinoise, un certain ordre, ou une syntaxe qui détermine la succession des mots d'une même phrase. Cette succession est fixée différemment par l'usage dans les différentes langues; mais elle n'est fondée sur aucun ordre naturel d'idées, ou, du moins, on l'a quelquefois supposé. Quoique dans le chinois, une phrase renferme plusieurs idées qui doivent être rendues par plusieurs mots, ces idées sont toutes liées ensemble au même instant, parce qu'on forme une peinture ou une image, dont toutes les parties sont conçues à la fois. La construction d'une phrase chinoise est la plus simple et la plus dénuée d'art qu'il soit possible, et telle qu'elle doit avoir

comparaisons que l'auteur a appliquées à l'anglais. (Note du Traducteur.) 


\section{Voyage dans l'intérieur de la Chine et en Tartarie}

été naturellement formée dans l'origine de la société. Par exemple, interroger, c'est ordinairement exiger la solution d'une question, soit que le sujet sur lequel on a des doutes se trouve dans une catégorie, soit qu'il se trouve dans une autre. Ainsi, un Chinois qui s'informe de la santé de son ami, dit quelquefois : « hou, pou hou ? ». La signification littérale de ces mots est : « bien, pas bien ? ». Un caractère simple, lorsqu'il est répété, suffit pour plus d'un des objets qu'il désigne simplement, et quelquefois même pour une quantité considérable de mêmes objets. Le caractère du mot moo ${ }^{1}$ désigne simplement un arbre ; doublé, c'est un bosquet ; triplé, c'est une forêt.

Dans la langue chinoise, il y a à peine quinze cents sons distincts, et plus de quatre-vingt mille caractères, ou différentes formes de lettres. Ce dernier nombre divisé par l'autre, donne près de cinquante sens ou caractère à chaque son; disproportion qui met moins en réalité qu'en apparence, de l'équivoque dans la langue parlée des Chinois. Le dictionnaire anglais de Johnson fournit des exemples de mots qui ont plus de cent significations différentes, sans que jamais ils occasionnent quelque incertitude dans la conversation en Angleterre ; et s'il y en avait, on ne pourrait pas, comme les Chinois, déterminer le sens précis des mots douteux par la forme des caractères écrits, qui sont différents pour tous les sens dans lesquels sont reçus les mots.

Dans quelque langue que ce soit, le nombre des mots, ou au moins de significations de chaque mot, dépend principalement du degré de civilisation auquel est parvenue la nation qui parle cette langue. Il dépend aussi, en partie, de la population, et de la culture des arts. C'est pourquoi il n'est pas étonnant que le dictionnaire chinois contienne au moins quatre-vingt mille caractères. Peut-être, si chaque sens dans lequel les termes anglais sont quelquefois reçus, était considéré comme un mot distinct, et que l'immense quantité de mots employés dans les arts et dans les occupations ordinaires de la vie fussent comptés, le nombre n'en serait pas beaucoup moindre que celui des mots chinois.

\footnotetext{
${ }^{1}$ On prononce $\ll \mathrm{mou} »$.
} 


\section{Voyage dans l'intérieur de la Chine et en Tartarie}

La plupart des caractères de la langue chinoise étaient originairement tracés pour présenter des images réelles ou allégoriques des idées. Un cercle désignait le soleil, et un croissant la lune. Un homme était représenté par une figure droite, avec des lignes pour marquer les extrémités. II est évident que la difficulté et la fatigue de l'imitation doit avoir bientôt fait préférer des traits plus simples et plus promptement tracés.

De la figure entière d'un homme, il ne reste plus que les extrémités inférieures qu'on trace par deux lignes formant un angle. Quelquefois, cependant, il y a dans les caractères hiéroglyphiques dont se servent à présent les Chinois, une faible ressemblance avec leur forme originaire. Les gradations de leurs changements se trouvent marquées dans les livres. Aujourd'hui, les caractères chinois qui ne consistent qu'en une seule ligne, ne passent pas le nombre de six; mais la plupart consistent en beaucoup de traits, et il en est quelques-uns qui en ont jusqu'à soixante-dix.

La forme de ces caractères n'a pas eu le même sort que le son des mots, ainsi qu'on en a l'exemple dans la plupart des contrées de l'orient de l'Asie ; contrées où l'on entend la langue chinoise écrite, mais non la langue chinoise parlée. Cette langue écrite est comprise de la même manière que des caractères arabes, qui expriment des nombres, et des notes de musique, sont intelligibles chez toutes les nations de l'Europe, quelles que soient les langues qu'elles parlent.

On aperçoit dans l'arrangement des caractères chinois un certain ordre qui semble indiquer que le système d'après lequel ils ont été créés était d'abord complet, et n'a pas achevé de se former lentement et à de longs intervalles ${ }^{1}$, comme les langues des autres nations. Plus de deux cents caractères chinois consistant en fort peu de lignes ou traits, désignent les principaux objets de la nature, à peu près de la même manière que les divisions qu'on voit dans le livre ingénieux de l'évêque Wilkin, sur une langue universelle.

${ }^{1}$ Cette observation n'est-elle pas à l'appui de l'opinion de Bailly, sur un peuple primitif qui, en disparaissant de dessus la terre, a laissé les débris de ses connaissances à d'autres nations ? Et les Chinois ne peuvent-ils pas avoir reçu de ce peuple leur langue et leur écriture hiéroglyphique, comme leur astronomie? (Note du Traducteur.). 


\section{Voyage dans l'intérieur de la Chine et en Tartarie}

Ces caractères peuvent être considérés comme les genres ou les racines de la langue, dans laquelle chaque autre mot ou espèce se trouve systématiquement rapporté au genre qui lui est propre. Le cœur est un genre représenté par une ligne courbe qui en imite à peu près la forme, et les espèces qui y ont rapport comprennent tous les sentiments, les passions, les affections qui agitent I'homme. Le caractère de chacune de ces espèces est accompagné d'une marque qui indique son genre, c'est-à-dire le cœur. La main est un autre genre dans lequel sont classés la plupart des métiers et des travaux que fait la main. Le genre parole comprend toute sorte de discours, d'étude, d'écrit, d'intelligence et de discussion. Une ligne horizontale marque une unité ; et quand elle est croisée par une autre ligne, elle signifie dix ; ce qui a également lieu chez toutes les nations qui répètent les unités après ce nombre.

Les cinq éléments dont les Chinois imaginent que sont composés tous les corps, forment autant de genres, chacun desquels comprend un grand nombre d'espèces. Comme chaque caractère composé, c'est-à-dire chaque espèce, est accompagné de la marque abrégée du genre ; ceux qui étudient la langue distinguent en peu de temps cette marque, et peuvent, dès lors, consulter le dictionnaire chinois, dans lequel les caractères composés ou les espèces sont classés sous leur propre genre.

Les caractères des genres sont placés au commencement du dictionnaire, dans un ordre qui, semblable à celui de l'alphabet, est invariable, et devient bientôt familier à celui qui l'étudie. Les espèces de chaque genre se suivent l'une l'autre, suivant le nombre de traits qui les composent, indépendamment d'un ou de quelques traits qui servent à indiquer le genre. Ainsi, on trouve bientôt l'espèce dont on a besoin. Sa signification et sa prononciation sont indiquées par d'autres mots d'un usage commun, le premier desquels désigne la signification, et le second, la prononciation. Quand on ne trouve pas un mot commun qui rende exactement le même son, ce son est indiqué par deux mots, avec des marques pour informer celui qui le cherche, que la consonne du premier mot et la voyelle du second, jointes ensemble, forment précisément le son dont il a besoin.

La composition de beaucoup de caractères chinois annonce une grande intelligence, et sert en même temps à faire connaître les opinions et les 


\section{Voyage dans l'intérieur de la Chine et en Tartarie}

mœurs de la nation. Le caractère qui exprime le bonheur contient plusieurs marques abrégées de terres et d'enfants; les premières indiquant la source des jouissances physiques des Chinois, et les autres, la source de leurs jouissances morales. Ce caractère, embelli de différentes manières, est suspendu dans presque toutes les maisons. Quelquefois, il est tracé de la main de l'empereur, et donné par lui comme un présent, dont on fait le plus grand cas. C'est ainsi que ce prince l'envoya à lord Macartney.

Les Chinois ont publié plusieurs milliers de volumes philologiques sur la formation, les changements et les allusions de leurs caractères composés. Nulle autre part, on ne voit plus de critique, ni une critique plus sévère. L'introduction ou l'altération d'un caractère est une entreprise très sérieuse, à la Chine, et ne manque guère de rencontrer beaucoup d'opposition. Les plus anciens écrits des Chinois sont encore classiques. La langue semble n'être dérivée que de ces écrits, et n'avoir eu des rapports qu'avec eux. La langue écrite paraît aussi avoir suivi de près la langue parlée, lorsque les hommes ont été formés en société régulière.

Quoiqu'il soit vraisemblable que toutes les langues hiéroglyphiques aient été originairement fondées sur des principes d'imitation, il est également probable que dans le progrès graduel vers les formes et les sons arbitraires, chaque société s'est écartée des originaux, d'une manière différente des autres; ainsi, chez toute société indépendante, s'est formée une langue hiéroglyphique particulière. Dès qu'il y a eu communication entre deux sociétés, chacune d'elles a voulu entendre les noms et les sons qui n'étaient point communs à toutes deux; chacun a voulu réciproquement écrire ces noms avec ses propres caractères qui, comme hiéroglyphes, avaient un sens différent ; et conséquemment ces caractères ont cessé d'être hiéroglyphes, et n'ont plus servi qu'à marquer des sons.

Si les sons étrangers n'ont pu être exprimés que par une partie de deux hiéroglyphes, de la même manière que nous avons dit être quelquefois employée dans le dictionnaire chinois, ces deux signes réunis sont devenus une syllabe. Lorsque de fréquentes relations ont eu lieu entre les sociétés qui parlaient différentes langues, la nécessité d'employer les hiéroglyphes à marquer simplement des sons, a dû se faire sentir fréquemment. L'usage a insensiblement conduit à découvrir qu'avec un petit nombre de hiéroglyphes, 


\section{Voyage dans l'intérieur de la Chine et en Tartarie}

tous les sons d'une langue étrangère pouvaient être exprimés; et les hiéroglyphes les plus propres à atteindre ce but, soit par l'exactitude des sons, soit par la simplicité des traits, ont été choisis pour cet usage particulier ; et servant, comme autant de lettres, ont formé collectivement ce qu'on appelle un alphabet.

Cette progression naturelle a actuellement lieu à Canton où, à cause du grand concours d'étrangers qui parlent la langue anglaise, on a publié, à l'usage des marchands du pays, un vocabulaire de mots anglais en caractères chinois, qui expriment simplement les sons. Par ce moyen, les Chinois apprennent à prononcer les mots anglais. A chaque caractère de ce vocabulaire est ajoutée une marque pour indiquer qu'il n'est point destiné à exprimer l'idée, mais simplement le son étranger qui y est attaché.

L'habitude d'appliquer à des mots étrangers le son, au lieu de la signification des hiéroglyphes, conduit nécessairement à les employer également comme sons, pour assister la mémoire dans la prononciation d'autres hiéroglyphes de la langue chinoise, lesquels sont d'un usage peu commun ; et l'on peut croire que, par l'emploi répété qu'on en fera de cette manière, on oubliera enfin leur usage primitif. Ainsi, le passage de l'écriture hiéroglyphique à l'écriture alphabétique peut être naturellement tracé sans qu'on soit dans la nécessité d'avoir recours à une instruction divine, comme l'ont conjecturé quelques savants, qui pensaient que l'art d'écrire, par le moyen d'un alphabet, était trop sublime, trop difficile pour la simple raison.

II est aussi peu naturel de supposer qu'un tel art n'a pu précéder l'établissement de la langue hiéroglyphique, que de croire qu'un mélange d'autres nations y a ajouté l'invention de la langue alphabétique. L'existence exclusive de la première de ces langues en Chine est encore une preuve que les étrangers qui y ont pénétré, comme les belliqueux et victorieux Tartares, étaient en si petit nombre, relativement aux vaincus, qu'ils n'ont pas apporté plus de changement dans leur langage, que dans leurs coutumes et dans leurs mœurs.

Les caractères imprimés des Chinois sont les mêmes dont on se sert dans la plupart des manuscrits. Ils sont principalement formés de lignes droites, dont les positions angulaires, comme la plupart des lettres des langues 


\section{Voyage dans l'intérieur de la Chine et en Tartarie}

orientales, surtout celles du Shanscrit, lesquelles, dans quelques endroits, admettent des additions à leur forme originale, additions qui produisent une modification dans le sens des mots. Les Chinois ont aussi une écriture courante, pour des choses de peu d'importance, pour des notes particulières, et pour la facilité et la promptitude de l'expédition. Cette écriture diffère autant de l'autre, que celle des manuscrits européens diffère des caractères imprimés. Il y a en Chine des livres avec des colonnes de deux écritures, pour que les étudiants apprennent à les expliquer l'une par l'autre.

La principale difficulté dans l'étude des écrits chinois vient de l'exclusion générale des particules auxiliaires du langage dialogué, lesquelles fixent la relation entre les mots indéclinables, comme le sont tous ceux de la langue chinoise. Le jugement de celui qui étudie cette langue doit s'exercer constamment pour suppléer au défaut de ce secours. II faut, en même temps, que ce jugement soit guidé par une grande attention aux mœurs, aux coutumes, aux lois, aux opinions des Chinois, ainsi qu'aux événements et aux circonstances locales, objets auxquels la langue fait sans cesse allusion.

Il est généralement vrai qu'une langue est difficile à apprendre à proportion de la distance qu'il y a du pays où elle parlée, au pays de celui qui l'étudie, parce que c'est dans cette proportion que les nombreuses allusions aux choses locales sont moins entendues d'un étranger. Ainsi, l'on peut se former quelque idée des obstacles qu'un Européen doit s'attendre à rencontrer en lisant le chinois, non seulement par rapport à l'éloignement qu'il y a de l'Europe à la Chine, mais par rapport à la différence qui se trouve, à tous égards, entre un Chinois et lui.

Les caractères chinois sont en effet des dessins ou des figures abrégées ; et une phrase est souvent une chaîne de métaphores. Les différents rapports qu'on a dans la vie ne sont point marqués en Chine par des sons arbitraires, qui indiquent simplement l'idée de ces rapports; mais les qualités qu'il est naturel d'en attendre, y deviennent fréquemment les noms par lesquels ils sont respectivement connus. Par exemple, la parenté à tous les degrés est distinguée dans le chinois, avec une précision inconnue dans les autres langues. Les Chinois ont des caractères particuliers pour exprimer les diverses modifications des objets, dans le monde physique et dans le monde intellectuel. Ils n'expriment les choses abstraites qu'en appliquant à chacune 


\section{Voyage dans l'intérieur de la Chine et en Tartarie}

le nom de l'objet le plus relevé auquel il puisse convenir ; ce qui, en général, est de même dans les autres langues. Parmi les latins, l'idée abstraite de la vertu était exprimée par le nom de la valeur ou de la force ${ }^{1}$, parce que c'était la qualité qu'ils estimaient le plus, de même que la piété filiale est ce qu'il y a de plus considéré en Chine.

Les mots d'une langue alphabétique étant formés de différentes combinaisons de lettres, ou de partie élémentaires, chacun avec un nom et un son distinct, quiconque les connaît et les combine, peut lire les mots sans avoir la moindre connaissance de leur signification. Mais il n'en est pas de même d'une langue hiéroglyphique, à chaque caractère de laquelle est ajouté un son qui n'a point un rapport certain avec les traits muets dont il est composé. On étudie et on apprend mieux un tel caractère, en acquérant la connaissance de l'idée qui est attachée. Un dictionnaire de hiéroglyphes est moins le vocabulaire des termes d'une langue, avec les termes correspondants d'une autre, qu'une encyclopédie, contenant l'explication des idées que représentent ces hiéroglyphes. C'est seulement dans ce sens qu'on peut justement dire que l'étude des mots chinois exige la plus grande partie du temps d'un lettré. Pour acquérir la connaissance des sciences imparfaites des Chinois et de leur immense littérature, il faut la vie entière d'un homme. Cependant, tous les Chinois apprennent assez leur langue pour traiter les affaires ordinaires; et avec de l'application, les étrangers peuvent partager cet avantage avec les Chinois. Le perfectionnement dépend ensuite de la capacité et des occasions.

Le vice-roi promit à l'ambassadeur que le gouvernement n'empêcherait point que les étrangers apprissent la langue chinoise. L'intention où était cet officier de protéger les Anglais venait d'être fortifiée par les dépêches de l'empereur. Ce prince lui mandait qu'il lui serait très agréable de revoir à sa cour un ministre anglais. Que dès que ce ministre arriverait à Canton, il désirait d'en être informé, afin d'envoyer des personnes convenables pour le recevoir et le conduire à Pékin.

\footnotetext{
1 Virtus.
} 


\section{Voyage dans l'intérieur de la Chine et en Tartarie}

Après avoir fait part de cette nouvelle à lord Macartney, le vice-roi ajouta que dans une autre de ses lettres, l'empereur lui disait que, comme il se proposait d'abdiquer sa couronne dans la cinquante-septième année ${ }^{1}$ du cycle courant, il serait bien aise de voir le ministre anglais vers ce temps-là, ou du moins, bientôt après. Ainsi l'ambassade, conformément aux motifs qui l'avaient fait entreprendre, mais contre l'attente pénible où depuis elle s'était quelquefois trouvée, réussit enfin, non seulement à obtenir la permission, mais à recevoir une invitation pour l'envoi d'un nouveau ministre à la cour de la Chine, lorsque le gouvernement de la Grande-Bretagne et la Compagnie des Indes le jugeront à propos.

L'ambassadeur, sa suite, et tous les Européens et Chinois qui étaient auprès d'eux, continuèrent à être défrayés de leurs dépenses par l'empereur, pendant tout le temps qu'ils furent à Canton.

Cette seule considération suffisait pour engager lord Macartney à quitter cette ville, et à s'embarquer sur le Lion pour se rendre à Macao, où l'on pourrait supposer que n'étant plus sur le territoire chinois, il cesserait conséquemment d'être à la charge de l'empereur.

A son départ de Canton, on lui rendit les mêmes honneurs qu'il y avait reçus à son arrivée. L'attention du vice-roi ne se démentit pas un seul instant. A mesure qu'il connut davantage l'ambassadeur, son estime pour lui s'accrut, ainsi que son inclination décidée pour les Anglais. Dès lors, les ennemis des Anglais devinrent, en secret, ceux du vice-roi.

Les mandarins, amis de l'ambassadeur, Chow-ta-Zhin et Van-ta-Zhin, versèrent des larmes en se séparant de lui et des autres Anglais avec lesquels ils avaient été le plus intimement liés. Ils avaient demeuré ensemble plusieurs mois de suite, fait pendant ce temps-là un voyage de plus de quinze cents milles, et toujours vécu les uns et les autres avec familiarité et cordialité. Les deux mandarins prenaient autant d'intérêt que les Anglais mêmes, à tout ce qui arrivait à l'ambassade. Après que ces Chinois eurent vu partir leurs amis, sans espoir de les revoir jamais, ils envoyèrent à bord du Lion des présents de rafraîchissements et quelques autres marques de souvenir et d'estime.

\footnotetext{
${ }^{1}$ Cette année répond à l'année 1796 de l'ère chrétienne.
} 


\section{Voyage dans l'intérieur de la Chine et en Tartarie}

En passant sous les forts qui défendent le passage de la rivière par où l'on se rend à Macao, l'ambassade s'aperçut qu'elle était presque dans la situation de ces aventuriers anglais, dont nous avons parlé au commencement de cet ouvrage. On voyait, de plus, un camp nombreux sur la rive orientale du Kiang-Ho. En général, les garnisons sont beaucoup plus fortes dans la province frontière de Canton que dans l'intérieur de l'empire. C'est une mesure de précaution qu'exige la situation de cette province. On veut par là inspirer de la crainte et du respect aux divers étrangers qui fréquentent son principal port.

L'ambassadeur anglais fut accueilli avec beaucoup de politesse par le gouverneur de Macao, qui s'empressa de lui donner des fêtes. L'établissement portugais de Macao est situé à l'extrémité méridionale d'une grande île, qui n'est séparée que par des rivières de la côte sud du continent de la Chine. Cette extrémité méridionale de l'île et le port qu'elle forme ont été accordés par les Chinois au gouvernement portugais. Elle n'est liée avec le reste de l'île que par une langue de terre fort longue, qui n'a pas plus de cent pas de large, et a été probablement formée par le sable qu'ont accumulé les vagues dont elle est battue des deux côtés.

Sur cette langue de terre, on a bâti une muraille qui, de chaque côté, s'avance dans la mer, et dans le milieu de laquelle il y a une porte et un corps de garde pour des soldats chinois. La muraille est construite d'écailles d'huîtres, qu'on trouve dans ces mers, et qui sont d'une prodigieuse grandeur. C'est avec ces mêmes écailles, divisées par lames, et polies, qu'on fait des carreaux pour les fenêtres de Macao et des parties méridionales de la Chine, comme on en fait avec du papier de Corée dans les provinces du nord, et avec du verre en Europe.

Il est rarement permis aux Portugais de passer la muraille servant de borne à leur territoire qui, à peine, a huit milles de circuit. Sa plus grande longueur du nord-est au sud-ouest n'est pas de trois milles, et sa largeur est de moins d'un mille. Ce petit coin de terre fut concédé aux Portugais dans le temps de leur puissance et de leurs grandes entreprises, et ils y firent longtemps un commerce considérable; non seulement avec la Chine, qu'ils 


\section{Voyage dans l'intérieur de la Chine et en Tartarie}

fréquentent presque seuls, mais avec d'autres contrées de l'Asie orientale, et particulièrement avec le Japon qui est à l'est, et le Tunquin, la Cochinchine, et le royaume de Siam, qui sont au sud-ouest de la Chine.

Ce commerce enrichit bientôt les Portugais, et l'on en voit encore des preuves dans plusieurs grands édifices publics et particuliers de Macao, dont quelques-uns sont maintenant fort négligés. La colonie de Macao était si commerçante, que son gouvernement faisait souvent des avances d'argent aux négociants à un intérêt que les profits de leurs expéditions les mettaient aisément en état de payer. Mais enfin le luxe suivit l'opulence. L'esprit de la nation portugaise perdit de sa vigueur. Les colons de Macao étaient déjà énervés par les effets du climat. Quelques événements leur firent perdre le commerce du Japon, l'une des principales sources de leurs richesses. Des révolutions de quelques autres pays, où ils trafiquaient, rendirent leurs spéculations incertaines et souvent malheureuses. La colonie perdit insensiblement sa splendeur première.

Les Portugais de Macao arment encore quelques navires, et envoient des cargaisons dans les contrées voisines. D'autres, pour obtenir une légère rétribution, prêtent leur nom aux agents des factoreries de Canton, lesquels résident une partie de l'année à Macao. Ceux-ci, avec plus de capitaux, de crédit, de relations et d'entreprises, ont plus de succès: mais il faut qu'ils soient nommément associés avec un Portugais pour pouvoir faire des expéditions de Macao. L'argent que dépensent, dans cette colonie, les factoreries de Canton, est aussi un avantage pour les habitants. Mais quelques-uns d'entre eux pensent que cet avantage est plus que balancé par les grands profits qu'ont les factoreries, à faire le commerce de Macao, profits qui, sans cela, resteraient aux Portugais.

Ces Portugais sont trop orgueilleux, trop insolents pour embrasser l'état de cultivateur ou d'artisan. Ils croiraient trop descendre. II n'y a peut-être pas dans tout le territoire de Macao, un laboureur, un ouvrier, ou un marchand, qui soit Portugais ou d'origine portugaise.

Le nombre des habitants de Macao s'élève à environ douze mille, dont plus de la moitié sont Chinois. La plus grande partie de cette petite péninsule se trouve au nord de la ville, et est entièrement cultivée par des Chinois. Le 


\section{Voyage dans l'intérieur de la Chine et en Tartarie}

tout est presque plat, et le sol en est léger et sablonneux ; mais par les soins et l'industrie des cultivateurs, il produit assez de légumes des espèces européennes et asiatiques, pour la consommation de la colonie.

Tous les arts utiles sont exercés, à Macao, par des Chinois. Le marché est fourni de grain et de viande, qu'on porte de la partie chinoise de l'île, et quelquefois du continent. Les Portugais croient au-dessous d'eux tout autre genre d'industrie que le commerce et la navigation.

Indépendamment du gouverneur militaire, il y a à Macao un conseil administratif, composé de l'évêque, du juge, et de quelques-uns des principaux habitants.

Pour exercer la dévotion d'un peu plus de quatre mille Portugais, il y a treize églises ou chapelles, et plus de cinquante prêtres. II y a aussi un ecclésiastique français et un ecclésiastique italien qui, l'un et l'autre, sont des modèles de vertu et de piété, et président aux missions de l'orient de l'Asie. L'on croit que dans les royaumes de Tunquin et de la Cochinchine, il y a environ cent missionnaires et deux cent mille néophytes. Cent soixante mille chrétiens, tout au plus, sont, dit-on, répandus dans le vaste empire de la Chine, où les prêtres sont surveillés avec exactitude, et exposés à des persécutions continuelles.

Presque partout ailleurs qu'à Pékin, les missionnaires mènent une vie laborieuse, indigente, précaire, et sans aucune espérance, du moins quant à ce monde. Les secours qu'on leur fait passer d'Europe sont très peu de chose; et souvent, ils les partagent avec leur troupeau, encore plus misérable qu'eux. La principale consolation des missionnaires vient de la persuasion où ils sont que leurs disciples les révèrent et leur sont sincèrement attachés. Quelques-uns de ces prêtres peuvent d'ailleurs préférer cette vie indépendante, telle qu'elle est, aux cloîtres dans lesquels ils ont été d'abord renfermés; mais, en général, leur conduite annonce des sentiments et des maximes rares, dont l'existence est à peine soupçonnée par le reste du genre humain.

Les Portugais ont à Macao une grande quantité d'officiers pour commander environ trois cents soldats, tous mulâtres ou nègres. Sans doute la garnison était autrefois plus considérable, pour pouvoir suffire au service 


\section{Voyage dans l'intérieur de la Chine et en Tartarie}

de la citadelle, des forts et des remparts qui défendent la ville. On y voit encore plusieurs pièces de canon de bronze et de fer.

L'évêque de Macao, prélat vertueux mais bigot, a beaucoup d'influence dans le gouvernement ; et, par son exemple et par les mesures qu'il prend, il contribue à maintenir un ton de dévotion et des pratiques religieuses, qui sont la principale occupation d'une très grande partie des habitants. II y a, dans la ville, trois couvents d'hommes, et un couvent de religieuses qui y sont au nombre d'environ quarante. On a aussi renfermé à Macao un pareil nombre de filles libertines, et on ne les relâche que lorsqu'elles trouvent à se marier.

Macao offre un frappant contraste entre l'industrie sans cesse agissante des Chinois, et l'éternelle indolence des Portugais, qui se promènent gravement sur la place du conseil, pendant l'intervalle qu'il y a de matines jusqu'à vêpres. II n'est pas très rare, pour un Anglais qui se trouve à Macao, d'être accosté par un Portugais portant un habit râpé, une bourse à cheveux, une épée, et demandant l'aumône.

Le palais du conseil de Macao est bâti à deux étages et en granit. On y voit plusieurs colonnes de la même matière, sur lesquelles sont sculptés des caractères chinois, contenant la cession solennelle que l'empereur de la Chine a faite de Macao aux Portugais. Cependant, ce monument solide est encore insuffisant contre les usurpations des Chinois qui, traitant les Portugais fort lestement, lèvent, de temps en temps, des droits dans le port de Macao, y punissent les individus pour des crimes commis contre les sujets de la Chine, surtout pour des meurtres, et ce qui n'est pas moins outrageant aux yeux d'un Portugais, font, quelquefois dans la ville, des processions idolâtres. Toutes les fois que les Portugais veulent faire la moindre résistance, le mandarin qui commande dans le petit fort situé près de Macao, arrête aussitôt les provisions destinées pour cette ville, et ne les laisse passer que quand on s'est soumis tranquillement.

Les Chinois ont à Macao deux temples consacré à l'idolâtrie. L'un est curieusement situé à l'extrémité méridionale de la ville, parmi plusieurs grandes masses de granit, entassées confusément. La terre, dans laquelle ces masses ont été sans doute ensevelies, a cédé à l'effort des pluies successives, et les rochers sont tombés au hasard, les uns sur les autres, et sont restés 


\section{Voyage dans l'intérieur de la Chine et en Tartarie}

comme on les voit à présent. Le temple consiste en trois différents édifices, placés l'un au-dessus de l'autre, et accessibles par un seul escalier tournant, pratiqué dans le roc. Ces édifices sont ombragés par des arbres dont le feuillage est si épais qu'on ne peut les découvrir à quelque distance.

D'autres rochers, arrangés de la même manière, sont un peu au-dessous d'une des plus hautes éminences de la ville, et forment une grotte, appelée la grotte du Camoens. C'est là que la tradition dit que le poète de ce nom, a composé son fameux poème de la Lusiade. Il est certain que le Camoens résida longtemps à Macao. L'intéressante grotte à laquelle il a donné son nom est située dans le jardin d'une maison où l'ambassadeur et deux personnes de sa suite résidèrent pendant leur séjour dans l'île. Ils avaient été invités à prendre ce logement par un des agents de la factorerie anglaise, lequel demeurait là lorsque ses affaires ne l'appelaient pas à Canton.

La maison et le jardin ont une très belle vue. En faisant le jardin, on n'a négligé aucun des avantages du terrain. Sa surface est très variée, et il contient un très grand nombre de beaux arbustes et d'arbres fruitiers qui y sont entremêlés avec une heureuse irrégularité, et semblent y croître spontanément. Les sentiers y suivent diverses pentes, traversent des bosquets, passent sous des rocs suspendus, et se croisent l'un l'autre, de manière que, quant à l'amusement et au plaisir de la promenade, l'étendue du sol en est véritablement augmentée.

Vis-à-vis de ce jardin, et dans le milieu du port, est une petite île ronde qui appartenait autrefois aux jésuites de Macao. On y a bâti une église, un collège et un observatoire. Cette île est naturellement romantique ; et comme beaucoup d'autres des environs de Macao, elle est en partie couverte de rochers énormes, entassés les uns sur les autres. Parmi ces rochers, on trouve un sentier ombragé, conduisant sur le sommet de la montagne qui occupe presque toute l'île, et forme un cône parfait. Tout autour de la base de cette montagne est une bande de terre plane d'environ trente ou quarante pas de large, dont on cultive la moitié en jardin botanique, et la moitié en jardin potager. Le tout est arrosé par des ruisseaux qui sortent des rochers.

L'île est défendue contre la mer par une muraille qui l'entoure. Tout ce qu'on y a fait jadis se ressent de la chute de la société à laquelle elle a 


\section{Voyage dans l'intérieur de la Chine et en Tartarie}

appartenu; et elle ne conserve plus que quelques traces de sa première beauté. Le port dans lequel est cette petite île s'appelle le port intérieur, par opposition au port extérieur qui est plus ouvert à la mer, et où les vaisseaux sont exposés au mauvais temps, surtout durant la mousson du nord-est.

Tous les marins de Macao observent que la profondeur de ce port extérieur diminue sensiblement depuis plusieurs années. D'un côté, quatre îles forment un bassin dans lequel fut autrefois radoubé le vaisseau que commandait l'amiral Anson. Mais à présent, un pareil vaisseau ne pourrait pas y entrer.

Bientôt après que lord Macartney fut à Macao, il se détermina sur le parti qu'il devait prendre d'après les lettres qu'il reçut d'Angleterre et de Batavia. Les lettres d'Angleterre portaient que le gouvernement britannique n'ayant point appris que la France eût envoyé dans I'Inde une flotte capable de mettre en danger les vaisseaux qui revenaient de la Chine sans convoi, et le service public exigeant ailleurs l'emploi de la marine anglaise, on n'avait point donné des ordres pour qu'aucune force protégeât le retour de la flotte qui était à Canton.

Mais les dépêches de Batavia annonçaient: «Que dans le détroit de la Sonde, passage direct des navires qui vont en Chine ou en reviennent, il était arrivé une escadre ennemie, consistant en un vaisseau de soixante-six canons, une frégate de quarante, et une autre de vingt ; que cette escadre avait pris le vaisseau de la Compagnie, la Princesse Royale, qu'on avait aussitôt converti en vaisseau de guerre. On craignait, en outre, que ces forces ne fussent bientôt suivies par d'autres. »

La nouvelle de la prise du vaisseau de la Compagnie, le Pigot, ne tarda pas à suivre celle dont nous venons de rendre compte. Alors le danger qui menaçait les quinze vaisseaux de la Compagnie, prêts à partir de Canton pour retourner en Angleterre, et dont les cargaisons montaient à trois millions sterling, décida l'ambassadeur à abandonner toute idée de politique générale dans l'archipel de la Chine, ainsi que les avantages qu'il pouvait espérer d'un plus long séjour dans ces contrées. II résolut donc d'accompagner dans le vaisseau le Lion qui était à ses ordres, la flotte de Canton, afin d'assurer, par 


\section{Voyage dans l'intérieur de la Chine et en Tartarie}

ce moyen, la protection d'une ligne de vaisseaux en état de combattre, à une partie considérable de la fortune publique.

Cette résolution étant bientôt annoncée dans différents ports de l'Asie orientale, deux vaisseaux richement chargés, l'un portugais, l'autre venant de Manille, se mirent sous le convoi du Lion. Aussitôt que tous les vaisseaux furent prêts et assemblés à Macao, l'ambassadeur s'embarqua avec toutes les principales personnes de l'ambassade, excepté M. Henry Baring, maintenant supercargue à Canton, et l'interprète chinois qui, sous un nom et sous un habit anglais, resta auprès de l'ambassadeur jusqu'au moment de son embarquement. Cet homme estimable et pieux, après avoir dit un adieu plein d'affection aux compagnons de ses voyages, se sépara d'eux avec beaucoup de regret, et se retira aussitôt dans un couvent, où il reprit ses vêtements chinois, afin de suivre ses premières intentions, et de se dévouer au service et à l'instruction des pauvres chrétiens des provinces occidentales de la Chine. 


\section{Voyage dans l'intérieur de la Chine et en Tartarie}

\section{APPENDICE I}

Tableau de la population et de l'étendue de la Chine propre, séparée de la Tartarie chinoise par la Grande Muraille ${ }^{1}$.

\begin{tabular}{|c|c|c|c|}
\hline Provinces & Population & Milles carrés & Acres \\
\hline $\begin{array}{l}\text { Pé-Ché-lée } \\
\text { Kiang-Nan, deux prov. } \\
\text { Kiang-Sée } \\
\text { Tche-Kiang } \\
\text { Fo-Chen } \\
\text { Hou-Pé } \\
\text { Hou-Nan } \\
\text { Ho-Nan } \\
\text { Shan-Tung } \\
\text { Shan-Sée } \\
\text { Shen-Sée } \\
\text { Kan-Sou } \\
\text { Se-Chuen } \\
\text { Quan-Tung } \\
\text { Quang-Sée } \\
\text { Yu-Nan } \\
\text { Koei-Cheou }\end{array}$ & 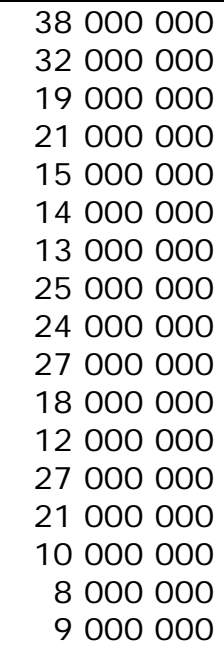 & $\begin{array}{rl}58 & 949 \\
92 & 961 \\
72 & 176 \\
39 & 150 \\
53 & 480 \\
144 & 770 \\
65 & 104 \\
65 & 104 \\
55 & 268 \\
154 & 008 \\
166 & 800 \\
79 & 456 \\
78 & 250 \\
107 & 969 \\
64 & 554\end{array}$ & 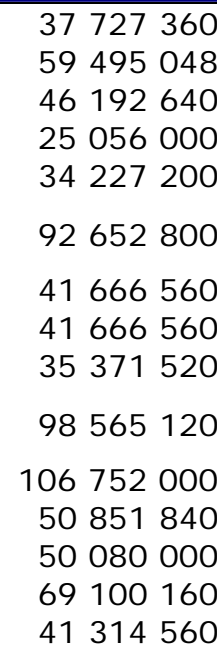 \\
\hline $\begin{array}{l}\text { TOTAL } \\
\end{array}$ & 353000000 & 1297999 & 830719360 \\
\hline
\end{tabular}

@

${ }^{1}$ Ce tableau a été pris en nombres ronds dans les documents fournis par le mandarin Chow-ta-Zhin.

Les provinces de Hou-Pé et de Hou-Nan portent ensemble le nom de Hou-Quang. 


\section{Voyage dans l'intérieur de la Chine et en Tartarie}

\section{APPENDICE II}

Tableau des revenus entrés dans le trésor impérial de Pékin, et provenant des différentes provinces de la Chine propre.

\begin{tabular}{|c|c|c|c|c|}
\hline \multicolumn{2}{|c|}{ Provinces } & $\begin{array}{l}\text { Tahels } \\
\text { ou } \\
\text { onces }\end{array}$ & $\begin{array}{c}\text { Total des } \\
\text { tahels } \\
\text { d'argent }\end{array}$ & $\begin{array}{c}\text { Mesures } \\
\text { de riz et } \\
\text { autres grains }\end{array}$ \\
\hline Pé-Ché-lée, & $\begin{array}{l}\text { sur les terres } \\
\text { sur le sel } \\
\text { autres taxes }\end{array}$ & $\begin{array}{r}2520000 \\
437000 \\
79000\end{array}$ & 3036000 & - \\
\hline Kiang-Nan & $\begin{array}{l}\text { terres } \\
\text { sel } \\
\text { taxes }\end{array}$ & $\begin{array}{rrr}5 & 200200 \\
2 & 100000 \\
910000\end{array}$ & 8210000 & 1440000 \\
\hline Kiang-Sée & $\begin{array}{l}\text { terres } \\
\text { taxes }\end{array}$ & $\begin{array}{r}1900000 \\
220000\end{array}$ & 2120000 & 795000 \\
\hline Tche-Kiang & $\begin{array}{l}\text { terres } \\
\text { sel } \\
\text { taxes }\end{array}$ & $\begin{array}{r}3100000 \\
520000 \\
190000\end{array}$ & 3810000 & 780000 \\
\hline Fo-Chen & $\begin{array}{l}\text { terres } \\
\text { sel } \\
\text { taxes }\end{array}$ & $\begin{array}{r}1100000 \\
87000 \\
80000\end{array}$ & 1277000 & - \\
\hline Hou-Pé & $\begin{array}{l}\text { terres } \\
\text { taxes }\end{array}$ & $\begin{array}{r}1300000 \\
10000\end{array}$ & 1310000 & 100000 \\
\hline Hou-Nan & $\begin{array}{l}\text { terres } \\
\text { taxes }\end{array}$ & $\begin{array}{r}1310000 \\
35000\end{array}$ & 1345000 & 100000 \\
\hline Ho-Nan & $\begin{array}{l}\text { terres } \\
\text { taxes }\end{array}$ & $\begin{array}{r}3200000 \\
13000\end{array}$ & 3213000 & 230000 \\
\hline Shan-Tung & $\begin{array}{l}\text { terres } \\
\text { sel } \\
\text { taxes }\end{array}$ & $\begin{array}{r}3440000 \\
130000 \\
30000\end{array}$ & 3600000 & 360000 \\
\hline Shan-Sée & $\begin{array}{l}\text { terres } \\
\text { sel } \\
\text { taxes }\end{array}$ & $\begin{array}{r}3100000 \\
510000 \\
112000\end{array}$ & 3722000 & - \\
\hline
\end{tabular}


Voyage dans l'intérieur de la Chine et en Tartarie

\begin{tabular}{|c|c|c|c|c|}
\hline \multicolumn{2}{|c|}{ Provinces } & $\begin{array}{l}\text { Tahels } \\
\text { ou } \\
\text { onces }\end{array}$ & $\begin{array}{c}\text { Total des } \\
\text { tahels } \\
\text { d'argent }\end{array}$ & $\begin{array}{c}\text { Mesures } \\
\text { de riz et } \\
\text { autres grains }\end{array}$ \\
\hline Shen-Sée & $\begin{array}{l}\text { terres } \\
\text { taxes }\end{array}$ & $\begin{array}{r}1660000 \\
40000\end{array}$ & 1700000 & - \\
\hline Kan-Sou & $\begin{array}{l}\text { terres } \\
\text { taxes }\end{array}$ & $\begin{array}{r}300000 \\
40000\end{array}$ & 340000 & 220000 \\
\hline Se-Chuen & $\begin{array}{l}\text { terres } \\
\text { taxes }\end{array}$ & $\begin{array}{r}640000 \\
30000\end{array}$ & 670000 & 一 \\
\hline Quan-Tung & $\begin{array}{l}\text { terres } \\
\text { sel } \\
\text { taxes }\end{array}$ & $\begin{array}{r}1280000 \\
50000 \\
10000\end{array}$ & 1340000 & - \\
\hline Quang-Sée t & $\begin{array}{l}\text { terres } \\
\text { sel } \\
\text { taxes }\end{array}$ & $\begin{array}{r}420000 \\
50000 \\
30000\end{array}$ & 500000 & - \\
\hline Yu-Nan & terres & 210000 & 210000 & 220000 \\
\hline Koei-Cheou & $\begin{array}{l}\text { terres } \\
\text { sel } \\
\text { taxes }\end{array}$ & $\begin{array}{r}120000 \\
10000 \\
15000\end{array}$ & 145000 & - \\
\hline TOTAL & & & 36548000 & 4245000 \\
\hline
\end{tabular}

@ 


\section{Voyage dans l'intérieur de la Chine et en Tartarie}

\section{APPENDICE III}

Liste des officiers civils de la Chine.

\begin{tabular}{|c|c|c|c|}
\hline Nombre & Titres & $\begin{array}{l}\text { Salaires / an } \\
\text { (tahels } \\
\text { d'argent }\end{array}$ & $\begin{array}{l}\text { Total } \\
\text { tahels }\end{array}$ \\
\hline 11 & $\begin{array}{l}\text { Tson-toos, ou vice-rois } \\
\text { d'une ou plusieurs provinces }\end{array}$ & 20000 & 220000 \\
\hline 15 & $\begin{array}{l}\text { Foyens, ou gouverneurs sous les } \\
\text { vice-rois }\end{array}$ & 16000 & 240000 \\
\hline 19 & $\begin{array}{l}\text { Hou-poos, ou administrateurs des } \\
\text { revenus }\end{array}$ & 9000 & 171000 \\
\hline 18 & $\begin{array}{l}\text { An-za-tzés, ou présidents des } \\
\text { tribunaux criminels }\end{array}$ & 6000 & 108000 \\
\hline 86 & $\begin{array}{l}\text { Tao-quens, ou présidents de plus } \\
\text { d'une cité du premier ordre et des } \\
\text { districts adjacents }\end{array}$ & 3000 & 258000 \\
\hline 184 & $\begin{array}{l}\text { Fou-quens, ou gouverneurs d'une } \\
\text { cité du premier ordre et de ses } \\
\text { dépendances }\end{array}$ & 2000 & 368000 \\
\hline 149 & $\begin{array}{l}\text { Kiou-quens, ou gouverneurs d'une } \\
\text { cité du second ordre }\end{array}$ & 1000 & 149000 \\
\hline 1305 & $\begin{array}{l}\text { Sien-quens, ou gouverneurs d'une } \\
\text { cité du troisième ordre }\end{array}$ & 800 & 1044000 \\
\hline 17 & $\begin{array}{l}\text { Siou-jous, ou présidents des } \\
\text { sciences et des examens }\end{array}$ & \} 3000 & 402000 \\
\hline 117 & $\begin{array}{l}\text { Cho-taos, ou inspecteurs } \\
\text { généraux. }\end{array}$ & & \\
\hline & TOTAL & & 2960000 \\
\hline
\end{tabular}

@ 


\section{APPENDICE IV}

Liste des principaux officiers militaires de la Chine, Avec leur nombre, leur rang et leurs appointements.

\begin{tabular}{|l|l|c|r|}
$\begin{array}{c}\text { Nombre } \\
\text { des } \\
\text { officiers }\end{array}$ & \multicolumn{1}{|c|}{ Rangs } & $\begin{array}{c}\text { Tahels que } \\
\text { chacun a } \\
\text { par an }\end{array}$ & \multicolumn{1}{|c|}{ Total } \\
\hline 18 & Tou-tous & 4000 & 72000 \\
62 & Zun-pings & 2400 & 148800 \\
121 & Fou-ziens & 1300 & 157300 \\
165 & Tchou-ziens & 800 & 132200 \\
373 & Giou-zis & 600 & 223800 \\
425 & Tou-tzés & 300 & 170000 \\
825 & Sciou-fous & 160 & 264000 \\
1680 & Zien-zuns & 130 & 470870 \\
3622 & Pa-zuns & & \\
44 & Commissaires du premier rang, & 320 & 14080 \\
& pour les grains et autres & 160 & 52800 \\
330 & provisions du second rang, & & 1974450 \\
& Commissaires dus & & \\
& pour les mêmes objets & & \\
\hline
\end{tabular}

État approximatif des établissements militaires de la Chine.

\begin{tabular}{|c|c|c|}
\hline $\begin{array}{l}\text { - } 1000000 \text { de fantassins, à } 2 \text { onces ou } \\
\text { tahels d'argent par mois, y compris les } \\
\text { provisions, font par an } \\
-800000 \text { hommes de cavalerie, à } 4 \text { tahels } \\
\text { par mois, les provisions comprises, font par an } \\
-\quad \mathrm{Si} 800000 \text { chevaux coûtent } 20 \text { tahels } \\
\text { chacun, } 16000000 \text { tahels, il y a de déficit/ an } \\
\text { L'uniforme, pour un } 1800000 \text { hommes, à } 4 \\
\text { tahels par an chacun } \\
\text { Le déficit annuel des armes, du fourniment, } \\
\text { etc., à } 1 \text { tahel par an }\end{array}$ & $\begin{array}{l}24000000 \\
38400000 \\
1600000 \\
7200000 \\
1800000\end{array}$ & 73000000 \\
\hline L'ar $^{\prime}$ & & 75 \\
\hline
\end{tabular}

